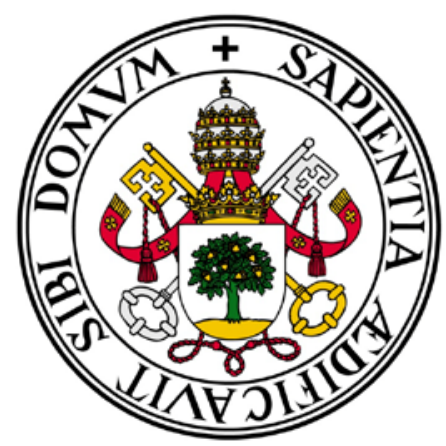

UNIVERSIDAD DE VALLADOLID

DEPARTAMENTO DE DIDÁCTICA DE LAS CIENCIAS EXPERIMENTALES, SOCIALES Y DE LA MATEMÁTICA

\title{
ANÁLISIS DE LAS PRUEBAS DE ACCESO A LAS UNIVERSIDADES DE CASTILLA Y LEÓN (MATEMÁTICAS II)
}

TESIS DOCTORAL

Ma Rosario Fátima Zamora Pérez

Valladolid, mayo de 2014 

Memoria presentada para optar al grado de Doctor por la Universidad de Valladolid por Dña. Ma Rosario Fátima Zamora Pérez, Licenciada en Ciencias Matemáticas en la Universidad de Valladolid, en el Programa de Doctorado: Investigación en Didáctica de las Ciencias Experimentales y Sociales, y Matemáticas.

Director de la Tesis: Dr. Tomás Ortega del Rincón

Departamento de Didáctica de las Ciencias

Experimentales, Sociales y de la Matemática.

Universidad de Valladolid 

TOMÁS ORTEGA DEL RINCÓN, CAUN de Didáctica de la Matemática de la Universidad de Valladolid

\section{CERTIFICA:}

Que la presente memoria, Análisis de la pruebas de Acceso a las Universidades de Castilla y León (Matemáticas II), ha sido realizada por Doña $M^{a}$ Rosario Fátima Zamora Pérez bajo mi dirección en la Universidad de Valladolid.

Valladolid, Mayo de 2014

Fdo.: Tomás Ortega del Rincón 

Mis agradecimientos a Tomás Ortega

Tw colaboración ha sido enriquecedora

Tus correcciones, precisas

Twapoyo, inestimable

Gracias. 


\section{ÍNDICE}

\section{INTRODUCCIÓN}

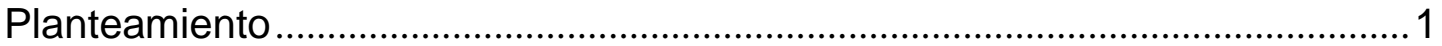

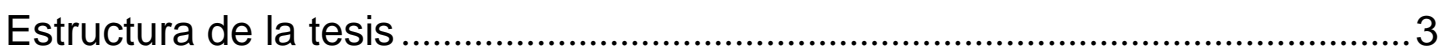

\section{CAPÍTULO I}

\section{CURRÍCULO Y EVALUACIÓN}

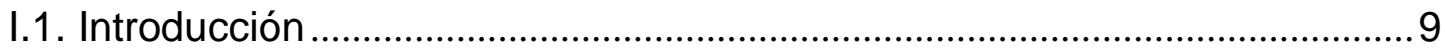

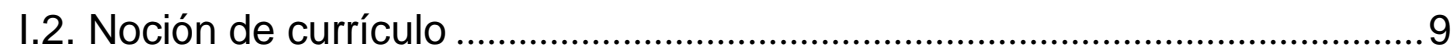

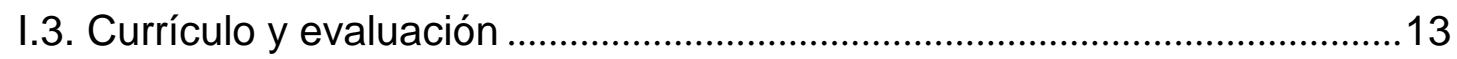

I.4. El currículo de Matemáticas de Enseñanza Secundaria del NCTM. ........20

I.5. Contenidos curriculares y pruebas de acceso de Matemáticas .................23

I.5.1. Los contenidos curriculares LOGSE ................................. 23

I.5.2. Las pruebas de acceso LOGSE.............................................. 33

\section{CAPÍTULO II}

MARCOS TEÓRICO Y METODOLÓGICO

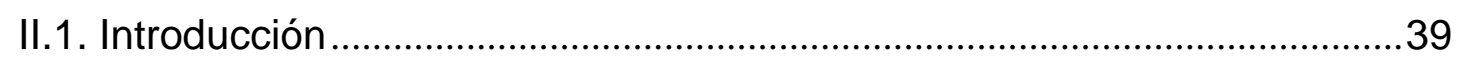

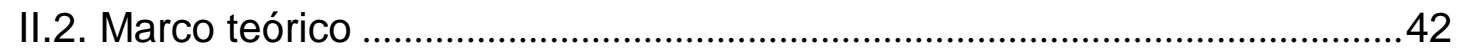

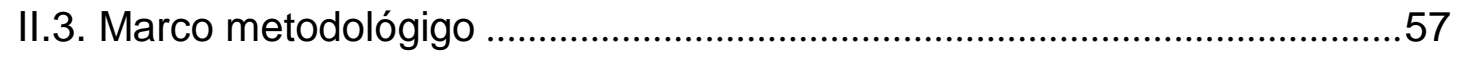

CAPÍTULO III

PRESENCIA DE CATEGORÍAS DE CONTENIDO

III.1. Introducción

III.2. Tablas de categorías de contenidos de Análisis Matemático..................67

III.3. Tablas de categorías de contenidos de Älgebra.....................................82 
CAPÍTULO IV

ANÁLISIS EN COMPETENCIAS DE LOS ENUNCIADOS DE ANÁLISIS MATEMÁTICO

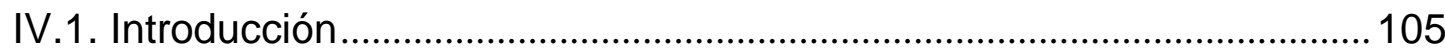

IV.2.Estudio de los problemas de Análisis Matemático................................. 107

IV.3.Estudio de las cuestiones de Análisis Matemático .................................. 183

IV.4. Reflexión del análisis sobre las PAEU de Análisis Matemático ........... 239

CAPÍTULO V

ANÁLISIS EN COMPETENCIAS DE LOS ENUNCIADOS DE ÁGEBRA

V.1 Introducción 243

V.2. Estudio de los problemas de Álgebra .................................................... 243

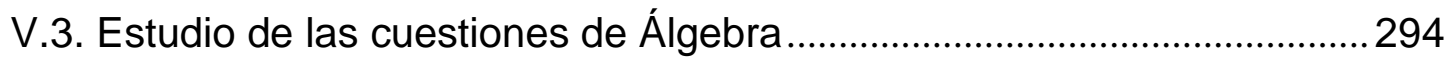

V.4. Reflexión del análisis sobre las PAEU de Álgebra ..................................336

CAPÍTULO VI

ANÁLISIS, EN COMPETENCIAS, DE LOS ENUNCIADOS DE GEOMETRÍA.

VI.1. Introducción 339

VI.2.Estudio de los problemas de Geometría .................................................. 341

VI.3.Estudio de las cuestiones de Geometría..................................................378

V.4. Reflexión del análisis sobre las PAEU de Geometría ........................... 413

\section{CAPÍTULO VII}

\section{ANÁLISIS MORFOSINTÁCTICO DE LOS ENUNCIADOS}

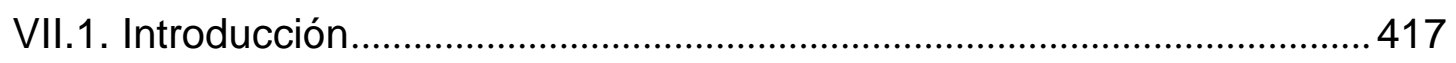

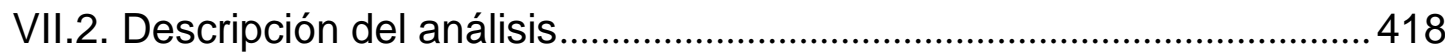

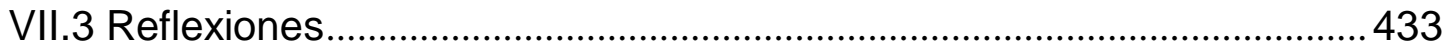




\section{CAPÍTULO VIII}

\section{CONCLUSIONES}

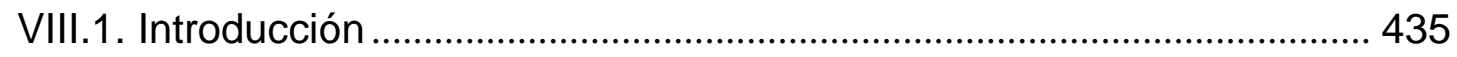

VIII.2. Aportaciones de la investigación............................................................ 436

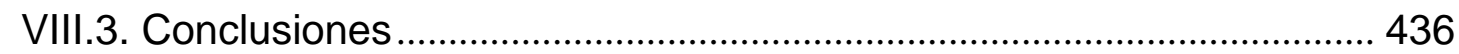

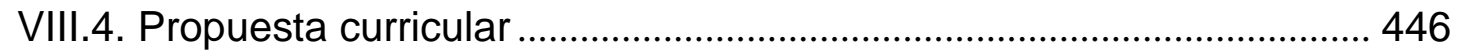

VIII.5. Dificultades de la investigación .............................................................. 452

VIII.5. Puntos fuertes y débiles ................................................................... 454

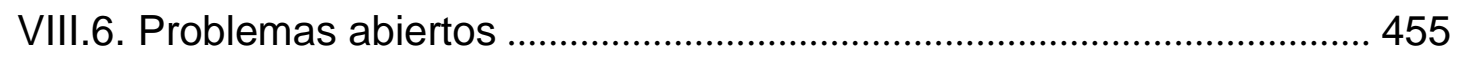

BIBLIOGRAFÍA ........................................................ 457 



\section{INTRODUCCIÓN}

\section{PLANTEAMIENTO}

La diversidad de las aulas en el periodo educativo de la Enseñanza Secundaria Obligatoria (ESO), reconocida por las propias leyes educativas, influye intrínsecamente en los estudios posteriores de Bachillerato, ya que la heterogeneidad de las mismas influye a la baja en los rendimientos académicos. En un análisis sociológico se puede considerar que las deficiencias estructurales del sistema general (formativas, curriculares, institucionales, sociales,...) provocan situaciones que tienen gran implicación en el diseño y desarrollo del currículo de Bachillerato de las que forma una parte importantísima la evaluación y, en consecuencia, las Pruebas de Acceso a Estudios Universitarios (PAEUs).

La experiencia docente acumulada como profesora durante más de tres décadas, instruyendo a alumnos que van a acceder a la Universidad, ha hecho que adquiera la creencia compartida de que los contenidos que se desarrollan en las aulas de bachillerato se restringen cada vez más y, especialmente, en el segundo curso de esta etapa educativa, donde la docencia de la asignatura de matemáticas se desarrolla en función de las limitaciones que proceden de la formación matemática de los cursos anteriores, por una parte, y de los problemas y cuestiones que habitualmente se proponen en las Pruebas de Acceso a la Universidad (PAEUs), por otra.

Esa experiencia se ha incrementado formando parte de los tribunales de las PAEU y con la recopilación de las pruebas que se han propuesto en la Universidad de Valladolid, que han influido en mi percepción sobre el currículo real de matemáticas de Segundo de Bachillerato, ya que los ejercicios y las cuestiones propuestas en dichas pruebas, a priori, son muy repetitivas y, presumiblemente, sólo cubren una parte del currículo oficial de matemáticas.

De ser ciertas las aseveraciones anteriores, y si la docencia que se practica en las aulas tiene como objetivo fundamental que los alumnos superen o saquen 
una buena puntuación en las PAEU, es evidente que el desarrollo curricular va a depender en gran medida de este objetivo y, en consecuencia, la formación matemática que alcanzan nuestros alumnos cuando terminan el bachillerato es escasa y muy deficiente en algunos de los contenidos de este nivel educativo, presentando lagunas curriculares formativas, e incluso, pudiera ser que ni siquiera se desarrollaran en las aulas todos los contenidos del currículo.

Estos planteamientos ajenos a la legalidad pueden producir un sesgo en la formación de los alumnos respecto al currículo oficial de Matemáticas y el objetivo fundamental de esta investigación, consiste en determinar hasta qué punto las PAEU influyen en este currículo legal de segundo de bachillerato. Otro aspecto interesante y que merece la pena ser investigado es la consideración o no de las competencias PISA y de los niveles de evaluación presentes en los problemas y en las cuestiones. Estas consideraciones nos permiten enunciar las siguientes preguntas de investigación:

¿Favorecen las PAEU el estudio de los contenidos curriculares?

¿Están bien formulados los enunciados de las pruebas?

¿Están implícitos de forma uniforme los niveles PISA de las competencias curriculares en las PAEU?

En nuestra investigación se hace un estudio sobre el currículo y el proceso de evaluación, que se describe en la presente memoria, así como las competencias matemáticas implícitas en los enunciados propuestos en las distintas pruebas PAEU desde 1995 a 2009, siguiendo un marco teórico-metodológico integrado por el marco de investigación histórica de Fox (1981) y por los marcos conceptuales de PISA 2003.

A partir del año 2010, la estructura de los exámenes de Acceso a la Universidad se modifica y la asignatura de Matemáticas II no es obligatoria. Por consiguiente, se desglosa en dos tipos de opción: una como materia de modalidad y, otra, como materia específica -para subir nota-. El tipo de examen cambia de estructura, pasando a tener cuatro cuestiones-problemas, manteniendo las dos opciones de prueba, A o B; aunque no ha variado el nivel de contenidos ni el modelo de ejercicios, incidiendo nuevamente en ese sesgo curricular al que hacemos mención, tanto en la opción específica como en la prueba general de modalidad. En el curso 2009-2010 se realizaron dos exámenes distintos según fuese la opción: como materia específica o de modalidad, pero en los cursos sucesivos se ha propuesto el mismo examen para las dos opciones. 
Para esta investigación se han diseñado y aplicado instrumentos de análisis correspondientes para estudiar, por un lado, la relación de competencias matemáticas $\mathrm{y}$, por otro, la estructura gramatical presente en los enunciados.

El estudio en competencias pormenorizado de cada uno de los enunciados unido a la resolución de los mismos configura un documento que puede ser una ayuda, tanto para alumnos (por la resolución de los problemas y cuestiones) como para profesores y responsables del planteamiento de los distintos exámenes de las PAEUs (por su implicación en el desarrollo curricular y por el análisis de competencias matemáticas asociadas a cada prueba).

\section{ESTRUCTURA DE LA TESIS}

Él trabajo se estructura en ocho capítulos, amén de esta Introducción que trata de presentar, de manera abarcadora las ideas que perfilan el trabajo concebido como un todo, de los seis Anexos que se presentan en soporte informático y de la Bibliografía. La síntesis de esta memoria se describe a continuación.

En el capítulo I se presenta una aproximación al concepto de currículo y un apunte sobre los primeros pasos que se dieron en investigación curricular, investigaciones que datan del año 1975. Asimismo, se expone un resumen histórico del currículo de Matemáticas para Bachillerato en España, desde el Real Decreto 160/1975 (Curso de Orientación Universitaria (COU)) hasta el Decreto 70/2002 de 23 de mayo, en el marco de la LOGSE y el Decreto 42/2008, de 5 de junio en el marco de la LOE ( $2^{\circ}$ de Bachillerato). Estos dos últimos decretos son autonómicos y determinan el currículo de Matemáticas II en Castilla y León. Por otra parte, también aparece una selección de la base legal que ha determinado la estructura y contenido curricular de las Pruebas de Acceso a la Universidad en los últimos años, desde las que establece el Curso de Orientación Universitaria (COU) hasta el año 2009 (Bachillerato LOGSE). En suma, nuestro análisis abarca desde 1995 hasta 2009; desde 1995 a 2002 coexisten las pruebas del COU y las de bachillerato LOGSE y desde 2003 hasta 2009, son pruebas exclusivamente de bachillerato LOGSE.

En el capítulo segundo se exponen los marcos teóricos y metodológicos, el proceso seguido para la recopilación de los enunciados, la clasificación de los documentos utilizados para la investigación y el análisis de los mismos., se muestra una revisión de trabajos de investigación y publicaciones de distintos autores, incidiendo en sus objetivos básicos y en las aportaciones realizadas a 
partir de su elaboración. Se realiza un acercamiento al mundo de la investigación sobre evaluación en Educación Matemática. Para el estudio de los contenidos curriculares desde el contexto de competencias un apartado de este capítulo está dedicado a la construcción de tablas de categorías competenciales en sus niveles de reproducción, conexión y reflexión y en cada una de las competencias (Pensar y razonar, Argumentar, Comunicar, Modelizar, Resolver problemas, Representar y Utilizar el lenguaje simbólico,formal y técnico y las operaciones) que determinan el criterio que se utiliza, posteriormente, para el estudio de las cuestiones y problemas propuestos.

En el tercer capítulo se contrastan los contenidos específicos del currículo, por una parte, y los contenidos propios de los problemas y de las cuestiones de las PAEU por otra. Se elaboran una serie de quince tablas: Tres tablas descriptivas y cuantitativas de contenidos curriculares y otras tres tablas de categorías de contenidos procedimentales, una para cada nivel conceptual (Análisis Matemático, Álgebra y Geometría) que se completan con seis figuras en las que se evidencia la presencia/ausencia de contenidos conceptuales propuestos, y otras nueve tablas, estas de frecuencias de aparición de contenidos en problemas,cuestiones y problemas y cuestiones juntos, por cada contenido conceptual, que permiten visualizar de una forma más cercana la presencia/ausencia de dichos contenidos.

Los capítulos siguientes, IV, V y VI presentan la resolución y el análisis en competencias de una selección de los enunciados de Análisis Matemático, Álgebra y Geometría, respectivamente. Todos ellos tienen una estructura similar en lo que respecta al desarrollo de los contenidos, que se concretan en los siguientes apartados:

- Estudio detallado de las competencias implícitas asociadas a cada cuestión o problema de los propuestos en las PAEUs LOGSE de Castilla y León, desde Junio de 1995 hasta Septiembre de 2009. En este estudio se presenta el enunciado del problema o cuestión en dos tablas, en la primera se consigna la convocatoria en la que fue propuesto, (año, junio o septiembre y opción A o B) y un estudio gramatical del enunciado con el tiempo verbal utilizado. Se señalan las incorrecciones de tipo gramatical que contienen los enunciados propuestos y, en cada caso, se escribe un enunciado alternativo salvando las deficiencias observadas. Este estudio se consigna en la misma tabla. 
- Al final de la resolución de cada problema o cuestión se presenta una segunda tabla en la que se analizan, explícitamente, las competencias matemáticas presentes en cada tarea y el nivel de las mismas.

Termina cada capítulo con dos tablas, una de los problemas y otra de las cuestiones, que resumen cuantitativamente la clasificación de los ejercicios y competencias presentes en su resolución y un análisis de las mismas.

El estudio completo de todos los enunciados propuestos en las pruebas correspondientes a los doce años de estudio se encuentra en los Anexos I a VI, que acompañan a este trabajo.

En el séptimo capítulo se muestra un análisis morfosintáctico de algunas de los inexactitudes detectadas en el estudio gramatical de los enunciados.

Se concluye esta memoria con el capítulo VIII. En él se manifiestan las conclusiones del estudio, se presentan las aportaciones, puntos fuertes y débiles y una serie de problemas que abre la investigación.

La figura siguiente representa los contenidos de la presente memoria de tesis. Con ella se pretende facilitar la comprensión de su estructura. 



\section{Análisis de la Pruebas de Acceso a las Universidades de Castilla y León (Matemáticas II)}

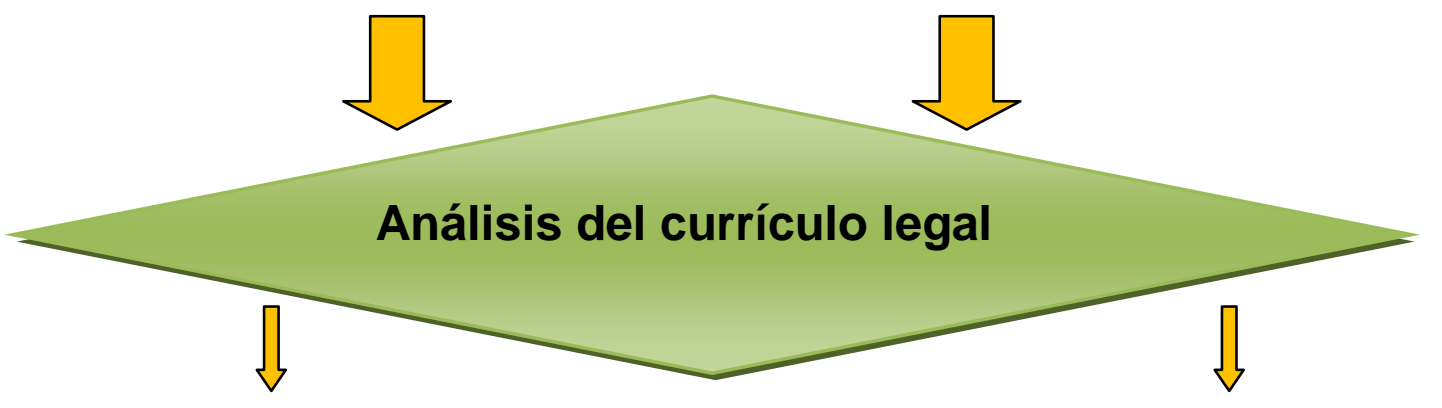

O1.- Analizar hasta qué punto las PAEUs contribuyen al desarroIlo del currículo de Bachillerato.

O2.- Determinar las competencias matemáticas implícitas tanto en los enunciados de los problemas y de las cuestiones de las PAEUs como en sus procesos de resolución

O3.- Analizar la redacción de los enunciados de los problemas y de las cuestiones.
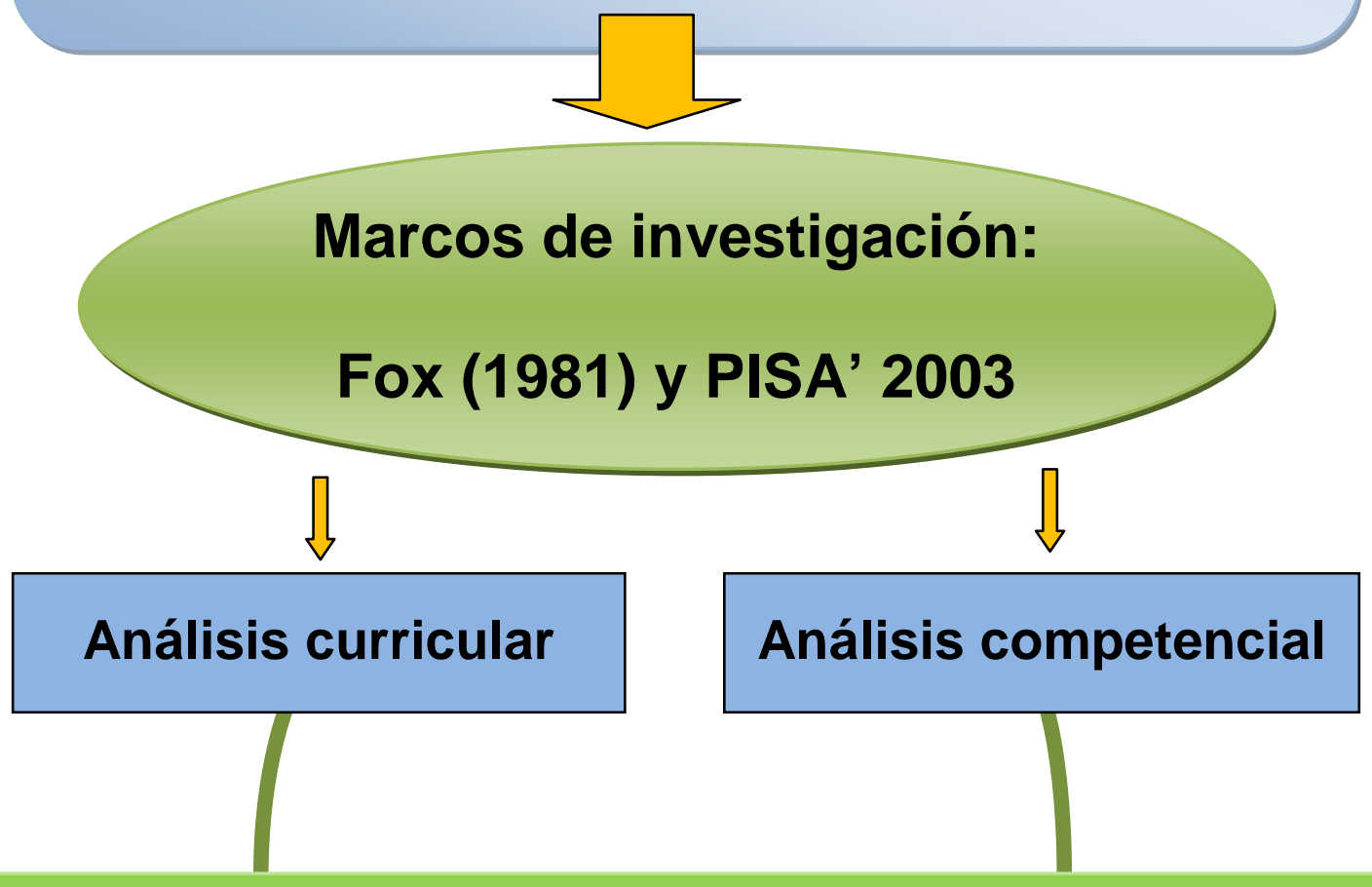

\section{Aportaciones y conclusiones}





\section{CAPÍTULO I}

\section{CURRÍCULO Y EVALUACIÓN}

\section{I.1. INTRODUCCIÓN}

Es indudable que el profesorado es el estamento encargado de la aplicación del currículo, motivo por el cual éste debe estar convencido de que es un buen currículo, que le va a facilitar su labor de enseñanza y que con él los alumnos aprenderán los fines programados. Si esto no es así, como afirma Howson (1991), invocando a R. Thom, "el currículo estará condenado al fracaso y será como una felicitación de Navidad". Por otra parte; las pruebas de evaluación, que deben guardar una relación muy estrecha con las actividades que se llevan a cabo en las aulas, juegan un papel muy importante, ya que si éstas no cambian y se adaptan al nuevo currículo, éste no cambiará. Así pues, desarrollo curricular y evaluación están íntimamente relacionados y no se pueden considerar de forma aislada. Por esta razón, en este capítulo se hace un breve estudio histórico sobre la evolución del currículo analizando documentos que reflejan investigaciones sobre la evaluación desde una perspectiva curricular, evocando a los trabajos de algunos investigadores que analizan y enuncian las características generales de una "buena evaluación" (Landsheere, Giménez, etc.) de las que nos hacemos eco. Currículo y evaluación están íntimamente relacionados y, en el estudio que se realiza, marcan el final de una etapa educativa y el comienzo de otra, en la Universidad.

\section{I.2. NOCIÓN DE CURRÍCULO}

Al unísono de investigaciones de autores como Gvirtz y Plamidessi (1998), Rico (1998), Coll (2007), etcétera, se puede establecer que el concepto de currículo es de carácter sistémico o que, en el campo de la educación, es un término polisémico, dado que adquiere una pluralidad de significados. Pero, cual- 
quiera que sea la perspectiva o enfoque de éste, el currículo está directamente vinculado con los procesos de selección, organización, distribución, transmisión y evaluación del contenido y de sus objetivos dentro de los sistemas educativos.

Dado que la noción de currículo ha sido objeto de extensos y profundos trabajos de reflexión; aquí se presenta una limitada selección de la labor realizada por especialistas en educación matemática.

Para Hirst (1973), citado en Grvitz y Plamidessi $(1998,8)$, es un programa de actividades, diseñado de forma que los alumnos alcancen, tanto como sea posible, determinados fines y objetivos educacionales. Para Stenhouse (1984), citado en Coll, $(2007,32)$ es un empeño para comunicar los principios y rasgos esenciales de un propósito educativo, de forma tal que permanezca abierto a discusión crítica y pueda ser trasladado efectivamente a la práctica.

Como referencia inicial fijamos el Decreto 160/1975, de 23 de enero, que aprueba el Plan de Estudios del Bachillerato; dado que en esta Orden, además del índice temático de los contenidos científicos, aparecen reflejados los objetivos y las orientaciones metodológicas que deben presidir enseñanzas y actividades. A raíz de este Decreto y de la implantación de los programas de Bachillerato, surge un proyecto de investigación curricular para este nivel educativo, llevado a cabo por los Grupos Cero de Valencia y Zero de Barcelona. La primera finalidad del trabajo de estos grupos era el ofrecer propuestas alternativas al currículo convencional que hasta ese momento se había desarrollado en la asignatura de Matemáticas, su influencia mediática se lleva a cabo mediante cursos y actividades de formación del profesorado, y su actuación combina un esquema de innovación con la adaptación, tras su lectura y asimilación, de las investigaciones que ya se estaban realizando en el extranjero, principalmente en Holanda y el Reino Unido.

En 1976 se celebra en Karlsruhe el tercer Congreso Internacional sobre Educación Matemática (ICME), en el que se reúnen unos dos mil educadores matemáticos de todo el mundo, con un tema central: el currículo de matemáticas. A raíz de este encuentro, utilizando como base los trabajos preparatorios del mismo y sus Actas, en 1979 la UNESCO publica un documento: Nuevas Tendencias en la Enseñanza de la Matemática, Volumen IV, extenso trabajo organizado en 13 capítulos, en el que se revisa mediante una perspectiva compara- 
tiva y de forma minuciosa los diferentes planes de formación en matemáticas, que se daban en el sistema educativo.

“Los Capítulos 7, 8 y 9 están dedicados a profundizar sobre tres nociones básicas para el currículo de matemáticas: el desarrollo curricular, la evaluación y las metas y objetivos generales de la educación matemática" (Rico, 1997a, 50)

Posteriormente, en el año 1980 se celebró en Osnabrück (Alemania) una conferencia internacional en la que se trata ampliamente la noción de currículo, reunión que tiene como objetivo la puesta a punto del proyecto del segundo estudio International Assessment of Mathematical Achievement de la IEA (Agencia de investigación International Educational Assessment), que se había presentado en la reunión de Karlsruhe y recoge en sus actas las pautas que definen el mismo y de las que Rico destaca las dimensiones que allí se establecen:

"Las cuatro dimensiones del concepto de currículo son los objetivos, contenidos, metodología y evaluación" (Rico, 1997a, 52)

En 1981 se celebran en Barcelona las Primeras Jornadas sobre Aprendizaje y Enseñanza de las Matemáticas (JAEM), que son un foro de debate para mejorar las competencias didáctica y metodológica y los recursos de los profesores de matemáticas y, en ellas, se ve la necesidad de una profunda reforma de los programas de Matemáticas del currículo español que hasta el momento se estaban impartiendo. Entre 1981 y 1984 tuvieron periodicidad anual, dejaron de celebrarse entre 1985 y 1990, y desde 1991 se han venido celebrando cada dos años.

Entre 1981 y 1982 se efectuó el segundo estudio internacional del rendimiento en matemáticas, en el que participaron veinte países, entre los que no se encuentra España.

Hasta la década de los ochenta, la formación matemática en España, y en otros países, se fundamentó en el desarrollo de capacidades de razonamiento lógico, en el reconocimiento de la matemática como elemento fundamental en el desarrollo de la ciencia, en una abstracción, rigor y precisión ligados a un conjunto estático de conocimientos, lo que llevó a que su estudio se centrase en el manejo de definiciones, propiedades, teoremas y procedimientos algorítmicos; pero, en ningún momento se cuestionaban factores sobre la enseñanza de contenidos curriculares tan importantes como: ¿cómo entendía el alumno esos conocimientos?, ¿cómo enseñar a aprender?, ¿cómo interpretar lo que había aprendido?, ¿cómo evaluar la adquisición de estos conocimientos? 
La programación de cada asignatura quedaba reducida a la introducción de nuevos conocimientos, pero, con el concepto de currículo, si nos referimos al currículo de matemáticas, surgen preguntas para profundizar en el mismo como, ¿en qué consiste el conocimiento en matemáticas? O bien, podemos cuestionarnos, ¿cómo podemos caracterizar el aprendizaje y la comprensión de los conceptos matemáticos? Así, nace la necesidad de considerar que una programación va unida a unas orientaciones metodológicas y, por tanto, hay que encontrar métodos que ayuden al alumno a obtener una formación matemática constructivista.

La Ley Orgánica 1/1990 del 3 de octubre, de la Ordenación General del Sistema Educativo (BOE. № 238, 28930, de 4 de octubre), en su Artículo cuarto establece lo siguiente:

"A los efectos de lo dispuesto en esta ley, se entiende por currículo el conjunto de objetivos, contenidos, métodos pedagógicos y criterios de evaluación de cada uno de los niveles, etapas, ciclos, grados y modalidades del sistema educativo que regulan la práctica docente.

A partir de la publicación de este texto la ley ampara una concepción curricular más amplia que la de programa de la asignatura, pasando a formar parte de él toda actividad que tenga algo que ver con la educación de los alumnos. En este sentido, es clarificadora la siguiente interpretación de Stenhouse (1984), que nos transcribe Rico al establecer las bases teóricas del Currículo de matemáticas en educación secundaria:

"En su acepción educativa, el concepto de currículo se ha convertido en un término genérico con el que se denomina toda actividad que planifique una formación". (Rico, 1997a, 28)

Este concepto del currículo considerado exclusivamente como plan de formación ha sido desbancado por esta reciente definición de currículo:

"Un plan operativo que detalla qué matemáticas necesitan conocer los alumnos, cómo deben alcanzar los alumnos estos objetivos curriculares, qué deben hacer los profesores para conseguir que los alumnos desarrollen su conocimiento matemático y el contexto en que se desarrolla el proceso de enseñanza-aprendizaje" (Curriculum and Evaluation Standards for School Mathematics, p.1) (Rico, 1997a, 245)

Con las ideas y matices aportados, la idea de currículo se incrementa e incluye la práctica desarrollada por alumnos y profesores en el aula; trasladando el fo- 
co del currículo del propio contenido matemático al entorno del aprendizaje desarrollado en un contexto social subyacente. Es pues, fundamental revisar la consideración sobre el currículo, tratando de evitar la identificación de currículo con contenidos y se tiene que diferenciar entre currículo pretendido y currículo alcanzado.

Según Coll (2007, 31), el currículo se asume como el proyecto que preside las actividades educativas escolares, precisa sus intenciones y proporciona guías de acción adecuadas y útiles para los profesores que tienen la responsabilidad directa de su ejecución. Para ellos, el currículo proporciona informaciones concretas sobre qué, cuándo y cómo enseñar y, por ende, qué, cuándo y cómo evaluar.

Se pueden aportar muchas definiciones, no todas son iguales, por el contrario tienen diferencias significativas y unas definiciones son más completas que otras en el sentido de que aportan indicaciones más precisas sobre la responsabilidad de los sectores que integran la docencia (Administración, Instituciones, alumnado, profesorado, padres)

Una definición clásica y, sin duda, la más simple es esta: "Currículo es un plan de estudios."

\section{I.3. CURRÍCULO Y EVALUACIÓN}

Uno de los elementos destacados del currículo, ya señalado en Osnabrück, es la evaluación, cuya orientación fundamental consiste en determinar el aprendizaje que adquieren los alumnos.

La pluralidad de planteamientos y formas de abordar la evaluación en matemáticas se puso de manifiesto en el IMCI Study (1991) de Calonge, dedicado monográficamente a este tema.

El concepto de evaluación atiende a la ordenación tanto de la organización de la docencia como de su proceso, constituyéndose, así, en pieza clave del proceso educativo; establece la base de lo que Giménez (1997) denomina la "regulación" del proceso educativo. Este mismo autor (p. 111), considera que la evaluación sumativa posee la misión de promover al estudiante para nuevos estadios, tratándose, por tanto, de una evaluación que se realiza al término de un proceso: nivel, ciclo o etapa. 
Para Howson (1993), la primera reflexión que se puede hacer sobre la evaluación es qué tipo de evaluación demanda la sociedad, si una evaluación formativa, que es la esencial para el educador, o una evaluación sumativa, que es la aplicada generalmente al alumno; resumiendo, la evaluación formativa es parte del sistema de control de la educación y la evaluación sumativa tiene una amplia componente social y determina la promoción o no del alumno.

Para entender la interrelación entre los exámenes, considerados como la parte más importante de la evaluación, y la sociedad, se presenta una breve reseña histórica.

Según Howson (1993), el primer sistema de examen escrito, del que se tiene conocimiento, parece que tuvo lugar en China, alrededor del año 200 A.C., sirvió para controlar la entrada en puestos oficiales, actuó como iniciativa e imagen de una apertura del poder jerárquico y como valedor de la tradición de escolarización.

De hecho, en Oriente se usaban procesos de evaluación formal muchos años antes que en Occidente, pues aunque a finales del siglo XIII se habían establecido algunos tipos de prueba en universidades de Europa, sus modelos de examen eran simples exposiciones orales o discusiones públicas. Por ejemplo, Cambrigde no introdujo exámenes de matemáticas escritos hasta 1750 y los estudiantes del King's Collage estuvieron exentos de su realización durante un siglo más; pues bastaba con residir en la universidad de Cambrigde para ser considerado suficientemente cualificado en sus estudios.

Durante el siglo XIX comienzan a utilizarse masivamente los exámenes escritos. Desde su implantación, la evaluación ha variado, dependiendo del sujeto que recibía la instrucción, del tipo de instrucción que se recibía y de los instrumentos utilizados para la misma. Aun cuando las diferentes teorías de aprendizaje establecen criterios referentes a la instrucción y a la forma de medir las habilidades alcanzadas, no asignan un modelo específico de evaluación para cada una de ellas, dado que algunas de estas teorías son coetáneas y la evaluación está influenciada por más de una corriente.

En Francia, se vio en los exámenes competitivos una forma de crear una escala educacional que recompensaba el mérito del alumno, de hecho tener acabado el bachillerato francés (baccalauréat) o el prusiano (abitur) era cualificación suficiente para entrar al servicio del estado o para acceder a la Universidad. Sin 
embargo, Lacroix (1805) cuestionó las ventajas de los exámenes escritos, pese a que permiten que los alumnos sean evaluados de una forma igualitaria.

Los expertos consideran la evaluación como parte integral de la instrucción. En Tortosa y otros (1992) se desarrolla con detalle que la conceptualización de la evaluación viene condicionada por los objetivos de la Educación Matemática; es decir, el fin de la evaluación determina qué y cómo enseñar; y el tipo de evaluación que se lleve a cabo incidirá directamente en el proceso de enseñanzaaprendizaje, en los contenidos y en los métodos. La evaluación se centra en la consideración de las habilidades cognitivas según el grado de excelencia, asociada a la idea de que las matemáticas están organizadas de forma jerárquica y sirven para regular la educación.

Los exámenes objetivos han sido los que más han predominado desde inicios del siglo XX pero, bajo la presión de mejorar los resultados, los profesores reorganizan la instrucción en clase ante la creencia de que la evaluación debe estar dirigida a metas específicas de la instrucción. Los profesores y examinadores especialistas estaban convencidos de que este tipo de instrucción, que consistía en "enseñar para el examen", mejoraba el aprendizaje. Estos, según Shepard (2001), usan dos formas de evaluación distintas para metas diferentes:

a) Un sistema de notación conocido como registro continuo para valorar el dominio de las destrezas; $y$

b) Resúmenes escritos para valorar la comprensión.

Para desarrollar un modelo de evaluación en el aula que se ajuste a la forma de enseñanza y aprendizaje acorde a una perspectiva constructivista, se debe considerar un nuevo concepto de la evaluación unida a los cambios de las teorías de aprendizaje y la epistemología (Shepard, 2001). Así, el foco de la instrucción de las Matemáticas debe ser la destreza del pensamiento y los procedimientos de evaluación aplicados deben establecer el pensamiento que contienen estas respuestas (Romberg, 1993). La evaluación debe reconocer la necesidad de considerarse parte del proceso de enseñanza-aprendizaje y no puede evadirse de las interacciones sociales que acontecen en el aula. Debe considerarse el papel del profesor y el del estudiante como protagonistas del proceso de enseñanza y aprendizaje. 
La evaluación auténtica, basada en ideas constructivistas, comienza con tareas complejas en las que se valoran los argumentos que describen conjeturas, estrategias y justificaciones. La evaluación auténtica se debe desarrollar determinando el grado en que, cada alumno, ha aumentado su habilidad para resolver problemas no rutinarios, comunicar, razonar y ver la aplicabilidad de las ideas matemáticas a una variedad de situaciones que están relacionadas (Romberg, 1993).

El estudio de Rico (1993) sobre la evaluación en matemáticas es muy interesante y aunque se centra en los estudios de Educación General Básica las conclusiones son extensivas para el currículo de bachillerato.

La reflexión sobre evaluación en el campo de la Educación Matemática encuentra su marco conceptual de referencia dentro de los estudios sobre el Currículo de Matemáticas. Rico, Castro, Castro, Fernández y Segovia (1997) señalan momentos importantes en la elaboración de un marco teórico sobre el currículo desde la Educación Matemática.

La inquietud del profesorado, en general, con respecto a la evaluación es un indicador del conocimiento que se tiene de que la misma ha de ser orientada hacia una dirección que contribuya al aprendizaje efectivo y al desarrollo de la auto-estima en el alumno. Es un campo de trabajo de mucha importancia, para la comunidad de educación matemática de España, en la actualidad, se considera fundamental y, entre otras debe tener las siguientes consideraciones:

La evaluación no puede ser tratada como un elemento aislado del currículo, ya que es interdependiente de los demás elementos del mismo, es decir, de los contenidos, los objetivos y la metodología.

La evaluación debe tener un papel formativo, tiene como fin orientar al alumno y promover en él un mayor control del conocimiento que posee, observar qué errores comete y qué defectos tiene su trabajo intelectual.

Sin embargo, los procesos de evaluación no son siempre adecuados y tienen que estar fundamentados en los objetivos curriculares (generales y específicos) y detectar los avances de los alumnos. En palabras de Rico, un programa de evaluación debe cumplir ciertos requisitos, entre los que, en relación con las PAEU, destacamos estos dos:

1) Debe ser amplio y compatible con los objetivos del currículo. 
2) Debe tener suficiente fuerza de diagnóstico como para distinguir los diversos niveles del rendimiento .(Rico, 1997a, 96)

Para Landsheere $(1992,100)$, un examen tiene que ser válido y equitativo y, para ello, en su propuesta debe presentar un elevado número de preguntas, algo que parece evidente si el campo a cubrir es muy extenso, -todo un curso lectivo, además del bagaje matemático adquirido antes de ese curso-. De no ser así; si, en exclusiva, se pregunta fundamentalmente sobre una parte, -a veces mínima-, de la materia, se puede potenciar la reducción de la calidad en el aprendizaje, pues se supone que todos los alumnos poseen un aprendizaje homogéneo.

En otra línea, la capacidad más necesaria para potenciar un examen, es saber proponer las cuestiones de una prueba, dado que es un arte difícil pues hay que tener presentes varios factores, por un lado, la materia sobre la que se quiere evaluar, y por otra parte, es fundamental tener celo en la elección del lenguaje que se utiliza en la propuesta, para evitar, con la redacción, errores de interpretación del contenido a evaluar. Si no se presta mucha atención a estas consideraciones se desemboca en un incremento del nivel de ineficacia de una prueba, en la que se combinan dos dificultades: La dificultad intrínseca del problema matemático y la dificultad del lenguaje abstracto.

Thorndike es considerado como el padre de la "medida científica" en educación (Giménez, 1997) y según Lansdheere, fue el racionalista Thorndike quien propuso una serie de características que deben estar implícitas en las pruebas de evaluación escritas y para él se deben observar las siguientes:

-Antes de comenzar a redactar el enunciado de una cuestión se debe considerar el proceso mental que se desea que el alumno utilice para dar respuesta a la misma.

- Las preguntas han de estar redactadas de forma que sean claras y concisas y que estén adaptadas en su complejidad al nivel de madurez del alumno; de hecho, en bastantes ocasiones, las respuestas equivocadas no se deben a la ignorancia de la materia, sino a la incomprensión del enunciado.

-El tiempo asignado para las pruebas debe ser lo suficientemente amplio para que los alumnos respondan sin agobio. 
Tan nefasto es el resultado si una prueba se basa únicamente sobre las partes "más raras" del currículo, que el alumno, generalmente, no llega a estudiar como si las cuestiones son tan elementales que, una simple distracción en la lectura del enunciado propuesto conduzca a una respuesta equivocada en un tema, sin embargo, sobradamente conocido.

La evaluación ha de ser eficaz pero, también, ha de tener poder discriminatorio. La excesiva facilidad de una prueba puede únicamente inducir a error en la apreciación de los aprendizajes alcanzados y no valorar, en justicia, los conocimientos matemáticos que ha adquirido el alumno. Es, pues, razonable acompañar la misma de un índice de eficacia que revele en qué medida determinadas preguntas discriminan a aquellos alumnos de distinto nivel académico.

Las pruebas que se presentan en los exámenes de la PAEU son pruebas externas (las propone una institución diferente de la que ha instruido a los alumnos) que se basan en conocimientos procedimentales, se construyen de forma artesanal por un grupo de "expertos" y, en teoría, tienen en cuenta los resultados de años anteriores.

También responden a fines formativos (sumativos) y criteriales, ya que tratan de medir si los alumnos alcanzan un cierto nivel de formación y, por tanto, son indicadoras de los niveles de rendimiento de los alumnos en el aprendizaje de las matemáticas, pero no constituyen un test adaptativo, pues no presentan cuestiones que permitan "individualizar" el examen, y, aunque tienen como metas la imparcialidad, establecer de manera justa el rendimiento del alumno y estar exentas de todo favoritismo (garantizado por el anonimato), no determinan si los alumnos han sido enseñados fielmente, pues para ello se tendría que analizar los errores de los alumnos y ver si aparecen errores didácticos, (eso no se hace).

Permiten apreciar la facilidad o dificultad de la prueba, aunque después no son integradoras en la docencia.

Sin embargo, no hacen justicia a la diferencia de nivel alcanzada por los alumnos, por lo cual no son imparciales ni adaptativas, la repetición de enunciados y contenidos no determina la fidelidad en el cumplimiento de un currículo oficial que queda seriamente sesgado.

Es usual considerar que la evaluación se emplea para decidir sobre los méritos para seleccionar a los alumnos, para valorar la calidad del sistema escolar y el 
rendimiento académico, quedando de esta manera probada su utilidad en el currículo, siendo necesaria una revisión para determinar hasta qué punto el currículo y la enseñanza satisfacen los objetivos de la educación. En cualquier caso es necesario elaborar un instrumento de evaluación que permita verificar los objetivos propuestos en la programación, de tal forma que responda a criterios de objetividad, fiabilidad y validez.

La evaluación también puede tener como finalidad detectar las dificultades de enseñanza-aprendizaje (evaluación diagnóstica), con ello es posible mejorar la actuación del profesor en el aula; es por eso por lo que debe jugar, entre otros roles, el de contraste; es decir, comprobar el nivel de conocimientos alcanzado, determinar el progreso educativo y situar al alumno respecto del grupo y el de diagnóstico, necesario para detectar cuáles son las mayores dificultades en el aprendizaje y en función de esta información programar y desarrollar la instrucción.

Dado que la evaluación es una parte fundamental de los procesos de enseñanza y aprendizaje, y puesto que los nuevos enfoques competenciales la han venido descentrando de la postura diagnóstica de tipo clasificatorio, al considerarla como un factor que incide en las prácticas, es preciso que los cambios en la evaluación conlleven una reorientación en los procesos, esto es, que el tipo de tareas, los materiales, la organización y la planificación de la docencia, nuestra intención en este trabajo es manifestar que la evaluación, además de emitir juicios sobre los estudiantes a partir de medidas de logros, debe interesarse en proporcionar información del nivel competencial que estos han adquirido para implementarlo en necesidades sociales concretas, cuyas actividades y cuya práctica se relacionan estrechamente con el contexto.

En particular, lo que interesa es que los estudiantes desarrollen una forma de pensar y razonar, una disposición hacia el estudio de las matemáticas donde exhiban distintas formas de representar fenómenos, identifiquen relaciones y patrones, formulen conjeturas, justifiquen y comuniquen resultados y que integren los medios tecnológicos.

Para Santos Trigo (2007), la idea es la necesidad de ir más allá de la propuesta de exámenes estandarizados y promover una forma de evaluación en la que los estudiantes tengan oportunidad de mostrar distintos procesos de razonamiento, extender o buscar conexiones y eventualmente formular sus propios 
problemas o preguntas. Esta consideración se corresponde con el nivel de reflexión de PISA'2003.

Evaluar la competencia matemática de los estudiantes incluye evaluar hasta qué punto cuentan con habilidades que puedan aplicar con éxito en situaciones problemáticas $\mathrm{y}$, aunque forma parte del marco teórico (capítulo II), aquí se describen las características del marco teórico relacionadas con los contenidos curriculares y la evaluación. Asimismo, consideramos las orientaciones del NCTM sobre pruebas de evaluación.

\section{I.4. EL CURRÍCULO DE MATEMÁTICAS DE ENSEÑANZA SE- CUNDARIA DEL NCTM.}

En 1980, la sociedad norteamericana de profesores de matemáticas National Council of Teachers of Mathematics (NCTM) publicó el documento An Agenda for Action: Recommendations for School Mathematics of the 1980s, en el que enunciaba 8 recomendaciones encaminadas a reestructurar el currículo de matemáticas, en las enseñanzas de la sociedad americana, de la educación obligatoria. Con estas recomendaciones se pretendía mejorar la atención que se presta a las necesidades de una población de estudiantes muy diversa, en la sociedad actual, sociedad que está dominada por la tecnología.

Entre las recomendaciones nos parece oportuno entresacar las siguientes, porque son las que tienen mayor relación con las PAEU:

1) La resolución de problemas debe ser el foco de las matemáticas escolares.

2) El concepto de destreza básica debe abarcar algo más que la facilidad para los cálculos.

3) Los programas de matemáticas deben obtener ventajas de la potencia de las calculadoras y ordenadores.

4) El éxito de los programas de matemáticas y el aprendizaje de los alumnos deben evaluarse mediante una variedad de instrumentos mayor que las pruebas convencionales. (Rico, 1997a, 241-242)

Para Rico (1997a), el problema de designar las finalidades o metas de la Educación Matemática, es una cuestión de especial relevancia para el diseño y el desarrollo de cualquier currículo de matemáticas. 
En N.C.T.M. (1989) se aprecian elementos cuyos planteamientos apuntan a las actuales competencias recogidas en nuestro currículo LOE, que no son otras que las formuladas en Pisa'2003:

1) Aprender a valorar las matemáticas. Comprender su evolución y el papel que desempeñan en la sociedad y en las ciencias.

2) Adquirir confianza en la aptitud propia. Llegar a confiar en el pensamiento matemático propio y poseer la capacidad de dar sentido a situaciones y resolver problemas.

3) Adquirir la capacidad de resolver problemas matemáticos. Esto es esencial para llegar a ser un ciudadano productivo y exige experiencia para resolver diversos problemas generalizados y no rutinarios.

4) Aprender a comunicarse matemáticamente. Aprender los signos, los símbolos y los términos matemáticos.

5) Aprender a razonar matemáticamente. Realizar conjeturas, reunir pruebas y construir argumentos matemáticos.

Las tareas relativas a la resolución y al planteamiento de problemas son instrumentos que posibilitan indagar sobre aprendizajes específicos de los estudiantes preuniversitarios. La resolución de problemas tiene su complemento ideal en el planteamiento de problemas ya que el trabajo de los estudiantes cuando resuelven y plantean problemas de matemáticas se considera como indicador de la construcción de conocimiento en el proceso de aprendizaje. El planteamiento de problemas tiene potencial para ser altamente significativo a la hora de investigar en pensamiento matemático avanzado.

Los procesos de resolución de problemas activan el razonamiento y la comprensión de los conceptos, mientras que los procesos de planteamiento de problemas añaden a lo anterior un mayor nivel de abstracción y la necesidad de utilizar adecuadamente el lenguaje natural y formal.

Mayoritariamente, en las pruebas que se han propuesto en la pruebas PAEU se concede total importancia a los problemas de solución única e inmediata, enfatizan en la mecanización de algoritmos y procedimientos y dan escasa importancia al pensamiento y al razonamiento matemático.

En lo referente a las pruebas de evaluación de contenidos, una de las recomendaciones del NCTM, es que estas pruebas deben centrarse en la evaluación de las estructuras conceptuales matemáticas considera 14 estándares curriculares, de los cuales, los relativos a la evaluación de las estructuras conceptuales son: Potencia matemática, Resolución de problemas, Comunicación, 
Conceptos matemáticos, Razonamiento, Procedimientos matemáticos y Actitud matemática. Para el NCTM, el objetivo fundamental de estas pruebas es evaluar aprendizajes y el vehículo que conduce a esa evaluación está formado por los contenidos contenidos y dan las siguientes orientaciones sobre la finalidad de las pruebas:

- Comprobar qué saben los alumnos y cómo piensan en cuanto a las matemáticas

- Considerar la evaluación parte integrante de la docencia.

- Centrarse en una gama amplia de tareas matemáticas y adoptar una visión global de las mismas.

- Plantear situaciones problema que requieran la aplicación de diversas ideas matemáticas.

- Utilizar técnicas múltiples de evaluación, incluyendo formatos escritos, orales y demostraciones.

- Utilizar en la evaluación calculadoras, ordenadores, y materiales de manipulación.

- Valorar el programa recogiendo sistemáticamente: información sobre resultados, currículo y docencia.

- Usar pruebas normalizadas de consecución de objetivos sólo como uno de muchos indicadores del resultado de un programa.

Las pruebas de evaluación deben ser consideradas como parte integrante de la docencia, pero, por el momento, parece que las PAEU no se consideran desde este punto de vista, sino que son utilizadas como un simple recuento de respuestas acertadas en un examen, con un único fin: poner una puntuación para distribuir a los alumnos en los estudios universitarios. Además, deben centrarse en una amplia gama de tareas matemáticas, planteando situaciones-problema que requieran la aplicación de varias ideas y contenidos matemáticos; adoptando una visión global de las mismas y no como parece que sucede en los exámenes de la PAEU, que se centran en unas destrezas específicas y aisladas, organizadas en el binomio contenido/actuación, utilizando ejercicios que sólo requieren una o dos destrezas.

Según las directrices del NCTM, las pruebas de acceso a la Universidad de Valladolid, que se realizan en este momento adolecen de excluir en el proceso el uso de ordenadores o calculadoras gráficas y en ellas se valora el desarrollo del programa basándose exclusivamente en la puntuación de los exámenes cuando se debe valorar, a partir de los resultados, el currículo y la docencia. 


\section{I.5. CONTENIDOS CURRICULARES Y PRUEBAS DE ACCESO DE MATEMÁTICAS}

En este apartado ser hace un breve estudio del marco legal desde el año 1975, en el que se implantan las Pruebas de Acceso a la Universidad hasta el Decreto $70 / 2002$ de 23 de mayo, pasando por las modificaciones derivadas de las distintas leyes que ha ido dictando el Ministerio de Educación y Cultura desarrollando la Ley Orgánica 1/1990 (LOGSE): Real Decreto de Mínimos 1178/ 1992, Real Decreto del Currículo de Bachillerato 1179/1992 y Real Decreto $3474 / 2000$ que modifica los anteriores y con ello la estructura de Bachillerato. Por otra parte, también aparece una relación de los distintos Decretos y Leyes que han determinado la estructura y contenido curricular de las Pruebas de Acceso a la Universidad en los últimos años, desde las que establece el Curso de Orientación Universitaria (COU), -Decreto 160/1975- hasta las pruebas de Acceso a la Universidad del curso 2008-09, del bachillerato LOGSE.

Aunque la Ley General de Educación ha cambiado (LOU, 2006), este cambio no afectó a las pruebas hasta el año 2010. Es más, el tipo de problemas que se proponen en la Universidad de Valladolid son idénticos a los enunciados en el período LOGSE, incluso algunas cuestiones LOGSE se proponen como problemas LOU. Por tanto, no haremos ningún comentario específico sobre esta ley.

\section{I.5.1. LOS CONTENIDOS CURRICULARES LOGSE}

Históricamente, durante la década de los setenta, en España hay un cambio político que conlleva un cambio social y por tanto un cambio en muchos aspectos de la vida; las mejoras conseguidas traen consigo un mejor desarrollo de los sistemas educativos en nuestro país y en muchos países de Europa occidental, potenciando una serie de trabajos hacia la conceptualización de currículo, desechando la tendencia, en educación matemática, a la simplificación que asocia la formación exclusivamente con el conocimiento de conceptos, con el currículo nos referimos a un desarrollo más amplio, el currículo incorpora mecanismos de control cuya misión es valorar el grado de eficiencia de la formación tanto en su fin como en su desarrollo.

En el año 1975 el Decreto 160/1975, de 23 de enero, (BOE 13/02/1975) aprueba el Plan de Estudios del Bachillerato, y la Ley General de Educación de 4 de agosto de 1970, en su artículo 34, determina que corresponde al Ministerio de 
Educación y Ciencia dictar las normas que regulan el Curso de Orientación Universitaria (COU). Dada la fuerte interrelación entre este curso y el Bachillerato, regula en la misma orden la programación de las materias constituyentes del Plan de Estudios del Bachillerato. En la citada ley podemos leer: sección $3^{a}$ de Bachillerato:

2. Este nivel será unificado, en cuanto que conduce a un título y polivalente, comprendiendo, junto con las materias comunes y las libremente elegidas, una actividad técnico-profesional.

3. Se desarrollará en tres cursos, que se cumplirán normalmente entre los catorce y dieciséis años. (BOE 06/08/1970)

En el alumno, estos estudios abarcan el período de edad entre los 14 y 18 años, y se divide en dos etapas: Bachillerato Unificado y Polivalente (BUP) (1417) y Curso de Orientación Universitaria (COU.) (17-18). Como vía usual para el ingreso en la universidad, la Ley General de Educación estableció el Curso de Orientación Universitaria (COU.), curso que para muchos efectos funciona como un curso más del bachillerato, pero que presenta unas características especiales, pues se trata de un curso cuyos contenidos y control final corresponden a la universidad, si bien el curso es impartido, y evaluado por los profesores de Educación Secundaria, en los centros de bachillerato.

Para aquellas materias que son objeto de las Pruebas de Acceso, la Universidad nombra a un profesor universitario coordinador de la materia correspondiente, es el responsable del programa que se desarrolla para cada asignatura además de la elaboración de las Pruebas de Acceso y mantiene reuniones de coordinación con los profesores de educación secundaria.

En el programa de COU de Matemáticas publicaron los siguientes bloques de contenidos, que no detallamos porque nuestro estudio se fundamenta en las pruebas que establece la Ley Orgánica1/1990 de Ordenación General del Sistema Educativo (LOGSE):

1) Sistemas de ecuaciones lineales.

2) Espacios afín y euclídeo tridimensional.

3) Ampliación del cálculo diferencial e integral.

4) Ampliación del cálculo de probabilidades. 
Los programas de matemáticas para el Bachillerato y para el Curso de Orientación Universitaria tienen una continuidad conceptual y se desarrollan con una coherencia metodológica. Esta continuidad se basa en la consideración del aprendizaje de las matemáticas entendido como memorización individualizada de hechos, propiedades y rutinas operatorias y por el predominio de que la finalidad formativa de las matemáticas es el desarrollo intelectual de los escolares, por encima de cualquier tipo de consideración práctica.

En relación con las Pruebas de Acceso a la Universidad, parece que lo único que tiene importancia es el éxito o fracaso del Centro, considerando como tal el porcentaje de alumnos que superan dichas pruebas, pero no se cuestiona la validez objetiva de las pruebas. (El grado de dificultad, la validez, fiabilidad, escalonamiento,...)

Como señala Rico (1997a):

Las especiales características de esta prueba han hecho que aumente en los centros el nivel de exigencia de los exámenes finales de la asignatura, de manera que los alumnos que cada centro presente tengan garantizado al máximo la superación de la prueba de acceso. Los claustros de profesores viven la prueba de acceso como una evaluación propia y del centro, convirtiéndose de esta manera en una confirmación para los profesores de lo acertado de sus criterios de selección. (Rico, 1997a,. 39)

Este currículo de matemáticas derivado de la Ley General de Educación del año 1970 comenzó a ser operativo para los escolares nacidos en el año 1960 y estuvo vigente durante 22 promociones escolares, hasta los escolares que nacieron en 1982. Este sistema educativo fue derogado y sustituido progresivamente por el de la LOGSE de 1990.

En el curso 1985-1986 se comienza la fase de experimentación de la reforma del segundo ciclo de las Enseñanzas Medias. Mediante esta reforma se busca unificar el Bachillerato con una Formación Técnica, estableciéndose cinco tipos de Bachillerato, cada uno de ellos con dos cursos de duración. Este tipo de estudios se configura como enseñanzas post obligatorias; especializadas y seguidas de una Prueba de Acceso a la Universidad que deben realizar aquellos alumnos que deseen seguir estudios superiores.

La Ley Orgánica 1/1990, de 3 de octubre, de Ordenación General del Sistema Educativo en su artículo 4.2, atribuye al Gobierno fijar los aspectos básicos del currículo que constituirán las enseñanzas mínimas para todo el Estado, con el 
fin de garantizar una formación común de todos los alumnos y la validez de los títulos correspondientes. En su Sección segunda: Del bachillerato, aparece:

Artículo 25.1. El Bachillerato comprenderá dos cursos académicos.

Artículo 27.3 Las modalidades de bachillerato serán como mínimo las siguientes modalidades: a) Artes, b) Ciencias de la Naturaleza y de la Salud; c) Humanidades y Ciencias Sociales; d) Tecnología.

Artículo 29.2. El título de Bachiller facultará para acceder a los estudios universitarios. En este caso será necesaria la superación de una prueba de acceso. (BOE n 238 de 4 de octubre, 28932-28933)

Aprobada la LOGSE, el Ministerio de Educación y Ciencia, a principios de 1991, presenta un diseño concreto de estructura del Bachillerato acorde con la Ley. Esta propuesta es debatida tanto por las Comunidades Autónomas como por colectivos educativos, sirviendo para redactar los Reales Decretos 1700/1991, de Estructura del Bachillerato, de 29 de noviembre, (BOE 02/12/1991), en el que siguiendo el espíritu de la LOGSE los artículos 1 y 3 indican la duración y las modalidades. En ese decreto se encuentra lo siguiente:

La Ley Orgánica 1/1990, de 3 de octubre, de Ordenación General del Sistema Educativo, ha fijado las características básicas del Bachillerato, como etapa educativa de dos años de duración, que forma parte de la Educación Secundaria, y que da acceso a estudios superiores. Ha establecido también los objetivos generales del Bachillerato, expresados en términos de capacidades. De acuerdo con la Ley, el Bachillerato se organizará en diferentes modalidades, con materias específicas, las cuales, junto con las materias comunes y con materias optativas, vendrán a constituir el currículo completo de los alumnos que cursen estas enseñanzas.

Artículo $1^{\circ} .1$. El Bachillerato forma parte de la Educación Secundaria y se extenderá a lo largo de dos cursos académicos.

Artículo $3^{\circ} .1$. El Bachillerato se desarrollará en las siguientes modalidades: a) Artes, b) Ciencias de la Naturaleza y de la Salud; c) Humanidades y Ciencias Sociales; d) Tecnología.

Artículo 15\%.2. El título de Bachiller facultará para acceder a los estudios universitarios. En este caso será necesaria la superación de una prueba de acceso. (BOE 02/12/1991, 39061-39062)

y los Reales Decretos de Enseñanzas Mínimas de Bachillerato (1178/1992), y de Currículo de Bachillerato (1179/1992), este último sólo para el territorio directamente administrado por el Ministerio de Educación y Ciencia. 
Este Bachillerato derivado de la nueva ordenación del sistema educativo constituye una etapa de la Educación Secundaria de carácter no obligatoria y se estructura en dos cursos para que, salvo excepciones, los alumnos realicen estos estudios entre los 16 y los 18 años; y tiene las finalidades de proporcionar a los alumnos una formación general que favorezca una mayor madurez intelectual y humana, así como una mayor capacidad para adquirir una amplia gama de conocimientos y habilidades.

El establecimiento de una diversidad de modalidades, Artes, Ciencias de la Naturaleza y de la Salud, Humanidades y Ciencias Sociales, Tecnología, caracteriza la nueva regulación del bachillerato, (16 a 18 años) al que se accede tras cuatro años de educación secundaria obligatoria (12 a 16 años) y que preparará al alumnado para la vida activa o para continuar estudios posteriores, bien una formación profesional de grado superior o estudios universitarios.

En el documento: Bachillerato, Estructura y Contenidos (1991), correspondiente al bachillerato se diferencian dos partes: la primera está dedicada a presentar este nivel educativo dentro del nuevo marco legal y, en la segunda, aparecen como Anexos las materias del Bachillerato.

El 2 de octubre de 1992 el MEC promulga el Real Decreto 1178/1992 por el que se establecen las enseñanzas mínimas de Bachillerato y el Real Decreto 1179/1992 por el que se establece el currículo de Bachillerato. (Suplemento del BOE $n^{\circ}$ 253). Los contenidos conceptuales de Matemáticas II son los siguientes:

\section{Álgebra lineal}

Estudio de las matrices como herramienta para manejar datos estructurados en tablas y grafos. Operaciones con matrices: suma, producto, cálculo de la inversa. Interpretación de las operaciones y de sus propiedades en problemas extraídos de contextos reales.

Aplicación del estudio de las matrices a la resolución de sistemas de ecuaciones lineales.

Determinante de una matriz: concepto, cálculo y propiedades, aplicados a la resolución de sistemas y al cálculo de productos vectoriales y mixtos para determinar áreas y volúmenes. 


\section{Análisis}

Introducción a los conceptos de límite y derivada de una función en un punto.

Cálculo de límites y derivadas de las familias de funciones conocidas. Derivada de la suma, el producto y el cociente de funciones y de la función compuesta. Aplicación al estudio de propiedades locales de las funciones.

Aplicación de los conceptos de límite y derivada a la representación de funciones y al estudio de situaciones susceptibles de ser tratadas mediante las funciones.

Introducción al concepto de integral definida a partir del cálculo de áreas definidas bajo una curva. Técnicas elementales para el cálculo de primitivas. Aplicación al cálculo de áreas.

\section{Geometría}

Vectores: introducción al concepto y operaciones a partir del estudio de problemas físicos concretos.

Aplicaciones del cálculo vectorial a la resolución de problemas físicos y geométricos en el plano y en el espacio. Interpretación geométrica de las operaciones con vectores. Productos escalar, vectorial y mixto.

Estudio de algunas formas geométricas (rectas, curvas, planos y superficies), relacionando las ecuaciones con sus características geométricas.

Introducción al conocimiento de algunas curvas y superficies comunes. Idea de lugar geométrico. Iniciación al estudio de las cónicas, combinando los enfoques analíticos y sintéticos. ${ }^{1}$

Por el Real Decreto 1340/1999, de 31 de julio, se traspasaron las funciones y servicios de la Administración del Estado a la Comunidad de Castilla y León en materia de enseñanza no universitaria. Corresponde a la Consejería de Educación y Cultura establecer el Currículo propio para Castilla y León.

El Real Decreto 3474/2000 de 29 de diciembre, (BOE del 16/01/2001) modifica el Real Decreto 1700/1991 de 29 de noviembre, por el que se establece la es-

\footnotetext{
${ }^{1}$ La relación que se determina corresponde al Real Decreto 1179/1992, de 2 de octubre, por el que se establece el currículo de bachillerato. Los contenidos que no aparecen subrayados son los correspondientes al Real Decreto 1178/1992, de contenidos mínimos.
} 
tructura del Bachillerato y el Real Decreto 1178/1992, de 2 de octubre, por el que se establecen las enseñanzas mínimas de Bachillerato; introduciendo nuevos planteamientos de algunos contenidos en la materias comunes y en las de modalidad, así como la propia formulación de los currículos, actualizándoles desde el punto de vista científico y didáctico, para obtener una adecuada conexión entre los currículos de la educación secundaria y el bachillerato. Los contenidos de Matemáticas II de enseñanzas mínimas son:

\section{Análisis}

Límite de una sucesión. Límite de una función. Cálculo de límites.

Continuidad y derivabilidad de una función. Propiedades elementales.

Cálculo de derivadas. Aplicación al estudio de las propiedades locales y la representación gráfica de las funciones elementales. Optimización.

Primitiva de una función. Cálculo de integrales indefinidas inmediatas, por cambio de variable o por otros métodos sencillos.

Integrales definidas. Regla de Barrow. Cálculo de áreas de regiones planas.

\section{Álgebra lineal}

Matrices de números reales. Operaciones con matrices.

Rango de una matriz: obtención por el método de Gauss

Sistemas de ecuaciones lineales. Representación matricial de un sistema.

Discusión y resolución de un sistema por el método de Gauss.

Determinantes. Cálculo de determinantes de órdenes 2 y 3 mediante la regla de Sarrus. Propiedades elementales de los determinantes.

Utilización de los determinantes en la discusión y resolución de sistemas de ecuaciones lineales.

\section{Geometría}

Vectores en el espacio tridimensional. Productos escalar, vectorial y mixto.

Obtención e interpretación de las ecuaciones de rectas y planos a partir de sistemas de referencia ortonormales. 
Resolución de problemas de incidencia, paralelismo y perpendicularidad entre rectas y planos.

Resolución de problemas métricos relacionados con el cálculo de ángulos, distancias, áreas y volúmenes. (BOE no 14, 16 enero 2001, 1896)

La Consejería de Educación de la Junta de Castilla y León en su Decreto 70/2002 de 23 de mayo (BOC y L. no 102 de 29 de mayo de 2002) establece el Currículo de Bachillerato de la Comunidad de Castilla y León. En este Decreto el currículo de Matemáticas en los Bachilleratos de Ciencias de la Naturaleza y de la Salud y de Tecnología se encuentra dentro del Currículo General de Bachillerato, y está vigente en la actualidad. Los objetivos del currículo de Matemáticas II son genéricos, vinculados a uno o varios bloques de contenidos. La organización de los contenidos del currículo se efectúa siguiendo dos criterios muy amplios: el criterio disciplinar, puramente matemático, y el criterio cognitivo.

\section{Análisis}

Límite de una sucesión. Cálculo de límites. El número e.

Límite de una función en un punto. Propiedades. Técnicas del cálculo de límites (cancelación, racionalización). Límites laterales. Límites en el infinito. Comportamiento asintótico de una función.

Funciones continuas. Propiedades. Continuidad y función compuesta. Determinación de discontinuidades. Continuidad en intervalos cerrados.

Derivada de una función en un punto. Funciones derivables. Propiedades. Cálculo de derivadas. Teorema de Rolle. Teorema del valor medio. Regla de L'Hôpital.

Intervalos de crecimiento y decrecimiento de una función. Máximos y mínimos en un intervalo. Representación gráfica de funciones. Optimización.

Primitiva de una función. Reglas básicas de integración. Cálculo de integrales indefinidas sencillas: inmediatas, por cambio de variable, de funciones racionales y por partes.

Sumas de Riemann e integral definida. Propiedades. Regla de Barrow. Teorema del valor medio para integrales. Áreas de regiones planas. 


\section{Álgebra}

Sistemas de ecuaciones lineales. Operaciones elementales y reducción Gaussiana. Discusión y resolución de un sistema de ecuaciones lineales por el método de Gauss.

Representación matricial de un sistema de ecuaciones lineales. Matrices de números reales. Operaciones con matrices. Matrices invertibles.

Combinación lineal de filas de una matriz. Obtención por el método de Gauss del rango de una matriz y de la matriz inversa.

Determinantes. Cálculo de determinantes de órdenes dos y tres mediante la regla de Sarrus. Desarrollo por una fila o columna. Propiedades de los determinantes. Cálculo de determinantes mediante operaciones elementales.

Utilización de los determinantes en la discusión y resolución de sistemas de ecuaciones lineales.

\section{Geometría}

Vectores en el espacio tridimensional. Operaciones y bases. Producto escalar. Ortogonalidad y bases ortonormales. Producto vectorial. Producto mixto.

Sistemas de referencia. Coordenadas de puntos. Obtención e interpretación de las ecuaciones de rectas y planos a partir de sistemas de referencia ortonormales. Resolución de problemas de incidencia, paralelismo y perpendicularidad entre rectas y planos.

Resolución de problemas métricos relacionados con el cálculo de ángulos, distancias, áreas y volúmenes.

Esfera y elipsoide. Utilización de programas informáticos como apoyo para introducir superficies comunes.

Desde un punto de vista cognitivo, para ser matemáticamente competentes, debemos considerar el conocimiento matemático organizado en dos amplios campos: el conceptual y el procedimental. El conocimiento conceptual se caracteriza por ser un conocimiento teórico que es fruto de una actividad cognitiva, rico en las relaciones entre sus componentes y que se asocia con el saber qué y porqué. En él se tienen que considerar las unidades de información: los 
hechos; la relación entre esos hechos, que se pueden identificar con los conceptos y las estructuras conceptuales para unir los conceptos.

El conocimiento procedimental se relaciona con técnicas y estrategias para representar conceptos y con las destrezas adecuadas para utilizar algoritmos, mediante el mismo se capacita al alumno para la construcción del conocimiento conceptual y permite el uso fluido, apropiado y acertado al contexto de los conceptos, definiciones y teoremas; estando de esta manera ligado al saber cómo hacer matemáticas, es decir, nos encontramos con las formas de actuación y realización de las tareas matemáticas, en conclusión, con el procedimiento de y para hacer matemáticas.

Dentro de los procedimientos se encuentran distintos niveles o estratos de desarrollo. Por un lado están las destrezas, esto es, la secuencia que se sigue para procesar hechos, por otro lado están los razonamientos que surgen al procesar relaciones entre los conceptos, y que permiten deducir secuencias entre los conceptos y por último las estrategias que utilizamos, estas se desenvuelven en la estructura conceptual y representan cualquier tipo de procedimiento que pueda utilizarse teniendo presentes los conceptos implicados y las relaciones entre ellos.

El planteamiento anterior permite aproximarse a una interpretación más enriquecedora del currículo real de Matemáticas II que determinan las PAU, desarrollo y organización curricular centrada en procedimientos; cómo se hace matemáticas; pero en menoscabo de la riqueza del saber qué y por qué es la matemática, es decir, valorar y considerar el conocimiento matemático como una herramienta fundamental para el desarrollo de habilidades de pensamiento; es decir, pasar de un logro de objetivos específicamente procedimentales a potenciar el razonamiento matemático.

Posteriormente, se promulga la Ley 10/2002 de 23 de diciembre de Calidad de la Educación (LOCE) y el Real Decreto 832/2003 de 27 de junio (BOE del 4 de julio) que establece la ordenación general y las enseñanzas comunes del Bachillerato.

En este Real Decreto se establece:

La fijación de estas enseñanzas es, en todo caso y por su propia naturaleza, competencia exclusiva del Estado, de acuerdo con lo previsto por la Ley Orgánica 8/1985, de 3 de julio, reguladora del Derecho a la Educación. (BOE no 159 de 4 de julio, 26039) 
En la página 26099 del mismo BOE se publican los contenidos de Matemáticas II. El estudio detallado de estos contenidos y de los Decretos que les promulgan, excede a nuestro actual estudio, pues no corresponde a los estudios derivados del bachillerato LOGSE

Esta PI tiene la creencia de que en la actualidad las PAEU están excesivamente estandarizadas $y$, aunque pueden medir con cierta precisión varios aspectos curriculares, tienen deficiencias notorias y hacemos nuestras las reflexiones que hace Rico en sus Consideraciones sobre el Currículo de Matemáticas para Educación Secundaria.

Las pruebas estandarizadas se pueden considerar instrumentos insuficientes para emitir un juicio útil sobre la competencia matemática de los alumnos.

Con estos instrumentos se puede poner de manifiesto fácilmente el conocimiento de hechos y el dominio en la ejecución de destrezas, también es posible comprobar el conocimiento de enunciados, definiciones y propiedades, junto con algunas secuencias de razonamiento, pero no es posible comprobar la comprensión real de los conceptos, el dominio de las estructuras conceptuales, la capacidad personal de razonamiento y la habilidad en la elección y desarrollo de estrategias. (Rico, 1997b, 36)

\section{I.5.2. LAS PRUEBAS DE ACCESO LOGSE}

En la Ley Orgánica 1/1990 de 3 de octubre de Ordenación General del Sistema Educativo (LOGSE) se legisla en su artículo 29.2 que para acceder a la Universidad será necesario superar una Prueba de Acceso que valorará, con carácter objetivo, la madurez académica del alumno y los conocimientos adquiridos en el bachillerato.

Artículo 29.2. El título de Bachiller facultará para acceder a los estudios universitarios. En este caso será necesaria la superación de una prueba de acceso. (BOE no 238 de 4 de octubre, 28933)

La estructura de la prueba de Matemáticas I de COU se vio modificada por las distintas leyes que derogaban las anteriores, así a lo largo de la década de los noventa, nos encontramos que hasta el año 1996 no se unifica el modelo de examen para toda la comunidad de Castilla y León, proponiendo pruebas diferentes en León, Salamanca y Valladolid. En los años anteriores a 1994 el examen de la Universidad de Valladolid constaba de dos proble- 
mas y dos temas de los cuales el alumno debía elegir un problema y un tema, siendo diferente a la estructura de prueba de León y Salamanca .y, en 1995, además de las Universidades citadas anteriormente, la Universidad de Burgos también hace otra prueba de Acceso.

En el año 1994, se propone al alumno un examen con mayor número de preguntas, se presenta más completo, con los cinco bloques de contenidos: Geometría, Álgebra, Continuidad y Cálculo Diferencial, Cálculo integral y Probabilidad, dos cuestiones por cada bloque, el alumno elige una de las dos cuestiones, con unas condiciones restrictivas de puntuación, sólo puede elegir una cuestión de las valoradas con cuatro puntos y el resto de las cuestiones (las otras cuatro), con puntuación de 1,5 puntos.

Este modelo de prueba solo dura dos cursos, puesto que en 1996 se unifican los criterios y se presenta para toda la comunidad de Castilla y León un único modelo de examen; se actualiza, asimismo, la estructura de la prueba de selectividad, a partir de este momento la propuesta del examen está formada por 10 preguntas, dos por cada bloque de contenidos, (Álgebra, Geometría, Continuidad y Análisis Diferencial, Cálculo Integral y Probabilidad), con distinta puntuación: cuatro de ellas con una puntuación máxima de 2,25 puntos y la relativa a Probabilidad valorada en 1 punto. Este modelo de prueba coexiste con la prueba de selectividad del Bachillerato LOGSE y permanece vigente hasta el año 2002, en que desaparece, quedando, a partir del año 2003, únicamente la prueba de acceso a estudios universitarios correspondiente al currículo de la LOGSE.

En la estructura de las Pruebas de Acceso del COU se proponían, además de ejercicios de resolución procedimental, cuestiones teóricas, con enunciados y demostración de algunos teoremas.

El Real Decreto 1640/1999 de 22 de octubre (BOE n 257 de 27 de octubre) regula la prueba de acceso a los estudios universitarios, en él hace mención a las pruebas de acceso a la Universidad para los alumnos que obtuvieron el título de Bachillerato de acuerdo con la implantación anticipada, a partir del curso 1992-1993, de los estudios de Bachillerato establecidos en la LOGSE. (Pruebas del año 1995 que son las primeras que recoge este estudio). La regulación de esas pruebas fue establecida mediante Orden de 10 de diciembre de 1992 (BOE de 12/01/1993) y como expresamente se indica en su preámbulo, reviste carácter transitorio y experimental. 
Este Real Decreto 1640/1999, en su artículo 8, (Segunda parte de la prueba), establece que la prueba de acceso tendrá como objetivos apreciar los conocimientos específicos de las materias propias de la modalidad, y evaluar los conocimientos adquiridos en el Bachillerato y destrezas básicas de la especialidad. Esta parte constará de tres ejercicios, en cada uno de los cuales se entregarla alumno dos propuestas diferenciadas, entre las cuales elegirá una. Como interpretación de esa ley, el ejercicio de Matemáticas II, de la Universidad de Valladolid, consta de dos opciones A y B.

El Real Decreto 990/2000 de 2 de junio modifica y completa el Real Decreto 1640/1999, de 22 de octubre, por el que se regulan las pruebas de acceso a estudios universitarios, no afecta a la materia de Matemáticas II.

El Real Decreto 1025/ 2002 de 4 de octubre, (BOE no 253 de 22 de octubre) modifica el Real Decreto 1640/1999, de 22 de octubre, modificado y completado por el Real Decreto 990/2000 de 2 de junio (BOE no 133 de 3 de junio) por el que se regula la Prueba de Acceso a Estudios Universitarios; aunque no se renueva el espíritu de lo legislado si no que, fundamentalmente, es una sustitución del texto en que estaban redactados algunos artículos.

Por ser elemento de nuestro estudio las pruebas de Matemáticas de la PAEU, nos fijamos en el bachillerato de Ciencias y Tecnología, en el que hay dos asignaturas obligatorias: Matemáticas I en el Primer curso y Matemáticas II en el Segundo curso; para aquellos alumnos que vayan a presentarse a la prueba de Acceso a la Universidad,

Durante los cursos 1994-95 y 1995-96 la prueba de acceso para los estudios del Bachillerato LOGSE constaba de cuatro problemas distribuidos en dos bloques de dos problemas cada uno, un bloque con un problema de Álgebra y otro de Geometría y el otro bloque con dos problemas de Análisis Matemático, y de seis cuestiones, una por cada bloque de contenidos. El alumno elegía un problema de cada uno de los bloques, con puntuación máxima de 3 puntos cada uno y cuatro de las seis cuestiones, de puntuación máxima 1 punto.

En el curso 1996-1997 se proponen dos bloques de problemas A y B y cuatro bloques de cuestiones $\mathrm{C}, \mathrm{D}, \mathrm{E}$ y F. Cada bloque consta de dos problemas o dos cuestiones, El alumno debía realizar un problema o una cuestión de cada uno de los bloques. La puntuación máxima del problema es de tres puntos y la de la cuestión de un punto. 
Desde 1998 y hasta el momento actual, la estructura de la prueba de acceso LOGSE consta de dos modelos de examen, A y B, con la siguiente distribución: Un problema de Análisis matemático, un problema de Álgebra y/o Geometría y cuatro cuestiones en las que al menos una es de álgebra, otra de análisis y otra de geometría. El alumno tiene que optar por uno de los dos modelos pudiendo contestar dentro del modelo elegido en el orden que desee. (Real Decreto 1640/1999, de 22 de octubre, -BOE no 257 de 27 de octubre-, artículo 8). En cuanto a su calificación, cada problema se puntúa sobre un máximo de tres puntos y cada cuestión sobre un máximo de un punto.

En la Prueba de Acceso del Bachillerato LOGSE las definiciones teóricas, enunciados de teoremas o propiedades dejan de plantearse como pregunta en el año 2002 y en ningún momento se planteó como pregunta la demostración de ningún teorema.

Esta orientación curricular es contraria a los procedimientos que se siguen en la actualidad para proponer las PAU, así en el Decreto 70/2002, de 23 de mayo, por el que se establece el Currículo de Bachillerato de la Comunidad de Castilla y León, en la introducción a los contenidos del currículo de Matemáticas I y II, se publica:

Es idea corriente suponer que esta práctica operacional es lo que se pretende en la enseñanza de la asignatura, sin embargo, para obtener el mayor provecho posible de esta práctica, es necesario establecer un fundamento teórico...

En la Educación Secundaria Obligatoria ya han sido iniciados en varios campos del conocimiento matemático, primando el aspecto operacional sobre el teórico. Estos conocimientos son los que han de constituir el punto de partida para las enseñanzas matemáticas de esta etapa. Es en ella cuando se comienza a dar respaldo teórico a los conocimientos matemáticos. Se deben introducir las definiciones, los teoremas, las demostraciones y la realización de los encadenamientos lógicos... Empezar en primer curso con razonamientos fáciles, para llegar en segundo a demostraciones con alguna complejidad. (BOC y L n 102 de 29 de mayo de 2002, 7081)

Las propuestas de examen correspondientes a las PAU se fundamentan en una serie de ejercicios basados en destrezas específicas aisladas, en lugar de presentar propuestas con situaciones que requieran la aplicación de diversas ideas matemáticas. 
Al referirse a las Pruebas de Acceso a la Universidad correspondientes a los estudios de COU, Rico (1997a), en su libro "Bases Teóricas del Currículo de Matemáticas en Educación Secundaria", puntualiza la siguiente reflexión:

En cuanto a lo relativo a de la Prueba de Acceso a la Universidad, las especiales características de esta prueba han hecho que aumente en los centros el nivel de exigencia de los exámenes finales de la asignatura, de manera que los alumnos que cada centro presente tengan garantizado al máximo la superación de la prueba de acceso. Los claustros de profesores viven la prueba de acceso como una evaluación propia y del centro, convirtiéndose de esta manera en una confirmación para los profesores de lo acertado de sus criterios de selección. (Rico 1997a,.39)

Esta reflexión que tenía perfecto significado años atrás ha ido perdiendo valor de año en año por varias razones: una, que los contenidos de examen, como se verá en esta memoria, han bajado en extensión y, otra, que también se verificará, la dificultad de las pruebas está en una línea regresiva, no aumenta el nivel de exigencia de los centros educativos, sino que, en cierto modo, se busca el éxito en las pruebas independientemente de la formación. 



\section{CAPÍTULO II}

\section{MARCOS TEÓRICO Y METODOLÓGICO}

\section{II.1. INTRODUCCIÓN}

El propósito de la Didáctica radica en el conocimiento de los fenómenos y procesos relativos a la enseñanza de una materia, en este caso de las Matemáticas, con el fin de perfeccionar el aprendizaje de los alumnos, sin excluir el supuesto de que cualquier idealización humana está inmersa en un contexto sociocultural y que las situaciones didácticas obedecen a determinadas características en función de los fundamentos epistemológicos que identifican su realización.

Se han realizado una extensa serie de trabajos de investigación en Didáctica de la Matemática con el objetivo de mejorar la calidad de la enseñanza, de identificar qué conduce al docente a tomar unas decisiones metodológicas concretas que, en cierta medida, implican una mejora en los procesos de enseñanza aprendizaje de las matemáticas. Sin embargo, en la mayoría de las veces no se reflejan cambios en la práctica del aula. Las clases tradicionales se mantienen, presentando las Matemáticas como un conjunto de hechos, procedimientos y soluciones tal y como se muestran en los libros de texto (Chamoso, 2000). (SUMA no 43, 2003)

Un marco teórico permite normalizar los conocimientos de una materia, lo que constituye un primer avance para alcanzar una perspectiva nítida de la unidad que pueda existir en nuestras impresiones. Para que un área de conocimiento obtenga la categoría de científica y pueda desempeñar su papel explicativo, es un requisito la teorización; la investigación científica significativa está siempre guiada por una teoría, aunque a veces esta orientación se haga de modo implícito. 
Como afirma Mosterín $(1987,146)$, "gracias a las teorías introducimos orden conceptual en el caos de un mundo confuso e informe, reducimos el cambio a fórmula, suministramos a la historia instrumentos de extrapolación y explicación $y$, en definitiva, entendemos y dominamos el mundo aunque sea con un entendimiento y un dominio siempre inseguros y problemáticos"

Un marco teórico guía las actividades de investigación por su dependencia de una teoría formal; esto es, una teoría que ha sido desarrollada usando una explicación coherente y establecida de ciertos tipos de fenómenos y relaciones.

En este capítulo, hacemos alusión a los marcos teórico y metodológico que orientan el desarrollo de nuestra investigación.

La contextualización del problema de investigación tiene un gran significado para definir el camino adecuado en la obtención de resultados y conclusiones del tema seleccionado para el estudio. Así, Freudenthal (1982) considera que una investigación es pertinente si puede influir sobre la enseñanza, y, en este sentido, consideramos que esta investigación cumple ese cometido, ya que, por una parte, el estudio de las competencias matemáticas inherentes a los ejercicios que nuestros pupilos efectúan influirá en la mejora de propuestas metodológicas y evaluadoras, $y$, por otra, el análisis de las pruebas desde la perspectiva curricular redundará en beneficio del desarrollo del currículo y en la propia elaboración de las pruebas.

Según Eisenhart $(1998,100)$ los problemas que se plantean en investigación en educación matemática derivan de la pregunta general: ¿cómo puede mejorarse la enseñanza/aprendizaje de las matemáticas?

El escepticismo de Freudenthal respecto a la investigación educativa está quizás justificado, pero esto no significa que carezca de utilidad. Todo trabajo de investigación debe responder a las preguntas ¿para qué sirve?, ¿para quién es útil? La importancia del trabajo de investigación se hace patente para el sector del profesorado porque se presentan un conjunto de trabajos para lograr aplicaciones prácticas en la docencia.

Citando un trabajo de Sierpinska y Kilpatrick (1993), Rico (1999) documenta que estos autores establecen distintas características de una investigación:

- La pertinencia de en base a ¿para qué o para quién es importante le investigación? ¿Qué va a mejorar? ¿Qué utilidad va a tener? La investigación será pertinente para los profesores si les permite formular hipótesis sobre 
sus métodos de enseñanza, verificar esas hipótesis y examinar sus consecuencias, lo que manifiesta que una investigación resulta pertinente en la medida en que esta permite la adaptación y uso de algunos de sus aspectos. (Puig y Calderón 1996)

- La originalidad en ¿hasta qué punto la investigación muestra ideas conocidas en una nueva perspectiva? Originalidad no significa desconexión con investigaciones precedentes. Si el modo de contar los resultados o el desenlace de la investigación aporta algo nuevo, aún cuando la situación estudiada sea conocida, o quizá, justamente por serlo, ese estudio es original.

- La validez en ¿qué consecuencias se derivan? Cuando indagamos acerca de la claridad en los resultados de la investigación, estamos cuestionando si nuestro método de investigación nos ha permitido investigar lo que efectivamente pretendíamos, en este sentido, la validez se refiere al modo en que justificamos las interpretaciones que hacemos de la investigación. Tal como Kvale (1989) ha afirmado, "validar es cuestionar". El valor de un estudio de investigación no es intrínseco sino que la validez se explica en función de las conclusiones extraídas del estudio, a partir de lo que se ha estudiado se desprende aquello a lo que se pretende extrapolar los resultados.

- El rigor y la precisión en ¿qué precisión tienen las observaciones realizadas? ¿Con qué exigencia se han llevado a cabo? ¿Qué precisión tienen los criterios para interpretar las informaciones obtenidas? En su aspecto negativo, rigor significa rigidez, excesiva y escrupulosa severidad inflexibilidad y un estricto acatamiento de normas y procedimientos. Desde un punto de vista positivo, rigor implica propiedad y precisión. El rigor y la precisión emanan del espíritu con el que se realiza la investigación, el cuidado con que se desarrolla la observación, la atención al detalle, la disposición a comprobar alternativas más que de la fidelidad a un procedimiento normalizado. En la aplicación al aula no se pueden predecir, con exactitud, unos comportamientos específicos como se puede hacer en una práctica de laboratorio, pero se pueden buscar estructuras causales encaminadas a producir determinados efectos.

- La predictibilidad con ¿qué explicación se deriva del estudio? Un método de aplicar el criterio de predictibilidad es cuestionando hasta qué punto las deducciones extraídas de la investigación permiten vaticinar lo que ocurrirá en una situación de enseñanza/aprendizaje. 
- La conexión con ¿de qué modo está relacionado el estudio con la matemática y con la educación? Respondiendo a las preguntas, consideramos que este trabajo satisface dichos interrogantes. Para el alumno es un trabajo en el que aparecen resueltos 342 ejercicios, con su nivel de dificultad y las competencias matemáticas que ejercitan en el proceso de resolución y puede servir, para el docente, como guía para el planteamiento de ejercicios, según el nivel competencial que desee alcanzar, por tanto; es importante tanto para alumnos como para docentes.

Esta investigación centra el interés en cuestiones básicas relacionadas con la Educación Secundaria no obligatoria actual, y más concretamente, el currículo de Matemáticas II de Segundo de Bachillerato de Ciencias y Tecnología. Es original, ya que se han hecho muchas presentaciones, análisis y planteamientos respecto a las competencias, pero ninguno de esos trabajos ha seguido esta línea ni ha alcanzado tanta profundidad como éste. Asimismo, previamente se ha realizado un análisis de los antecedentes de investigación concernientes con la temática a investigar, para conocer el estado actual de la cuestión, se ha delimitado el marco teórico, se ha definido una metodología de trabajo y se han enunciado los objetivos correspondientes.

El resto de los interrogantes tiene respuesta extensa y detallada en cada uno de los capítulos de la presente memoria, pero, sucintamente, el estudio demuestra el sesgo curricular que los contenidos de Bachillerato están sufriendo tanto conceptual como procedimentalmente, excluyendo en el mismo, entre otros, la resolución de problemas, que correspondería a un nivel competencial de reflexión.

\section{II.2. MARCO TEÓRICO}

En este apartado se describe el marco que se ha utilizado para efectuar el análisis de los documentos recopilados y de la resolución de los problemas y cuestiones propuestas en las PAEU. Se trata de un marco de concentración formado por el currículo español LOGSE (ya descrito en el capítulo precedente), los marcos teóricos de PISA y la teoría morfológica sintáctica. Con esta última se ha analizado la redacción de los enunciados y con la perspectiva de PISA, fundamentalmente PISA'2003, se han analizado las competencias implícitas en los enunciados y en la resolución de los problemas y cuestiones propuestas como las podría resolver un alumno de principio a fin. 
Podemos fijar el comienzo del marco general de PISA en el año 2000 y en el proyecto danés de educación de Niss (1999). El proyecto OCDE/PISA evalúa los currículos nacionales a través de las habilidades de los estudiantes para analizar, razonar y comunicar ideas matemáticas al interpretar y resolver problemas matemáticos en diferentes situaciones, y tanto el marco de análisis como los resultados aportados por este proyecto están siendo de gran interés para los investigadores en educación matemática.

El énfasis en una educación centrada en el aprendizaje en contraposición a una educación centrada en la enseñanza ha instado a los gobiernos europeos a mejorar y redefinir sus sistemas educativos para crear un sistema europeo que permita comparar, difundir y evaluar las competencias básicas y las mejores metodologías para su adquisición, es decir, en una enseñanza que promueva la adquisición de capacidades, habilidades, competencias y valores que permitan al individuo una actualización permanente de los conocimientos para desenvolverse con soltura en un mundo cambiante y complejo.

Para el proyecto OCDE/PISA (2000) se elige el término de "formación matemática" enfatizando que el conocimiento matemático se lleva a la práctica en multitud de contextos que necesitan reflexión y razonamiento, para lo que son necesarios gran cantidad de conocimientos fundamentales y utilización de destrezas matemáticas.

Para organizar el área de matemáticas, el proyecto utiliza dos aspectos principales, con el propósito de puntualizar el alcance de la evaluación y el rendimiento. Las competencias matemáticas y las grandes ideas matemáticas. Para PISA'2000, "Las competencias matemáticas son destrezas y competencias generales como la resolución de problemas, el uso del lenguaje matemático y el diseño matemático" (INCE, 2000, 73).

Para asegurar que haya una adecuada cobertura del área de conocimiento y un equilibrio en la variedad de las tareas seleccionadas, se consideran los aspectos secundarios que son: Los temas matemáticos del currículo y las situaciones y contextos.

De esos aspectos mencionados, "los temas matemáticos del currículo" y "las grandes ideas matemáticas" son ideas alternativas para la descripción del contenido matemático. El primero representa el contenido de las matemáticas escolares, tal como se aplica en el plan de estudios del centro, mientras que el segundo aspecto representa un conjunto de conceptos matemáticos fundamentales y conectados que aparecen en situaciones y contextos reales. 
En el proyecto PISA'2000 se enuncian 8 destrezas (de pensamiento matemático, de argumentación matemática, de diseño, para planteasr y resolver problemas, de representación, simbólica formal y técnica, de comunicación, de utilización de ayudas y herramientas), que las organiza en tres clases de competencias: reproducción, definiciones y cálculos; Conexiones e integración para resolución de problemas; pensamiento matemático, generalización y comprensión súbita.

Niss fue y sigue siendo uno de los miembros destacados del Proyecto PISA, de hecho su Project Kom de 1999 está escrito en términos de competencias y en él aparecen las mismas que en PISA'2003. Niss (2004), considera que el proceso de formación de los estudiantes debe contribuir a la adquisición de dos grupos de competencias: uno, relacionado con la destreza para preguntar y responder cuestiones matemáticas por medio de las matemáticas, y el segundo concerniente a la práctica en el uso de las herramientas y el lenguaje matemático. A continuación se describen las competencias de Niss y su equivalencia con PISA (OECD, 2004, 40).

Dentro de las competencias del primer grupo hemos de considerar:

1. Pensar matemáticamente (Pensar y razonar en PISA'2003). Es la primera de las ocho competencias matemáticas que establecen Niss y PISA. Esta competencia se evalúa en base a cuestiones del tipo: ¿Hay...? En este caso, ¿cuántos? ¿Cómo podemos encontrar?, y de los diferentes tipos de respuestas matemáticas que podemos dar a estas preguntas. En consecuencia, una actividad de práctica, o de evaluación, propuesta para trabajar esta subcompetencia demanda el uso de una pregunta; y si, por ejemplo, la actividad sólo consiste en explicar, escribir o describir, con ella no se trabajará esta subcompetencia. Si la respuesta que se pide es una respuesta única e inmediata, que se obtiene sin necesidad de relacionar datos o de establecer una cadena de pensamientos, estaremos ante una actividad considerada en el nivel más superficial de la competencia: El grupo de reproducción. También se considera que la actividad está incluida en este grupo si las preguntas dan una ayuda directa para la resolución de la actividad ya que generalmente el proceso de resolución de la actividad implicará un solo paso.

2. Formular y resolver problemas matemáticos (Pantear y resolver problemas en PISA). Esta competencia se refiere a proponer y resolver diferentes cla- 
ses de problemas de matemáticas: Teórico o aplicado, con solución única o múltiple, problemas propuestos de diferentes modos, etc.).

3. Ser capaz de analizar y construir modelos matemáticos en relación a otras áreas (Modelar -modelizar- en PISA). Llevar a término modelizaciones en contextos dados, matematizar situaciones. La competencia de modelización se vincula a analizar fundamentos y propiedades de modelos existentes o bien aplicar un modelo a un contexto dado, lo que requiere, entre otras habilidades, las de analizar, validar o criticar el modelo, observando y controlando el proceso de modelización, comunicando ese modelo y sus resultados.

4. Ser capaz de razonar matemáticamente (Argumentar). Seguir y evaluar los razonamientos matemáticos ajenos, comprender el qué es y qué no es una demostración, ser capaz de realizar razonamientos informales y formales. La competencia está vinculada a seguir y valorar cadenas de argumentos, como, por ejemplo, diferenciar una demostración matemática de otras clases de razonamiento matemático, como puede ser el razonamiento heurístico.

Y, del grupo relacionado con la práctica en el uso de las herramientas y el lenguaje matemático, tenemos:

1. Utilizar diversas representaciones (Representar en PISA). Ser capaz de pasar de una a la otra. Consiste en comprender, utilizar e interpretar diferentes clases de representaciones de situaciones matemáticas y distinguir entre ellas; en utilizar las relaciones entre diferentes representaciones de la misma entidad u objeto y en elegir entre diferentes representaciones y pasar de unas a otras

2. Utilizar el lenguaje de los símbolos y de sistemas formales matemáticos (Utilizar el lenguaje simbólico, formal y técnico y las operaciones en PISA). Es decir, codificar símbolos y lenguaje formal; traducir de un lenguaje a otro; tratar fórmulas y expresiones simbólicas, etc. La competencia se entronca con interpretar el lenguaje matemático simbólico y formal y comprender sus relaciones con el lenguaje natural; utilizar expresiones que contienen símbolos y fórmulas, comprendiendo la naturaleza y las reglas de los procedimientos matemáticos formales desde distintos puntos de vista: sintáctico y semántico, así como traducir el lenguaje natural al lenguaje simbólico/formal y viceversa. 
3. Ser capaz de comunicarse en, con y sobre las matemáticas, (Comunicar) es decir, interpretar textos escritos en los diversos lenguajes; escribir textos con diferentes niveles de precisión, etc.

Niss ubica la competencia comunicación en el bloque que hace referencia a "La habilidad de manejarse con las herramientas y el lenguaje matemático" y dentro de este bloque la coloca en tercer lugar, lo que indica que la considera como una competencia situada en un nivel superior al puramente matemático.

Se refiere a comprender los textos escritos, los enunciados orales o las expresiones visuales sobre temas de contenido matemático, en expresarse uno mismo sobre tales cuestiones, materias o temas, con diferentes niveles de precisión teórica y técnica, de forma oral, visual o escrita. Estamos, pues ante dos aspectos importantes, el de expresarse correctamente para hacernos entender y el de comprender los mensajes que recibimos.

Para fomentar y profundizar en esta subcompetencia, se deberá trabajar a diversos niveles, por un lado un trabajo individual de comprensión de textos y de mensajes orales, un trabajo en grupo, que irreparablemente deberá incluir el trabajo de comunicar los resultados de los trabajos al resto de compañeros, bien en grupos pequeños o en gran grupo.

Para discriminar el nivel alcanzado en la competencia habrá que prestar atención a los resultados que nos solicite la actividad. Si la actividad sólo nos pide que expresemos el resultado de unas operaciones matemáticas sin tener que justificar lo que hemos hecho, estaremos en el grado más elemental de la competencia. Si la actividad pide explicar propiedades y justificar procesos, estaremos en el grado medio de la competencia. El grado más alto de la competencia se sitúa cuando se pida a los estudiantes explicar relaciones más complejas, por ejemplo, del tipo de relación lógica.

Tanto en las orientaciones curriculares del MEC como en numerosas investigaciones de didáctica de la Matemática (Niss 1999, Nesher 2000, Godino 2001, etc.), se muestra, en el aprendizaje de las Matemáticas, el papel del lenguaje y la capacidad de comunicarse matemáticamente. Así, Nesher (2000) distingue entre dos acciones: "hablar de matemáticas"o "hablar matemáticamente". Con la expresión "hablar de matemáticas" hace referencia al hecho de utilizar el lenguaje natural como metalenguaje para expresar ideas matemáticas, mientras que con el término "hablar matemáticamente" se refiere a usar el lenguaje 
matemático, aplicándolo a variados contextos, pero teniendo en cuenta su propia sintaxis.

Coincidimos con las ideas de Nesher, así cuando los alumnos explican, justifican o/y describen el procedimiento que han empleado para la resolución de un problema, es decir, cuando comunican sus estrategias están desarrollando un aprendizaje en el que se adapata la expresión "hablar de matemáticas" el lenguaje natural como metalenguaje.

En el BOE 158 (2003), se refleja la importancia de la competencia "comunicar" matemáticamente:

"Es importante habituar a los alumnos a expresarse oral, escrita y gráficamente en situaciones susceptibles de ser tratadas matemáticamente, mediante la adquisición y el manejo de un vocabulario específico de notaciones y términos matemáticos." (BOE 158, 2003, 256839),

Asimismo, en el Proyecto OCDE/PISA, se define el dominio "alfabetización matemática" para referirse a "las capacidades de los estudiantes para analizar, razonar y comunicar eficazmente cuando identifican, formulan y resuelven problemas matemáticos en una variedad de dominios y situaciones" (Rico, 2003).

4. Manejar las ayudas y herramientas matemáticas, tener conocimiento, saber sus limitaciones y usarlas reflexivamente (usar herramientas y recursos, según PISA).

Es necesario distinguir, por tanto, entre tareas de diagnóstico, tareas de aprendizaje y tareas de aplicación o utilización práctica de dichas competencias, si bien todas pueden cumplir todas las funciones con las orientaciones adecuadas.

Requisitos básicos y necesarios, pero no suficientes, para tener competencia matemática son poseer conocimiento factual y poseer destrezas técnicas

El currículo español LOE incorpora la formación en competencias descritas en PISA 2003 y en consecuencia, la formación en competencias adquiere una dimensión importantísima en la formación de nuestros alumnos. Todo esto significa que es preciso prestar atención a un aprendizaje orientado al desarrollo de competencias y a la consecución de lo que se conoce como "alfabetización matemática". No basta con restringirse a la enseñanza y aprendizaje de contenidos, a los aspectos funcionales y formativos de las matemáticas, a los aspectos instrumentales y técnicos, sino que los conceptos de competencia, matemati- 
zación y alfabetización matemática, ponen el acento en aquello que el alumno es capaz de hacer al término del proceso educativo y en los procedimientos que le permitirán continuar aprendiendo de forma adquiere una dimensión autónoma a lo largo de su vida.

El proceso inherente que los estudiantes tienen que emplear para resolver problemas de la vida real se denomina, en el proyecto OCDE/PISA, matematización. Este tipo de resolución de problemas obliga a los estudiantes a valerse de las destrezas y competencias que han adquirido a lo largo de su periodo de escolarización.

Se ha elegido el vocablo alfabetización (Mathematical Literacy) para acentuar que el conocimiento y las destrezas matemáticas, tal como están definidos en el currículo tradicional de matemáticas, no constituyen el foco de atención preferente; antes bien, el acento está en el conocimiento matemático utilizado en una multitud de contextos diferentes, basado en la intuición personal y utilizado de una manera reflexiva, mediante métodos variados.

Indudablemente, para que este uso sea factible, es preciso poseer una buena cantidad de conocimientos matemáticos básicos y de destrezas; los cuales forman, también, parte de esta definición de alfabetización.

El dominio sobre matemáticas que se estudia en el proyecto PISA 2003 se conoce como alfabetización matemática -Mathematical Literacy- (OECD, 2003), y también se denomina competencia matemática (OCDE, 2004, 2005). Alude a las capacidades de los estudiantes para analizar, razonar y comunicar convenientemente cuando resuelven o enuncian problemas matemáticos en variadas situaciones.

Se conoce como alfabetización matemática o "mathematical literacy" a:

"La capacidad individual para identificar y entender el papel que las matemáticas tienen en el mundo, hacer juicios bien fundados y usar e implicarse con las matemáticas en aquéllos momentos en que se presenten necesidades en la vida de cada individuo como ciudadano constructivo, comprometido y reflexivo" (INECSE, 2005, 15).

Rico hace una interpretación de este concepto de alfabetización matemática en los siguientes términos: 
La alfabetización matemática "...Se refiere a las capacidades de los estudiantes para analizar, razonar y comunicar eficazmente, cuando enuncian, formulan y resuelven problemas matemáticos en una variedad de dominios y situaciones".y es incuestionable como elemento básico a tener en cuenta para el desarrollo individual, social y científico de cualquier país. (Rico, 2005, 8)

Se centraliza en el uso, por los estudiantes, de las herramientas matemáticas adecuadas para resolver problemas y necesidades, poniendo en funcionamiento unas determinadas competencias. En este sentido, la consideración de las matemáticas como "modo de hacer" y la noción de alfabetización responden a un modelo funcional sobre aprendizaje de las matemáticas, así, cuando el estudiante trata de abordar las tareas mediante las herramientas disponibles, pone de manifiesto su competencia en la ejecución de los procesos correspondientes.

Cimentada en la base teórica del marco conceptual de Matemáticas del proyecto OCDE/PISA, se diseña una descripción de la matematización, mediante el siguiente esquema, siguiendo el modelo de PISA 2003 (INECSE, 2004, 40):

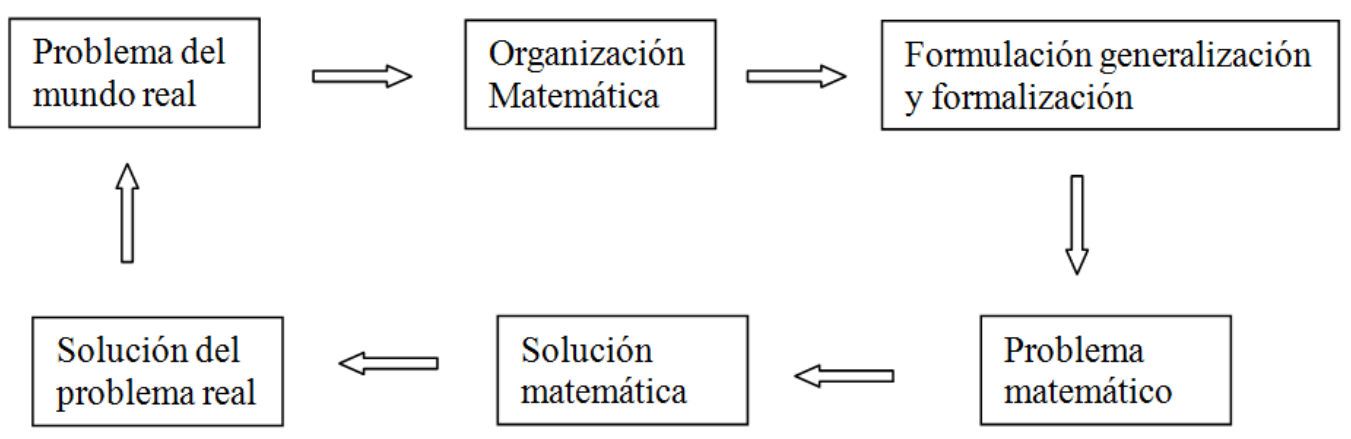

Figura 1. Esquema de matematización

El proceso que caracteriza cómo los matemáticos hacen matemáticas y cómo los individuos utilizan esas matemáticas, de una manera competente, en una variedad de profesiones y trabajos, es esta acción secuenciada. Mediante este proceso, en un sentido amplio, se caracteriza cómo al afrontar la respuesta a cuestiones y problemas reales se produce una abstracción y, por consiguiente, una matematización sobre los datos de su contexto de trabajo.

El estudio PISA considera que los logros de los estudiantes en matemáticas se pueden expresar mediante el conjunto de competencias descrito anteriormente, y en cada una de ellas se explicitan los procesos que se requieren para un domino matemático general aplicado a tareas matemáticas. Cada una de estas 
tareas enunciadas en las pruebas de evaluación admite diferentes niveles de complejidad, lo cual afecta al modo en que se deben ejecutar los correspondientes procesos. Estos niveles son: Reproducción, conexión y reflexión.

Cada uno de estos ítems, quedan definidos por indicadores, -tres para reproducción y conexión y dos para reflexión- que caracterizan la diferente pericia "proficiency" que el estudiante necesita para resolver el problema. Hemos considerado estos indicadores partiendo de la tabla correspondiente de Rico y Lupiañez (2008), teniendo en cuenta las acciones verbales de los tres niveles de evaluación de INECSE (2004).

Los niveles son acumulativos, esto es, a medida que se aumenta el nivel de competencia, se entiende que se domina las capacidades propias de los niveles anteriores. Así por ejemplo, el estudiante que esté en el nivel de conexión habrá superado el nivel de reproducción, aunque en el estudio de algunos ejercicios se consideren ambos niveles de competencia, dado que un apartado puede referirse al nivel de reproducción y otro al de conexión.

Según Rico y Lupiañez $(2008,176)$ hay cuatro modos de entender el conocimiento matemático escolar que de algún modo se puede considerar que es otra variante más de los niveles de evaluación de PISA, pero estos hacen referencia a la adquisición del conocimiento y, por tanto, pueden incluso marcar una metodología:

1. Enfoque instrumental o tecnológico, centrado en el dominio y uso de hechos, destrezas y conceptos básicos, que se toman como herramientas.

2. Enfoque estructural o técnico, donde el conocimiento consiste en un sistema estructurado de reglas y conceptos, formalizado y basado en la deducción.

3. Enfoque funcional, donde el conocimiento permite modelizar situaciones reales y está orientado a la resolución de cuestiones y problemas en diferentes contextos.

4. Enfoque integrado, donde el conocimiento es un objeto de actividad intelectual autónoma, creación e interacción en diversidad de situaciones y contextos.

Utilizando como referencia general las publicaciones relacionadas con el análisis de competencias, y, en particular, la publicación de Rico y Lupiañez (2008) y la de Moreno, M.; Mesa, G. y Azcárate, C. (2007, 78-79). Aquí aparece una tabla de evaluación de competencias que ha sido utilizada como modelo para construir nuestra tabla de evaluación adaptándola a las características de las PAU, pero siguiendo la estructura de INCE 2000, 76-77; donde ya aparecen los tres niveles de evaluación de competencias y que en esa publicación se registran como clase 1 , clase 2 y clase 3 . La desglosamos en tres por razones de espacio. 
Tabla II.1. Categorías de análisis de competencias I.

\begin{tabular}{|c|c|c|c|}
\hline \multicolumn{4}{|c|}{ REPRODUCCIÓN } \\
\hline $\begin{array}{l}\text { Competenciasl } \\
\text { Niveles }\end{array}$ & Nivel 1 & Nivel 2 & Nivel 3 \\
\hline $\begin{array}{l}\text { Pensar y razo- } \\
\text { nar }\end{array}$ & $\begin{array}{l}\text { Reconoce repre- } \\
\text { sentaciones de los } \\
\text { datos del ejercicio. } \\
\text { (RPRn1) }\end{array}$ & $\begin{array}{l}\text { Plantea los algo- } \\
\text { ritmos correspon- } \\
\text { dientes. (RPRn2) }\end{array}$ & $\begin{array}{l}\text { Asocia con fórmu- } \\
\text { las establecidas y } \\
\text { realiza los cálculos. } \\
\text { (RPRn3) }\end{array}$ \\
\hline Argumentar & $\begin{array}{l}\text { Identifica el pro- } \\
\text { blema. (RAn1) }\end{array}$ & $\begin{array}{l}\text { Expone el proceso } \\
\text { de cálculo. (RAn2) }\end{array}$ & $\begin{array}{l}\text { Justifica las fór- } \\
\text { mulas utilizadas y } \\
\text { los resultados. } \\
\text { (RAn3) }\end{array}$ \\
\hline Comunicar & $\begin{array}{l}\text { Comprende la ex- } \\
\text { presión } \\
\text { (RCn1) }\end{array}$ & $\begin{array}{ll}\text { Realiza } & \text { explicacio- } \\
\text { nes } & \text { sencillas. } \\
(\mathrm{RCn} 2) & \end{array}$ & $\begin{array}{l}\text { Describe los re- } \\
\text { sultados obteni- } \\
\text { dos. (RCn3) }\end{array}$ \\
\hline Modelizar & $\begin{array}{l}\text { Identifica que un } \\
\text { modelo es similar a } \\
\text { otros modelos vis- } \\
\text { tos con anteriori- } \\
\text { dad. (RMn1) }\end{array}$ & $\begin{array}{l}\text { Pasa sucesiva- } \\
\text { mente de los mo- } \\
\text { delos concretos a la } \\
\text { realidad (fórmulas) } \\
\text { y viceversa. (RMn2) }\end{array}$ & $\begin{array}{l}\text { Comunica de ma- } \\
\text { nera elemental los } \\
\text { resultados del mo- } \\
\text { delo. (RMn3) }\end{array}$ \\
\hline $\begin{array}{l}\text { Resolver pro- } \\
\text { blemas }\end{array}$ & $\begin{array}{l}\text { Reconoce proble- } \\
\text { mas ya practicados. } \\
\text { (RRPn1) }\end{array}$ & $\begin{array}{l}\text { Reproduce pro- } \\
\text { blemas ya practi- } \\
\text { cados de manera } \\
\text { cerrada. (RRPn2) }\end{array}$ & $\begin{array}{l}\text { Resuelve proble- } \\
\text { mas rutinarios es- } \\
\text { tandarizados. } \\
\text { (RRPn3) }\end{array}$ \\
\hline Representar & $\begin{array}{l}\text { Usa un único tipo } \\
\text { de representación } \\
\text { estándar ya utili- } \\
\text { zada. (RRn1) }\end{array}$ & $\begin{array}{l}\text { Interpreta repre- } \\
\text { sentaciones es- } \\
\text { tándar de objetos } \\
\text { matemáticos. } \\
\text { (RRn2) }\end{array}$ & 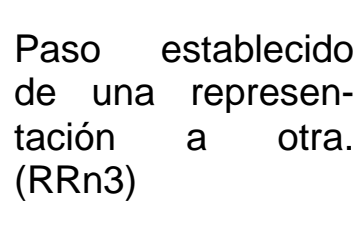 \\
\hline $\begin{array}{l}\text { Utilizar el len- } \\
\text { guaje simbólico, } \\
\text { formal y técnico } \\
\text { y las operacio- } \\
\text { nes }\end{array}$ & $\begin{array}{l}\text { Realiza operacio- } \\
\text { nes elementales en } \\
\text { contextos conoci- } \\
\text { dos.(RLSOn1) }\end{array}$ & $\begin{array}{l}\text { Interpreta el len- } \\
\text { guaje formal y } \\
\text { simbólico rutinario. } \\
\text { (RLSOn2) }\end{array}$ & $\begin{array}{l}\text { Maneja procedi- } \\
\text { mientos y fórmu- } \\
\text { las, resolviendo y } \\
\text { calculando. } \\
\text { (RLSOn3) }\end{array}$ \\
\hline $\begin{array}{l}\text { Reproducción d } \\
\text { ciones de probler } \\
\text { blemas rutinarios, } \\
\text { jo de expresiones }\end{array}$ & comunes, reconc & $\begin{array}{l}\text { o: Conocimiento } \\
\text { niento de equivale }\end{array}$ & $\begin{array}{l}\text { hechos, representa- } \\
\text { s, ejecución de pro- } \\
\text { s habituales, mane- } \\
\text { os. }\end{array}$ \\
\hline
\end{tabular}


Tabla II.2. Categorías de análisis de competencias II.

\begin{tabular}{|c|c|c|c|}
\hline \multicolumn{4}{|c|}{ CONEXIÓN } \\
\hline $\begin{array}{l}\text { Competencias/ } \\
\text { Niveles }\end{array}$ & Nivel 1 & Nivel 2 & Nivel 3 \\
\hline $\begin{array}{l}\text { Pensar y } \\
\text { razonar }\end{array}$ & $\begin{array}{l}\text { Piensa en el tra- } \\
\text { tamiento mate- } \\
\text { mático necesario. } \\
(\mathrm{CPRn} 1)\end{array}$ & $\begin{array}{l}\text { Comprende que } \\
\text { tiene que emplear } \\
\text { conceptos mate- } \\
\text { máticos interme- } \\
\text { dios. (CPRn2) }\end{array}$ & $\begin{array}{l}\text { Aplica conceptos } \\
\text { matemáticos apro- } \\
\text { piados. (CPRn3) }\end{array}$ \\
\hline Argumentar & $\begin{array}{l}\text { Razona matemáti- } \\
\text { camente de ma- } \\
\text { nera } \\
(\mathrm{CAn} 1)\end{array}$ & $\begin{array}{l}\text { Sigue el encade- } \\
\text { namiento de ar- } \\
\text { gumentos mate- } \\
\text { máticos particula- } \\
\text { res. (CAn2) }\end{array}$ & $\begin{array}{l}\text { Evalúa el encade- } \\
\text { namiento de ar- } \\
\text { gumentos mate- } \\
\text { máticos particula- } \\
\text { res. (CAn3) }\end{array}$ \\
\hline Comunicar & $\begin{array}{l}\text { Sabe expresarse } \\
\text { sobre cuestiones } \\
\text { matemáticas. } \\
(\mathrm{CCn} 1)\end{array}$ & $\begin{array}{l}\text { Explica los cálcu- } \\
\text { los y sus propie- } \\
\text { dades. (CCn2) }\end{array}$ & $\begin{array}{l}\text { Interpreta las rela- } \\
\text { ciones implicadas. } \\
\text { (CCn3) }\end{array}$ \\
\hline Modelizar & $\begin{array}{l}\text { Estructura la si- } \\
\text { tuación que debe } \\
\text { modelizar. (CMn1) }\end{array}$ & $\begin{array}{l}\text { Traduce en la prá- } \\
\text { ctica el modelo a } \\
\text { seguir que es algo } \\
\text { diferente de los es- } \\
\text { tudiados. (CMn2) }\end{array}$ & $\begin{array}{l}\text { Sabe interpretar y } \\
\text { alternar diferentes } \\
\text { modelos y comu- } \\
\text { nicar los resulta- } \\
\text { dos. (CMn3) }\end{array}$ \\
\hline $\begin{array}{l}\text { Resolver pro- } \\
\text { blemas }\end{array}$ & $\begin{array}{l}\text { Desarrolla proce- } \\
\text { dimientos intuitivos } \\
\text { ya practicados, pe- } \\
\text { ro no rutinarios. } \\
\text { (CRPn1) }\end{array}$ & $\begin{array}{l}\text { Elige estrategias } \\
\text { apropiadas más in- } \\
\text { dependientes que } \\
\text { conexionen áreas } \\
\text { matemáticas. } \\
\text { (CRPn2) }\end{array}$ & $\begin{array}{l}\text { Aplica las estrate- } \\
\text { gias apropiadas } \\
\text { más independien- } \\
\text { tes. (CRPn3) }\end{array}$ \\
\hline Representar & $\begin{array}{l}\text { Interpreta formas } \\
\text { de representación. } \\
(\mathrm{CRn} 1)\end{array}$ & $\begin{array}{l}\text { Selecciona y cam- } \\
\text { bia entre las dife- } \\
\text { rentes formas de } \\
\text { representación. } \\
(\mathrm{CRPn} 2)\end{array}$ & $\begin{array}{l}\text { Traduce y diferen- } \\
\text { cia entre distintas } \\
\text { formas de repre- } \\
\text { sentación. (CRPn3) }\end{array}$ \\
\hline $\begin{array}{l}\text { Utilizar el len- } \\
\text { guaje simbólico, } \\
\text { formal y técnico } \\
\text { y las operacio- } \\
\text { nes }\end{array}$ & $\begin{array}{l}\text { Interpreta el len- } \\
\text { guaje formal y } \\
\text { simbólico básico, } \\
\text { en situaciones me- } \\
\text { nos conocidas. } \\
\text { (CLSOn1) }\end{array}$ & $\begin{array}{l}\text { Maneja afirmacio- } \\
\text { nes sencillas y ex- } \\
\text { presiones con } \\
\text { símbolos y fórmu- } \\
\text { las no rutinarias. } \\
\text { (CLSOn2) }\end{array}$ & $\begin{array}{l}\text { Utiliza variables, y } \\
\text { realiza ecuaciones } \\
\text { y cálculos median- } \\
\text { te procedimientos } \\
\text { familiares. } \\
\text { (CLSOn3) }\end{array}$ \\
\hline mera rutina & r & 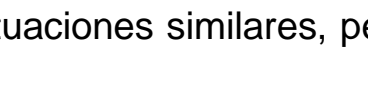 & yue ya 110 so \\
\hline
\end{tabular}


Tabla II.3. Categorías de análisis de competencias III.

\begin{tabular}{|c|c|c|}
\hline \multicolumn{3}{|c|}{ REFLEXIÓN } \\
\hline $\begin{array}{l}\text { Competencias/ } \\
\text { Niveles }\end{array}$ & Nivel 1 & Nivel 2 \\
\hline $\begin{array}{l}\text { Pensar y razo- } \\
\text { nar }\end{array}$ & $\begin{array}{l}\text { Elabora estrategias no rutina- } \\
\text { rias conexionadas con pro- } \\
\text { blemas reales. (RfPRn1) }\end{array}$ & $\begin{array}{l}\text { Aplica estrategias no rutina- } \\
\text { rias. (RfPRn2) }\end{array}$ \\
\hline Argumentar & $\begin{array}{l}\text { Razona de forma sencilla, dis- } \\
\text { tinguiendo formas más am- } \\
\text { plias de argumentación. } \\
\text { (RfAn1) }\end{array}$ & $\begin{array}{l}\text { Elabora encadenamientos de } \\
\text { argumentos de diferentes ti- } \\
\text { pos. (RfAn2) }\end{array}$ \\
\hline Comunicar & $\begin{array}{l}\text { Sabe explicar cuestiones ma- } \\
\text { temáticas, cálculos y resulta- } \\
\text { dos. (RfCn1) }\end{array}$ & $\begin{array}{l}\text { Explica asuntos que implican } \\
\text { relaciones complejas. (RfCn2) }\end{array}$ \\
\hline Modelizar & $\begin{array}{l}\text { Estructura la situación de la } \\
\text { que hay que realizar un mode- } \\
\text { lo, traduciendo la realidad. } \\
(\mathrm{RfMn} 1)\end{array}$ & $\begin{array}{l}\text { Reflexiona llevando a cabo } \\
\text { una comunicación sobre la } \\
\text { construcción del modelo. } \\
\text { (RfMn1) }\end{array}$ \\
\hline $\begin{array}{l}\text { Resolver pro- } \\
\text { blemas }\end{array}$ & $\begin{array}{l}\text { Expone problemas más allá de } \\
\text { la reproducción de los ya prac- } \\
\text { ticados. (RfRPn1) }\end{array}$ & $\begin{array}{l}\text { Resuelve problemas es- } \\
\text { tableciendo conexiones entre } \\
\text { las distintas áreas matemáti- } \\
\text { cas. (RfRPn2) }\end{array}$ \\
\hline Representar & $\begin{array}{l}\text { Interpreta y cambia entre dife- } \\
\text { rentes formas de representa- } \\
\text { ción de las situaciones ma- } \\
\text { temáticas. (RfRn1) }\end{array}$ & $\begin{array}{l}\text { Combina representaciones de } \\
\text { forma creativa e inventa nue- } \\
\text { vas. (RfRn2) }\end{array}$ \\
\hline $\begin{array}{l}\text { Utilizar el len- } \\
\text { guaje simbólico, } \\
\text { formal y técnico } \\
\text { y las opera- } \\
\text { ciones }\end{array}$ & $\begin{array}{l}\text { Interpreta el lenguaje formal y } \\
\text { simbólico en } \begin{array}{l}\text { situaciones y } \\
\text { contextos } \\
\text { (RfLSOn1) }\end{array}\end{array}$ & $\begin{array}{l}\text { Sabe tratar con expresiones } \\
\text { complejas y con lenguaje } \\
\text { simbólico o formal inusual. } \\
\text { (RfLSOn2) }\end{array}$ \\
\hline Reflexión por pa & del estudiante para planificar es & $\begin{array}{l}\text { trategias y aplicarlas en la reso- } \\
\text { uales. }\end{array}$ \\
\hline
\end{tabular}

Los ítems de reproducción incluyen tareas que requieren, esencialmente, conocimientos usuales tales como conocimiento de representaciones, el uso de objetos y propiedades matemáticas familiares, procesos rutinarios, aplicación de algoritmos estandarizados y de habilidades prácticas, manejo de expresiones con símbolos familiares y realización de operaciones sencillas. 
Las competencias del nivel 1, (Tabla II.1. REPRODUCCIÓN) implican esencialmente a la reproducción del conocimiento estudiado. Incluyen aquellas que se emplean más frecuentemente en las pruebas estandarizadas y en los libros de texto: conocimiento de hechos, representaciones de problemas comunes, reconocimiento de equivalentes, recopilación de propiedades y objetos matemáticos familiares, ejecución de procedimientos rutinarios, aplicación de destrezas técnicas y de algoritmos habituales, el manejo de expresiones con símbolos y fórmulas establecidas y realización de cálculos.

Las competencias del nivel 2 (Tabla II.2. CONEXIÓN) se apoyan sobre las del grupo de reproducción, conduciendo a situaciones de solución de problemas que se sitúan en contextos familiares pero que no son meramente rutinarios; por tanto, plantean mayores exigencias en su interpretación y requieren establecer relaciones entre distintas representaciones de una situación o enlazar diferentes aspectos de la situación con el fin de desarrollar una solución.

Los ítems del nivel 3 (Tabla II.3 REFLEXIÓN) requieren competencias que necesitan perspicacia y discernimiento por parte del alumno, creatividad para identificar conceptos matemáticos relevantes o establecer vínculos con los conocimientos adecuados para encontrar la solución. Estas competencias se requieren para problemas que exigen procesos más complejos, creativos o estructurados.

Las competencias de este grupo incluyen un elemento de reflexión por parte del estudiante sobre los procesos necesarios o empleados para resolver un problema. Relacionan las capacidades de los alumnos para planificar estrategias de resolución y aplicarlas en escenarios de problema que contienen más elementos y pueden ser más «originales» (o inusuales) que los del grupo de conexión.

En el nivel de reproducción, en la competencia de pensar y razonar, el alumno al reconocer la representación de los datos, suscita que pase a plantear los algoritmos correspondientes, asociándoles a fórmulas establecidas y realiza los cálculos, mientras que en el nivel de conexión tiene que pensar en el tratamiento matemático necesario, y a partir de esa reflexión comprende que tiene que emplear conceptos matemáticos intermedios para pasar a aplicar los conceptos matemáticos apropiados. El nivel de reflexión en dicha competencia, exhorta al alumno para que elabore y aplique estrategias no rutinarias que conexionen el saber matemático con problemas reales. 
En la competencia de argumentar el alumno identifica el problema, expone el proceso de cálculo y justifica las fórmulas utilizadas y los resultados, en el nivel de reproducción, mientras que en el nivel de conexión, además de identificar, razona matemáticamente de manera simple y despliega y evalúa el encadenamiento de argumentos matemáticos particulares (situación que se presenta en el estudio de ejercicios cuya resolución depende de la existencia de parámetros). En el nivel de reflexión se insta al alumno a razonar de forma sencilla, pero distinguiendo formas más amplias de argumentación, encadenando razonamientos de diferentes tipos.

La competencia comunicar, en el nivel de reproducción, sugiere que el alumno comprende la expresión escrita, mientras que en el nivel de conexión sabe expresarse sobre cuestiones matemáticas. La acción de expresarse comprende una connotación de nivel superior, pues, para ello, el alumno debe haber comprendido anteriormente y además explicar cálculos y propiedades que inducen esa resolución. En el nivel de reflexión el alumno sabe explicar cuestiones matemáticas, cálculos y resultados en contenidos que implican relaciones complejas.

El alumno identifica que un modelo es similar a otros modelos vistos con anterioridad, otros modelos practicados durante la instrucción, en el nivel de reproducción de la competencia modelizar; mientras que en el nivel de conexión estructura la situación que debe modelizar, dispone de un bagaje de conocimientos adecuado para saber alternar e interpretar diferentes modelos y posteriormente comunicar los resultados. En reflexión es cuando el alumno realmente modeliza, es decir, construye un modelo traduciendo la realidad y reflexiona comunicando sobre la construcción del modelo. En los demás niveles, lo que el alumno hace realmente es modelar.

El nivel de reproducción de la competencia resolver problemas se reduce a reconocer problemas ya practicados, reproducir esos problemas de una manera cerrada y resolver problemas rutinarios estandarizados, resolución automática de modelos normalizados, mientras en el nivel de conexión esos problemas, aun siendo intuitivos no son mecánicos, lo que obliga al alumno a elegir las estrategias apropiadas que conexionen áreas matemáticas y aplicarlas, se pasa de una resolución de autómata a una resolución deducida, cavilada. En el nivel de reflexión de esta competencia, el alumno expone y resuelve problemas más allá de los practicados anteriormente, estableciendo conexiones entre las distintas áreas matemáticas. No se trata de reconocer y reproducir problemas ya 
practicados repetidamente, aún cuando se generalicen mediante parámetros; sino en resolver efectivamente problemas y no ejercicios.

Salvo en el subnivel 1 del nivel de reproducción, en la competencia de representar, en la que el alumno usa un único tipo de representación estándar, la competencia representar en los niveles de reproducción y conexión tienen matices parecidos, es el nivel de las demás competencias inherentes al ejercicio el que hace decantarse por un nivel u otro de representación. En el nivel de reproducción el alumno interpreta reproducciones estándar de objetos matemáticos y pasa de una representación a otra; en el nivel de conexión interpreta formas de representación, pero suelen ser representaciones habituales: gráfica, aritmética, algebraica, geométrica; selecciona y cambia entre diferentes formas de representación, es decir, pasa de una representación a otra según va solucionando el ejercicio.

En el nivel de reflexión, el subnivel 1 de representar considerado superficialmente se puede suponer equivalente al correspondiente a los niveles de reproducción y conexión, es decir, el alumno interpreta y cambia entre diferentes formas de representación de las situaciones matemáticas, pero, como es obvio, se refiere a situaciones matemáticas extraídas de contextos reales en problemas no triviales, se trata de combinar representaciones de forma creativa, generando y aplicando representaciones nuevas, o sea, se trata de representar ejercicios que en otras competencias están encuadrados en un nivel de reflexión.

El alumno utiliza el lenguaje simbólico, formal y técnico y realiza operaciones en un nivel de reproducción en prácticamente todos los ejercicios de matemáticas, para entender la expresión escrita, o identificar el problema, tiene que realizar operaciones elementales (sumas, productos), interpretar el lenguaje formal simbólico y rutinario, como son las operaciones aritméticas. Sin embargo el nivel de conexión exige interpretar ese lenguaje en situaciones menos conocidas, utilizar expresiones con símbolos y fórmulas no rutinarias, como son las derivadas o las integrales

¿Qué diferencia el nivel de reproducción del nivel de conexión en el subnivel 3 de esta competencia?

En reproducción el alumno maneja procedimientos y fórmulas resolviendo y calculando, es decir, resuelve ecuaciones algebraicas, calcula raíces, y en conexión utiliza variables, realiza ecuaciones y cálculos mediante procedimientos 
familiares, en este caso ecuaciones matriciales, cálculo de operaciones con matrices, con determinantes, derivadas, integrales,...En el nivel de reflexión el alumno debe saber interpretar $y$ tratar con expresiones complejas con lenguaje simbólico o formal, inusual.

\section{II.3. MARCO METODOLÓGIGO}

Hay muchos autores que proponen metodologías de investigación y entre ellos consideramos que la metodología descrita por Fox (1981) tiene unas características muy adecuadas para el desarrollo de nuestra investigación. Se trata de una metodología de corte cualitativo y, en su descripción, el autor establece diecisiete etapas que son clasificadas en tres apartados: 13 para el diseño del Plan de Investigación, 3 para la ejecución del Plan y la etapa 17 que versa sobre la aplicación de los resultados.

\section{Etapas del Plan de Investigación (Fox, 1981, p. 56)}

PRIMERA PARTE: DISEÑO DEL PLAN DE INVESTIGACIÓN

1. Idea o necesidad impulsora y área problemática

2. Examen inicial de la Bibliografía

3. Definición del problema concreto de la investigación

4. Estimación del éxito potencial de la investigación planteada

5. Segundo examen de la bibliografía

6. Selección del enfoque de la investigación

7. Formulación de las hipótesis de la investigación

8. Selección de métodos y técnicas de recogida de datos

9. Selección y elaboración de los instrumentos de recogida de datos

10. Diseño del plan de análisis de datos

11. Diseño del plan de recogida de datos

12. Identificación de la población y muestra a utilizar

13. Estudios pilotos del enfoque de recogida de datos, métodos e instrumentos y del plan de análisis de datos 


\section{SEGUNDA PARTE: EJECUCIÓN DEL PLAN DE INVESTIGACIÓN}

14. Ejecución del plan de recogida de datos

15. Ejecución del plan de análisis de datos

16. Preparación de los informes de la investigación

\section{TERCERA PARTE: APLICACIÓN DE LOS RESULTADOS}

17. Diseminación de los resultados y propuestas de medidas de Actuación

De las 17 etapas que considera Fox, sólo comentamos algunas, ya que otras (Estimación del éxito potencial de la investigación planteada, Segundo examen de la bibliografía, Selección del enfoque de la investigación, Identificación de la población y muestra a utilizar, Estudios pilotos del enfoque de recogida de datos, métodos e instrumentos y del plan de análisis de datos) corresponden a un análisis previo e implícito en el estudio

\section{Etapa 1. Idea o necesidad impulsora}

Las evaluaciones externas inciden notablemente en el desarrollo de la docencia ya que los profesores están influenciados por sus percepciones del contenido de estas pruebas, sobre todo cuando los resultados pueden tener consecuencias importantes para ellos o sus alumnos (Shepard, 2001; Van den Heuvel-Panhuizen y Becker, 2003). Esta situación es claramente observable en las respuestas que se obtienen en pruebas como la prueba de diagnóstico que realiza la Junta de Castilla y León con los alumnos de Educación Primaria y Secundaria Obligatoria o con los informes de las Pruebas PISA que se realizan periódicamente y que inciden directamente en las programaciones de los centros educativos. Si queremos que los alumnos investiguen, exploren y descubran, la evaluación no debe medir sólo matemática de imitación.

Los estándares del NCTM exponen claramente los contenidos que hay que aprender y cómo se deberían aprender y aconsejan desarrollar las capacidades de los estudiantes para investigar y representar relaciones, utilizando procedimientos que intensifiquen la resolución de problemas, la comunicación, el razonamiento y las conexiones matemáticas; por eso, los Estándares del NCTM (1991, 2000) presentan una visión de unos estudiantes como personas que piensan y razonan. 
Es apremiante hacer cambios sustanciosos en los métodos pedagógicos y en la práctica educativa con el fin de poder afrontar los cambios que exige la sociedad actual; aunque esto no es una labor sencilla, ya que la actividad matemática en el aula se entiende como un componente cultural e histórico, fundamentada en unas necesidades sociales concretas y cuyas tareas tienen que ver con el contexto. Este interés por la evaluación se origina debido a la importancia que, en las evaluaciones internacionales, se da a las competencias y a la aplicación de las matemáticas a las situaciones de la vida real, y se caracteriza en el uso de un enfoque contextualizado (informe PISA'2003).

Es patente que, en el aprendizaje de las matemáticas, los procesos de abstracción son complejos y difíciles de identificar, como apuntan Ron, Dreyfus y Hershkowitz (2006). Entre los usos tradicionales de la palabra conocimiento, encontramos denominaciones diferentes como exposición, competencias, herramientas y prácticas. Es decir, estamos familiarizados con un tema cuando somos capaces de estructurarlo mediante sus relaciones en un contexto preciso. El fundamento de estas afirmaciones se basa en diversos estudios que determinan las características de la actividad matemática que desarrollan los estudiantes cuando resuelven o plantean problemas de matemáticas, tareas relevantes en sus respectivos procesos de aprendizaje así, para Hudson (2008), el conocimiento se considera como una relación contextualizada.

Para Serradó, Cardeñoso y Azcárate (2004), la función del docente se debe caracterizar por ser un intermediario en el proceso de construcción del conocimiento, impulsando en los alumnos un aprendizaje significativo. Los criterios e instrumentos que éste despliegue en el aula deben fundamentarse en las funciones y finalidades de la evaluación, así el estudio en competencias debe derivar en un estilo determinado de plantear ejercicios adecuados a los distintos niveles, incluido el nivel de reflexión.

\section{Etapa 2. Examen inicial de la Bibliografía}

Ademas de la bibliografía inicial considerada en currículo y evaluación, aquí se describe el pensamiento de otros autores.

Rico et al. (1993) incluyen la revisión de 313 documentos específicos sobre el tema y realiza una primera delimitación conceptual en los estudios sobre evaluación. Respecto a las Pruebas de Selectividad (Rico et al. 1997) indican que 
son la manifestación final del sistema educativo y denuncia la insatisfacción social (no profesional). Parafraseando a estos autores:

Las pruebas de selectividad son sólo un ejemplo, quizás el más difundido y menos popular, de la evaluación que se lleva a cabo en nuestro sistema educativo... Pero estas pruebas son solamente la manifestación final de todo un sistema organizado para valorar el conocimiento de nuestros jóvenes. La insatisfacción social con este sistema se manifiesta especialmente en estos momentos, pero no cabe duda que sus raíces se extienden a lo largo de todos los años de escolaridad (Rico et al. 1997)

Webb (1992) estima que una teoría correcta de la evaluación en matemáticas favorece el desarrollo de la Educación Matemática y es procedente para evaluar a los alumnos con orientación crítica. Justifica su teoría en especificar el contenido de la evaluación y en base a esto, formular la evaluación. Precisar el contenido de la evaluación incumbe al propósito de la misma, a las matemáticas implicadas en la prueba y a las consideraciones prácticas sobre el tiempo, la puntuación y los criterios de promoción. Igualmente, la forma en que se especifica el contenido influye tanto en la evaluación como en sus resultados. El procedimiento utilizado en la evaluación evidencia un concepto subyacente de las matemáticas y de su enseñanza y aprendizaje, y, en consecuencia, influirá en los resultados del aprendizaje.

Ligado a la aparición de los movimientos de reforma en la educación, al comienzo de los años 80 , se produce un incremento en el uso de test en las pruebas de evaluación; no obstante esta práctica es pronto criticada dado que el uso masivo de los test provoca la limitación del curriculo al dominio de lo que se exige en las pruebas, y éstas no suelen incluir preguntas en las que se evalúen niveles complejos de comprensión (Giménez, 1997).

Las pruebas matemáticas que se proponen en las PAU se han conformado procurando atender a criterios de imparcialidad, de objetividad, relativas a unos conocimientos establecidos públicamente, adaptadas a los conocimientos medios exigibles, y aplicables con los mismos criterios a todos los estudiantes. El formato de las cuestiones debe atender a una variedad de tareas que impliquen diferentes niveles de complejidad, ser coherentes con los criterios de valoración, proporcionar objetividad en los juicios emitidos, facilitar la comparación de resultados y tener simplicidad para expresar datos sobre una escala.

El intento de ajustarse a estas normas ha producido unos formatos delimitados y una simplificación en las cuestiones propuestas, lo cual repercute directamen- 
te en el aula, como se refleja en las investigaciones realizadas sobre el contenido de las pruebas que hacen los docentes. En las investigaciones precedentes se ha constatado que la mayoría de preguntas propuestas por los docentes requieren un bajo nivel de conocimiento y actuación por parte de los estudiantes, que los exámenes de aula, con frecuencia, no reflejan los objetivos instruccionales declarados por los profesores y, a menudo, requieren poco más que la repetición de tareas presentadas en el libro de texto y en las pruebas se pide resolver problemas muy parecidos a los propuestos en la docencia.

Las evaluaciones externas pesan considerablemente en la práctica docente ya que los profesores están influenciados por sus aprehensiones del contenido de estas pruebas, sobre todo cuando los resultados implican resultados importantes para sus alumnos, e incluso, para ellos mismos (Shepard, 2001; Van den Heuvel-Panhuizen y Becker, 2003). Los profesores tienden a ceñir la instrucción dedicando una cantidad excesiva del tiempo lectivo a enseñar el contenido específico que se pregunta en éstas, adaptando su enseñanza a la evaluación externa (PAU), en detrimento de enseñar los conceptos y los contenidos menos examinados en dichas pruebas. Según (Silver y Kenney, 1995), estudios realizados en esta línea han apreciado que las pruebas formales ocupan aproximadamente el quince por ciento del tiempo de los estudiantes de educación secundaria.

Según Silver y Kilpatrick (1988), “otra función de la evaluación es señalar a los estudiantes, profesores y al público en general los aspectos que se valoran en el aprendizaje”. Cuando los alumnos preguntan: “¿esto entrará en el examen?”, están consultando el valor del conocimiento en cuestión.

En España, se puede considerar que las Pruebas de Acceso a la Universidad son un modelo de evaluación externa. Se realizan distintas pruebas en las diferentes Comunidades Autónomas.

A modo de resumen, y de acuerdo con Romberg (1992), cada forma de evaluación comienza con lo que se espera que responda un estudiante a una o más tareas y se diseña para examinar las respuestas de los estudiantes. Rico y otros (1997) reflejan la importancia del tipo de cuestiones que se preguntan en los exámenes recordando un estudio exhaustivo de las características de las pruebas y de los tipos de cuestiones convencionales para evaluar matemáticas que realizó Sydam en 1974 y que revisa posteriormente, en 1986, en el que 
hace una extensa investigación de los procedimientos e instrumentos usuales para la evaluación en matemáticas. Entre estos se encuentran, fundamentalmente, gran variedad de test que pueden ser de distintos tipos con relación a la norma, con relación al criterio, estandarizados, de diagnóstico y escalas de actitud. Parece que las diferentes pruebas escritas son la principal herramienta de evaluación en el aula de Matemáticas.

Finalmente, Cáceres $(2005,15)$ hace una brevísima referencia a los niveles de las pruebas, pero no realiza ningún tipo de análisis competencial.

\section{Etapa 3. Definición del problema concreto de la investigación.}

Este estudio curricular junto con la experiencia de la investigadora permite enunciar los objetivos fundamentales del trabajo de investigación que se describe en esta memoria:

O1. Analizar hasta qué punto las PAEUs contribuyen al desarrollo del currículo de Bachillerato.

O2. Determinar las competencias matemáticas implícitas tanto en los enunciados de los problemas y de las cuestiones de las PAEUs como en sus procesos de resolución.

O3. Analizar la redacción de los enunciados de los problemas y de las cuestiones.

Estos dos objetivos generales dan lugar a las hipótesis de investigación:

H1. Hay muchos conceptos matemáticos que o no se preguntan o se pregunta escasas veces. Las frecuencias de aparición de algunos conceptos como preguntas de examen son nulas o muy bajas.

H2. Algunos conceptos matemáticos se preguntan excesivamente. Las frecuencias de aparición de algunos conceptos como preguntas de examen son muy altas.

H3. Se pueden adaptar los niveles de evaluación proporcionados por PISA (reproducción, conexión y reflexión) en función de las acciones verbales implícitas en sus enunciados. 
H4. El nivel de reproducción es el que más se repite en las cuestiones de las PAEU.

H5. Los niveles de reflexión apenas aparecen en los problemas propuestos en las PAEU

H6. Se puede mejorar sustancialmente la redacción de los enunciados.

\section{Etapa 8. Selección de métodos y técnicas de recogida de datos.}

En la Comunidad de Castilla y León se han realizado Pruebas de Acceso con todas las variantes que se han ido estableciendo desde su creación, pero para nuestro estudio nos interesan las más recientes. Concretamente, consideramos como punto de partida las que se han realizado con el currículo LOGSE y que datan desde el curso 1994-1995. En este año y hasta el curso 2000-2001 estas pruebas externas coexistieron con otras que seguían las directrices de la Ley General de Educación y del Curso de Orientación Universitaria, que fue establecido en el Decreto 160/1975, pero no van a ser objeto de nuestra atención, ya que nuestro objetivo es únicamente el estudio de las primeras.

Como profesora preocupada por la mejor preparación de sus alumnos para que éstos alcancen los mejores resultados en las PAU, la Profesora Investigadora (PI) fue archivando todas las pruebas que se propusieron en la Universidad de Valladolid en las convocatorias de junio y septiembre, tanto de los bachilleratos de Ciencias de la Salud y Tecnología como de Ciencias Sociales. Asimismo, la PI fue archivando modelos de pruebas de otras universidades durante varios años.

Etapa 9. Selección y elaboración de los instrumentos de recogida de datos.

La investigación que se ha llevado a cabo y que se describe en esta memoria se ha realizado exclusivamente con las pruebas que corresponden a los Bachilleratos de Ciencias de la Naturaleza y de la Salud, y Tecnológico, y de los contenidos del Nuevo currículo que entra en vigor en el curso 2003 - 2004, regulados por el Decreto 70/2002 de 23 de mayo, promulgado por la Consejería de Educación de la Junta de Castilla y León. (A partir de este curso el tema de cónicas desaparece del currículo, por lo que los ejercicios de ese tema no se han considerado). 
Como ya se ha indicado las Pruebas de Acceso que son objeto de nuestro estudio comienzan en el curso 1994-95, cuando se empiezan a realizar los exámenes de selectividad LOGSE, la PI recopila todos los enunciados de las distintas convocatorias con los siguientes fines:

a) Para comparar y contrastar los enunciados de los ejercicios propuestos en las pruebas de selectividad COU y los enunciados de la nueva selectividad LOGSE.

b) Tener una extensa colección de ejercicios y cuestiones y disponer de modelos variados, organizados cronológicamente, que me ayudaran a preparar a mis alumnos para superar con un buen nivel los contenidos de esta materia.

c) Contrastar entre los enunciados de los ejercicios en las convocatorias de Junio y Septiembre y de otras autonomías y comparar el nivel de exigencia, la repetición de enunciados y la frecuencia de aparición de unos y otros conceptos.

d) Ver la adecuación de nivel entre los acuerdos mínimos de Selectividad y el temario general del Bachillerato.

\section{Etapa 10. Diseño del plan de análisis de datos.}

Se ha efectuado la investigación teniendo en cuenta dos facetas diferenciadas. Por una parte se realizó un estudio de las características de la actividades matemáticas que se proponen, mientras que en la segunda faceta nos centramos en el estudio de los procesos de abstracción matemática que generan los estudiantes cuando resuelven dichas tareas, el tipo de razonamiento y la demanda cognitiva de las tareas, un núcleo centrado en las características del proceso de abstracción matemática.

Adoptando el modelo de la abstracción en contexto (Hershkowitz, Schwarz y Dreyfus, 2001) se ha intentado acercarse al conocimiento de la realidad a través del estudio de los significados que tienen los conceptos para los estudiantes, centrando la investigación en los supuestos estudiantes que han resuelto las tareas propuestas y después han explicado su trabajo.

\section{Etapa 14. Ejecución del plan de recogida de datos.}

Para recopilar estos enunciados de exámenes he utilizado las siguientes fuentes: 
a) La presencia de un Representante de Centro en las sedes donde se realizan las pruebas de selectividad, quien acompaña a los alumnos del Centro y recoge modelos de los exámenes que se han propuesto para esa asignatura. La PI tiene todos estos modelos.

b) El libro que la Universidad envía a los centros de enseñanza, a lo largo del curso siguiente, con todos los enunciados de las pruebas que se han efectuado en las convocatorias de Junio y Septiembre del curso anterior.

c) Los textos de la editorial Anaya que contienen el enunciado y las soluciones, de algunos de estos problemas, concretamente los de la convocatoria de Junio.

d) Las publicaciones en Internet, www.selectividad.profes.net, de la editorial SM con los enunciados y las correspondientes soluciones y las de la Universidad coordinadora de las Pruebas en la que aparecen los enunciados de los exámenes propuestos y los criterios de evaluación de los mismos.

e) Las publicaciones en Internet de la página web de las Universidades de Salamanca y de Valladolid.

\section{Etapa 15. Ejecución del plan de análisis de datos.}

Para reordenar los ejercicios propuestos en las pruebas la PI ha seguido el criterio curricular de los distintos contenidos, en el orden en que aparecen en el ANEXO IV (Análisis del Currículo: Acuerdos de mínimos) de la Comisión Organizadora P.A.E.U. de Castilla y León y en el BOC y L (Decreto 70/2002, de 23 de mayo) por el que se establece el Currículo de Bachillerato de la Comunidad de Castilla y León y se agrupan siguiendo el orden de los tres bloques de contenidos curriculares.

a) Análisis (Límites, Continuidad, Derivadas, Integrales)

b) Álgebra (Matrices, Determinantes, Sistemas de ecuaciones lineales)

c) Geometría (Vectores, Rectas y Planos, Esfera y elipsoide)

Se han transcrito los enunciados de casi todos los problemas y cuestiones propuestos para las Pruebas de Acceso a la Universidad, de Matemáticas II de los bachilleratos de Ciencias de la Naturaleza y de la Salud y Tecnológico desde el curso 1994-95,- salvo los correspondientes a Cónicas, por no estar incluidos en 
el desarrollo curricular relativo a este estudio, y por tanto no se ha hecho estudio pormenorizado de los mismos.

En los capítulos IV, V y VI se presentan algunos enunciados para que se comprenda el tipo de análisis que se ha realizado en Análisis Matemático, Álgebra y Geometría. Asimismo, en cada caso se realizan los análisis correspondientes. La totalidad de los enunciados y sus soluciones figuran en los ANEXOS I, II, III, IV, V y VI del CD que acompaña a la memoria.

Con el objeto de analizar los problemas y las cuestiones que han sido propuestas en las PAU recopiladas se confeccionan quince tablas de categorías, En las tablas III.1, III.6 y III.11, la PI, se fundamenta en los contenidos conceptuales del currículo, las tablas III.2, III.7 y III.12 completan, respectivamente, las anteriores, en ellas se adjuntan contenidos procedimentales, incluidos en los enunciados; y esta clasificación se efectúa basándonos exclusivamente en la orden del enunciado y no en las determinaciones intermedias, así como las restantes tablas, que son de frecuencias de aparición de los contenidos conceptuales y procedimentales, catalogadas por años y conceptos.

Las figuras III.1 a III.6 son diagramas de barras, en las que se observa la frecuencia de los contenidos conceptuales en las distintas propuestas de examen realizadas a lo largo de los 15 cursos del estudio.

\section{Etapas 16 y 17. Preparación de los informes de investigación. Difusión de los resultados y propuestas de medidas de actuación.}

El último capítulo de la memoria de la tesis está dedicado a las conclusiones de la investigación y será la base de la elaboración de algunos artículos. Ya se han presentado dos comunicaciones en congresos: la primera en el XI Congreso Regional de la Sociedad de Profesores Miguel de Guzman (2012) y la segunda en las XVI JAEM (2013) de Palma de Mallorca. Una vez defendida la tesis se mandaran al menos tres artículos (uno sobre el sesgo curricular, otro sobre competencias y un tercero sobre la redacción de enunciados) a revistas especializadas. Finalmente, en el último capítulo se hace una propuesta curricular. 


\section{CAPÍTULO III}

\section{PRESENCIA DE CATEGORÍAS DE CONTENIDO}

\section{III.1. INTRODUCCIÓN}

Se presenta a continuación el estudio pormenorizado, mediante tablas, que la $\mathrm{PI}$ hace de todos los exámenes de Pruebas LOGSE que se han propuesto durante los quince años, -desde el curso 1994-95 al curso 2008-09-, que son el referente del trabajo.

Se puede enfocar este estudio de diferentes formas, por eso se presenta, para cada uno de los bloques de contenidos, en primer lugar una tabla conceptual siguiendo el currículo con su correspondiente tabla de frecuencias y gráficos derivados de ella, a continuación una tabla conceptual y procedimental, en la que se incluye el currículo y el procedimiento requerido para contestar a la incógnita planteada en el ejercicio y tomando como base este segundo modelo de categorización se diseñan, en tabla de doble entrada, por años y conceptos, la frecuencia de aparición de los contenidos, como si se tratara de una "nube de puntos", aunque, lo que en ellas aparecen, en lugar de ser puntos son frecuencias.

\section{III.2. TABLAS DE CATEGORÍAS DE CONTENIDOS DE ANÁLISIS MATEMÁTICO.}

Para confeccionar la tabla III.1 consideramos los contenidos curriculares de Análisis Matemático, correspondientes a la asignatura de Matemáticas II, publicado oficialmente en el BOCyL, siguiendo el orden del Decreto 70/2002 de 23 de mayo por el que se establece el currículo de Bachillerato de la comunidad de Castilla y León y el ANEXO IV Análisis del Currículo: Acuerdos de mínimos 
de la Comisión Organizadora PAEU de esta Comunidad, actualizado en abril de 2003, que está vigente durante los años a los que se refiere este estudio.

Sobre la base de estos contenidos curriculares de Análisis Matemático, que se han detallado en 35 categorías en la tabla III.1 se indica la presencia de los mismos, tanto en los problemas como en las cuestiones de las PAEU y además se contabiliza su frecuencia de aparición. Esta tabla está elaborada a partir de los ANEXOS I y II, los enunciados se presentan señalados con una P si se trata de un Problema o con una $\mathrm{C}$, si es una Cuestión, y están numerados siguiendo el orden cronológico de aparición en los ejercicios propuestos en las pruebas de las PAU desde 1995 hasta 2009. Este número que indica a estas letras es el correspondiente al lugar que ocupa el problema o cuestión de referencia en los citados ANEXOS.

Tabla III.1. Categorías curriculares de Análisis Matemático

\begin{tabular}{|c|c|c|c|c|}
\hline Contenidos curriculares & Problemas & $\mathbf{N}^{\circ}$ & Cuestiones & $\mathbf{N}^{\mathbf{0}}$ \\
\hline $\begin{array}{l}\text { Límite de una sucesión. Cálculo } \\
\text { de límites. }\end{array}$ & & 0 & & 0 \\
\hline El número e & & 0 & & 0 \\
\hline $\begin{array}{l}\text { Límite de una función en un } \\
\text { punto. Propiedades. }\end{array}$ & & 0 & $\mathrm{C} 10, \mathrm{C} 23$ & 2 \\
\hline $\begin{array}{l}\text { Técnicas de cálculo de límites } \\
\text { (cancelación, racionalización) }\end{array}$ & & 0 & C10, C61 & 2 \\
\hline Límites laterales & P35, P55 & 2 & $\mathrm{C} 7$ & 1 \\
\hline $\begin{array}{l}\text { Límites en el infinito. Compor- } \\
\text { tamiento asintótico de una fun- } \\
\text { ción. Calcular las asíntotas }{ }^{2}\end{array}$ & $\begin{array}{lll}\text { P24, } & \text { P27, } & \text { P29, } \\
\text { P38, P42, } & \text { P43, } \\
\text { P47, P48, } & \text { P49, } \\
\text { P50, P51, } & \text { P52, } \\
\text { P53, P54, P57, P60 }\end{array}$ & 16 & C33, C87 & 2 \\
\hline Dominio de una función ${ }^{3}$ & P24, P29, P49, P60 & 4 & $\mathrm{C} 12, \mathrm{C} 20$ & 2 \\
\hline
\end{tabular}

\footnotetext{
${ }^{2}$ Este contenido aparece en el currículo de Primer Curso de forma específica, pero no en segundo curso. Está implícito en el comportamiento asintótico, pero en el enunciado de los ejercicios se pide: Calcular las asíntotas.

${ }^{3}$ Este contenido no aparece de forma específica en los contenidos curriculares de Matemáticas II, aunque aparece reflejado en la orden del enunciado de algunos ejercicios.
} 
Tabla III.1. Categorías curriculares de Análisis Matemático (continuación)

\begin{tabular}{|c|c|c|c|c|}
\hline Contenidos curriculares & Problemas & $\mathrm{N}^{\circ}$ & Cuestiones & $\mathbf{N}^{\circ}$ \\
\hline $\begin{array}{l}\text { Funciones continuas. Propieda- } \\
\text { des }\end{array}$ & & 0 & & 0 \\
\hline $\begin{array}{l}\text { Continuidad y función compues- } \\
\text { ta. }\end{array}$ & P6, P35, P55 & 3 & $\begin{array}{l}\text { C7, C10, C13, } \\
\text { C64, C79, C89 }\end{array}$ & 6 \\
\hline $\begin{array}{l}\text { Determinación de discontinui- } \\
\text { dades }\end{array}$ & & 0 & & 0 \\
\hline $\begin{array}{l}\text { Continuidad en intervalos cerra- } \\
\text { dos. }\end{array}$ & $\begin{array}{l}\text { P12, P32, P43, } \\
\text { P48, P51, P52, P57 }\end{array}$ & 7 & $\begin{array}{lll}\text { C2, C17, } & \text { C36, } \\
\text { C49, C55, C75, } \\
\text { C78, C83, C88, } \\
\text { C98 }\end{array}$ & 10 \\
\hline $\begin{array}{l}\text { Derivada de una función en un } \\
\text { punto. }\end{array}$ & P35 & 1 & C52 & 1 \\
\hline $\begin{array}{l}\text { Funciones derivables. Estudio } \\
\text { de la derivabilidad de una fun- } \\
\text { ción }^{4}\end{array}$ & $\begin{array}{l}\text { P3, P6, P35, P40, } \\
\text { P44, P55, P58 }\end{array}$ & 7 & C4, C7, C13, C53 & 4 \\
\hline Cálculo de derivadas & P35 & 1 & $\begin{array}{l}\text { C16, C24, C27, } \\
\text { C42, C46 }\end{array}$ & 5 \\
\hline $\begin{array}{l}\text { Recta tangente a una curva, en } \\
\text { un punto }{ }^{5}\end{array}$ & P17, P20, P28 & 3 & $\begin{array}{l}\text { C5, C25, C52, } \\
\text { C76, C81, C86, } \\
\text { C97 }\end{array}$ & 7 \\
\hline Teorema de Rolle & & 0 & C8, C28 & 2 \\
\hline Teorema del valor medio & P17, P32 & 2 & C31, C63 & 2 \\
\hline Regla de L’Hôpital & & 0 & $\begin{array}{l}\text { C1, C21, C34, } \\
\text { C38, C43, C44, } \\
\text { C48, C51, C56, } \\
\text { C58, C62, C66, } \\
\text { C68, C69, C72, } \\
\text { C73, C77, C84, } \\
\text { C85, C91, C96 }\end{array}$ & 21 \\
\hline
\end{tabular}

\footnotetext{
${ }^{4}$ Detallamos el contenido pues así aparece en el enunciado de los ejercicios.

${ }^{5}$ Contenido de Primer Curso que aparece como orden en los ejercicios de las PAU.
} 
Tabla III.1. Categorías curriculares de Análisis Matemático (continuación)

\begin{tabular}{|c|c|c|c|c|}
\hline Contenidos curriculares & Problemas & $\mathrm{N}^{\circ}$ & Cuestiones & $\mathbf{N}^{\circ}$ \\
\hline $\begin{array}{l}\text { Intervalos de crecimiento y de- } \\
\text { crecimiento de una función }\end{array}$ & 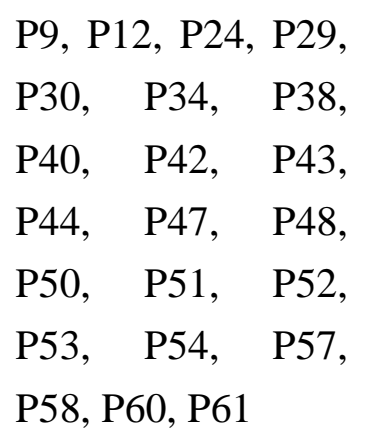 & 22 & $\begin{array}{l}\text { C12, C18, C20, } \\
\text { C22, C94 }\end{array}$ & 5 \\
\hline $\begin{array}{l}\text { Máximos y mínimos en un in- } \\
\text { tervalo }\end{array}$ & 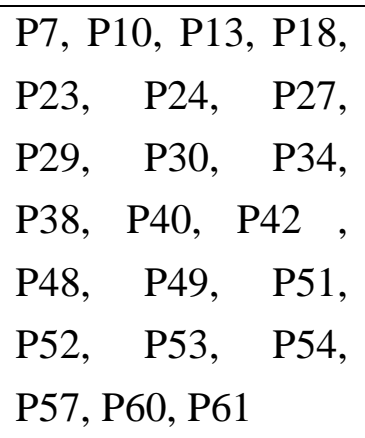 & 22 & C2, C75 & 2 \\
\hline $\begin{array}{l}\text { Intervalos de concavidad y con- } \\
\text { vexidad }^{6}\end{array}$ & $\begin{array}{l}\text { P30, P47, P50, } \\
\text { P51, P57, P58, P60 }\end{array}$ & 7 & & 0 \\
\hline Puntos de inflexión ${ }^{7}$ & $\begin{array}{l}\text { P24, P30, P42, } \\
\text { P43, P44, P47, } \\
\text { P48, P50, P60 }\end{array}$ & 9 & & 0 \\
\hline $\begin{array}{l}\text { Representación gráfica de fun- } \\
\text { ciones }\end{array}$ & 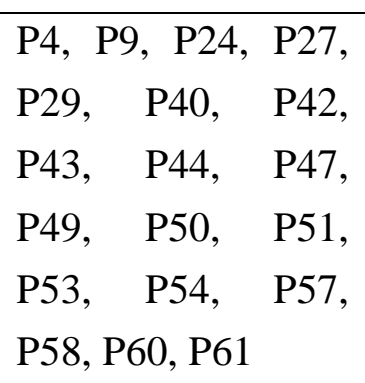 & 19 & & 0 \\
\hline Optimización & $\begin{array}{l}\begin{array}{l}\text { P1, P8, } \\
\text { P16, }\end{array} \text { P18, } \\
\begin{array}{ll}\text { P23, } \\
\text { P25, }\end{array} \\
\begin{array}{ll}\text { P41, } & \text { P45, } \\
\text { P56, P59 }\end{array}\end{array}$ & 15 & C37 & 1 \\
\hline
\end{tabular}

\footnotetext{
${ }^{6}$ Este contenido no aparece como específico en los contenidos curriculares de Matemáticas II, aunque sí en los enunciados de los ejercicios.

${ }^{7}$ Contenido objeto de examen, aunque específicamente no aparezca desglosado en los contenidos curriculares de Matemáticas II
} 
Tabla III.1. Categorías curriculares de Análisis Matemático (continuación)

\begin{tabular}{|c|c|c|c|c|}
\hline Contenidos curriculares & Problemas & $\mathrm{N}^{\circ}$ & Cuestiones & $\mathrm{N}^{\circ}$ \\
\hline Primitiva de una función & P19, P22, P41 & 3 & C14, C54 & 2 \\
\hline Reglas básicas de integración & P41 & 1 & & 0 \\
\hline $\begin{array}{l}\text { Cálculo de integrales indefinidas } \\
\text { sencillas: Inmediatas }\end{array}$ & P19 & 1 & $\begin{array}{l}\text { C3, C6, C9, C41, } \\
\text { C45, C54, C57, } \\
\text { C92 }\end{array}$ & 8 \\
\hline $\begin{array}{l}\text { Cálculo de integrales indefinidas } \\
\text { sencillas: Cambio de variable. }\end{array}$ & & $\mathbf{0}$ & $\begin{array}{l}\text { C29, C35, C39, } \\
\text { C67, C99 }\end{array}$ & 5 \\
\hline Integral de funciones racionales & P60 & 1 & $\begin{array}{l}\text { C29, C90, C93, } \\
\text { C99 }\end{array}$ & 4 \\
\hline Integral por partes. & P19, P22, P54 & 3 & C19, C30 & 2 \\
\hline Sumas de Riemann & & 0 & & 0 \\
\hline Integral definida. Propiedades & P42, P49, P55, P60 & 4 & $\mathrm{C} 26$ & 1 \\
\hline Regla de Barrow & P11, P31 & 2 & & 0 \\
\hline $\begin{array}{l}\text { Teorema del valor medio para } \\
\text { integrales }\end{array}$ & & 0 & & 0 \\
\hline Áreas de regiones planas & 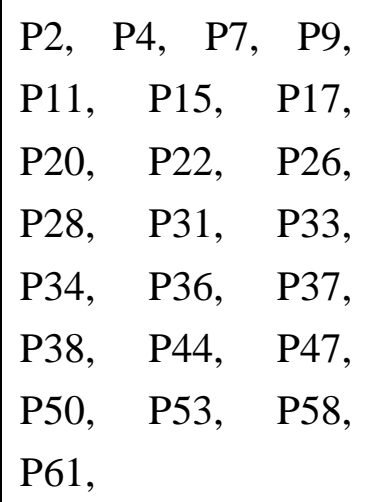 & 23 & $\begin{array}{lll}\text { C32, } & \text { C50, } & \text { C59, } \\
\text { C60, } & \text { C65, } & \text { C70, } \\
\text { C74, } & \text { C80, } & \text { C82, } \\
\text { C95 } & & \end{array}$ & 10 \\
\hline
\end{tabular}

Además hay dos cuestiones que son difíciles de clasificar, -dado que son cuestiones teóricas en las que intervienen varios conceptos-, y que transcribimos a continuación:

C11.- Lea atentamente el siguiente enunciado: "Dada una función $f$ definida y derivable en un intervalo abierto $(a, b)$ de los números reales, si $f$ es estric- 
tamente creciente en dicho intervalo, entonces $f^{\prime}(x)>0$ ". ¿Es cierto? En caso afirmativo razonar la respuesta y en caso contrario poner un contraejemplo. (Junio 1997)

C40.- Sean $f(x)$ y $g(x)$ dos funciones derivables para todo valor de $x$, que verifican $f(0)=g(0)$ y que $f^{\prime}(x)>g^{\prime}(x)$ para $x \geq 0$. ¿Se puede asegurar que $f(x)>g(x)$ para $x>0$ ? Razona la respuesta indicando en que resultados te basas. $\quad$ (Sep. 2001)

El P5, P39, y las C47 y C71 son problemas recíprocos, que se encuadran en varios contenidos de la tabla, para los cuales nos dan las condiciones y lo que se trata es de calcular la función que las cumple.

En los contenidos mínimos de la comisión armonizadora de 2003 no se contempla como contenido de examen el Teorema Fundamental del Cálculo Integral, al cual corresponden los ejercicios P22, P30 y C16, por lo que no se han contabilizado en esta tabla de contenidos curriculares, aunque sí se tienen en cuenta en las tablas III.3, III.4 y III.5, correspondientes al estudio de las categorías teniendo como base los enunciados de los ejercicios propuestos.

Algunos enunciados aparecen en el currículo de una manera muy general, sin detallar aspectos particulares, pero a la hora de clasificar los enunciados hay que tenerlo en cuenta. Por citar un ejemplo, en el contenido curricular "Derivada de una función en un punto" hay que considerar enunciados que hacen referencia a la definición pero también a otros como el cálculo de la recta tangente en un punto; no obstante en la tabla III.1 se ha presentado como contenido curricular el de "Recta tangente en un punto", por lo que, en dicha tabla, estos ejercicios se contabilizan únicamente en este apartado y no en el de "Derivada de una función en un punto".

A continuación se presentan las figuras III.1 y III.2 con los datos recogidos en la Tabla III.1 de contenidos curriculares. Aún cuando un simple vistazo a la tabla manifiesta que hay algunos contenidos que aparecen muchas veces mientras que otros no aparecen nunca, los gráficos de frecuencias complementan y confirman esa primera percepción.

En dicha tabla se observa que 11 contenidos curriculares no se han propuesto ni como cuestión ni como problema, en los 15 años que abarca el estudio realizado. 
Figura III.1.- Análisis curricular de los problemas de Análisis Matemático

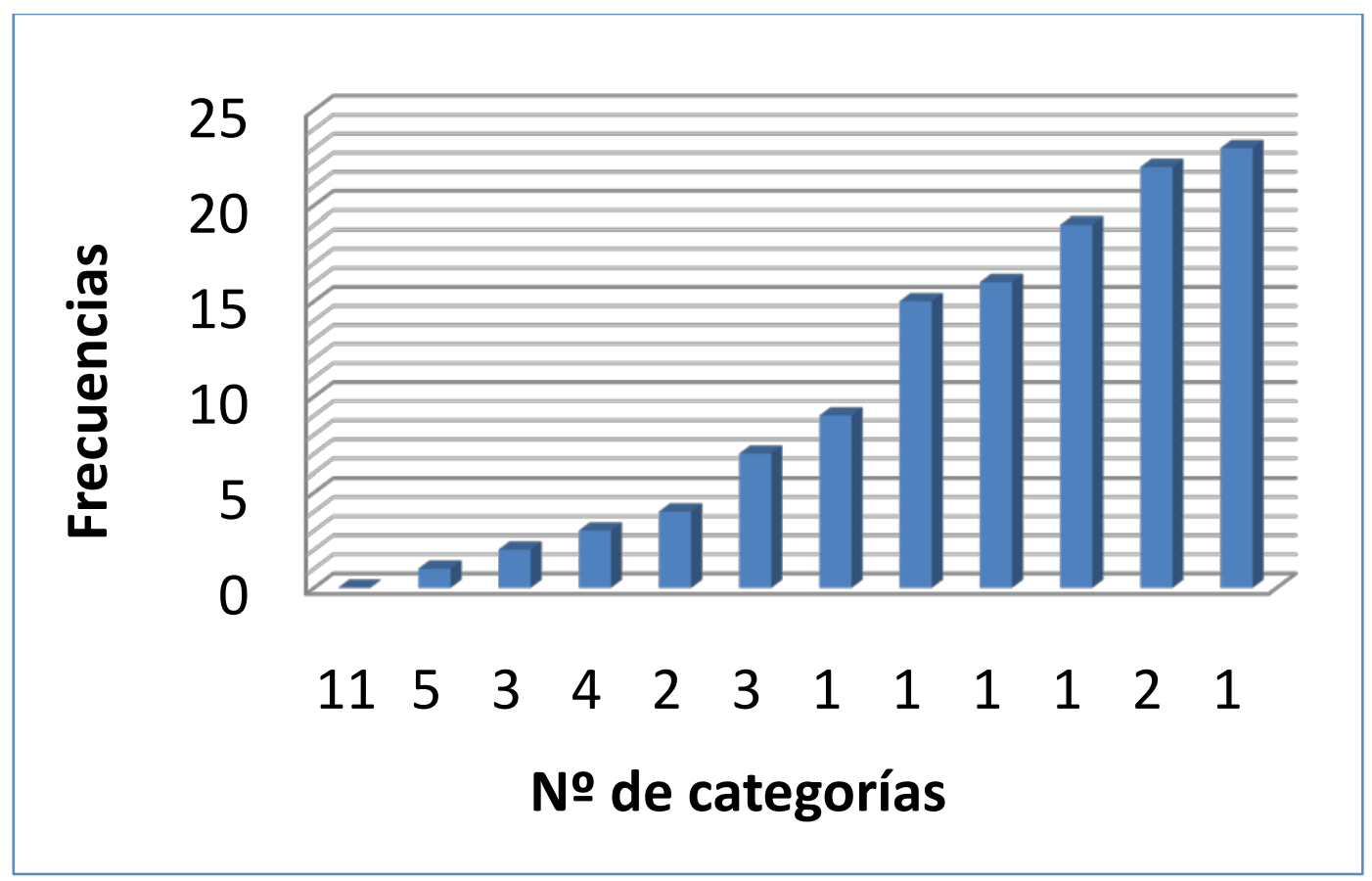

En sentido opuesto, los contenidos de mayor frecuencia en problemas son: Cálculo de áreas de regiones planas, 23 obtención de máximos relativos y mínimos relativos, 22; estudio del crecimiento y decrecimiento de una función, 22.

Figura III.2.- Análisis curricular de las cuestiones de Análisis Matemático

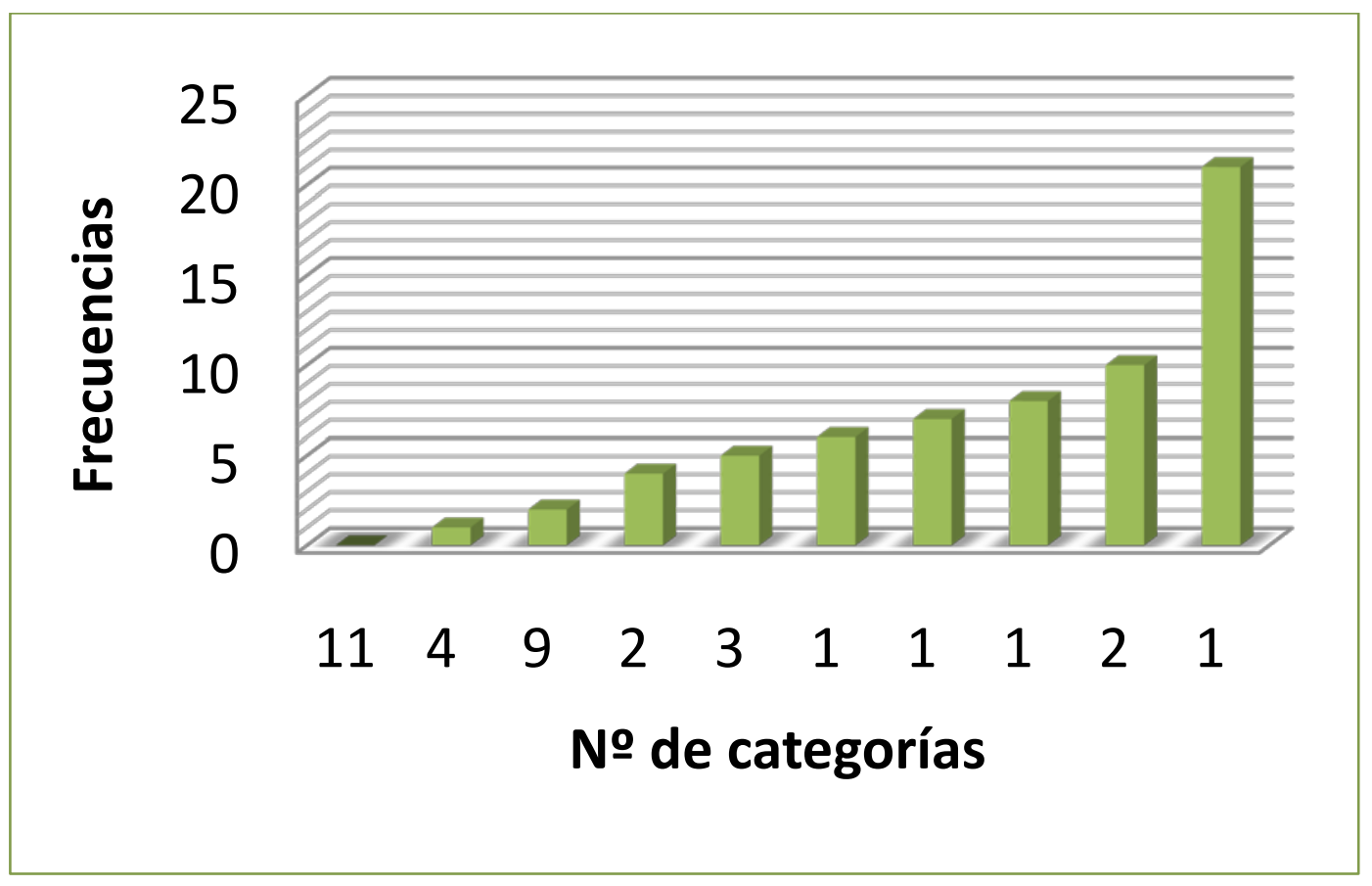


En cuestiones los contenidos de mayor frecuencia son: Cálculo de límites en los que es preciso utilizar la regla de L'Hôpital, 22, cuestiones relacionadas con el cálculo del área de regiones planas, 10; cuestiones relativas a continuidad en intervalos cerrados 10.

Las tablas III.2, III.3, III.4 y III.5, que se presentan posteriormente, son tablas de categorías de contenidos conceptuales y procedimentales de Análisis Matemático, basadas en el procedimiento más apropiado, según el criterio de la PI, para dar respuesta directa a la orden que los enunciados de los distintos ejercicios de Análisis Matemático, propuestos en las distintas pruebas PAU que se ha celebrado en Castilla y León en el período comprendido entre el año 1995 y el año 2009.

Así, por ejemplo, en el ejercicio que se enuncia a continuación:

C54.- Demuéstrese que las gráficas de las funciones

$$
f(x)=e^{x} \text { y } g(x)=\frac{1}{x} \text { se cortan en un punto } x>0 . \quad \text { (Junio 2004) }
$$

puede enfocarse su resolución utilizando el Teorema de Darboux o bien definiendo una función $h(x)=f(x)-g(x)$, diferencia de las dos dadas, y resolver la cuestión utilizando el Teorema de Bolzano, analizando la existencia de una raíz de la ecuación $h(x)=0$. Se ha considerado como un enunciado resoluble por cualquiera de los dos métodos.

En lo relativo a ejercicios del estilo del siguiente:

C31.- Hallar el área del recinto limitado por la recta $y=3-2 x$ y la parábola $y=2 x-x^{2} \quad$ (Sep. 2000)

pueden ser encuadrados en dos apartados, el de cálculo de áreas y el de cálculo de integrales inmediatas sencillas, pero se ha hecho la clasificación atendiendo como pilar fundamental al requerimiento de la orden directa que establece el enunciado, en este caso, CA (Calcular el Área).

Los ejercicios que contienen parámetros en su enunciado se han clasificado en el apartado de Parámetro $(P)$ y en el de la orden del enunciado, así, por citar un ejemplo,

C71. - Determínense los valores de a y b para los cuales 


$$
\lim _{x \rightarrow 0} \frac{a x^{2}+b x+1-\cos (x)}{\operatorname{sen}\left(x^{2}\right)}=1
$$

aparece considerado en las filas P de Parámetro, y en RLH (Regla de L'Hôpital), que es el método de resolución de este límite según los contenidos de la tabla III.1, debido a que los infinitésimos equivalentes no aparecen como contenido curricular en el desarrollo del currículo del Decreto 70/2002, en la tabla III.4 de Cuestiones y en la tabla III. 5 de Cuestiones y Problemas de Análisis Matemático; pues también se podía encuadrar, además, dentro de otro apartado más general como es CL (Cálculo de Límites) -de funciones-.

Dado que en ningún enunciado se ha preguntado al alumno por el cálculo de límites en sucesiones, -que es uno de los contenidos conceptuales del currículo oficial de Matemáticas II-, no se hace referencia a esta categoría en las tablas III.2, III.3, III.4 y III.5.

En la tabla III.2 se presentan las categorías correspondientes a los contenidos curriculares y procedimentales, siguiendo la orden establecida en los enunciados de los ejercicios de Análisis Matemático, propuestos en los exámenes de las P.A.E.U. y la interpretación de las mismas:

\section{Tabla III.2. Categorías de Análisis matemático en las PAEU}

\begin{tabular}{|l|l|l|}
\hline A & Calcular asíntotas & Manda calcular las asíntotas de una función. \\
\hline CA & Calcular área & Ordena calcular el área de regiones planas \\
\hline CD & Calcular coeficientes & $\begin{array}{l}\text { El enunciado del ejercicio viene dado con unos } \\
\text { coeficientes que es preciso calcular a partir de } \\
\text { las condiciones impuestas. }\end{array}$ \\
\hline CL & Cálculo de límites & $\begin{array}{l}\text { Solicita que se calcule la derivada de una fun- } \\
\text { ción. }\end{array}$ \\
\hline ello no se usa la regla de L'Hôpital
\end{tabular}


Tabla III.2. Categorías de Análisis matemático en las PAEU (Continuación)

\begin{tabular}{|c|c|c|}
\hline $\mathrm{D}$ & Dominio & Se ordena estudiar el dominio de una función \\
\hline DCD & $\begin{array}{l}\text { Discrimina continui- } \\
\text { dad y derivabilidad }\end{array}$ & $\begin{array}{l}\text { Es una cuestión en la que se pide discriminar en- } \\
\text { tre las condiciones necesarias para que exista la } \\
\text { continuidad de una función y para que sea deri- } \\
\text { vable }\end{array}$ \\
\hline EC & Estudiar continuidad & $\begin{array}{l}\text { Se pide estudiar la continuidad de una función, } \\
\text { en un punto o en su dominio. }\end{array}$ \\
\hline ED & Estudiar derivabilidad & $\begin{array}{l}\text { Se insta estudiar la derivabilidad de una función, } \\
\text { en un punto o en su dominio. }\end{array}$ \\
\hline ICC & $\begin{array}{l}\text { Intervalos de concavi- } \\
\text { dad y convexidad }\end{array}$ & $\begin{array}{l}\text { Se solicita estudiar la curvatura de una función } \\
\text { y/o calcular los intervalos de concavidad y/o } \\
\text { convexidad. }\end{array}$ \\
\hline ICD & $\begin{array}{l}\text { Intervalos de creci- } \\
\text { miento y decrecimien- } \\
\text { to }\end{array}$ & $\begin{array}{l}\text { Manda estudiar la monotonía de una función y/o } \\
\text { calcular los intervalos de crecimiento y/o decre- } \\
\text { cimiento. }\end{array}$ \\
\hline ICV & $\begin{array}{l}\text { Integral con cambio de } \\
\text { variable }\end{array}$ & $\begin{array}{l}\text { Tenemos que calcular una integral haciendo } \\
\text { previamente un cambio de variable. }\end{array}$ \\
\hline ID & Integral definida & $\begin{array}{l}\text { Hay que calcular una integral definida, y se nos } \\
\text { dan los límites de integración. }\end{array}$ \\
\hline II & Integral inmediata & $\begin{array}{l}\text { Hay que calcular una integral que es inmediata, } \\
\text { sin necesidad de hacer ningún cambio de varia- } \\
\text { ble. }\end{array}$ \\
\hline IP & Integral por partes & $\begin{array}{l}\text { Requiere calcular una integral, y el método para } \\
\text { hacerla, es el de integración por partes. }\end{array}$ \\
\hline IR & Integral racional & $\begin{array}{l}\text { Hay que calcular una integral por el método de } \\
\text { integración de funciones racionales. }\end{array}$ \\
\hline MMA & $\begin{array}{l}\text { Máximo-mínimo abso- } \\
\text { luto }\end{array}$ & $\begin{array}{l}\text { Exige calcular el o los puntos en los que aparece } \\
\text { el máximo y/o mínimo absoluto de una función, } \\
\text { en un intervalo cerrado. }\end{array}$ \\
\hline
\end{tabular}


Tabla III.2. Categorías de Análisis matemático en las PAEU (Continuación)

\begin{tabular}{|c|c|c|}
\hline MMR & $\begin{array}{l}\text { Máximo-mínimo rela- } \\
\text { tivo }\end{array}$ & $\begin{array}{l}\text { Manda calcular el o los puntos en los que apare- } \\
\text { ce un máximo y/o mínimo relativo de una fun- } \\
\text { ción. }\end{array}$ \\
\hline $\mathrm{O}$ & Optimizar & $\begin{array}{l}\text { Es un ejercicio en el cual hay que optimizar una } \\
\text { función supeditada a unas condiciones. }\end{array}$ \\
\hline $\mathrm{P}$ & Parámetros & $\begin{array}{l}\text { En el enunciado del ejercicio aparece uno o va- } \\
\text { rios parámetros, y en función de ellos hay que } \\
\text { dar respuesta a la orden requerida en el mismo. }\end{array}$ \\
\hline PI & Puntos de inflexión & $\begin{array}{l}\text { Se pide calcular los puntos de inflexión de una } \\
\text { función }\end{array}$ \\
\hline $\mathrm{RF}$ & Representar función & $\begin{array}{l}\text { Sugiere que se haga una representación aproxi- } \\
\text { mada de la función. }\end{array}$ \\
\hline RT & Recta tangente & $\begin{array}{l}\text { Manda calcular la ecuación de la recta tangente } \\
\text { a una curva en un punto. }\end{array}$ \\
\hline RLH & Regla de L'Hôpital & $\begin{array}{l}\text { Se pide calcular el límite de una función y el } \\
\text { método que se utiliza es la regla de L’Hôpital. }\end{array}$ \\
\hline $\mathrm{T}$ & Enunciado de teoría & $\begin{array}{l}\text { Solicita que se escriba el enunciado de un teo- } \\
\text { rema o de una definición. }\end{array}$ \\
\hline TB & Teorema de Bolzano & $\begin{array}{l}\text { Hay que utilizar el teorema de Bolzano para re- } \\
\text { solver el ejercicio. }\end{array}$ \\
\hline TD & Teorema de Darboux & $\begin{array}{l}\text { Se emplean teoremas del valor medio de conti- } \\
\text { nuidad. }\end{array}$ \\
\hline $\mathrm{TF}$ & $\begin{array}{l}\text { Teorema Fundamental } \\
\text { del cálculo integral }\end{array}$ & $\begin{array}{l}\text { Se pide utilizar el teorema fundamental del } \\
\text { cálculo integral. }\end{array}$ \\
\hline $\mathrm{TL}$ & Teorema de Lagrange & $\begin{array}{l}\text { Ordena utilizar el teorema de los incrementos fi- } \\
\text { nitos de Lagrange. }\end{array}$ \\
\hline TR & Teorema de Rolle & $\begin{array}{l}\text { Es preciso utilizar el teorema de Rolle para re- } \\
\text { solver el ejercicio. }\end{array}$ \\
\hline TW & $\begin{array}{l}\text { Teorema de Weiers- } \\
\text { trass }\end{array}$ & $\begin{array}{l}\text { Se requiere utilizar el teorema de Weierstrass } \\
\text { para resolver el ejercicio. }\end{array}$ \\
\hline
\end{tabular}


En esta tabla III.2 se han tenido en cuenta todos los contenidos de Análisis Matemático que han aparecido a lo largo de los quince años de este estudio, aunque no estén explicitados en el Decreto 70/2002 del Currículo de Bachillerato ni en el ANEXO IV (Análisis del Currículo: acuerdo de mínimos) de la Comisión Organizadora P.A.E.U -Castilla y León-, de abril de 2003 y vigente en los años relativos a este estudio, pero que aparecen en el apartado referido a los tipos de cuestiones, ejercicios y problemas, del citado ANEXO IV, como son:

...Interpretación geométrica de la derivada en un punto: determinación de las rectas tangente y normal a una curva.

...Conocer el concepto de integral definida y su relación con el de primitiva mediante el teorema fundamental del cálculo integral.

Tomando como referencia la tabla III.2, con las abreviaturas correspondientes a las distintas categorías y su interpretación, se presentan a continuación las tablas III.3, III.4 y III.5, de cuestiones, problemas, y cuestiones y problemas juntos, en las que se analizan, por años, las categorías procedimentales que corresponden a los problemas y las cuestiones que han sido propuestas en las pruebas, desde el curso 1994-95 hasta el 2009-09. Consideradas como una "nube de puntos"correspondiente una tabla de doble entrada, se observa la dispersión existente en los datos que en ella aparecen; por un lado se visualizan contenidos que aparecen muchos años y muchas veces, como puede ser el "Cálculo de límites, utilizando la regla de L'Hôpital", que aparece desde el año 2001 en todos los exámenes que se proponen, o el "Cálculo del área comprendida entre dos curvas", correspondiente a funciones elementales; en la mayoría de los casos, dos parábolas, que se ha propuesto, asimismo, en los últimos años, en todas las convocatorias.

En otro nivel, el opuesto, de frecuencia de aparición, se encuentran conceptos como el "Teorema Fundamental del cálculo integral" que no se presenta, como cuestión, desde el año 1998 y como problema se propone en el 2002 o el "Teorema de Rolle" que dejó de proponerse en 2000 y fue como contenido teórico, es decir, escribir el enunciado del teorema.

Asimismo, en problemas, no hay ningún ejercicio que inste al alumno a discriminar que continuidad no implica derivabilidad y las integrales que se proponen son inmediatas o casi inmediatas, no exigen la necesaria utilización de un cambio de variable. 
Tabla III.3. Frecuencias de las categorías de Análisis Matemático en problemas

\begin{tabular}{|c|c|c|c|c|c|c|c|c|c|c|c|c|c|c|c|c|}
\hline Problemas & 95 & 96 & 97 & 98 & 99 & 00 & 01 & 02 & 03 & 04 & 05 & 06 & 07 & 08 & 09 & Total \\
\hline A & & & & & & 1 & 2 & & & 1 & 2 & 3 & 4 & 2 & 1 & 16 \\
\hline $\mathrm{CA}$ & 2 & 2 & 1 & 2 & 1 & 1 & 2 & 2 & 3 & 1 & 1 & 1 & 2 & & 2 & 23 \\
\hline $\mathrm{CC}$ & & 1 & 1 & & & & & & & 1 & & & & & & 3 \\
\hline$C D$ & & & & & & & & & 1 & & & & & & & 1 \\
\hline$C L$ & & & & & & & & & & & & & & & & 0 \\
\hline CR & & 1 & & & & & & & & 1 & & & & & & 2 \\
\hline D & & & & & & 1 & 1 & & & & & 1 & & & & 3 \\
\hline DCD & & & & & & & & & & & & & & & & 0 \\
\hline $\mathrm{EC}$ & & 1 & & & & & & & 1 & & & & & 1 & & 3 \\
\hline ED & 1 & 1 & & & & & & & 1 & 1 & 1 & & & 1 & 1 & 7 \\
\hline ICC & & & & & & & & 1 & & & & 1 & 2 & 1 & & 5 \\
\hline ICD & & 1 & 1 & & & 1 & 1 & 1 & 1 & 2 & 3 & 2 & 4 & 2 & 3 & 22 \\
\hline ICV & & & & & & & & & & & & & & & & \\
\hline ID & & & & & & & & & & & 1 & 1 & & 1 & 1 & 4 \\
\hline II & & & & & 1 & & & & & 1 & & & & & & 2 \\
\hline IP & & & & & 1 & 1 & & & & 1 & 1 & 1 & & 1 & & 6 \\
\hline IR & & & & & & & & & & & & & & & 1 & 1 \\
\hline MMA & & & & & & & 1 & & & & & & & & & 1 \\
\hline MMR & & 1 & 2 & & & 1 & 2 & 1 & 1 & 2 & 1 & 2 & 3 & 2 & 3 & 21 \\
\hline $\mathrm{O}$ & 1 & 1 & 1 & 2 & 2 & 2 & & & 1 & 1 & 1 & 1 & & 1 & 1 & 15 \\
\hline $\mathrm{P}$ & 1 & 1 & 1 & & & & 1 & & 1 & 1 & & & & & & 6 \\
\hline $\mathrm{PI}$ & & & & & & 1 & & 1 & & & 3 & 2 & 1 & & 1 & 9 \\
\hline RF & 1 & 1 & & & & 1 & 2 & & & 1 & 3 & 2 & 3 & 2 & 3 & 19 \\
\hline RT & & & & 1 & 1 & & 1 & & & & & & & & & 3 \\
\hline RLH & & & & & & & & & & & & & & & & 0 \\
\hline$T$ & & & 3 & & 2 & 2 & & 2 & & & & & & & & 9 \\
\hline TB & & & 1 & & & & & & & & 1 & 1 & 2 & 1 & & 6 \\
\hline TD & & & & & & & & 1 & & & & & & & & 1 \\
\hline $\mathrm{TF}$ & & & & & & 1 & & 1 & & & & & & & & 2 \\
\hline TL & & & & 1 & & & & 1 & & & & & & & & 2 \\
\hline TR & & & & & & & & & & & & & 1 & & & 1 \\
\hline TW & & & & & & & & & & & & & & & & 0 \\
\hline
\end{tabular}


Tabla III.4. Frecuencias de las categorías de Análisis Matemático en cuestiones.

\begin{tabular}{|c|c|c|c|c|c|c|c|c|c|c|c|c|c|c|c|c|}
\hline Cuestiones & 95 & 96 & 97 & 98 & 99 & 00 & 01 & 02 & 03 & 04 & 05 & 06 & 07 & 08 & 09 & Total \\
\hline A & & & & & & 1 & & & & & & & & 1 & & 2 \\
\hline CA & & & & & & 1 & & & 1 & 2 & 1 & 2 & 2 & & & 9 \\
\hline $\mathrm{CC}$ & & & & & & & & 1 & & & & 1 & & & & 2 \\
\hline$C D$ & & & & 1 & 1 & 1 & & 2 & & & & & & & & 5 \\
\hline$C L$ & & & 1 & & 1 & & & & & 1 & & & & & & 3 \\
\hline $\mathrm{CR}$ & & & & & & & & 1 & & & & 1 & & & 1 & 3 \\
\hline $\mathrm{D}$ & & & 1 & 1 & & & & & & & & & & & & 2 \\
\hline DCD & & 1 & & & & & & & & & & & & & & 1 \\
\hline EC & & 1 & 2 & & & & & & & & 1 & & 1 & 1 & & 6 \\
\hline ED & & 1 & 1 & & & & & & 1 & & & & & & & 3 \\
\hline ICC & & & & & & & & & & & & & & & & 0 \\
\hline ICD & & & 1 & 2 & 1 & & & & & & & & & & 1 & 5 \\
\hline ICV & & & & & & 1 & 2 & & & & 1 & & & & 1 & 5 \\
\hline ID & & & & & 1 & & & & & & & & & & & 1 \\
\hline II & 1 & 3 & 1 & & & & 2 & 2 & & 2 & 1 & & & 1 & & 13 \\
\hline IP & & & & 1 & & 1 & & & & & & & & & & 2 \\
\hline IR & & & & & & 1 & & & & & & & & 1 & 1 & 3 \\
\hline MMA & 1 & & & & & & & & & & & 1 & & & & 2 \\
\hline MMR & & & & & & & & & & & & & & & & 0 \\
\hline $\mathrm{O}$ & & & & & & & 1 & & & & & & & & & 1 \\
\hline $\mathrm{P}$ & 1 & 2 & & & & & & 1 & & 1 & 2 & 2 & 1 & 2 & 1 & 13 \\
\hline $\mathrm{PI}$ & & & & & & & & & & & & & & & & 0 \\
\hline $\mathrm{RF}$ & & & & & & & & & & & & & & & & 0 \\
\hline RT & & 1 & & & 1 & & & & 1 & & & 1 & 1 & 1 & 1 & 7 \\
\hline RLH & 1 & & & & 2 & & 2 & 2 & 2 & 2 & 3 & 3 & 2 & 2 & 1 & 22 \\
\hline $\mathrm{T}$ & & 2 & 2 & 1 & & 1 & & & & & & & & & & 6 \\
\hline TB & & & & 1 & & & 1 & & 1 & 1 & & & 2 & 1 & 1 & 8 \\
\hline TD & & & & & & & & & & 1 & & & 1 & & & 2 \\
\hline TF & & & & 1 & & & & & & & & & & & & 1 \\
\hline TL & & 1 & & & & 1 & & & & & 1 & & & & & 3 \\
\hline TR & & 1 & & 1 & & 1 & & & & & & & & & & 3 \\
\hline TW & 1 & & & & & & & & & & & 1 & & & & 2 \\
\hline
\end{tabular}


Tabla III.5. Frecuencias de las categorías de A. M. en problemas y cuestiones.

\begin{tabular}{|c|c|c|c|c|c|c|c|c|c|c|c|c|c|c|c|c|}
\hline $\begin{array}{l}\text { Problemas } \\
\text { Cuestiones }\end{array}$ & 95 & 96 & 97 & 98 & 99 & 00 & 01 & 02 & 03 & 04 & 05 & 06 & 07 & 08 & 09 & Total \\
\hline A & & & & & & 2 & 2 & & & 1 & 2 & 3 & 4 & 3 & 1 & 18 \\
\hline CA & 2 & 2 & 1 & 2 & 1 & 2 & 2 & 2 & 4 & 3 & 2 & 3 & 4 & & 2 & 32 \\
\hline $\mathrm{CC}$ & & 1 & 1 & & & & & 1 & & 1 & & 1 & & & & 5 \\
\hline$C D$ & & & & 1 & 1 & 1 & & 2 & 1 & & & & & & & 6 \\
\hline $\mathrm{CL}$ & & & 1 & & 1 & & & & & 1 & & & & & & 3 \\
\hline $\mathrm{CR}$ & & 1 & & & & & & 1 & & 1 & & 1 & & & 1 & 5 \\
\hline D & & & 1 & 1 & & 1 & 1 & & & & & 1 & & & & 5 \\
\hline DCD & & 1 & & & & & & & & & & & & & & 1 \\
\hline EC & & 2 & 2 & & & & & & 1 & & 1 & & 1 & 2 & & 9 \\
\hline ED & 1 & 2 & 1 & & & & & & 2 & 1 & 1 & & & 1 & 1 & 10 \\
\hline ICC & & & & & & & & 1 & & & & 1 & 2 & 1 & & 5 \\
\hline$I C D$ & & 1 & 2 & 2 & 1 & 1 & 1 & 1 & 1 & 2 & 3 & 2 & 4 & 2 & 4 & 27 \\
\hline ICV & & & & & & 1 & 2 & & & & 1 & & & & 1 & 5 \\
\hline ID & & & & & 1 & & & & & & 1 & 1 & & 1 & 1 & 5 \\
\hline II & 1 & 3 & 1 & & 1 & & 2 & 2 & & 3 & 1 & & & 1 & & 15 \\
\hline IP & & & & 1 & 1 & 2 & & & & 1 & 1 & 1 & & 1 & & 8 \\
\hline IR & & & & & & 1 & & & & & & & & 1 & 2 & 4 \\
\hline MMA & 1 & & & & & & 1 & & & & & 1 & & & & 3 \\
\hline MMR & & 1 & 2 & & & 1 & 2 & 1 & 1 & 2 & 1 & 2 & 3 & 2 & 3 & 21 \\
\hline 0 & 1 & 1 & 1 & 2 & 2 & 2 & 1 & & 1 & 1 & 1 & 1 & & 1 & 1 & 16 \\
\hline $\mathrm{P}$ & 2 & 3 & 1 & & & & 1 & 1 & 1 & 2 & 2 & 2 & 1 & 2 & 1 & 19 \\
\hline $\mathrm{PI}$ & & & & & & 1 & & 1 & & & 3 & 2 & 1 & & 1 & 9 \\
\hline $\mathrm{RF}$ & 1 & 1 & & & & 1 & 2 & & & 1 & 3 & 2 & 3 & 2 & 3 & 19 \\
\hline RT & & 1 & & 1 & 2 & & 1 & & 1 & & & 1 & 1 & 1 & 1 & 10 \\
\hline RLH & 1 & & & & 2 & & 2 & 2 & 2 & 2 & 3 & 3 & 2 & 2 & 1 & 22 \\
\hline $\mathrm{T}$ & & 2 & 5 & 1 & 2 & 3 & & 2 & & & & & & & & 15 \\
\hline TB & & & 1 & 1 & & & 1 & & 1 & 1 & 1 & 1 & 4 & 2 & 1 & 14 \\
\hline TD & & & & & & & & 1 & & 1 & & & 1 & & & 3 \\
\hline TF & & & & 1 & & 1 & & 1 & & & & & & & & 3 \\
\hline TL & & 1 & & 1 & & 1 & & 1 & & & 1 & & & & & 5 \\
\hline TR & & 1 & & 1 & & 1 & & & & & & & 1 & & & 4 \\
\hline TW & 1 & & & & & & & & & & & 1 & & & & 2 \\
\hline
\end{tabular}


Recopilando los datos de las tablas III.2 y III.3, en la tabla III.4 aparecen los problemas y las cuestiones juntos y en ella se puede ver que el cálculo del área de figuras planas aparece en 32 propuestas de examen; el estudio del crecimiento/decrecimiento de una función aparece en 27 ocasiones, asociado al mismo los máximos y/o mínimos relativos se presenta en 21 ejercicios propuestos y un ejercicio de optimización es un contenido que se presenta como orden en 16 de las 30 pruebas propuestas.

\section{III.3. TABLAS DE CATEGORÍAS DE CONTENIDOS DE ÁLGE- BRA}

Para elaborar la Tabla III.6, análogamente que en la confección de la Tabla III.1, se toman como referencia los contenidos curriculares de Álgebra, correspondientes a la asignatura de Matemáticas II, publicado oficialmente en el BOC y L., siguiendo el orden del Decreto 70/2002 de 23 de mayo por el que se establece el currículo de Bachillerato de la comunidad de Castilla y León y el ANEXO IV Análisis del Currículo: Acuerdos de mínimos, actualizado en abril de 2003 y vigente entodos los años correspondientes a este estudio, de la Comisión Organizadora PAEU de esta misma Comunidad.

Esta Tabla III.6 está elaborada a partir de los ANEXOS III y IV, los enunciados se presentan señalados con una $P$ si se trata de un Problema o con una $C$, si es una Cuestión, y están numerados, siguiendo el orden cronológico de aparición en los ejercicios propuestos en las pruebas de las PAEU desde 1995 hasta 2009. El número que indica a estas letras es el correspondiente al lugar que ocupa el problema o cuestión de referencia en el citado ANEXO.

Tabla III.6. Categorías curriculares de Álgebra

\begin{tabular}{|l|l|l|l|c|}
\hline Contenidos curriculares & Problemas & $\mathbf{N}^{\mathbf{0}}$ & Cuestiones & $\mathbf{N}^{\mathbf{0}}$ \\
\hline Sistemas de ecuaciones lineales. & $\mathbf{0}$ & C6, C15, C19 & $\mathbf{3}$ \\
\hline $\begin{array}{l}\text { Operaciones elementales y re- } \\
\text { ducción Gaussiana. }\end{array}$ & $\mathbf{0}$ & & $\mathbf{0}$ \\
\hline $\begin{array}{l}\text { Discusión de un sistema de } \\
\text { ecuaciones lineales por el méto- } \\
\text { do de Gauss }\end{array}$ & $\mathbf{0}$ & & $\mathbf{0}$ \\
\hline
\end{tabular}


Tabla III.6. Categorías curriculares de Álgebra (continuación)

\begin{tabular}{|c|c|c|c|c|}
\hline Contenidos curriculares & Problemas & $\mathbf{N}^{0}$ & Cuestiones & $\mathbf{N}^{\circ}$ \\
\hline $\begin{array}{l}\text { Resolución de un sistema de } \\
\text { ecuaciones lineales por el méto- } \\
\text { do de Gauss }\end{array}$ & & 0 & & 0 \\
\hline $\begin{array}{l}\text { Representación matricial de un } \\
\text { sistema de ecuaciones lineales }\end{array}$ & $\mathrm{P} 15$ & 1 & C43 & 1 \\
\hline $\begin{array}{l}\text { Matrices de números reales. Es- } \\
\text { tudio del rango }\end{array}$ & P15, P23 & 2 & $\begin{array}{l}\text { C17, C18, C24, } \\
\text { C28, C39, C48, } \\
\text { C50, C57 }\end{array}$ & 7 \\
\hline Operaciones con matrices. & P4, P10, P23 & 3 & $\begin{array}{l}\text { C3,.C12, C14, } \\
\text { C16, C30, C40 }\end{array}$ & 6 \\
\hline Matrices invertibles. & P8, P10, P23 & 3 & $\begin{array}{l}\text { C3, C23, C26, } \\
\text { C27, C30, C40, } \\
\text { C44, C45 }\end{array}$ & 8 \\
\hline $\begin{array}{l}\text { Combinación lineal de filas de } \\
\text { una matriz }\end{array}$ & & 0 & & 0 \\
\hline $\begin{array}{l}\text { Obtención por el método de } \\
\text { Gauss del rango de una matriz }\end{array}$ & & 0 & & 0 \\
\hline $\begin{array}{l}\text { Obtención por el método de } \\
\text { Gauss de la matriz inversa. }\end{array}$ & & 0 & & 0 \\
\hline $\begin{array}{l}\text { Resolución de ecuaciones con } \\
\text { matrices }^{8}\end{array}$ & P4, P11, P14, P23 & 4 & $\begin{array}{l}\text { C1, C2, C5, C7, } \\
\text { C8, C9, C22, } \\
\text { C25, C33, C35, } \\
\text { C37, C41, C42, } \\
\text { C47, C49, C54 }\end{array}$ & 16 \\
\hline $\begin{array}{l}\text { Cálculo de determinantes de } \\
\text { órdenes dos y tres mediante la } \\
\text { regla de Sarrus. }\end{array}$ & P8 & 1 & C38 & 1 \\
\hline $\begin{array}{l}\text { Desarrollo de un determinante } \\
\text { por una fila o columna. }\end{array}$ & P5 & 1 & & 0 \\
\hline
\end{tabular}

\footnotetext{
${ }^{8}$ Este contenido no aparece explícitamente en los contenidos curriculares de Matemáticas II, pero se incluye en el desglose por aparecer, como se observa, con frecuencia en los enunciados de los ejercicios.
} 
Tabla III.6. Categorías curriculares de Álgebra (continuación)

\begin{tabular}{|l|l|l|l|c|}
\hline Contenidos curriculares & Problemas & $\mathbf{N}^{\mathbf{0}}$ & Cuestiones & $\mathbf{N}^{\mathbf{0}}$ \\
\hline $\begin{array}{l}\text { Propiedades de los determinan- } \\
\text { tes }\end{array}$ & P5, P9, P14 & $\mathbf{3}$ & $\begin{array}{l}\text { C10, C13, C20, } \\
\text { C21, C27, C32, } \\
\text { C34, C36, C51, } \\
\text { C53 }\end{array}$ & $\mathbf{1 0}$ \\
\hline $\begin{array}{l}\text { Cálculo de determinantes me- } \\
\text { diante operaciones elementales }\end{array}$ & P5 & $\mathbf{1}$ & C38, C55, C56 & $\mathbf{3}$ \\
\hline $\begin{array}{l}\text { Utilización de los determinantes } \\
\text { en la discusión de sistemas de } \\
\text { ecuaciones lineales. }\end{array}$ & $\begin{array}{l}\text { P12, P13, P16, P18, P19, } \\
\text { P20, P21, P22, } \\
\text { P24, P25, P26, } \\
\text { P27, P28 }\end{array}$ & $\mathbf{1 9}$ & C43, C46, C52 & $\mathbf{3}$ \\
\hline $\begin{array}{l}\text { Utilización de los determinantes } \\
\text { en la resolución de sistemas de } \\
\text { ecuaciones lineales. }\end{array}$ & $\begin{array}{l}\text { P12, P13, P15, P17, P1, } \\
\text { P16, P20, P21, } \\
\text { P19, P24, P25, } \\
\text { P26, P27 }\end{array}$ & $\mathbf{1 9}$ & C1, C6, C15, C19 & $\mathbf{4}$ \\
\hline
\end{tabular}

Las cuestiones que se presentan a continuación:

C4.- Escribe, si es posible, un sistema de dos ecuaciones lineales con tres incógnitas que sea:

a) Compatible, con una solución igual a $(1,-1,3)$.

b) Incompatible.

c) Compatible y determinado.

(Junio 1996)

C11.- Dar un ejemplo, si es posible, de un sistema de 2 ecuaciones lineales con 3 incógnitas de cada uno de los siguientes tipos:

a) Incompatible.

b) Compatible determinado.

(Sep. 1998) 
C29.- Si A es una matriz cuadrada, ¿la matriz $A+A^{t}$ es igual a su traspuesta? Razonar la respuesta. ( $A^{t}$ es la matriz traspuesta de A.) (Junio 2003)

C31.- Si $A$ y $B$ son dos matrices cuadradas que verifican $A B=B^{2}$, ¿cuándo se puede asegurar que $A=B$ ?

(Sep. 2003)

son difíciles de clasificar en la Tabla III.6 pues se refieren a contenidos que no están explícitamente detallados en la misma.

Estos contenidos curriculares de Álgebra, que se han desglosado en 18 categorías, son la base para la elaboración de las Figuras III.3 y III.4, que son gráficos de frecuencias de aparición de contenidos curriculares, en las que aparece contabilizada la frecuencia de aparición de estos contenidos, tanto en los problemas como en las cuestiones relativas a las propuestas de examen de las Pruebas de Acceso a Estudios Universitarios (PAEU), de los quince años relativos al presente estudio.

Figura III.3.- Análisis curricular de los problemas de Álgebra

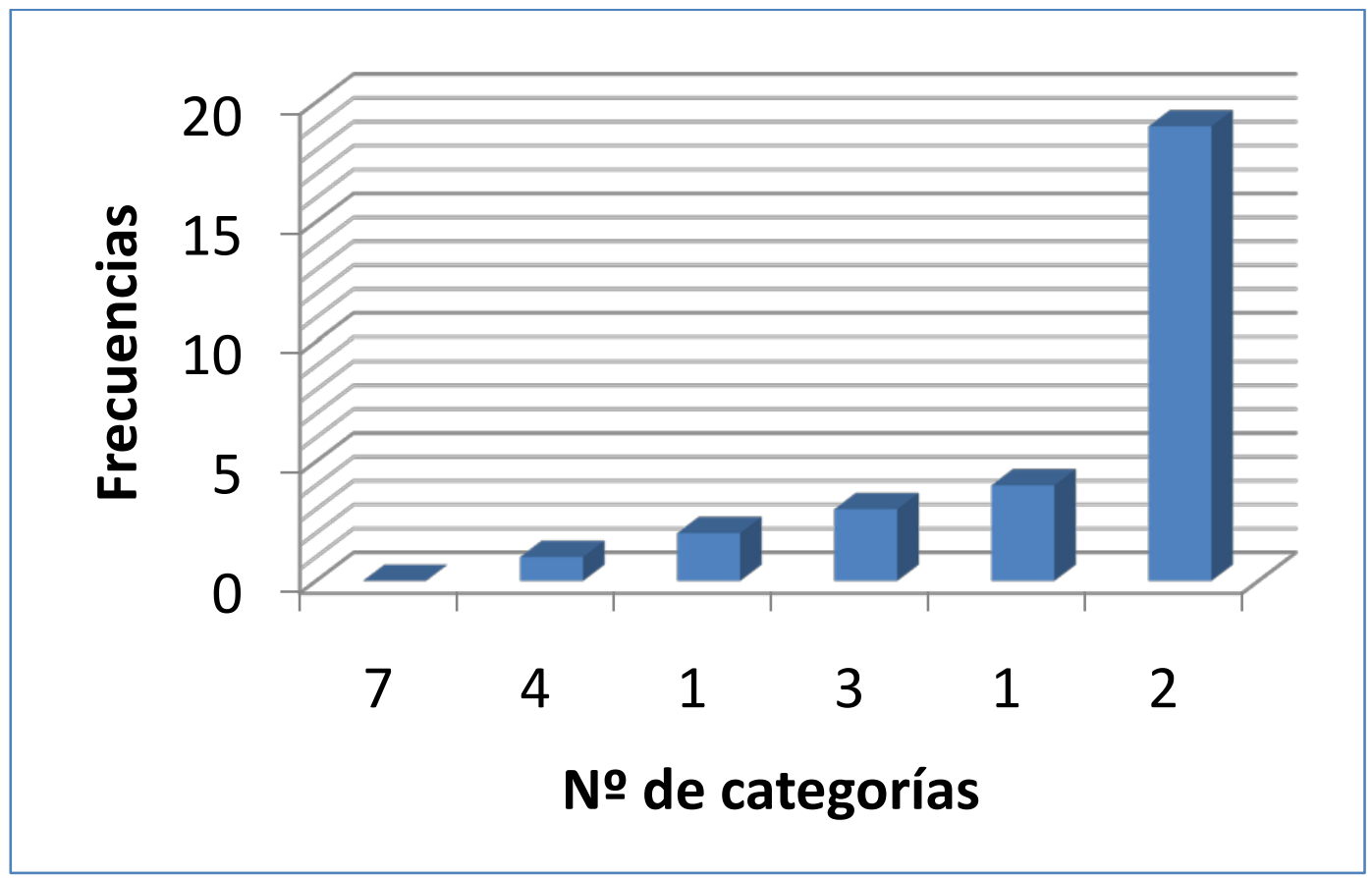

En problemas los contenidos de mayor frecuencias son: Uso de determinantes en la discusión de sistemas de ecuaciones lineales, 19; uso de determinantes en la resolución de sistemas de ecuaciones lineales, 19. 
Figura III.4.- Análisis curricular de las cuestiones de Álgebra

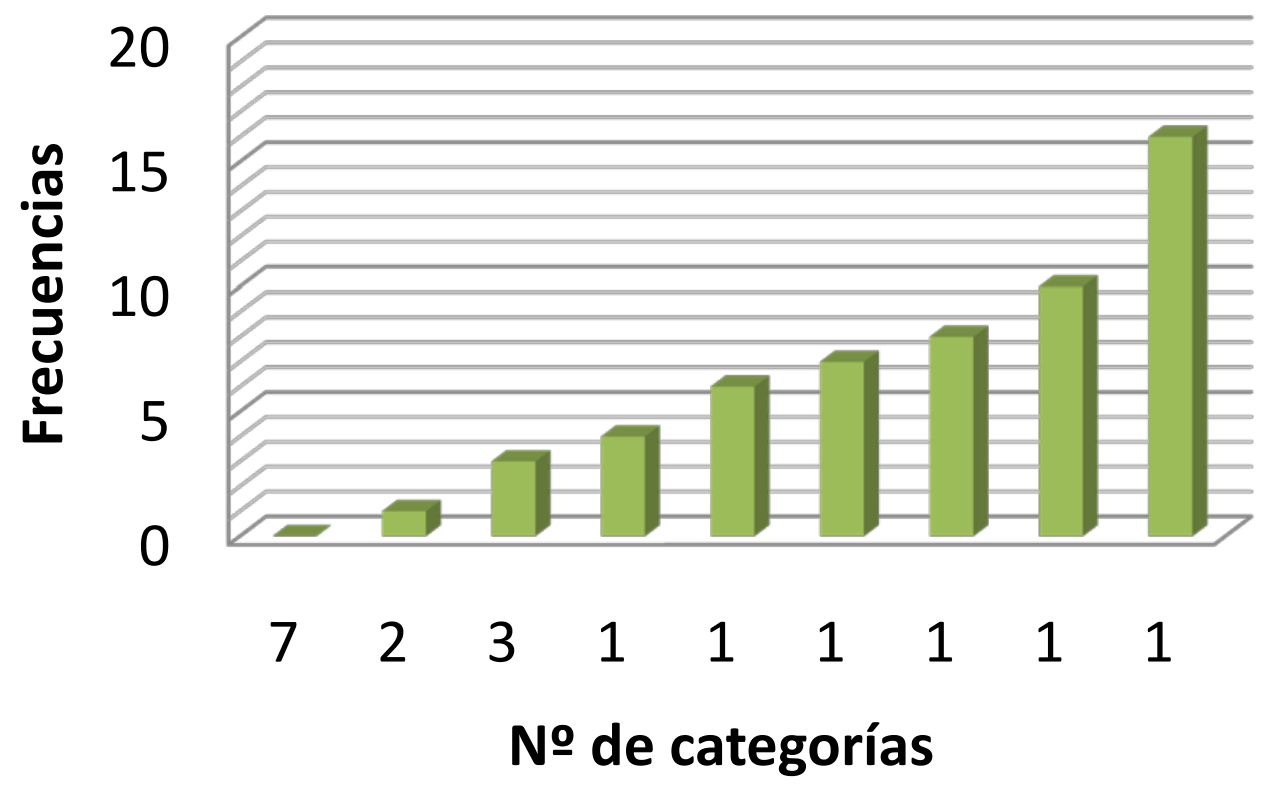

Contenidos de mayor frecuencia en cuestiones: Resolución de ecuaciones con matrices, 16; Propiedades de determinantes, 10.

Las tablas III.7, III.8, III.9 y III.10, que se presentan posteriormente, son tablas de categorías de contenidos conceptuales y procedimentales de Álgebra, basadas en el procedimiento más apropiado, según el criterio de la PI, para dar respuesta directa a la orden que los enunciados de los distintos ejercicios propuestos en las distintas pruebas PAU que se ha celebrado en Castilla y León en el período comprendido entre el año 1995 y el año 2009.

Así, por ejemplo, en el apartado P de Parámetros aparecen clasificados aquellos ejercicios en los que su enunciado se ve generalizado con la presencia de letras, -parámetros-, pero dichos ejercicios se contabilizan también en la fila correspondiente a la orden directa que da el ejercicio. Por ejemplo, el ejercicio que aparece a continuación:

P2.- Discutir y resolver, según los valores de a, el sistema: $\left\{\begin{array}{l}a x+y=a^{2} \\ x+a^{2} y=1\end{array}\right.$ (Sep. 1995)

Se encuentra considerado en las filas P, SED y SE, (Parámetros, Discusión y resolución de Sistemas de Ecuaciones lineales, respectivamente) de las tablas III.8 de Problemas de Álgebra y III.10 de Cuestiones y Problemas de Álgebra. 
El siguiente ejercicio

C28.- Estudiar el rango de la matriz A, según los distintos valores de " $m$ ":

$$
A=\left(\begin{array}{lll}
1 & 1 & 1 \\
1 & 2 & 2 \\
1 & 2 & m
\end{array}\right)
$$

(Junio 2003)

Aparece contabilizado en la columna 03 (Año 2003) y en las filas P (Parámetros) y ER (Estudiar el Rango) de una matriz, en la Tabla III.9 de Cuestiones y en la Tabla III.10 de Cuestiones y Problemas.

En la tabla III.7 se presentan las categorías correspondientes a los contenidos curriculares y procedimentales de Álgebra, su abreviatura e interpretación, siguiendo la orden establecida en los enunciados de los ejercicios de Álgebra, propuestos en los exámenes de las P.A.E.U.

En esta tabla no aparece el "Método de Gauss", pues en ningún enunciado se ordena de forma explícita que tenga que ser este método el utilizado para la resolución del ejercicio, por lo que la PI. no le incluye como contenido procedimental.

Tabla III.7. Categorías de Álgebra en las PAEU

\begin{tabular}{|l|l|l|}
\hline CD & Determinante & Manda calcular un determinante. \\
\hline CMI & Matriz inversa & Ordena calcular la matriz inversa de una dada. \\
\hline EM & Calcular rango & $\begin{array}{l}\text { En esta categoría se clasifican los ejercicios en } \\
\text { los que hay que calcular el rango de una matriz. }\end{array}$ \\
\hline ER & Estudiar rango & Hay que resolver una ecuación con matrices. \\
\hline MI & $\begin{array}{l}\text { Satriz inversible } \\
\text { OM }\end{array}$ & $\begin{array}{l}\text { Se pide estudiar, dependiendo de un parámetro, } \\
\text { las condiciones necesarias para que una matriz } \\
\text { admita inversa; pero aquí no se ordena el cálculo } \\
\text { de la matriz inversa }\end{array}$ \\
\hline trices. & $\begin{array}{l}\text { En esta categoría hemos clasificado los ejerci- } \\
\text { cios en los cuales pide realizar unos cálculos del } \\
\text { álgebra matricial. }\end{array}$ \\
\hline
\end{tabular}


Tabla III.7. Categorías de Álgebra en las PAEU (Continuación)

\begin{tabular}{|c|c|c|}
\hline$P$ & Parámetros & $\begin{array}{l}\text { Se consideran los ejercicios en los cuales el es- } \\
\text { tudio del mismo se hace dependiendo de pará- } \\
\text { metros. }\end{array}$ \\
\hline PD & $\begin{array}{l}\text { Propiedades de los de- } \\
\text { terminantes }\end{array}$ & $\begin{array}{l}\text { Hay que utilizar propiedades de los determinan- } \\
\text { tes, para calcular el valor de un determinante o } \\
\text { el orden del mismo, a partir de unas condiciones. }\end{array}$ \\
\hline PM & $\begin{array}{l}\text { Propiedades de las } \\
\text { operaciones con matri- } \\
\text { ces }\end{array}$ & $\begin{array}{l}\text { En esta categoría hemos clasificado los ejerci- } \\
\text { cios en los cuales pide realizar unos cálculos del } \\
\text { álgebra matricial y utilizar sus propiedades. }\end{array}$ \\
\hline SED & $\begin{array}{l}\text { Discusión de un siste- } \\
\text { ma de ecuaciones li- } \\
\text { neales dependiente de } \\
\text { un parámetro }\end{array}$ & $\begin{array}{l}\text { En esta categoría hemos clasificado los ejerci- } \\
\text { cios en los cuales pide estudiar una familia de } \\
\text { sistemas de ecuaciones lineales, que dependen } \\
\text { de un parámetro. }\end{array}$ \\
\hline SE & $\begin{array}{l}\text { Resolución de un sis- } \\
\text { tema de ecuaciones }\end{array}$ & $\begin{array}{l}\text { Se insta para que se obtenga la solución de un } \\
\text { sistema de ecuaciones. }\end{array}$ \\
\hline $\mathrm{T}$ & Teoría & $\begin{array}{l}\text { Se pide el enunciado o demostración de una } \\
\text { propiedad, definición o teorema }\end{array}$ \\
\hline TR & Teorema de Rouché & Pide enunciar el teorema de Rouché-Frobenius. \\
\hline
\end{tabular}

Tomando como referencia la Tabla III.7, con las abreviaturas correspondientes a las distintas categorías y su interpretación, se presentan a continuación las tablas III.8, III.9 y III.10 de categorías de contenidos conceptuales y procedimentales de Álgebra, basadas en el procedimiento más apropiado, -según el criterio de la PI- para dar respuesta directa a la orden que los enunciados de los problemas, las cuestiones y las cuestiones y los problemas juntos, que han sido propuestos en las pruebas PAU que se ha celebrado en Castilla y León en el período comprendido entre el año 1995 y el año 2009.

En los quince años de estudio, se proponen 28 problemas de Álgebra y en 19 de ellos se pide el análisis de los múltiples tipos de sistemas de ecuaciones lineales que se pueden presentar según los distintos valores de un parámetro, y posteriormente la resolución del sistema en casos particulares. En la tabla III.8 observamos que los valores se concentran en tres filas, quedando las demás 
casi desiertas. Dos de ellas corresponden al "Estudio y resolución de sistemas de ecuaciones lineales, dependientes de un parámetro" y la tercera, como es obvio, a Parámetro.

Tabla III.8. Frecuencias de las categorías de Álgebra en problemas

\begin{tabular}{|c|c|c|c|c|c|c|c|c|c|c|c|c|c|c|c|c|}
\hline Problemas & $\mathbf{9 5}$ & $\mathbf{9 6}$ & $\mathbf{9 7}$ & $\mathbf{9 8}$ & $\mathbf{9 9}$ & $\mathbf{0 0}$ & $\mathbf{0 1}$ & $\mathbf{0 2}$ & $\mathbf{0 3}$ & $\mathbf{0 4}$ & $\mathbf{0 5}$ & $\mathbf{0 6}$ & $\mathbf{0 7}$ & $\mathbf{0 8}$ & $\mathbf{0 9}$ & Total \\
\hline $\mathrm{CD}$ & & & 1 & & 1 & & & & & & & & & & & $\mathbf{2}$ \\
\hline $\mathrm{CMI}$ & & & & & & 1 & & & & & & & & & & $\mathbf{1}$ \\
\hline $\mathrm{CR}$ & & & & & & & & & & & & & & & & $\mathbf{0}$ \\
\hline $\mathrm{EM}$ & & & 1 & & & 1 & & 1 & & & & & 1 & & & $\mathbf{4}$ \\
\hline ER & & & & & & & & & 1 & & & & & & & $\mathbf{1}$ \\
\hline MI & & & & & 1 & 1 & & & & & & & & & & $\mathbf{2}$ \\
\hline OM & & & 1 & & & 1 & & & & & & & 1 & & & $\mathbf{3}$ \\
\hline P & 2 & 1 & & 2 & 1 & 2 & 2 & & 2 & 2 & 2 & 2 & 1 & 2 & 2 & $\mathbf{2 3}$ \\
\hline PD & & & 1 & & 1 & & & 1 & & & & & & & & $\mathbf{3}$ \\
\hline PM & & & 1 & & & & & & & & & & & & & $\mathbf{1}$ \\
\hline SED & 2 & 1 & & 2 & & & 2 & & 1 & 2 & 2 & 2 & 1 & 2 & 2 & $\mathbf{1 9}$ \\
\hline SE & 2 & 1 & & 2 & & & 2 & & 2 & 2 & 2 & 2 & 1 & 2 & 1 & $\mathbf{1 9}$ \\
\hline T & & & 2 & & 2 & 1 & 1 & & & & & & & & & $\mathbf{6}$ \\
\hline TR & & & & & & 1 & & & & & & & & $\mathbf{1}$ \\
\hline
\end{tabular}

A la vista de la siguiente Tabla III.9, observamos que no se ha propuesto en ningún examen una cuestión teórica, -enunciado de teoremas, definiciones- y sin embargo aparece con elevada frecuencia, en 16 de las 57 cuestiones planteadas la resolución de una ecuación en la que la incógnita y los coeficientes son matrices (Ecuaciones Matriciales).

Solamente en una ocasión se solicita que el alumno calcule una matriz inversa, quedando reducidos los ejercicios de este concepto al estudio de la existencia.

La vista de la tabla III.10 de presencia de contenidos conceptuales y procedimentales revela que hay tres contenidos en los que se concentran los datos: La resolución de ecuaciones matriciales y la discusión y/o resolución de sistemas de ecuaciones lineales. 
Tabla III.9. Frecuencias de las categorías de Álgebra en cuestiones

\begin{tabular}{|c|c|c|c|c|c|c|c|c|c|c|c|c|c|c|c|c|}
\hline Cuestiones & $\mathbf{9 5}$ & $\mathbf{9 6}$ & $\mathbf{9 7}$ & $\mathbf{9 8}$ & $\mathbf{9 9}$ & $\mathbf{0 0}$ & $\mathbf{0 1}$ & $\mathbf{0 2}$ & $\mathbf{0 3}$ & $\mathbf{0 4}$ & $\mathbf{0 5}$ & $\mathbf{0 6}$ & $\mathbf{0 7}$ & $\mathbf{0 8}$ & $\mathbf{0 9}$ & Total \\
\hline $\mathrm{CD}$ & & & 1 & & & & & & & & 1 & & & & $\mathbf{2}$ & $\mathbf{4}$ \\
\hline $\mathrm{CMI}$ & & & & & & & & & & & & & 1 & & & $\mathbf{1}$ \\
\hline $\mathrm{CR}$ & & & & & & 1 & 1 & & & & & & & 1 & 1 & $\mathbf{4}$ \\
\hline $\mathrm{EM}$ & 2 & 1 & 2 & 1 & & & 1 & 1 & & 2 & 1 & 2 & 1 & 1 & 1 & $\mathbf{1 6}$ \\
\hline $\mathrm{ER}$ & & & & & 1 & & & & 1 & & 1 & & 1 & & & $\mathbf{4}$ \\
\hline $\mathrm{MI}$ & & 1 & & & & & 1 & 1 & 1 & & 1 & 1 & & & & $\mathbf{6}$ \\
\hline OM & & & & & 2 & & & & 1 & & & & & & & $\mathbf{3}$ \\
\hline $\mathrm{P}$ & & & & & & 1 & & 1 & 2 & & 3 & 2 & 2 & & 1 & $\mathbf{1 2}$ \\
\hline PD & & & 1 & 1 & 1 & 1 & 1 & & & 1 & & & 1 & 1 & $\mathbf{8}$ \\
\hline PM & & & 1 & & & & & 2 & 2 & & & & & & $\mathbf{5}$ \\
\hline SED & & & & & & & & & & & 1 & 1 & 1 & & $\mathbf{3}$ \\
\hline SE & & & 1 & & 1 & & & & & & & & & & & $\mathbf{2}$ \\
\hline T & & & & & & & & & & & & & & & $\mathbf{0}$ \\
\hline TR & & & & & & & & & & & & & & & & $\mathbf{0}$ \\
\hline
\end{tabular}

Tabla III.10. Frecuencias de las categorías de Álgebra en cuestiones y problemas

\begin{tabular}{|c|c|c|c|c|c|c|c|c|c|c|c|c|c|c|c|c|}
\hline Cuestiones & $\mathbf{9 5}$ & $\mathbf{9 6}$ & $\mathbf{9 7}$ & $\mathbf{9 8}$ & $\mathbf{9 9}$ & $\mathbf{0 0}$ & $\mathbf{0 1}$ & $\mathbf{0 2}$ & $\mathbf{0 3}$ & $\mathbf{0 4}$ & $\mathbf{0 5}$ & $\mathbf{0 6}$ & $\mathbf{0 7}$ & $\mathbf{0 8}$ & $\mathbf{0 9}$ & Total \\
\hline $\mathrm{CD}$ & & & 2 & & 1 & & & & & & 1 & & & & 2 & $\mathbf{6}$ \\
\hline $\mathrm{CMI}$ & & & & & & 1 & & & & & & & 1 & & & $\mathbf{2}$ \\
\hline $\mathrm{CR}$ & & & & & & 1 & 1 & & & & & & & 1 & 1 & $\mathbf{4}$ \\
\hline $\mathrm{EM}$ & 2 & 1 & 3 & 1 & & 1 & 1 & 2 & & 2 & 1 & 2 & 2 & 1 & 1 & $\mathbf{2 0}$ \\
\hline ER & & & & & 1 & & & & 2 & & 1 & & 1 & & & $\mathbf{5}$ \\
\hline MI & & 1 & & & 1 & 1 & 1 & 1 & 1 & & 1 & 1 & & & & $\mathbf{8}$ \\
\hline OM & & & 1 & & 2 & 1 & & & 1 & & & 1 & & & & $\mathbf{6}$ \\
\hline P & 2 & 1 & & 2 & 1 & 3 & 2 & 1 & 4 & 2 & 5 & 4 & 3 & 2 & 3 & $\mathbf{3 5}$ \\
\hline PD & & & 1 & 1 & 2 & 1 & 1 & 2 & & & 1 & & & 1 & 1 & $\mathbf{1 1}$ \\
\hline PM & & 1 & 1 & & & & & 2 & 2 & & & & & & $\mathbf{6}$ \\
\hline SED & 2 & 1 & & 2 & & & 2 & & 1 & 2 & 2 & 3 & 2 & 3 & 2 & $\mathbf{2 2}$ \\
\hline SE & 2 & 1 & 1 & 2 & 1 & & 2 & & 2 & 2 & 2 & 2 & 1 & 2 & 1 & $\mathbf{2 1}$ \\
\hline T & & & 2 & & 2 & 2 & 0 & & & & & & & & & $\mathbf{6}$ \\
\hline TR & & & & & & & 1 & & & & & & & & & $\mathbf{1}$ \\
\hline
\end{tabular}


En la comisión armonizadora de las Pruebas de Acceso a Estudios Universitarios (PAEU), se tomó el acuerdo, -y como tal se transmite a los profesores de Educación Secundaria que asisten a las reuniones de coordinación- de no especificar el método (Gauss o determinantes) que era preciso utilizar en el estudio y resolución de sistemas de ecuaciones lineales y cálculo de matrices inversas; para facilitar al alumno la posible resolución del ejercicio. Aún así, se podría considerar la opción de utilizar el método de Gauss, si se manifestase abiertamente en la propuesta.

El argumento anterior condiciona que la P.I. haya considerado oportuno ubicar el "Estudio y resolución de sistemas de ecuaciones lineales" en los contenidos curriculares "Utilización de los determinantes en la discusión de ecuaciones lineales" y "Utilización de los determinantes en la resolución de ecuaciones lineales", de las tablas III.8, III.9 y III.10; dado que es el método generalmente utilizado para la resolución de ese tipo de ejercicios en los Bachilleratos de Ciencias de la Naturaleza y de la Salud y en el de Tecnología, aún cuando en la resolución de los mismos (que se presenta completa en los Anexos III y IV) se hayan utilizados ambos métodos, en algunos ejercicios.

Asimismo, tampoco se especifica que el método utilizado para el "Estudio o Cálculo de la matriz inversa" o para el "Estudio del rango de una matriz" tenga que ser el método de Gauss, si bien es cierto que seguramente esté pensado para dar mayor libertad al alumno, y que pueda elegir el método que le sea más familiar de emplear, esto lleva a un peligro estructural: Como no piden método específico no se enseña a los alumnos todos los posibles contenidos curriculares, fundamentando esta opción en la "falta de tiempo" para desarrollar el programa.

\section{III.4. TABLAS DE CATEGORÍAS DE CONTENIDOS DE GEO- METRÍA}

Para confeccionar la tabla III.11, se considera como referencia los contenidos curriculares de Geometría, correspondientes a la asignatura de Matemáticas II, publicado oficialmente en el BOC y L., siguiendo el orden del Decreto 70/2002 de 23 de mayo por el que se establece el currículo de Bachillerato de la comunidad de Castilla y León y el ANEXO IV Análisis del Currículo: Acuerdos de mínimos, actualizado en abril de 2003, de la Comisión Organizadora PAEU de esta misma Comunidad. 
Estos contenidos curriculares de Geometría se han detallado en la tabla III.11 en 25 apartados y además se contabiliza su frecuencia de aparición. Esta tabla está elaborada a partir de los ANEXOS $\vee$ y $\mathrm{VI}$, los enunciados se presentan señalados con una $P$ si se trata de un Problema o con una $C$, si es una Cuestión y están numerados siguiendo el orden cronológico de aparición.

Tabla III.11. Categorías curriculares de Geometría

\begin{tabular}{|c|c|c|c|c|}
\hline Contenidos curriculares & Problemas & $\mathbf{N}^{\circ}$ & Cuestiones & $\mathrm{N}^{\circ}$ \\
\hline $\begin{array}{l}\text { Vectores en el espacio n-dimensional. } \\
\text { Operaciones y bases. }\end{array}$ & & 0 & C14 & 1 \\
\hline Producto escalar. & & 0 & C31 & 1 \\
\hline Ortogonalidad y bases ortonormales. & & 0 & $\begin{array}{l}\text { C3, C4, C8, } \\
\text { C26, C35, C42, } \\
\text { C55, C57 }\end{array}$ & 8 \\
\hline Producto vectorial. & & 0 & $\begin{array}{l}\text { C7, C8, C38, } \\
\text { C42 }\end{array}$ & 4 \\
\hline Producto mixto. & & 0 & & 0 \\
\hline $\begin{array}{l}\text { Sistemas de referencia. Coordenadas } \\
\text { de puntos }\end{array}$ & & 0 & & 0 \\
\hline $\begin{array}{l}\text { Obtención e interpretación de las } \\
\text { ecuaciones de rectas a partir de siste- } \\
\text { mas de referencia ortonormales. }\end{array}$ & $\begin{array}{l}\mathrm{P} 1, \mathrm{P} 11, \mathrm{P} 12, \\
\mathrm{P} 15, \mathrm{P} 16, \mathrm{P} 19, \\
\mathrm{P} 22, \mathrm{P} 26, \mathrm{P} 27, \\
\mathrm{P} 28\end{array}$ & 10 & $\begin{array}{l}\text { C23, C30, C41, } \\
\text { C54 }\end{array}$ & 4 \\
\hline $\begin{array}{l}\text { Obtención e interpretación de las } \\
\text { ecuaciones de planos a partir de sis- } \\
\text { temas de referencia ortonormales. }\end{array}$ & $\begin{array}{l}\text { P3, P4, P8, P9, } \\
\text { P11, P16, P17, } \\
\text { P18, P20, P23, } \\
\text { P24, P25, P29, } \\
\text { P30 }\end{array}$ & 14 & $\begin{array}{l}\text { C20, C28, C34, } \\
\text { C39, C45, C47, } \\
\text { C67 }\end{array}$ & 7 \\
\hline $\begin{array}{l}\text { Resolución de problemas de inciden- } \\
\text { cia entre rectas. }\end{array}$ & $\begin{array}{l}\text { P5, P10, P11, } \\
\text { P15, P18, P23, } \\
\text { P28, P29 }\end{array}$ & 8 & $\begin{array}{l}\text { C6, C12, C15, } \\
\text { C16, C25 }\end{array}$ & 5 \\
\hline $\begin{array}{l}\text { Resolución de problemas de inciden- } \\
\text { cia entre rectas y planos. }\end{array}$ & P7, P13, P20 & 3 & C18 & 1 \\
\hline
\end{tabular}


Tabla III.11. Categorías curriculares de Geometría (continuación)

\begin{tabular}{|c|c|c|c|c|}
\hline Contenidos curriculares & Problemas & $\mathbf{N}^{\circ}$ & Cuestiones & $\mathbf{N}^{\circ}$ \\
\hline $\begin{array}{l}\text { Resolución de problemas de inci- } \\
\text { dencia entre planos. }\end{array}$ & P1, P6, P8, P17 & 4 & & 0 \\
\hline $\begin{array}{l}\text { Resolución de problemas de parale- } \\
\text { lismo entre rectas. }\end{array}$ & & 0 & & 0 \\
\hline $\begin{array}{l}\text { Resolución de problemas de parale- } \\
\text { lismo entre rectas y planos. }\end{array}$ & $\begin{array}{l}\text { P14, P16, P24, } \\
\text { P27, P30 }\end{array}$ & 5 & & 0 \\
\hline $\begin{array}{l}\text { Resolución de problemas de parale- } \\
\text { lismo entre planos. }\end{array}$ & P6 & 1 & C2, C33 & 2 \\
\hline $\begin{array}{l}\text { Resolución de problemas de per- } \\
\text { pendicularidad entre rectas. }\end{array}$ & $\begin{array}{l}\text { P3, P11, P12, } \\
\text { P19, P22, P28 }\end{array}$ & 6 & $\begin{array}{l}\text { C15, C22, C23, } \\
\text { C54, C61 }\end{array}$ & 5 \\
\hline $\begin{array}{l}\text { Resolución de problemas de per- } \\
\text { pendicularidad entre rectas y pla- } \\
\text { nos. }\end{array}$ & P14, P20 & 2 & C19 & 1 \\
\hline $\begin{array}{l}\text { Resolución de problemas de per- } \\
\text { pendicularidad entre planos. }\end{array}$ & P16 & 1 & C45, C47 & 2 \\
\hline $\begin{array}{l}\text { Resolución de problemas métricos } \\
\text { relacionados con el cálculo de } \\
\text { ángulos. }\end{array}$ & P13, P14, P16 & 3 & $\begin{array}{l}\text { C37, C43, C63, } \\
\text { C66 }\end{array}$ & 4 \\
\hline $\begin{array}{l}\text { Resolución de problemas métricos } \\
\text { relacionados con el cálculo de dis- } \\
\text { tancias. }\end{array}$ & $\begin{array}{l}\text { P2, P5, P15, P21, } \\
\text { P24, P25, P26, } \\
\text { P28 }\end{array}$ & 8 & $\begin{array}{l}\text { C2, C10, C11, } \\
\text { C17, C24, C29, } \\
\text { C32, C33, C36, } \\
\text { C40, C46, C48, } \\
\text { C52, C53, C62, } \\
\text { C64, C65 }\end{array}$ & 17 \\
\hline $\begin{array}{l}\text { Punto simétrico respecto de un } \\
\text { punto. }^{9}\end{array}$ & & 0 & $\mathrm{C} 21$ & 1 \\
\hline $\begin{array}{l}\text { Punto simétrico respecto de una re- } \\
\text { cta. }{ }^{10}\end{array}$ & P2, P21, P30 & 3 & & 0 \\
\hline $\begin{array}{l}\text { Punto simétrico respecto de un pla- } \\
\text { no. }{ }^{11}\end{array}$ & P4, P25 & 2 & C50, C58 & 2 \\
\hline
\end{tabular}

\footnotetext{
${ }^{9}$ Este contenido no aparece explícitamente como contenido del currículo, pero sí en los enunciados de los ejercicios.

${ }^{10}$ Contenido curricular en que se presenta el enunciado de los ejercicios.
} 
Tabla III.11. Categorías curriculares de Geometría (continuación)

\begin{tabular}{|l|l|l|l|c|}
\hline Contenidos curriculares & Problemas & $\mathbf{N}^{\mathbf{0}}$ & Cuestiones & $\mathbf{N}^{\mathbf{0}}$ \\
\hline $\begin{array}{l}\text { Resolución de problemas métricos } \\
\text { relacionados con el cálculo de } \\
\text { áreas. }\end{array}$ & $\begin{array}{l}\text { P7, P8, P10, P12, } \\
\text { P13 }\end{array}$ & $\mathbf{5}$ & $\begin{array}{l}\text { C1, C13, C55, } \\
\text { C56, C60 }\end{array}$ & $\mathbf{5}$ \\
\hline $\begin{array}{l}\text { Resolución de problemas métricos } \\
\text { relacionados con el cálculo de } \\
\text { volúmenes. }\end{array}$ & P1, P6 & $\mathbf{2}$ & C18, C51, C59 & $\mathbf{3}$ \\
\hline \begin{tabular}{l} 
Esfera. \\
\hline
\end{tabular} & $\mathbf{0}$ & & $\mathbf{0}$ \\
\hline
\end{tabular}

Las cuestiones que se transcriben a continuación, son difíciles de clasificar en la tabla anterior, pues su contenido conceptual no se encuadra explícitamente en ninguno de los apartados de la tabla III.11:

C5.- ¿Son coplanarios los puntos $A(1,0,0), B(0,1,0)$ $C(2,1,0)$ y $D(-1,2,1)$ ?

(Sep. 1995)

C9.- Halla para qué valores de $m$ los vectores $(1, m,-1),(2, m+1,0)$, $(0, m-1,-2)$ son linealmente dependientes.

(Sep. 1996)

C27.- ¿Qué relación debe existir entre a y $b$ para que los tres vectores $(a, b, 1),(-b,-1, a)$ y $(-a, b, a)$ estén sobre un mismo plano? (Junio 2000)

C44.- Determínese si el plano $\pi \equiv 2 x+3 y-4=0$ corta o no al segmento de extremos $A(2,1,3)$ y $B(3,2,1)$.

(Junio 2004)

C49.- Dados el punto $A(3,5,-1)$ y la recta $r \equiv \frac{x-1}{2}=y+2=\frac{z+1}{4}$, hállese el punto B perteneciente a $r$ tal que el vector de extremos A y B es paralelo al plano $\pi$ de ecuación $3 x-2 y+z+5=0$

(Junio 2005)

\footnotetext{
${ }^{11} \mathrm{Al}$ igual que el apartado anterior, este enunciado podría englobarse en perpendicularidad de rectas y planos, pero se ha explicitado de esta manera, por ser esa la orden que está propuesta en el enunciado del ejercicio.
} 
Estos contenidos curriculares de Geometría, que se han desglosado en 25 categorías, son la base para la elaboración de las Figuras III.5 y III.6, que son gráficos de frecuencias de aparición de contenidos curriculares, en las que aparece contabilizada la frecuencia de aparición de estos contenidos, tanto en los problemas como en las cuestiones relativas a las propuestas de examen de las Pruebas de Acceso a Estudios Universitarios (PAEU), de los quince años relativos al presente estudio.

Aún cuando un simple vistazo a la tabla manifiesta que hay algunos contenidos que aparecen muchas veces mientras que otros no aparecen nunca, los gráficos de frecuencias complementan y confirman esa primera percepción. En dicha tabla se observa que 9 contenidos curriculares no se han propuesto como problema, en los 15 años que abarca el estudio realizado.

\section{Figura III.5. Análisis curricular de los problemas de Geometría}

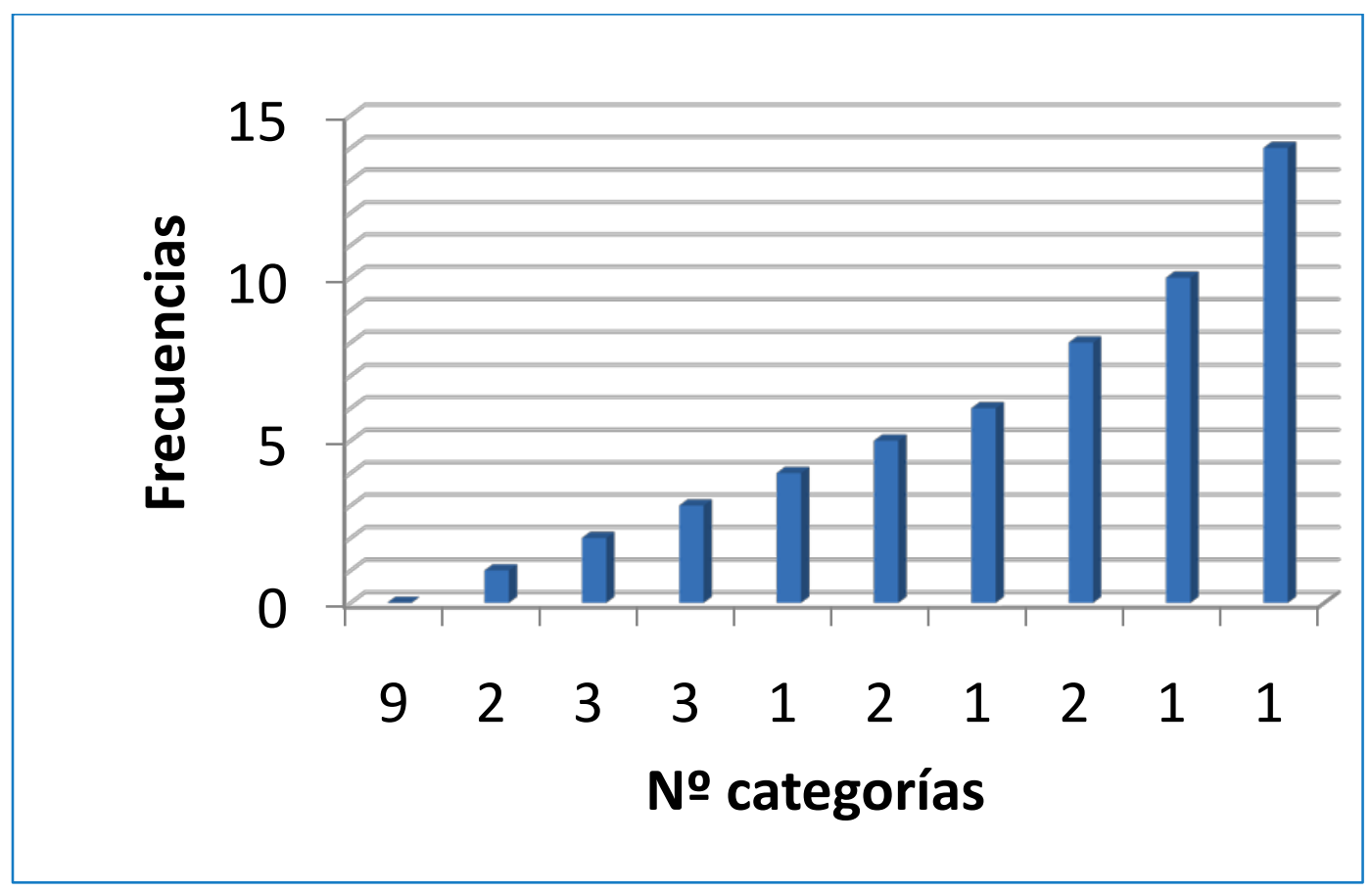

En sentido contrario, los contenidos que se han presentado con mayor frecuencia son: La obtención e interpretación de ecuaciones de planos, 14; Obtención e interpretación de ecuaciones de rectas, 10, Problemas de incidencia de rectas y Resolución de problemas métricos relacionados con el cálculo de distancias, 8.

En cuestiones, los contenidos con mayor frecuencia de aparición son: Problemas métricos relacionados con el cálculo de distancias, 17; Ortogonalidad y bases ortonormales, 8; Obtención e interpretación de las ecuaciones de planos 
a partir de sistemas de referencia ortonormales, 7. En sentido contrario, 7 contenidos no se han propuesto nunca como cuestión.

Figura III.6. Análisis curricular de las cuestiones de Geometría

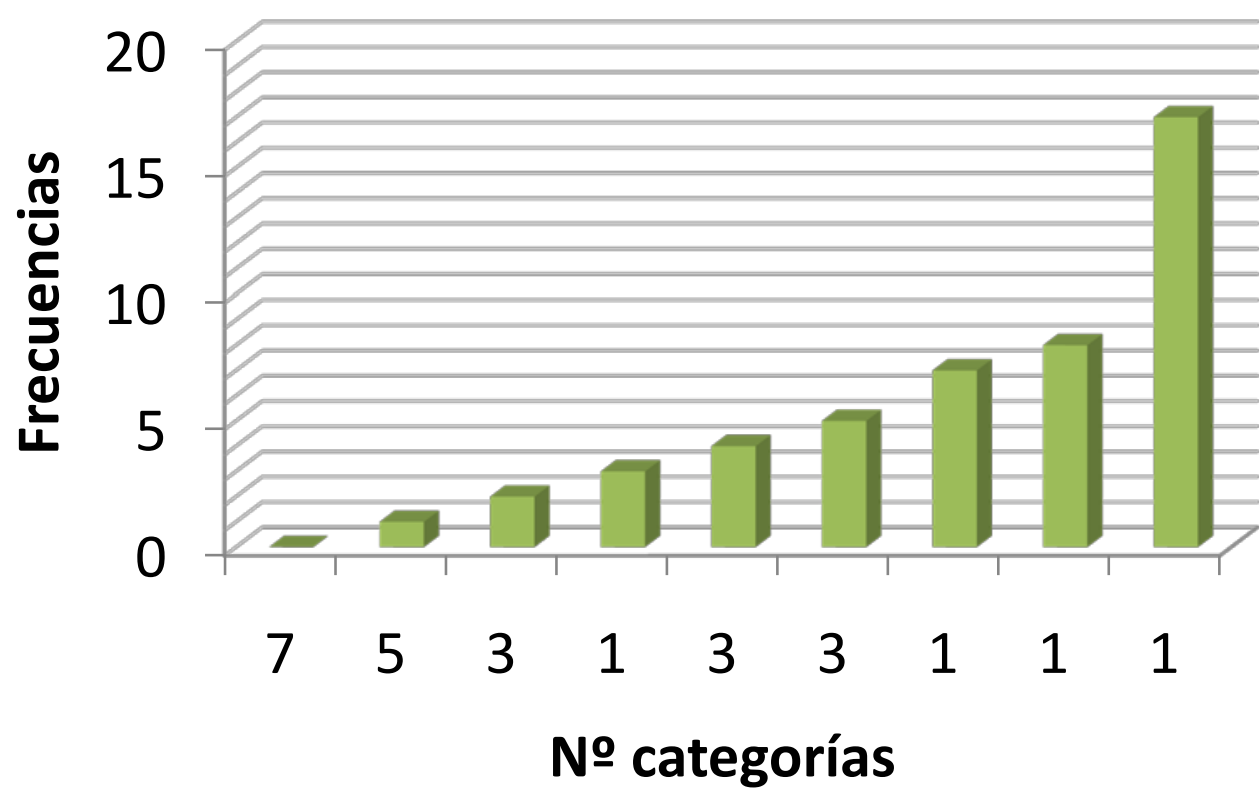

Tanto en el Real Decreto1178/1992 y en el Real Decreto 1179/1992, de 2 de octubre, por el que se establecen las enseñanzas mínimas del bachillerato y el currículo, respectivamente, como en el ANEXO IV Análisis del Currículo: acuerdos de mínimos de julio de 2001; se encuentra, en el apartado de Geometría, entre los contenidos de Matemáticas II: "Idea de lugar geométrico. Iniciación al estudio de las cónicas, combinando los enfoques analíticos y sintéticos"; pero en el Real Decreto 3474/2000 de 29 de diciembre, y, en consecuencia, en el ANEXO IV Análisis del Currículo: acuerdos de mínimos de abril de 2003; modifican los contenidos conceptuales anteriores, y el tema: "Lugares geométricos del plano. Cónicas" se establece en Matemáticas I, por lo que los ejercicios relativos a cónicas no son objeto de examen, desde el curso 2004, en que la hoja de examen aparece con el distintivo "Nuevo currículo".

Dada su efímera presencia en los ejercicios de las PAU y no ser contenido curricular de Matemáticas II en el decreto 70/2002 de Currículo de Bachillerato de Castilla y León, -base sobre la que fundamentamos este estudio-, no se ha hecho un estudio exhaustivo de presencia, frecuencia de aparición y variedad. 
En la tabla III.12 que se presenta a continuación, se encuentran las categorías correspondientes a los contenidos conceptuales y procedimentales de Geometría, su abreviatura e interpretación. Para la elaboración de esta tabla se tienen presentes los contenidos conceptuales y los procedimentales de los enunciados propuestos en las Pruebas de Acceso, teniendo en cuenta la orden del enunciado del problema o cuestión propuestos en los distintos exámenes objeto del estudio.

Aunque están desglosados según la orden directa que se da, hay ejercicios cuyo contenido procedimental corresponde a varias categorías de análisis, así; por ejemplo, en ejercicios como los que se presentan a continuación:

P14.- a) Calcular el valor de $\alpha$ para que la recta $r \equiv\left\{\begin{array}{l}2 x-3 y=-1 \\ x+y-z=2\end{array} y\right.$ el plano $\pi \equiv \alpha x-y+z=5$ sean paralelos.

b) ¿Existe algún valor de $\alpha$ para el que $r$ y $\pi$ sean perpendiculares?

c) Hallar el valor de $\alpha$ para que el ángulo formado por la recta $r$ y el plano $\pi$ sea $30^{\circ}$

(Sep. 2001)

C43.- ¿Cuál es el ángulo que forma la recta $x=y=z$ con el eje OX? (Sep. 2003)

cuyo contenido curricular es: "Resolución de problemas métricos relacionados con el cálculo de ángulos" se consideran, en la tabla de contenidos curricular y procedimental, en el apartado : A (Ángulo determinado por dos rectas o por dos vectores y en ARP (Ángulo de recta y plano).

Análogamente, el ejercicio que se detalla a continuación:

P16. - Se consideran los planos $\pi_{1} \equiv x+y+z=0$ y $\pi_{2} \equiv x-y+z=1$. Se pide:

i) Hallar un plano perpendicular a ambos pasando por el punto $(1,2,-1)$

ii) Determinar una recta paralela a ambos pasando por el punto $(2,1,1)$

iii) Calcular el ángulo que forman $\pi_{1}$ y $\pi_{2}$.

(Sep. 2002)

aparece reseñado en AP (Calcular el ángulo determinado por dos planos), EPP (Escribir la ecuación del plano perpendicular a una recta u otro plano), ER (Escribir la ecuación de una recta) y ERPa (Escribir la expresión analítica de una recta paralela a un plano o a dos planos). 
Tabla III.12. Categorías de Geometría en las PAEU

\begin{tabular}{|c|c|c|}
\hline A & Ángulo & $\begin{array}{l}\text { Manda calcular el ángulo determinado por dos } \\
\text { rectas, o dos vectores. }\end{array}$ \\
\hline AP & Ángulo entre planos & $\begin{array}{l}\text { Ordena calcular el ángulo determinado por dos } \\
\text { planos }\end{array}$ \\
\hline ARP & $\begin{array}{l}\text { Ángulo de recta y pla- } \\
\text { no }\end{array}$ & $\begin{array}{l}\text { Hay que calcular el ángulo determinado por una } \\
\text { recta y un plano. }\end{array}$ \\
\hline CA & Calcular área & $\begin{array}{l}\text { Solicita que se calcule el área de una figura ge- } \\
\text { ométrica. }\end{array}$ \\
\hline $\mathrm{CV}$ & Cálculo del volumen & $\begin{array}{l}\text { Hay que calcular el volumen de un cuerpo ge- } \\
\text { ométrico. }\end{array}$ \\
\hline DPP & $\begin{array}{l}\text { Distancia de punto a } \\
\text { plano }\end{array}$ & $\begin{array}{l}\text { Tenemos que calcular la distancia de un punto a } \\
\text { un plano dados, o entre dos planos paralelos. }\end{array}$ \\
\hline DPPs & $\begin{array}{l}\text { Distancia entre dos } \\
\text { puntos }\end{array}$ & Manda calcular la distancia de dos puntos. \\
\hline DPR & $\begin{array}{l}\text { Distancia de punto a } \\
\text { recta }\end{array}$ & $\begin{array}{l}\text { Hay que calcular la distancia de un punto a una } \\
\text { recta. }\end{array}$ \\
\hline DRP & $\begin{array}{l}\text { Distancia de recta a } \\
\text { plano }\end{array}$ & $\begin{array}{l}\text { Requiere calcular una distancia, de una recta a } \\
\text { un plano, o viceversa.. }\end{array}$ \\
\hline DRR & $\begin{array}{l}\text { Distancia entre dos } \\
\text { rectas }\end{array}$ & Tenemos que calcular la distancia de dos rectas. \\
\hline EP & Ecuación del plano & $\begin{array}{l}\text { En esta categoría hemos clasificado los ejerci- } \\
\text { cios en los cuales pide escribir la expresión } \\
\text { analítica de la ecuación de un plano. }\end{array}$ \\
\hline EPP & $\begin{array}{l}\text { Ecuación del plano } \\
\text { perpendicular }\end{array}$ & $\begin{array}{l}\text { Manda escribir la ecuación del plano perpendi- } \\
\text { cular a una recta u otro plano. }\end{array}$ \\
\hline $\mathrm{EPPa}$ & $\begin{array}{l}\text { Ecuación del plano pa- } \\
\text { ralelo. }\end{array}$ & $\begin{array}{l}\text { Se pide escribir la expresión analítica de la } \\
\text { ecuación del plano paralelo a una recta u otro } \\
\text { plano. }\end{array}$ \\
\hline ER & Ecuación de una recta & $\begin{array}{l}\text { Se pide escribir la expresión de las ecuaciones } \\
\text { de una recta, en cualquiera de sus formas: pa- } \\
\text { ramétrica, continua, etc. }\end{array}$ \\
\hline ERP & $\begin{array}{l}\text { Ecuación de recta per- } \\
\text { pendicular }\end{array}$ & $\begin{array}{l}\text { Se insta para que se escriba la ecuaciones de una } \\
\text { recta perpendicular a otra recta o a un plano. }\end{array}$ \\
\hline
\end{tabular}


Tabla III.12. Categorías de Geometría en las PAEU (Continuación)

\begin{tabular}{|c|c|c|}
\hline ERPa & $\begin{array}{l}\text { Ecuación de recta pa- } \\
\text { ralela }\end{array}$ & $\begin{array}{l}\text { Pide que se obtenga la expresión analítica de una } \\
\text { recta paralela a un plano o a dos planos. }\end{array}$ \\
\hline $\mathrm{P}$ & Parámetros & $\begin{array}{l}\text { Se manda estudiar posiciones relativas, de rec- } \\
\text { tas, planos o recta y plano, dependiendo de } \\
\text { parámetros }\end{array}$ \\
\hline PIP & $\begin{array}{l}\text { Punto de intersección } \\
\text { de tres planos }\end{array}$ & $\begin{array}{l}\text { Manda calcular el punto de intersección de tres } \\
\text { planos. }\end{array}$ \\
\hline PIRP & $\begin{array}{l}\text { Punto de intersección } \\
\text { de recta y plano }\end{array}$ & $\begin{array}{l}\text { Solicita que se calcule el punto de intersección } \\
\text { de una recta y un plano. }\end{array}$ \\
\hline $\operatorname{PrR}$ & $\begin{array}{l}\text { Posición relativa de } \\
\text { dos rectas }\end{array}$ & $\begin{array}{l}\text { Ordena que se estudie la posición relativa de dos } \\
\text { rectas. }\end{array}$ \\
\hline PrRP & $\begin{array}{l}\text { Posición relativa de } \\
\text { recta y plano }\end{array}$ & $\begin{array}{l}\text { Pide que se estudie la posición relativa de una } \\
\text { recta y un plano. }\end{array}$ \\
\hline PrP & $\begin{array}{l}\text { Posición relativa de } \\
\text { dos planos }\end{array}$ & $\begin{array}{l}\text { Es un ejercicio en el cual hay que estudiar la po- } \\
\text { sición relativa de dos planos. }\end{array}$ \\
\hline PSP & $\begin{array}{l}\text { Punto simétrico res- } \\
\text { pecto a otro punto }\end{array}$ & $\begin{array}{l}\text { Hay que calcular el punto simétrico de un punto } \\
\text { respecto de otro punto. }\end{array}$ \\
\hline PSR & $\begin{array}{l}\text { Punto simétrico res- } \\
\text { pecto a una recta }\end{array}$ & $\begin{array}{l}\text { Se pide calcular el punto simétrico de uno dado, } \\
\text { respecto de una recta. }\end{array}$ \\
\hline PSPl & $\begin{array}{l}\text { Punto simétrico res- } \\
\text { pecto a un plano }\end{array}$ & $\begin{array}{l}\text { Ordena calcular el punto simétrico de uno dado, } \\
\text { respecto de un plano. }\end{array}$ \\
\hline RIP & $\begin{array}{l}\text { Recta de intersección } \\
\text { de dos o tres planos }\end{array}$ & $\begin{array}{l}\text { Se pide calcular la ecuación de la recta de inter- } \\
\text { sección entre dos o entre tres planos. }\end{array}$ \\
\hline $\mathrm{T}$ & Enunciado teórico & Se demanda enunciar un teorema \\
\hline VO & Vectores ortogonales & $\begin{array}{l}\text { Hay que calcular un vector que sea ortogonal a } \\
\text { otros dados. }\end{array}$ \\
\hline
\end{tabular}

A partir de esta tabla, en la Tabla III.13 se analiza, por años, la frecuencia con la que los problemas correspondientes a esas categorías procedimentales han sido propuestos en las Pruebas de Acceso a la Universidad. 
Tabla III.13. Frecuencias de las categorías de Geometría en problemas

\begin{tabular}{|c|c|c|c|c|c|c|c|c|c|c|c|c|c|c|c|c|}
\hline Problemas & 95 & 96 & 97 & 98 & 99 & 00 & 01 & 02 & 03 & 04 & 05 & 06 & 07 & 08 & 09 & Total \\
\hline A & & & & & & & 1 & & & & & & & & & 1 \\
\hline AP & & & & & & & & 1 & & & & & & & & 1 \\
\hline ARP & & & & & & & 1 & & & & & & & & & 1 \\
\hline $\mathrm{CA}$ & & & & 2 & 1 & 1 & 1 & & & & & & & & & 5 \\
\hline $\mathrm{CV}$ & 1 & & 1 & & & & & & & & & & & & & 2 \\
\hline DPP & & & & & & & & & & & & & & & & 0 \\
\hline DPPs & & & & & & & & & & & & & & & & 0 \\
\hline DPR & 1 & & & & & & & 1 & & & 1 & & & & & 3 \\
\hline DRP & & & & & & & & & & & & 1 & 2 & & & 3 \\
\hline DRR & & & 1 & & & & & & & & & & & 1 & & 2 \\
\hline EP & & 1 & & & 1 & 1 & & & 2 & 1 & & 1 & 1 & & 1 & 9 \\
\hline EPP & & & & 1 & & & & 1 & & 1 & & 1 & 1 & & & 5 \\
\hline EPPa & & & & & & & & & & & & & & & 1 & 1 \\
\hline ER & 1 & & & & & 2 & & 1 & & 1 & 1 & & 1 & 2 & & 9 \\
\hline ERP & & & & & & 2 & & & & 1 & & & & 1 & & 4 \\
\hline ERPa & & & & & & & & 1 & & & & & & & & 1 \\
\hline $\mathrm{P}$ & & 1 & 1 & & & 1 & 1 & & 2 & 1 & 1 & 2 & & & & 10 \\
\hline PIP & 1 & & & & & & & & & & & & & & & 1 \\
\hline PIRP & & & & 2 & & & 1 & & & & & & & & & 3 \\
\hline PrR & & 1 & 1 & & 1 & 1 & & & 1 & & 1 & 1 & & 1 & 1 & 9 \\
\hline PrRP & & & & & & & 1 & & & 1 & & 1 & & 1 & & 4 \\
\hline PrP & & & 1 & & & & & & & & & & & & & 1 \\
\hline PSP & & & & & & & & & & & & & & & & 0 \\
\hline PSR & 1 & & & & & & & & & & 1 & & & & & 2 \\
\hline PSPI & & 1 & & & & & & & & & & & 1 & & & 2 \\
\hline RIP & 1 & & & & & & & & 1 & & & & & & & 2 \\
\hline $\mathrm{T}$ & & & & & & & & & & & & & & & & 0 \\
\hline vo & & & & & & & 1 & & & & & & & & 1 & 2 \\
\hline
\end{tabular}

En la Tabla III.14 se analizan los enunciados de las cuestiones que han sido propuestos en las PAEU, la frecuencia y años de aparición,siguiendo las correspondientes categorías procedimentales de la Tabla III.12. 
Tabla III.14. Frecuencias de las categorías de Geometría en cuestiones

\begin{tabular}{|c|c|c|c|c|c|c|c|c|c|c|c|c|c|c|c|c|}
\hline Problemas & 95 & 96 & 97 & 98 & 99 & 00 & 01 & 02 & 03 & 04 & 05 & 06 & 07 & 08 & 09 & Total \\
\hline A & & & & & & & 1 & & 1 & & & & & & & 2 \\
\hline $\mathrm{AP}$ & & & & & & & & & & & & & & & & 0 \\
\hline ARP & & & & & & & & 1 & & & & & & 1 & 1 & 3 \\
\hline CA & 1 & & 1 & & & & & & & & & 1 & 1 & 1 & & 5 \\
\hline $\mathrm{CV}$ & 1 & & 1 & 1 & & & & & & & 1 & & 1 & & & 5 \\
\hline DPP & 1 & & 1 & & & & 1 & 1 & & & 1 & 1 & & & & 6 \\
\hline DPPs & & & & & & & & & & & & & & & & 0 \\
\hline DPR & & & & & & 1 & & & 1 & & & 1 & & 1 & 1 & 5 \\
\hline DRP & & 1 & & & & & 1 & & & & & & & & & 2 \\
\hline DRR & & & & & 1 & & & & & 1 & & & & & 1 & 3 \\
\hline EP & & & & & & 1 & & & & & & & & & 1 & 2 \\
\hline EPP & & & & 1 & & & & & & 2 & & & & & & 3 \\
\hline EPPa & & & & & & & 1 & 1 & & & & & & & & 2 \\
\hline ER & & & & & & & & & 1 & & & & & & & 1 \\
\hline ERP & & & & & 1 & & & & & & & 1 & & 1 & & 3 \\
\hline ERPa & & & & & & 1 & & & & & & & & & & 1 \\
\hline$P$ & 1 & 1 & 1 & 2 & & 1 & 2 & 1 & & & & 1 & & & 1 & 11 \\
\hline PIP & & & & & & & & & & & & & & & & 0 \\
\hline PIRP & & & & & & & & & & & & & & & & 0 \\
\hline PrR & 1 & & 3 & 1 & 1 & & & & & & & & & & 1 & 7 \\
\hline PrRP & & & & 1 & & & & & & & & & & & & 1 \\
\hline PrP & 1 & & & & & & 1 & & & & & & & & & 2 \\
\hline PSP & & & & 1 & & & & & & & & & & & & 1 \\
\hline PSR & & & & & & & & & & & & & & & & 0 \\
\hline PSPI & & & & & & & & & & & 1 & & 1 & & & 2 \\
\hline RIP & & & & & & & & & & & & & & & & 0 \\
\hline $\mathrm{T}$ & 1 & 1 & 2 & & 1 & & & & & & & & & & & 5 \\
\hline VO & 3 & 1 & & & & & & 2 & 1 & & & 1 & 1 & & & 9 \\
\hline
\end{tabular}

Finalmente, en la Tabla III.15, tomando como referencia la Tabla III.12, con las abreviaturas correspondientes a las distintas categorías y su interpretación aparecen las cuestiones y los problemas juntos. 
Tabla III.15. Frecuencias de las categorías de Geometría en problemas y cuestiones

\begin{tabular}{|c|c|c|c|c|c|c|c|c|c|c|c|c|c|c|c|c|}
\hline $\begin{array}{c}\text { Problemas y } \\
\text { cuestiones }\end{array}$ & 95 & 96 & 97 & 98 & 99 & 00 & 01 & 02 & 03 & 04 & 05 & 06 & 07 & 08 & 09 & Total \\
\hline A & & & & & & & 2 & & 1 & & & & & & & 3 \\
\hline AP & & & & & & & & 1 & & & & & & & & 1 \\
\hline ARP & & & & & & & 1 & 1 & & & & & & 1 & 1 & 4 \\
\hline CA & 1 & & 1 & 2 & 1 & 1 & 1 & & & & & 1 & 1 & 1 & & 10 \\
\hline $\mathrm{CV}$ & & & & 1 & & & & & & & 1 & & 1 & & & 2 \\
\hline DPP & 1 & & 1 & & & & 1 & 1 & & & 1 & 1 & & & & 0 \\
\hline DPPs & & & & & & & & & & & & & & & & 0 \\
\hline DPR & 1 & & & & & 1 & & 1 & 1 & & 1 & 1 & & 1 & 1 & 8 \\
\hline DRP & & 1 & & & & & 1 & & & & & 1 & 2 & & & 5 \\
\hline DRR & & & 1 & & 1 & & & & & 1 & & & & 1 & 1 & 5 \\
\hline EP & & 1 & & & 1 & 2 & & & 2 & 1 & & 1 & 1 & & 2 & 11 \\
\hline EPP & & & & 2 & & & & 1 & & 3 & & 1 & 1 & & & 8 \\
\hline EPPa & & & & & & & 1 & 1 & & & & & & & 1 & 3 \\
\hline ER & 1 & & & & & 2 & & 1 & 1 & 1 & 1 & & 1 & 2 & & 10 \\
\hline ERP & & & & & 1 & 2 & & & & 1 & & 1 & & 2 & & 7 \\
\hline ERPa & & & & & & 1 & & 1 & & & & & & & & 2 \\
\hline$P$ & 1 & 2 & 2 & 2 & & 2 & 3 & 1 & 2 & 1 & 1 & 3 & & & 1 & 21 \\
\hline PIP & 1 & & & & & & & & & & & & & & & 1 \\
\hline PIRP & & & & 2 & & & 1 & & & & & & & & & 3 \\
\hline PrR & 1 & 1 & 4 & 1 & 2 & 1 & & & 1 & & 1 & 1 & & 1 & 2 & 16 \\
\hline PrRP & & & & 1 & & & 1 & & & 1 & & 1 & & 1 & & 5 \\
\hline PrP & 1 & & 1 & & & & 1 & & & & & & & & & 3 \\
\hline PSP & & & & 1 & & & & & & & & & & & & 0 \\
\hline PSR & 1 & & & & & & & & & & 1 & & & & & 2 \\
\hline PSPI & & 1 & & & & & & & & & 1 & & 2 & & & 4 \\
\hline RIP & 1 & & & & & & & & 1 & & & & & & & 2 \\
\hline $\mathrm{T}$ & 1 & 1 & 2 & & 1 & & & & & & & & & & & 5 \\
\hline VO & 3 & 1 & & & & & 1 & 2 & 1 & & & 1 & 1 & & 1 & 11 \\
\hline
\end{tabular}

Al igual que en las tablas presentadas anteriormente, correspondientes al estudio cronológico de la aparición de contenidos de Álgebra y de Análisis Matemá- 
tico, se puede observar las celdas vacías que aparecen, esto es debido a la dispersión de los datos tanto en cantidad de aparición como en variedad, concentrándose en pocas filas, que son las correspondientes al estudio de la posición relativa de dos rectas ( $\mathrm{PrR}$ ), o VO (Hay que calcular un vector que sea ortogonal a otros dados), en cuestiones.

La "nube de puntuaciones" correspondiente a la tabla de doble entrada precedente refleja una dispersión aún más acusada que en las precedentes y hay muchos contenidos carentes de puntuación porque no aparecen reflejados ni en los problemas ni en las cuestiones.

Se puede enfatizar el hecho de que en el año 2000 aparece la última cuestión correspondiente a la categoría de Teoría " $\mathrm{T}$ " propuesta, y en los problemas nunca se ha solicitado expresamente ningún contenido de teoría. Demostraciones de propiedades de productos escalar, vectorial o mixto son contenidos teóricos que se podrían proponer como apartado de un problema.

El cálculo de distancias aparece propuesto en 17 de las 67 cuestiones planteadas, pero dado que se trata de una pregunta valorada en un punto el método de resolución suele ser procedimental, es decir, se escribe la fórmula correspondiente y se resuelve sustituyendo los datos. 



\section{CAPÍTULO IV}

\section{ANÁLISIS EN COMPETENCIAS DE LOS ENUNCIADOS DE ANÁLISIS MATEMÁTICO}

\section{IV.1. INTRODUCCIÓN}

En este capítulo se presenta el estudio de algunos de los 61 problemas y de las 99 cuestiones de Análisis Matemático propuestos en los quince años de estudio, según las tablas de indicadores en competencias presentadas en el capítulo anterior.

Ya se ha detectado que las PAU no responden a la totalidad de los contenidos curriculares y que sesgan el currículo. En lo que se refiere a Análisis Matemático, los ejercicios propuestos básicamente tienen un método más directo de resolución y en raras ocasiones se puede emplear varios.

Los ejercicios de continuidad en los que hay que utilizar el teorema de Bolzano eventualmente pueden, ser resueltos por algún otro teorema derivado del mismo, pero en ambas situaciones se presentan las mismas competencias.

Aquellos ejercicios en los que se pide calcular las asíntotas, estudiar continuidad y/o derivabilidad de una función se basan en el cálculo de límites y por descontado, aquellos en los que directamente la orden es calcular el límite.

Los ejercicios en los que hay que estudiar y representar una función o que son problemas de optimización se basan en el uso de derivadas.

Los ejercicios de cálculo de áreas o de integrales definidas recurren a la regla de Barrow para su resolución.

La gran mayoría de los ejercicios propuestos corresponden a un nivel de reproducción del conocimiento adquirido. Se trata de la ejecución de un proble- 
ma rutinario mediante la aplicación de destrezas técnicas y de algoritmos habituales, pero dado que son ejercicios que reproducen una situación similar a la referente en su etapa de aprendizaje, pero no es una mera rutina; pues, para su resolución, el alumno tiene que pensar en el tratamiento matemático necesario (CPRn1), razonar matemáticamente de manera simple (CAn1), estructurar la situación que se debe modelizar (CMn1) y desarrollar procedimientos ya practicados, pero no rutinarios (CRPn1) se vinculan a un nivel de conexión y en muy pocos ejercicios aparece el nivel de reflexión.

Aunque los ejercicios no pidan transformaciones en otros sistemas de representación diferente al que utilizan los enunciados, el alumno debe hacer traducciones, especialmente al sistema gráfico, representando la función correspondiente. Así el alumno tiene que interpretar formas de representación (CRn1), seleccionar y cambiar entre las diferentes formas de representación (CRn2), e interpretar el lenguaje formal y simbólico (CLSOn1).

Una vez que ha pasado esta primera etapa en la que reconoce los datos del ejercicio y pasa a la fase de resolución, el alumno comprende que tiene que emplear métodos matemáticos intermedios (CPRn2), manejando afirmaciones sencillas y expresiones con símbolos y fórmulas no rutinarias (CLSOn2), en la práctica traduce el modelo a seguir, que es algo diferente de los estudiados (CMn2) eligiendo las estrategias apropiadas que conexionen áreas matemáticas (CRPn2) y aplicándolas (CRPn3). Así, utiliza conceptos matemáticos apropiados (CPRn3).

A lo largo del proceso de resolución y al término del mismo, el alumno debe comunicar los resultados obtenidos, y, en esta fase, tiene que: seguir el encadenamiento del argumento matemático particular (CAn2), hacer una evaluación del mismo (CAn3); saber expresarse sobre cuestiones matemáticas (CCn1); explicar los cálculos y sus propiedades (CCn2) e interpretar las relaciones implicadas (CCn3).

En el transcurso de la resolución el alumno, en muchas ocasiones, utiliza variables, realiza ecuaciones y cálculos mediante procedimientos familiares (CLSOn3), también maneja procedimientos y fórmulas, resuelve y calcula (RLSOn3).

El alumno evalúa el encadenamiento del argumento matemático (CAn3) y comunica los resultados (CMn3). 
El alumno tiene una función definida analíticamente, que es preciso interpretar, seleccionar y cambiar entre diferentes formas de representación (CRn1, CRn2), analítica y gráfica, diferenciando entre ambas formas de representación (CRn3), aún cuando en algunos ejercicios no se solicite expresamente la representación gráfica, la "visualización" de la misma, es una componente esencial en la resolución del ejercicio.

En repetidas ocasiones el alumno tiene que calcular una integral por partes. El E.I. ha considerado que es un ejercicio de reproducción del conocimiento adquirido, dado que es la ejecución de un problema rutinario mediante la aplicación de destrezas técnicas y de algoritmos habituales.

La misma reflexión es la que ha derivado en considerar los límites propuestos, en los que lo acostumbrado es utilizar la regla de L'Hôpital para su resolución, como ejercicios de reproducción.

\section{IV.2.ESTUDIO DE LOS PROBLEMAS DE ANÁLISIS MATEMÁTI- CO}

En este apartado se muestra una síntesis del análisis que se ha realizado sobre todos los problemas de A.M. que se han propuesto en la Universidad de Valladolid al amparo del currículo LOGSE. Como ya se ha mencionado se presenta una tabla para cada problema que contiene el enunciado, su análisis gramatical y las competencias que se detectan en su resolución.

\section{ANÁLISIS DEL PROBLEMA P1}

El problema de la ficha 1.1.1 es un ejercicio de optimización, que se corresponde con un nivel de conexión; reproduce una situación similar a la referente en su etapa de aprendizaje, pero no es una mera rutina, dado que el alumno tiene que pensar en el tratamiento matemático necesario (CPRn1), definir una función, obtener la función derivada e igualar a cero dicha derivada, razonar matemáticamente de manera simple (CAn1), estructurar la situación que se debe modelizar (CMn1), es decir, desarrolla procedimientos intuitivos ya practicados, pero no rutinarios (CRPn1).

Por otra parte, interpreta formas de representación (CRn1), selecciona y cambia entre las diferentes formas de representación (CRn2), sabe expresarse sobre cuestiones matemáticas (CCn1) e interpreta el lenguaje formal y simbólico 
básico, en situaciones menos conocidas (CLSOn1). Estas categorías están inertes en el primer nivel de análisis, ya que, en primer lugar, el alumno debe comprender el enunciado. Figura1.1.1.

FICHA 1.1.1.

ESTUDIO DEL ENUNCIADO DEL P1

P1.- Un segmento de longitud 5 apoya sus extremos en los semiejes positivos $O X$ y $O Y$, de manera que forma con éstos un triángulo rectángulo. Hallar las dimensiones del triángulo de área máxima así construido.

\begin{tabular}{|c|c|c|c|c|c|c|c|c|c|c|c|}
\hline CONVOCATORIA & \multicolumn{5}{|c|}{$\underline{\text { JUNIO }}$} & \multicolumn{6}{|c|}{ SEPTIEMBRE } \\
\hline AÑO & \begin{tabular}{|l|l|}
$\underline{95}$ & 96 \\
\end{tabular} & \begin{tabular}{l|l}
6 & 97 \\
\end{tabular} & \begin{tabular}{|l|l|}
98 & 99 \\
\end{tabular} & 00 & 01 & \begin{tabular}{l|l}
02 & 03 \\
\end{tabular} & 04 & 05 & \begin{tabular}{l|l|}
06 & 07 \\
\end{tabular} & 08 & 09 \\
\hline OPCIÓN & \multicolumn{5}{|c|}{ BLOQUE I } & \multicolumn{6}{|c|}{ BLOQUE II } \\
\hline TIPO DE PROBLEMA & \multicolumn{5}{|c|}{ TEÓRICO } & \multicolumn{6}{|c|}{ PRÁCTICO } \\
\hline \multirow{3}{*}{ APARTADOS } & \multirow{3}{*}{ SI } & \multirow{2}{*}{\multicolumn{3}{|c|}{ Forma explícita }} & & & & \multirow{3}{*}{\begin{tabular}{|l}
5 \\
\end{tabular}} & \multirow[b]{2}{*}{6} & \multirow{3}{*}{\multicolumn{2}{|c|}{ No }} \\
\hline & & & & & 2 & 3 & 4 & & & & \\
\hline & & \multicolumn{3}{|c|}{ Forma implícita } & & & & & & & \\
\hline VERBO UTILIZADO & \multicolumn{11}{|c|}{ HALLAR } \\
\hline TIEMPO VERBAL & \multicolumn{11}{|c|}{ INFINITIVO } \\
\hline ESCRITURA & \multicolumn{7}{|c|}{ MULTIPLICATIVA } & \multicolumn{4}{|c|}{ FUNCIONAL } \\
\hline \multirow{3}{*}{$\begin{array}{l}\text { FALLOS DEL ENUN- } \\
\text { CIADO }\end{array}$} & \multicolumn{7}{|c|}{ PUNTUACIÓN } & & & & \\
\hline & \multicolumn{7}{|c|}{ ERROR MORFOLÓGICO } & & & & \\
\hline & \multicolumn{7}{|c|}{ AUSENCIA DE ESPECIFICACIONES } & & & & \\
\hline \multicolumn{12}{|c|}{ ENUNCIADO ALTERNATIVO } \\
\hline \multicolumn{12}{|c|}{$\begin{array}{l}\text { P1.- Un segmento de longitud } 5 \text { apoya sus extremos en los semiejes positivos } O X \text { y } \\
O Y \text {, de manera que forma con éstos un triángulo rectángulo. Halla las dimensiones } \\
\text { del triángulo de área máxima así construido. }\end{array}$} \\
\hline
\end{tabular}

Comprende que tiene que emplear métodos matemáticos intermedios (CPRn2), manejando afirmaciones sencillas y expresiones con símbolos y fórmulas no rutinarias (CLSOn2).

Como el segmento tiene longitud 5 , llamando $(a, 0)$ y $(0, b)$ a los puntos de corte de dicho segmento con los ejes $O X$ y $O Y$, tiene la condición:

$$
5^{2}=a^{2}+b^{2}
$$

El alumno explica los cálculos y sus propiedades (CCn2) e interpreta las relaciones implicadas (CCn3). Asimismo, sigue el encadenamiento del argumento matemático particular (CAn2) haciendo una evaluación del mismo (CAn3). 
Plantea la fórmula de la función área del triángulo obtenido:

$$
A=\frac{a \cdot b}{2},
$$

Interpretando, así, las relaciones implicadas (cCn3).

Despejando una variable en la condición:

$$
a^{2}=5^{2}-b^{2}=25-b^{2}
$$

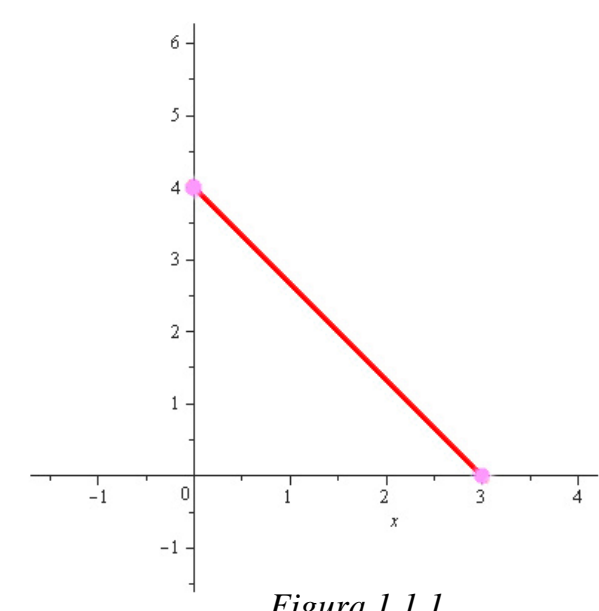

Figura 1.1.1.

Explica los cálculos y sus propiedades (CCn2) y,

como el enunciado dice: "Apoya sus extremos en los semiejes positivos":

$$
a=+\sqrt{25-b^{2}}
$$

Maneja afirmaciones sencillas en expresiones y fórmulas no rutinarias (CLSOn2).

Sustituyendo en la función Área

$$
A(b)=\frac{1}{2} \cdot \sqrt{25-b^{2}} \cdot b=\frac{1}{2} \cdot \sqrt{25 b^{2}-b^{4}}
$$

Con lo que evalúa el encadenamiento de argumentos matemáticos particulares (CAn3) e interpreta las relaciones implicadas (CCn3); traduce, en la práctica, el modelo a seguir, que es algo diferente de los estudiados (CMn2) eligiendo las estrategias apropiadas que conexionen áreas matemáticas (CRPn2) y aplicándolas (CRPn3).

Calcula la función derivada:

$$
A^{\prime}=\frac{1}{2} \cdot \frac{25 b-2 b^{3}}{\sqrt{25 b^{2}-b^{4}}}
$$

Iguala a cero la función derivada:

$$
A^{\prime}=\frac{1}{2} \cdot \frac{25 b-2 b^{3}}{\sqrt{25 b^{2}-b^{4}}}=0
$$

Aplicando, de este modo, conceptos matemáticos apropiados (CPRn3).

Resolviendo la ecuación planteada: 


$$
25 b-2 b^{3}=0 \Rightarrow b=0 \quad ; b_{1}=-\frac{5 \sqrt{2}}{2}, b_{2}=+\frac{5 \sqrt{2}}{2}
$$

Con lo que, el alumno maneja procedimientos y fórmulas, resolviendo y calculando (RLSOn3), -está en el nivel de reproducción-, utiliza variables y realiza ecuaciones y cálculos mediante procedimientos familiares (CLSOn3).

Teóricamente, el nivel de reproducción tiene menos dificultad que el de conexión; sin embargo el hecho de que para llegar a él el alumno haya tenido que superar los segundos niveles de conexión se puede interpretar como un nivel superior, hecho que se repetirá en muchos enunciados y nos referiremos a ello indicando que es un nivel inferior incluido en otros superiores.

Dado que el enunciado afirma que el segmento se apoya en el semieje positivo,

$$
b=+\frac{5 \sqrt{2}}{2}
$$

Con lo que, el alumno, evalúa el encadenamiento del argumento matemático (CAn3), interpreta las relaciones implicadas (CCn3) y comunica los resultados (CMn3), y por tanto

$$
a=+\frac{5 \sqrt{2}}{2}
$$

Finalmente, es preciso comprobar que la solución obtenida satisface las condi-

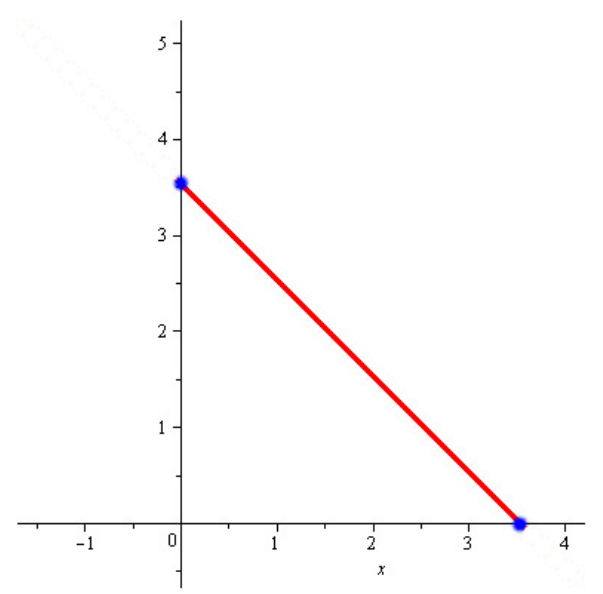

Figura 1.1.2. ciones del enunciado, es decir, que el área es máxima; -evalúa el encadenamiento del argumento matemático (CAn3)-, calculando la derivada segunda y comprobando que para los valores obtenidos dicha derivada es menor que cero.

Se constata que el triángulo rectángulo de área máxima es isósceles y tiene catetos de longitud:

$$
\begin{aligned}
& a=b=+\frac{5 \sqrt{2}}{2} u \\
A^{\prime \prime}=\frac{b^{4}\left(2 b^{2}-75\right)}{2\left(25 b^{2}-b^{4}\right)^{3 / 2}} ; & A^{\prime \prime}\left(\frac{5 \sqrt{2}}{2}\right)<0
\end{aligned}
$$




$$
\text { Y, por tanto, es un máximo. }
$$

El alumno explica los cálculos y sus propiedades (CCn2) e interpreta las relaciones implicadas (CCn3). Figura 1.1.2.

\begin{tabular}{|l|c|c|c|c|c|c|c|c|}
\hline \multicolumn{7}{|l}{ FICHA 1.1.2. COMPETENCIAS IMPLÍCITAS EN LA RESOLUCIÓN DEL P1 } \\
\hline & Nivel 1 & Nivel 2 & Nivel 3 & Nivel 1 & Nivel 2 & Nivel 3 & Nivel 1 & Nivel 2 \\
\hline PR & & & & $*$ & $*$ & $*$ & & \\
\hline A & & & & $*$ & $*$ & $*$ & & \\
\hline C & & & & $*$ & $*$ & $*$ & & \\
\hline M & & & & $*$ & $*$ & $*$ & & \\
\hline RP & & & & $*$ & $*$ & $*$ & & \\
\hline R & & & & $*$ & $*$ & & & \\
\hline LSO & & & $*$ & $*$ & $*$ & $*$ & & \\
\hline & Reproducción & & Conexión & & Reflexión \\
\hline
\end{tabular}

\section{ANÁLISIS DEL PROBLEMA P3}

El problema que aparece en la tabla 1.3.1 se encuadra en los niveles de conexión y reflexión; es un problema que reproduce situaciones similares a las ya practicadas, pero que no son de mera rutina.

Al resolver el ejercicio, el alumno piensa en el tratamiento matemático necesario (CPRn1), comprende que tiene que emplear conceptos matemáticos intermedios (CPRn2) y aplica conceptos matemáticos apropiados (CPRn3).

Asimismo, razona matemáticamente de manera simple (CAn1), siguiendo y evaluando el encadenamiento de argumentos matemáticos particulares (CAn2, CAn3).

a) Para estudiar la derivabilidad en $x=0$, hay que calcular:

$$
\lim _{h \rightarrow 0} \frac{f(0+h)-f(0)}{h}
$$

Estructura la situación que debe modelizar (CMn1), traduce en la práctica el modelo a seguir, que es algo diferente de los estudiados (CMn2). 
FICHA 1.3.1.

ESTUDIO DEL ENUNCIADO DEL P3

P3.- Determinar, si existen, todos los valores de $p$ y $k(p>0, k$ entero positivo) que hacen derivable a la función

$$
f(x)=\left\{\begin{array}{c}
0 \quad x \leq 0 \\
x^{p} \quad 0<x<1 \\
k x^{2}-k x+1 \quad x \geq 1
\end{array}\right.
$$

En a) $x=0$, b) $x=1$, c) todos los puntos.

\begin{tabular}{|c|c|c|c|c|c|c|c|c|c|c|c|c|c|c|}
\hline CONVOCATORIA & \multicolumn{7}{|c|}{ JUNIO } & \multicolumn{7}{|c|}{ SEPTIEMBRE } \\
\hline AÑO & $\underline{95}$ & 96 & 97 & 98 & 99 & 00 & 01 & $02 \quad 03$ & 04 & 05 & 06 & 07 & 08 & 09 \\
\hline OPCIÓN & \multicolumn{7}{|c|}{ BLOQUE I } & \multicolumn{7}{|c|}{ BLOQUE II } \\
\hline TIPO DE PROBLEMA & \multicolumn{7}{|c|}{ TEÓRICO } & \multicolumn{7}{|c|}{ PRÁCTICO } \\
\hline \multirow{3}{*}{ APARTADOS } & \multirow{3}{*}{\multicolumn{2}{|c|}{$\underline{\text { SI }}$}} & Form & exp & lícita & & & 3 & & & & & \multirow{3}{*}{\multicolumn{2}{|c|}{ NO }} \\
\hline & & & & & & & 2 & 3 & 4 & 5 & & 6 & & \\
\hline & & & \multicolumn{4}{|c|}{ Forma implícita } & & & & & & & & \\
\hline VERBO UTILIZADO & \multicolumn{14}{|c|}{ DETERMINAR } \\
\hline TIEMPO VERBAL & \multicolumn{14}{|c|}{ INFINITIVO } \\
\hline ESCRITURA & \multicolumn{9}{|c|}{ ALGEBRAICA } & \multicolumn{5}{|c|}{ FUNCIONAL } \\
\hline \multirow{3}{*}{$\begin{array}{l}\text { FALLOS DEL ENUN- } \\
\text { CIADO }\end{array}$} & \multicolumn{9}{|c|}{ PUNTUACIÓN } & & & & & \\
\hline & \multicolumn{9}{|c|}{ ERROR SINTÁCTICO } & & & & & \\
\hline & \multicolumn{9}{|c|}{ AUSENCIA DE ESPECIFICACIONES } & & & & & \\
\hline \multicolumn{15}{|c|}{ ENUNCIADO ALTERNATIVO } \\
\hline
\end{tabular}

P3.- Determina todos los valores de $p$ y $k(p>0, k$ entero positivo) que hacen derivable a la función:

$$
f(x)=\left\{\begin{array}{cc}
0 & x \leq 0 \\
x^{p} & 0<x<1 \\
k x^{2}-k & x+1 \quad x \geq 1
\end{array}\right. \text {, si existen: }
$$

a) En $x=0$, b) En $x=1$, c) En todos los puntos.

\section{NIVELES DE COMPETENCIAS IMPLÍCITAS}

$$
\begin{aligned}
& \lim _{h \rightarrow 0^{-}} \frac{f(0+h)-f(0)}{h}=\lim _{h \rightarrow 0^{-}} \frac{0}{h}=0 \\
& \lim _{h \rightarrow 0^{+}} \frac{f(0+h)-f(0)}{h}=\lim _{h \rightarrow 0^{+}} \frac{h^{p}-0}{h}
\end{aligned}
$$

Aparece aquí el nivel de reflexión por parte del estudiante para aplicar estrategias en la resolución de un problema que contiene elementos inusuales, dado 
que el enunciado da como condición $p>0$, sin especificar si $p$ es un número natural, con lo que aplica estrategias no rutinarias (RfPRn2), razona de manera sencilla, distinguiendo formas más amplias de argumentación (RfAn1) y sabe explicar cuestiones matemáticas, cálculos y resultados (RfCn1).

Si $p<1$, se verifica que $\lim _{h \rightarrow 0^{+}} \frac{f(0+h)-f(0)}{h}=\lim _{h \rightarrow 0^{+}} \frac{h^{p}-0}{h}=+\infty$

Si $p=1$, entonces $\lim _{h \rightarrow 0^{+}} \frac{f(0+h)-f(0)}{h}=\lim _{h \rightarrow 0^{+}} \frac{h^{p}-0}{h}=\lim _{h \rightarrow 0^{+}} \frac{h}{h}=1$

$Y$, en esos casos, la función no sería derivable en $x=0$.

Luego, para que $f(x)$ sea derivable en $x=0$, se tiene que cumplir que $p>1$, para cualquier valor de $k$.

El alumno sabe expresarse sobre cuestiones matemáticas (CCn1), explica los cálculos y sus propiedades (CCn2) e interpreta las relaciones implicadas (CCn3). Asimismo, sigue el encadenamiento del argumento matemático particular (CAn2) haciendo una evaluación del mismo (CAn3).

b) Derivabilidad en $x=1$

El alumno puede pensar que $p \in N$, y en ese caso:

$$
\lim _{h \rightarrow 0^{-}} \frac{f(1+h)-f(1)}{h}=\lim _{h \rightarrow 0^{-}} \frac{(1+h)^{p}-1}{h}=\lim _{h \rightarrow 0^{-}} \frac{p h+\cdots+h^{p}}{h}=p
$$

(Si $p$ es un número natural, utilizaría el desarrollo de un Binomio de Newton). Sin embargo, el enunciado no indica que $p \in N$ y, por tanto, el alumno debería haber utilizado la regla de L'Hôpital:

$$
\lim _{h \rightarrow 0^{-}} \frac{f(1+h)-f(1)}{h}=\lim _{h \rightarrow 0^{-}} \frac{(1+h)^{p}-1}{h}=\lim _{h \rightarrow 0^{-}} \frac{p(1+h)^{p-1}}{1}=p
$$

Elabora encadenamientos de argumentos de diferentes tipos (RfAn2), explica asuntos que implican relaciones complejas (RfCn2) y sabe tratar con expresiones complejas y con lenguaje formal inusual (RfLSOn2).

Asimismo, interpreta el lenguaje formal y simbólico básico en situaciones menos conocidas (CLSOn1), maneja expresiones con símbolos y fórmulas no ruti- 
narias (CLSOn2), realiza cálculos mediante procedimientos familiares (CLSOn3), evalúa el encadenamiento de argumentos matemáticos particulares (CAn3) e interpreta las relaciones implicadas (CCn3).

$$
\lim _{h \rightarrow 0^{+}} \frac{f(1+h)-f(1)}{h}=\lim _{h \rightarrow 0^{+}} \frac{k(1+h)^{2}-k(1+h)+1-1}{h}=k
$$

Para que $f(x)$ sea derivable en $x=1$, se tiene que cumplir que $p=k$, es decir, $p$ entero positivo (natural) e igual a $k$, dado que el enunciado impone la condición de que $k$ sea un entero positivo.

c) Para que $f(x)$ sea derivable en todos los puntos deben darse las dos condiciones anteriores, y en consecuencia:

$$
p=k \text { y } p>1 \Rightarrow \forall p=k \in N-\{1\}
$$

Expone problemas más allá de la reproducción de los ya practicados (RfRPn1) y explica resultados que implican relaciones complejas (RfCn2), interpreta las relaciones implicadas (CCn3) y describe los resultados obtenidos (RCn3).

\begin{tabular}{|l|c|c|c|c|c|c|c|c|}
\hline \multicolumn{7}{|l|}{ FICHA 1.3.2. COMPETENCIAS IMPLÍCITAS EN LA RESOLUCIÓN DEL P3 } \\
\hline & Nivel 1 & Nivel 2 & Nivel 3 & Nivel 1 & Nivel 2 & Nivel 3 & Nivel 1 & Nivel 2 \\
\hline PR & & & & $*$ & $*$ & $*$ & & $*$ \\
\hline A & & & & $*$ & $*$ & $*$ & $*$ & $*$ \\
\hline C & & & $*$ & $*$ & $*$ & $*$ & $*$ & $*$ \\
\hline M & & & & $*$ & $*$ & & & \\
\hline RP & & & & $*$ & & & $*$ & \\
\hline R & & & & & & & & \\
\hline LSO & & & & $*$ & $*$ & $*$ & & $*$ \\
\hline
\end{tabular}

\section{ANÁLISIS DEL PROBLEMA P5}

El problema que se presenta en la ficha 1.5 .1 se encuadra en el nivel de conexión dado que reproduce situaciones similares a las estudiadas, pero no son de mera rutina.

El alumno tiene que pensar en el tratamiento matemático necesario (CPRn1). 


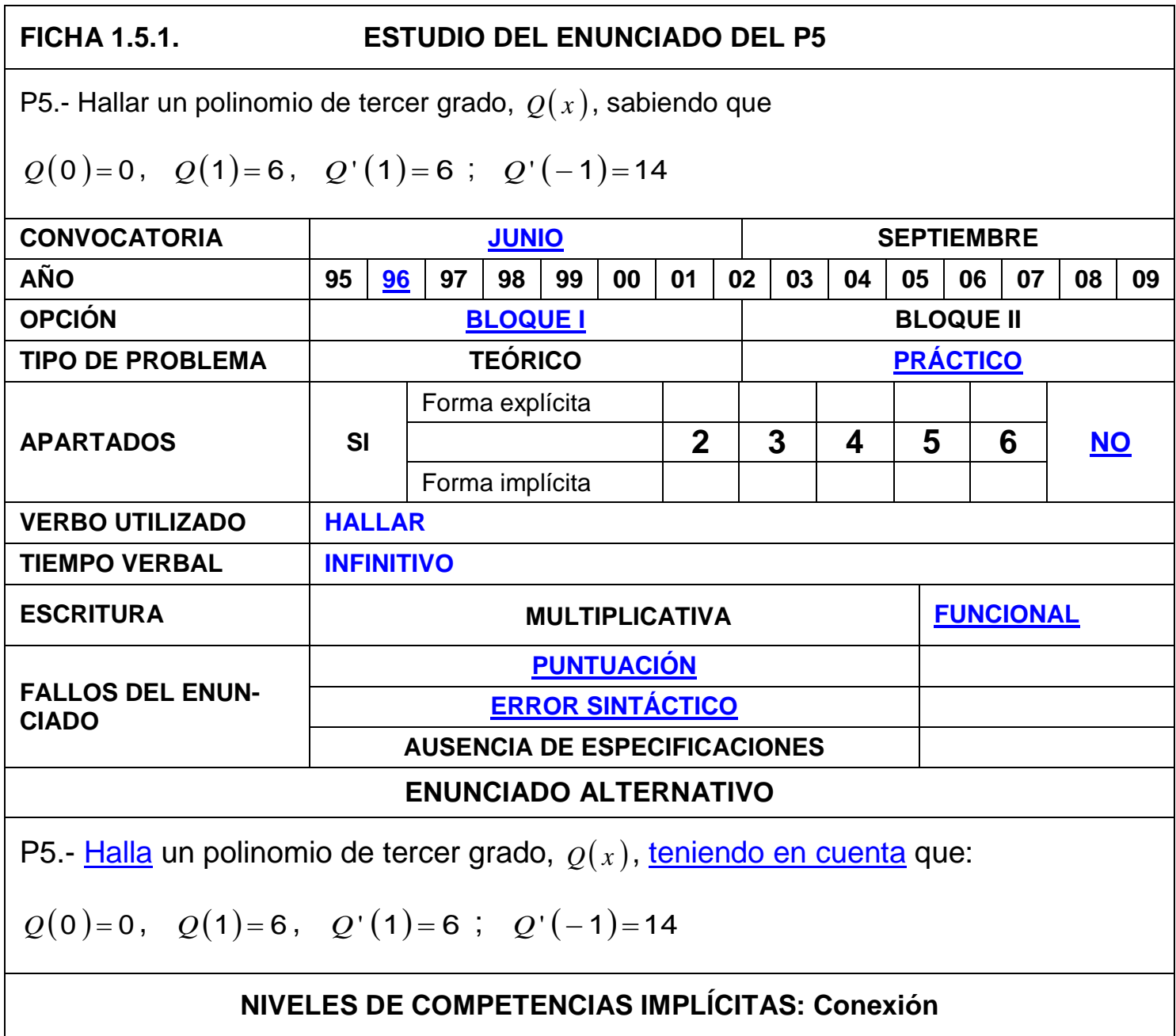

Expresión general de un polinomio de tercer grado: $Q(x)=a x^{3}+b x^{2}+c x+d$.

Calcula la función derivada: $Q^{\prime}(x)=3 a x^{2}+2 b x+c$

El alumno comprende que tiene que emplear conceptos matemáticos intermedios (CPRn2) y aplica conceptos matemáticos apropiados (CPRn3) al sustituir los valores que proporciona el enunciado, tanto en la función como en la función derivada, y, por tanto, debe calcular esta función.

$$
Q^{\prime}(x)=3 a x^{2}+2 b x+c
$$

Razona matemáticamente de manera simple (CAn1) y sigue el encadenamiento de argumentos matemáticos particulares (CAn2).

$$
\begin{aligned}
& Q(0)=d=0 \Rightarrow d=0 \\
& Q(1) \Rightarrow a+b+c=6
\end{aligned}
$$




$$
\begin{aligned}
& Q^{\prime}(1)=6 \Rightarrow 3 a+2 b+c=6 \\
& Q^{\prime}(-1)=14 \Rightarrow 3 a-2 b+c=14
\end{aligned}
$$

El alumno estructura la situación que debe modelizar (CMn1), traduce en la práctica el modelo a seguir, que es algo diferente de los estudiados (CMn2) e interpreta las relaciones implicadas (CCn3), sabe comunicar los resultados (CMn3) al tiempo que evalúa el encadenamiento de argumentos matemáticos particulares (CAn3).

Hay que resolver un sistema de ecuaciones.

El alumno sabe expresarse sobre cuestiones matemáticas (CCn1), explica los cálculos y sus propiedades $(\mathrm{CCn} 2)$ e interpreta las relaciones implicadas (CCn3), con lo que desarrolla procedimientos intuitivos ya practicados, pero no rutinarios (CRPn1), elige estrategias apropiadas más independientes que conexionen áreas matemáticas (CRPn2) y las aplica (CRPn3).

Asimismo, interpreta el lenguaje formal y simbólico básico en situaciones menos conocidas (CLSOn1), como son el cálculo de la función derivada y la resolución del sistema de ecuaciones, maneja afirmaciones sencillas y expresiones con símbolos y fórmulas no rutinarias (CLSOn2) y utiliza variables y realiza ecuaciones y cálculos mediante procedimientos familiares (CLSOn3).

Resolviendo el sistema:

$$
\left\{\begin{array}{c}
d=0 \\
a+b+c=6 \\
3 a+2 b+c=6 \\
3 a-2 b+c=14
\end{array}\right.
$$

Obtiene las soluciones:

$$
a=1 \quad, \quad b=-2 \quad c=7 \quad d=0
$$

$\mathrm{Y}$, por tanto, el polinomio pedido es:

$$
Q(x)=x^{3}-2 x^{2}+7 x
$$

El alumno, al resolver el sistema, maneja procedimientos y fórmulas, resolviendo y calculando (RLSOn3).

Para concluir, describe los resultados obtenidos (RCn3) y comunica de manera elemental los resultados del modelo (RMn3). 


\begin{tabular}{|l|c|c|c|c|c|c|c|c|}
\hline \multicolumn{7}{|l|}{ FICHA 1.5.2. COMPETENCIAS IMPLÍCITAS EN LA RESOLUCIÓN DEL P5 } \\
\hline & Nivel 1 & Nivel 2 & Nivel 3 & Nivel 1 & Nivel 2 & Nivel 3 & Nivel 1 & Nivel 2 \\
\hline PR & & & & $*$ & $*$ & $*$ & & \\
\hline A & & & & $*$ & $*$ & $*$ & & \\
\hline C & & & $*$ & $*$ & $*$ & $*$ & & \\
\hline M & & & $*$ & $*$ & $*$ & $*$ & & \\
\hline RP & & & & $*$ & $*$ & $*$ & & \\
\hline R & & & & & & & & \\
\hline LSO & & & $*$ & $*$ & $*$ & $*$ & & \\
\hline & Reproducción & & Conexión & & Reflexión \\
\hline
\end{tabular}

\section{ANÁLISIS DEL PROBLEMA P10}

El problema que se presenta en la ficha 1.10.1 requiere pensar en conceptos teóricos, que aunque no entrañan demasiada dificultad, no son de mera rutina, por lo que se considera un ejercicio correspondiente al nivel de reflexión por parte del estudiante para planificar y aplicar estrategias, en la resolución de un problema que contenga elementos inusuales.

El alumno razona de forma sencilla, distinguiendo formas más amplias de argumentación (RfAn1) y reflexiona llevando a cabo una comunicación sobre la construcción del modelo (RfMn2).

Para calcular máximos y mínimos relativos hay que efectuar la primera derivada

$$
f^{\prime}(x)=3 x^{2}+2 b x+c
$$

Resolviendo la ecuación $f^{\prime}(x)=3 x^{2}+2 b x+c=0$ obtenemos las soluciones:

$$
x_{1}=\frac{-b+\sqrt{b^{2}-3 c}}{2} \text { y } x_{2}=\frac{-b-\sqrt{b^{2}-3 c}}{2}
$$

Para que la ecuación no tenga soluciones reales, y por consiguiente, la función carezca de extremos relativos, se tiene que cumplir:

$$
b^{2}-3 c<0 \Rightarrow b^{2}<3 c \quad \forall d
$$

El alumno aplica estrategias no rutinarias (RfPRn2) y sabe explicar cuestiones matemáticas, cálculos y resultados (RfCn1). 
FICHA 1.10.1.

ESTUDIO DEL ENUNCIADO DEL P10

P10.- Dada la función $f(x)=x^{3}+b x^{2}+c x+d$. Se pide:

a) Poner un ejemplo de $b, c, y d$ de forma que la función carezca de máximos y mínimos relativos.

b) Demostrar que si $c=0$ y $b<0$, entonces la función presenta un máximo y un mínimo relativo.

\begin{tabular}{|c|c|c|c|c|c|c|c|c|c|c|c|c|c|}
\hline CONVOCATORIA & \multicolumn{6}{|c|}{ JUNIO } & \multicolumn{7}{|c|}{ SEPTIEMBRE } \\
\hline AÑO & \begin{tabular}{l|l}
95 & 96
\end{tabular} & 97 & 98 & 99 & 00 & 01 & \begin{tabular}{l|l}
02 & 03
\end{tabular} & 04 & 05 & 06 & 07 & 08 & 09 \\
\hline OPCIÓN & \multicolumn{6}{|c|}{ A } & \multicolumn{7}{|c|}{ B1 } \\
\hline TIPO DE PROBLEMA & \multicolumn{6}{|c|}{ TEÓRICO } & \multicolumn{7}{|c|}{ PRÁCTICO } \\
\hline \multirow{3}{*}{ APARTADOS } & \multirow{3}{*}{$\underline{\text { SI }}$} & \multicolumn{4}{|c|}{ Forma explícita } & 2 & & & \multirow{3}{*}{5} & \multirow{2}{*}{\multicolumn{2}{|c|}{6}} & \multirow{3}{*}{\multicolumn{2}{|c|}{ NO }} \\
\hline & & & & & & 2 & 3 & 4 & & & & & \\
\hline & & \multicolumn{4}{|c|}{ Forma implícita } & & & & & & & & \\
\hline VERBO UTILIZADO & \multicolumn{13}{|c|}{ PONER I DEMOSTRAR } \\
\hline TIEMPO VERBAL & \multicolumn{13}{|c|}{ IMPERSONAL REFLEJO / INFINITIVO } \\
\hline ESCRITURA & \multicolumn{8}{|c|}{ ALGEBRAICA } & \multicolumn{5}{|c|}{ FUNCIONAL } \\
\hline \multirow{3}{*}{$\begin{array}{l}\text { FALLOS DEL ENUN- } \\
\text { CIADO }\end{array}$} & \multicolumn{8}{|c|}{ PUNTUACIÓN } & & & & & \\
\hline & \multicolumn{8}{|c|}{ ERROR MORFOLÓGICO } & & & & & \\
\hline & \multicolumn{8}{|c|}{ AUSENCIA DE ESPECIFICACIONES } & & & & & \\
\hline \multicolumn{14}{|c|}{ ENUNCIADO ALTERNATIVO } \\
\hline
\end{tabular}

P10.- Dada la función $f(x)=x^{3}+b x^{2}+c x+d$, se pide:

a) Escribe un ejemplo de $b, c, y d$ de forma que la función carezca de máximos y mínimos relativos.

b) Demuestra que si $c=0$ y $b<0$, entonces la función presenta un máximo y un mínimo relativo.

NIVELES DE COMPETENCIAS IMPLÍCITAS: Reproducción, conexión y reflexión

La resolución de la ecuación corresponde al nivel de reproducción, interpretando el lenguaje formal y simbólico rutinario (RLSOn2) y manejando procedimientos y fórmulas, resolviendo y calculando (RLSOn3).

La discusión del problema requiere los niveles de competencia descritos. Sin embargo, los alumnos pueden dar valores a los parámetros y comprobar que se verifican las exigencias del enunciado. (Por ejemplo, para $b=c=d=0$ se obtiene la función $f(x)=x^{3}$ que es siempre creciente). En estos casos se podría interpretar como un problema en el que los niveles de competencia son reproducciones. 
Con este razonamiento identifica el problema (RAn1), reconoce representaciones de los datos del ejercicio (RPRn1), comprende la expresión escrita (RCn1), identifica que es un modelo similar a otros vistos con anterioridad (RMn1) y le reconoce como problema ya practicado (RRPn1). A continuación, plantea los algoritmos correspondientes (RPRn2).

Expone el proceso de cálculo (RAn2) realizando explicaciones sencillas (RCn2), asocia con fórmulas establecidas y realiza los cálculos (RPRn3), con lo que resuelve problemas rutinarios estandarizados (RRPn3).

$$
f(x)=x^{3} \Rightarrow f^{\prime}(x)=3 x^{2}
$$

Resolviendo la ecuación $f^{\prime}(x)=3 x^{2}=0$ obtiene el valor $x=0$.

Sustituyendo en la derivada segunda, para comprobar máximo o mínimo, se tiene: $f^{\prime \prime}(0)=0$, con lo que $x=0$ no es máximo ni mínimo.

$$
f^{\prime \prime \prime}(x)=6 \neq 0 \text {, luego } x=0 \text { es un punto de inflexión. }
$$

El alumno justifica las fórmulas utilizadas y los resultados (RAn3), describe los resultados obtenidos (RCn3) comunicando de manera elemental los resultados del modelo (RMn3) y maneja procedimientos resolviendo y calculando (RLSOn3).

El apartado b) del problema 1.10.1 se encuadra en el nivel de conexión, reproduce una situación similar a las estudiadas, pero que no es una mera rutina, dado que en la resolución del problema, el alumno debe pensar en el tratamiento matemático necesario (CPRn1), comprender que tiene que emplear conceptos matemáticos intermedios (CPRn2) y aplicar esos conceptos matemáticos apropiados (CPRn3).

Con las condiciones del apartado b), tenemos: $c=0$ y $b<0$,

Entonces, como la derivada es $f^{\prime}(x)=3 x^{2}+2 b x$, Igualando a cero, se tiene una ecuación de segundo grado:

$$
3 x^{2}+2 b x=0
$$

que tiene dos soluciones:

$$
x_{1}=0 \text { y } x_{2}=-\frac{2 b}{3}
$$


El alumno utiliza variables y realiza ecuaciones y cálculos mediante procedimientos familiares (CLSOn3); al tiempo que maneja procedimientos y fórmulas, resolviendo y calculando (RLSOn3).

Calcula la segunda derivada para comprobar si esos valores son máximo o mínimo relativos.

$$
f^{\prime \prime}(x)=6 x+2 b
$$

Si $b<0 \Rightarrow f^{\prime \prime}\left(-\frac{2 b}{3}\right)>0$ y, entonces:

$$
\begin{gathered}
x=-\frac{2 b}{3} \text { es un mínimo relativo. } \\
f^{\prime \prime}(0)=2 b<0 \text { pues, por la hipótesis, } b<0 .
\end{gathered}
$$

Y, por tanto:

$$
x=0 \text { es un máximo relativo. }
$$

El alumno desarrolla procedimientos intuitivos ya practicados, pero no rutinarios (CRPn1), aplica conceptos matemáticos apropiados (CPRn3), evalúa el encadenamiento de argumentos matemáticos particulares (CAn3), explica los cálculos y sus propiedades (CCn2) e interpreta las relaciones implicadas (CCn3).

Finalmente, describe los resultados obtenidos (RCn3) y comunica de manera elemental los resultados del modelo (CMn3).

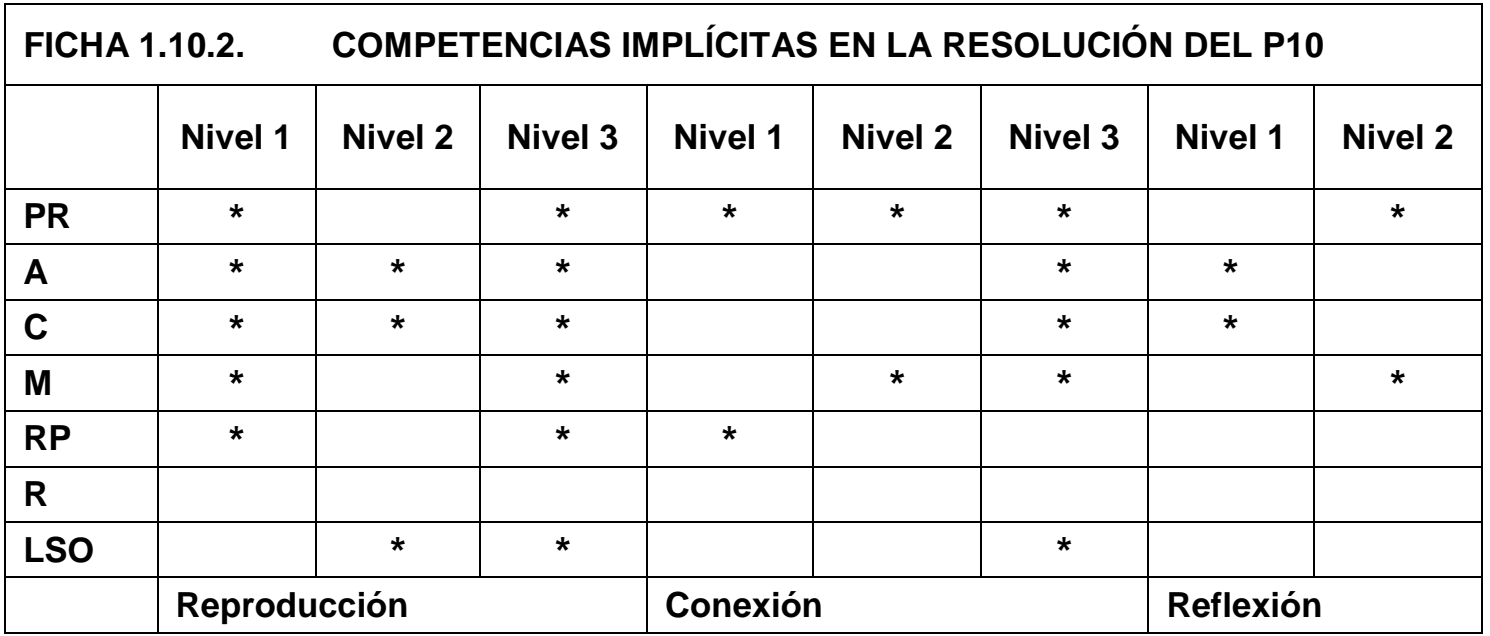




\section{ANÁLISIS DEL PROBLEMA P13}

\section{FICHA 1.13.- \\ ESTUDIO DEL ENUNCIADO DEL P13}

P13.- a) Concepto de máximo y mínimo relativo.

b) El coste de un marco para una ventana se estima en 1.250 ptas. por cada metro de altura y 880 ptas. por cada metro de anchura. La ventana tendrá una superficie de un metro cuadrado. ¿Qué dimensiones debe tener la ventana para que el marco resulte lo más económico posible?

\begin{tabular}{|c|c|c|c|c|c|c|c|c|c|c|c|}
\hline CONVOCATORIA & \multicolumn{5}{|c|}{ JUNIO } & \multicolumn{6}{|c|}{ SEPTIEMBRE } \\
\hline AÑO & \begin{tabular}{l|l}
95 & 96
\end{tabular} & 97 & \begin{tabular}{l|l}
98 & 99
\end{tabular} & 00 & 01 & \begin{tabular}{l|l|}
02 & 03
\end{tabular} & 04 & \begin{tabular}{l|l}
05 & 0 \\
\end{tabular} & \begin{tabular}{l|l|}
06 & 07
\end{tabular} & 08 & 09 \\
\hline OPCIÓN & \multicolumn{5}{|c|}{ A } & \multicolumn{6}{|c|}{$\underline{B}$} \\
\hline TIPO DE PROBLEMA & \multicolumn{5}{|c|}{ TEÓRICO } & \multicolumn{6}{|c|}{ PRÁCTICO } \\
\hline \multirow{3}{*}{ APARTADOS } & \multirow{3}{*}{ SI } & Form & explícita & & 2 & & & & \multirow{3}{*}{6} & \multirow{3}{*}{\multicolumn{2}{|c|}{ NO }} \\
\hline & & & & & 2 & 3 & 4 & 5 & & & \\
\hline & & \multicolumn{3}{|c|}{ Forma implícita } & & & & & & & \\
\hline VERBO UTILIZADO & \multicolumn{11}{|c|}{ DEBER TENER } \\
\hline TIEMPO VERBAL & \multicolumn{11}{|c|}{ PERÍFRASES DE INFINITIVO } \\
\hline ESCRITURA & \multicolumn{7}{|c|}{ MULTIPLICATIVA } & \multicolumn{4}{|c|}{ FUNCIONAL } \\
\hline \multirow{3}{*}{$\begin{array}{l}\text { FALLOS DEL ENUN- } \\
\text { CIADO }\end{array}$} & \multicolumn{7}{|c|}{ PUNTUACIÓN } & \\
\hline & \multicolumn{7}{|c|}{ ORDEN DE LAS PALABRAS EN LA ORACIÓN } & & & & \\
\hline & \multicolumn{7}{|c|}{ ERROR MORFOSINTÁCTICO } & & & & \\
\hline
\end{tabular}

P13.- a) Escribe el concepto de máximo y mínimo relativo.

b) La superficie de una ventana es de $1 \mathrm{~m}^{2}$. Calcula qué dimensiones debe tener para que el marco resulte lo más económico posible; sabiendo que el metro lineal de los listones verticales es de 1.250 ptas y el de los horizontales 880 ptas.

\section{NIVELES DE COMPETENCIAS IMPLÍCITAS Conexión}

El apartado a) del problema que aparece en la ficha 1.13.1 corresponde al nivel de reproducción, pues, para definir los conceptos de máximo y mínimo relativo, el alumno interpreta representaciones estándar de objetos matemáticos (RRn2) e interpreta el lenguaje formal y simbólico rutinario (RLSOn2).

El apartado b) es un ejercicio de optimización, que se encuadra principalmente en un nivel de conexión pues reproduce una situación similar a la referente en su etapa de aprendizaje, pero no es una mera rutina.

El alumno tiene que pensar en el tratamiento matemático necesario (CPRn1), razonar matemáticamente de manera simple (CAn1), estructurar la situación 
que se debe modelizar ( $\mathrm{CMn} 1)$, definir una función, -en este caso la función precio-, con la condición de que el área sea $1 \mathrm{~m}^{2}$.

Llamando $x$ a la base del rectángulo e $y$ a su altura, tenemos:

$$
A=x \cdot y=1
$$

Se tiene la condición del precio del marco según los distintos lados del rectángulo.

$$
2 \cdot(880 x+1250 y)=P(x, y)
$$

Despejando una variable en esta condición $x \cdot y=1$, se obtiene: $y=\frac{1}{x}$

Sustituyendo en la función:

$$
2 \cdot\left(880 x+1250 \cdot \frac{1}{x}\right)=P(x)
$$

A continuación es preciso obtener la función derivada e igualarla a cero; es decir, desarrolla procedimientos ya practicados, pero no rutinarios (CRPn1), interpreta formas de representación (CRn1), sabe expresarse sobre cuestiones matemáticas (CCn1) e interpreta el lenguaje formal y simbólico (CLSOn1).

Comprende que tiene que emplear métodos matemáticos intermedios (CPRn2),

$$
\begin{gathered}
2 \cdot\left(880-\frac{1250}{x^{2}}\right)=P^{\prime}(x) \\
P^{\prime}(x)=0 \Rightarrow\left(880-\frac{1250}{x^{2}}\right)=0
\end{gathered}
$$

Explica los cálculos y sus propiedades (CCn2) e interpreta las relaciones implicadas (CCn3). Asimismo, sigue el encadenamiento del argumento matemático particular (CAn2) haciendo una evaluación del mismo (CAn3).

Al resolver la ecuación

$$
880 x^{2}-1250=0
$$

Obtiene las soluciones: $\quad x_{1}=\sqrt{\frac{1250}{880}} \quad y \quad x_{2}=-\sqrt{\frac{1250}{880}}$

El alumno maneja procedimientos y fórmulas, resolviendo y calculando (RLSOn3). 
La lógica nos indica que el valor negativo no tiene sentido en la medida del marco, por lo que:

$$
x=\sqrt{\frac{1250}{880}}=\frac{5 \sqrt{110}}{44} \cong 1,19 \text { metros de ancho }
$$

Aplicando, de este modo, conceptos matemáticos apropiados (CPRn3).

De donde se deduce que $y=\frac{1}{x}=\frac{2 \sqrt{110}}{25} \cong 0,84$ metros de altura.

Con lo que evalúa el encadenamiento de argumentos matemáticos particulares (CAn3) e interpreta las relaciones implicadas (CCn3); traduce, en la práctica, el modelo a seguir, que es algo diferente de los estudiados (CMn2) eligiendo las estrategias apropiadas que conexionen áreas matemáticas (CRPn2) y aplicándolas (CRPn3).

Finalmente, es preciso comprobar que la solución obtenida satisface las condiciones del enunciado, es decir, que el coste sea mínimo; calculando la derivada segunda y comprobando que para los valores obtenidos dicha derivada es mayor que cero.

$$
P^{\prime \prime}(x)=\frac{5000}{x^{3}} ; \quad P^{\prime \prime}\left(\frac{5 \sqrt{110}}{44}\right)>0
$$

Y por tanto es un mínimo.

El alumno interpreta las relaciones implicadas (CCn3), describe los resultados obtenidos (RCn3) comunicando de manera elemental los resultados del modelo (RMn3).

\begin{tabular}{|l|c|c|c|c|c|c|c|c|}
\hline \multicolumn{6}{|c|}{ FICHA 1.13.2. COMPETENCIAS IMPLÍCITAS EN LA RESOLUCIÓN DEL P13 } \\
\hline & Nivel 1 & Nivel 2 & Nivel 3 & Nivel 1 & Nivel 2 & Nivel 3 & Nivel 1 & Nivel 2 \\
\hline PR & & & & $*$ & $*$ & $*$ & & \\
\hline A & & & & $*$ & $*$ & $*$ & & \\
\hline C & & & $*$ & $*$ & $*$ & $*$ & & \\
\hline M & & & $*$ & $*$ & $*$ & & & \\
\hline RP & & & & $*$ & $*$ & $*$ & & \\
\hline R & & $*$ & & $*$ & & & & \\
\hline LSO & & $*$ & $*$ & $*$ & & & & \\
\hline & \multicolumn{2}{|l|}{ Reproducción } & & Conexión & & Reflexión \\
\hline
\end{tabular}




\section{ANÁLISIS DEL PROBLEMA P15}

\section{FICHA 1.15.1. \\ ESTUDIO DEL ENUNCIADO DEL P15}

P15.- Por el punto de abscisa $x=1$ de la parábola de ecuación $y=x-x^{2}$ se traza una recta $r$ perpendicular a la tangente a la curva en dicho punto. Hallar el área del recinto limitado por la recta $r$ y la parábola.

\begin{tabular}{|c|c|c|c|c|c|c|c|c|c|c|c|c|c|c|}
\hline CONVOCATORIA & \multicolumn{7}{|c|}{ JUNIO } & \multicolumn{7}{|c|}{ SEPTIEMBRE } \\
\hline AÑO & 95 & 96 & 97 & 98 & 99 & 00 & 01 & \begin{tabular}{l|l}
02 & 03
\end{tabular} & 04 & 05 & 06 & 07 & 08 & 09 \\
\hline OPCIÓN & \multicolumn{7}{|c|}{ A } & \multicolumn{7}{|c|}{ B } \\
\hline TIPO DE PROBLEMA & \multicolumn{7}{|c|}{ TEÓRICO } & \multicolumn{7}{|c|}{ PRÁCTICO } \\
\hline \multirow{3}{*}{ APARTADOS } & \multirow{3}{*}{\multicolumn{2}{|c|}{ SI }} & \multicolumn{4}{|c|}{ Forma explícita } & & & & \multirow[b]{2}{*}{5} & \multirow{2}{*}{\multicolumn{2}{|c|}{6}} & \multirow{3}{*}{\multicolumn{2}{|c|}{$\underline{\text { NO }}$}} \\
\hline & & & & & & & 2 & 3 & 4 & & & & & \\
\hline & & & \multicolumn{4}{|c|}{ Forma implícita } & & & & & & & & \\
\hline VERBO UTILIZADO & \multicolumn{14}{|c|}{ HALLAR } \\
\hline TIEMPO VERBAL & \multicolumn{14}{|c|}{ INFINITIVO } \\
\hline ESCRITURA & \multicolumn{9}{|c|}{ ALGEBRAICA } & \multicolumn{5}{|c|}{ ECUACIONAL } \\
\hline \multirow{3}{*}{$\begin{array}{l}\text { FALLOS DEL ENUN- } \\
\text { CIADO }\end{array}$} & \multicolumn{9}{|c|}{ PUNTUACIÓN } & & & & & \\
\hline & \multicolumn{9}{|c|}{ ORDEN DE LAS PALABRAS EN LA ORACIÓN } & & & & & \\
\hline & \multicolumn{9}{|c|}{ ERROR SEMÁNTICO } & & & & & \\
\hline \multicolumn{15}{|c|}{ ENUNCIADO ALTERNATIVO } \\
\hline \multicolumn{15}{|c|}{$\begin{array}{l}\text { P15.- } \underline{\text { Considera la recta tangente en el punto }} x=1 \text { a la parábola de ecuación } \\
y=x-x^{2} \text {. Por dicho punto, se traza una recta } r \underline{\text { que es }} \text { perpendicular a esta tangen- }\end{array}$} \\
\hline
\end{tabular}

\section{NIVELES DE COMPETENCIAS IMPLÍCITAS: Conexión}

El problema que se presenta en la ficha 1.15.1 es un ejercicio que se encuadra en los niveles de reproducción, conexión y reflexión.

El cálculo del área del recinto corresponde al nivel de reproducción del conocimiento estudiado, reconocimiento de equivalentes, ejecución de problemas rutinarios mediante la aplicación de destrezas técnicas y algoritmos habituales. El alumno identifica el problema (RAn1), expone el proceso de cálculo (RAn2) mediante la integral definida y la regla de Barrow- y justifica las fórmulas utilizadas y los resultados (RAn3).

Es un problema que reproduce situaciones similares a las estudiadas, pero que no son de mera rutina, con lo cual, fundamentalmente, se encuadra en el nivel de conexión dado que el alumno tiene que pensar en el tratamiento matemático necesario (CPRn1), comprender que tiene que emplear conceptos matemá- 
ticos intermedios (CPRn2),- como es el cálculo de la derivada para obtener la pendiente de la recta tangente y la obtención de la ecuación de una recta perpendicular a otra dada- y aplicar los conceptos matemáticos apropiados (CPRn3); tales como la integral definida para el cálculo del área comprendida.

El alumno razona matemáticamente de manera simple (CAn1) y sigue el encadenamiento de argumentos matemáticos particulares (CAn2), al escribir la ecuación de la recta perpendicular a la recta tangente en el punto $x=1$, evaluando, así, el encadenamiento de argumentos matemáticos particulares (CAn3).

A continuación estructura la situación que debe modelizar (CMn1) y traduce en la práctica el modelo a seguir, que es algo diferente de los estudiados (CMn2).

$$
f(x)=x-x^{2} \quad ; \quad f^{\prime}(x)=1-2 x \quad \Rightarrow \quad f^{\prime}(1)=-1
$$

La función derivada, evaluada en el punto, es la pendiente de la recta tangente a la curva, en dicho punto.

Reflexión por parte del estudiante, razonando de forma sencilla distinguiendo formas más amplias de argumentación (RfAn1) para planificar estrategias y aplicarlas en la resolución del problema.

La recta perpendicular tiene como pendiente $m=1$ y pasa por el punto $(1, f(1))=(1,0)$.

El alumno sabe expresarse sobre cuestiones matemáticas (CCn1), explica los cálculos y sus propiedades (CCn2) e interpreta las relaciones implicadas (CCn3).

La ecuación de la recta pedida es:

$$
y=x-1
$$

Para obtener esta ecuación, el alumno interpreta y alterna diferentes modelos, comunicando los resultados (CMn3), desarrolla procedimientos intuitivos ya practicados, pero no rutinarios (CRPn1), eligiendo y aplicando las estrategias apropiadas más independientes que conexionan áreas matemáticas (CRPn2, CRPn3), -álgebra y geometría-.

Se tiene una función definida analíticamente,

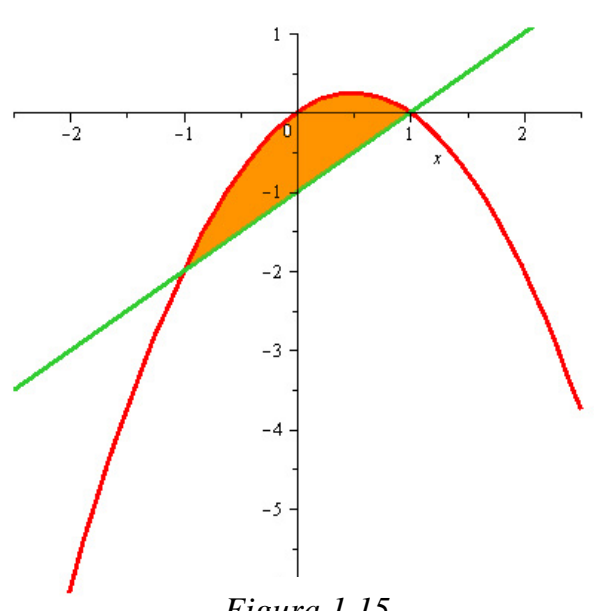

Figura 1.15 . 
que es preciso interpretar, seleccionar y cambiar entre diferentes formas de interpretación (CRn1, CRn2), analítica y gráficamente, diferenciando entre ambas formas de representación (CRn3). Figura 1.15.

Para resolver este problema es preciso utilizar derivadas, ecuaciones de las rectas tangente y normal a la curva, con lo que el alumno interpreta el lenguaje formal y simbólico básico, en situaciones menos conocidas (CLSOn1), maneja afirmaciones sencillas y expresiones con símbolos y fórmulas no rutinarias (CLSOn2) y utiliza variables y realiza cálculos mediante procedimientos familiares (CLSOn3).

Calcula los puntos de corte entre la curva y la recta. Para ello resuelve la ecuación:

$$
x-1=x-x^{2}
$$

Cuyas soluciones son:

$$
x=1 \text { y } x=-1
$$

El alumno maneja procedimientos y fórmulas, resolviendo y calculando (RLSOn3).

En este momento, al calcular la integral definida, el alumno aplica las estrategias apropiadas más independientes (CRPn3), realizando cálculos mediante procedimientos familiares (CLSOn3), - con el cálculo de la integral definida, mediante la regla de Barrow-, maneja afirmaciones sencillas y expresiones con símbolos y fórmulas no rutinarios (CLSOn2).

$$
\text { Área }=\int_{-1}^{1}\left(x-x^{2}\right) d x-\int_{-1}^{1}(x-1) d x=\frac{4}{3} u^{2}
$$

El alumno describe los resultados obtenidos (RCn3) y comunica de manera elemental los resultados del modelo (RMn3).

FICHA 1.15.2. COMPETENCIAS IMPLÍCITAS EN LA RESOLUCIÓN DEL P15

\begin{tabular}{|l|c|c|c|c|c|c|c|c|}
\hline & Nivel 1 & Nivel 2 & Nivel 3 & Nivel 1 & Nivel 2 & Nivel 3 & Nivel 1 & Nivel 2 \\
\hline PR & & & & $*$ & $*$ & $*$ & & \\
\hline A & $*$ & $*$ & $*$ & $*$ & $*$ & $*$ & $*$ & \\
\hline C & & & $*$ & $*$ & $*$ & $*$ & & \\
\hline M & & & $*$ & $*$ & $*$ & $*$ & & \\
\hline RP & & & & $*$ & $*$ & $*$ & & \\
\hline R & & & & $*$ & $*$ & $*$ & & \\
\hline LSO & & & $*$ & $*$ & $*$ & $*$ & & \\
\hline
\end{tabular}


ANÁLISIS DEL PROBLEMA P18

FICHA 1.18.1.

ESTUDIO DEL ENUNCIADO DEL P18

P18.- a) Concepto de máximo y mínimo local.

b) Se quiere dividir un alambre de 2 unidades de longitud en dos partes para construir un triángulo equilátero y una circunferencia, de forma que la suma del área del triángulo y del círculo correspondiente sea mínima. Determinar las longitudes de cada una de las partes.

\begin{tabular}{|c|c|c|c|c|c|c|c|c|c|c|c|c|c|c|c|}
\hline \multirow{2}{*}{$\begin{array}{l}\text { CONVOCATORIA } \\
\text { AÑO }\end{array}$} & \multicolumn{8}{|c|}{ JUNIO } & \multicolumn{7}{|c|}{ SEPTIEMBRE } \\
\hline & 95 & 96 & 97 & 98 & $\underline{99}$ & 00 & 01 & 02 & 03 & 04 & 05 & 06 & 07 & 08 & 09 \\
\hline OPCIÓN & \multicolumn{8}{|c|}{$\underline{A}$} & \multicolumn{7}{|c|}{ B } \\
\hline TIPO DE PROBLEMA & \multicolumn{7}{|c|}{ TEÓRICO } & \multicolumn{8}{|c|}{ PRÁCTICO } \\
\hline \multirow{3}{*}{ APARTADOS } & \multirow{3}{*}{\multicolumn{2}{|c|}{$\underline{\text { SI }}$}} & \multicolumn{4}{|c|}{ Forma explícita } & 2 & & & & \multirow{3}{*}{5} & & \multirow[b]{2}{*}{6} & \multirow{3}{*}{\multicolumn{2}{|c|}{ NO }} \\
\hline & & & & & & & 2 & & 3 & 4 & & & & & \\
\hline & & & \multicolumn{4}{|c|}{ Forma implícita } & & & & & & & & & \\
\hline VERBO UTILIZADO & \multicolumn{15}{|c|}{ DETERMINAR } \\
\hline TIEMPO VERBAL & \multicolumn{15}{|c|}{ INFINITIVO } \\
\hline ESCRITURA & \multicolumn{10}{|c|}{ MULTIPLICATIVA } & \multicolumn{5}{|c|}{ FUNCIONAL } \\
\hline \multirow{3}{*}{$\begin{array}{l}\text { FALLOS DEL ENUN- } \\
\text { CIADO }\end{array}$} & \multicolumn{10}{|c|}{ PUNTUACIÓN } & & & & & \\
\hline & \multicolumn{10}{|c|}{ ERROR MORFOSINTÁCTICO } & & & & & \\
\hline & \multicolumn{10}{|c|}{ AUSENCIA DE ESPECIFICACIONES } & & & & & \\
\hline
\end{tabular}

P18.- a) Escribe el concepto de máximo y mínimo local.

b) Se quiere dividir un alambre de 2 unidades de longitud en dos partes para construir un triángulo equilátero y una circunferencia, de forma que la suma del área del triángulo y del círculo correspondiente sea mínima. Determina la longitud de cada una de las partes.

\section{NIVELES DE COMPETENCIAS IMPLÍCITAS: Conexión}

El problema de la ficha 1.18.1 se encuadra en los niveles de reproducción y conexión.

El apartado a) corresponde al nivel de reproducción, para definir los conceptos de máximo y mínimo relativo, el alumno identifica el problema (RAn1), interpreta representaciones estándar de objetos matemáticos (RRn2) e interpreta el lenguaje formal y simbólico rutinario (RLSOn2).

El apartado b) se trata de un ejercicio que reproduce una situación similar a la referente en la instrucción, pero no es una mera rutina, por lo que se encuadra principalmente en un nivel de conexión. 
En primer lugar, el alumno debe pensar en el tratamiento matemático necesario (CPRn1) y estructurar la situación que se debe modelizar (CMn1), -definir una función, en este caso la función área-.

El alumno razona matemáticamente de manera simple (CAn1).

Llamando $x$ y $2-x$, a la longitud de cada una de las partes en las que se divide el alambre, y teniendo en cuenta que ambas partes son el perímetro del triángulo y del círculo, se tiene:

$$
\begin{gathered}
2-x=3 l \quad \Rightarrow \quad l=\frac{2-x}{3} \\
x=2 \pi r \Rightarrow r=\frac{x}{2 \pi}
\end{gathered}
$$

Siendo $l$ el lado del triángulo y $r$ el radio del círculo.

Así, desarrolla procedimientos ya practicados, pero no rutinarios (CRPn1), interpreta formas de representación (CRn1), sabe expresarse sobre cuestiones matemáticas (CCn1), e interpreta el lenguaje formal y simbólico básico en situaciones menos conocidas (CLSOn1).

El área del triángulo equilátero, en función del lado, es $A=\frac{l^{2} \cdot \sqrt{3}}{4}$, por lo que:

$$
A(x)=\left(\frac{\sqrt{3}}{4}\right) \cdot\left(\frac{2-x}{3}\right)^{2}+\pi \cdot\left(\frac{x}{2 \pi}\right)^{2}
$$

A continuación es preciso obtener la función derivada:

$$
A^{\prime}(x)=-\frac{\sqrt{3}}{18}(2-x)+\frac{1}{2 \pi} x
$$

El alumno comprende que tiene que emplear métodos matemáticos intermedios (CPRn2), explica los cálculos y sus propiedades (CCn2) e interpreta las relaciones implicadas (CCn3). Asimismo, sigue el encadenamiento del argumento matemático particular (CAn2) haciendo una evaluación del mismo (CAn3).

Tiene que resolver la ecuación:

$$
\begin{gathered}
A^{\prime}(x)=0 \Rightarrow \frac{\sqrt{3}}{18}(2-x)=\frac{1}{2 \pi} x \\
\pi \cdot \sqrt{3} \cdot(2-x)=9 x \Rightarrow x(\pi \sqrt{3}+9)=2 \pi \sqrt{3}
\end{gathered}
$$


Aplicando, de este modo, conceptos matemáticos apropiados (CPRn3). A continuación maneja procedimientos y fórmulas, resolviendo y calculando (RLSOn3) y utiliza variables y realiza ecuaciones y cálculos mediante procedimientos familiares (CLSOn3).

De donde se deduce que:

$$
x=\frac{2 \pi \sqrt{3}}{9+\pi \sqrt{3}} \text { y } 2-x=2-\frac{2 \pi \sqrt{3}}{9+\pi \sqrt{3}}=\frac{18}{9+\pi \sqrt{3}}
$$

Con lo que, el alumno evalúa el encadenamiento de argumentos matemáticos particulares (CAn3) e interpreta las relaciones implicadas (CCn3); traduce, en la práctica, el modelo a seguir, que es algo diferente de los estudiados (CMn2) eligiendo las estrategias apropiadas que conexionen áreas matemáticas (CRPn2) y aplicándolas (CRPn3).

Las longitudes de cada uno de esos trozos son:

$$
\begin{aligned}
& \frac{2 \pi \sqrt{3}}{9+\pi \sqrt{3}} \text { unidades de longitud para el triángulo. } \\
& \frac{18}{9+\pi \sqrt{3}} \text { unidades de longitud para el círculo. }
\end{aligned}
$$

El alumno describe los resultados obtenidos (RCn3) y comunica de manera elemental los resultados del modelo (RMn3).

Finalmente, es preciso comprobar que la solución obtenida satisface las condiciones del enunciado, es decir, que el área es mínima; calculando la derivada segunda y comprobando que para los valores obtenidos dicha derivada es mayor que cero.

$$
A^{\prime \prime}(x)=\frac{\sqrt{3}}{18}+\frac{1}{2 \pi}>0 \quad \forall x \text {, luego } A^{\prime \prime}\left(\frac{2 \pi \sqrt{3}}{9+\pi \sqrt{3}}\right)>0
$$

El alumno maneja afirmaciones sencillas y expresiones con símbolos y fórmulas no rutinarias (CLSOn2), e interpreta las relaciones implicadas (CCn3).

Y por tanto es un mínimo.

El alumno sabe expresarse sobre cuestiones matemáticas (CCn1), explica los cálculos y sus propiedades (CCn2) e interpreta las relaciones implicadas (CCn3) evaluando así, el encadenamiento de argumentos matemáticos particulares (CAn3). 


\begin{tabular}{|l|c|c|c|c|c|c|c|c|}
\hline \multicolumn{7}{|c|}{ FICHA 1.18.2. } & COMPETENCIAS IMPLÍCITAS EN LA RESOLUCIÓN DEL P18 \\
\hline & Nivel 1 & Nivel 2 & Nivel 3 & Nivel 1 & Nivel 2 & Nivel 3 & Nivel 1 & Nivel 2 \\
\hline PR & & & & $*$ & $*$ & $*$ & & \\
\hline A & $*$ & & & $*$ & $*$ & $*$ & & \\
\hline C & & & $*$ & $*$ & $*$ & $*$ & & \\
\hline M & & & $*$ & $*$ & $*$ & & & \\
\hline RP & & & & $*$ & $*$ & $*$ & & \\
\hline R & & $*$ & & $*$ & & & & \\
\hline LSO & & $*$ & $*$ & $*$ & $*$ & $*$ & & \\
\hline & Reproducción & & Conexión & & Reflexión \\
\hline
\end{tabular}

\section{ANÁLISIS DEL PROBLEMA P20}

El problema que aparece en la ficha 1.20.1 es un ejercicio que se encuadra en los niveles de reproducción, conexión y reflexión. En el nivel de reproducción maneja procedimientos y fórmulas, resolviendo y calculando (RLSOn3) y en el de reflexión, razonando de forma sencilla, distinguiendo formas más amplias de argumentación (RfAn1) para planificar estrategias y aplicarlas en la resolución del problema.

Es un problema que reproduce situaciones similares a las estudiadas, pero que no son de mera rutina, con lo cual se encuadra en el nivel de conexión, piensa en el tratamiento matemático necesario (CPRn1), comprende que tiene que emplear conceptos matemáticos intermedios (CPRn2), como es el cálculo de la derivada para obtener la pendiente de la recta tangente y aplica los conceptos matemáticos apropiados (CPRn3).

El alumno estructura la situación que debe modelizar (CMn1).

Tiene la función $f(x)=\frac{2 x+1}{x-2}$.

Calcula su función derivada:

$$
f^{\prime}(x)=\frac{-5}{(x-2)^{2}}
$$

El valor de la derivada en el punto es la pendiente de la recta tangente a la curva, en dicho punto. Evalúa esta función en $x=3$

$$
f^{\prime}(3)=-5
$$


FICHA 1.20.1.

ESTUDIO DEL ENUNCIADO DEL P20

P20.- Una partícula se mueve por la curva $y=\frac{2 x+1}{x-2} \quad x>2$. En el punto $P$ de abscisa $x=3$, abandona la curva y se desplaza a lo largo de la recta tangente a la curva en dicho punto.

a) Calcular la ecuación de la recta tangente en $P$.

b) Hallar el punto en el que la partícula encuentra a la asíntota horizontal de la curva.

c) Hallar el área encerrada por la curva, la recta tangente y las rectas cuyas ecuaciones son $x=3$ y $x=4$.

\begin{tabular}{|c|c|c|c|c|c|c|c|c|c|c|c|c|c|c|c|}
\hline \multirow{2}{*}{$\begin{array}{l}\text { CONVOCATORIA } \\
\text { AÑO }\end{array}$} & \multicolumn{8}{|c|}{ JUNIO } & \multicolumn{7}{|c|}{ SEPTIEMBRE } \\
\hline & 95 & 96 & 97 & 98 & $\underline{99}$ & 00 & 01 & 02 & 03 & 04 & 05 & 06 & 07 & 08 & 09 \\
\hline OPCIÓN & \multicolumn{8}{|c|}{$\underline{A}$} & \multicolumn{7}{|c|}{ B } \\
\hline TIPO DE PROBLEMA & \multicolumn{7}{|c|}{ TEÓRICO } & & \multicolumn{7}{|c|}{ PRÁCTICO } \\
\hline \multirow{3}{*}{ APARTADOS } & \multirow{3}{*}{\multicolumn{2}{|c|}{ SI }} & \multicolumn{4}{|c|}{ Forma explícita } & & & 3 & & \multirow[b]{2}{*}{5} & \multirow{2}{*}{\multicolumn{2}{|c|}{6}} & \multirow{3}{*}{\multicolumn{2}{|c|}{ NO }} \\
\hline & & & & & & & 2 & & 3 & 4 & & & & & \\
\hline & & & \multicolumn{4}{|c|}{ Forma implícita } & & & & & & & & & \\
\hline VERBO UTILIZADO & \multicolumn{15}{|c|}{ CALCULAR I HALLAR } \\
\hline TIEMPO VERBAL & \multicolumn{15}{|c|}{ INFINITIVO } \\
\hline ESCRITURA & \multicolumn{10}{|c|}{ ALGEBRAICA } & \multicolumn{5}{|c|}{ ECUACIONAL } \\
\hline \multirow{3}{*}{$\begin{array}{l}\text { FALLOS DEL ENUN- } \\
\text { CIADO }\end{array}$} & \multicolumn{10}{|c|}{ PUNTUACIÓN } & & & & & \\
\hline & \multicolumn{10}{|c|}{ ERROR MORFOSINTÁCTICO } & & & & & \\
\hline & \multicolumn{10}{|c|}{ AUSENCIA DE ESPECIFICACIONES } & & & & & \\
\hline
\end{tabular}

P20.- Una partícula se mueve por la curva $y=\frac{2 x+1}{x-2} \quad x>2$. En el punto $\underline{P}$, de abscisa $x=3$, abandona la curva y se desplaza a lo largo de la recta tangente a la curva en dicho punto.

a) Calcula la ecuación de la recta tangente en el punto $P$.

b) Halla el punto en el que la partícula corta a la asíntota horizontal de la curva.

c) Halla el área encerrada por la curva, la recta tangente y las rectas cuyas ecuaciones son $x=3$ y $x=4$.

NIVELES DE COMPETENCIAS IMPLÍCITAS: Reproducción, conexión y reflexión

En los pasos anteriores, el alumno razona matemáticamente de manera simple (CAn1) sigue el encadenamiento de argumentos matemáticos particulares (CAn2) y traduce en la práctica el modelo a seguir, que es algo diferente de los estudiados (CMn2), sabe expresarse sobre cuestiones matemáticas (CCn1), explica los cálculos y sus propiedades (CCn2) e interpreta las relaciones implicadas (CCn3). 
La ecuación de la recta tangente, en el punto $P(3,7)$ es:

$$
y=-5 x+22
$$

Evaluando, así, el encadenamiento de argumentos matemáticos particulares (CAn3), describe los resultados obtenidos (RCn3) y comunica de manera elemental los resultados del modelo (RMn3).

El apartado b) del problema 1.20.1 se encuadra también en el nivel de reproducción.

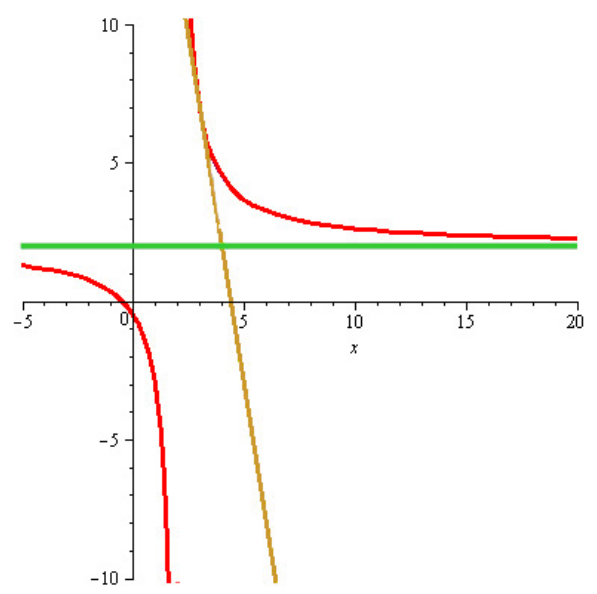

Figura 1.20.1.

En este nivel identifica el problema (RAn1) y expone el proceso de cálculo (RAn2).

Hay que calcular el punto de corte de la recta tangente, obtenida anteriormente, y la asíntota horizontal; por lo que pasa a calcular la ecuación de esta asíntota.

$$
\lim _{x \rightarrow+\infty} \frac{2 x+1}{x-2}=2
$$

La asíntota horizontal es la recta $y=2$.

A continuación, resuelve la ecuación:

$-5 x+22=2$

Cuya solución es:

$$
x=4
$$

$\mathrm{Y}$, el punto pedido en el apartado b) es:

$$
I(4,2)
$$

El alumno justifica las fórmulas utilizadas y los resultados (RAn3) y comunica de manera elemental los resultados del modelo (RMn3).

Se tiene una función definida analíticamente, que es preciso interpretar, seleccionar y cambiar entre diferentes formas de interpretación (CRn1, CRn2), analítica y gráficamente, diferenciando entre ambas formas de representación (CRn3). Figura 1.20.1.

Para resolver este problema se han utilizado derivadas, ecuaciones de rectas, cálculo de una asíntota, etc., con lo que el alumno interpreta el lenguaje formal 
y simbólico básico, en situaciones menos conocidas (CLSOn1), maneja afirmaciones sencillas y expresiones con símbolos y fórmulas no rutinarias (CLSOn2) y utiliza variables y realiza cálculos mediante procedimientos familiares (CLSOn3).

En el apartado c), el cálculo del área del recinto corresponde al nivel de reproducción del conocimiento estudiado, reconocimiento de equivalentes, ejecución de problemas rutinarios mediante la aplicación de destrezas técnicas y algoritmos habituales.

El alumno identifica el problema (RAn1) y expone el proceso de cálculo (RAn2) mediante la integral definida y la regla de Barrow.

Identifica que el modelo es similar a otros modelos vistos con anterioridad (RMn1), re-

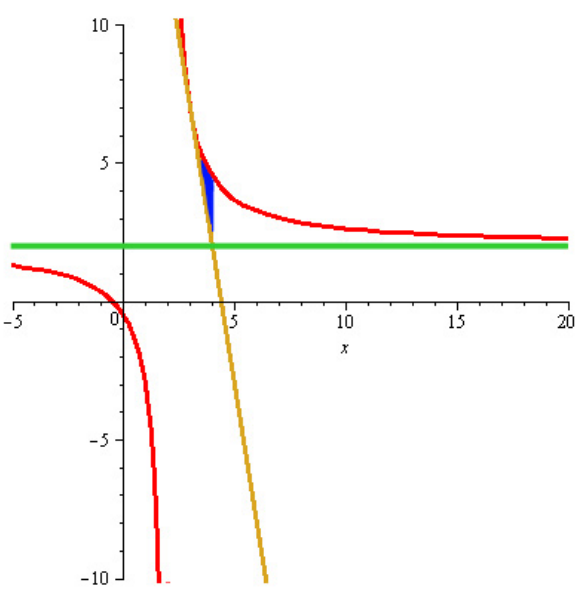

Figura 1.20.2. conoce el problema como ya practicado en la instrucción (RRPn1), le reproduce de manera cerrada (RRPn2) y resuelve problemas rutinarios estandarizados (RRPn3).

El alumno interpreta y alterna diferentes modelos, comunicando los resultados (CMn3), desarrolla procedimientos intuitivos ya practicados, pero no rutinarios (CRPn1), eligiendo y aplicando las estrategias apropiadas más independientes que conexionen áreas matemáticas (CRPn2, CRPn3).

$$
\text { Área }=\int_{3}^{4} \frac{2 x+1}{x-2} d x-\int_{3}^{4}(-5 x+2) d x=\left(5 \ln (2)-\frac{5}{2}\right) u^{2}
$$

Al calcular la integral definida, el alumno aplica las estrategias apropiadas más independientes (CRPn3), realizando cálculos mediante procedimientos familiares (CLSOn3) y maneja procedimientos y fórmulas, resolviendo y calculando (RLSOn3).

Se tiene una función definida analíticamente, que es preciso interpretar, seleccionar y cambiar entre diferentes formas de interpretación (CRn1, CRn2), analítica y gráficamente, diferenciando entre ambas formas de representación (CRn3). Figura 1.20.2. 
Se presenta lenguaje algebraico, aritmético y geométrico, con lo que interpreta el lenguaje formal y simbólico básico, en situaciones menos conocidas (CLSOn1), maneja afirmaciones sencillas y expresiones con símbolos y fórmulas no rutinarias (CLSOn2) y utiliza variables y realiza cálculos mediante procedimientos familiares (CLSOn3).

\begin{tabular}{|c|c|c|c|c|c|c|c|c|}
\hline \multicolumn{2}{|c|}{ FICHA 1.20.2. } & \multicolumn{7}{|c|}{ COMPETENCIAS IMPLÍCITAS EN LA RESOLUCIÓN DEL P20 } \\
\hline & Nivel 1 & Nivel 2 & Nivel 3 & Nivel 1 & Nivel 2 & Nivel 3 & Nivel 1 & Nivel 2 \\
\hline PR & & & & * & * & * & & \\
\hline A & * & * & * & * & * & * & * & \\
\hline C & & & * & * & * & * & & \\
\hline M & * & & * & * & * & * & & \\
\hline RP & * & * & * & * & * & * & & \\
\hline $\mathbf{R}$ & & & & * & * & * & & \\
\hline LSO & & & * & * & * & * & & \\
\hline & \multicolumn{3}{|c|}{ Reproducción } & \multicolumn{3}{|c|}{ Conexión } & \multicolumn{2}{|c|}{ Reflexión } \\
\hline
\end{tabular}

\section{ANÁLISIS DEL PROBLEMA P23}

Los apartados a) y b) del problema que aparece en la ficha 1.23.1 son conceptos teóricos, por tanto son una mera reproducción del conocimiento estudiado, interpretando representaciones estándar de objetos matemáticos (RRn2) e interpretando el lenguaje formal y simbólico rutinario (RLSOn2).

El apartado c) de este problema 1.23.1 se encuadra en los niveles de conexión y reflexión. Es un problema que reproduce una situación similar a la referente en su etapa de aprendizaje, pero no es una mera rutina, con lo que se

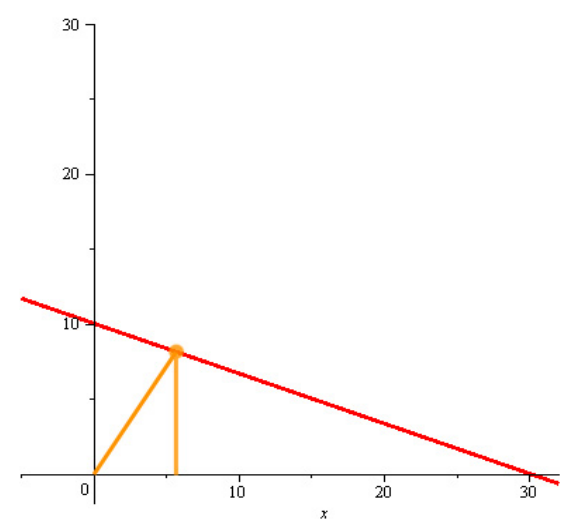
sitúa en un nivel de conexión;

El alumno tiene que pensar en el tratamiento matemático necesario (CPRn1), razonar matemáticamente de manera simple (CAn1), estructurar la situación que se debe modelizar (CMn1).

Define una función que tiene que optimizar, en este caso la función distancia-. Figura 1.23.

Figura 1.23. 
FICHA 1.23.1.

ESTUDIO DEL ENUNCIADO DEL P23

P23.- a) Definir los conceptos de máximo y mínimo locales de una función.

b) Caracterizar, en función de la derivada, la condición de que un punto sea máximo o mínimo local de una función.

c) Hallar sobre la recta $x+3 y=30$ un punto $P$ con la propiedad de que la suma de sus distancias al origen y al eje $O X$ sea mínima.

\begin{tabular}{|c|c|c|c|c|c|c|c|c|c|c|c|c|c|c|c|}
\hline \multirow{2}{*}{$\begin{array}{l}\text { CONVOCATORIA } \\
\text { AÑO }\end{array}$} & \multicolumn{8}{|c|}{ JUNIO } & \multicolumn{7}{|c|}{ SEPTIEMBRE } \\
\hline & 95 & 96 & 97 & 98 & 99 & $\underline{00}$ & 01 & 02 & 03 & 04 & 05 & 06 & 07 & 08 & 09 \\
\hline OPCIÓN & \multicolumn{8}{|c|}{ A } & \multicolumn{7}{|c|}{$\underline{B}$} \\
\hline TIPO DE PROBLEMA & \multicolumn{7}{|c|}{ TEÓRICO } & \multicolumn{8}{|c|}{ PRÁCTICO } \\
\hline \multirow{3}{*}{ APARTADOS } & \multirow{3}{*}{\multicolumn{2}{|c|}{ SI }} & \multicolumn{4}{|c|}{ Forma explícita } & & & 3 & & \multirow[b]{2}{*}{5} & \multirow{2}{*}{\multicolumn{2}{|c|}{6}} & \multirow{3}{*}{\multicolumn{2}{|c|}{ NO }} \\
\hline & & & & & & & 2 & & 3 & 4 & & & & & \\
\hline & & & \multicolumn{4}{|c|}{ Forma implícita } & & & & & & & & & \\
\hline VERBO UTILIZADO & \multicolumn{15}{|c|}{ DEFINIR / CARACTERIZAR / HALLAR } \\
\hline TIEMPO VERBAL & \multicolumn{15}{|c|}{ INFINITIVO } \\
\hline ESCRITURA & \multicolumn{10}{|c|}{ MULTIPLICATIVA } & \multicolumn{5}{|c|}{ FUNCIONAL } \\
\hline \multirow{3}{*}{$\begin{array}{l}\text { FALLOS DEL ENUN- } \\
\text { CIADO }\end{array}$} & \multicolumn{10}{|c|}{ PUNTUACIÓN } & & & & & \\
\hline & \multicolumn{10}{|c|}{ ERROR MORFOLÓGICO } & & & & & \\
\hline & \multicolumn{10}{|c|}{ AUSENCIA DE ESPECIFICACIONES } & & & & & \\
\hline
\end{tabular}

P23.- a) Define los conceptos de máximo y mínimo locales de una función.

b) Caracteriza, en función de la derivada, la condición de que un punto sea máximo o mínimo local de una función.

c) Halla sobre la recta $x+3 y=30$ un punto $P$ con la propiedad de que la suma de sus distancias al origen y al eje $O X_{1}$ sea mínima.

\section{NIVELES DE COMPETENCIAS IMPLÍCITAS: Conexión y reflexión}

Como el punto $P$ pertenece a la recta $x+3 y=30$, podemos expresarle en la forma $P=(30-3 y, y)$

La suma de las distancias del punto $P(30-3 y, y)$ al punto $(0,0)$ y al eje $y=0$, viene dada por la función:

$$
D(y)=\sqrt{(30-3 y)^{2}+y^{2}}+|y|
$$

El alumno maneja procedimientos y fórmulas, resolviendo y calculando (RLSOn3), desarrolla procedimientos ya practicados, pero no rutinarios 
(CRPn1), interpreta formas de representación (CRn1), Figura 1.23, sabe expresarse sobre cuestiones matemáticas (CCn1), e interpreta el lenguaje formal y simbólico básico en situaciones menos conocidas (CLSOn1).

Comprende que tiene que emplear métodos matemáticos intermedios (CPRn2).

Si $y>0$, esa función se escribe de la forma:

$$
D(y)=\sqrt{900-180 y+y^{2}}+y
$$

El alumno explica los cálculos y sus propiedades (CCn2) e interpreta las relaciones implicadas (CCn3). Asimismo, sigue el encadenamiento del argumento matemático particular (CAn2) haciendo una evaluación del mismo (CAn3).

A continuación es preciso obtener la función derivada e igualar a cero dicha función derivada, es decir,

$$
\begin{gathered}
D^{\prime}(y)=\frac{-90+10 y}{\sqrt{900-180 y+10 y^{2}}}+1 \\
D^{\prime}(y)=0 \Rightarrow \frac{90-10 y}{\sqrt{900-180 y+10 y^{2}}}=1
\end{gathered}
$$

Utiliza variables y realiza ecuaciones y cálculos mediante procedimientos familiares (CLSOn3), aplicando, de este modo, conceptos matemáticos apropiados (CPRn3).

Resuelve la ecuación irracional, obteniendo como resultados:

$$
y_{1}=10 ; y_{2}=8
$$

Comprueba que el valor $y=10$ no satisface la ecuación irracional, y que aparece como solución no válida cuando se eleva al cuadrado.

Con lo que, el alumno evalúa el encadenamiento de argumentos matemáticos particulares (CAn3) e interpreta las relaciones implicadas (CCn3); traduce, en la práctica el modelo a seguir, que es algo diferente de los estudiados (CMn2) eligiendo las estrategias apropiadas que conexionen áreas matemáticas (CRPn2) y aplicándolas (CRPn3).

De donde se deduce que el punto buscado es:

$$
P(6,8) \text {. }
$$

Si $y<0$, la función $D(y)=\sqrt{(30-3 y)^{2}+y^{2}}+|y|$ se escribe de la forma: 


$$
D(y)=\sqrt{900-180 y+y^{2}}-y
$$

Y entonces la función derivada será:

$$
\begin{gathered}
D^{\prime}(y)=\frac{-90+10 y}{\sqrt{900-180 y+10 y^{2}}}-1 \\
\frac{-90+10 y}{\sqrt{900-180 y+10 y^{2}}}=1
\end{gathered}
$$

Con soluciones:

$$
y_{1}=10 \quad ; \quad y_{2}=8
$$

En este caso, la solución no válida para la ecuación irracional es $y=8$, y la solución $y=10$ no satisface la hipótesis, si $y<0$, que se ha tomado para la resolución.

El alumno evalúa el encadenamiento de argumentos matemáticos particulares (CAn3) e interpreta las relaciones implicadas (CCn3); traduce en la práctica el modelo a seguir, que es algo diferente de los estudiados (CMn2) eligiendo las estrategias apropiadas que conexionen áreas matemáticas (CRPn2) y aplicándolas (CRPn3), al tiempo que sabe interpretar y alternar diferentes modelos $y$ comunicar los resultados (CMn3).

El razonamiento anterior le sitúa en un un nivel de reflexión, pues planifica estrategias para la resolución de un problema que contiene elementos inusuales, aplica estrategias no rutinarias (RfPRn2), razonando de forma sencilla, distinguiendo formas más amplias de argumentación (RfAn1) y elaborando encadenamientos de argumentos de diferentes tipos (RfAn2).

Finalmente, es preciso comprobar que la solución obtenida satisface las condiciones del enunciado, es decir, quela suma de las distancias es mínima, calculando la derivada segunda y comprobando que para los valores obtenidos dicha derivada es mayor que cero.

$$
\begin{gathered}
D^{\prime \prime}(8)=\frac{900}{\left(900-180 y+10 y^{2}\right)^{\frac{3}{2}}}>0 \\
\text { Y, por tanto, es un mínimo. }
\end{gathered}
$$


Con este proceso el alumno interpreta las relaciones implicadas (CCn3), describe los resultados obtenidos (RCn3) y comunica de manera elemental los resultados del modelo (RMn3).

FICHA 1.23.2. COMPETENCIAS IMPLÍCITAS EN LA RESOLUCIÓN DEL P23

\begin{tabular}{|l|c|c|c|c|c|c|c|c|}
\hline & Nivel 1 & Nivel 2 & Nivel 3 & Nivel 1 & Nivel 2 & Nivel 3 & Nivel 1 & Nivel 2 \\
\hline PR & & & & $*$ & $*$ & $*$ & & $*$ \\
\hline A & & & & $*$ & $*$ & $*$ & $*$ & $*$ \\
\hline C & & & $*$ & $*$ & $*$ & $*$ & & \\
\hline M & & & $*$ & $*$ & $*$ & $*$ & & \\
\hline RP & & & & $*$ & $*$ & $*$ & & \\
\hline R & & $*$ & & $*$ & & & & \\
\hline LSO & & $*$ & $*$ & $*$ & $*$ & $*$ & & \\
\hline & \multicolumn{2}{|l|}{ Reproducción } & & & $*$ & \\
\hline
\end{tabular}

\section{ANÁLISIS DEL PROBLEMA P25}

El problema de la ficha 1.25.1 es un ejercicio de optimización que reproduce una situación similar a la referente en la instrucción, pero no es una mera rutina, por lo que se encuadra principalmente en un nivel de conexión dado que el alumno tiene que pensar en el tratamiento matemático necesario (CPRn1) y estructurar la situación que debe modelizar (CMn1), en este caso definir la función área.

Llamando $x$ y $150-x$, a cada una de las partes en las que se divide la cerca, y teniendo en cuenta que ambas partes son el perímetro de tres lados del cuadrado y la longitud de la circunferencia, pues, por lógica, en el lado de la casa no se colocará una valla.

El alumno razona matemáticamente de manera simple (CAn1) y sabe expresarse sobre cuestiones matemáticas (CCn1).

Llamando $l$ al lado del cuadrado y $r$ al radio del círculo.

$$
\begin{gathered}
150-x=3 l \quad \Rightarrow \quad l=\frac{150-x}{3} \\
x=2 \pi r \Rightarrow r=\frac{x}{2 \pi}
\end{gathered}
$$


FICHA 1.25.1.

ESTUDIO DEL ENUNCIADO DEL P25

P25.- Tenemos que vallar un terreno circular y un terreno cuadrado, que por uno de sus lados está limitado por una casa. Calcular el área del terreno circular y del terreno cuadrado que se pueden cercar, utilizando 150 metros de valla, con la condición de que la suma de dichas áreas sea mínima.

\begin{tabular}{|c|c|c|c|c|c|c|c|c|c|c|c|c|c|c|}
\hline CONVOCATORIA & \multicolumn{7}{|c|}{ JUNIO } & \multicolumn{7}{|c|}{ SEPTIEMBRE } \\
\hline AÑO & 95 & 96 & 97 & 98 & 99 & $\underline{00}$ & 01 & \begin{tabular}{|l|l|}
02 & 03
\end{tabular} & 04 & 05 & 06 & 07 & 08 & 09 \\
\hline OPCIÓN & \multicolumn{7}{|c|}{ A } & \multicolumn{7}{|c|}{$\underline{B}$} \\
\hline TIPO DE PROBLEMA & \multicolumn{7}{|c|}{ TEÓRICO } & \multicolumn{7}{|c|}{ PRÁCTICO } \\
\hline \multirow{3}{*}{ APARTADOS } & \multirow{3}{*}{\multicolumn{2}{|c|}{ SI }} & \multicolumn{4}{|c|}{ Forma explícita } & & & & & \multirow{3}{*}{\multicolumn{2}{|c|}{$\underline{\text { NO }}$}} \\
\hline & & & & & & & 2 & 3 & 4 & 5 & & 6 & & \\
\hline & & & \multicolumn{4}{|c|}{ Forma implícita } & & & & & & & & \\
\hline VERBO UTILIZADO & \multicolumn{14}{|c|}{ CALCULAR } \\
\hline TIEMPO VERBAL & \multicolumn{14}{|c|}{ INFINITIVO } \\
\hline ESCRITURA & \multicolumn{9}{|c|}{ MULTIPLICATIVA } & \multicolumn{5}{|c|}{ FUNCIONAL } \\
\hline \multirow{3}{*}{$\begin{array}{l}\text { FALLOS DEL ENUN- } \\
\text { CIADO }\end{array}$} & \multicolumn{9}{|c|}{ PUNTUACIÓN } & & & & & \\
\hline & \multicolumn{9}{|c|}{ ERROR MORFOSINTÁCTICO } & & & & & \\
\hline & \multicolumn{9}{|c|}{ AUSENCIA DE ESPECIFICACIONES } & & & & & \\
\hline \multicolumn{15}{|c|}{ ENUNCIADO ALTERNATIVO } \\
\hline
\end{tabular}

P25.- Tenemos que vallar dos terrenos: uno circular y otro cuadrado. El cuadrado tiene uno de sus lados limitado por una casa. Calcula las áreas del terreno circular y del terreno cuadrado que se pueden cercar, utilizando 150 metros de valla, con la condición de que la suma de dichas áreas sea mínima.

\section{NIVELES DE COMPETENCIAS IMPLÍCITAS: Conexión}

El alumno desarrolla procedimientos intuitivos ya practicados, pero no rutinarios (CRPn1), interpreta formas de representación (CRn1) e interpreta el lenguaje formal y simbólico básico en situaciones menos conocidas (CLSOn1) manejando afirmaciones sencillas y expresiones con símbolos y fórmulas no rutinarias (CLSOn2).

La suma de las áreas de círculo y cuadrado es:

$$
A(x)=\left(\frac{150-x}{3}\right)^{2}+\pi \cdot\left(\frac{x}{2 \pi}\right)^{2}
$$

El alumno comprende que tiene que emplear métodos matemáticos intermedios (CPRn2), explica los cálculos y sus propiedades (CCn2) e interpreta las relaciones implicadas (CCn3). A continuación, obtiene la función derivada: 


$$
A^{\prime}(x)=-\frac{2}{9}(150-x)+\frac{1}{2 \pi} x
$$

Igualando a cero dicha función, obtiene la ecuación:

$$
A^{\prime}(x)=0 \Rightarrow \frac{2}{9}(150-x)=\frac{1}{2 \pi} x
$$

El alumno maneja procedimientos y fórmulas, resolviendo y calculando (RLSOn3) y utiliza variables y realiza ecuaciones y cálculos mediante procedimientos familiares (CLSOn3), aplicando, de este modo, conceptos matemáticos apropiados (CPRn3).

$$
4 \pi \cdot(150-x)=9 x \Rightarrow x(4 \pi+9)=600 \pi
$$

Obtiene el valor:

$$
x=\frac{600 \pi}{9+4 \pi}
$$

$\mathrm{Y}$, en consecuencia,

$$
150-x=150-\frac{600 \pi}{9+4 \pi}=\frac{1350}{9+4 \pi}
$$

Para calcular el área, se necesita el lado del cuadrado y el radio del círculo, por tanto, manejando procedimientos y fórmulas, resolviendo y calculando (RLSOn3), obtiene:

$$
\begin{aligned}
& l=50-\frac{x}{3}=50-\frac{200 \pi}{9+4 \pi}=\frac{450}{9+4 \pi} \\
& x=2 \pi r \quad \Rightarrow r=\frac{x}{2 \pi}=\frac{300}{9+4 \pi}
\end{aligned}
$$

El alumno sigue el encadenamiento del argumento matemático particular (CAn2), evalúa el encadenamiento de argumentos matemáticos particulares (CAn3) e interpreta las relaciones implicadas (CCn3).

Y a partir de ello traduce en la práctica el modelo a seguir, que es algo diferente de los estudiados (CMn2) eligiendo las estrategias apropiadas que conexionen áreas matemáticas (CRPn2) y aplicándolas (CRPn3).

El área de ambos terrenos es: $A_{1}=\left(\frac{450}{9+4 \pi}\right)^{2} \mathrm{~m}^{2}$ el terreno cuadrado. 


$$
A_{2}=\pi \cdot\left(\frac{300}{9+4 \pi}\right)^{2}, \text { metros cuadrados, el terreno circular. }
$$

Finalmente, es preciso comprobar que la solución obtenida satisface las condiciones del enunciado, es decir, que el área es mínima; calculando la derivada segunda y comprobando que para los valores obtenidos dicha derivada es mayor que cero.

$$
\begin{aligned}
& A^{\prime \prime}\left(\frac{600 \pi}{9+4 \pi}\right)=\frac{2}{9}+\frac{1}{2 \pi}>0 \\
& \text { Y por tanto es un mínimo. }
\end{aligned}
$$

El alumno interpreta las relaciones implicadas (CCn3), justifica las fórmulas utilizadas y los resultados (RAn3) y describe los resultados obtenidos (RCn3) y comunica de manera elemental los resultados del modelo (RMn3).

Comentario. El problema como tal carace de sentido, ya que si los terrenos existen antemano el área está definida y, habría que comprar los metros de vaIla necesarios para cercarlo.

\begin{tabular}{|l|c|c|c|c|c|c|c|c|}
\hline \multicolumn{6}{|c|}{ FICHA 1.25.2. COMPETENCIAS IMPLíCITAS EN LA RESOLUCIÓN DEL P25 } \\
\hline & Nivel 1 & Nivel 2 & Nivel 3 & Nivel 1 & Nivel 2 & Nivel 3 & Nivel 1 & Nivel 2 \\
\hline PR & & & & $*$ & $*$ & $*$ & & \\
\hline A & & & $*$ & $*$ & $*$ & $*$ & & \\
\hline C & & & $*$ & $*$ & $*$ & $*$ & & \\
\hline M & & & & $*$ & $*$ & & & \\
\hline RP & & & & $*$ & $*$ & $*$ & & \\
\hline R & & & & $*$ & & & & \\
\hline LSO & & & $*$ & $*$ & $*$ & $*$ & & \\
\hline & \multicolumn{2}{|l|}{ Reproducción } & & Conexión & & Reflexión \\
\hline
\end{tabular}

\section{ANÁLISIS DEL PROBLEMA P26}

El problema que se presenta en la ficha 1.26 es un ejercicio que se encuadra en los niveles de reproducción, conexión y reflexión. 
FICHA 1.26.1.

ESTUDIO DEL ENUNCIADO DEL P26

P26.- Dos hermanos heredan una parcela que han de repartirse. La parcela es la región plana limitada por la curva $y=\sqrt{x-1}$ y la recta $y=\frac{1}{2}(x-1)$.

a) Calcular el área de la parcela.

b) Deciden dividir la parcela, en partes iguales, mediante una recta de la forma $y=a,(a>0)$. Hallar el valor de $a$.

\begin{tabular}{|c|c|c|c|c|c|c|c|c|c|c|c|c|c|c|c|}
\hline CONVOCATORIA & \multicolumn{7}{|c|}{ JUNIO } & \multicolumn{8}{|c|}{ SEPTIEMBRE } \\
\hline AÑO & 95 & 96 & 97 & 98 & 99 & 00 & 01 & 02 & 03 & 04 & 05 & 06 & 07 & 08 & 09 \\
\hline OPCIÓN & \multicolumn{8}{|c|}{$\underline{A}$} & \multicolumn{7}{|c|}{ B } \\
\hline TIPO DE PROBLEMA & \multicolumn{7}{|c|}{ TEÓRICO } & & \multicolumn{7}{|c|}{ PRÁCTICO } \\
\hline \multirow{3}{*}{ APARTADOS } & \multirow{3}{*}{\multicolumn{2}{|c|}{$\underline{\text { SI }}$}} & \multicolumn{4}{|c|}{ Forma explícita } & 2 & & & & & & \multirow[b]{2}{*}{6} & \multirow{3}{*}{\multicolumn{2}{|c|}{ NO }} \\
\hline & & & & & & & 2 & & 3 & 4 & 5 & & & & \\
\hline & & & \multicolumn{4}{|c|}{ Forma implícita } & & & & & & & & & \\
\hline VERBO UTILIZADO & \multicolumn{15}{|c|}{ CALCULAR I HALLAR } \\
\hline TIEMPO VERBAL & \multicolumn{15}{|c|}{ INFINITIVO } \\
\hline ESCRITURA & \multicolumn{10}{|c|}{ ALGEBRAICA } & \multicolumn{5}{|c|}{ ECUACIONAL } \\
\hline \multirow{3}{*}{$\begin{array}{l}\text { FALLOS DEL ENUN- } \\
\text { CIADO }\end{array}$} & \multicolumn{10}{|c|}{ PUNTUACIÓN } & & & & & \\
\hline & \multicolumn{10}{|c|}{ ERROR MORFOLÓGICO } & & & & & \\
\hline & \multicolumn{10}{|c|}{ AUSENCIA DE ESPECIFICACIONES } & & & & & \\
\hline \multicolumn{16}{|c|}{ ENUNCIADO ALTERNATIVO } \\
\hline
\end{tabular}

P26.- Dos hermanos heredan una parcela que han de repartirse. La parcela es la región plana limitada por la curva $y=\sqrt{x-1}$ y la recta $y=\frac{1}{2}(x-1)$.

a) Calcula el área de la parcela.

b) Deciden dividir la parcela en partes iguales mediante una recta de la forma $y=a,(a>0)$. Halla el valor de $a$.

NIVELES DE COMPETENCIAS IMPLÍCITAS: Reproducción, conexión y reflexión

El cálculo del área del recinto corresponde al nivel de reproducción del conocimiento estudiado, reconocimiento de equivalentes, ejecución de problemas rutinarios mediante la aplicación de destrezas técnicas y algoritmos habituales. Identifica el problema (RAn1), expone el proceso de cálculo (RAn2) -mediante la integral definida y la regla de Barrow- y justifica las fórmulas utilizadas y los resultados (RAn3).

También, identifica que el modelo es similar a otros modelos vistos con anterioridad (RMn1) y reconoce el problema como ya practicado (RRPn1). 
En el apartado a) del problema que aparece en la ficha 1.26.1 se pide calcular el área delimitada por dos curvas; es, pues, un problema que reproduce situaciones similares a las estudiadas, pero que no son de mera rutina, con lo cual se encuadra, también, en el nivel de conexión.

En este momento, el alumno tiene que pensar en el tratamiento matemático necesario (CPRn1), comprender que tiene que emplear conceptos matemáticos intermedios (CPRn2) y aplicar los conceptos matemáticos apropiados (CPRn3); con el cálculo de una integral definida para el obtener el área delimitada por ambas funciones.

El alumno tiene la ecuación:

$$
\sqrt{x-1}=\frac{1}{2}(x-1)
$$

El alumno razona matemáticamente de manera simple (CAn1) y sigue el encadenamiento de argumentos matemáticos particulares (CAn2), al calcular los puntos de corte entre ambas curvas, evaluando, así, el encadenamiento de argumentos matemáticos particulares (CAn3).

Mediante el manejo de fórmulas, resolviendo y calculando (RLSOn3), obtiene las soluciones: $\quad x=1$ y $x=5$

Valores que corresponden a los límites de la integral definida, evaluando así, el encadenamiento de argumentos matemáticos particulares (CAn3).

Se presenta lenguaje algebraico (la forma de definir la función), aritmético (cálculo de operaciones aritméticas al utilizar la regla de Barrow) y geométrico (visualización del recinto geométrico del que hay que calcular su área,figura 1.26.1), por tanto, se tiene una función definida analíticamente, que es preciso interpretar, seleccionar y cambiar entre diferentes formas de representación (CRn1, CRn2), analítica y gráficamente, diferenciando entre ambas formas de representación (CRn3).

Se presenta lenguaje algebraico, aritmético y geométrico, con lo que interpreta el lenguaje formal y simbólico básico, en situaciones menos conocidas (CLSOn1), maneja afirmaciones sencillas y expresiones con símbolos y fórmulas no rutinarias (CLSOn2).

Aplica las estrategias apropiadas más independientes y calcula la integral (CRPn3), realizando cálculos mediante procedimientos familiares (CLSOn3). 


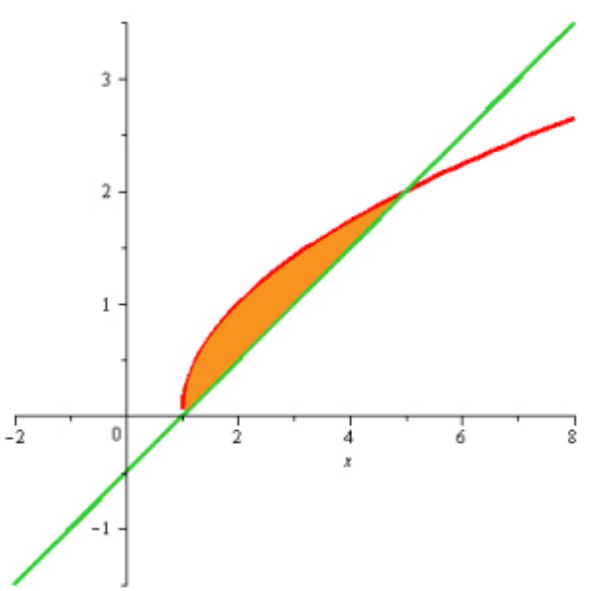

Figura 1.26.1

Sabe expresarse sobre cuestiones matemáticas (CCn1), explica los cálculos y sus propiedades (CCn2) e interpreta las relaciones implicadas (CCn3), la Regla de Barrow, a la vez que sabe interpretar y alternar diferentes modelos, comunicando los resultados (CMn3).

Por consiguiente, desarrolla procedimientos intuitivos ya practicados, pero no rutinarios (CRPn1), eligiendo y aplicando las estrategias apropiadas más independientes que conexionen áreas matemáticas (CRPn2, CRPn3).

$$
\text { Área }=\int_{1}^{5} \sqrt{x-1} d x-\int_{1}^{5} \frac{1}{2}(x-1) d x=\frac{4}{3} u^{2}
$$

El apartado b) del problema que se presenta en la ficha 1.26 corresponde a los niveles de conexión y reflexión. En un nivel de reflexión, planifica estrategias para la resolución de un problema que contiene elementos inusuales, aplica estrategias no rutinarias (RfPRn2), razonando de forma sencilla, distinguiendo formas más amplias de argumentación (RfAn1) y elaborando encadenamientos de argumentos de diferentes tipos (RfAn2).

El alumno piensa en el tratamiento matemático necesario (CPRn1), comprende que tiene que emplear conceptos matemáticos intermedios (CPRn2) calculando la integral definida para la obtención del área comprendida entre ambas funciones, con lo que estructura la situación que debe modelizar (CMn1) y aplica esos conceptos matemáticos apropiados (CPRn3).

Calcula los puntos de corte entre las curvas:

$$
\begin{aligned}
& y=\sqrt{x-1} \quad y=\frac{1}{2}(x-1) \quad \text { e } \quad y=a \\
& a=\sqrt{x-1} \Rightarrow x=a^{2}+1 \\
& a=\frac{1}{2}(x-1) \Rightarrow x=2 a+1
\end{aligned}
$$

El alumno puede calcular el área del recinto mediante el siguiente proceso:

$$
\int_{1}^{1+a^{2}} \sqrt{x-1} d x+\int_{1+a^{2}}^{2 a+1} a d x-\int_{1}^{2 a+1} \frac{1}{2}(x-1) d x=\frac{2}{3}
$$


Como el área del recinto es $\frac{4}{3} u^{2}$, y los hermanos quieren dividir la parcela en partes iguales, ambas partes tendrán el misma área, es decir $\frac{2}{3} u^{2}$.

Sabe expresarse sobre cuestiones matemáticas (CCn1), explica los cálculos y sus propiedades (CCn2) e interpreta las relaciones implicadas (CCn3).

Aplica las estrategias apropiadas más in-

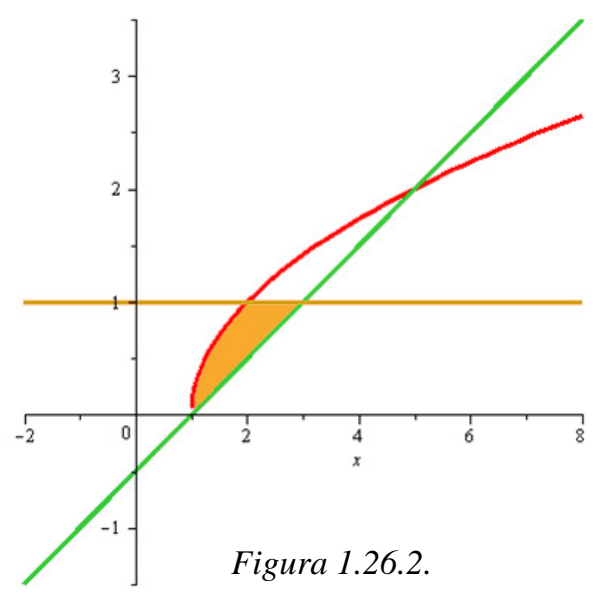
dependientes (CRPn3), y calcula la integral.

$$
\begin{gathered}
\int_{1}^{1+a^{2}} \sqrt{x-1} d x+\int_{1+a^{2}}^{2 a+1} a d x-\int_{1}^{2 a+1} \frac{1}{2}(x-1) d x= \\
\left.\left.\left.=(x-1)^{\frac{3}{2}}\right]_{1}^{1+a^{2}}+a x\right]_{a^{2}+1}^{2 a+1}-\frac{1}{4}(x-1)^{2}\right]_{1}^{2 a+1}=-\frac{1}{3} a^{3}+a^{2}
\end{gathered}
$$

Resuelve la ecuación:

$$
-\frac{1}{3} a^{3}+a^{2}=\frac{2}{3}
$$

Obteniendo soluciones:

$$
a_{1}=1, a_{2}=1+\sqrt{3} \text { y } a_{3}=1-\sqrt{3}
$$

El alumno interpreta el lenguaje formal y simbólico básico, en situaciones menos conocidas (CLSOn1), maneja afirmaciones sencillas y expresiones con símbolos y fórmulas no rutinarias (CLSOn2) y utiliza variables y realiza cálculos mediante procedimientos familiares (CLSOn3).

La solución $a_{2}=1+\sqrt{3}$ no es válida, dado que $1+\sqrt{3}>2$ y para el límite del recinto $x=5$ se obtiene $y=2$, luego ese valor excede los límites del recinto.

La solución $a_{3}=1-\sqrt{3}$ no es válida, dado que $1-\sqrt{3}<0$ y el enunciado pide $a>0$.

Sabe expresarse sobre cuestiones matemáticas (CCn1), explica los cálculos y sus propiedades (CCn2) e interpreta las relaciones implicadas (CCn3). 
Sin embargo, el alumno también puede hacer el área del recinto considerando la integral respecto al eje $O Y$.

Al realizar este procedimiento se encuentra en un nivel de reflexión, planifica estrategias para la resolución de un problema que contiene elementos inusuales, aplica estrategias no rutinarias (RfPRn2), razonando de forma sencilla, distinguiendo formas más amplias de argumentación (RfAn1) y elaborando encadenamientos de argumentos de diferentes tipos (RfAn2).

$$
\begin{aligned}
y & =\sqrt{x-1} \Rightarrow x=y^{2}+1 \\
y=\frac{1}{2}(x-1) \Rightarrow x & =2 y+1
\end{aligned}
$$

Y calcula la integral:

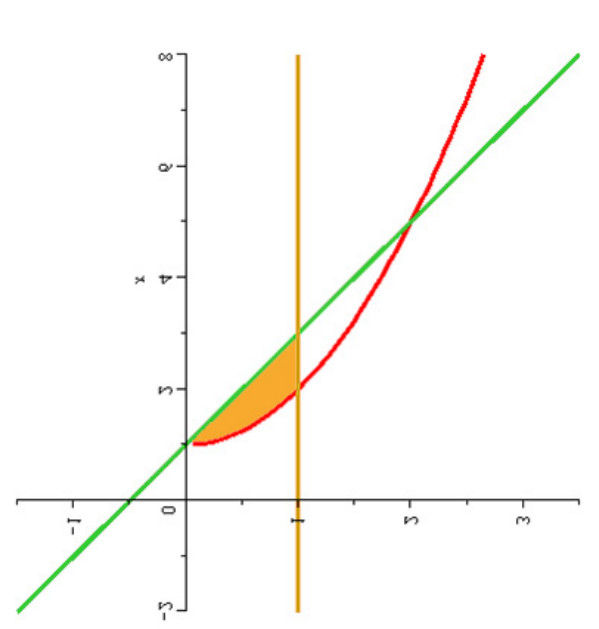

Figura 1.26.3

$$
\int_{0}^{a}(2 y+1) d x-\int_{0}^{a}\left(y^{2}+1\right) d x=\frac{2 a^{3}}{3}=\frac{2}{3}
$$

Que tiene como solución real $a=1$

Finalmente, el alumno describe los resultados obtenidos (RCn3) al tiempo que expone problemas más allá de la reproducción de los ya practicados (RfRPn1), sabe explicar cuestiones matemáticas, cálculos y resultados (RfCn1) y explica asuntos que implican relaciones complejas (RfCn2).

\begin{tabular}{|l|c|c|c|c|c|c|c|c|}
\hline \multicolumn{6}{|l|}{ FICHA 1.26.2. COMPETENCIAS IMPLÍCITAS EN LA RESOLUCIÓN DEL P26 } \\
\hline & Nivel 1 & Nivel 2 & Nivel 3 & Nivel 1 & Nivel 2 & Nivel 3 & Nivel 1 & Nivel 2 \\
\hline PR & $*$ & $*$ & $*$ & $*$ & $*$ & $*$ & & $*$ \\
\hline A & $*$ & $*$ & $*$ & $*$ & $*$ & $*$ & $*$ & $*$ \\
\hline C & $*$ & $*$ & $*$ & $*$ & $*$ & $*$ & $*$ & $*$ \\
\hline M & $*$ & & $*$ & $*$ & & $*$ & & \\
\hline RP & $*$ & & $*$ & $*$ & $*$ & $*$ & $*$ & \\
\hline R & & & & $*$ & $*$ & $*$ & & \\
\hline LSO & \multicolumn{2}{|l|}{ Reproducción } & & Conexión & $*$ & $*$ & Reflexión \\
\hline
\end{tabular}




\section{ANÁLISIS DEL PROBLEMA P27}

\section{FICHA 1.27.1. \\ ESTUDIO DEL ENUNCIADO DEL P27}

P27.- Dada la función $f(x)=a x+\frac{b}{x}$, siendo $a$ y $b$ constantes positivas, se pide:

i) Demostrar que el mínimo valor de $f(x)$ en $(0,+\infty)$ es $2 \sqrt{a b}$.

ii) Deducir que $\sqrt{a b} \leq \frac{a+b}{2}$.

iii) Para $a=2, b=8$, hallar las asíntotas y la gráfica de $f(x)$ en $(0,+\infty)$.

\begin{tabular}{|c|c|c|c|c|c|c|c|c|c|c|c|c|}
\hline CONVOCATORIA & \multicolumn{5}{|c|}{ JUNIO } & \multicolumn{7}{|c|}{ SEPTIEMBRE } \\
\hline AÑO & \begin{tabular}{l|l}
95 & 96
\end{tabular} & 97 & \begin{tabular}{l|l|}
98 & 99 \\
\end{tabular} & 00 & $\underline{01}$ & \begin{tabular}{l|l}
02 & 03
\end{tabular} & 04 & 05 & 06 & 07 & 08 & 09 \\
\hline OPCIÓN & \multicolumn{5}{|c|}{ A } & \multicolumn{7}{|c|}{$\underline{B}$} \\
\hline TIPO DE PROBLEMA & \multicolumn{5}{|c|}{ TEÓRICO } & \multicolumn{7}{|c|}{ PRÁCTICO } \\
\hline \multirow{3}{*}{ APARTADOS } & \multirow{3}{*}{$\underline{\text { SI }}$} & \multicolumn{3}{|c|}{ Forma explícita } & & 3 & & \multirow[b]{2}{*}{5} & \multirow{2}{*}{\multicolumn{2}{|c|}{6}} & \multirow{3}{*}{\multicolumn{2}{|c|}{ NO }} \\
\hline & & & & & 2 & 3 & 4 & & & & & \\
\hline & & \multicolumn{3}{|c|}{ Forma implícita } & 2 & & & & & & & \\
\hline VERBO UTILIZADO & \multicolumn{12}{|c|}{ DEMOSTRAR / DEDUCIR / HALLAR } \\
\hline TIEMPO VERBAL & \multicolumn{12}{|c|}{ INFINITIVO } \\
\hline ESCRITURA & \multicolumn{7}{|c|}{ ALGEBRAICA } & \multicolumn{5}{|c|}{ FUNCIONAL } \\
\hline \multirow{3}{*}{$\begin{array}{l}\text { FALLOS DEL ENUN- } \\
\text { CIADO }\end{array}$} & \multicolumn{7}{|c|}{ PUNTUACIÓN } & & & & & \\
\hline & \multicolumn{7}{|c|}{ ERROR MORFOSINTÁCTICO } & & & & & \\
\hline & \multicolumn{7}{|c|}{ AUSENCIA DE ESPECIFICACIONES } & & & & & \\
\hline \multicolumn{13}{|c|}{ ENUNCIADO ALTERNATIVO } \\
\hline
\end{tabular}

P27.- Dada la función $f(x)=a x+\frac{b}{x}$, siendo $a$ y $b$ constantes positivas, se pide:

i) Demuestra que el mínimo valor de $f(x)$ en $(0,+\infty)$ es $2 \sqrt{a b}$.

ii) Deduce a partir del apartado anterior que $\sqrt{a b} \leq \frac{a+b}{2}$.

iii) Para $a=2, b=8$, determina las ecuaciones de las asíntotas.

iv) Dibuja la gráfica de $f(x)$ en $(0,+\infty)$.

NIVELES DE COMPETENCIAS IMPLÍCITAS: Reproducción, conexión y reflexión

El problema que se presenta en la ficha 1.27.1 corresponde a los niveles de reproducción, conexión y reflexión. 
En el apartado a) del problema que aparece en la ficha 1.27 .1 se pide calcular el mínimo de una función; es, pues, un problema que reproduce situaciones similares a las estudiadas, pero que no son de mera rutina, con lo cual se encuadra en el nivel de conexión.

El alumno identifica el problema (RAn1), realiza explicaciones sencillas (RCn2) y expone el proceso de cálculo (RAn1).

Para calcular máximos y mínimos relativos hay que encontrar los valores que anulan la primera derivada

$$
f^{\prime}(x)=a-\frac{b}{x^{2}}
$$

Resolviendo la ecuación $f^{\prime}(x)=0$ obtiene las soluciones:

$$
\begin{gathered}
x_{1}=\sqrt{\frac{b}{a}} \text { y } x_{2}=-\sqrt{\frac{b}{a}} \\
f^{\prime}(x)=a-\frac{b}{x^{2}} \\
x_{1}=\sqrt{\frac{b}{a}} \text { y } x_{2}=-\sqrt{\frac{b}{a}}
\end{gathered}
$$

La resolución de la ecuación corresponde al nivel de reproducción, manejando procedimientos y fórmulas, resolviendo y calculando (RLSOn3).

Los valores $x_{1}=\sqrt{\frac{b}{a}}$ y $x_{2}=-\sqrt{\frac{b}{a}}$ son números reales, pues por hipótesis del enunciado $a>0$ y $b>0$.

El alumno sabe expresarse sobre cuestiones matemáticas (CCn1), explica los cálculos y sus propiedades (CCn2) e interpreta las relaciones implicadas (CCn3).

Hay que demostrar que el mínimo valor de $f(x)$ en $(0,+\infty)$ es $2 \sqrt{a b}$, lo cual se comprueba con el cálculo de la segunda derivada que $x_{1}=\sqrt{\frac{b}{a}}$ es el valor que resuelve la cuestión, porque $x_{1} \in(0,+\infty)$.

El alumno razona matemáticamente de manera simple (CAn1) y sigue el encadenamiento de argumentos matemáticos particulares (CAn2). 


$$
f^{\prime \prime}(x)=\frac{2 b}{x^{3}} \Rightarrow f^{\prime \prime}\left(\sqrt{\frac{b}{a}}\right)>0
$$

Explica los cálculos y sus propiedades (CCn2) e interpreta las relaciones implicadas (CCn3)

También se encuadra en el nivel de conexión. En la resolución del problema, el alumno debe pensar en el tratamiento matemático necesario (CPRn1), comprender que tiene que emplear conceptos matemáticos intermedios (CPRn2), y aplicar esos conceptos matemáticos apropiados (CPRn3).

Maneja afirmaciones sencillas y expresiones con símbolos y fórmulas no rutinarias (CLSOn2) -radicales- y utiliza variables y realiza cálculos mediante procedimientos familiares (CLSOn3).

$$
f\left(\sqrt{\frac{b}{a}}\right)=a \sqrt{\frac{b}{a}}+\frac{b}{\sqrt{\frac{b}{a}}}=\sqrt{a b}+\sqrt{a b}=2 \sqrt{a b}
$$

El apartado b) del problema 1.27.1 se encuadra en el nivel de reflexión por parte del estudiante para planificar y aplicar estrategias, en la resolución de un problema que contenga elementos inusuales.

En el apartado a) ya se ha demostrado que el mínimo valor de la función es $2 \sqrt{a b}$; como $f(1)=a+b$, se tiene que:

$$
2 \sqrt{a b}<a+b \Rightarrow \sqrt{a b}<\frac{a+b}{2}
$$

El alumno razona de forma sencilla, distinguiendo formas más amplias de argumentación (RfAn1) y reflexiona llevando a cabo una comunicación sobre la construcción del modelo (RfMn2), aplica estrategias no rutinarias (RfPRn2) y sabe explicar cuestiones matemáticas, cálculos y resultados (RfCn1).

El apartado b) del problema 1.27.1 también se encuadra en el nivel de conexión, reproduce una situación similar a las estudiadas, pero que no es una mera rutina, dado que en la resolución del problema, el alumno debe pensar en el tratamiento matemático necesario (CPRn1), comprender que tiene que emplear conceptos matemáticos intermedios (CPRn2) y aplicar esos conceptos matemáticos apropiados (CPRn3). 
Como ya se ha expuesto anteriormente, niveles inferiores están implícitos en el estudio de otros niveles de orden superior.

Sabe expresarse sobre cuestiones matemáticas (CCn1), explicar los cálculos y sus propiedades (CCn2) e interpretar las relaciones implicadas (CCn3), a la vez

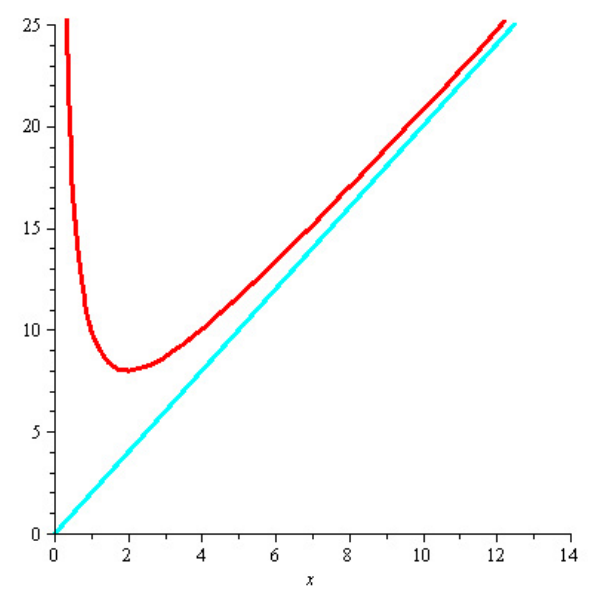

Figura 1.27 que debe interpretar $y$ alternar diferentes modelos, comunicando los resultados (CMn3).

El apartado c) del problema 1.27.1 se encuadra en el nivel de reproducción del conocimiento estudiado, reconocimiento de equivalentes, ejecución de problemas rutinarios, aplicación de destrezas técnicas y de algoritmos habituales, manejo de expresiones y fórmulas establecidas $y$

realización de cálculos.

Con este razonamiento identifica el problema (RAn1), reconoce representaciones de los datos del ejercicio (RPRn1), comprende la expresión escrita, (RCn1), identifica que es un modelo similar a otros vistos con anterioridad, (RMn1) y le reconoce como problema ya practicado (RRPn1), le reproduce de manera cerrada (RRPn2) y le resuelve (RRPn3).

Para $a=2, b=8$, se tiene la función $f(x)=2 x+\frac{8}{x}$

Utilizando los apartados anteriores:

$$
f^{\prime}(x)=2-\frac{8}{x^{2}}
$$

Y el mínimo se tiene en el punto $(2,8)$.

Como el enunciado pide las asíntotas en el intervalo $(0,+\infty)$ para calcular la asíntota vertical se calcula el límite cuando $x$ tiende a cero por la derecha.

Esta argumentación indica que el alumno razona matemáticamente de manera simple (CAn1), estructura la situación que debe modelizar ( $\mathrm{CMn} 1)$ al tiempo que sabe expresarse sobre cuestiones matemáticas (CCn1) explicando los cálculos y sus propiedades (CCn2). 


$$
\lim _{x \rightarrow 0^{+}}\left(2 x+\frac{8}{x}\right)=+\infty
$$

Con lo que $x=0$ es asíntota vertical.

Asíntota horizontal:

$$
\lim _{x \rightarrow+\infty}\left(2 x+\frac{8}{x}\right)=+\infty
$$

\section{No tiene asíntota horizontal}

Asíntota oblícua:

$$
\begin{gathered}
\lim _{x \rightarrow+\infty} \frac{f(x)}{x}=2 \quad \text { y } \quad \lim _{x \rightarrow+\infty}\left(2 x+\frac{8}{x}-2 x\right)=0 \\
y=2 x \text { es una asíntota oblicua. }
\end{gathered}
$$

El alumno interpreta formas de representación (CRn1), selecciona y cambia entre diferentes formas de representación (CRn2) y traduce y diferencia entre distintas formas de representación (CRn3), al tiempo que utiliza variables y realiza ecuaciones y cálculos mediante procedimientos familiares (CLSOn3), como es el cálculo de los límites.

La representación de la gráfica de la función es la figura 1.27.

El alumno justifica las fórmulas utilizadas y los resultados (RAn3), describe los resultados obtenidos (RCn3) y comunica de manera elemental los resultados del modelo (RMn3).

\begin{tabular}{|l|c|c|c|c|c|c|c|c|}
\hline \multicolumn{6}{|l}{ FICHA 1.27.2. } \\
\hline & Nivel 1 & Nivel 2 & Nivel 3 & Nivel 1 & Nivel 2 & Nivel 3 & Nivel 1 & Nivel 2 \\
\hline PR & $*$ & $*$ & $*$ & $*$ & $*$ & $*$ & & $*$ \\
\hline A & $*$ & $*$ & $*$ & $*$ & $*$ & $*$ & $*$ & \\
\hline C & $*$ & $*$ & $*$ & $*$ & $*$ & $*$ & $*$ & \\
\hline M & $*$ & & $*$ & $*$ & & $*$ & & $*$ \\
\hline RP & $*$ & $*$ & $*$ & & & & & \\
\hline R & & & & $*$ & $*$ & $*$ & & \\
\hline LSO & & & $*$ & & $*$ & $*$ & & \\
\hline & \multicolumn{2}{|l|}{ Reproducción } & & Conexión & & Reflexión \\
\hline
\end{tabular}




\section{ANÁLISIS DEL PROBLEMA P30}

\section{FICHA 1.30.1. \\ ESTUDIO DEL ENUNCIADO DEL P30}

P30.- Dada la función $F(x)=\int_{0}^{x}\left(t^{2}-1\right) e^{-t^{2}} d t$, definida para todo $x \in R$,

a) Calcular $F^{\prime}(x)$, estudiar el crecimiento de $F(x)$ y hallar las abscisas de sus máximos y mínimos relativos.

b) Calcula $F^{\prime \prime}(x)$, estudiar la concavidad y convexidad de $F(x)$ y hallar las abscisas de sus puntos de inflexión.

\begin{tabular}{|c|c|c|c|c|c|c|c|c|c|c|c|}
\hline \multirow{2}{*}{$\begin{array}{l}\text { CONVOCATORIA } \\
\text { AÑO }\end{array}$} & \multicolumn{5}{|c|}{$\underline{\mathrm{JUNIO}}$} & \multicolumn{6}{|c|}{ SEPTIEMBRE } \\
\hline & \begin{tabular}{l|l}
95 & 96
\end{tabular} & 97 & \begin{tabular}{l|l}
98 & 99
\end{tabular} & 00 & 01 & \begin{tabular}{l|l}
$\underline{02}$ & 03
\end{tabular} & 04 & 05 & \begin{tabular}{l|l}
06 & 07
\end{tabular} & 08 & 09 \\
\hline OPCIÓN & \multicolumn{5}{|c|}{$\underline{A}$} & \multicolumn{6}{|c|}{ B } \\
\hline TIPO DE PROBLEMA & \multicolumn{5}{|c|}{ TEÓRICO } & \multicolumn{6}{|c|}{ PRÁCTICO } \\
\hline \multirow{3}{*}{ APARTADOS } & \multirow{3}{*}{$\underline{\text { SI }}$} & \multicolumn{3}{|c|}{ Forma explícita } & 2 & & & \multicolumn{2}{|c|}{\begin{tabular}{l|l} 
&
\end{tabular}} & \multirow{3}{*}{\multicolumn{2}{|c|}{ NO }} \\
\hline & & & & & 2 & 3 & 4 & \multirow[t]{2}{*}{5} & 6 & & \\
\hline & & \multicolumn{3}{|c|}{ Forma implícita } & 2 & & & & & & \\
\hline VERBO UTILIZADO & \multicolumn{11}{|c|}{ CALCULAR / HALLAR } \\
\hline TIEMPO VERBAL & \multicolumn{11}{|c|}{ INFINITIVO } \\
\hline ESCRITURA & \multicolumn{7}{|c|}{ MULTIPLICATIVA } & \multicolumn{4}{|c|}{ FUNCIONAL } \\
\hline \multirow{3}{*}{$\begin{array}{l}\text { FALLOS DEL ENUN- } \\
\text { CIADO }\end{array}$} & \multicolumn{7}{|c|}{ PUNTUACIÓN } & & & & \\
\hline & \multicolumn{7}{|c|}{ ERROR MORFOLÓGICO } & & & & \\
\hline & \multicolumn{7}{|c|}{ AUSENCIA DE ESPECIFICACIONES } & & & & \\
\hline \multicolumn{12}{|c|}{ ENUNCIADO ALTERNATIVO } \\
\hline
\end{tabular}

P30.- Dada la función $F(x)=\int_{0}^{x}\left(t^{2}-1\right) e^{-t^{2}} d t$, definida para todo $x \in R$,

a) Calcula $F^{\prime}(x)$, estudia el crecimiento de $F(x)$ y halla las abscisas de sus máximos y mínimos relativos.

b) $\underline{\text { Calcula }} F^{\prime \prime}(x)$, estudia la concavidad y convexidad de $F(x)$ y halla las abscisas de sus puntos de inflexión.

\section{NIVELES DE COMPETENCIAS IMPLÍCITAS: Conexión}

El problema que se presenta en la ficha 1.30.1 reproduce situaciones similares a las estudiadas en clase, pero no son de mera rutina, por tanto se trata de un nivel de conexión.

Para estudiar la monotonía de la función es preciso pensar en el tratamiento matemático necesario (CPRn1), analizar el signo de la primera derivada, con lo 
que comprende que tiene que emplear conceptos matemáticos intermedios (CPRn2), aplicar los conceptos matemáticos apropiados, (CPRn3), además tiene que estructurar la situación que debe modelizar (CMn1) y traducir en la práctica el modelo a seguir, que es algo diferente de los estudiados (CMn2).

La función $f(t)=\left(t^{2}-1\right) e^{-t^{2}}$ es continua en $R$.

Utilizando el teorema fundamental del cálculo integral, la función $F(x)$ es derivable y su derivada es:

$$
F^{\prime}(x)=\left(x^{2}-1\right) e^{-x^{2}}
$$

El alumno razona matemáticamente de manera simple (CAn1) y evalúa el encadenamiento de argumentos matemáticos particulares (CAn3).

Desarrolla procedimientos intuitivos ya practicados, pero no rutinarios (CRPn1), eligiendo y aplicando las estrategias apropiadas más independientes que conexionen áreas matemáticas (CRPn2, CRPn3).

Interpreta el lenguaje formal y simbólico básico, en situaciones menos conocidas (CLSOn1), maneja afirmaciones sencillas y expresiones con símbolos y fórmulas no rutinarias (CLSOn2) y utiliza variables y realiza cálculos mediante procedimientos familiares (CLSOn3).

Resolviendo la ecuación $F^{\prime}(x)=0$, obtiene soluciones:

$$
x_{1}=-1 \text { y } \quad x_{2}=1
$$

Estudia el signo de la función derivada en los intervalos $(-\infty,-1),(-1,1)$ y $(1, \infty)$, de lo que se deduce:

$$
\begin{gathered}
\text { Crece en los intervalos: }(-\infty,-1) \cup(1, \infty) \text { y } \\
\text { Decrece en el intervalo }(-1,1)
\end{gathered}
$$

Efectuar este paso supone que sabe expresarse sobre cuestiones matemáticas (CCn1) explicando los cálculos y sus propiedades (CCn2) e interpretando las relaciones implicadas $(\mathrm{CCn} 3)$.

A partir del estudio del crecimiento de la función deduce que ésta tiene:

Máximo relativo en el punto de abscisa $x=-1$ y

mínimo relativo en el punto de abscisa $x=1$ 
En el apartado b) tiene que estudiar la curvatura de la función $F(x)$, para lo que calcula la segunda derivada.

$$
F^{\prime \prime}(x)=\left(-2 x^{3}+4 x\right) e^{-x^{2}}
$$

Resolviendo la ecuación $F^{\prime \prime}(x)=0$, obtiene soluciones:

$$
x_{1}=0, x_{2}=-\sqrt{2} \text { y } x_{3}=\sqrt{2}
$$

Valores que corresponden a las abscisas de los puntos de inflexión.

Estudia el signo de la función $F^{\prime \prime}(x)$ en los intervalos $(-\infty,-\sqrt{2}),(-\sqrt{2}, 0)$ $(0, \sqrt{2})$ y $(\sqrt{2}, \infty)$, de lo que se deduce:

Es convexa en los intervalos: $(-\infty,-\sqrt{2}) \cup(0, \sqrt{2})$ y cóncava en los intervalos $(-\sqrt{2}, 0) \cup(\sqrt{2}, \infty)$.

Efectuar este paso supone que sabe expresarse sobre cuestiones matemáticas (CCn1) explicando los cálculos y sus propiedades (CCn2) e interpretando las relaciones implicadas (CCn3).

También puede utilizar la segunda derivada, $F^{\prime \prime}(x)$ para obtener máximos y/o mínimos.

$F^{\prime \prime}(1)=e^{-1}(-2+4)=\frac{2}{e}>0 \Rightarrow x=1$, es un mínimo relativo.

$F^{\prime \prime}(-1)=e^{-1}(2-4)=-\frac{2}{e}<0 \Rightarrow x=-1$, es un máximo relativo.

El alumno describe los resultados obtenidos (RCn3) y comunica de manera

\begin{tabular}{|c|c|c|c|c|c|c|c|c|}
\hline \multicolumn{2}{|c|}{ FICHA 1.30.2. } & \multicolumn{7}{|c|}{ COMPETENCIAS IMPLÍCITAS EN LA RESOLUCIÓN DEL P31 } \\
\hline & Nivel 1 & Nivel 2 & Nivel 3 & Nivel 1 & Nivel 2 & Nivel 3 & Nivel 1 & Nivel 2 \\
\hline PR & & & & * & * & * & & \\
\hline A & & & & * & & * & & \\
\hline C & & & * & * & * & * & & \\
\hline M & & & * & * & * & & & \\
\hline $\mathbf{R P}$ & & & & * & * & * & & \\
\hline \multicolumn{9}{|l|}{$\mathbf{R}$} \\
\hline \multirow[t]{2}{*}{ LSO } & & & & * & * & * & & \\
\hline & \multicolumn{3}{|c|}{ Reproducción } & \multicolumn{3}{|c|}{ Conexión } & \multicolumn{2}{|c|}{ Reflexión } \\
\hline
\end{tabular}
elemental los resultados del modelo (RMn3). 


\section{ANÁLISIS DEL PROBLEMA P32}

\section{FICHA 1.32.1.}

ESTUDIO DEL ENUNCIADO DEL P32

P32.- a) Enunciar el teorema de los incrementos finitos.

b) Una función $f(x)$, derivable en toda la recta, verifica:

$$
f(0)=-2, \quad f(2)=6
$$

b1) Aplicando el teorema anterior, probar que existe un punto $c$ en el intervalo $(0,2)$ tal que $f^{\prime}(c)=4$.

b2) Si además $f(x)$ tiene derivada continua y $f^{\prime}(0)=0$, probar que hay un punto en el intervalo $(0,2)$ en el que la derivada de $f$ toma el valor 3 .

\begin{tabular}{|c|c|c|c|c|c|c|c|c|c|c|c|c|c|c|c|}
\hline CONVOCATORIA & \multicolumn{7}{|c|}{ JUNIO } & \multicolumn{8}{|c|}{ SEPTIEMBRE } \\
\hline AÑO & 95 & 96 & 97 & 98 & 99 & 00 & 01 & $\underline{02}$ & 03 & 04 & 05 & 06 & 07 & 08 & 09 \\
\hline OPCIÓN & \multicolumn{8}{|c|}{$\underline{A}$} & \multicolumn{7}{|c|}{ B } \\
\hline TIPO DE PROBLEMA & \multicolumn{7}{|c|}{ TEÓRICO } & \multicolumn{8}{|c|}{ PRÁCTICO } \\
\hline \multirow{3}{*}{ APARTADOS } & \multirow{3}{*}{\multicolumn{2}{|c|}{ SI }} & \multicolumn{4}{|c|}{ Forma explícita } & 2 & & & & & \multirow{3}{*}{\multicolumn{2}{|c|}{ NO }} \\
\hline & & & & & & & 2 & & 3 & 4 & 5 & & 6 & & \\
\hline & & & \multicolumn{4}{|c|}{ Forma implícita } & & & & & & & & & \\
\hline VERBO UTILIZADO & \multicolumn{15}{|c|}{ ENUNCIAR I PROBAR } \\
\hline TIEMPO VERBAL & \multicolumn{15}{|c|}{ INFINITIVO } \\
\hline ESCRITURA & \multicolumn{10}{|c|}{ MULTIPLICATIVA } & \multicolumn{5}{|c|}{ FUNCIONAL } \\
\hline \multirow{3}{*}{$\begin{array}{l}\text { FALLOS DEL ENUN- } \\
\text { CIADO }\end{array}$} & \multicolumn{10}{|c|}{ PUNTUACIÓN } & & & & & \\
\hline & \multicolumn{10}{|c|}{ ERROR MORFOLÓGICO } & & & & & \\
\hline & \multicolumn{10}{|c|}{ AUSENCIA DE ESPECIFICACIONES } & & & & & \\
\hline
\end{tabular}

P32.- a) Enuncia el teorema de los incrementos finitos.

b) Una función $f(x)$, derivable en toda la recta, verifica:

$$
f(0)=-2, \quad f(2)=6
$$

b1) Aplicando el teorema anterior, prueba que existe un punto $c$ en el intervalo $(0,2)$ tal que $f^{\prime}(c)=4$.

b2) Si además $f(x)$ tiene derivada continua y $f^{\prime}(0)=0$, prueba que hay un punto en el intervalo $(0,2)$ en el que la derivada de $f(x)$ toma el valor 3 . 
El apartado a) del problema que aparece en la ficha 1.32 es una definición teórica, por tanto es una mera reproducción del conocimiento estudiado.

Comienza con la identificación del problema, (RAn1), interpreta representaciones estándar de objetos matemáticos (RRn2) e interpreta el lenguaje formal y simbólico rutinario (RLSOn2).

El apartado b) del problema que aparece en la ficha 1.32, se encuadra en el nivel de conexión, dado que en la resolución del problema, el alumno debe pensar en el tratamiento matemático necesario (CPRn1), comprender que tiene que emplear conceptos matemáticos intermedios (CPRn2), y aplicar esos conceptos matemáticos apropiados (CPRn3).

El enunciado dice que aplique el teorema de los incrementos finitos y que "la función $f(x)$ es derivable".

$$
\text { Se tienen los valores } f(0)=-2 \text { y } f(2)=6
$$

Dado que el enunciado dice: "aplicando el teorema de los incrementos finitos" se tiene:

$$
f^{\prime}(c)=\frac{f(2)-f(0)}{2-0}=\frac{6-(-2)}{2}=4, \text { con } c \in(0,2)
$$

El alumno maneja procedimientos y fórmulas, resolviendo y calculando (RLSOn3), razona matemáticamente de manera simple (CAn1) y sigue el encadenamiento de argumentos matemáticos particulares (CAn2), sabe expresarse sobre cuestiones matemáticas (CCn1) y explica los cálculos y sus propiedades (CCn2).

Luego:

$$
\text { Existe } c \in(0,2) \text { con } f^{\prime}(c)=4
$$

El alumno evalúa el encadenamiento de argumentos matemáticos particulares (CAn3) e interpreta las relaciones implicadas (CCn3). Asimismo, traduce en la práctica el modelo a seguir que es algo diferente de los estudiados (CMn2) y desarrolla procedimientos intuitivos ya practicados pero no rutinarios (CRPn1).

En la resolución del apartado b2) del problema de la ficha 1.32.1 es preciso, también, pensar en el tratamiento matemático necesario (CPRn1), comprender que tiene que emplear conceptos matemáticos intermedios (CPRn2), y aplicar 
esos conceptos matemáticos apropiados (CPRn3), nos encontramos, pues, en el nivel de conexión.

El alumno razona matemáticamente de manera simple (CAn1) y sigue el encadenamiento de argumentos matemáticos particulares (CAn2).

El enunciado dice que $f^{\prime}(x)$ es una función continua y que $f^{\prime}(0)=0$.

Dado que el apartado anterior se ha demostrado que $\exists c \in(0,2)$, con $f^{\prime}(c)=4$, utilizando el teorema de los valores intermedios de Darboux, se tiene que:

En el intervalo $(0, c) \subset(0,2), f^{\prime}(x)$ toma todos los valores intermedios entre 0 y 4.

$$
\begin{gathered}
f^{\prime}(0)=0<3<4=f^{\prime}(c) \\
\text { Luego, } \exists d \in(0, c) \subset(0,2) \text { con } f^{\prime}(d)=3
\end{gathered}
$$

El alumno sabe expresarse sobre cuestiones matemáticas (CCn1), explica los cálculos y sus propiedades (CCn2) e interpreta las relaciones implicadas (CCn3), a la par que evalúa el encadenamiento de argumentos matemáticos particulares (CAn3) y comunica de manera elemental los resultados del modelo (RMn3).

\begin{tabular}{|l|c|c|c|c|c|c|c|c|}
\hline \multicolumn{6}{|l|}{ FICHA 1.32.2. COMPETENCIAS IMPLÍCITAS EN LA RESOLUCIÓN DEL P32 } \\
\hline & Nivel 1 & Nivel 2 & Nivel 3 & Nivel 1 & Nivel 2 & Nivel 3 & Nivel 1 & Nivel 2 \\
\hline PR & & & & $*$ & $*$ & $*$ & & \\
\hline A & $*$ & & & $*$ & $*$ & $*$ & & \\
\hline C & & & & $*$ & $*$ & $*$ & & \\
\hline M & & & $*$ & $*$ & $*$ & & & \\
\hline RP & & & & $*$ & & & & \\
\hline R & & $*$ & & $*$ & & & & \\
\hline LSO & & $*$ & $*$ & & & & & \\
\hline & Reproducción & & Conexión & & Reflexión \\
\hline
\end{tabular}

\section{ANÁLISIS DEL PROBLEMA P35}

En el problema que se presenta en la ficha 1.35.1 se encuentran presentes los tres niveles de competencia matemática: Reproducción, conexión y re- 
flexión. El apartado b) corresponde al nivel de reflexión, pues es una función definida a trozos y el estudio depende de parámetros; los otros apartados corresponden al niveles competenciales inferiores.

FICHA 1.35.1.

\section{ESTUDIO DEL ENUNCIADO DEL P35}

P35.- a) Hallar $a$ y $b$ para que la función siguiente sea continua en $x=0$ :

$$
f(x)=\left\{\begin{array}{ccc}
\ln (e+\operatorname{sen} x) & \text { si } & x<0 \\
x^{3}+a x+b & \text { si } & x \geq 0
\end{array}\right.
$$

b) Hallar $a$ y $b$ para que $f(x)$ sea derivable en $x=0$.

c) Calcular $f^{\prime}\left(-\frac{\pi}{2}\right)$.

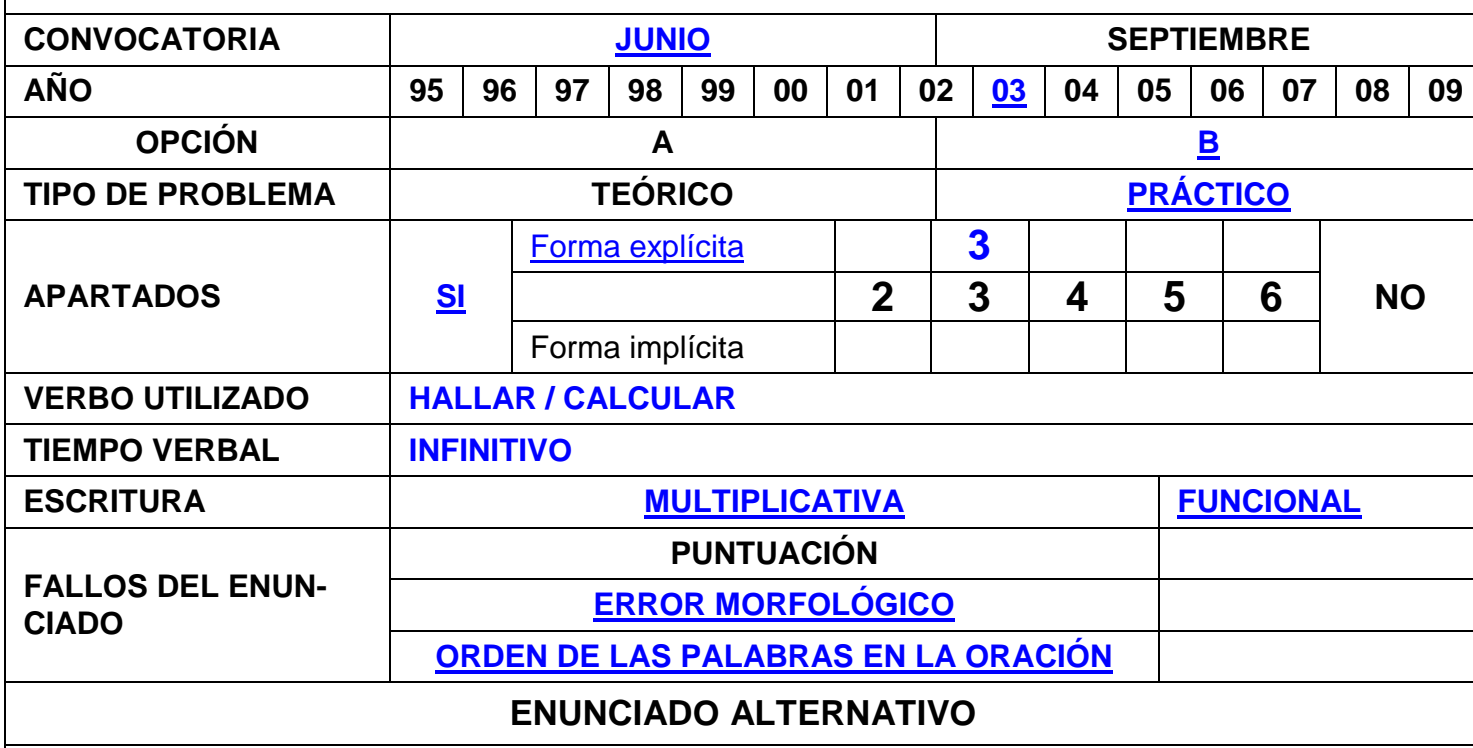

P35.- a) Halla $a$ y $b$ para que la siguiente función sea continua en $x=0$ :

$$
f(x)=\left\{\begin{array}{ccc}
\ln (e+\operatorname{sen} x) & \text { si } & x<0 \\
x^{3}+a x+b & \text { si } & x \geq 0
\end{array}\right.
$$

b) Halla $a$ y $b$ para que $f(x)$ sea derivable en $x=0$

c) Calcula $f^{\prime}\left(-\frac{\pi}{2}\right)$.

NIVELES DE COMPETENCIAS IMPLÍCITAS: Reproducción, conexión y reflexión

El apartado a) del problema que se presenta en el ficha 1.35.1, es decir, el estudio de la continuidad y derivabilidad en el punto $x=0$, corresponde a un nivel 
de conexión, pues reproduce situaciones similares a las estudiadas en la instrucción, pero no son de mera rutina.

El alumno debe pensar en el tratamiento matemático necesario (CPRn1). Después, comprende que tiene que emplear conceptos matemáticos intermedios (CPRn2) en esta ocasión, el cálculo de límites, y aplica los conceptos matemáticos apropiados (CPRn3), razona matemáticamente de manera simple (CAn1), sigue el encadenamiento de argumentos matemáticos particulares (CAn2) y evalúa dicho encadenamiento (CAn3).

$$
\begin{gathered}
\lim _{x \rightarrow 0^{-}} f(x)=\lim _{x \rightarrow 0^{-}}(\ln (e+\operatorname{sen}(x)))=1 \\
\lim _{x \rightarrow 0^{+}} f(x)=\lim _{x \rightarrow 0^{+}} x^{3}+a x+b=b \\
f(0)=b
\end{gathered}
$$

Para que $f(x)$ sea continua en $x=0$ :

$$
f(0)=\lim _{x \rightarrow 0^{-}} f(x)=\lim _{x \rightarrow 0^{+}} f(x)
$$

Con lo que:

$$
b=1, \quad \forall a \in R
$$

Sabe expresarse sobre cuestiones matemáticas, (CCn1) explica los cálculos (CCn2) e interpreta las relaciones implicadas (CCn3). Tras estructurar la situación que debe modelizar (CMn1), traduce en la práctica el modelo a seguir (CMn2) que es algo diferente a los estudiados, interpreta formas de representación (CRn1) y sabe interpretar diferentes modelos y comunicar los resultados (CMn3). Figura 1.35.

Es un problema ya practicado, pero no es ruti-

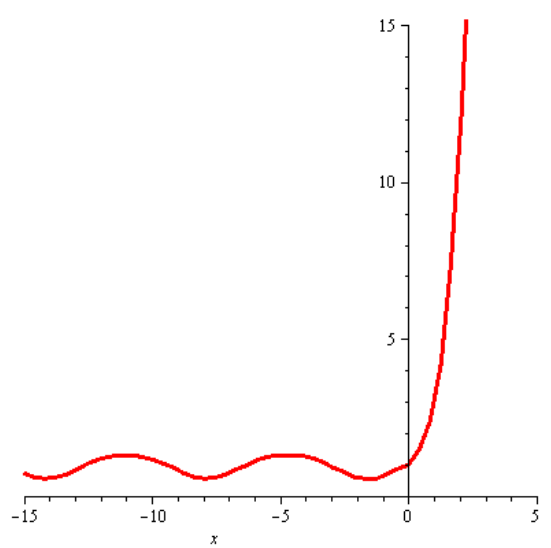

Figura 1.35. nario, con lo que desarrolla procedimientos intuitivos ya practicados pero no rutinarios (CRPn1).

El apartado b) del problema de la ficha 1.35.1 se encuentra el tercer nivel de competencia matemática: reflexión, razonando de forma sencilla, distinguiendo formas más amplias de argumentación (RfAn1),-para que una función sea deri- 
vable en un punto, primero tiene que ser continua en dicho punto-, sabe explicar cuestiones matemáticas, cálculos y resultados (RfCn1).

Para ser derivable en $x=0$ tiene que cumplir que

$$
\begin{gathered}
\lim _{h \rightarrow 0^{-}} \frac{f(0+h)-f(0)}{h}=\lim _{h \rightarrow 0^{+}} \frac{f(0+h)-f(0)}{h} \\
\lim _{h \rightarrow 0^{-}} \frac{\ln (e+\operatorname{sen}(h))-1}{h}=\text { Regla de L`Hôpital }=\lim _{h \rightarrow 0^{-}} \frac{\cos h}{h(e+\operatorname{sen}(h))}=1
\end{gathered}
$$

Explica asuntos que implican relaciones complejas ( $\mathrm{RfCn} 2)$, evalúa encadenamientos matemáticos (CAn3) y aplica las estrategias apropiadas más independientes (CRPn3)

$$
\lim _{h \rightarrow o^{+}} \frac{\left(h^{3}+a h+1\right)-1}{h}=a
$$

Realiza ecuaciones y cálculos mediante procedimientos familiares (CLSOn3), interpreta las relaciones implicadas (CCn3) y sabe comunicar los resultados (CMn3).

Para ser derivable en $x=0$ se tiene que verificar $a=1, b=1$.

El apartado c) del problema de la ficha 1.35.1 corresponde a los niveles de reproducción y conexión.

En el nivel de reproducción el alumno debe reconocer que se pide el cálculo de la derivada de una función en un punto $\left(x=-\frac{\pi}{2}\right)$,

Asimismo, identifica el problema (RAn1), comprende la expresión escrita (RCn1), reconoce representaciones de los datos del ejercicio (RPRn1), expone el proceso de cálculo (RAn2), identifica el problema como similar a otros vistos con anterioridad (RMn1) y le reconoce como problema ya practicado (RRPn1).

A continuación plantea los algoritmos correspondientes (RPRn2), -calculando la derivada de la función $f(x)=\ln (e+\operatorname{sen}(x))$-, asociándola a fórmulas establecidas y realizando los cálculos (RPRn3) con lo que reproduce problemas ya practicados de manera cerrada (RRPn2) y calcula la derivada realizando cálculos mediante procedimientos familiares (CLSOn3). 


$$
\begin{gathered}
f^{\prime}(x)=\frac{\cos (x)}{e+\operatorname{sen}(x)} \\
f^{\prime}\left(-\frac{\pi}{2}\right)=\frac{\cos \left(-\frac{\pi}{2}\right)}{e+\operatorname{sen}\left(-\frac{\pi}{2}\right)}=0
\end{gathered}
$$

Utiliza un único tipo de representación estándar ya utilizada (RRn1), maneja fórmulas y realiza los cálculos (RLSOn3), resuelve problemas rutinarios estandarizados (RRPn3) y describe los resultados obtenidos (RCn3).

En el proceso de resolución interpreta el lenguaje formal y simbólico básico (límites) en situaciones menos conocidas (CLSOn1) manejando afirmaciones sencillas y expresiones con fórmulas y símbolos no rutinarios (CLSOn2)- logaritmo, trigonometría- y utiliza variables y cálculos mediante procedimientos familiares (CLSOn3), como es el cálculo de los valores de las funciones trigo-

\begin{tabular}{|c|c|c|c|c|c|c|c|c|}
\hline \multicolumn{2}{|c|}{ FICHA 1.35.2. } & \multicolumn{7}{|c|}{ COMPETENCIAS IMPLÍCITAS EN LA RESOLUCIÓN DEL P35 } \\
\hline & Nivel 1 & Nivel 2 & Nivel 3 & Nivel 1 & Nivel 2 & Nivel 3 & Nivel 1 & Nivel 2 \\
\hline PR & * & * & * & * & * & * & & \\
\hline A & * & * & & * & * & * & * & \\
\hline C & & & * & * & * & * & * & * \\
\hline$M$ & * & & & * & * & * & & \\
\hline RP & * & * & * & * & & & & \\
\hline $\mathbf{R}$ & * & & & * & & & & \\
\hline LSO & & & * & * & * & * & & \\
\hline & \multicolumn{3}{|c|}{ Reproducción } & \multicolumn{3}{|c|}{ Conexión } & \multicolumn{2}{|c|}{ Reflexión } \\
\hline
\end{tabular}
nométricas.

\section{ANÁLISIS DEL PROBLEMA P39}

El problema que se presenta en la ficha 1.39.1 corresponde a los niveles de conexión y reflexión.

En primer lugar, el alumno piensa en el tratamiento matemático necesario (CPRn1), estructura la situación que debe modelizar (CMn1) y desarrolla procedimientos intuitivos ya practicados, pero no rutinarios (CRPn1). 
FICHA 1.39.1.

ESTUDIO DEL ENUNCIADO DEL P39

P39.- Sea $f(x)=x^{3}+a x^{2}+b x+c$. Determínense $a, b$ y c de modo que $f(x)$ tenga un extremo relativo en $x=0$, la recta tangente a la gráfica de $f(x)$ en $x=1$ sea paralela a la recta $y-4 x=0$, y el área comprendida por la gráfica de $f(x)$, el eje $O X$ y las rectas $x=0$, $x=1$, sea igual a 1 .

\begin{tabular}{|c|c|c|c|c|c|c|c|c|c|c|c|c|c|c|}
\hline CONVOCATORIA & \multicolumn{7}{|c|}{$\underline{\text { JUNIO }}$} & \multicolumn{7}{|c|}{ SEPTIEMBRE } \\
\hline AÑO & 95 & 96 & 97 & 98 & 99 & 00 & 01 & \begin{tabular}{l|l}
02 & 03
\end{tabular} & $\underline{04}$ & 05 & 06 & 07 & 08 & 09 \\
\hline OPCIÓN & \multicolumn{7}{|c|}{ A } & \multicolumn{7}{|c|}{ B } \\
\hline TIPO DE PROBLEMA & \multicolumn{7}{|c|}{ TEÓRICO } & \multicolumn{7}{|c|}{ PRÁCTICO } \\
\hline \multirow{3}{*}{ APARTADOS } & \multirow{3}{*}{\multicolumn{2}{|c|}{ SI }} & \multicolumn{4}{|c|}{ Forma explícita } & & & & & \multirow{2}{*}{\multicolumn{2}{|c|}{6}} & \multirow{3}{*}{\multicolumn{2}{|c|}{ NO }} \\
\hline & & & & & & & 2 & 3 & 4 & 5 & & & & \\
\hline & & & \multicolumn{4}{|c|}{ Forma implícita } & & & & & & & & \\
\hline VERBO UTILIZADO & \multicolumn{14}{|c|}{ DETERMINAR } \\
\hline TIEMPO VERBAL & \multicolumn{14}{|c|}{ PRESENTE DE SUBJUNTIVO CON PRONOMBRE CLÍTICO } \\
\hline ESCRITURA & \multicolumn{9}{|c|}{ ALGEBRAICA } & \multicolumn{5}{|c|}{ FUNCIONAL } \\
\hline \multirow{3}{*}{$\begin{array}{l}\text { FALLOS DEL ENUN- } \\
\text { CIADO }\end{array}$} & \multicolumn{9}{|c|}{ PUNTUACIÓN } & & & & & \\
\hline & \multicolumn{9}{|c|}{ ERROR MORFOSINTÁCTICO } & & & & & \\
\hline & \multicolumn{9}{|c|}{ AUSENCIA DE ESPECIFICACIONES } & & & & & \\
\hline \multicolumn{15}{|c|}{ ENUNCIADO ALTERNATIVO } \\
\hline
\end{tabular}

P39.- Sea $f(x)=x^{3}+a x^{2}+b x+c$. Determina los valores de $a, b$ y $c$ de modo que $f(x)$ tenga un extremo relativo en $x=0$, la recta tangente a la gráfica de $f(x)$ en $x=1$ sea paralela a la recta $y-4 x=0$, y el área comprendida entre la gráfica de $f(x)$, el eje $O X$ y las rectas $x=0, x=1$, sea igual a 1 .

\section{NIVELES DE COMPETENCIAS IMPLÍCITAS : Conexión y reflexión}

Como, por condiciones del enunciado, la función tiene un extremo relativo en el punto $x=0$, verifica $f^{\prime}(0)=0$.

Como la recta tangente en $x=1$ es paralela a la recta $y-4 x=0$, la pendiente de la recta tangente es $m=4$.

Dado que la derivada, evaluada en el punto, es la pendiente de la recta tangente a la curva en dicho punto, se tiene $f^{\prime}(1)=4$.

El alumno razona matemáticamente de manera simple (CAn1) y sabe expresarse sobre cuestiones matemáticas (CCn1), comprende que tiene que emplear conceptos matemáticos intermedios (CPRn2), -la función derivada-, sigue el 
encadenamiento de argumentos matemáticos particulares (CAn2) y explica los cálculos y sus propiedades (CCn2).

$$
f^{\prime}(x)=3 x^{2}+2 a x+b
$$

Sustituyendo, obtiene el sistema de ecuaciones:

$$
\begin{aligned}
& f^{\prime}(0)=b=0 \\
& f^{\prime}(1)=3+2 a
\end{aligned}
$$

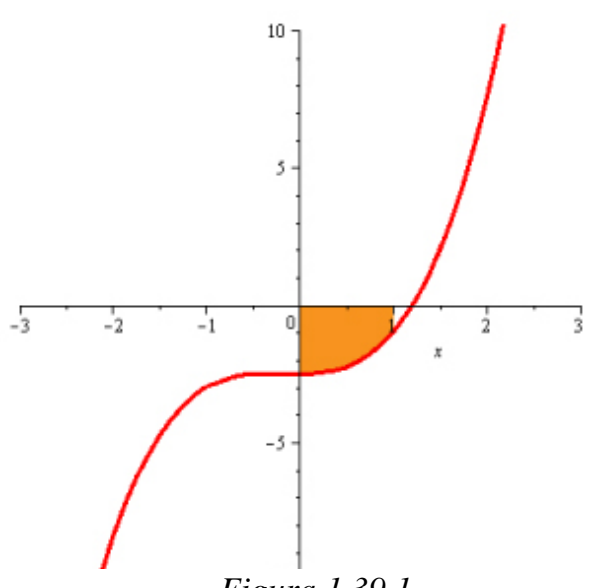

Figura 1.39.1

Cuya solución es $\quad b=0$ y $a=\frac{1}{2}$

En este momento, si el alumno razonase de la siguiente forma, estaría en un nivel de reflexión.

El enunciado dice: "...y el área comprendida por la gráfica de $f(x)$, el eje OX y las rectas $x=0, x=1$, sea igual a 1", pero dado que la función presenta parámetros, se tiene:

$$
f(x)=x^{3}+\frac{1}{2} x^{2}+c
$$

Que cumple

$$
f(0)=c \text { y } f(1)=\frac{3}{2}+c
$$

Si se verificase la condición $c<-\frac{3}{2}$, al calcular

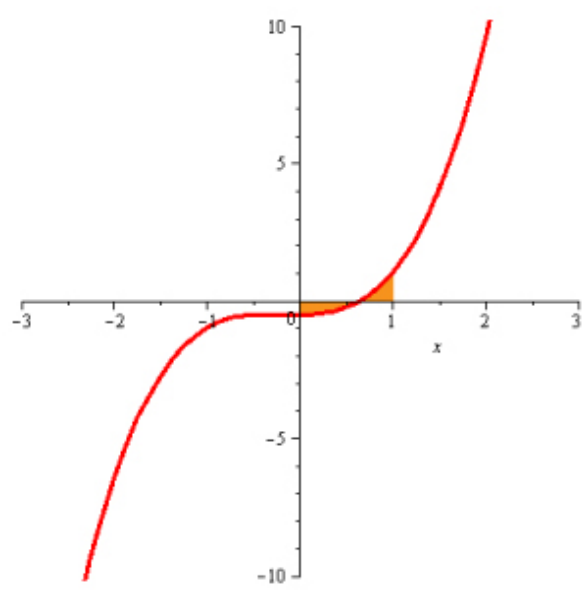

Figura 1.39.2

el área tendría que tomar el valor absoluto de la integral (Figura 1.39.1), pero si $-\frac{3}{2}<c<0$, habría que calcular el punto de corte de la curva $f(x)=x^{3}+\frac{1}{2} x^{2}+c$ con el eje $O X$, en el intervalo $(0,1)$, con lo que, a priori, al calcular el área no podría hacerse calculando $\int_{0}^{1} f(x) d x$.Figura 1.39.2.

Con este argumento, el alumno razona de forma sencilla distinguiendo formas más amplias de argumentación (RfAn1) y sabe explicar cuestiones matemáti- 
cas, cálculos y resultados (RfCn1), es decir, se encuentra en el nivel de reflexión.

Se tiene una función definida analíticamente, que es preciso interpretar, seleccionar y cambiar entre diferentes formas de representación (CRn1, CRn2), analítica y gráficamente, diferenciando entre ambas formas de representación (CRn3). Figura 1.39.2.

Si la función no tiene puntos de corte con el eje de abscisas la condición del enunciado "el área comprendida por la gráfica de $f(x)$, el eje $O X$ y las rectas $x=0, x=1$, sea igual a 1 " implica que

$$
\int_{0}^{1}\left(x^{3}+\frac{1}{2} x^{2}+c\right) d x=1
$$

Aplica conceptos matemáticos apropiados (CPRn3), interpretando las relacio-

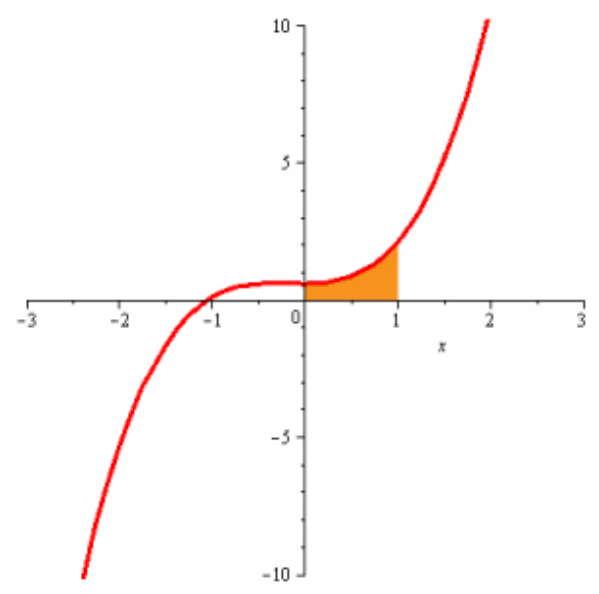

Figura 1.39.3 nes implicadas (CCn3).

$$
\left.\int_{0}^{1}\left(x^{3}+\frac{1}{2} x^{2}+c\right) d x=\frac{x^{4}}{4}+\frac{x^{3}}{6}+c x\right]_{0}^{1}=1
$$

Utilizando la regla de Barrow

$$
\frac{1}{4}+\frac{1}{6}+c=1 \Rightarrow c=\frac{7}{12}
$$

Por ende, los valores obtenidos son:

$$
a=\frac{1}{2}, b=0 \text { y } c=\frac{7}{2}
$$

El alumno comunica de manera elemental los resultados del modelo (RMn3).

El resultado $c=\frac{7}{12}$ ratifica que el cálculo de la integral es correcto, (el enunciado se propone a partir de la solución del mismo) pero, a priori con las condiciones dadas, nada indica que el estudio realizado sobre los posibles valores de $c$ sea innecesario.

Interpreta formas de representación (CRn1), selecciona y cambia entre formas de representación $(\mathrm{CRn} 2)$ y traduce y diferencia entre distintas formas de representación (CRn3). Figura 1.39.3.

Interpreta el lenguaje formal y simbólico básico, en situaciones menos conocidas (CLSOn1), maneja afirmaciones sencillas y expresiones con símbolos y 
fórmulas no rutinarias (CLSOn2), -derivadas, integrales- y utiliza variables y realiza cálculos mediante procedimientos familiares (CLSOn3)

\begin{tabular}{|c|c|c|c|c|c|c|c|c|}
\hline \multicolumn{2}{|c|}{ FICHA 1.39.2. } & \multicolumn{7}{|c|}{ COMPETENCIAS IMPLÍCITAS EN LA RESOLUCIÓN DEL P39 } \\
\hline & Nivel 1 & Nivel 2 & Nivel 3 & Nivel 1 & Nivel 2 & Nivel 3 & Nivel 1 & Nivel 2 \\
\hline PR & & & & * & * & * & & \\
\hline A & & & & * & * & & * & \\
\hline C & & & & * & * & * & * & \\
\hline M & & & * & * & & & & \\
\hline RP & & & & * & & & & \\
\hline $\mathbf{R}$ & & & & * & * & * & & \\
\hline LSO & & & & * & * & * & & \\
\hline 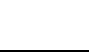 & \multicolumn{3}{|c|}{ Reproducción } & \multicolumn{3}{|c|}{ Conexión } & \multicolumn{2}{|c|}{ Reflexión } \\
\hline
\end{tabular}

\section{ANÁLISIS DEL PROBLEMA P43}

El problema que se presenta en la ficha 1.43 .1 corresponde a los niveles de reproducción y conexión.

Calcular los intervalos de crecimiento y decrecimiento de una función reproduce el conocimiento estudiado.

Calcular los intervalos de crecimiento y decrecimiento de una función reproduce el conocimiento estudiado: Reconocimiento de equivalentes, aplicación de destrezas técnicas y de algoritmos habituales, manejo de expresiones y fórmulas establecidas y realización de cálculos.

Asimismo, el problema reproduce situaciones similares a las estudiadas en clase, pero no son de mera rutina, por tanto se trata de un nivel de conexión. Es preciso pensar en el tratamiento matemático necesario (CPRn1).

$$
f^{\prime}(x)=e^{x}+\frac{1}{x}
$$

Para estudiar la monotonía de la función, hay que estudiar el signo de la primera derivada, con lo que el alumno comprende que tiene que emplear conceptos matemáticos intermedios (CPRn2), aplica los conceptos matemáticos apropiados, (CPRn3), además estructura la situación que debe modelizar (CMn1) y traduce en la práctica el modelo a seguir, que es algo diferente de los estudiados (CMn2). 
FICHA 1.43.1.

ESTUDIO DEL ENUNCIADO DEL P43

P43.- Sea $f(x)=e^{x}+\ln (x), x \in(0, \infty)$.

a) Estúdiense los intervalos de crecimiento y decrecimiento de $f$ y sus asíntotas.

b) Pruébese que $f$ tiene un punto de inflexión en el intervalo $\left[\frac{1}{2}, 1\right]$ y esbócese la gráfica de $f$.

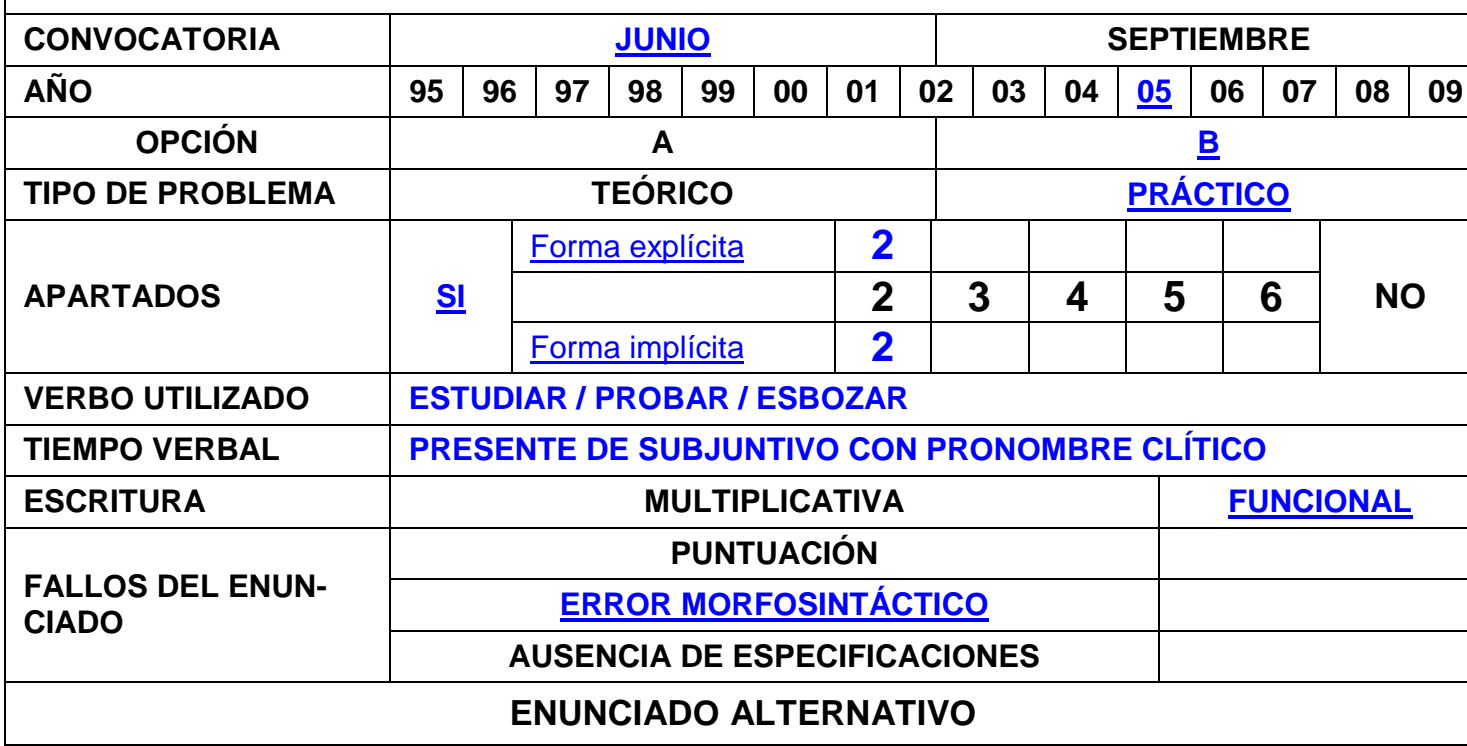

P43.- Dada la función $f(x)=e^{x}+\ln (x), x \in(0, \infty)$.

a) Calcula los intervalos de crecimiento y decrecimiento de $\underline{f(x)}$.

b) Escribe las ecuaciones de sus asíntotas.

c) Prueba que $f(x)$ tiene un punto de inflexión en el intervalo $\left[\frac{1}{2}, 1\right]$.

d) Esboza la gráfica de $f(x)$.

NIVELES DE COMPETENCIAS IMPLÍCITAS: Reproducción y conexión

El cálculo de los valores que anulan esa función derivada corresponde al nivel de reproducción, manejo de procedimientos y fórmulas, resolviendo y calculando (RLSOn3).

$$
f^{\prime}(x)>0 \quad \forall x>0
$$

La función crece en el intervalo $(0,+\infty)$

Mediante el cálculo de límites, obtiene las asíntotas. 
Efectuar este paso supone que sabe expresarse sobre cuestiones matemáticas (CCn1), explica los cálculos y sus propiedades (CCn2) e interpreta las relaciones implicadas (CCn3).

Razona matemáticamente de manera simple (CAn1), sigue el encadenamiento de argumentos matemáticos particulares (CAn2) y evalúa ese encadenamiento de argumentos matemáticos (CAn3), a la vez que desarrolla procedimientos intuitivos ya practicados, pero no rutinarios (CRPn1).

Se presenta lenguaje algebraico, aritmético y geométrico, con lo que interpreta el lenguaje formal y simbólico básico, en situaciones menos conocidas (CLSOn1), maneja afirmaciones sencillas y expresiones con símbolos y fórmulas no rutinarias (CLSOn2) y utiliza variables y realiza cálculos mediante procedimientos familiares (CLSOn3).

$$
\begin{gathered}
\lim _{x \rightarrow 0^{+}}\left(e^{x}+\ln (x)\right)=-\infty \text { luego } \\
x=0 \text { es asíntota vertical. } \\
\lim _{x \rightarrow+\infty}\left(e^{x}+\ln (x)\right)=+\infty
\end{gathered}
$$

por lo que no tiene asíntota horizontal.

$$
\lim _{x \rightarrow+\infty} \frac{e^{x}+\ln (x)}{x}=+\infty
$$

con lo que no tiene asíntota oblicua.

El alumno razona matemáticamente de manera simple (CAn1), sigue el encadenamiento

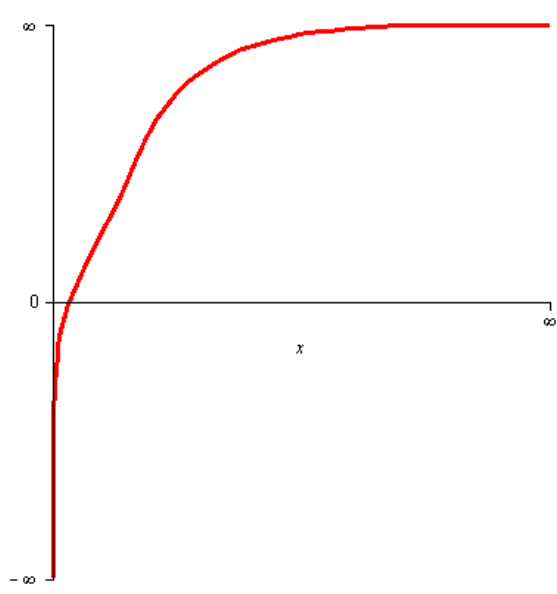

Figura 1.43 de argumentos matemáticos particulares (CAn2) y evalúa ese encadenamiento de argumentos matemáticos (CAn3), a la vez que desarrolla procedimientos intuitivos ya practicados, pero no rutinarios (CRPn1).

Se tiene una función definida analíticamente, que es preciso interpretar, seleccionar y cambiar entre diferentes formas de representación (CRn1, CRn2), analítica y gráficamente, diferenciando entre ambas formas de representación (CRn3).

El apartado b) del problema que se presenta en la ficha 1.43.1 es un ejercicio en el que hay que utilizar el teorema de Bolzano y corresponde al nivel de reproducción. 
Con este razonamiento identifica el problema (RAn1), reconoce representaciones de los datos del ejercicio (RPRn1), comprende la expresión escrita (RCn1), identifica que es un modelo similar a otros vistos con anterioridad (RMn1) y le reconoce como problema ya practicado (RRPn1). A continuación, plantea los algoritmos correspondientes (RPRn2).

Consideramos la función:

$$
f^{\prime \prime}(x)=e^{x}-\frac{1}{x^{2}}
$$

Es una función continua en su dominio $(0, \infty)$, por ser suma algebraica de funciones continuas.

$$
\begin{gathered}
f^{\prime \prime}\left(\frac{1}{2}\right)=e^{\left(\frac{1}{2}\right)}-4<0 \\
f^{\prime \prime}(1)=e-1>0
\end{gathered}
$$

El alumno expone el proceso de cálculo (RAn2), realizando explicaciones sencillas (RCn2), asocia con fórmulas establecidas y realiza los cálculos (RPRn3).

Es una función continua en el intervalo cerrado $\left[\frac{1}{2}, 1\right]$ que toma valores de signo contrario en los extremos del intervalo, por el teorema de Bolzano, existe un punto $c \in\left(\frac{1}{2}, 1\right)$, con $f^{\prime \prime}(c)=0$, que es el punto de inflexión.

Justifica las fórmulas utilizadas y los resultados (RAn3), maneja procedimientos resolviendo y calculando (RLSOn3) y resuelve problemas rutinarios estandarizados (RRPn3). Concluye describiendo los resultados obtenidos (RCn3) y comunicando de manera elemental los resultados del modelo (RMn3).

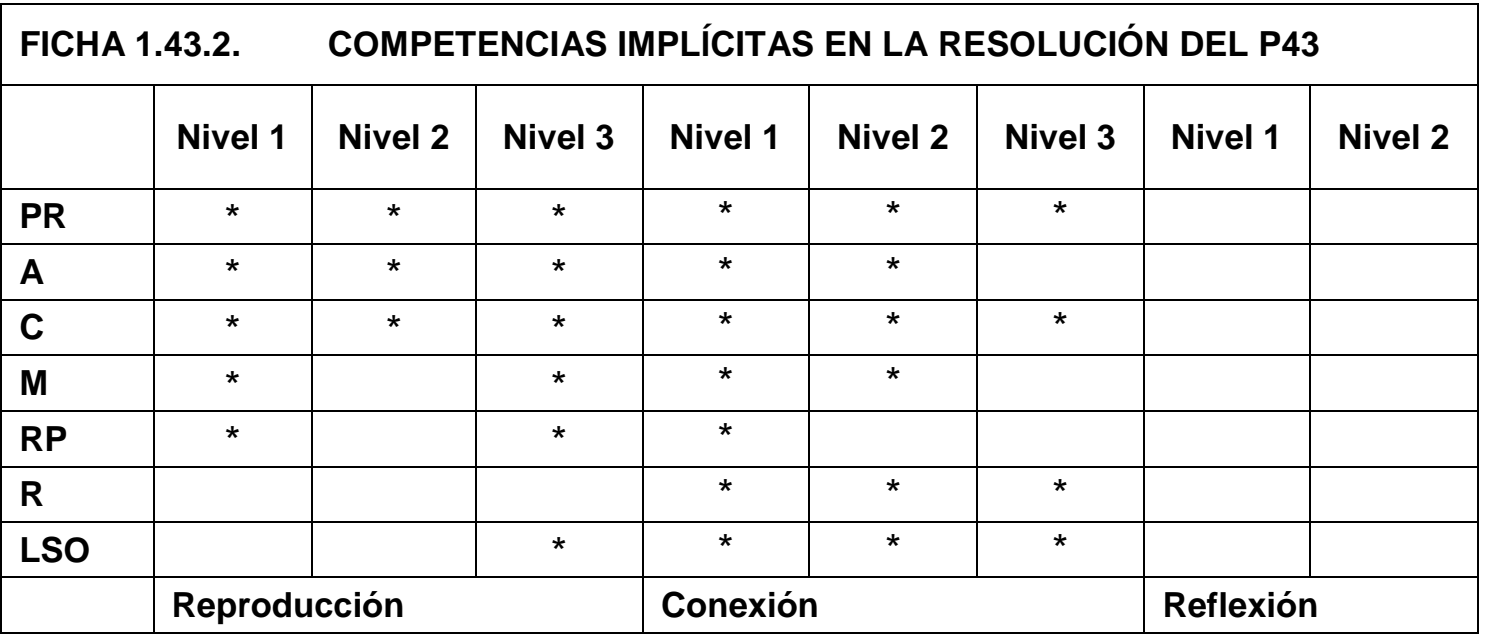




\section{ANÁLISIS DEL PROBLEMA P45}

\section{FICHA 1.45.1. \\ ESTUDIO DEL ENUNCIADO DEL P45}

P45.- Sea $P(a$, sen $a)$ un punto de la gráfica de la función $f(x)=\operatorname{sen}(x)$ en el intervalo $[0, \pi]$. Sea $r_{P}$ la recta tangente a dicha gráfica en el punto $P$ y $A_{P}$ el área de la región determinada por las rectas $r_{P}, x=0, x=\pi, y=0$.

Calcúlese el punto $P$ para el cual el área $A_{P}$ es mínima. (Nota: Puede asumirse, sin demostrar, que la recta $r_{P}$ se mantiene por encima del eje $O X$ entre 0 y $\pi$ )

\begin{tabular}{|c|c|c|c|c|c|c|c|c|c|c|c|c|c|c|}
\hline CONVOCATORIA & \multicolumn{7}{|c|}{ JUNIO } & \multicolumn{7}{|c|}{ SEPTIEMBRE } \\
\hline AÑO & 95 & 96 & 97 & 98 & 99 & 00 & 01 & $02 \quad 03$ & 04 & $\underline{05}$ & 06 & 07 & 08 & 09 \\
\hline OPCIÓN & \multicolumn{7}{|c|}{ A } & \multicolumn{7}{|c|}{$\underline{B}$} \\
\hline TIPO DE PROBLEMA & \multicolumn{7}{|c|}{ TEÓRICO } & \multicolumn{7}{|c|}{ PRÁCTICO } \\
\hline \multirow{3}{*}{ APARTADOS } & \multirow{3}{*}{\multicolumn{2}{|c|}{ SI }} & \multicolumn{4}{|c|}{ Forma explícita } & & & & & & \multirow[b]{2}{*}{6} & \multirow{3}{*}{\multicolumn{2}{|c|}{$\underline{\mathrm{NO}}$}} \\
\hline & & & & & & & 2 & 3 & 4 & 5 & & & & \\
\hline & & & \multicolumn{4}{|c|}{ Forma implícita } & & & & & & & & \\
\hline VERBO UTILIZADO & \multicolumn{14}{|c|}{ CALCULAR } \\
\hline TIEMPO VERBAL & \multicolumn{14}{|c|}{ PRESENTE DE SUBJUNTIVO CON PRONOMBRE CLÍTICO } \\
\hline ESCRITURA & \multicolumn{9}{|c|}{ MULTIPLICATIVA } & \multicolumn{5}{|c|}{ FUNCIONAL } \\
\hline \multirow{3}{*}{$\begin{array}{l}\text { FALLOS DEL ENUN- } \\
\text { CIADO }\end{array}$} & \multicolumn{9}{|c|}{ PUNTUACIÓN } & & & & & \\
\hline & \multicolumn{9}{|c|}{ ESTRUCTURA DE LA ORACIÓN } & & & & & \\
\hline & \multicolumn{9}{|c|}{ AUSENCIA DE ESPECIFICACIONES } & & & & & \\
\hline \multicolumn{15}{|c|}{ ENUNCIADO ALTERNATIVO } \\
\hline
\end{tabular}

P45.- $P=(a, \operatorname{sen}(a))$ es un punto de la gráfica de la función $f(x)=\operatorname{sen}(x)$ en el inter-

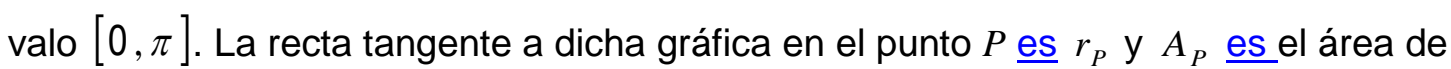
la región determinada por las rectas $r_{P}, x=0, x=\pi, y=0$.

Calcula el punto $P$ para el cual el área $A_{P}$ es mínima. (Nota: Puede asumirse, sin demostrar, que la recta $r_{P}$ se mantiene por encima del eje $O X$ entre 0 y $\pi$ )

\section{NIVELES DE COMPETENCIAS IMPLÍCITAS: Conexión}

El ejercicio que se presenta en la ficha 1.45 .1 corresponde a los niveles de conexión y reflexión.

El Reproduce una situación similar a la referente en la instrucción, pero no es una mera rutina, dado que el alumno tiene que pensar en el tratamiento matemático necesario (CPRn1) y estructurar la situación que se debe modelizar (CMn1). 
Hay que definir una función, obtener la función derivada e igualar a cero dicha derivada. Es decir, razona matemáticamente de manera simple (CAn1) y desarrolla procedimientos ya practicados, pero no rutinarios (CRPn1).

Por otra parte, el alumno interpreta formas de representación (CRn1), sabe expresarse sobre cuestiones matemáticas (CCn1), e interpreta el lenguaje formal y simbólico (CLSOn1).

Comprende que tiene que emplear métodos matemáticos intermedios (CPRn2), manejando afirmaciones sencillas y expresiones con símbolos y fórmulas no rutinarias (CLSOn2).

El alumno empieza escribiendo la ecuación de la recta tangente a la curva de la función $f(x)=\operatorname{sen}(x)$, en ese punto.

$$
f^{\prime}(x)=\cos (x) \Rightarrow m(a)=\cos (a)
$$

Esa es la pendiente de la recta tangente en el punto $P=(a, \operatorname{sen}(a))$.

Explica los cálculos y sus propiedades (CCn2) e interpreta las relaciones implicadas (CCn3), a la vez que maneja afirmaciones sencillas en expresiones $y$ fórmulas no rutinarias (CLSOn2).

Para escribir la ecuación de la recta tangente, utiliza la expresión puntopendiente, es decir:

El punto de tangencia de la curva es $P=(a, \operatorname{sen}(a))$ y la pendiente es $m(a)=\cos (a)$.

Ecuación de la recta tangente:

$$
y-\operatorname{sen}(a)=\cos (a) \cdot(x-a)
$$

Aplica conceptos matemáticos apropiados (CPRn3), aplica las estrategias apropiadas más independientes (CRPn3) y utiliza variables y realiza ecuaciones y cálculos mediante procedimientos familiares (CLSOn3).

El alumno tiene que obtener la función área del "trapecio" determinado por las rectas $r_{P} \equiv y-\operatorname{sen}(a)=\cos (a) \cdot(x-a), x=0, x=\pi, y=0$.

$$
A=\frac{(B+b)}{2} \cdot h
$$

Esa es la función que debe optimizar, para lo cual calcula la función derivada. Previamente, obtiene los valores de las bases y de la altura del trapecio. 
Obteniendo el punto

$$
y=-a \cos (a)+\operatorname{sen}(a)
$$

Que es el punto de intersección de la recta $r_{P} \equiv y-\operatorname{sen}(a)=\cos (a) \cdot(x-a)$ con la recta $x=0$

El punto $y=\operatorname{sen}(a)+\cos (a) \cdot(\pi-a)$, es el punto de intersección de la recta $x=\pi$ con la recta $r_{P} \equiv y-\operatorname{sen}(a)=\cos (a) \cdot(x-a)$.

Esos puntos corresponden a la longitud de las bases del trapecio y la altura es la distancia de $x=0$ a $x=\pi$, es decir $h=\pi$.

Este ejercicio también corresponde a un nivel de reflexión dado que el estudio de la recta tangente y del recinto tienen parámetros, por lo que el alumno necesita hacer un ejercicio de reflexión para planificar estrategias y aplicarlas en la resolución de un problema que contiene elementos inusuales.

Aplica estrategias no rutinarias (RfPRn2) y sabe explicar cuestiones matemáticas,

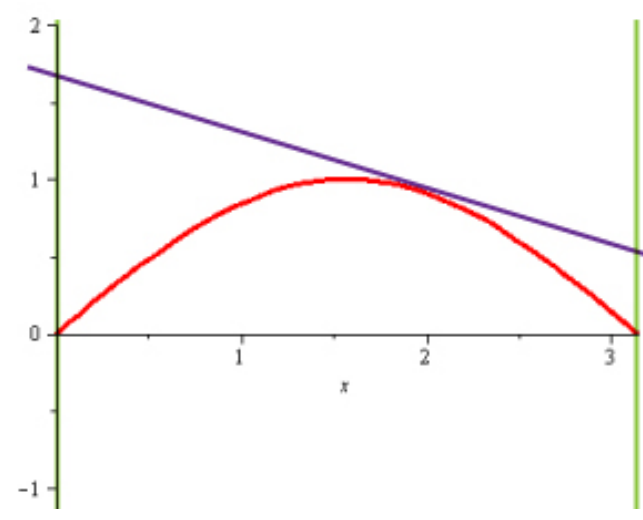

Figura 1.45 cálculos y resultados (RfCn1).

De lo que se desprende que:

$$
A=\frac{\pi}{2}(\pi \cos (a)-2 a \cos (a)+2 \operatorname{sen}(a))
$$

Interpreta las relaciones implicadas (CCn3) y sabe interpretar y alternar diferentes modelos y comunicar los resultados (CMn3).

Calcula la función derivada:

$$
A^{\prime}=\frac{\pi}{2}(-\pi \operatorname{sen}(a)+2 a \operatorname{sen}(a))
$$

Iguala a cero la función derivada:

$$
(-\pi+2 a) \operatorname{sen}(a)=0
$$

Resolviendo la ecuación planteada, obtiene valores:

$$
a=0, a=\pi, a=\frac{\pi}{2}
$$


Asimismo, sigue el encadenamiento del argumento matemático particular, haciendo una evaluación del mismo (CAn2), traduce, en la práctica, el modelo a seguir, que es algo diferente de los estudiados (CMn2), eligiendo las estrategias apropiadas que conexionen áreas matemáticas (CRPn2) aplicando, de este modo, conceptos matemáticos apropiados (CPRn3) y selecciona y cambia entre diferentes formas de representación (CRn2). Figura 1.45.

En el desarrollo del ejercicio el alumno resuelve ecuaciones con parámetros y realiza derivadas, es decir utiliza variables y realiza ecuaciones y cálculos mediante procedimientos familiares (CLSOn3).

Es preciso comprobar que la solución obtenida satisface las condiciones del enunciado, es decir, que el área es máxima; calculando la derivada segunda y comprobando que para los valores obtenidos dicha derivada es menor que cero.

El alumno sigue el encadenamiento del argumento matemático particular, haciendo una evaluación del mismo (CAn2), explica los cálculos y sus propiedades (CCn2), e interpreta las relaciones implicadas (CCn3).

$$
\begin{gathered}
A^{\prime \prime}=\frac{\pi}{2}(2 \operatorname{sen}(a)+\cos (a) \cdot(-\pi+2 a)) \\
A^{\prime \prime}\left(\frac{\pi}{2}\right)=\frac{\pi}{2}\left(2 \operatorname{sen}\left(\frac{\pi}{2}\right)+\cos \left(\frac{\pi}{2}\right) \cdot(-\pi+\pi)\right)=\pi>0 \\
A^{\prime \prime}(\pi)=\frac{\pi}{2}(2 \operatorname{sen}(\pi)+\cos (\pi) \cdot(-\pi+2 \pi))=-\frac{\pi^{2}}{2}<0 \\
A^{\prime \prime}(0)=\frac{\pi}{2}(2 \operatorname{sen}(0)+\cos (0) \cdot(-\pi+2 \cdot 0))=-\frac{\pi^{2}}{2}<0 \\
Y, \text { por tanto, se obtiene el área mínima para } a=\frac{\pi}{2} .
\end{gathered}
$$

El punto pedido es:

$$
P\left(\frac{\pi}{2}, \operatorname{sen}\left(\frac{\pi}{2}\right)\right)=\left(\frac{\pi}{2}, 1\right)
$$

Concluye describiendo los resultados obtenidos (RCn3) y comunicando de manera elemental los resultados del modelo (RMn3). 


\begin{tabular}{|l|c|c|c|c|c|c|c|c|}
\hline \multicolumn{7}{|l|}{ FICHA 1.45.2. COMPETENCIAS IMPLÍCITAS EN LA RESOLUCIÓN DEL P45 } \\
\hline & Nivel 1 & Nivel 2 & Nivel 3 & Nivel 1 & Nivel 2 & Nivel 3 & Nivel 1 & Nivel 2 \\
\hline PR & & & & $*$ & $*$ & $*$ & & $*$ \\
\hline A & & & & $*$ & $*$ & & & \\
\hline C & & & $*$ & $*$ & $*$ & $*$ & $*$ & \\
\hline M & & & $*$ & $*$ & $*$ & $*$ & & \\
\hline RP & & & & $*$ & $*$ & $*$ & & \\
\hline R & & & & $*$ & $*$ & & & \\
\hline LSO & & & & $*$ & $*$ & $*$ & & \\
\hline & Reproducción & & Conexión & & Reflexión \\
\hline
\end{tabular}

\section{ANÁLISIS DEL PROBLEMA P52}

El apartado a) del problema que aparece en la ficha 1.52.1 es un ejercicio que se encuadra en el nivel de conexión.

Hay que hacer el estudio de una función con el fin de representarla y eso reproduce situaciones similares a las estudiadas en clase, pero no son de mera rutina, por tanto se trata de un nivel de conexión.

Por tanto, el alumno tiene que pensar en el tratamiento matemático necesario (CPRn1), con lo que comprende que tiene que emplear conceptos matemáticos intermedios (CPRn2) y aplicar los conceptos matemáticos apropiados (CPRn3).

Para estudiar la monotonía de la función y extremos relativos, hay que observar el signo de la primera derivada y para escribir las ecuaciones de las asíntotas hay que calcular límites.

\section{El dominio de la función es $R$.}

Con este razonamiento, el alumno sabe expresarse sobre cuestiones matemáticas (CCn1) explicando los cálculos y sus propiedades (CCn2), estructura la situación que debe modelizar (CMn1) y traduce en la práctica el modelo a seguir, que es algo diferente de los estudiados (CMn2).

Calcula la función derivada

$$
f^{\prime}(x)=(2-2 x) e^{2 x-x^{2}}
$$

La ecuación $(2-2 x) e^{2 x-x^{2}}=0$ tiene como solución $x=1$. 
FICHA 1.52.1

ESTUDIO DEL ENUNCIADO DEL P52

P52.- Sea $f$ la función dada por $f(x)=e^{2 x-x^{2}}$.

a) Calcular los intervalos de crecimiento y decrecimiento, los extremos relativos y las asíntotas de $f$.

b) Determinar el número de soluciones de la ecuación $f(x)=2$ en el intervalo $[0,1]$.

\begin{tabular}{|c|c|c|c|c|c|c|c|c|c|c|c|c|c|c|c|}
\hline \multirow{2}{*}{$\begin{array}{l}\text { CONVOCATORIA } \\
\text { AÑO }\end{array}$} & \multicolumn{7}{|c|}{ JUNIO } & \multicolumn{8}{|c|}{ SEPTIEMBRE } \\
\hline & 95 & 96 & 97 & 98 & 99 & 00 & 01 & 02 & 03 & 04 & 05 & 06 & $\underline{07}$ & 08 & 09 \\
\hline OPCIÓN & \multicolumn{7}{|c|}{$\underline{A}$} & \multicolumn{8}{|c|}{ B } \\
\hline TIPO DE PROBLEMA & \multicolumn{7}{|c|}{ TEÓRICO } & \multicolumn{8}{|c|}{ PRÁCTICO } \\
\hline \multirow{3}{*}{ APARTADOS } & \multirow{3}{*}{\multicolumn{2}{|c|}{ SI }} & \multicolumn{4}{|c|}{ Forma explícita } & 2 & & & & \multirow[b]{2}{*}{5} & & \multirow[b]{2}{*}{6} & \multirow{3}{*}{\multicolumn{2}{|c|}{ NO }} \\
\hline & & & & & & & 2 & & 3 & 4 & & & & & \\
\hline & & & \multicolumn{4}{|c|}{ Forma implícita } & & & 3 & & & & & & \\
\hline VERBO UTILIZADO & \multicolumn{15}{|c|}{ CALCULAR / DETERMINAR } \\
\hline TIEMPO VERBAL & \multicolumn{15}{|c|}{ INFINITIVO } \\
\hline ESCRITURA & \multicolumn{10}{|c|}{ MULTIPLICATIVA } & \multicolumn{5}{|c|}{ FUNCIONAL } \\
\hline \multirow{3}{*}{$\begin{array}{l}\text { FALLOS DEL ENUN- } \\
\text { CIADO }\end{array}$} & \multicolumn{10}{|c|}{ PUNTUACIÓN } & & & & & \\
\hline & \multicolumn{10}{|c|}{ ESTRUCTURA / SIGNIFICADO DE LA ORACIÓN } & & & & & \\
\hline & \multicolumn{10}{|c|}{ AUSENCIA DE ESPECIFICACIONES } & & & & & \\
\hline
\end{tabular}

P52.- Dada la función $f(x)$ definida por $f(x)=e^{2 x-x^{2}}$.

a) Calcula los intervalos de crecimiento y decrecimiento.

b) Halla los extremos relativos.

c) Escribe las ecuaciones de las asíntotas de $f(x)$.

d) Determina el número de soluciones de la ecuación $f(x)=2$ en el intervalo $[0,1]$.

NIVELES DE COMPETENCIAS IMPLÍCITAS: Reproducción y conexión

Al resolver esta ecuación, el alumno interpreta el lenguaje formal y simbólico básico, en situaciones menos conocidas (CLSOn1), maneja afirmaciones sencillas y expresiones con símbolos y fórmulas no rutinarias (CLSOn2) y utiliza variables y realiza cálculos mediante procedimientos familiares (CLSOn3).

Estudia el signo de la función derivada en los intervalos $(-\infty, 1)$ y $(1,+\infty)$, de lo que se deduce: 
La función crece en el intervalo $(-\infty, 1)$ y decrece en el intervalo $(1,+\infty)$

Presenta un máximo en el punto $(1, e)$

Efectuar este paso supone que sabe expresarse sobre cuestiones matemáticas (CCn1) explicando los cálculos y sus propiedades (CCn2) e interpretando las relaciones implicadas (CCn3).

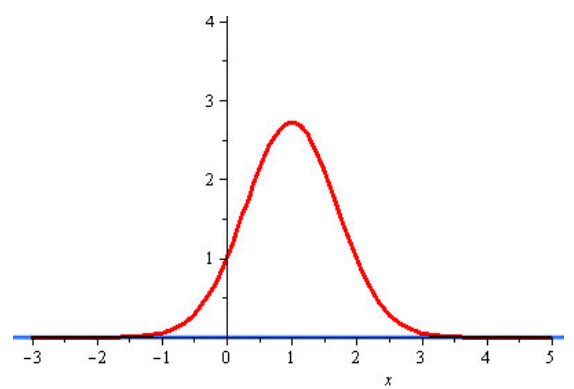

Figura 1.52.1

Como el dominio de la función es $R$, no tiene asíntotas verticales.

$$
\lim _{x \rightarrow-\infty}\left(e^{2 x-x^{2}}\right)=\lim _{x \rightarrow-\infty} \frac{e^{2 x}}{e^{x^{2}}}=0
$$

Análogamente, $\lim _{x \rightarrow+\infty}\left(e^{2 x-x^{2}}\right)=e^{-\infty}=0$ pues $\lim _{x \rightarrow \pm \infty} 2 x-x^{2}=-\infty$

La función tiene como asíntota horizontal la recta $y=0$.

Como tiene asíntota horizontal no tiene asíntota oblicua.

Se tiene una función definida analíticamente, que es preciso interpretar, seleccionar y cambiar entre diferentes formas de representación (CRn1, CRn2), analítica y gráficamente, diferenciando entre ambas formas de representación (CRn3). Figura 1.52.1.

El apartado b) del ejercicio de la ficha 1.52.1 corresponde al nivel de reproducción y conexión.

Con este razonamiento identifica el problema (RAn1), reconoce representaciones de los datos del ejercicio (RPRn1), comprende la expresión escrita (RCn1), identifica que es un modelo similar a otros vistos con anterioridad (RMn1) y le reconoce como problema ya practicado (RRPn1). Continúa planteando los algoritmos correspondientes (RPRn2).

El alumno resuelve la ecuación

$$
e^{2 x-x^{2}}=2
$$

Es una ecuación exponencial, para resolverla el alumno interpreta el lenguaje formal y simbólico básico, en situaciones menos conocidas (CLSOn1), maneja afirmaciones sencillas y expresiones con símbolos y fórmulas no rutinarias 
(CLSOn2) y utiliza variables y realiza cálculos mediante procedimientos familiares (CLSOn3).

Tomando logaritmos

$$
\begin{gathered}
\ln \left(e^{2 x-x^{2}}\right)=2 x-x^{2}=\ln (2) \\
x^{2}-2 x+\ln (2)=0
\end{gathered}
$$

El alumno expone el proceso de cálculo (RAn2) realizando explicaciones sencillas (RCn2), asocia con fórmulas establecidas y realiza los cálculos (RPRn3).

Es una ecuación de segundo grado, que tiene como soluciones:

$$
x_{1}=1+\sqrt{1-\ln (2)} \text { y } \quad x_{2}=1-\sqrt{1-\ln (2)}
$$

Dado que el enunciado pide que las soluciones estén en el intervalo [0,1], la solución es $x_{2}=1-\sqrt{1-\ln (2)}$.

Como, al resolver la ecuación, ha encontrado la solución puede afirmar que

La ecuación $e^{2 x-x^{2}}=2$ tiene una solución en el intervalo $[0,1]$

Con este razonamiento realiza explicaciones sencillas (RCn2), justifica las fórmulas utilizadas y los resultados (RAn3), maneja procedimientos resolviendo y calculando (RLSOn3) y resuelve problemas rutinarios estandarizados (RRPn3). En conclusión, describe los resultados obtenidos (RCn3) comunicando de manera elemental los resultados del modelo (RMn3).

El alumno podía haber hecho un razonamiento más elaborado utilizando los teoremas de Bolzano y Rolle.

Piensa en el tratamiento matemático necesario (CPRn1), razona matemáticamente de manera simple (CAn1) y estructura la situación que debe modelizar (CMn1).

Define la función

$$
g(x)=e^{2 x-x^{2}}-2
$$

Es una función continua en todo $R$ y en particular en el intervalo cerrado $[0,1]$, por ser suma algebraica de funciones continuas. 


$$
\begin{aligned}
& g(0)=e^{0}-2<0 \\
& g(1)=e^{1}-2>0
\end{aligned}
$$

Es una función continua en el intervalo cerrado $[0,1]$ que toma valores de signo contrario en los extremos del intervalo, por el teorema de Bolzano, existe un punto $c \in(0,1)$, con $g(c)=e^{2 c-c^{2}}-2=0$, que es la solución de la ecuación

$$
e^{2 x-x^{2}}=2
$$

El alumno sabe expresarse sobre cuestiones matemáticas (CCn1), explica los cálculos y sus propiedades (CCn2) e interpreta las relaciones implicadas (CCn3).

Para demostrar que la solución es única razona por reducción al absurdo, suponiendo que existen dos valores $c_{1}$ y $c_{2}$, soluciones de la ecuación

$$
e^{2 x-x^{2}}=2
$$

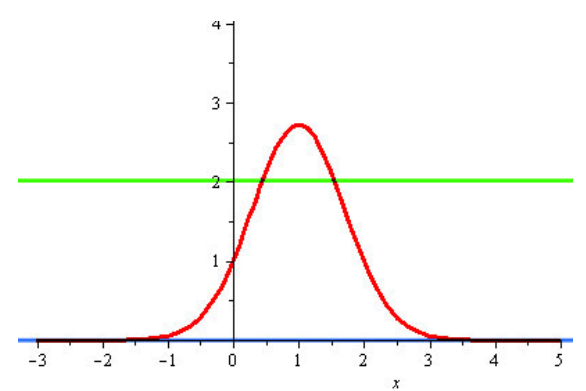

Es decir, $g\left(c_{1}\right)=g\left(c_{2}\right)=0$

Figura 1.52 .2

La función $g(x)=e^{2 x-x^{2}}-2$ es derivable y

su derivada es

$$
g^{\prime}(x)=(2-2 x) e^{2 x-x^{2}}
$$

Por el teorema de Rolle, tiene que existir un punto $d \in\left(c_{1}, c_{2}\right) \subset(0,1)$ con la condición $g^{\prime}(d)=0$

$$
\text { La ecuación } g^{\prime}(x)=0 \text { tiene solución } x=1
$$

Lo cual contradice el teorema de Rolle.

Luego el razonamiento era falso y la solución es única.

De este modo desarrolla procedimientos intuitivos ya practicados pero no rutinarios (CRPn1), evalúa el encadenamiento de argumentos matemáticos particulares (CAn3) y sabe interpretar y alternar diferentes modelos y comunicar los resultados (CMn3). 
El alumno interpreta formas de representación (CRn1) y selecciona y cambia entre diferentes formas de representación $(\mathrm{CRn} 2)$, analítica y gráficamente. Figura 1.52.2.

\begin{tabular}{|c|c|c|c|c|c|c|c|c|}
\hline \multicolumn{2}{|c|}{ FICHA 1.52.2. } & \multicolumn{7}{|c|}{ COMPETENCIAS IMPLÍCITAS EN LA RESOLUCIÓN DEL P52 } \\
\hline & Nivel 1 & Nivel 2 & Nivel 3 & Nivel 1 & Nivel 2 & Nivel 3 & Nivel 1 & Nivel 2 \\
\hline PR & * & * & * & * & * & * & & \\
\hline$A$ & * & * & * & * & & * & & \\
\hline C & * & * & * & * & * & * & & \\
\hline M & * & & * & * & * & * & & \\
\hline $\mathbf{R P}$ & * & & * & * & & & & \\
\hline $\mathbf{R}$ & & & & * & * & * & & \\
\hline LSO & & & * & * & * & * & & \\
\hline & \multicolumn{3}{|c|}{ Reproducción } & \multicolumn{3}{|c|}{ Conexión } & \multicolumn{2}{|c|}{ Reflexión } \\
\hline
\end{tabular}

\section{ANÁLISIS DEL PROBLEMA P57}

En el apartado a) del problema que aparece en la ficha 1.57 .1 se pide el estudio y representación de una función, es un ejercicio que se encuadra en los niveles de reproducción, conexión y reflexión.

El problema reproduce situaciones similares a las estudiadas en clase, pero no son de mera rutina, por tanto se trata de un nivel de conexión.

Para estudiar la monotonía de la función y extremos relativos, hay que observar el signo de la primera derivada, para estudiar la curvatura y puntos de inflexión hay que calcular y estudiar el signo la segunda derivada y para escribir las ecuaciones de las asíntotas hay que calcular límites.

Efectuar este paso supone que sabe expresarse sobre cuestiones matemáticas (CCn1) explicando los cálculos y sus propiedades (CCn2).

El alumno estructura la situación que debe modelizar (CMn1), traduce en la práctica el modelo a seguir, que es algo diferente de los estudiados (CMn2) y desarrolla procedimientos intuitivos ya practicados, pero no rutinarios (CRPn1).

Por tanto, el alumno tiene que pensar en el tratamiento matemático necesario (CPRn1), con lo que comprende que tiene que emplear conceptos matemáticos intermedios (CPRn2) y aplicar los conceptos matemáticos apropiados (CPRn3). 
FICHA 1.57.1.

ESTUDIO DEL ENUNCIADO DEL P57

P57.- Sea $f(x)=2-x+\ln x$ con $x \in(0,+\infty)$.

a) Determinar los intervalos de crecimiento y decrecimiento, los extremos relativos, los intervalos de concavidad y convexidad y las asíntotas de $f$. Esbozar la gráfica de $f$.

b) Probar que existe un punto $c \in\left[\frac{1}{e^{2}}, 1\right]$ tal que $f(c)=0$.

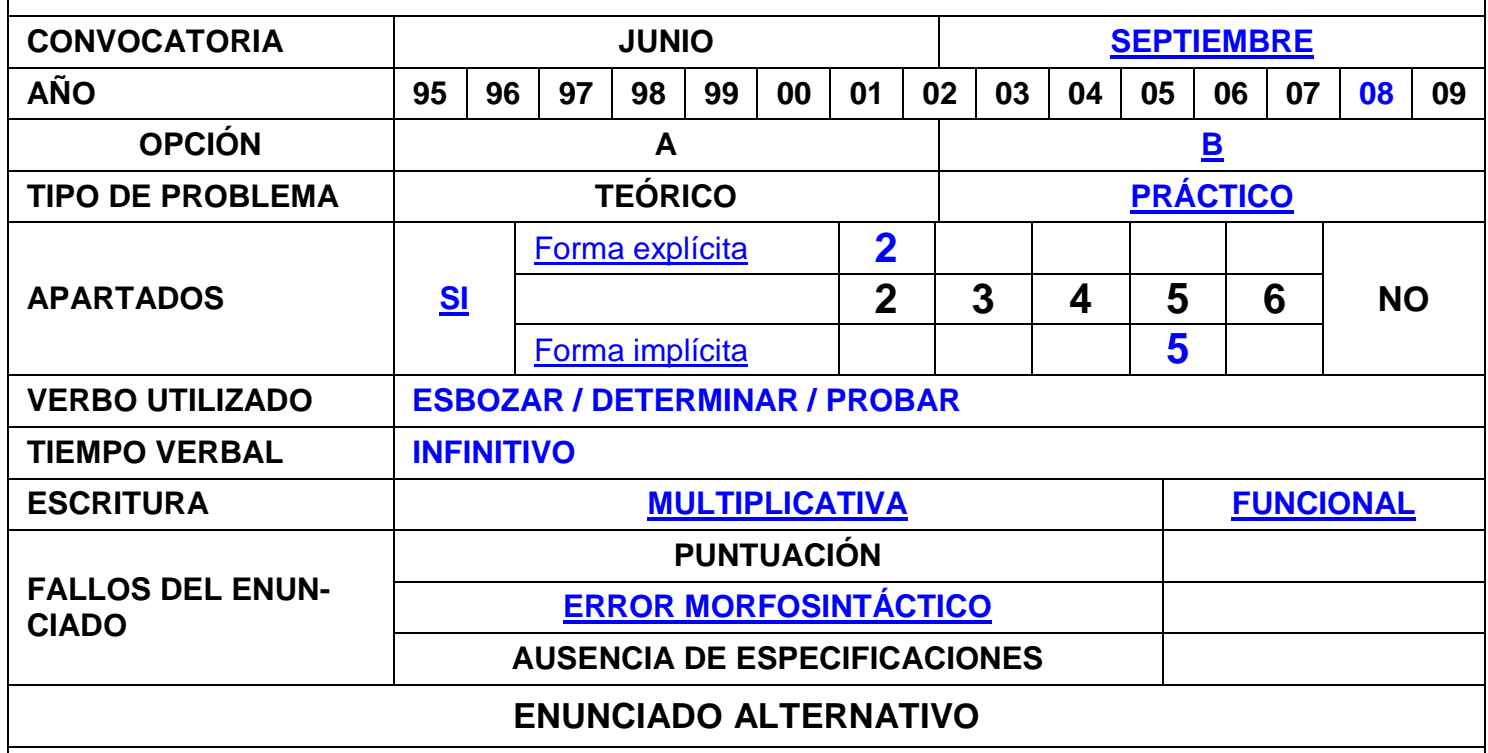

P57.- Dada la función $f(x)=2-x+\ln (x)$ con $x \in(0,+\infty)$.

a) Determina los intervalos de crecimiento y decrecimiento.

b) Calcula los extremos relativos.

c) Halla los intervalos de concavidad y convexidad

d) Escribe las ecuaciones de las asíntotas de $f(x)$.

e) Esboza la gráfica de $\underline{f(x)}$.

f) Prueba que existe un punto $c \in\left[\frac{1}{e^{2}}, 1\right]$ tal que $f(c)=0$.

NIVELES DE COMPETENCIAS IMPLÍCITAS: Reproducción, conexión y reflexión

La función $f(x)=2-x-\ln (x)$ está definida en el intervalo $(0,+\infty)$

Calcula la función derivada

$$
f^{\prime}(x)=-1+\frac{1}{x}=\frac{1-x}{x}
$$


Calcula los valores que anulan esa función derivada, lo que corresponde al nivel de reproducción, manejo de procedimientos y fórmulas, resolviendo y calculando (RLSOn3).

Resuelve la ecuación $\frac{1-x}{x}=0$ obteniendo la solución $x=1$.

Estudia el signo de la función derivada en los intervalos $(0,1)$ y $(1,+\infty)$, de lo que se deduce:

La función crece en el intervalo $(0,1)$ y decrece en el intervalo $(1,+\infty)$

Tiene un máximo en el punto $(1,1)$.

Efectuar este paso supone que sabe expresarse sobre cuestiones matemáticas (CCn1) explicando los cálculos y sus propiedades (CCn2) e interpretando las relaciones implicadas $(\mathrm{CCn} 3)$.

Calcula la función derivada segunda

$$
f^{\prime \prime}(x)=-\frac{1}{x^{2}}
$$

La ecuación $f^{\prime \prime}(x)=-\frac{1}{x^{2}}=0$ no tiene solución.

El alumno razona matemáticamente de manera simple (CAn1) y sabe expresarse sobre cuestiones matemáticas (CCn1).

La función $f^{\prime \prime}(x)$ es siempre $<0$ en el intervalo $(0,+\infty)$ de lo que se deduce que la función es concava en $(0,+\infty)$.

Para efectuar este estudio el alumno ha tenido que estudiar el signo de las funciones derivadas con lo que interpreta el lenguaje formal y simbólico básico, en situaciones menos conocidas (CLSOn1), maneja afirmaciones sencillas y expresiones con símbolos y fórmulas no rutinarias (CLSOn2) y utiliza variables y realiza cálculos mediante procedimientos familiares (CLSOn3).

$$
\begin{gathered}
\lim _{x \rightarrow 0^{+}}(2-x+\ln (x))=-\infty, \text { por lo que } \\
x=0 \text { es asíntota vertical }
\end{gathered}
$$

Como el crecimiento de la función $f(x)=x$ es más rápido que el de la función $g(x)=\ln (x)$, utilizando órdenes de infinitud,

$$
\lim _{x \rightarrow+\infty}(2-x+\ln (x))=-\infty
$$




\section{No tiene asíntota horizontal}

$$
\lim _{x \rightarrow+\infty} \frac{2-x+\ln (x)}{x}=\lim _{x \rightarrow+\infty} \frac{2}{x}-\lim _{x \rightarrow+\infty} 1+\lim _{x \rightarrow+\infty} \frac{\ln (x)}{x} \stackrel{(1)}{=}-1
$$

(1) Utilizando la regla de L'Hôpital

$$
\lim _{x \rightarrow+\infty}(2-x+\ln (x)-(-x))=+\infty
$$

La función no tiene asíntota oblicua

El alumno, para representar la función también puede hacer la siguiente reflexión

Dado que $\lim _{x \rightarrow 0^{+}}(2-x+\ln (x))=-\infty$, para pasar de $-\infty$ al punto $(1,1)$ en algún punto del intervalo $(0,1)$ tiene que cortar al eje de abscisas $y$ dado que $\lim _{x \rightarrow+\infty}(2-x+\ln (x))=-\infty$ tiene que

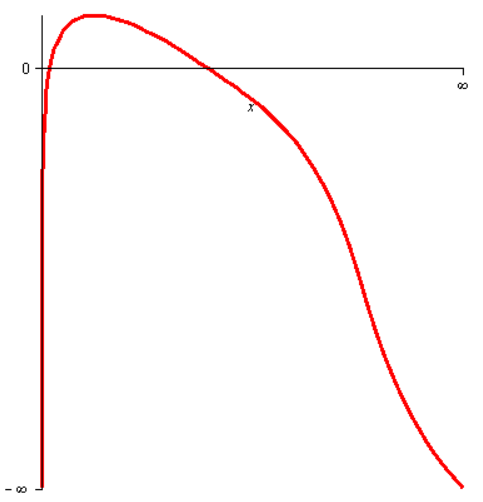

Figura 1.57

existir otro punto de corte con el eje de abscisas en el intervalo $(1,+\infty)$.

Aparece aquí el nivel de reflexión por parte del estudiante para aplicar estrategias en la resolución de un problema que contiene elementos inusuales, con lo que aplica estrategias no rutinarias (RfPRn2), razona de manera sencilla, distinguiendo formas más amplias de argumentación (RfAn1), sabe explicar cuestiones matemáticas, cálculos y resultados (RfCn1).

Se tiene una función definida analíticamente, que es preciso interpretar, seleccionar y cambiar entre diferentes formas de representación (CRn1, CRn2), analítica y gráficamente, diferenciando entre ambas formas de representación (CRn3).

La gráfica de la función es la figura 1.57.

El apartado b) del ejercicio que se presenta en la ficha 1.57.1 es un ejercicio de reproducción, en el que hay que utilizar el teorema de Bolzano para su resolución.

Con este razonamiento identifica el problema (RAn1), reconoce representaciones de los datos del ejercicio (RPRn1), comprende la expresión escrita (RCn1), identifica que es un modelo similar a otros vistos con anterioridad (RMn1) y le reconoce como problema ya practicado (RRPn1). A continuación, plantea los 
algoritmos correspondientes (RPRn2) y reproduce un problema ya practicado de manera cerrada (RRPn2).

Consideramos la función

$$
f(x)=2-x+\ln (x)
$$

Es una función continua en su dominio $(0, \infty)$, por ser suma algebraica de funciones continuas.

$$
\begin{gathered}
f\left(\frac{1}{e^{2}}\right)=2-\frac{1}{e^{2}}+\ln \left(\frac{1}{e^{2}}\right)=-\frac{1}{e^{2}}<0 \\
f(1)=2-1+\ln (1)=1>0
\end{gathered}
$$

El alumno expone el proceso de cálculo (RAn2), realizando explicaciones sencillas (RCn2), asocia con fórmulas establecidas y realiza los cálculos (RPRn3).

Es una función continua en el intervalo cerrado $\left[\frac{1}{e^{2}}, 1\right]$ que toma valores de signo contrario en los extremos del intervalo, por el teorema de Bolzano,

$$
\text { existe un punto } c \in\left(\frac{1}{e^{2}}, 1\right) \operatorname{con} f(c)=0
$$

El alumno justifica las fórmulas utilizadas y los resultados (RAn3), maneja procedimientos y fórmulas, resolviendo y calculando (RLSOn3) y resuelve problemas rutinarios estandarizados (RRPn3).

Concluye describiendo los resultados obtenidos $(\mathrm{RCn} 3)$ y comunicando de manera elemental los resultados del modelo (RMn3).

\begin{tabular}{|l|c|c|c|c|c|c|c|c|}
\hline \multicolumn{6}{|c|}{ FICHA 1.57.2. } & \multicolumn{7}{l|}{ COMPETENCIAS IMPLÍCITAS EN LA RESOLUCIÓN DEL P57 } \\
\hline & Nivel 1 & Nivel 2 & Nivel 3 & Nivel 1 & Nivel 2 & Nivel 3 & Nivel 1 & Nivel 2 \\
\hline PR & $*$ & $*$ & $*$ & $*$ & $*$ & $*$ & & $*$ \\
\hline A & $*$ & $*$ & $*$ & $*$ & & & $*$ & \\
\hline C & $*$ & $*$ & $*$ & $*$ & $*$ & $*$ & $*$ & \\
\hline M & $*$ & & $*$ & $*$ & $*$ & & & \\
\hline RP & $*$ & $*$ & $*$ & $*$ & & & & \\
\hline R & & & & $*$ & $*$ & $*$ & & \\
\hline LSO & & & $*$ & $*$ & $*$ & $*$ & & \\
\hline & \multicolumn{2}{|l|}{ Reproducción } & & Conexión & & Reflexión \\
\hline
\end{tabular}




\section{IV.3. ESTUDIO DE LAS CUESTIONES DE ANÁLISIS MATEMÁ- TICO}

En este apartado se muestra una síntesis del análisis que se ha realizado sobre todas las cuestiones de A.M. que se han propuesto en las Universidades de Castilla y León al amparo del currículo LOGSE. Como ya se ha mencionado se presentan dos tablas para cada cuestión, una que contiene el enunciado y las competencias implícitas en el mismo, su ubicación temporal, un análisis gramatical y enunciaddo altenativo y, tras la conclusión, se presenta otra tabla de competencias que se detectan en su resolución.

\section{ANÁLISIS DE LA CUESTIÓN C1}

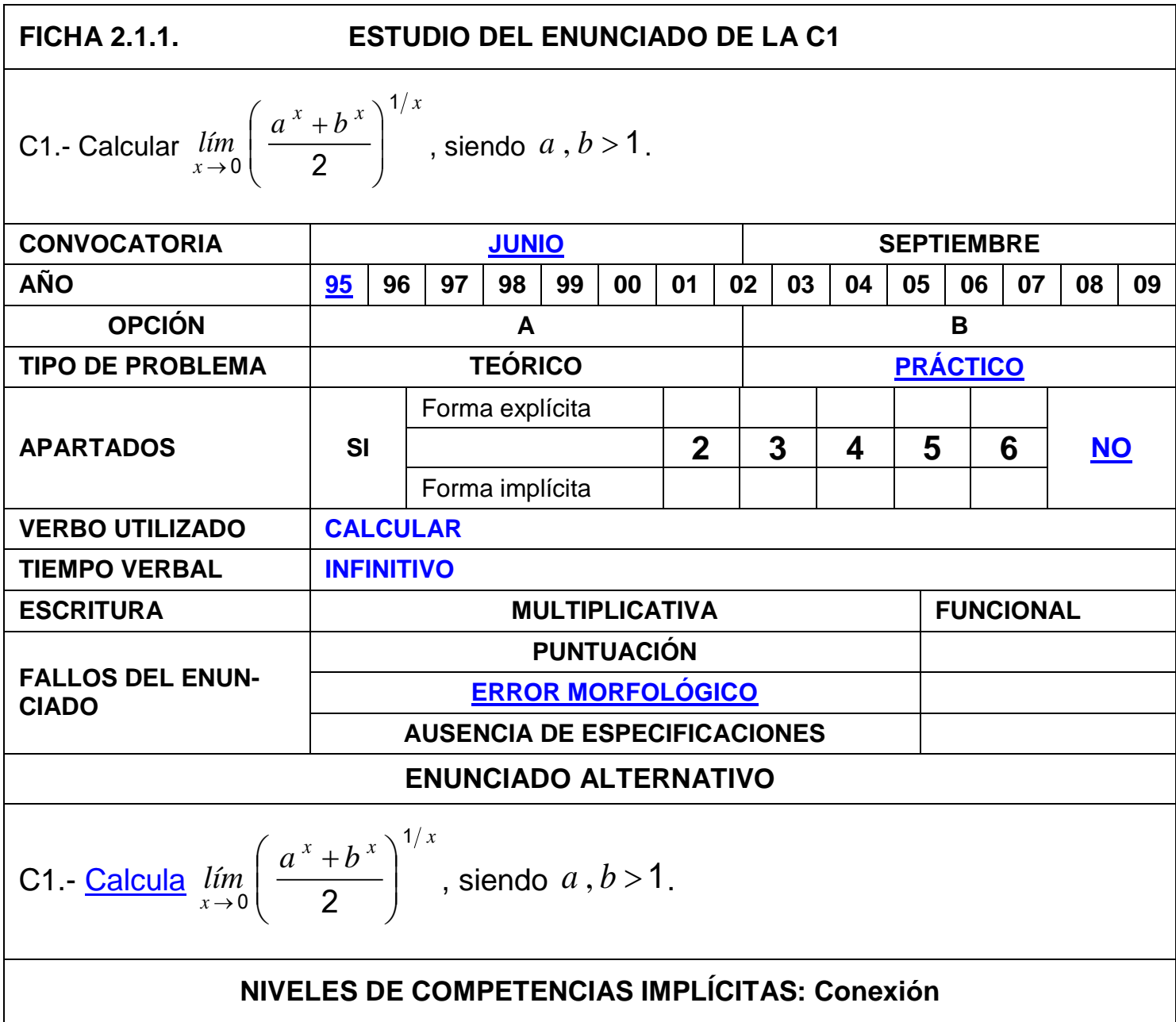

El ejercicio que se presenta en la ficha 2.1.1 es un ejercicio con parámetros, en el que hay que utilizar la regla de L'Hôpital para su resolución, es, por consi- 
guiente, un ejercicio de conexión pues reproduce situaciones similares a las practicadas durante la instrucción pero que no son de mera rutina.

El alumno estructura la situación que debe modelizar (CMn1) y traduce en la práctica el modelo a seguir, que es algo diferente de los estudiados (CMn2) dado que tiene que trabajar con parámetros.

Por tanto, piensa en el tratamiento matemático necesario (CPRn1), razona matemáticamente de manera simple (CAn1), sabe expresarse sobre cuestiones matemáticas (CCn1) y desarrolla procedimientos intuitivos ya practicados, pero no rutinarios (CRPn1).

Hay que calcular el $\lim _{x \rightarrow 0}\left(\frac{a^{x}+b^{x}}{2}\right)^{1 / x}=L$

Para $x \rightarrow 0, a^{x} \rightarrow 1$ y $b^{x} \rightarrow 1 \Rightarrow \frac{a^{x}+b^{x}}{2} \rightarrow 1, \frac{1}{x} \rightarrow \pm \infty$, por tanto, es una indeterminación del tipo $1^{\infty}$.

Tomando logaritmos neperianos

$$
\begin{aligned}
& \ln (L)=\ln \left[\lim _{x \rightarrow 0}\left(\frac{a^{x}+b^{x}}{2}\right)^{1 / x}\right]=\text { como el logaritmo es una función continua } \\
&= \lim _{x \rightarrow 0}\left[\ln \left(\left(\frac{a^{x}+b^{x}}{2}\right)^{1 / x}\right]=\right.\text { utilizando las propiedades de los logaritmos } \\
&= \lim _{x \rightarrow 0} \frac{1}{x} \cdot \ln \left(\frac{a^{x}+b^{x}}{2}\right)=\lim _{x \rightarrow 0} \frac{\ln \left(a^{x}+b^{x}\right)-\ln (2)}{x}=\text { utilizando la regla de L'Hôpital } \\
&= \lim _{x \rightarrow 0} \frac{\frac{a^{x} \cdot \ln (a)+b^{x} \cdot \ln (b)}{a^{x}+b^{x}}}{1}=\frac{\ln (a)+\ln (b)}{2}=\text { utilizando las propiedades de los } \\
& \ln (L)=\ln \sqrt{a b} \Rightarrow L=\sqrt{a b}
\end{aligned}
$$

Efectuar estos pasos supone que el alumno justifica las fórmulas utilizadas y los resultados (RAn3), sabe expresarse sobre cuestiones matemáticas (CCn1) explicando los cálculos y sus propiedades $(\mathrm{CCn} 2)$ e interpretando las relaciones implicadas (CCn3). 
El alumno comprende que tiene que emplear conceptos matemáticos intermedios (CPRn2) y aplica los conceptos matemáticos apropiados (CPRn3).

Con el cálculo de límites y la aplicación de las propiedades de logaritmos y regla de L'Hôpital, interpreta el lenguaje formal y simbólico básico, en situaciones menos conocidas (CLSOn1), maneja afirmaciones sencillas y expresiones con símbolos y fórmulas no rutinarias (CLSOn2) y realiza cálculos mediante procedimientos familiares (CLSOn3).

\section{FICHA 2.1.2. COMPETENCIAS IMPLÍCITAS EN LA RESOLUCIÓN DE LA C1}

\begin{tabular}{|c|c|c|c|c|c|c|c|c|}
\hline & Nivel 1 & Nivel 2 & Nivel 3 & Nivel 1 & Nivel 2 & Nivel 3 & Nivel 1 & Nivel 2 \\
\hline PR & & & & * & * & * & & \\
\hline A & & & * & * & & & & \\
\hline C & & & & * & * & * & & \\
\hline $\mathbf{M}$ & & & & * & * & & & \\
\hline RP & & & & * & & & & \\
\hline \multicolumn{9}{|l|}{$\mathbf{R}$} \\
\hline LSO & & & & * & * & * & & \\
\hline & \multicolumn{3}{|c|}{ Reproducción } & \multicolumn{3}{|c|}{ Conexión } & \multicolumn{2}{|c|}{ Reflexión } \\
\hline
\end{tabular}

\section{ANÁLISIS DE LA CUESTIÓN C5}

La cuestión que se presenta en la ficha 2.5.1 es un ejercicio con parámetros, es, por consiguiente, un ejercicio de conexión pues reproduce situaciones similares a las practicadas durante la instrucción pero que no son de mera rutina.

El alumno estructura la situación que debe modelizar (CMn1), por tanto, piensa en el tratamiento matemático necesario (CPRn1), razona matemáticamente de manera simple (CAn1) y sabe expresarse sobre cuestiones matemáticas (CCn1).

Traduce en la práctica el modelo a seguir, que es algo diferente de los estudiados (CMn2) y desarrolla procedimientos intuitivos ya practicados, pero no rutinarios (CRPn1).

Los puntos $A$ y $B$ son puntos de la gráfica de la función $f(x)=a x^{2}+b x+c$, por tanto sus coordenadas son:

$$
A=\left(x_{1}, y_{1}\right)=\left(x_{1}, a x_{1}^{2}+b x_{1}^{2}+c\right) \text { y } B=\left(x_{2}, y_{2}\right)=\left(x_{2}, a x_{2}^{2}+b x_{2}^{2}+c\right)
$$


FICHA 2.5.1.

ESTUDIO DEL ENUNCIADO DE LA C5

C5.- Si sobre la parábola $y=a x^{2}+b x+c$ se toman dos puntos $A$ y $B$, de abscisas $x_{1}$ y $x_{2}$, comprueba que la tangente en el punto de abscisas $\frac{x_{1}+x_{2}}{2}$ es paralela a la cuerda $A B$.

\begin{tabular}{|c|c|c|c|c|c|c|c|c|c|c|c|}
\hline CONVOCATORIA & \multicolumn{5}{|c|}{$\underline{\mathrm{JUNIO}}$} & \multicolumn{6}{|c|}{ SEPTIEMBRE } \\
\hline AÑO & \begin{tabular}{l|l}
95 & $\underline{96}$ \\
\end{tabular} & 97 & \begin{tabular}{|l|l|}
98 & 99 \\
\end{tabular} & 00 & 01 & \begin{tabular}{l|l}
02 & 03 \\
\end{tabular} & 04 & 05 & \begin{tabular}{l|l}
06 & 07 \\
\end{tabular} & 08 & 09 \\
\hline OPCIÓN & \multicolumn{5}{|c|}{ A } & \multicolumn{6}{|c|}{ B } \\
\hline TIPO DE PROBLEMA & \multicolumn{5}{|c|}{ TEÓRICO } & \multicolumn{6}{|c|}{ PRÁCTICO } \\
\hline \multirow{3}{*}{ APARTADOS } & \multirow{3}{*}{ SI } & \multicolumn{3}{|c|}{ Forma explícita } & & & & \multirow[b]{2}{*}{5} & \multirow[b]{2}{*}{6} & \multirow{3}{*}{\multicolumn{2}{|c|}{$\underline{\text { NO }}$}} \\
\hline & & & & & 2 & 3 & 4 & & & & \\
\hline & & \multicolumn{3}{|c|}{ Forma implícita } & & & & & & & \\
\hline VERBO UTILIZADO & \multicolumn{11}{|c|}{ COMPROBAR } \\
\hline TIEMPO VERBAL & \multicolumn{11}{|c|}{ IMPERATIVO } \\
\hline ESCRITURA & \multicolumn{7}{|c|}{ ALGEBRAICA } & \multicolumn{4}{|c|}{ ECUACIONAL } \\
\hline \multirow{3}{*}{$\begin{array}{l}\text { FALLOS DEL ENUN- } \\
\text { CIADO }\end{array}$} & \multicolumn{7}{|c|}{ PUNTUACIÓN } & & & & \\
\hline & \multicolumn{7}{|c|}{ SIGNIFICADO DE LA ORACIÓN } & & & & \\
\hline & \multicolumn{7}{|c|}{ AUSENCIA DE ESPECIFICACIONES } & & & & \\
\hline \multicolumn{12}{|c|}{ ENUNCIADO ALTERNATIVO } \\
\hline \multicolumn{12}{|c|}{ El enunciado está bien. } \\
\hline \multicolumn{12}{|c|}{ NIVELES DE COMPETENCIAS IMPLÍCITAS: Conexión } \\
\hline
\end{tabular}

La pendiente de la cuerda $A B$ es

$$
m_{\overline{A B}}=\frac{y_{2}-y_{1}}{x_{2}-x_{1}}=\frac{a\left(x_{2}^{2}-x_{1}^{2}\right)+b\left(x_{2}-x_{1}\right)}{x_{2}-x_{1}} \stackrel{(1)}{=} a\left(x_{2}+x_{1}\right)+b
$$

(1) Factorizando y simplificando

De donde se deduce que

$$
m_{\overline{A B}}=a\left(x_{2}+x_{1}\right)+b
$$

Efectuar estos pasos supone que el alumno razona matemáticamente de manera simple (CAn1), sabe expresarse sobre cuestiones matemáticas (CCn1) explicando los cálculos y sus propiedades (CCn2) e interpretando las relaciones implicadas (CCn3).

Derivando

$$
f^{\prime}(x)=2 a x+b \Rightarrow f^{\prime}\left(\frac{x_{1}+x_{2}}{2}\right)=2 a\left(\frac{x_{1}+x_{2}}{2}\right)+b=a\left(x_{1}+x_{2}\right)+b
$$


Como la derivada, evaluada en el punto, es la pendiente de la recta tangente a la curva en dicho punto, calcula el valor de la función derivada.

$$
f^{\prime}\left(\frac{x_{1}+x_{2}}{2}\right)=a\left(x_{1}+x_{2}\right)+b
$$

El alumno comprende que tiene que emplear conceptos matemáticos intermedios (CPRn2), pues trabaja con parámetros, y aplica los conceptos matemáticos apropiados (CPRn3).

Con el cálculo de la pendiente de la recta y de la derivada interpreta el lenguaje formal y simbólico básico, en situaciones menos conocidas (CLSOn1), maneja afirmaciones sencillas y expresiones con símbolos y fórmulas no rutinarias (CLSOn2) y realiza cálculos mediante procedimientos familiares (CLSOn3).

La pendiente de la recta tangente en el punto $\frac{x_{1}+x_{2}}{2}$ es:

$$
a\left(x_{1}+x_{2}\right)+b=m_{\overline{A B}}
$$

El alumno describe los resultados obtenidos (RCn3) y comunica de manera elemental los resultados del modelo (RMn3).

\begin{tabular}{|l|c|c|c|c|c|c|c|c|}
\hline \multicolumn{7}{|c|}{ FICHA 2.5.2. COMPETENCIAS IMPLÍCITAS EN LA RESOLUCIÓN DE LA C5 } \\
\hline & Nivel 1 & Nivel 2 & Nivel 3 & Nivel 1 & Nivel 2 & Nivel 3 & Nivel 1 & Nivel 2 \\
\hline PR & & & & $*$ & $*$ & $*$ & & \\
\hline A & & & & $*$ & & & & \\
\hline C & & & $*$ & $*$ & $*$ & $*$ & & \\
\hline M & & & $*$ & $*$ & $*$ & & & \\
\hline RP & & & & $*$ & & & & \\
\hline R & & & & & & & & \\
\hline LSO & & & & $*$ & $*$ & $*$ & & \\
\hline & Reproducción & & Conexión & & Reflexión \\
\hline
\end{tabular}

\section{ANÁLISIS DE LA CUESTIÓN C8}

La cuestión que se presenta en la ficha 2.8.1 es un ejercicio de reproducción del conocimiento estudiado, reconocimiento de equivalentes, ejecución de problemas rutinarios, aplicación de destrezas técnicas y de algoritmos habituales, manejo de expresiones y fórmulas establecidas y realización de cálculos. 
FICHA 2.8.1.

ESTUDIO DEL ENUNCIADO DE LA C8

C8- La derivada de la función $f(x)=(x-1)(x+2) e^{-x^{2}}+3$ ¿Se anula por lo menos en un punto del intervalo $(-2,1)$ ? Razona tu respuesta, indicando en qué resultado teórico te has basado.

\begin{tabular}{|c|c|c|c|c|c|c|c|c|c|c|c|c|c|}
\hline \multirow{2}{*}{$\begin{array}{l}\text { CONVOCATORIA } \\
\text { AÑO }\end{array}$} & \multicolumn{6}{|c|}{ JUNIO } & \multicolumn{7}{|c|}{ SEPTIEMBRE } \\
\hline & $95 \underline{96}$ & 97 & 98 & 99 & 00 & 01 & $02 \quad 03$ & 04 & 05 & 06 & 07 & 08 & 09 \\
\hline OPCIÓN & \multicolumn{6}{|c|}{ A } & \multicolumn{7}{|c|}{ B } \\
\hline TIPO DE PROBLEMA & \multicolumn{6}{|c|}{ TEÓRICO } & \multicolumn{7}{|c|}{ PRÁCTICO } \\
\hline \multirow{3}{*}{ APARTADOS } & \multirow{3}{*}{$\underline{\text { SI }}$} & \multicolumn{4}{|c|}{ Forma explícita } & & & & \multirow[b]{2}{*}{5} & \multirow{2}{*}{\multicolumn{2}{|c|}{6}} & \multirow{3}{*}{\multicolumn{2}{|c|}{ NO }} \\
\hline & & & & & & 2 & 3 & 4 & & & & & \\
\hline & & \multicolumn{4}{|c|}{ Forma implícita } & 2 & & & & & & & \\
\hline VERBO UTILIZADO & \multicolumn{13}{|c|}{ RAZONAR } \\
\hline TIEMPO VERBAL & \multicolumn{13}{|c|}{ IMPERATIVO } \\
\hline ESCRITURA & \multicolumn{8}{|c|}{ ALEBRAICA } & \multicolumn{5}{|c|}{ FUNCIONAL } \\
\hline \multirow{3}{*}{$\begin{array}{l}\text { FALLOS DEL ENUN- } \\
\text { CIADO }\end{array}$} & \multicolumn{8}{|c|}{ PUNTUACIÓN } & & & & & \\
\hline & \multicolumn{8}{|c|}{ ESTRUCTURA DE LA ORACIÓN } & & & & & \\
\hline & \multicolumn{8}{|c|}{ AUSENCIA DE ESPECIFICACIONES } & & & & & \\
\hline \multicolumn{14}{|c|}{ ENUNCIADO ALTERNATIVO } \\
\hline
\end{tabular}

C8- Se considera la función $f(x)=(x-1)(x+2) e^{-x^{2}}+3$. Explica si la función derivada se anula por lo menos en un punto del intervalo $(-2,1)$, indicando en qué resultado teórico te has basado.

NIVELES DE COMPETENCIAS IMPLÍCITAS: Reproducción

El alumno identifica el problema (RAn1), comprende la expresión escrita (RCn1), reconoce representaciones de los datos del ejercicio (RPRn1), identifica que el modelo es similar a otros vistos con anterioridad (RMn1) y reconoce el problema como practicado durante la instrucción (RRPn1).

El alumno continúa exponiendo el proceso de cálculo (RAn2) y reproduce el ejercicio de manera cerrada (RRPn2).

La función $f(x)=(x-1)(x+2) e^{-x^{2}}+3$ es continua en el intervalo cerrado $[-2,1]$ y derivable en el intervalo abierto $(-2,1)$.

$$
f(-2)=0 \text { y } f(1)=0
$$

Por el teorema de Rolle, existe un punto $c \in(-2,1)$ con $f^{\prime}(c)=0$.

Con este razonamiento, el alumno maneja procedimientos y fórmulas, resolviendo y calculando (RLSOn3), realiza explicaciones sencillas (RCn2), plantea 
los algoritmos correspondientes (RPRn2), asocia con fórmulas establecidas y realiza los cálculos (RPRn3) y, así, resuelve problemas rutinarios estandarizados (RRPn3).

El alumno describe los resultados obtenidos (RCn3) y termina justificando las fórmulas utilizadas y los resultados (RAn3) y comunicando de manera elemental los resultados del modelo (RMn3).

\section{FICHA 2.8.2. COMPETENCIAS IMPLÍCITAS EN LA RESOLUCIÓN DE LA C8}

\begin{tabular}{|c|c|c|c|c|c|c|c|c|}
\hline & Nivel 1 & Nivel 2 & Nivel 3 & Nivel 1 & Nivel 2 & Nivel 3 & Nivel 1 & Nivel 2 \\
\hline PR & * & * & * & & & & & \\
\hline A & * & * & * & & & & & \\
\hline C & & * & * & & & & & \\
\hline$M$ & * & & * & & & & & \\
\hline RP & * & * & * & & & & & \\
\hline \multicolumn{9}{|l|}{$\mathbf{R}$} \\
\hline \multirow[t]{2}{*}{ LSO } & & & * & & & & & \\
\hline & \multicolumn{3}{|c|}{ Reproducción } & \multicolumn{3}{|c|}{ Conexión } & \multicolumn{2}{|c|}{ Reflexión } \\
\hline
\end{tabular}

\section{ANÁLISIS DE LA CUESTIÓN C11}

La cuestión de la ficha 2.11.1 es un ejercicio de conexión y reflexión por parte del estudiante para planificar estrategias y aplicarlas en la resolución de un problema que contenga elementos inusuales.

El alumno piensa en el tratamiento matemático necesario (CPRn1), sigue el encadenamiento de argumentos matemáticos particulares (CAn2), sabe expresarse sobre cuestiones matemáticas (CCn1), estructura la situación que debe modelizar (CMn1) y traduce en la práctica el modelo a seguir, que es algo diferente de los estudiados (CMn2).

Como ejemplo:

Considerando el intervalo $(-1,1)$ y la función $f(x)=x^{3}$

Es una función derivable y estrictamente creciente en $(-1,1)$.

Sin embargo

$$
f^{\prime}(0)=0
$$


Lo que contradice que $f^{\prime}(x)>0 \quad \forall x \in(-1,1)$

FICHA 2.11.1.

ESTUDIO DEL ENUNCIADO DE LA C11

C11.- Lea atentamente el siguiente enunciado: "Dada una función $f$ definida y derivable en un intervalo abierto $(a, b)$ de los números reales, si $f$ es estrictamente creciente en dicho intervalo, entonces $f^{\prime}(x)>0$ ". ¿Es cierto? En caso afirmativo razonar la respuesta y en caso contrario poner un contraejemplo.

\begin{tabular}{|c|c|c|c|c|c|c|c|c|c|c|c|c|c|}
\hline CONVOCATORIA & \multicolumn{6}{|c|}{ JUNIO } & \multicolumn{7}{|c|}{ SEPTIEMBRE } \\
\hline AÑo & \begin{tabular}{l|l}
95 & 96
\end{tabular} & $\underline{97}$ & 98 & 99 & 00 & 01 & \begin{tabular}{l|l}
02 & 03
\end{tabular} & 04 & 05 & 06 & 07 & 08 & 09 \\
\hline OPCIÓN & \multicolumn{6}{|c|}{ A } & \multicolumn{7}{|c|}{ B } \\
\hline TIPO DE PROBLEMA & \multicolumn{6}{|c|}{ TEÓRICO } & \multicolumn{7}{|c|}{ PRÁCTICO } \\
\hline \multirow{3}{*}{ APARTADOS } & \multirow{3}{*}{ SI } & Form & $\exp$ & ícita & & & & & & & & \multirow{3}{*}{\multicolumn{2}{|c|}{$\underline{\text { NO }}$}} \\
\hline & & & & & & 2 & 3 & 4 & 5 & & 6 & & \\
\hline & & \multicolumn{4}{|c|}{ Forma implícita } & & & & & & & & \\
\hline VERBO UTILIZADO & \multicolumn{13}{|c|}{ RAZONAR } \\
\hline TIEMPO VERBAL & \multicolumn{13}{|c|}{ INFINITIVO } \\
\hline ESCRITURA & \multicolumn{8}{|c|}{ MULTIPLICATIVA } & \multicolumn{5}{|c|}{ FUNCIONAL } \\
\hline \multirow{3}{*}{$\begin{array}{l}\text { FALLOS DEL ENUN- } \\
\text { CIADO }\end{array}$} & \multicolumn{8}{|c|}{ PUNTUACIÓN } & & & & & \\
\hline & \multicolumn{8}{|c|}{ ESTRUCTURA DE LA ORACIÓN } & & & & & \\
\hline & \multicolumn{8}{|c|}{ AUSENCIA DE ESPECIFICACIONES } & & & & & \\
\hline \multicolumn{14}{|c|}{ ENUNCIADO ALTERNATIVO } \\
\hline
\end{tabular}

C11.- Lea atentamente el siguiente enunciado: "Dada una función $f(x)$ definida y derivable en un intervalo abierto de números reales $(a, b)$, si $f(x)$ es estrictamente creciente en dicho intervalo, entonces $f^{\prime}(x)>0$ ".

El enunciado puede ser verdadero o falso. Explica de forma razonada la veracidad del mismo y si es falso escribe un contraejemplo.

NIVELES DE COMPETENCIAS IMPLÍCITAS: Conexión y reflexión

El alumno expone problemas más allá de la reproducción de los ya practicados (RfRPn1), razona de forma sencilla, distinguiendo formas más amplias de argumentación (RfAn1), sabe explicar cuestiones matemáticas, cálculos y resultados (RfCn1) y explica asuntos que implican relaciones complejas ( $\mathrm{RfCn} 2)$.

Interpreta el lenguaje formal y simbólico básico, en situaciones menos conocidas (CLSOn1), maneja afirmaciones sencillas y expresiones con símbolos y 
fórmulas no rutinarias (CLSOn2) y realiza cálculos mediante procedimientos familiares (CLSOn3).

\begin{tabular}{|c|c|c|c|c|c|c|c|c|}
\hline \multicolumn{2}{|c|}{ FICHA 2.11.2. } & \multicolumn{7}{|c|}{ COMPETENCIAS IMPLÍCITAS EN LA RESOLUCIÓN DE LA C11 } \\
\hline & Nivel 1 & Nivel 2 & Nivel 3 & Nivel 1 & Nivel 2 & Nivel 3 & Nivel 1 & Nivel 2 \\
\hline PR & & & & * & & & & \\
\hline A & & & & * & & & * & \\
\hline C & & & & * & & & * & * \\
\hline M & & & & * & * & & & \\
\hline RP & & & & & & & * & \\
\hline \multicolumn{9}{|l|}{$\mathbf{R}$} \\
\hline LSO & & & & * & * & * & & \\
\hline & \multicolumn{3}{|c|}{ Reproducción } & \multicolumn{3}{|c|}{ Conexión } & \multicolumn{2}{|c|}{ Reflexión } \\
\hline
\end{tabular}

\section{ANÁLISIS DE LA CUESTIÓN C15}

\section{FICHA 2.15.1. \\ ESTUDIO DEL ENUNCIADO DE LA C15}

C15.- ¿Una función polinómica de grado 2 puede tener dos máximos? ¿Y algún punto de inflexión? Razonar las respuestas.

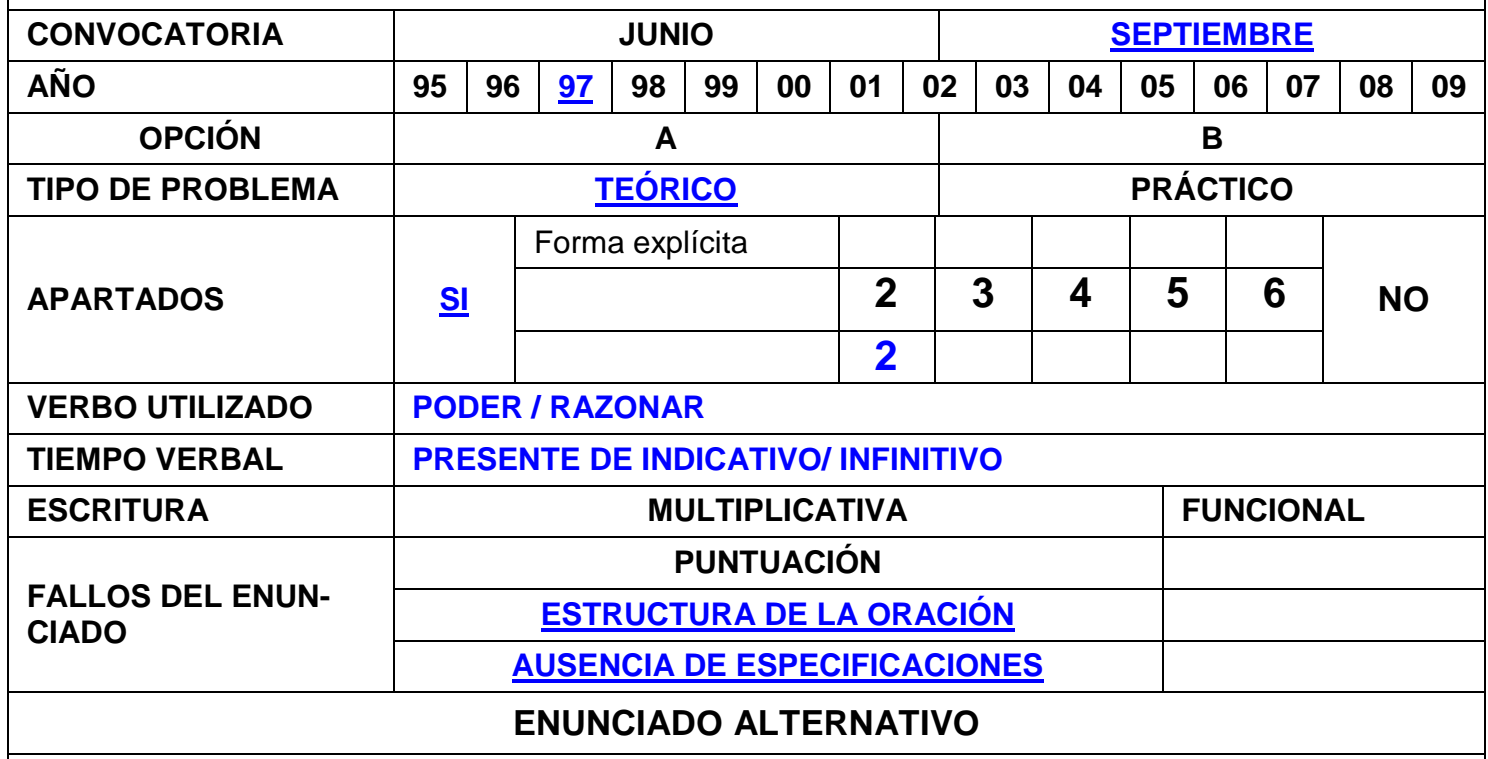

C15.- a) Analiza de forma razonada si una función polinómica de grado 2 puede tener dos máximos

b) Estudia si dicha función polinómica puede tener algún punto de inflexión.

NIVELES DE COMPETENCIAS IMPLÍCITAS: Reproducción 
La cuestión que se presenta en la ficha 2.15.1 es un ejercicio de reproducción del conocimiento estudiado, reconocimiento de equivalentes, ejecución de problemas rutinarios, aplicación de destrezas técnicas y de algoritmos habituales, manejo de expresiones y fórmulas establecidas y realización de cálculos.

Consideremos la función $f(x)=a x^{2}+b x+c$

Su función derivada es: $f^{\prime}(x)=2 a x+b$

Es una ecuación de primer grado que tiene una solución

$$
2 a x+b=0 \Rightarrow x=-\frac{b}{2 a}
$$

Como el enunciado dice expresamente "una función polinómica de grado dos", el coeficiente $a \neq 0$, luego esa ecuación tiene solución.

Pero como sólo tiene una solución, la ecuación no puede tener dos máximos.

Con este razonamiento identifica el problema (RAn1), reconoce representaciones de los datos del ejercicio (RPRn1), comprende la expresión escrita (RCn1), identifica que es un modelo similar a otros vistos con anterioridad (RMn1) y le reconoce como problema ya practicado (RRPn1).

Seguidamente, expone el proceso de cálculo (RAn2), realizando explicaciones sencillas ( $\mathrm{RCn} 2)$, asocia con fórmulas establecidas y realiza los cálculos (RPRn3).

El alumno describe los resultados obtenidos (RCn3), justifica las fórmulas utilizadas y los resultados (RAn3), comunicando de manera elemental los resultados del modelo (RMn3) y maneja procedimientos resolviendo y calculando (RLSOn3), resolviendo, de tal forma, problemas rutinarios estandarizados (RRPn3).

El apartado b) de la cuestión también corresponde al nivel de reproducción.

$$
f^{\prime \prime}(x)=2 a \neq 0 \quad \forall a \neq 0
$$

Por tanto una función polinómica de grado 2, $f(x)=a x^{2}+b x+c$ no tiene puntos de inflexión.

El alumno expone el proceso de cálculo (RAn2), realizando explicaciones sencillas (RCn2), asocia con fórmulas establecidas y realiza los cálculos (RPRn3), 
describe los resultados obtenidos (RCn3), comunicando de manera elemental los resultados del modelo (RMn3),

\begin{tabular}{|l|c|c|c|c|c|c|c|c|}
\hline \multicolumn{7}{|c|}{ FICHA 2.15.2. COMPETENCIAS IMPLÍCITAS EN LA RESOLUCIÓN DE LA C15 } \\
\hline & Nivel 1 & Nivel 2 & Nivel 3 & Nivel 1 & Nivel 2 & Nivel 3 & Nivel 1 & Nivel 2 \\
\hline PR & $*$ & & $*$ & & & & & \\
\hline A & $*$ & $*$ & $*$ & & & & & \\
\hline C & $*$ & $*$ & $*$ & & & & & \\
\hline M & $*$ & & $*$ & & & & & \\
\hline RP & $*$ & & $*$ & & & & & \\
\hline R & & & & & & & & \\
\hline LSO & & & $*$ & & & & & \\
\hline & Reproducción & & Conexión & & Reflexión \\
\hline
\end{tabular}

\section{ANÁLISIS DE LA CUESTIÓN C16}

El apartado a) de la cuestión que se presenta en la ficha 2.16.1 es un ejercicio de reproducción del conocimiento estudiado, reconocimiento de equivalentes, ejecución de problemas rutinarios, aplicación de destrezas técnicas y de algoritmos habituales, manejo de expresiones y fórmulas establecidas y realización de cálculos.

La función:

$$
f(x)=\ln \left(\frac{1+x}{1-x}\right) \stackrel{(1)}{=} \ln (1+x)-\ln (1-x)
$$

(1) Utilizando propiedades de los logaritmos

Con este razonamiento identifica el problema (RAn1), reconoce representaciones de los datos del ejercicio (RPRn1), comprende la expresión escrita (RCn1), identifica que es un modelo similar a otros vistos con anterioridad (RMn1) y le reconoce como problema ya practicado (RRPn1).

Expone el proceso de cálculo (RAn2), realizando explicaciones sencillas (RCn2), asocia con fórmulas establecidas y realiza los cálculos (RPRn3).

$$
f^{\prime}(x)=\frac{1}{1+x}-\frac{(-1)}{1-x}=\frac{2}{2-x^{2}}
$$


FICHA 2.16.1.

ESTUDIO DEL ENUNCIADO DE LA C16

C16.- Calcular, simplificando todo lo posible el resultado, la derivada de las siguientes funciones:
a) $f(x)=\ln \frac{1+x}{1-x}$
b) $g(x)=\int_{1}^{x} e^{-t^{2}}\left(1+t^{2}\right) d t$

\begin{tabular}{|c|c|c|c|c|c|c|c|c|c|c|c|c|c|c|}
\hline CONVOCATORIA & \multicolumn{7}{|c|}{ JUNIO } & \multicolumn{7}{|c|}{ SEPTIEMBRE } \\
\hline AÑO & 95 & 96 & 97 & $\underline{98}$ & 99 & 00 & 01 & \begin{tabular}{l|l}
02 & 03
\end{tabular} & 04 & 05 & 06 & 07 & 08 & 09 \\
\hline OPCIÓN & \multicolumn{7}{|c|}{$\underline{A}$} & \multicolumn{7}{|c|}{ B } \\
\hline TIPO DE PROBLEMA & \multicolumn{7}{|c|}{ TEÓRICO } & \multicolumn{7}{|c|}{ PRÁCTICO } \\
\hline \multirow{3}{*}{ APARTADOS } & \multirow{3}{*}{\multicolumn{2}{|c|}{ SI }} & \multicolumn{4}{|c|}{ Forma explícita } & 2 & & & & \multirow{2}{*}{\multicolumn{2}{|c|}{6}} & \multirow{3}{*}{\multicolumn{2}{|c|}{ NO }} \\
\hline & & & & & & & 2 & 3 & 4 & 5 & & & & \\
\hline & & & \multicolumn{4}{|c|}{ Forma implícita } & & & & & & & & \\
\hline VERBO UTILIZADO & \multicolumn{14}{|c|}{ CALCULAR } \\
\hline TIEMPO VERBAL & \multicolumn{14}{|c|}{ INFINITIVO } \\
\hline ESCRITURA & \multicolumn{9}{|c|}{ MULTIPLICATIVA } & \multicolumn{5}{|c|}{ FUNCIONAL } \\
\hline \multirow{3}{*}{$\begin{array}{l}\text { FALLOS DEL ENUN- } \\
\text { CIADO }\end{array}$} & \multicolumn{9}{|c|}{ PUNTUACIÓN } & & & & & \\
\hline & \multicolumn{9}{|c|}{ ERROR MORFOLÓGICO } & & & & & \\
\hline & \multicolumn{9}{|c|}{ AUSENCIA DE ESPECIFICACIONES } & & & & & \\
\hline \multicolumn{15}{|c|}{ ENUNCIADO ALTERNATIVO } \\
\hline
\end{tabular}

C16.- Calcula, simplificando todo lo posible el resultado, la derivada de las siguientes funciones:

a) $f(x)=\ln \left(\frac{1+x}{1-x}\right)$

b) $g(x)=\int_{1}^{x} e^{-t^{2}}\left(1+t^{2}\right) d t$.

NIVELES DE COMPETENCIAS IMPLÍCITAS: Reproducción

El alumno reproduce problemas ya practicados de manera cerrada (RRPn2), al efectuar la derivada utiliza variables y realiza cálculos mediante procedimientos familiares (CLSOn3) resolviendo, de tal forma, problemas rutinarios estandarizados (RRPn3). A continuación describe los resultados obtenidos (RCn3), justifica las fórmulas utilizadas y los resultados (RAn3), comunicando de manera elemental los resultados del modelo (RMn3). 
El apartado b) de la cuestión que se presenta en la ficha 2.16.1 es, también, un ejercicio de reproducción.

Para calcular la derivada de la función $g(x)=\int_{1}^{x} e^{-t^{2}}\left(1+t^{2}\right) d t$ hay que utilizar el teorema fundamental del cálculo integral.

Con este razonamiento identifica el problema (RAn1), reconoce representaciones de los datos del ejercicio (RPRn1), comprende la expresión escrita (RCn1), identifica que es un modelo similar a otros vistos con anterioridad (RMn1) y le reconoce como problema ya practicado (RRPn1).

La función $h(t)=e^{-t^{2}}\left(1+t^{2}\right)$ es una función continua en $R$ y en particular en el intervalo $[1, x]$.

Por el teorema fundamental del cálculo integral $g(x)$ es derivable y su derivada es

$$
g^{\prime}(x)=e^{-x^{2}}\left(1+x^{2}\right)
$$

De esta manera expone el proceso de cálculo (RAn2), realizando explicaciones sencillas (RCn2), asocia con fórmulas establecidas y realiza los cálculos (RPRn3), resolviendo, de tal forma, problemas rutinarios estandarizados (RRPn3).

El alumno describe los resultados obtenidos ( $\mathrm{RCn} 3)$, justifica las fórmulas utilizadas y los resultados (RAn3), comunicando de manera elemental los resultados del modelo (RMn3).

\begin{tabular}{|c|c|c|c|c|c|c|c|c|}
\hline \multicolumn{2}{|c|}{ FICHA 2.16.2. } & \multicolumn{7}{|c|}{ COMPETENCIAS IMPLÍCITAS EN LA RESOLUCIÓN DE LA C16 } \\
\hline & Nivel 1 & Nivel 2 & Nivel 3 & Nivel 1 & Nivel 2 & Nivel 3 & Nivel 1 & Nivel 2 \\
\hline PR & * & & * & & & & & \\
\hline A & * & * & * & & & & & \\
\hline $\mathbf{C}$ & * & * & * & & & & & \\
\hline$M$ & * & & * & & & & & \\
\hline RP & * & * & * & & & & & \\
\hline \multicolumn{9}{|l|}{$\mathbf{R}$} \\
\hline \multirow[t]{2}{*}{ LSO } & & & & & & * & & \\
\hline & \multicolumn{3}{|c|}{ Reproducción } & \multicolumn{3}{|c|}{ Conexión } & \multicolumn{2}{|c|}{ Reflexión } \\
\hline
\end{tabular}




\section{ANÁLISIS DE LA CUESTIÓN C17}

\section{FICHA 2.17.1. \\ ESTUDIO DEL ENUNCIADO DE LA C17}

C17.- ¿Se puede asegurar que la función $x^{3}-3 \operatorname{sen} x+4$ toma el valor cero en algún punto del intervalo $[-2,2]$ ? Razonar la respuesta indicando el resultado teórico utilizado.

\begin{tabular}{|c|c|c|c|c|c|c|c|c|c|c|c|c|c|c|}
\hline CONVOCATORIA & \multicolumn{7}{|c|}{$\underline{\text { JUNIO }}$} & \multicolumn{7}{|c|}{ SEPTIEMBRE } \\
\hline AÑO & 95 & 96 & 97 & $\underline{98}$ & 99 & 00 & 01 & 0203 & 04 & 05 & 06 & 07 & 08 & 09 \\
\hline OPCIÓN & \multicolumn{7}{|c|}{ A } & \multicolumn{7}{|c|}{$\underline{B}$} \\
\hline TIPO DE PROBLEMA & \multicolumn{7}{|c|}{ TEÓRICO } & \multicolumn{7}{|c|}{ PRÁCTICO } \\
\hline \multirow{3}{*}{ APARTADOS } & \multirow{3}{*}{\multicolumn{2}{|c|}{ SI }} & \multicolumn{4}{|c|}{ Forma explícita } & & & & \multirow{2}{*}{5} & \multirow{2}{*}{\multicolumn{2}{|c|}{6}} & \multirow{3}{*}{\multicolumn{2}{|c|}{ NO }} \\
\hline & & & & & & & 2 & 3 & 4 & & ( & & & \\
\hline & & & \multicolumn{4}{|c|}{ Forma implícita } & & & & & & & & \\
\hline VERBO UTILIZADO & \multicolumn{14}{|c|}{ RAZONAR } \\
\hline TIEMPO VERBAL & \multicolumn{14}{|c|}{ INFINITIVO } \\
\hline ESCRITURA & \multicolumn{9}{|c|}{ MULTIPLICATIVA } & \multicolumn{5}{|c|}{ FUNCIONAL } \\
\hline \multirow{3}{*}{$\begin{array}{l}\text { FALLOS DEL ENUN- } \\
\text { CIADO }\end{array}$} & \multicolumn{9}{|c|}{ PUNTUACIÓN } & & & & & \\
\hline & \multicolumn{9}{|c|}{ ESTRUCTURA DE LA ORACIÓN } & & & & & \\
\hline & \multicolumn{9}{|c|}{ AUSENCIA DE ESPECIFICACIONES } & & & & & \\
\hline \multicolumn{15}{|c|}{ ENUNCIADO ALTERNATIVO } \\
\hline
\end{tabular}

C17.- Se considera la función $f(x)=x^{3}-3 \operatorname{sen}(x)+4$. Analiza si tiene por imagen el valor cero en algún punto del intervalo $[-2,2]$.

Enuncia el resultado teórico utilizado.

NIVELES DE COMPETENCIAS IMPLÍCITAS: Reproducción

Para resolver la cuestión de la ficha 2.17.1 el alumno tiene que utilizar el teorema de Bolzano, o resultados deducidos a partir del teorema de Bolzano; se trata pues, de un ejercicio de reproducción del conocimiento estudiado, reconocimiento de equivalentes, ejecución de problemas rutinarios, aplicación de destrezas técnicas y de algoritmos habituales y realización de cálculos.

Con este razonamiento identifica el problema (RAn1), identifica que es un modelo similar a otros vistos con anterioridad (RMn1), reconoce representaciones de los datos del ejercicio (RPRn1), comprende la expresión escrita (RCn1), y le reconoce como problema ya practicado (RRPn1).

A continuación, plantea los algoritmos correspondientes (RPRn2).

Tenemos la función: 


$$
f(x)=x^{3}-3 \operatorname{sen}(x)+4
$$

Es una función continua en $[-2,2]$, por ser suma algebraica de funciones continuas.

Los valores del intervalo están dados en radianes, y dado que

$$
\begin{gathered}
-1<\operatorname{sen}(x)<1 \forall x \in[-2,2] \\
f(-2)=(-2)^{3}-3 \operatorname{sen}(-2)+4<0 \\
f(2)=(2)^{3}-3 \operatorname{sen}(2)+4>0
\end{gathered}
$$

Es una función continua en el intervalo cerrado $[-2,2]$ que toma valores de signo contrario en los extremos del intervalo, por el teorema de Bolzano, existe un punto $c \in(-2,2)$, con $f(c)=0$.

El alumno expone el proceso de cálculo (RAn2), realizando explicaciones sencillas (RCn2), reproduce problemas ya practicados de manera cerrada (RRPn2), asocia con fórmulas establecidas y realiza los cálculos (RPRn3).

Justifica las fórmulas utilizadas y los resultados (RAn3), maneja procedimientos resolviendo y calculando (RLSOn3) y resuelve problemas rutinarios estandarizados (RRPn3).

$$
f(c)=c^{3}-3 \operatorname{sen}(c)+4=0
$$

Por último, describe los resultados obtenidos (RCn3), comunicando de manera elemental los resultados del modelo (RMn3).

\begin{tabular}{|l|c|c|c|c|c|c|c|c|}
\hline \multicolumn{6}{|c|}{ FICHA 2.17.2. COMPETENCIAS IMPLíCITAS EN LA RESOLUCIÓN DE LA C17 } \\
\hline & Nivel 1 & Nivel 2 & Nivel 3 & Nivel 1 & Nivel 2 & Nivel 3 & Nivel 1 & Nivel 2 \\
\hline PR & $*$ & $*$ & $*$ & & & & & \\
\hline A & $*$ & $*$ & $*$ & & & & & \\
\hline C & $*$ & $*$ & $*$ & & & & & \\
\hline M & $*$ & & $*$ & & & & & \\
\hline RP & $*$ & $*$ & $*$ & & & & & \\
\hline R & & & & & & & & \\
\hline LSO & & & $*$ & & & & & \\
\hline & \multicolumn{2}{|l|}{ Reproducción } & & Conexión & & Reflexión \\
\hline
\end{tabular}




\section{ANÁLISIS DE LA CUESTIÓN C24}

\section{FICHA 2.24.1. \\ ESTUDIO DEL ENUNCIADO DE LA C24}

C24.- Siendo $f(x)=(x+1)^{2}$ y $g(x)=3 x$, calcular la derivada de la función compuesta $(g(f(x)))$.

\begin{tabular}{|c|c|c|c|c|c|c|c|c|c|c|c|c|c|}
\hline CONVOCATORIA & \multicolumn{7}{|c|}{ JUNIO } & \multicolumn{6}{|c|}{ SEPTIEMBRE } \\
\hline AÑO & 95 & 96 & 97 & 98 & $\underline{99}$ & 00 & 01 & 0203 & 04 & 05 & \begin{tabular}{l|l}
06 & 07
\end{tabular} & 08 & 09 \\
\hline OPCIÓN & \multicolumn{7}{|c|}{$\underline{A}$} & \multicolumn{6}{|c|}{ B } \\
\hline TIPO DE PROBLEMA & \multicolumn{7}{|c|}{ TEÓRICO } & \multicolumn{6}{|c|}{ PRÁCTICO } \\
\hline \multirow{3}{*}{ APARTADOS } & \multirow{3}{*}{\multicolumn{2}{|c|}{ SI }} & \multicolumn{4}{|c|}{ Forma explícita } & & & & \multirow{2}{*}{5} & \multirow[b]{2}{*}{6} & \multirow{3}{*}{\multicolumn{2}{|c|}{$\underline{\text { NO }}$}} \\
\hline & & & & & & & 2 & 3 & 4 & & & & \\
\hline & & & \multicolumn{4}{|c|}{ Forma implícita } & & & & & & & \\
\hline VERBO UTILIZADO & \multicolumn{13}{|c|}{ CALCULAR } \\
\hline TIEMPO VERBAL & \multicolumn{13}{|c|}{ INFINITIVO } \\
\hline ESCRITURA & \multicolumn{9}{|c|}{ ALGEBRAICA } & \multicolumn{4}{|c|}{ FUNCIONAL } \\
\hline \multirow{3}{*}{$\begin{array}{l}\text { FALLOS DEL ENUN- } \\
\text { CIADO }\end{array}$} & \multicolumn{9}{|c|}{ PUNTUACIÓN } & & & & \\
\hline & \multicolumn{9}{|c|}{ ERROR MORFOLÓGICO } & & & & \\
\hline & \multicolumn{9}{|c|}{ AUSENCIA DE ESPECIFICACIONES } & & & & \\
\hline \multicolumn{14}{|c|}{ ENUNCIADO ALTERNATIVO } \\
\hline \multicolumn{14}{|c|}{$\begin{array}{l}\text { C24.- Siendo } f(x)=(x+1)^{2} \text { y } g(x)=3 x \text {, calcula la derivada de la función com- } \\
\text { puesta }(g(f(x))) \text {. }\end{array}$} \\
\hline
\end{tabular}

La cuestión que se presenta en la ficha 2.24.1 es un ejercicio de reproducción del conocimiento estudiado, reconocimiento de equivalentes, ejecución de problemas rutinarios, aplicación de destrezas técnicas y de algoritmos habituales, manejo de expresiones y fórmulas establecidas y realización de cálculos.

La función compuesta es

$$
g(f(x))=g\left((x+1)^{2}\right)=3(x+1)^{2}
$$

Con este razonamiento identifica el problema (RAn1), reconoce representaciones de los datos del ejercicio (RPRn1), comprende la expresión escrita (RCn1), identifica que es un modelo similar a otros vistos con anterioridad (RMn1) y le reconoce como problema ya practicado (RRPn1).

$$
g(f(x))^{\prime}=6(x+1)
$$


El alumno podía haber utilizado la regla de la cadena para la derivación de la función compuesta. En este supuesto

$$
(g \circ f)^{\prime}(x)=g^{\prime}(f(x)) \cdot f^{\prime}(x)=3 \cdot 2(x+1)=6(x+1)
$$

En este caso, el alumno expone el proceso de cálculo (RAn2), reproduce problemas ya practicados de manera cerrada (RRPn2), realizando explicaciones sencillas (RCn2), asocia con fórmulas establecidas y realiza los cálculos (RPRn3).

Asimismo describe los resultados obtenidos (RCn3), justifica las fórmulas utilizadas y los resultados (RAn3), comunicando de manera elemental los resultados del modelo (RMn3) y utiliza variables y realiza cálculos mediante procedimientos familiares (RLSOn3), resolviendo, de tal forma, problemas rutinarios estandarizados (RRPn3).

\section{FICHA 2.24.2. COMPETENCIAS IMPLÍCITAS EN LA RESOLUCIÓN DE LA C24}

\begin{tabular}{|l|c|c|c|c|c|c|c|c|}
\hline & Nivel 1 & Nivel 2 & Nivel 3 & Nivel 1 & Nivel 2 & Nivel 3 & Nivel 1 & Nivel 2 \\
\hline PR & $*$ & & $*$ & & & & & \\
\hline A & $*$ & $*$ & $*$ & & & & & \\
\hline C & $*$ & $*$ & $*$ & & & & & \\
\hline M & $*$ & & $*$ & & & & & \\
\hline RP & $*$ & $*$ & $*$ & & & & & \\
\hline R & & & & & & & & \\
\hline LSO & & & & & & $*$ & & \\
\hline
\end{tabular}

\section{ANÁLISIS DE LA CUESTIÓN C26}

La cuestión que se presenta en la ficha 2.26.1 es un ejercicio de reproducción del conocimiento estudiado, reconocimiento de equivalentes, ejecución de problemas rutinarios, aplicación de destrezas técnicas y de algoritmos habituales, manejo de expresiones y fórmulas establecidas y realización de cálculos.

Hay que calcular la integral definida de una función definida por un valor absoluto, comenzando por reescribir la función en dos intervalos.

Con este razonamiento identifica el problema (RAn1), reconoce representaciones de los datos del ejercicio (RPRn1), comprende la expresión escrita (RCn1), 
identifica que es un modelo similar a otros vistos con anterioridad (RMn1) y le reconoce como problema ya practicado (RRPn1).

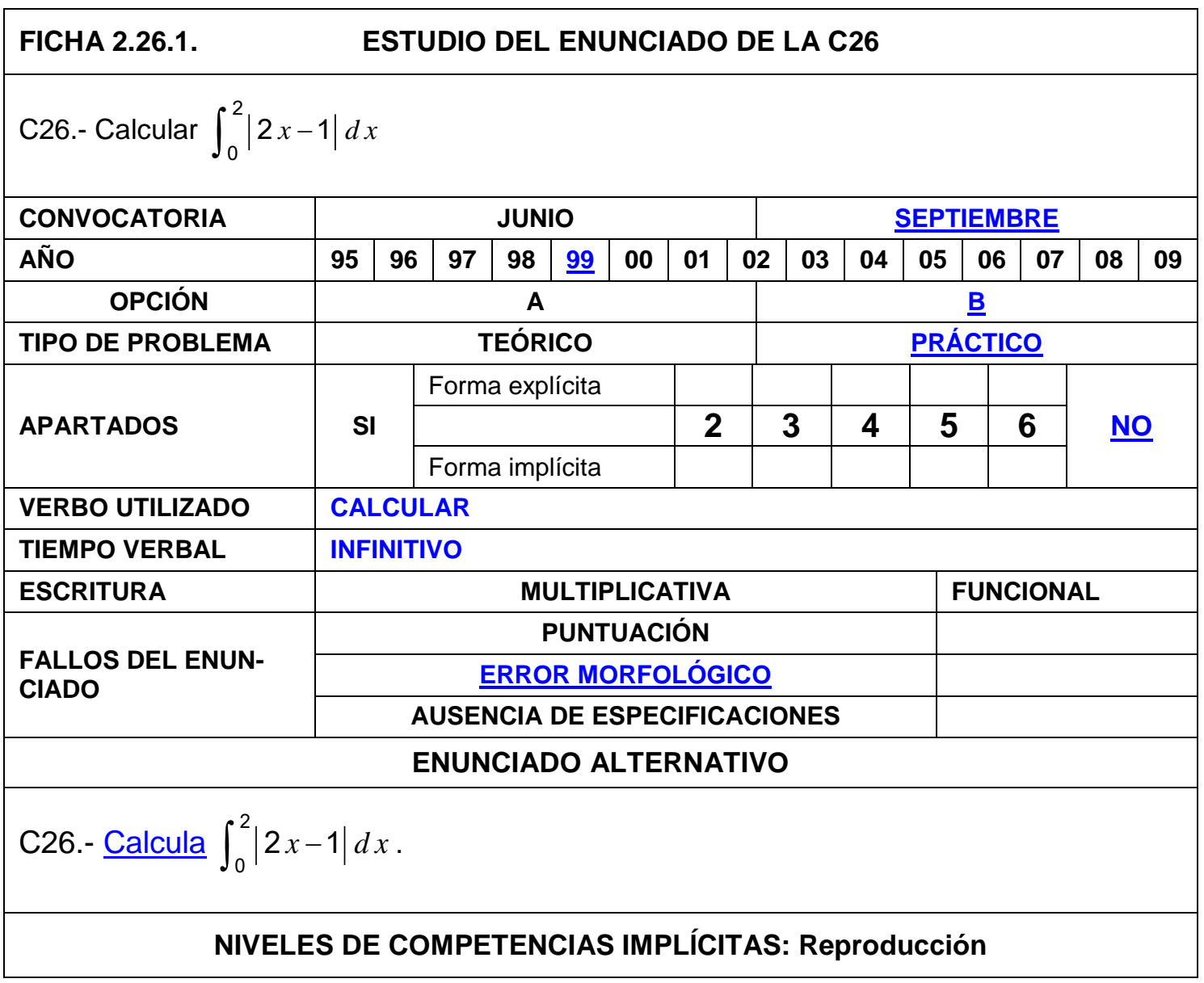

La función está definida como: $f(x)=|2 x-1|=\left\{\begin{array}{lll}1-2 x & \text { si } & x \leq \frac{1}{2} \\ 2 x-1 & \text { si } & x>\frac{1}{2}\end{array}\right.$

En este caso, el alumno plantea los algoritmos correspondientes (RPRn2), expone el proceso de cálculo (RAn2), realiza explicaciones sencillas ( $\mathrm{RCn} 2)$, asocia con fórmulas establecidas y realiza los cálculos (RPRn3) reproduciendo, así, problemas practicados de manera cerrada (RRPn2).

$$
\left.\left.\int_{0}^{2}|2 x-1| d x=\int_{0}^{\frac{1}{2}}(1-2 x) d x+\int_{\frac{1}{2}}^{2}(2 x-1) d x=\left(x-x^{2}\right)\right]_{0}^{\frac{1}{2}}+\left(x^{2}-x\right)\right]_{\frac{1}{2}}^{2}=\frac{5}{2}
$$

El alumno describe los resultados obtenidos ( $\mathrm{RCn} 3$ ), justifica las fórmulas utilizadas y los resultados (RAn3), comunicando de manera elemental los resulta- 
dos del modelo (RMn3) y, al calcular la integral, utiliza variables y realiza cálculos mediante procedimientos familiares (CLSOn3), resolviendo, de tal forma, problemas rutinarios estandarizados (RRPn3).

\begin{tabular}{|c|c|c|c|c|c|c|c|c|}
\hline & Nivel 1 & Nivel 2 & Nivel 3 & Nivel 1 & Nivel 2 & Nivel 3 & Nivel 1 & Nivel 2 \\
\hline PR & * & * & * & & & & & \\
\hline A & * & * & * & & & & & \\
\hline C & * & * & * & & & & & \\
\hline$M$ & * & & * & & & & & \\
\hline $\mathbf{R P}$ & * & * & * & & & & & \\
\hline \multicolumn{9}{|l|}{$\mathbf{R}$} \\
\hline LSO & & & & & & * & & \\
\hline & \multicolumn{3}{|c|}{ Reproducción } & \multicolumn{3}{|c|}{ Conexión } & \multicolumn{2}{|c|}{ Reflexión } \\
\hline
\end{tabular}

\section{ANÁLISIS DE LA CUESTIÓN C30}

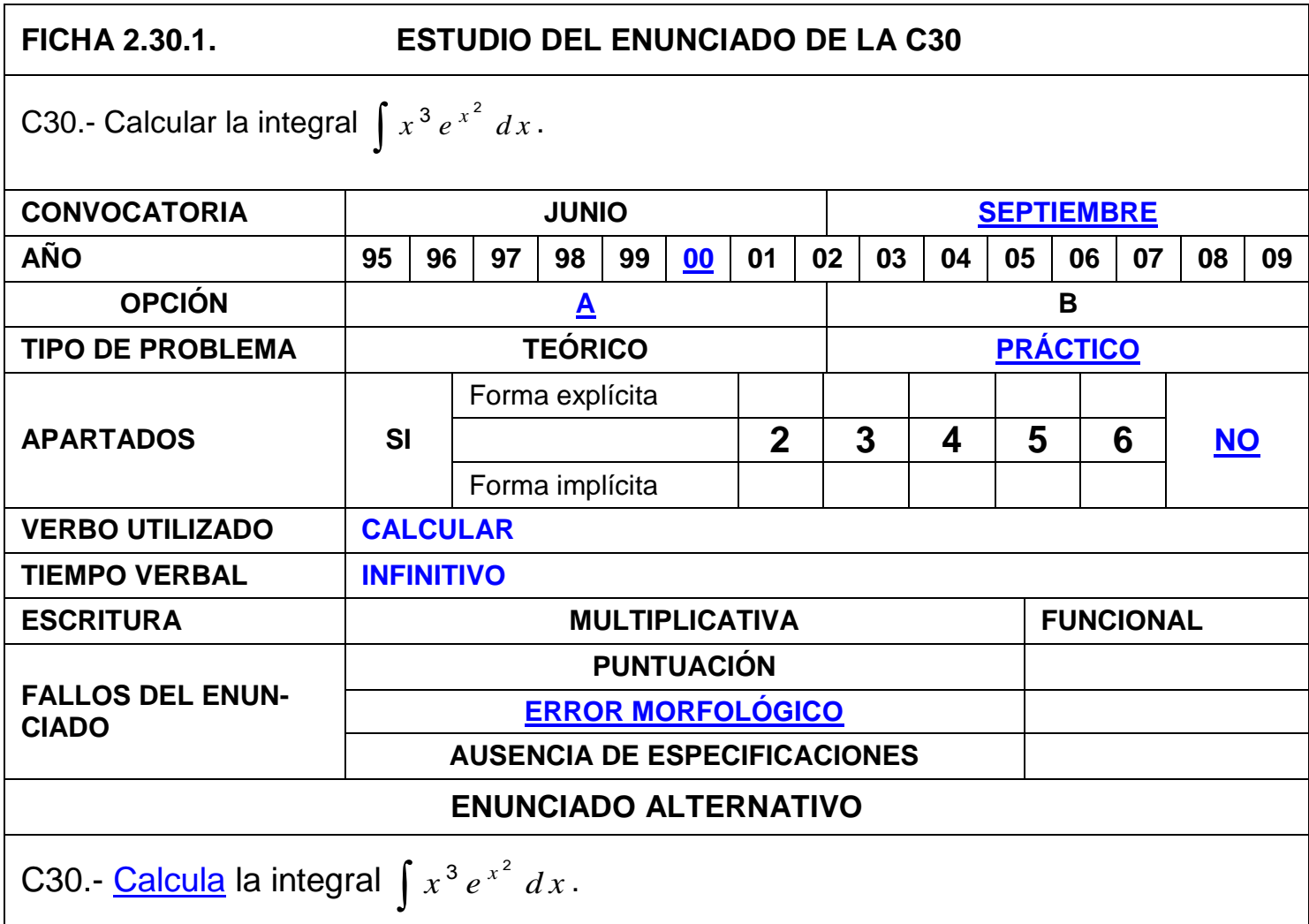

NIVELES DE COMPETENCIAS IMPLÍCITAS: Reproducción y conexión 
En la cuestión que se presenta en la ficha 2.30.1 hay que calcular una integral por partes, $\int x^{3} e^{x^{2}} d x$, es un problema que reproduce situaciones similares, pero que no son de mera rutina, por lo que se encuadra en el nivel de conexión.

El alumno identifica el problema (RAn1), piensa en el tratamiento matemático necesario (CPRn1), estructura la situación que debe modelizar (CMn1), desarrolla procedimientos intuitivos ya practicados, pero no rutinarios (CRPn1), plantea los algoritmos correspondientes (RPRn2) y aplica los conceptos matemáticos apropiados (CPRn3).

Es una integral que tiene elementos distintos a los habituales, pues la elección de la función $d v(x)$ requiere observar qué necesitamos para que la obtención de $v(x)$ se realice mediante el cálculo de una integral inmediata.

Llamando $u(x)=x^{2} \Rightarrow d u(x)=2 x d x$

$$
d v(x)=x e^{x^{2}} d x \Rightarrow v(x)=\frac{1}{2} e^{x^{2}}
$$

El alumno sabe expresarse sobre cuestiones matemáticas (CCn1) y expone el proceso de cálculo (RAn2), realizando explicaciones sencillas (RCn2) y traduce en la práctica el modelo a seguir que es algo diferente de los estudiados (CMn2).

$$
\int x^{3} e^{x^{2}} d x=\frac{1}{2} x^{2} e^{x^{2}}-\int x e^{x^{2}} d x=\frac{1}{2} e^{x^{2}}\left(x^{2}-1\right)+C
$$

El alumno aplica conceptos matemáticos apropiados (CPRn3), explica los cálculos y sus propiedades (CCn2), e interpreta las relaciones implicadas (CCn3), al tiempo que utiliza variables y realiza cálculos mediante procedimientos familiares (CLSOn3) y asocia con fórmulas establecidas y realiza los cálculos (RPRn3).

$$
\int x^{3} e^{x^{2}} d x=\frac{1}{2} e^{x^{2}}\left(x^{2}-1\right)+C
$$

Finalmente, describe los resultados obtenidos (RCn3) y comunica de manera elemental los resultados del modelo (RMn3). 


\section{FICHA 2.30.2. COMPETENCIAS IMPLÍCITAS EN LA RESOLUCIÓN DE LA C30}

\begin{tabular}{|l|c|c|c|c|c|c|c|c|}
\hline & Nivel 1 & Nivel 2 & Nivel 3 & Nivel 1 & Nivel 2 & Nivel 3 & Nivel 1 & Nivel 2 \\
\hline PR & & $*$ & $*$ & $*$ & & $*$ & & \\
\hline A & $*$ & $*$ & & & & & & \\
\hline C & & $*$ & $*$ & $*$ & $*$ & $*$ & & \\
\hline M & & & $*$ & $*$ & $*$ & & & \\
\hline RP & & & & $*$ & & & & \\
\hline R & & & & & & & & \\
\hline LSO & & & & & & $*$ & & Reflexión \\
\hline & \multicolumn{2}{|l|}{ Reproducción } & & \multicolumn{7}{l|}{ Conexión } & & & \\
\hline
\end{tabular}

\section{ANÁLISIS DE LA CUESTIÓN C33}

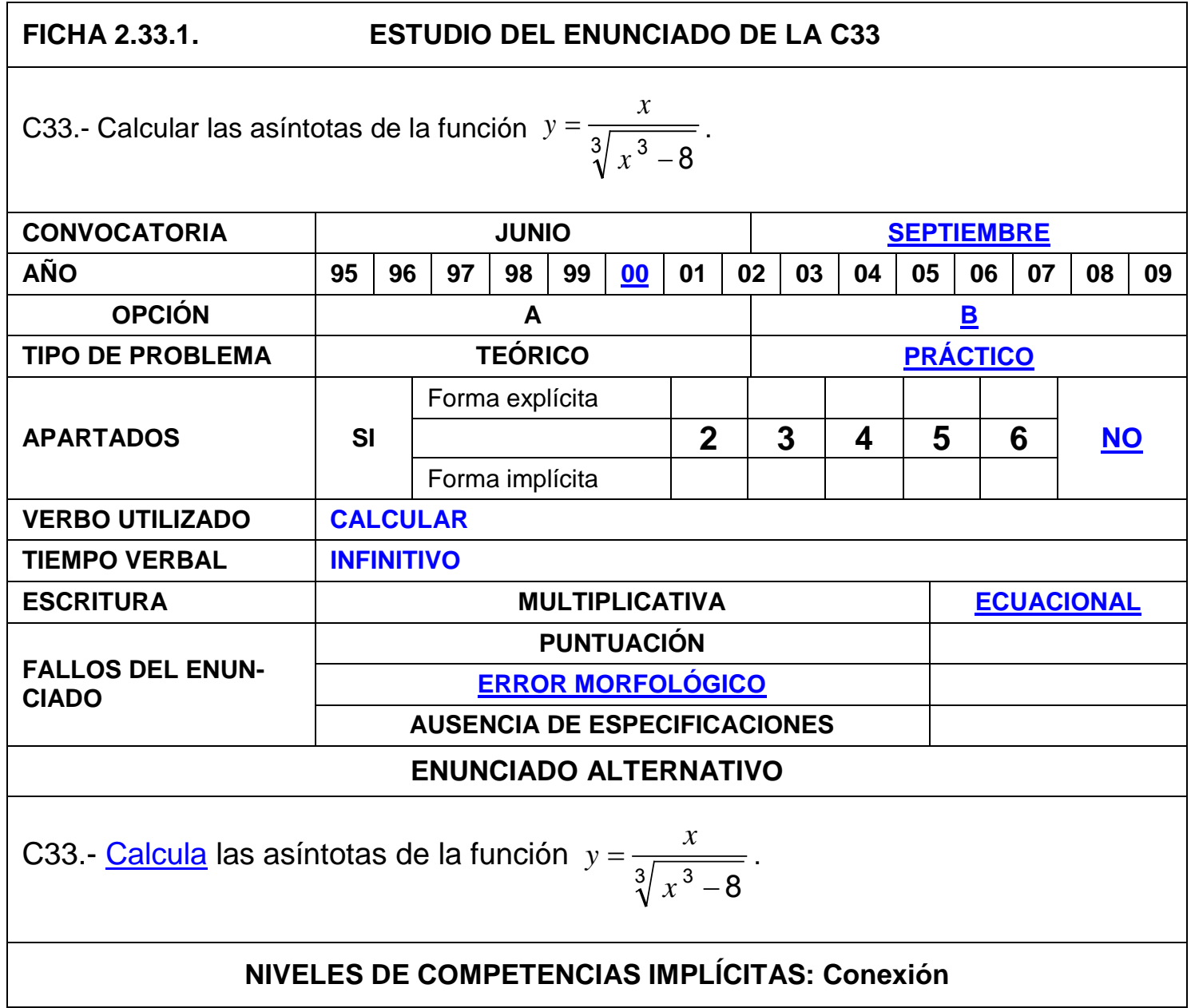

La cuestión de la ficha 2.33.1 reproduce situaciones similares a las estudiadas, pero que no son de mera rutina, con lo cual se encuadra en el nivel de conexión. 
El alumno debe pensar en el tratamiento matemático necesario (CPRn1), comprender que tiene que emplear conceptos matemáticos intermedios (CPRn2), y aplicar esos conceptos matemáticos apropiados (CPRn3) con lo que estructura la situación que debe modelizar (CMn1).

Asimismo, debe razonar matemáticamente de manera simple (CAn1) y seguir el encadenamiento de argumentos matemáticos particulares (CAn2).

Identifica que el modelo es similar a otros vistos con anterioridad (RMn1), reconoce el problema como practicado durante la instrucción (RRPn1) y le reproduce de manera cerrada (RRPn2).

Las asíntotas verticales están asociadas a los puntos en los que la función no está definida y, en consecuencia, el alumno calcula el dominio de la función El alumno sabe expresarse sobre cuestiones matemáticas (CCn1), explica los cálculos y sus propiedades (CCn2) e interpreta las relaciones implicadas (CCn3).

Para calcular el dominio de definición de la función $f(x)=\frac{x}{\sqrt[3]{x^{3}-8}}$ hay que estudiar los puntos que anulan el denominador.

\section{Resuelve la ecuación $x^{3}-8=0$}

Mediante el manejo de fórmulas, resolviendo y calculando (RLSOn3) obtiene la solución $x=2$, por tanto el dominio de la función es $D=R-\{2\}$.

Calcula límites cuando $x \rightarrow 2$, para calcular la ecuación de la asíntota vertical.

$$
\lim _{x \rightarrow 2^{-}} \frac{x}{\sqrt[3]{x^{3}-8}}=-\infty \quad \lim _{x \rightarrow 2^{+}} \frac{x}{\sqrt[3]{x^{3}-8}}=+\infty
$$

La recta $x=2$ es asíntota vertical.

$$
\lim _{x \rightarrow+\infty} \frac{x}{\sqrt[3]{x^{3}-8}}=1
$$

$$
\lim _{x \rightarrow-\infty} \frac{x}{\sqrt[3]{x^{3}-8}}=1
$$

La función tiene asíntota horizontal la recta $y=1$.

Como tiene asíntota horizontal no tiene asíntota oblicua.

Describe los resultados obtenidos (RCn3) evaluando, así, el encadenamiento de argumentos matemáticos particulares (CAn3). 
El alumno tiene que calcular límites con lo que utiliza variables y realiza cálculos mediante procedimientos familiares (CLSOn3), debe desarrollar procedimientos intuitivos ya practicados, pero no rutinarios (CRPn1), eligiendo y aplicando las estrategias apropiadas más independientes que conexionen áreas matemáticas (CRPn2, CRPn3).

\begin{tabular}{|l|c|c|c|c|c|c|c|c|}
\hline \multicolumn{7}{|c|}{ FICHA 2.33.2. COMPETENCIAS IMPLíCITAS EN LA RESOLUCIÓN DE LA C33 } \\
\hline & Nivel 1 & Nivel 2 & Nivel 3 & Nivel 1 & Nivel 2 & Nivel 3 & Nivel 1 & Nivel 2 \\
\hline PR & & & & $*$ & $*$ & $*$ & & \\
\hline A & & & & $*$ & $*$ & $*$ & & \\
\hline C & & & $*$ & $*$ & $*$ & $*$ & & \\
\hline M & $*$ & & & $*$ & & & & \\
\hline RP & $*$ & $*$ & & $*$ & $*$ & $*$ & & \\
\hline R & & & & & & & & \\
\hline LSO & & & $*$ & & & $*$ & & \\
\hline & Reproducción & & Conexión & & Reflexión \\
\hline
\end{tabular}

\section{ANÁLISIS DE LA CUESTIÓN C40}

La cuestión de la ficha 2.40.1 corresponde a un nivel de conexión. Reproduce una situación similar a la referente en su etapa de aprendizaje, pero no es una mera rutina, dado que el alumno tiene que pensar en el tratamiento matemático necesario (CPRn1), razonar matemáticamente de manera simple (CAn1) y estructurar la situación que debe modelizar (CMn1). En base a esto, realiza explicaciones sencillas (RCn2).

Es una cuestión teórica; y su resolución se basa en el teorema del valor medio de Lagrange.

A continuación comprende que tiene que emplear métodos matemáticos intermedios (CPRn2), desarrolla procedimientos ya practicados, pero no rutinarios (CRPn1), manejando afirmaciones sencillas y expresiones co $n$ símbolos $y$ fórmulas no rutinarias (CLSOn2).

Consideramos la función:

$$
h(x)=f(x)-g(x)
$$

La función $h(x)$ es derivable, por ser diferencia de funciones derivables. 
FICHA 2.40.1.

ESTUDIO DEL ENUNCIADO DE LA C40

C40.- Sean $f(x)$ y $g(x)$ dos funciones derivables para todo valor de $x$, que verifican $f(0)=g(0)$ y que $f^{\prime}(x)>g^{\prime}(x)$ para $x \geq 0$. ¿Se puede asegurar que $f(x)>g(x)$ para $x>0$ ? Razona la respuesta indicando en que resultados te basas.

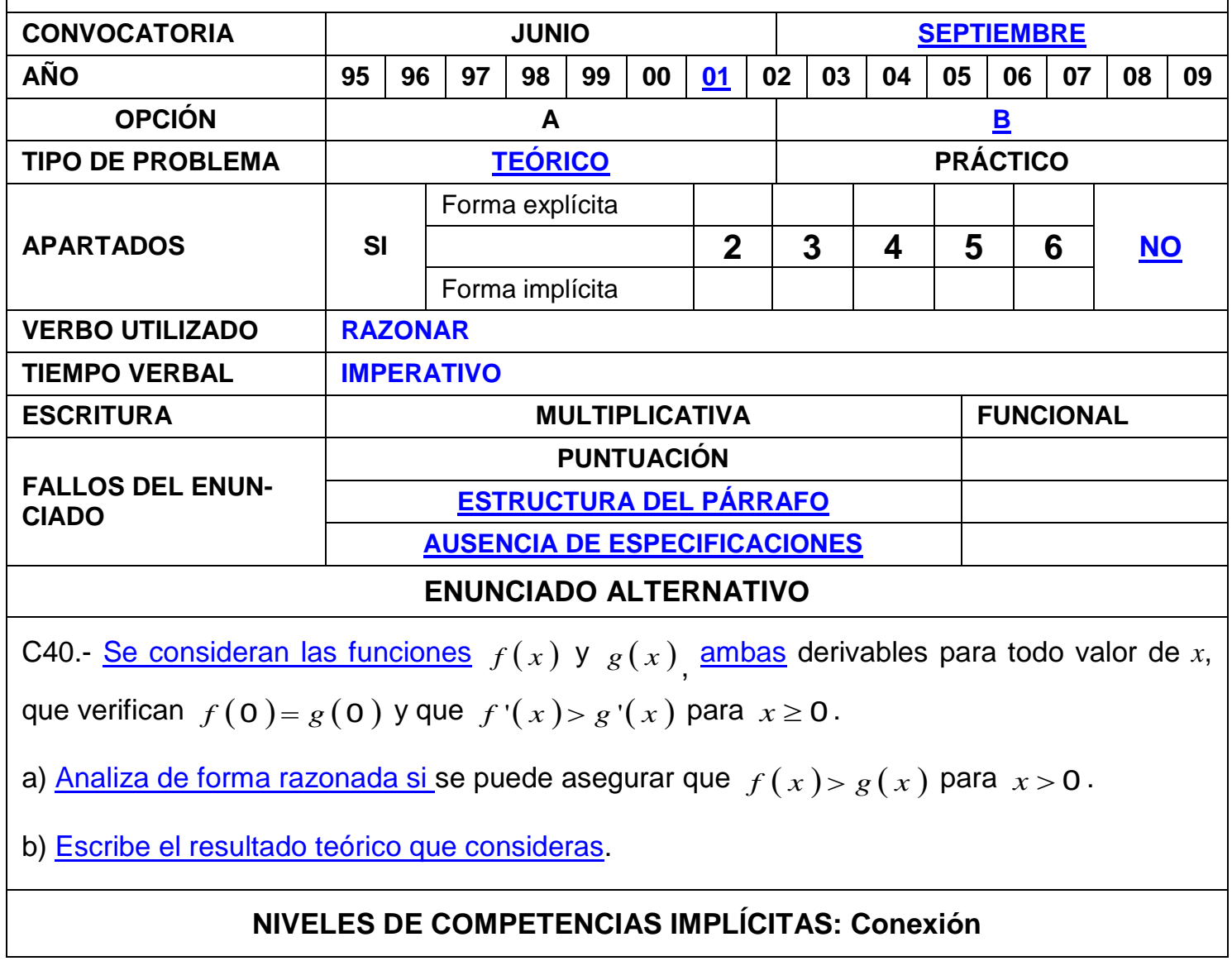

Calculamos su derivada

$$
h^{\prime}(x)=[f(x)-g(x)]^{\prime}=f^{\prime}(x)-g^{\prime}(x)>0 \quad \forall x \geq 0,
$$

dado que por hipótesis $f^{\prime}(x)>g^{\prime}(x) \quad \forall x \geq 0$

El alumno sabe expresarse sobre cuestiones matemáticas (CCn1), explica los cálculos y sus propiedades (CCn2), interpreta las relaciones implicadas (CCn3) e interpreta el lenguaje formal y simbólico (CLSOn1).

Utilizando el teorema de Lagrange

$$
\frac{h(x)-h(0)}{x}=h^{\prime}(c) \quad \forall c \in(0, x)
$$

Como, por hipótesis 


$$
f(0)=g(0) \Rightarrow h(0)=f(0)-g(0)=0
$$

Asimismo, sigue el encadenamiento del argumento matemático particular, haciendo una evaluación del mismo (CAn2, CAn3), interpretando las relaciones implicadas (CCn3).

De donde

$$
\frac{h(x)-h(0)}{x}=\frac{f(x)-g(x)}{x}=h^{\prime}(c)>0 \quad \forall c \in(0, x)
$$

El alumno explica los cálculos y sus propiedades (CCn2) y traduce, en la práctica, el modelo a seguir, que es algo diferente de los estudiados (CMn2) aplicando, de este modo, conceptos matemáticos apropiados (CPRn3).

$Y$ como el enunciado pide $x>0$,

$$
\frac{f(x)-g(x)}{x}>0 \quad \forall c \in(0, x) \Rightarrow f(x)-g(x)>0 \quad \forall x>0
$$

Posteriormente evalúa el encadenamiento de argumentos matemáticos particulares (CAn3) e interpreta las relaciones implicadas (CCn3) y comunica de manera elemental los resultados del modelo (RMn3).

\section{FICHA 2.40.2. COMPETENCIAS IMPLÍCITAS EN LA RESOLUCIÓN DE LA C40}

\begin{tabular}{|l|c|c|c|c|c|c|c|c|}
\hline & Nivel 1 & Nivel 2 & Nivel 3 & Nivel 1 & Nivel 2 & Nivel 3 & Nivel 1 & Nivel 2 \\
\hline PR & & & & $*$ & $*$ & $*$ & & \\
\hline A & & & & $*$ & & $*$ & & \\
\hline C & & $*$ & & $*$ & $*$ & $*$ & & \\
\hline M & & & & $*$ & & & & \\
\hline RP & & & & $*$ & & & & \\
\hline R & & & & & & & & \\
\hline LSO & & & & $*$ & $*$ & & & \\
\hline
\end{tabular}

\section{ANÁLISIS DE LA CUESTIÓN C42}

La cuestión de la ficha 2.42.1 es un ejercicio de reproducción del conocimiento estudiado, reconocimiento de equivalentes, ejecución de problemas rutinarios, aplicación de destrezas técnicas y de algoritmos habituales, manejo de expresiones y fórmulas establecidas y realización de cálculos. 


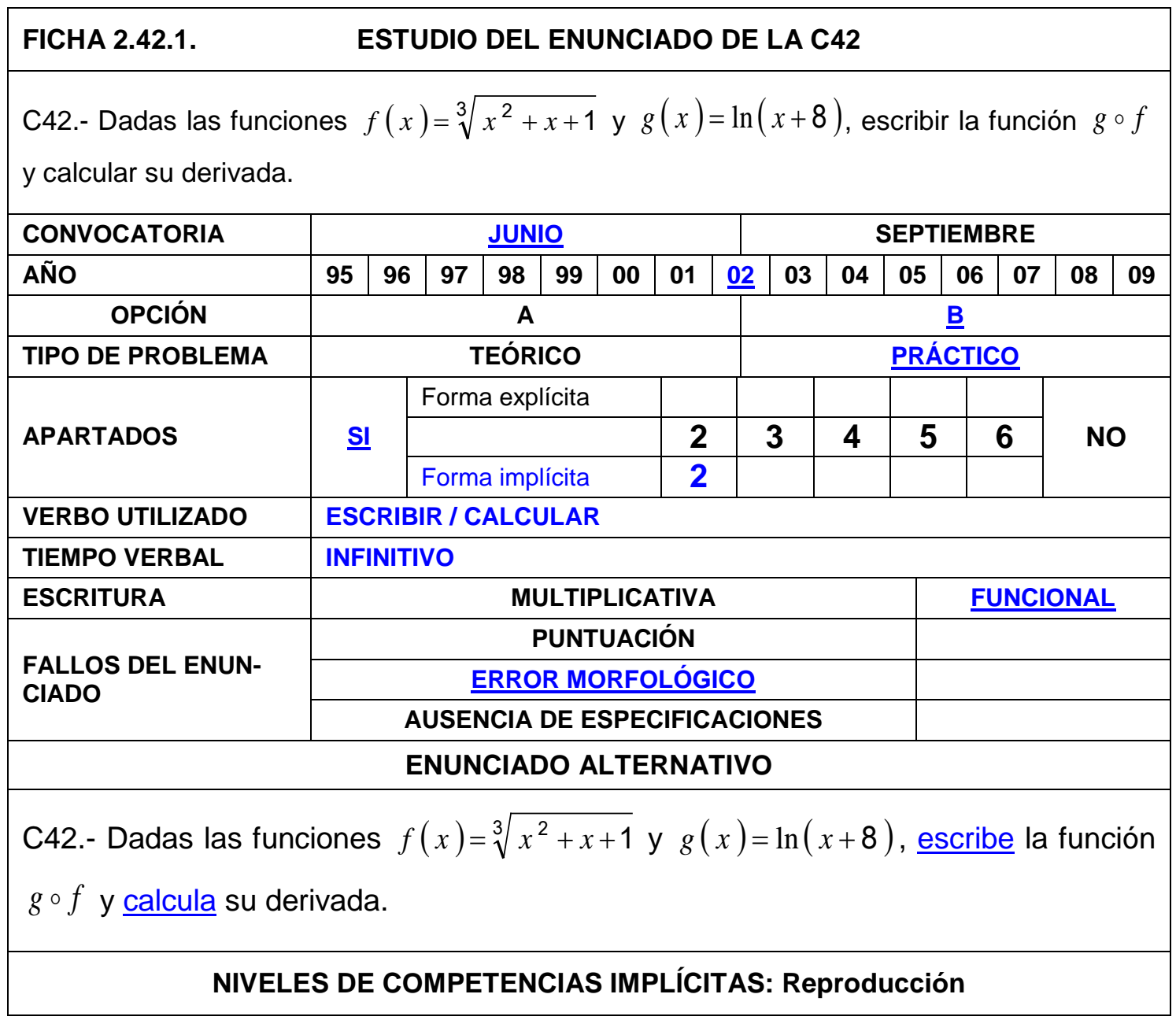

Hay que calcular la función $(g \circ f)(x)=g(f(x))$

Con este razonamiento, el alumno identifica el problema (RAn1), comprende la expresión escrita (RCn1), reconoce representaciones de los datos del ejercicio (RPRn1), identifica que es un modelo similar a otros vistos con anterioridad (RMn1) y le reconoce como problema ya practicado (RRPn1).

A continuación, plantea los algoritmos correspondientes (RPRn2).

$$
(g \circ f)(x)=g\left(\sqrt[3]{x^{2}+x+1}\right)=\ln \left(\sqrt[3]{x^{2}+x+1}+8\right)
$$

Expone el proceso de cálculo (RAn2), realizando explicaciones sencillas (RCn2), asocia con fórmulas establecidas y realiza los cálculos (RPRn3).

$$
(g \circ f)^{\prime}(x)=g^{\prime}(f(x)) \cdot f^{\prime}(x)=\frac{1}{\sqrt[3]{x^{2}+x+1}} \cdot \frac{1}{3}\left(x^{2}+x+1\right)^{-\frac{2}{3}} \cdot(2 x+1)
$$




$$
(g \circ f)^{\prime}(x)=\frac{2 x+1}{3 \sqrt[3]{x^{2}+x+1}\left(\sqrt[3]{x^{2}+x+1}+8\right)}
$$

El alumno reproduce problemas ya practicados de manera cerrada (RRPn2), al calcular la derivada utiliza variables y realiza cálculos mediante procedimientos familiares (CLSOn3) y así resuelve problemas rutinarios estandarizados (RRPn3).

Concluye justificando las fórmulas utilizadas y los resultados (RAn3), describiendo los resultados obtenidos (RCn3) y comunicando de manera elemental los resultados del modelo (RMn3).

\begin{tabular}{|l|c|c|c|c|c|c|c|c|}
\hline \multicolumn{7}{|c|}{ FICHA 2.42.2. COMPETENCIAS IMPLÍCITAS EN LA RESOLUCIÓN DE LA C42 } \\
\hline & Nivel 1 & Nivel 2 & Nivel 3 & Nivel 1 & Nivel 2 & Nivel 3 & Nivel 1 & Nivel 2 \\
\hline PR & $*$ & $*$ & $*$ & & & & & \\
\hline A & $*$ & $*$ & $*$ & & & & & \\
\hline C & $*$ & $*$ & $*$ & & & & & \\
\hline M & $*$ & & $*$ & & & & & \\
\hline RP & $*$ & $*$ & $*$ & & & & & \\
\hline R & & & & & & & & \\
\hline LSO & & & & & & $*$ & & \\
\hline & Reproducción & & Conexión & & Reflexión \\
\hline
\end{tabular}

\section{ANÁLISIS DE LA CUESTIÓN C46}

La cuestión que se presenta en la ficha 2.46.1 se encuadra en el nivel de reproducción. Es un ejercicio de cálculo de derivadas, lo que corresponde al nivel de reproducción del conocimiento estudiado, reconocimiento de equivalentes, ejecución de problemas rutinarios mediante la aplicación de destrezas técnicas y algoritmos habituales.

Comienza con la identificación del problema (RAn1), reconoce representaciones de los datos del ejercicio (RPRn1), comprende la expresión escrita (RCn1), identifica que es un modelo similar a otros vistos con anterioridad (RMn1) y le reconoce como problema ya practicado (RRPn1).

A continuación, reproduce problemas ya practicados de manera cerrada (RRPn2) y plantea los algoritmos correspondientes (RPRn2). 


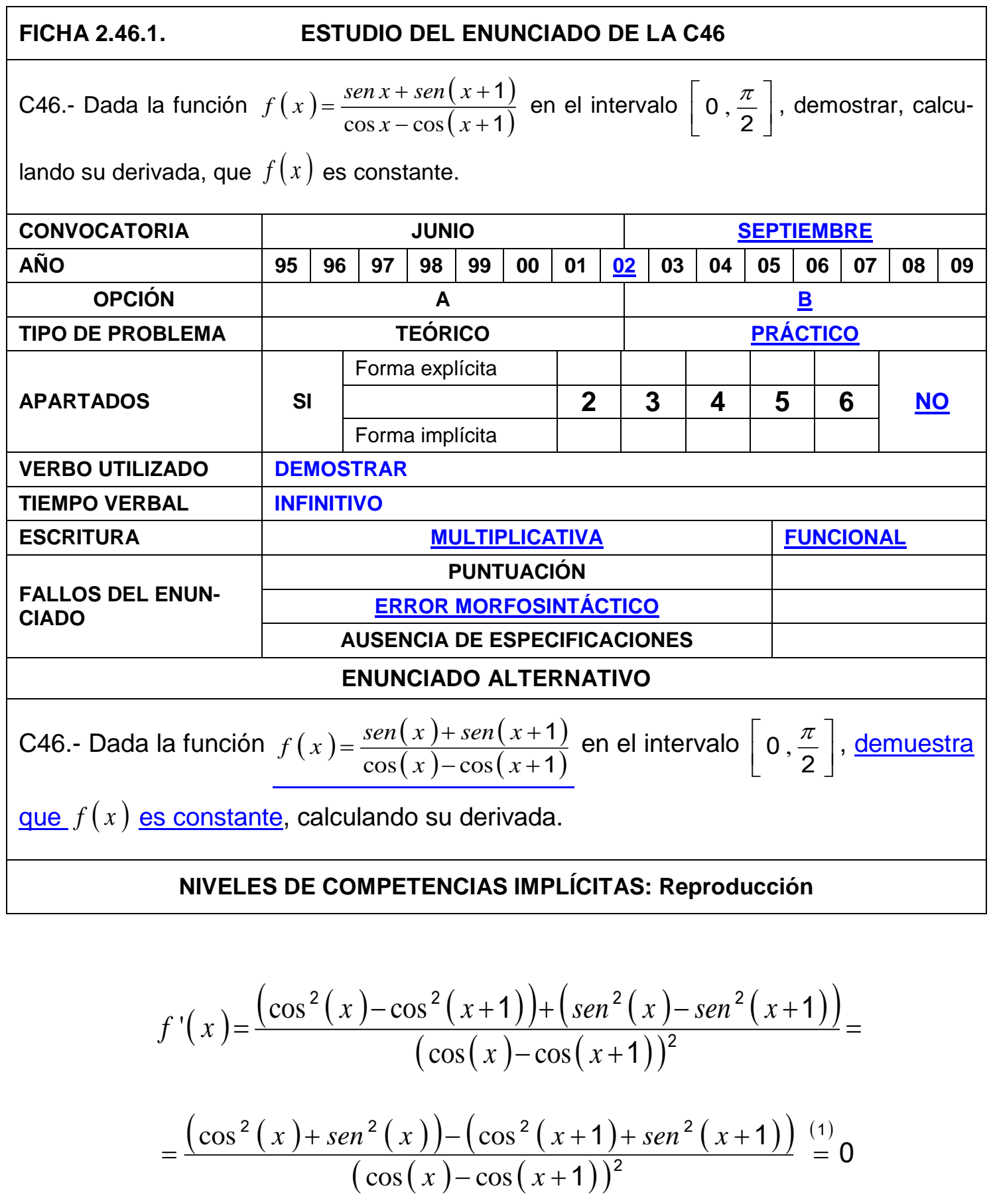

(1) Utilizando la fórmula fundamental de la trigonometría

Expone el proceso de cálculo (RAn2), realizando explicaciones sencillas (RCn2), asocia con fórmulas establecidas y realiza los cálculos (RPRn3).

El alumno resuelve problemas rutinarios estandarizados (RRPn3), al calcular la derivada, utiliza variables y realiza cálculos mediante procedimientos familiares (CLSOn3), justifica las fórmulas utilizadas y los resultados (RAn3), describe los 
resultados obtenidos, (RCn3) y comunica de manera elemental los resultados del modelo (RMn3).

\begin{tabular}{|c|c|c|c|c|c|c|c|c|}
\hline \multicolumn{2}{|c|}{ FICHA 2.46.2. } & \multicolumn{7}{|c|}{ COMPETENCIAS IMPLÍCITAS EN LA RESOLUCIÓN DE LA C46 } \\
\hline & Nivel 1 & Nivel 2 & Nivel 3 & Nivel 1 & Nivel 2 & Nivel 3 & Nivel 1 & Nivel 2 \\
\hline PR & * & * & * & & & & & \\
\hline A & * & * & * & & & & & \\
\hline C & * & * & * & & & & & \\
\hline M & * & & * & & & & & \\
\hline RP & * & * & * & & & & & \\
\hline \multicolumn{9}{|l|}{$\mathbf{R}$} \\
\hline \multirow[t]{2}{*}{ LSO } & & & & & & * & & \\
\hline & \multicolumn{3}{|c|}{ Reproducción } & \multicolumn{3}{|c|}{ Conexión } & \multicolumn{2}{|c|}{ Reflexión } \\
\hline
\end{tabular}

\section{ANÁLISIS DE LA CUESTIÓN C51}

\begin{tabular}{|c|c|c|c|c|c|c|c|c|c|c|c|c|}
\hline FICHA 2.51.1. & \multicolumn{12}{|c|}{ ESTUDIO DEL ENUNCIADO DEL C51 } \\
\hline \multicolumn{13}{|c|}{ C51.- Calcular $\lim _{x \rightarrow \infty} x(\ln (x+1)-\ln x)$. } \\
\hline CONVOCATORIA & \multicolumn{6}{|c|}{ JUNIO } & \multicolumn{6}{|c|}{ SEPTIEMBRE } \\
\hline AÑO & \begin{tabular}{|l|l|}
95 & 96 \\
\end{tabular} & 97 & 98 & 99 & 00 & 01 & \begin{tabular}{|l|l|}
02 & $\underline{03}$ \\
\end{tabular} & 04 & 05 & \begin{tabular}{l|l|}
06 & 07
\end{tabular} & 08 & 09 \\
\hline OPCIÓN & \multicolumn{6}{|c|}{$\underline{A}$} & \multicolumn{6}{|c|}{ B } \\
\hline TIPO DE PROBLEMA & \multicolumn{6}{|c|}{ TEÓRICO } & \multicolumn{6}{|c|}{ PRÁCTICO } \\
\hline \multirow{3}{*}{ APARTADOS } & \multirow{3}{*}{ SI } & \multicolumn{4}{|c|}{ Forma explícita } & & & & \multirow{3}{*}{\begin{tabular}{|l}
5 \\
\end{tabular}} & \multirow[b]{2}{*}{6} & \multirow{3}{*}{\multicolumn{2}{|c|}{ No }} \\
\hline & & & & & & 2 & 3 & 4 & & & & \\
\hline & & \multicolumn{4}{|c|}{ Forma implícita } & & & & & & & \\
\hline VERBO UTILIZADO & \multicolumn{12}{|c|}{ CALCULAR } \\
\hline TIEMPO VERBAL & \multicolumn{12}{|c|}{ INFINITIVO } \\
\hline ESCRITURA & \multicolumn{8}{|c|}{ MULTIPLICATIVA } & \multicolumn{4}{|c|}{ FUNCIONAL } \\
\hline \multirow{3}{*}{$\begin{array}{l}\text { FALLOS DEL ENUN- } \\
\text { CIADO }\end{array}$} & \multicolumn{8}{|c|}{ PUNTUACIÓN } & & & & \\
\hline & \multicolumn{8}{|c|}{ ERROR MORFOLÓGICO } & & & & \\
\hline & \multicolumn{8}{|c|}{ AUSENCIA DE ESPECIFICACIONES } & & & & \\
\hline \multicolumn{13}{|c|}{ ENUNCIADO ALTERNATIVO } \\
\hline \multicolumn{13}{|c|}{ C51.- Calcula $\lim _{x \rightarrow \infty} x(\ln (x+1)-\ln (x))$. } \\
\hline
\end{tabular}

En la cuestión de la ficha 2.51.1 se pide el cálculo del $\lim _{x \rightarrow \infty} x(\ln (x+1)-\ln (x))$. 
Es un ejercicio en el que hay que utilizar la regla de L'Hôpital para su resolución, es pues un ejercicio de reproducción del conocimiento estudiado, reconocimiento de equivalentes, es la ejecución de problemas rutinarios, mediante la aplicación de destrezas técnicas y de algoritmos habituales, con el manejo de expresiones y fórmulas establecidas y la realización de cálculos.

Se trata de una indeterminación del tipo $\infty \cdot 0$

Con este razonamiento, identifica el problema (RAn1), reconoce representaciones de los datos del ejercicio (RPRn1), comprende la expresión escrita (RCn1), identifica que es un modelo similar a otros vistos con anterioridad (RMn1) y le reconoce como problema ya practicado (RRPn1).

A continuación, plantea los algoritmos correspondientes (RPRn2).

$$
\begin{aligned}
& \lim _{x \rightarrow \infty} x(\ln (x+1)-\ln (x)) \stackrel{(1)}{=} \\
& =\lim _{x \rightarrow \infty} \frac{\ln (x+1)-\ln (x)}{\frac{1}{x}} \stackrel{(2)}{=} \lim _{x \rightarrow \infty} \frac{\frac{1}{x+1}-\frac{1}{x}}{-\frac{1}{x^{2}}}=\lim _{x \rightarrow \infty} \frac{x^{2}}{x(x+1)}=1
\end{aligned}
$$

(1) Para poder utilizar la regla de L'Hôpital es preciso expresarlo en forma de cociente

(2) Utilizando la regla de L'Hôpital

(3) Operando y simplificando

Es decir, expone el proceso de cálculo (RAn2), reproduce problemas ya practicados de manera cerrada (RRPn2), realizando explicaciones sencillas (RCn2) y asocia con fórmulas establecidas y realiza los cálculos (RPRn3).

El alumno justifica las fórmulas utilizadas y los resultados (RAn3), realizando cálculos mediante procedimientos familiares (CLSOn3) y resuelve problemas rutinarios estandarizados (RRPn3).

$$
\lim _{x \rightarrow \infty} x(\ln (x+1)-\ln (x))=1
$$

Concluye describiendo los resultados obtenidos (RCn3) y comunicando de manera elemental los resultados del modelo (RMn3). 


\section{FICHA 2.51.2. COMPETENCIAS IMPLÍCITAS EN LA RESOLUCIÓN DE LA C51}

\begin{tabular}{|c|c|c|c|c|c|c|c|c|}
\hline & Nivel 1 & Nivel 2 & Nivel 3 & Nivel 1 & Nivel 2 & Nivel 3 & Nivel 1 & Nivel 2 \\
\hline PR & * & * & * & & & & & \\
\hline A & * & * & * & & & & & \\
\hline C & * & * & * & & & & & \\
\hline$M$ & * & & * & & & & & \\
\hline $\mathbf{R P}$ & * & * & * & & & & & \\
\hline \multicolumn{9}{|l|}{$\mathbf{R}$} \\
\hline \multirow[t]{2}{*}{ LSO } & & & & & & * & & \\
\hline & \multicolumn{3}{|c|}{ Reproducción } & \multicolumn{3}{|c|}{ Conexión } & \multicolumn{2}{|c|}{ Reflexión } \\
\hline
\end{tabular}

\section{ANÁLISIS DE LA CUESTIÓN C53}

\section{FICHA 2.53.1. \\ ESTUDIO DEL ENUNCIADO DEL C53}

C53.- Utilizando la definición de derivada, estudiar la derivabilidad de la función $f(x)=x|x-1|$ en $x=1$.

\begin{tabular}{|c|c|c|c|c|c|c|c|c|c|c|c|c|c|}
\hline CONVOCATORIA & \multicolumn{7}{|c|}{ JUNIO } & \multicolumn{6}{|c|}{ SEPTIEMBRE } \\
\hline AÑO & 95 & 96 & 97 & 98 & 99 & 00 & 01 & \begin{tabular}{l|l}
02 & $\underline{03}$ \\
\end{tabular} & 04 & 05 & \begin{tabular}{l|l|}
06 & 07
\end{tabular} & 08 & 09 \\
\hline OPCIÓN & \multicolumn{7}{|c|}{ A } & \multicolumn{6}{|c|}{$\underline{B}$} \\
\hline TIPO DE PROBLEMA & \multicolumn{7}{|c|}{ TEÓRICO } & \multicolumn{6}{|c|}{ PRÁCTICO } \\
\hline \multirow{3}{*}{ APARTADOS } & \multirow{3}{*}{\multicolumn{2}{|c|}{ SI }} & \multicolumn{4}{|c|}{ Forma explícita } & & & & \multirow[b]{2}{*}{5} & \multirow[b]{2}{*}{6} & \multirow{3}{*}{\multicolumn{2}{|c|}{ No }} \\
\hline & & & & & & & 2 & 3 & 4 & & & & \\
\hline & & & \multicolumn{4}{|c|}{ Forma implícita } & & & & & & & \\
\hline VERBO UTILIZADO & \multicolumn{13}{|c|}{ ESTUDIAR } \\
\hline TIEMPO VERBAL & \multicolumn{13}{|c|}{ INFINITIVO } \\
\hline ESCRITURA & \multicolumn{9}{|c|}{ MULTIPLICATIVA } & \multicolumn{4}{|c|}{ FUNCIONAL } \\
\hline \multirow{3}{*}{$\begin{array}{l}\text { FALLOS DEL ENUN- } \\
\text { CIADO }\end{array}$} & \multicolumn{9}{|c|}{ PUNTUACIÓN } & & & & \\
\hline & \multicolumn{9}{|c|}{ ERROR MORFOLÓGICO } & & & & \\
\hline & \multicolumn{9}{|c|}{ AUSENCIA DE ESPECIFICACIONES } & & & & \\
\hline
\end{tabular}

C53.- Utilizando la definición de derivada, estudia la derivabilidad de la función $f(x)=x|x-1|_{2}$ en el punto $x=1$.

\section{NIVELES DE COMPETENCIAS IMPLÍCITAS: Reproducción}

La cuestión que se presenta en la ficha 2.53.1 corresponde a un nivel de reproducción, pues es una aplicación de conocimientos teóricos, como solicita la orden. 
El alumno reconoce representaciones de los datos del ejercicio (RPRn1), comprende la expresión escrita (RCn1), identifica el problema (RAn1), identifica que es un modelo similar a otros vistos con anterioridad (RMn1) y le reconoce como problema ya practicado (RRPn1).

La función $f(x)=x|x-1|$ está definida como

$$
f(x)=\left\{\begin{array}{cc}
x(1-x) & x \leq 1 \\
x(x-1) & x>1
\end{array} \Rightarrow f(x)=\left\{\begin{array}{cc}
x-x^{2} & x \leq 1 \\
x^{2}-x & x>1
\end{array}\right.\right.
$$

Para ser derivable en $x=1$ :

$$
\lim _{h \rightarrow 0^{-}} \frac{f(1+h)-f(1)}{h}=\lim _{h \rightarrow 0^{+}} \frac{f(1+h)-f(1)}{h}
$$

El alumno plantea los algoritmos correspondientes (RPRn2), expone el proceso de cálculo (RAn2), realizando explicaciones sencillas (RCn2), asocia con fórmulas establecidas y realiza los cálculos (RPRn3).

$$
\begin{aligned}
& \lim _{h \rightarrow 0^{-}} \frac{f(1+h)-f(1)}{h}=\lim _{h \rightarrow 0^{-}} \frac{(1+h)-(1+h)^{2}}{h}=\lim _{h \rightarrow 0^{-}} \frac{-h-h^{2}}{h}=-1 \\
& \lim _{h \rightarrow 0^{+}} \frac{f(1+h)-f(1)}{h}=\lim _{h \rightarrow 0^{+}} \frac{(1+h)^{2}-(1+h)}{h}=\lim _{h \rightarrow 0^{-}} \frac{h^{2}+h}{h}=1
\end{aligned}
$$

Por consiguiente, la función no es derivable en $x=1$.

El alumno resuelve problemas rutinarios estandarizados (RRPn3), maneja procedimientos y fórmulas, resolviendo y calculando (RLSOn3), justifica las fórmulas utilizadas y los resultados (RAn3), describe los resultados obtenidos (RCn3) y comunica de manera elemental los resultados del modelo (RMn3).

\begin{tabular}{|l|c|c|c|c|c|c|c|c|}
\hline \multicolumn{7}{|c|}{ FICHA 2.53.2. COMPETENCIAS IMPLÍCITAS EN LA RESOLUCIÓN DE LA C53 } \\
\hline & Nivel 1 & Nivel 2 & Nivel 3 & Nivel 1 & Nivel 2 & Nivel 3 & Nivel 1 & Nivel 2 \\
\hline PR & $*$ & $*$ & $*$ & & & & & \\
\hline A & $*$ & $*$ & $*$ & & & & & \\
\hline C & $*$ & $*$ & $*$ & & & & & \\
\hline M & $*$ & & $*$ & & & & & \\
\hline RP & $*$ & & $*$ & & & & & \\
\hline R & & & & & & & & \\
\hline LSO & & & $*$ & & & & & \\
\hline & Reproducción & & Conexión & & Reflexión \\
\hline
\end{tabular}




\section{ANÁLISIS DE LA CUESTIÓN C54}

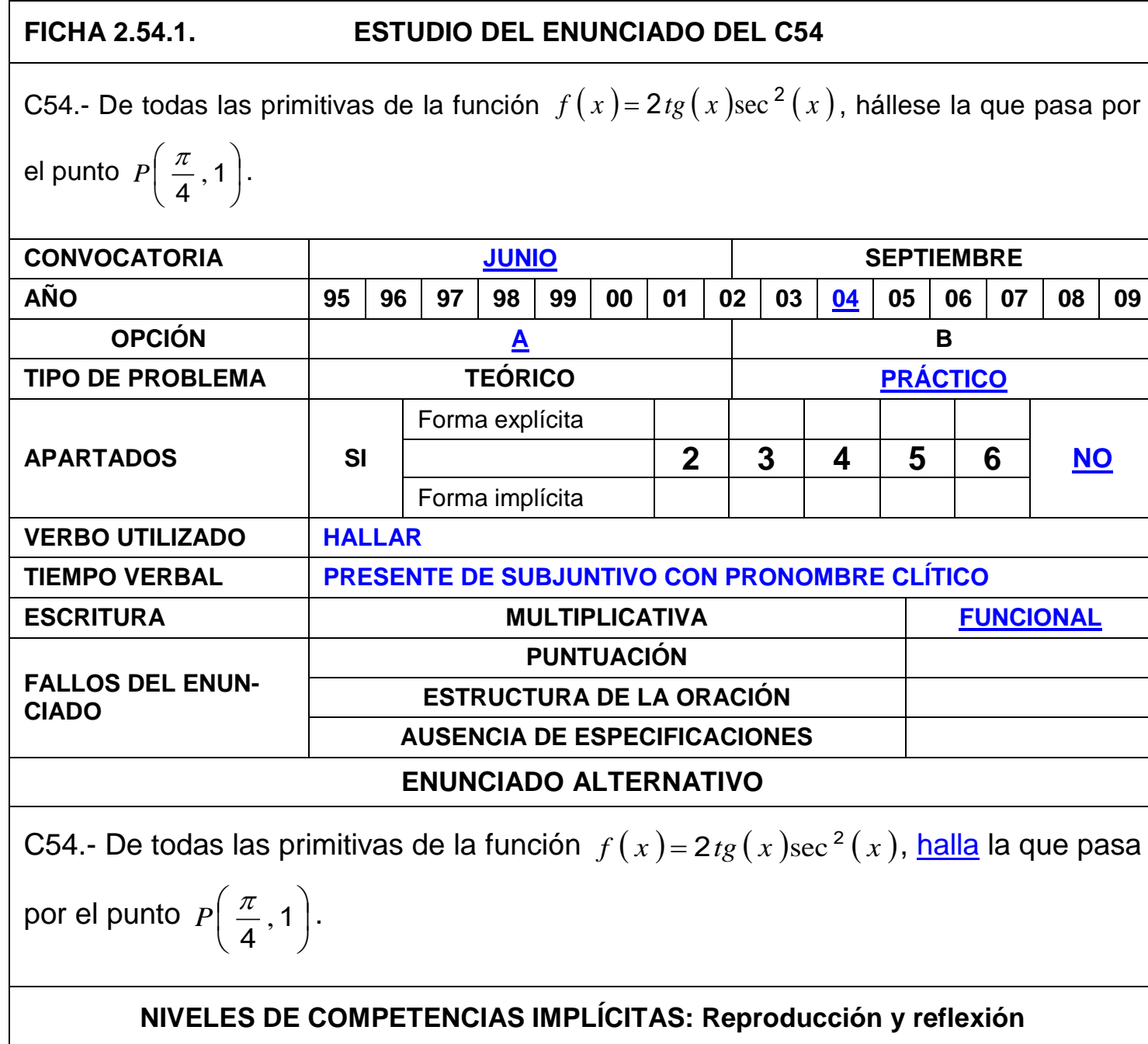

La cuestión que se presenta en la ficha 2.54 .1 se trata de un ejercicio de reproducción.

Reproducción del conocimiento estudiado, reconocimiento de equivalentes, ejecución de problemas rutinarios, aplicación de destrezas técnicas y de algoritmos habituales, manejo de expresiones y fórmulas establecidas y realización de cálculos.

Es una integral trigonométrica.

Con este razonamiento, el alumno identifica el problema (RAn1), reconoce representaciones de los datos del ejercicio (RPRn1), comprende la expresión escrita (RCn1), identifica que es un modelo similar a otros vistos con anterioridad (RMn1) y le reconoce como problema ya practicado (RRPn1).

A continuación, plantea los algoritmos correspondientes (RPRn2). 
Mediante el cambio de variable $\cos (x)=t$ la integral propuesta se convierte en una de las de la tabla de integrales inmediatas.

El alumno expone el proceso de cálculo (RAn2), realizando explicaciones sencillas (RCn2), asocia con fórmulas establecidas y realiza los cálculos (RPRn3).

Es una integral inmediata

$$
\int 2 \operatorname{tg}(x) \sec ^{2}(x) d x=\int \frac{2 \operatorname{sen}(x)}{\cos ^{3}(x)} d x=\frac{1}{\cos ^{2}(x)}+C
$$

Como la función primitiva

$$
F(x)=\frac{1}{\cos ^{2}(x)}+C
$$

Verifica

$$
F\left(\frac{\pi}{4}\right)=1 \Rightarrow F\left(\frac{\pi}{4}\right)=\frac{1}{\cos ^{2}\left(\frac{\pi}{4}\right)}+C=1
$$

De donde se deduce $C=-1$

Maneja procedimientos resolviendo y calculando (RLSOn3), en consecuencia, el alumno resuelve problemas rutinarios estandarizados (RRPn3).

Y la función es :

$$
F(x)=\frac{1}{\cos ^{2}(x)}-1
$$

El alumno justifica las fórmulas utilizadas y los resultados (RAn3), describe los resultados obtenidos (RCn3) comunicando de manera elemental los resultados del modelo (RMn3)

También podía haber hecho el siguiente razonamiento:

Haciendo el cambio de variable $\operatorname{tg}(x)=t, d(\operatorname{tg}(x))=\frac{1}{\cos ^{2}(x)}=\sec ^{2}(x)$

Comienza con la identificación del problema (RAn1), continúa con la exposición del proceso de cálculo (RAn2), mediante el cálculo de la integral y termina justificando las fórmulas utilizadas y los resultados (RAn3).

Reconoce representaciones de los datos del ejercicio (RPRn1), comprende la expresión escrita (RCn1), identifica que es un modelo similar a otros vistos con anterioridad (RMn1) y le reconoce como problema ya practicado (RRPn1).

Continúa planteando los algoritmos correspondientes (RPRn2). 


$$
\int 2 \operatorname{tg}(x) \sec ^{2}(x) d x=\operatorname{tg}^{2}(x)+K
$$

Como la función primitiva $G(x)=\operatorname{tg}^{2}(x)+K$ verifica

$$
G\left(\frac{\pi}{4}\right)=1 \Rightarrow G\left(\frac{\pi}{4}\right)=\operatorname{tg}^{2}\left(\frac{\pi}{4}\right)+K=1
$$

De donde, se deduce $K=0$

El alumno maneja procedimientos resolviendo y calculando (RLSOn3), en consecuencia, el alumno resuelve problemas rutinarios estandarizados (RRPn3).

Y la función es

$$
G(x)=\operatorname{tg}^{2}(x)
$$

Con el desarrollo del ejercicio el alumno expone el proceso de cálculo (RAn2), realizando explicaciones sencillas (RCn2), asocia con fórmulas establecidas y realiza los cálculos (RPRn3) y, al calcular la integral, utiliza variables y realiza cálculos mediante procedimientos familiares (CLSOn3).

Aparentemente las soluciones son completamente distintas, pero utilizando identidades trigonométricas se obtiene

$$
G(x)=\operatorname{tg}^{2}(x)=\frac{\operatorname{sen}^{2}(x)}{\cos ^{2}(x)}=\frac{1-\cos ^{2}(x)}{\cos ^{2}(x)}=\frac{1}{\cos ^{2}(x)}-\frac{\cos ^{2}(x)}{\cos ^{2}(x)}=\frac{1}{\cos ^{2}(x)}-1=F(x)
$$

Aparece aquí el nivel de reflexión por parte del estudiante para aplicar estrategias en la resolución de un problema que contiene elementos inusuales, con lo que razona de manera sencilla, distinguiendo formas más amplias de argumentación (RfAn1) y sabe explicar cuestiones matemáticas, cálculos y resultados (RfCn1).

\section{FICHA 2.54.2. COMPETENCIAS IMPLÍCITAS EN LA RESOLUCIÓN DE LA C54}

\begin{tabular}{|l|c|c|c|c|c|c|c|c|}
\hline & Nivel 1 & Nivel 2 & Nivel 3 & Nivel 1 & Nivel 2 & Nivel 3 & Nivel 1 & Nivel 2 \\
\hline PR & $*$ & $*$ & $*$ & & & & & \\
\hline A & $*$ & $*$ & $*$ & & & & $*$ & \\
\hline C & $*$ & $*$ & $*$ & & & & $*$ & \\
\hline M & $*$ & & $*$ & & & & & \\
\hline RP & $*$ & & $*$ & & & & & \\
\hline R & & & & & & & & \\
\hline LSO & & & $*$ & & & & & \multicolumn{2}{l|}{ Reflexión } \\
\hline
\end{tabular}




\section{ANÁLISIS DE LA CUESTIÓN C55}

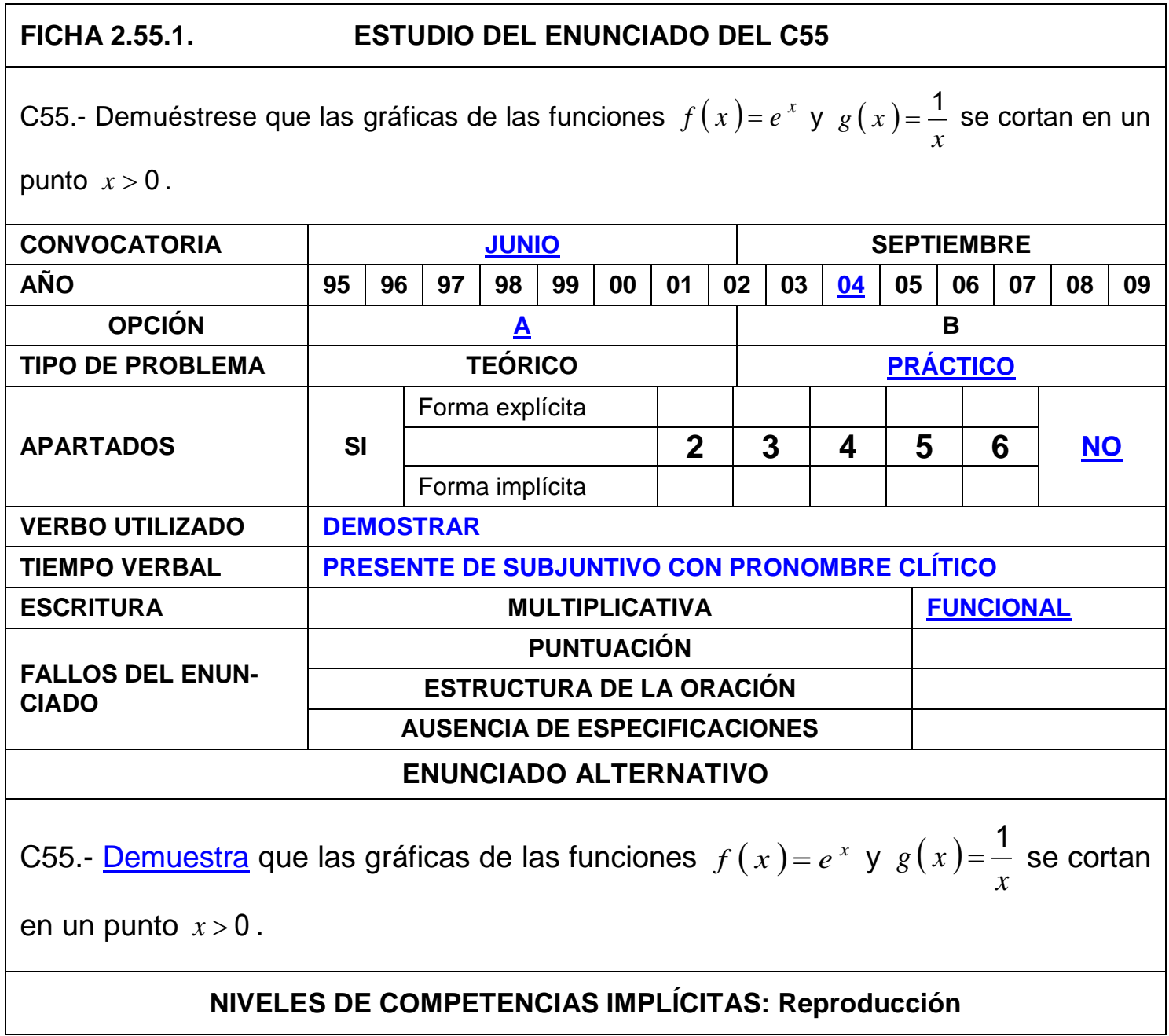

La cuestión de la ficha 2.55.1 es un ejercicio de reproducción del conocimiento estudiado, reconocimiento de equivalentes, ejecución de problemas rutinarios, aplicación de destrezas técnicas y de algoritmos habituales, manejo de expresiones y fórmulas establecidas y realización de cálculos, en el cual hay que utilizar el teorema de Bolzano, -o resultados deducidos a partir del teorema de Bolzano-, para su resolución.

Con este razonamiento identifica el problema (RAn1), reconoce representaciones de los datos del ejercicio (RPRn1), comprende la expresión escrita (RCn1), identifica que es un modelo similar a otros vistos con anterioridad (RMn1) y le reconoce como problema ya practicado (RRPn1).

A continuación, plantea los algoritmos correspondientes (RPRn2).

Consideramos la función: 


$$
h(x)=e^{x}-\frac{1}{x}
$$

Es una función continua, por ser suma algebraica de funciones continuas. Como nos pide un punto $x>0$, dado que en $x=0$ la función $g(x)=\frac{1}{x}$ no está definida, consideramos un intervalo $(0,1]$, aunque, si queremos que sea cerrado consideramos el intervalo $[0,01,1]$, por

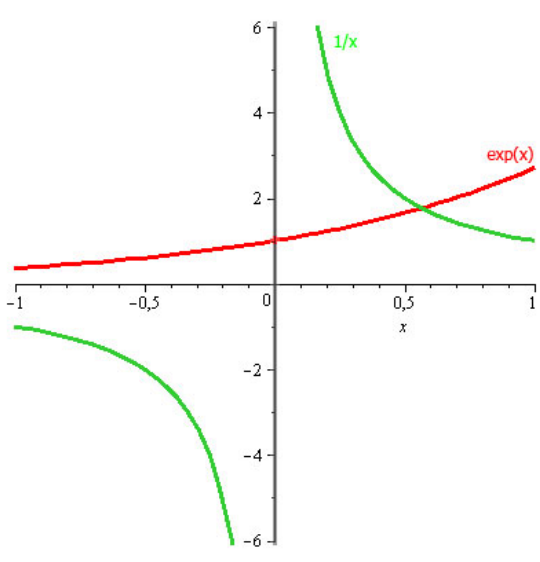

Figura 2.55 ejemplo.

$$
\begin{gathered}
h(0,01)=e^{0,01}-\frac{1}{0,01}<0 \\
h(1)=e^{1}-\frac{1}{1}>0
\end{gathered}
$$

Es una función continua en el intervalo cerrado que toma valores de signo contrario en los extremos del intervalo, por el teorema de Bolzano, existe un punto $c \in(0,01,1)$, con $h(c)=0$

El alumno expone el proceso de cálculo (RAn2), realizando explicaciones sencillas (RCn2), asocia con fórmulas establecidas y realiza los cálculos (RPRn3).

$$
h(c)=e^{c}-\frac{1}{c}=0, \Rightarrow \quad e^{c}=\frac{1}{c}
$$

Como solo pide probar que tiene alguna solución, hemos "encontrado" ese valor $c \in(0,01,1)$ que el teorema de Bolzano nos garantiza que es solución de la ecuación $e^{x}-\frac{1}{x}=0$, y por tanto punto de corte de ambas curvas.

Justifica las fórmulas utilizadas y los resultados (RAn3), maneja procedimientos resolviendo y calculando (RLSOn3) y resuelve problemas rutinarios estandarizados (RRPn3), con lo que describe los resultados obtenidos (RCn3), comunicando de manera elemental los resultados del modelo (RMn3).

Se tiene una función definida analíticamente, que es preciso interpretar, seleccionar y cambiar entre diferentes formas de representación (CRn1, CRn2), analítica y gráficamente. Figura 2.55 . 


\begin{tabular}{|l|c|c|c|c|c|c|c|c|}
\hline \multicolumn{6}{|c|}{ FICHA 2.55.2. } & COMPETENCIAS IMPLÍCITAS EN LA RESOLUCIÓN DE LA C55 \\
\hline & Nivel 1 & Nivel 2 & Nivel 3 & Nivel 1 & Nivel 2 & Nivel 3 & Nivel 1 & Nivel 2 \\
\hline PR & $*$ & $*$ & $*$ & & & & & \\
\hline A & $*$ & $*$ & $*$ & & & & & \\
\hline C & $*$ & $*$ & $*$ & & & & & \\
\hline M & $*$ & & $*$ & & & & & \\
\hline RP & $*$ & $*$ & $*$ & & & & & \\
\hline R & & & & $*$ & $*$ & $*$ & & \\
\hline LSO & & & $*$ & & & & & \\
\hline & \multicolumn{2}{|l|}{ Reproducción } & & Conexión & & Reflexión \\
\hline
\end{tabular}

\section{ANÁLISIS DE LA CUESTIÓN C61}

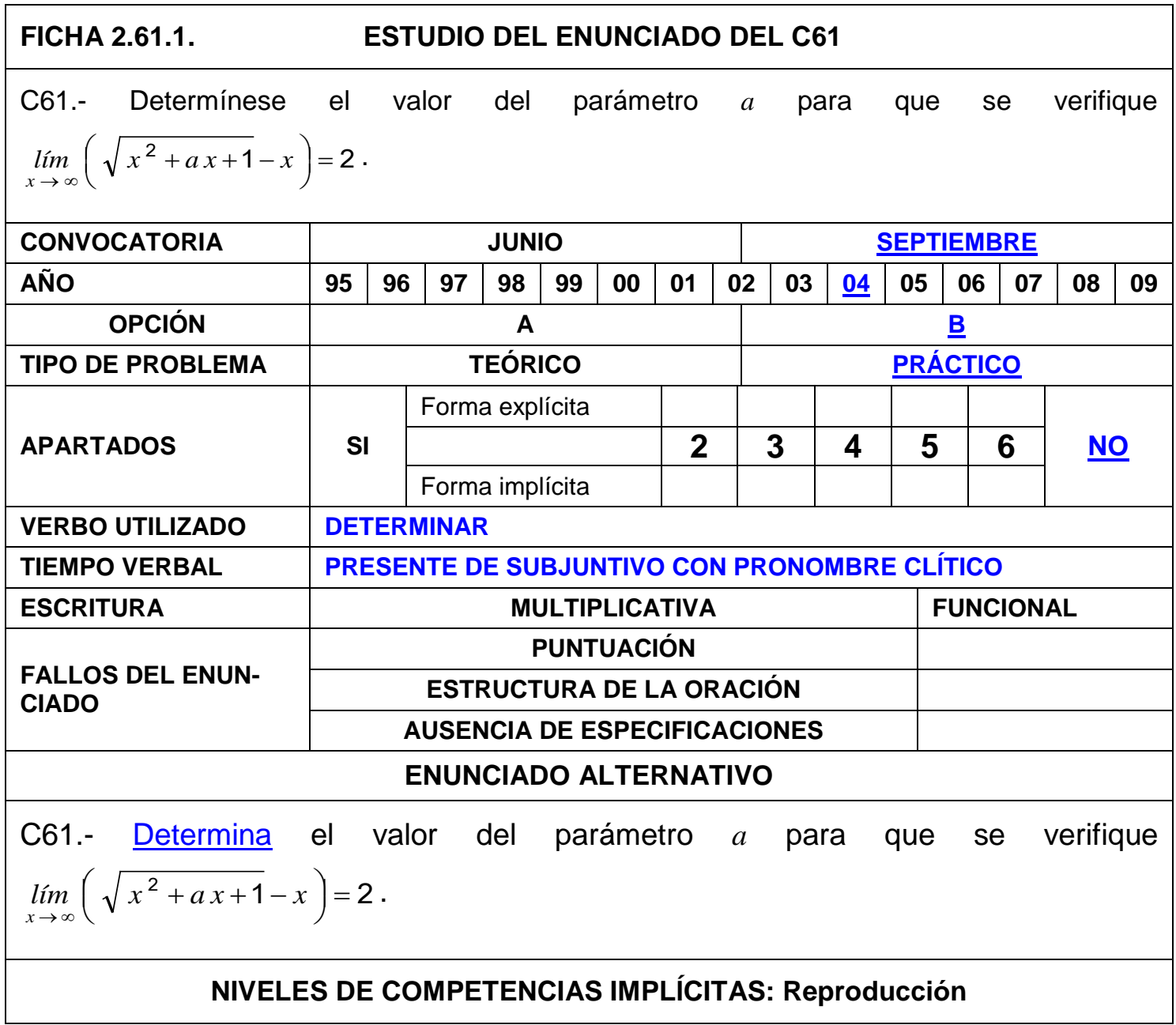

La cuestión que se presenta en la ficha 2.61.1 se encuadra en el nivel de reproducción, es el cálculo de un límite, lo que corresponde al nivel de repro- 
ducción del conocimiento estudiado, reconocimiento de equivalentes, ejecución de problemas rutinarios mediante la aplicación de destrezas técnicas y algoritmos habituales.

El alumno comienza con la identificación del problema (RAn1), reconoce representaciones de los datos del ejercicio (RPRn1), comprende la expresión escrita $(\mathrm{RCn} 1)$, identifica que es un modelo similar a otros vistos con anterioridad (RMn1) y le reconoce como problema ya practicado (RRPn1).

A continuación, realiza explicaciones sencillas (RCn2).

Es una indeterminación del tipo $\infty-\infty$, que se resuelve multiplicando y dividiendo por la expresión conjugada.

El alumno sabe expresarse sobre cuestiones matemáticas (CCn1), comprende que tiene que emplear métodos matemáticos intermedios (CPRn2) y aplica los conceptos matemáticos apropiados (CPRn3).

Con el desarrollo del ejercicio el alumno expone el proceso de cálculo (RAn2), plantea los algoritmos correspondientes (RPRn2).asocia con fórmulas establecidas y realiza los cálculos (RPRn3).

$$
\lim _{x \rightarrow \infty}\left(\sqrt{x^{2}+a x+1}-x\right)=\lim _{x \rightarrow \infty} \frac{\left(\sqrt{x^{2}+a x+1}-x\right) \cdot\left(\sqrt{x^{2}+a x+1}+x\right)}{\sqrt{x^{2}+a x+1}+x}=
$$

El alumno razona matemáticamente de manera simple (CAn1) y maneja procedimientos y fórmulas, resolviendo y calculando (RLSOn3)

$$
\begin{aligned}
&\left(\sqrt{x^{2}+a x+1}-x\right) \cdot\left(\sqrt{x^{2}+a x+1}+x\right)=\left(\sqrt{x^{2}+a x+1}\right)^{2}-x^{2}=a x+1 \\
&= \lim _{x \rightarrow \infty} \frac{a x+1}{\sqrt{x^{2}+a x+1}+x}=\frac{a}{2} \\
& \lim _{x \rightarrow \infty}\left(\sqrt{x^{2}+a x+1}-x\right)=\frac{a}{2}=2 \Rightarrow a=4
\end{aligned}
$$

El alumno resuelve problemas rutinarios estandarizados (RRPn3), justifica las fórmulas utilizadas y los resultados (RAn3), describe los resultados obtenidos, (RCn3) y comunica de manera elemental los resultados del modelo (RMn3). 
FICHA 2.61.2. COMPETENCIAS IMPLÍCITAS EN LA RESOLUCIÓN DE LA C61

\begin{tabular}{|l|c|c|c|c|c|c|c|c|}
\hline & Nivel 1 & Nivel 2 & Nivel 3 & Nivel 1 & Nivel 2 & Nivel 3 & Nivel 1 & Nivel 2 \\
\hline PR & $*$ & $*$ & $*$ & & & & & \\
\hline A & $*$ & $*$ & $*$ & $*$ & & & & \\
\hline C & $*$ & $*$ & $*$ & & & & & \\
\hline M & $*$ & & $*$ & & & & & \\
\hline RP & $*$ & & $*$ & & & & & \\
\hline R & & & & & & & & \\
\hline LSO & & & $*$ & & & & & \\
\hline
\end{tabular}

\section{ANÁLISIS DE LA CUESTIÓN C63}

\section{FICHA 2.63.1. \\ ESTUDIO DEL ENUNCIADO DEL C63}

C63.- Aplicando el teorema de Lagrange de los incrementos finitos, demuéstrese que para $x>0$ se verifica $\operatorname{arctg}(2 x)-\operatorname{arctg}(x)<\frac{x}{1+x^{2}}$.

\begin{tabular}{|c|c|c|c|c|c|c|c|c|c|c|c|c|c|c|}
\hline CONVOCATORIA & \multicolumn{7}{|c|}{ JUNIO } & \multicolumn{7}{|c|}{ SEPTIEMBRE } \\
\hline AÑO & 95 & 96 & 97 & 98 & 99 & 00 & 01 & \begin{tabular}{l|l}
02 & 03
\end{tabular} & 04 & $\underline{05}$ & 06 & 07 & 08 & 09 \\
\hline OPCIÓN & \multicolumn{7}{|c|}{$\underline{A}$} & \multicolumn{7}{|c|}{ B } \\
\hline TIPO DE PROBLEMA & \multicolumn{7}{|c|}{ TEÓRICO } & \multicolumn{7}{|c|}{ PRÁCTICO } \\
\hline \multirow{3}{*}{ APARTADOS } & \multirow{3}{*}{\multicolumn{2}{|c|}{ SI }} & \multicolumn{4}{|c|}{ Forma explícita } & & & & \multirow{3}{*}{5} & \multirow{2}{*}{\multicolumn{2}{|c|}{6}} & \multirow{3}{*}{\multicolumn{2}{|c|}{ NO }} \\
\hline & & & & & & & 2 & 3 & 4 & & & & & \\
\hline & & & \multicolumn{4}{|c|}{ Forma implícita } & & & & & & & & \\
\hline VERBO UTILIZADO & \multicolumn{14}{|c|}{ DEMOSTRAR } \\
\hline TIEMPO VERBAL & \multicolumn{14}{|c|}{ PRESENTE DE SUBJUNTIVO CON PRONOMBRE CLÍTICO } \\
\hline ESCRITURA & \multicolumn{9}{|c|}{ MULTIPLICATIVA } & \multicolumn{5}{|c|}{ FUNCIONAL } \\
\hline \multirow{3}{*}{$\begin{array}{l}\text { FALLOS DEL ENUN- } \\
\text { CIADO }\end{array}$} & \multicolumn{9}{|c|}{ PUNTUACIÓN } & & & & & \\
\hline & \multicolumn{9}{|c|}{ ESTRUCTURA DE LA ORACIÓN } & & & & & \\
\hline & \multicolumn{9}{|c|}{ AUSENCIA DE ESPECIFICACIONES } & & & & & \\
\hline \multicolumn{15}{|c|}{ ENUNCIADO ALTERNATIVO } \\
\hline
\end{tabular}

C63.- Aplicando el teorema de Lagrange de los incrementos finitos, demuestra que para $x>0$ se verifica $\operatorname{arctg}(2 x)-\operatorname{arctg}(x)<\frac{x}{1+x^{2}}$.

\section{NIVELES DE COMPETENCIAS IMPLÍCITAS: Conexión}

La cuestión que aparece en la ficha 2.63.1 se encuadra en el nivel de conexión. 
Es un problema que reproduce una situación similar a la practicada durante la instrucción, pero no es mera rutina, pues en la resolución del problema, el alumno debe pensar en el tratamiento matemático necesario (CPRn1), comprender que tiene que emplear conceptos matemáticos intermedios (CPRn2) y aplicar esos conceptos matemáticos apropiados (CPRn3).

El enunciado dice que $x>0 \Rightarrow 2 x>x$.

La función $f(x)=\operatorname{arctg}(x)$ es una función continua en $[x, 2 x]$ y derivable en $(x, 2 x)$

El alumno estructura la situación que debe modelizar (CMn1), sabe expresarse sobre cuestiones matemáticas (CCn1), explica los cálculos y sus propiedades (CCn2) e interpreta las relaciones implicadas (CCn3).

Utilizando el teorema de los incrementos finitos

$$
\frac{\operatorname{arctg}(2 x)-\operatorname{arctg}(x)}{x}=\frac{1}{1+c^{2}}, \text { con } c \in(x, 2 x)
$$

Como $0<x<c<2 x \Rightarrow x^{2}<c^{2} \Rightarrow 1+x^{2}<1+c^{2} \Rightarrow \frac{1}{1+c^{2}}<\frac{1}{1+x^{2}}$

El alumno razona matemáticamente de manera simple (CAn1) siguiendo y evaluando el encadenamiento de argumentos matemáticos particulares (CAn2, CAn3).

$$
\frac{\operatorname{arctg}(2 x)-\operatorname{arctg}(x)}{x}=\frac{1}{1+c^{2}}<\frac{1}{1+x^{2}}
$$

Dado que $x>0$ multiplicando por $x$ los dos miembros de la desigualdad

$$
\operatorname{arctg}(2 x)-\operatorname{arctg}(x)<\frac{x}{1+x^{2}}
$$

Traduce en la práctica el modelo a seguir que es algo diferente de los estudiados (CMn2), desarrolla procedimientos intuitivos ya practicados pero no rutinarios (CRPn1) y maneja procedimientos y fórmulas resolviendo y calculando (RLSOn3).

Finalmente, describe los resultados obtenidos (RCn3) comunicando de manera elemental los resultados del modelo (RMn3). 


\begin{tabular}{|l|c|c|c|c|c|c|c|c|}
\hline \multicolumn{7}{|l}{ FICHA 2.63.2. COMPETENCIAS IMPLÍCITAS EN LA RESOLUCIÓN DE LA C63 } \\
\hline & Nivel 1 & Nivel 2 & Nivel 3 & Nivel 1 & Nivel 2 & Nivel 3 & Nivel 1 & Nivel 2 \\
\hline PR & & & & $*$ & $*$ & $*$ & & \\
\hline A & & & & $*$ & $*$ & $*$ & & \\
\hline C & & & $*$ & $*$ & $*$ & $*$ & & \\
\hline M & & & $*$ & $*$ & $*$ & & & \\
\hline RP & & & & $*$ & & & & \\
\hline R & & & & & & & & \\
\hline LSO & & & $*$ & & & & & \\
\hline & \multicolumn{2}{|l|}{ Reproducción } & & Conexión & & \multicolumn{2}{|c|}{ Reflexión } \\
\hline
\end{tabular}

\section{ANÁLISIS DE LA CUESTIÓN C64}

La cuestión que se presenta en la ficha 2.64.1 se encuadra en el nivel de conexión dado que reproduce situaciones similares a las dadas en la instrucción, pero no son de mera rutina, ya que el estudio de la continuidad de la función depende del valor de parámetros.

El alumno tiene que pensar en el tratamiento matemático necesario (CPRn1), comprende que tiene que emplear métodos matemáticos intermedios (CPRn2) y aplica esos conceptos matemáticos apropiados (CPRn3), en este caso el cálculo de límites para el estudio de la continuidad, estructura la situación que debe modelizar (CMn1), traduce en la práctica el modelo a seguir, que es algo diferente de los estudiados (CMn2) y sabe interpretar y alternar diferentes modelos y comunicar los resultados (CMn3).

La función es continua $\forall x \neq 0$, por ser cociente de funciones continuas con denominador no nulo.

Estudiamos la continuidad en $x=0$.

El alumno razona matemáticamente de manera simple (CAn1), sigue el encadenamiento de argumentos matemáticos particulares (CAn2), sabe expresarse sobre cuestiones matemáticas (CCn1), explica los cálculos y sus propiedades (CCn2) e interpreta las relaciones implicadas (CCn3).

$$
\begin{gathered}
\text { Cuando } x \rightarrow 0^{-} \Rightarrow \frac{1}{x} \rightarrow-\infty \Rightarrow \lim _{x \rightarrow 0^{-}}\left(1+e^{1 / x}\right)=1 \\
\lim _{x \rightarrow 0^{-}} \frac{x+\alpha}{1+e^{1 / x}}=\frac{\alpha}{1}=\alpha
\end{gathered}
$$


FICHA 2.64.1.

ESTUDIO DEL ENUNCIADO DEL C64

C64.- Estúdiese, según los valores de los números reales $\alpha$ y $\beta$, la continuidad de la función $f$ definida por

$$
f(x)=\left\{\begin{array}{ccc}
\frac{x+\alpha}{1+e^{1 / x}} & \text { si } \quad x \neq 0 \\
\beta & \text { si } & x=0
\end{array}\right. \text {. }
$$

\begin{tabular}{|c|c|c|c|c|c|c|c|c|c|c|c|c|c|c|}
\hline CONVOCATORIA & \multicolumn{7}{|c|}{ JUNIO } & \multicolumn{7}{|c|}{ SEPTIEMBRE } \\
\hline AÑO & 95 & 96 & 97 & 98 & 99 & 00 & 01 & \begin{tabular}{|l|l|}
02 & 03
\end{tabular} & 04 & $\underline{05}$ & 06 & 07 & 08 & 09 \\
\hline OPCIÓN & \multicolumn{7}{|c|}{ A } & \multicolumn{7}{|c|}{$\underline{B}$} \\
\hline TIPO DE PROBLEMA & \multicolumn{7}{|c|}{ TEÓRICO } & \multicolumn{7}{|c|}{ PRÁCTICO } \\
\hline \multirow{3}{*}{ APARTADOS } & \multirow{3}{*}{\multicolumn{2}{|c|}{ SI }} & \multicolumn{4}{|c|}{ Forma explícita } & & & & & & \multirow[b]{2}{*}{6} & \multirow{3}{*}{\multicolumn{2}{|c|}{$\underline{\text { NO }}$}} \\
\hline & & & & & & & 2 & 3 & 4 & 5 & & & & \\
\hline & & & \multicolumn{4}{|c|}{ Forma implícita } & & & & & & & & \\
\hline VERBO UTILIZADO & \multicolumn{14}{|c|}{ ESTUDIAR } \\
\hline TIEMPO VERBAL & \multicolumn{14}{|c|}{ PRESENTE DE SUBJUNTIVO CON PRONOMBRE CLÍTICO } \\
\hline ESCRITURA & \multicolumn{9}{|c|}{ MULTIPLICATIVA } & \multicolumn{5}{|c|}{ FUNCIONAL } \\
\hline \multirow{3}{*}{$\begin{array}{l}\text { FALLOS DEL ENUN- } \\
\text { CIADO }\end{array}$} & \multicolumn{9}{|c|}{ PUNTUACIÓN } & & & & & \\
\hline & \multicolumn{9}{|c|}{ ORDEN DE LAS PALABRAS EN LA ORACIÓN } & & & & & \\
\hline & \multicolumn{9}{|c|}{ AUSENCIA DE ESPECIFICACIONES } & & & & & \\
\hline \multicolumn{15}{|c|}{ ENUNCIADO ALTERNATIVO } \\
\hline
\end{tabular}

C64.- Estudia la continuidad de la función $\underline{f(x)}$ definida por

$$
f(x)=\left\{\begin{array}{ccc}
\frac{x+\alpha}{1+e^{1 / x}} & \text { si } \quad x \neq 0 \\
\beta & \text { si } \quad x=0
\end{array}\right.
$$

según los valores de los números reales $\alpha$ y $\beta$.

\section{NIVELES DE COMPETENCIAS IMPLÍCITAS: Conexión}

$$
\begin{gathered}
\text { Cuando } x \rightarrow 0^{+} \Rightarrow \frac{1}{x} \rightarrow+\infty \Rightarrow \lim _{x \rightarrow 0^{+}}\left(1+e^{1 / x}\right)=\infty \\
\qquad \lim _{x \rightarrow 0^{+}} \frac{x+\alpha}{1+e^{1 / x}}=0 \quad \forall \alpha
\end{gathered}
$$

Para ser continua en $x=0$,

$$
\begin{aligned}
& \lim _{x \rightarrow 0^{-}} f(x)=\lim _{x \rightarrow 0^{+}} f(x)=f(0) \Rightarrow \alpha=0=\beta \\
& \text { Si } \alpha \neq 0 \text { la función es continua en } R-\{0\}
\end{aligned}
$$


Si $\beta \neq 0$ la función es continua en $R-\{0\}$

Si $\alpha=0$ y $\alpha \neq \beta$ la función es continua en $R-\{0\}$

El alumno describe los resultados obtenidos ( $\mathrm{RCn} 3)$, desarrolla procedimientos intuitivos ya practicados, pero no rutinarios (CRPn1) y utiliza variables y realiza ecuaciones y cálculos mediante procedimientos familiares (CLSOn3).

\begin{tabular}{|l|c|c|c|c|c|c|c|c|}
\hline \multicolumn{7}{|l}{ FICHA 2.64.2. COMPETENCIAS IMPLÍCITAS EN LA RESOLUCIÓN DE LA C64 } \\
\hline & Nivel 1 & Nivel 2 & Nivel 3 & Nivel 1 & Nivel 2 & Nivel 3 & Nivel 1 & Nivel 2 \\
\hline PR & & & & $*$ & $*$ & $*$ & & \\
\hline A & & & & $*$ & $*$ & & & \\
\hline C & & & $*$ & $*$ & $*$ & $*$ & & \\
\hline M & & & & $*$ & $*$ & $*$ & & \\
\hline RP & & & & $*$ & & & & \\
\hline R & & & & & & & & \\
\hline LSO & & & & & & $*$ & & \\
\hline & \multicolumn{2}{|l|}{ Reproducción } & & \multicolumn{7}{|l|}{ Conexión } & & Reflexión \\
\hline
\end{tabular}

\section{ANÁLISIS DE LA CUESTIÓN C67}

La cuestión que se presenta en la ficha 2.67.1 se encuadra en el nivel de reproducción, es el cálculo de una integral inmediata, lo que corresponde al nivel de reproducción del conocimiento estudiado, reconocimiento de equivalentes, ejecución de problemas rutinarios mediante la aplicación de destrezas técnicas y algoritmos habituales.

$$
\int \frac{1}{x^{2}+4 x+13} d x=\int \frac{1}{(x+2)^{2}+9}
$$

Es una integral de tipo arco tangente.

Comienza con la identificación del problema (RAn1), continúa con la exposición del proceso de cálculo (RAn2), reproduce problemas ya practicados de manera cerrada (RRPn2) y termina justificando las fórmulas utilizadas y los resultados (RAn3).

Reconoce representaciones de los datos del ejercicio (RPRn1), comprende la 
expresión escrita (RCn1), identifica que es un modelo similar a otros vistos con anterioridad (RMn1) y le reconoce como problema ya practicado (RRPn1).

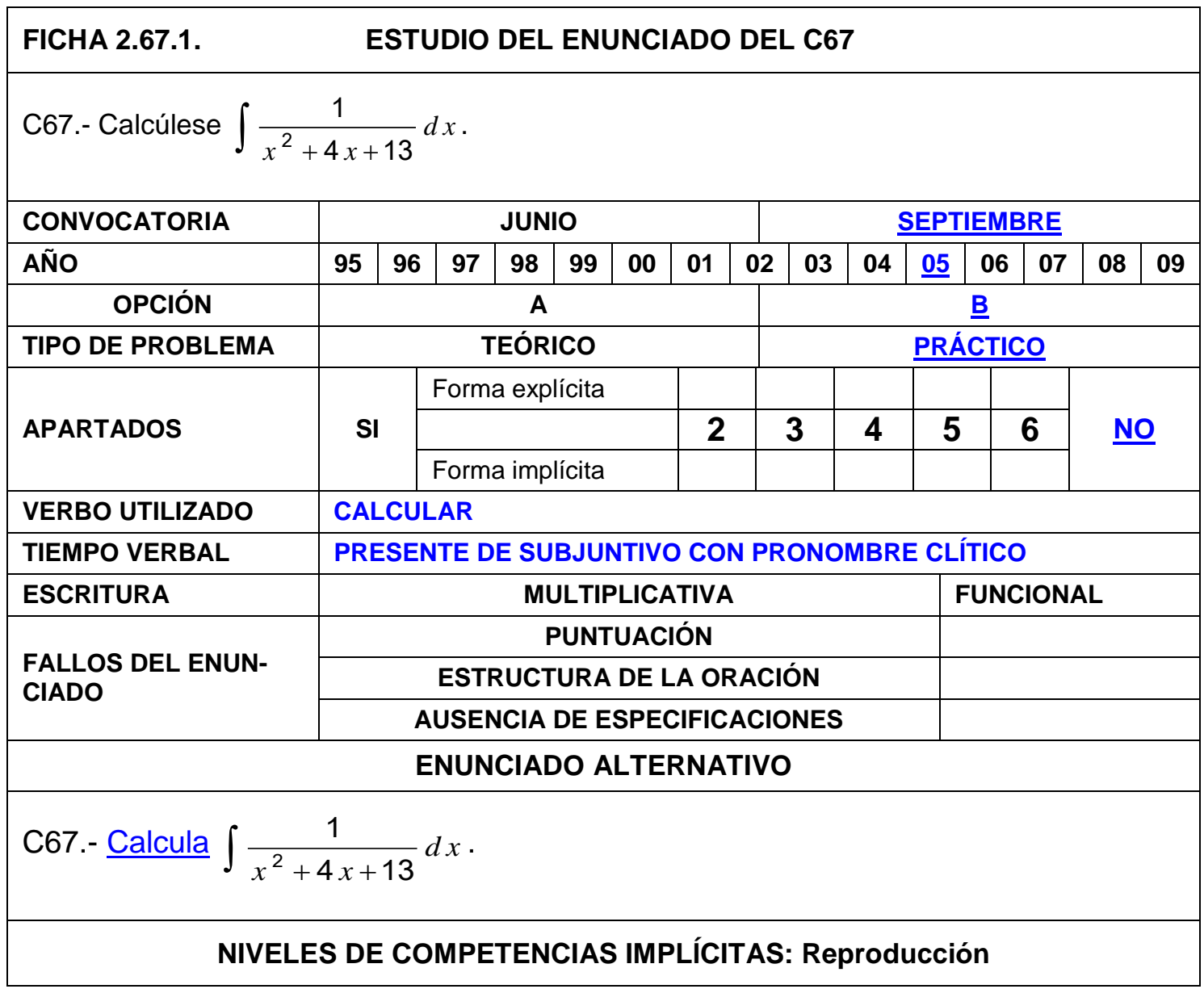

A continuación, plantea los algoritmos correspondientes (RPRn2).

$$
\int \frac{1}{x^{2}+4 x+13} d x=\int \frac{1}{(x+2)^{2}+9} d x=\frac{1}{9} \int \frac{d x}{1+\left(\frac{x+2}{3}\right)^{2}}=\frac{1}{3} \operatorname{arctg}\left(\frac{x+2}{3}\right)+C
$$

Con el desarrollo del ejercicio el alumno expone el proceso de cálculo (RAn2), realizando explicaciones sencillas (RCn2), asocia con fórmulas establecidas y realiza los cálculos (RPRn3).

El alumno resuelve problemas rutinarios estandarizados (RRPn3), al hacer la integral, utiliza variables y realiza cálculos mediante procedimientos familiares (CLSOn3), justifica las fórmulas utilizadas y los resultados (RAn3), describe los resultados obtenidos, (RCn3) y comunica de manera elemental los resultados del modelo (RMn3). 


\section{FICHA 2.67.2. COMPETENCIAS IMPLÍCITAS EN LA RESOLUCIÓN DE LA C67}

\begin{tabular}{|l|c|c|c|c|c|c|c|c|}
\hline & Nivel 1 & Nivel 2 & Nivel 3 & Nivel 1 & Nivel 2 & Nivel 3 & Nivel 1 & Nivel 2 \\
\hline PR & $*$ & $*$ & $*$ & & & & & \\
\hline A & $*$ & $*$ & $*$ & & & & & \\
\hline C & $*$ & $*$ & $*$ & & & & & \\
\hline M & $*$ & & $*$ & & & & & \\
\hline RP & $*$ & $*$ & $*$ & & & & & \\
\hline R & & & & & & & & \\
\hline LSO & & & & & & $*$ & & \\
\hline
\end{tabular}

\section{ANÁLISIS DE LA CUESTIÓN C71}

FICHA 2.71.1.

\section{ESTUDIO DEL ENUNCIADO DEL C71}

C71.- Sea $f(x)=a x^{3}+b x^{2}+c x+d$. Determínense $a, b, c$ y $d$ para que la recta $y+1=0$ sea tangente a la gráfica de $f$ en el punto $(0,-1)$, y la recta $x-y-2=0$ sea tangente a la gráfica de $f$ en el punto $(1,-1)$.

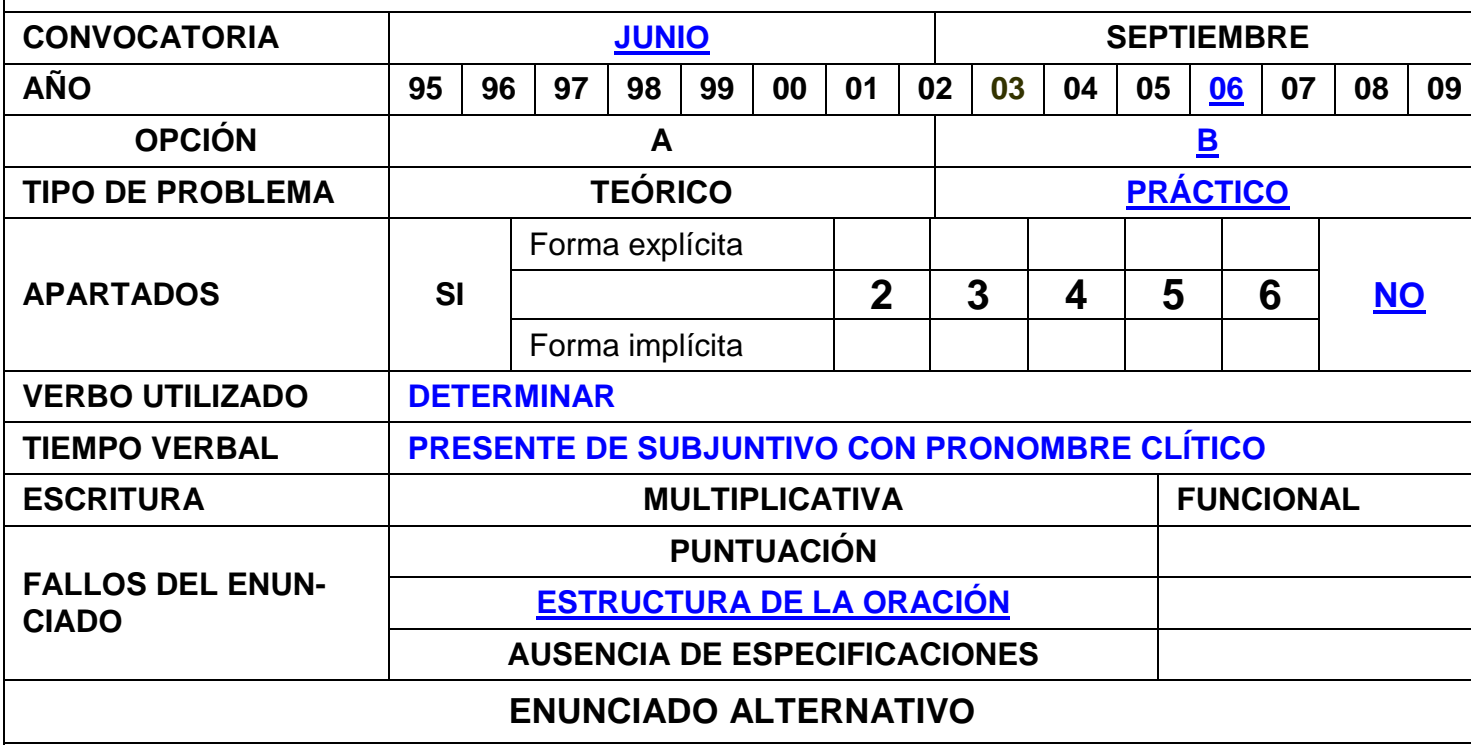

C71.- Considerada la función $f(x)=a x^{3}+b x^{2}+c x+d$, determina los valores de los parámetros $a, b, c$ y $d$ para que la recta $y+1=0$ sea tangente a la gráfica de $f(x)$ en el punto $(0,-1)$ y la recta $x-y-2=0$ sea tangente a la gráfica de $f(x)$ en el punto $(1,-1)$.

NIVELES DE COMPETENCIAS IMPLÍCITAS: Conexión 
La cuestión que se presenta en la ficha 2.71.1 corresponde al nivel de conexión dado que reproduce una situación similar a la que se presenta durante la instrucción, pero no es mera rutina.

En primer lugar, el alumno piensa en el tratamiento matemático necesario (CPRn1), estructura la situación que debe modelizar (CMn1), desarrolla procedimientos intuitivos ya practicados, pero no rutinarios (CRPn1) y razona matemáticamente de manera simple (CAn1).

Como la recta tangente en $x=0$ es la recta $y+1=0$, por tanto, la pendiente de la recta tangente es $m=0$.

Dado que la derivada, evaluada en el punto, es la pendiente de la recta tangente a la curva, en dicho punto, se tiene $f^{\prime}(0)=0$.

Como la recta tangente en $x=1$ es la recta $x-y-2=0$, la pendiente de la recta tangente, en ese punto, es $m=1$.

Dado que la derivada, evaluada en el punto, es la pendiente de la recta tangente a la curva, en dicho punto, se tiene $f^{\prime}(1)=1$.

La gráfica de la función pasa por los puntos $(0,-1)$ y $(1,-1)$, de lo que se deduce que

$$
f(0)=-1 \text { y } f(1)=-1
$$

El alumno sabe expresarse sobre cuestiones matemáticas (CCn1), comprende que tiene que emplear conceptos matemáticos intermedios (CPRn2), -la función derivada-, seguir el encadenamiento de argumentos matemáticos particulares (CAn2) y explica los cálculos y sus propiedades (CCn2), a la par que maneja afirmaciones sencillas y expresiones con símbolos y fórmulas no rutinarias (CLSOn2).

$$
f^{\prime}(x)=3 a x^{2}+2 b x+c
$$

Sustituyendo, obtiene el sistema de ecuaciones:

$$
\begin{gathered}
f^{\prime}(0)=c=0 \\
f^{\prime}(1)=3 a+2 b+c=1 \\
f(0)=d=-1 \\
f(1)=a+b+c+d=-1
\end{gathered}
$$


El alumno utiliza derivadas (cálculo), resuelve un sistema de ecuaciones (álgebra) con lo que elige y aplica las estrategias apropiadas más independientes que conexionen áreas matemáticas (CRPn2, CRPn3), interpretando las relaciones implicadas (CCn3).

Aplica los conceptos matemáticos apropiados (CPRn3), sabe expresarse sobre cuestiones matemáticas (CCn1), explica los cálculos y sus propiedades (CCn2) e interpreta las relaciones implicadas (CCn3).

Mediante el manejo de fórmulas, resolviendo y calculando (RLSOn3), obtiene los valores:

$$
\begin{gathered}
a=1, b=-1, c=0 \text { y } d=-1 \\
f(x)=x^{3}-x^{2}-1
\end{gathered}
$$

Concluye describiendo los resultados obtenidos (RCn3) y comunicando de manera elemental los resultados del modelo (RMn3).

Interpreta el lenguaje formal y simbólico básico, en situaciones menos conocidas (CLSOn1), maneja afirmaciones sencillas y expresiones con símbolos $y$ fórmulas no rutinarias (CLSOn2) y utiliza variables y realiza cálculos mediante procedimientos familiares (CLSOn3).

\begin{tabular}{|l|c|c|c|c|c|c|c|c|}
\hline \multicolumn{7}{|l|}{ FICHA 2.71.2. COMPETENCIAS IMPLíCITAS EN LA RESOLUCIÓN DE LA C71 } \\
\hline & Nivel 1 & Nivel 2 & Nivel 3 & Nivel 1 & Nivel 2 & Nivel 3 & Nivel 1 & Nivel 2 \\
\hline PR & & & & $*$ & $*$ & $*$ & & \\
\hline A & & & & $*$ & $*$ & & & \\
\hline C & & & $*$ & $*$ & $*$ & $*$ & & \\
\hline M & & & $*$ & $*$ & & & & \\
\hline RP & & & & $*$ & $*$ & $*$ & & \\
\hline R & & & & & & & & \\
\hline LSO & & & $*$ & $*$ & $*$ & $*$ & & \\
\hline & \multicolumn{2}{|l|}{ Reproducción } & & \multicolumn{7}{c|}{ Conexión } & & Reflexión \\
\hline
\end{tabular}

\section{ANÁLISIS DE LA CUESTIÓN C72}

La cuestión de la ficha 2.72.1 es un ejercicio en el que hay que utilizar la regla de L'Hôpital para su resolución, es pues un ejercicio de reproducción. 


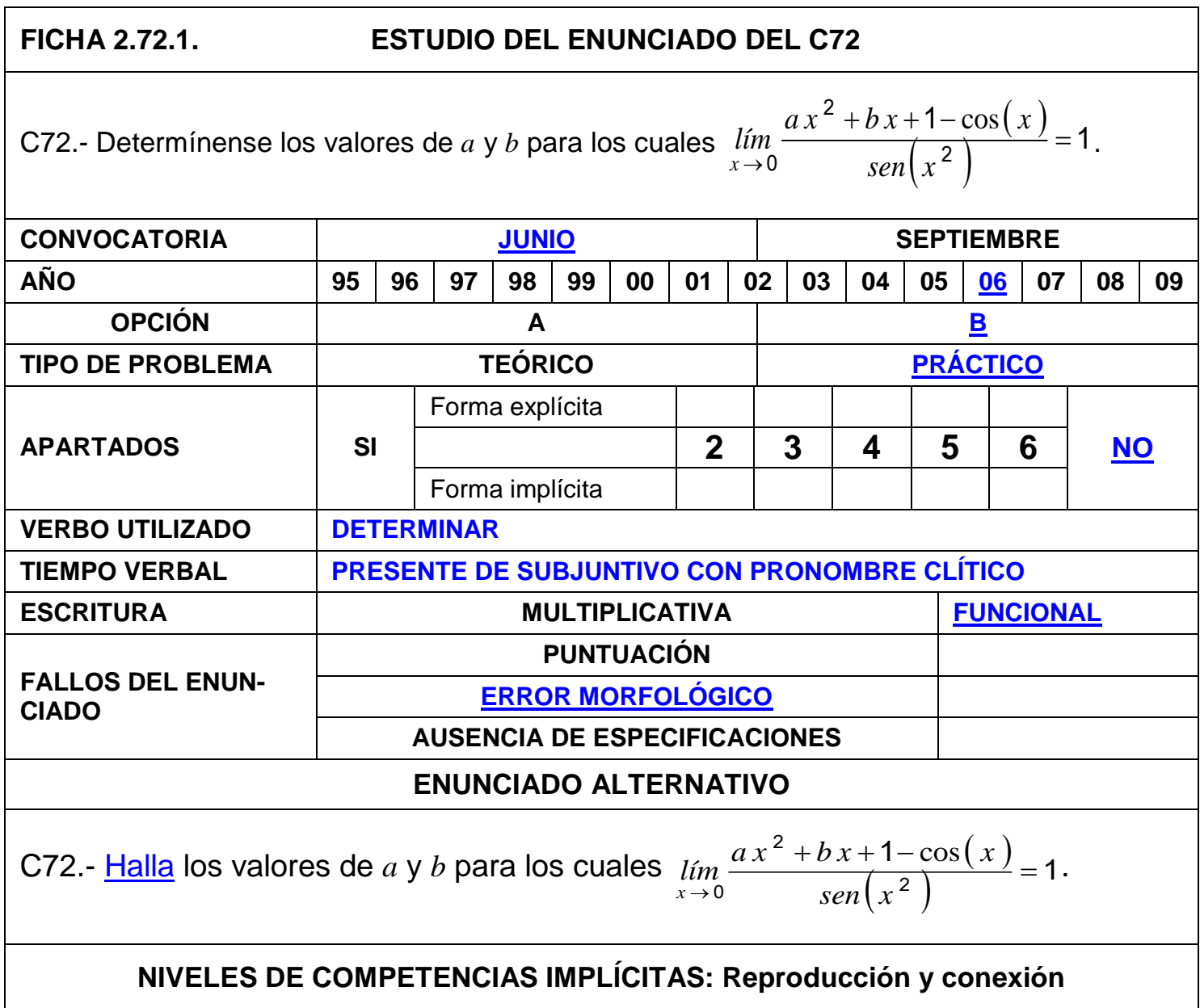

Al ser un límite que depende de parámetros, también se encuadra en el nivel de conexión, dado que es un problema que reproduce situaciones similares, pero que no son de mera rutina.

Con este razonamiento identifica el problema (RAn1), comprende la expresión escrita (RCn1), reconoce representaciones de los datos del ejercicio (RPRn1), identifica que es un modelo similar a otros vistos con anterioridad, (RMn1) y le reconoce como problema ya practicado (RRPn1).

Cuando $\quad x \rightarrow 0, \quad a x^{2}+b x \rightarrow 0, \quad y \quad \cos (x) \rightarrow 1$, por lo que $a x^{2}+b x+1-\cos (x) \rightarrow 0$ y, como $\operatorname{sen}\left(x^{2}\right) \rightarrow 0$, cuando, $x \rightarrow 0$, Se trata, pues, de una indeterminación del tipo $\frac{\rightarrow 0}{\rightarrow 0}$.

El alumno plantea los algoritmos correspondientes (RPRn2), -utilizamos la regla de L'Hôpital-.

Expone el proceso de cálculo (RAn2), realizando explicaciones sencillas (RCn2), asocia con fórmulas establecidas y realiza los cálculos (RPRn3), 


$$
\lim _{x \rightarrow 0} \frac{a x^{2}+b x+1-\cos (x)}{\operatorname{sen}\left(x^{2}\right)}=\text { Regla de L'Hôpital }=\lim _{x \rightarrow 0} \frac{2 a x+b+\operatorname{sen}(x)}{2 x \cos \left(x^{2}\right)}=
$$

Si $b \neq 0$ el límite es $\infty$, pues el denominador $2 x \cos \left(x^{2}\right) \rightarrow 0$, mientras el numerador no tiende a 0 , justifica las fórmulas utilizadas y los resultados (RAn3).

Por tanto, para que ese límite pueda valer $1, b=0$

Utilizando la regla de L'Hôpital $=\lim _{x \rightarrow 0} \frac{2 a+\cos (x)}{2 \cos \left(x^{2}\right)-4 x^{2} \operatorname{sen}\left(x^{2}\right)}==\frac{2 a+1}{2}$

El alumno maneja procedimientos resolviendo y calculando (RLSOn3) y resuelve problemas rutinarios estandarizados (RRPn3) y describe los resultados obtenidos (RCn3), comunicando de manera elemental los resultados del modelo (RMn3).

Ahora hay que obtener el valor de a para que se cumpla una igualdad, con lo que piensa en el tratamiento matemático necesario (CPRn1), comprende que tiene que emplear conceptos matemáticos intermedios y le aplica (CPRn2, CPRn3).

Estructura la situación que debe modelizar (CMn1), traduce en la práctica el modelo a seguir, que es algo diferente de los estudiados (CMn2).

Como el enunciado dice que el límite vale 1, tenemos:

$$
\frac{2 a+1}{2}=1 \Rightarrow a=\frac{1}{2}
$$

Por tanto,

$$
\lim _{x \rightarrow 0} \frac{a x^{2}+b x+1-\cos (x)}{\operatorname{sen}\left(x^{2}\right)}=1 \Leftrightarrow a=\frac{1}{2} \text { y } b=0
$$

En este momento razona matemáticamente de manera simple (CAn1), sabe expresarse sobre cuestiones matemáticas (CCn1), explica los cálculos y sus propiedades (CCn2) e interpreta las relaciones implicadas (CCn3).

El alumno desarrolla procedimientos intuitivos ya practicados, pero no rutinarios (CRPn1), elige estrategias apropiadas que conexionen áreas matemáticas (CRPn2) -resolver la ecuación- y las aplica (CRPn3). Asimismo, al calcular las derivadas, utiliza variables y realiza ecuaciones mediante procedimientos familiares (CLSOn3). 


\section{FICHA 2.72.2. COMPETENCIAS IMPLÍCITAS EN LA RESOLUCIÓN DE LA C72}

\begin{tabular}{|l|c|c|c|c|c|c|c|c|}
\hline & Nivel 1 & Nivel 2 & Nivel 3 & Nivel 1 & Nivel 2 & Nivel 3 & Nivel 1 & Nivel 2 \\
\hline PR & $*$ & $*$ & $*$ & $*$ & $*$ & $*$ & & \\
\hline A & $*$ & $*$ & $*$ & $*$ & & & & \\
\hline C & $*$ & $*$ & $*$ & $*$ & $*$ & $*$ & & \\
\hline M & $*$ & & $*$ & $*$ & $*$ & & & \\
\hline RP & $*$ & & $*$ & $*$ & $*$ & $*$ & & \\
\hline R & & & & & & & & \\
\hline LSO & & & $*$ & & & $*$ & & \\
\hline
\end{tabular}

\section{ANÁLISIS DE LA CUESTIÓN C75}

FICHA 2.75.1.

\section{ESTUDIO DEL ENUNCIADO DEL C75}

C75.- ¿Existen máximo y mínimo absolutos de la función $f(x)=\cos (x)+1$ en el intervalo $[0, \pi]$ ? Justifíquese su existencia y calcúlense.

\begin{tabular}{|c|c|c|c|c|c|c|c|c|c|c|c|c|}
\hline CONVOCATORIA & \multicolumn{6}{|c|}{ JUNIO } & \multicolumn{6}{|c|}{ SEPTIEMBRE } \\
\hline AÑO & \begin{tabular}{l|l}
95 & 96
\end{tabular} & 97 & 98 & 99 & 00 & 01 & 0203 & 04 & 05 & \begin{tabular}{|l|l|}
$\underline{06}$ & 07
\end{tabular} & 08 & 09 \\
\hline OPCIÓN & \multicolumn{6}{|c|}{ A } & \multicolumn{6}{|c|}{ B } \\
\hline TIPO DE PROBLEMA & \multicolumn{6}{|c|}{ TEÓRICO } & \multicolumn{6}{|c|}{ PRÁCTICO } \\
\hline \multirow{3}{*}{ APARTADOS } & \multirow{3}{*}{ SI } & Form & $a \operatorname{expl}$ & lícita & & & & & & & \multirow{3}{*}{\multicolumn{2}{|c|}{ No }} \\
\hline & & & & & & 2 & 3 & 4 & 5 & 6 & & \\
\hline & & Form & a impl & lícita & & & & & & & & \\
\hline VERBO UTILIZADO & \multicolumn{12}{|c|}{ JUSTIFICAR I CALCULAR } \\
\hline TIEMPO VERBAL & \multicolumn{12}{|c|}{ PRESENTE DE SUBJUNTIVO CON PRONOMBRE CLÍTICO } \\
\hline ESCRITURA & \multicolumn{8}{|c|}{ MULTIPLICATIVA } & \multicolumn{4}{|c|}{ FUNCIONAL } \\
\hline \multirow{3}{*}{$\begin{array}{l}\text { FALLOS DEL ENUN- } \\
\text { CIADO }\end{array}$} & \multicolumn{8}{|c|}{ PUNTUACIÓN } & & & & \\
\hline & \multicolumn{8}{|c|}{ ERROR MORFOLÓGICO } & & & & \\
\hline & \multicolumn{8}{|c|}{ AUSENCIA DE ESPECIFICACIONES } & & & & \\
\hline \multicolumn{13}{|c|}{ ENUNCIADO ALTERNATIVO } \\
\hline \multicolumn{13}{|c|}{ C75.- Considerada la función $f(x)=\cos (x)+1$ en el intervalo $[0, \pi]$} \\
\hline
\end{tabular}

NIVELES DE COMPETENCIAS IMPLÍCITAS: Reproducción

La cuestión de la ficha 2.75.1 es un ejercicio de reproducción. 
El alumno comprende la expresión escrita ( $\mathrm{RCn} 1)$, reconoce representaciones de los datos del ejercicio (RPRn1), identifica que el modelo es similar a otros vistos con anterioridad (RMn1) y reconoce el problema como practicado durante la instrucción (RRPn1).

Comienza con la identificación del problema (RAn1) y continúa con la exposición del proceso de cálculo (RAn2).

La función $f(x)=\cos (x)+1$ es continua en todos los números reales $\mathrm{y}$, en particular, en el intervalo cerrado $[0, \pi]$.

Por el teorema de Weierstrass alcanza el máximo y el mínimo absoluto en ese intervalo.

Con este razonamiento, el alumno realiza explicaciones sencillas (RCn2), reproduce problemas ya practicados de manera cerrada (RRPn2), plantea los algoritmos correspondientes (RPRn2), asocia con fórmulas establecidas y realiza los cálculos (RPRn3).

Derivando

$$
f^{\prime}(x)=-\operatorname{sen}(x) .
$$

Resolviendo la ecuación

$$
-\operatorname{sen}(x)=0
$$

En el intervalo $[0, \pi]$, se obtienen las soluciones

$$
x=0, x=\pi
$$

Estudiamos el signo de la segunda derivada en esos puntos obtenidos.

$$
\begin{gathered}
f^{\prime \prime}(x)=-\cos (x) \\
f^{\prime \prime}(0)<0 \Rightarrow x=0 \text { es un máximo relativo. } \\
f^{\prime \prime}(\pi)>0 \Rightarrow x=\pi \text { es un mínimo relativo. }
\end{gathered}
$$

El alumno tiene una función definida analíticamente, que es preciso interpretar, seleccionar y cambiar entre diferentes formas de interpretación (CRn1, CRn2), analítica y gráficamente, diferenciando entre ambas formas de representación (CRn3). Figura 2.75. 
Estos valores coinciden con los extremos del intervalo, luego los valores obtenidos son también máximo y mínimo absolutos.

Calculando los valores de la función en esos puntos

$$
\begin{gathered}
f(0)=2, f(\pi)=0 \\
\text { Máximo absoluto }(0,2) \\
\text { Mínimo absoluto }(\pi, 0)
\end{gathered}
$$

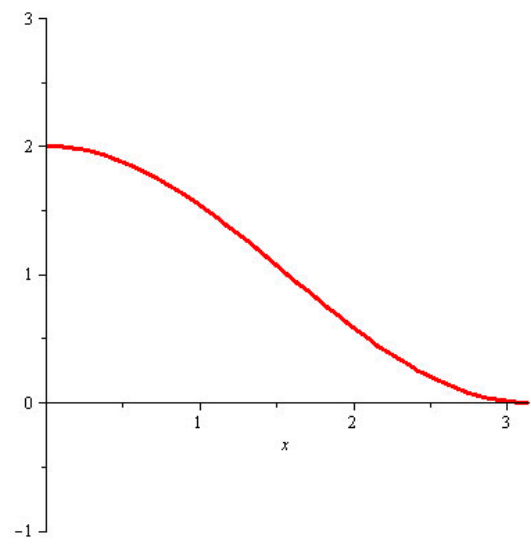

Figura 2.75

Asimismo calcula derivadas, utiliza varia-

bles y realiza cálculos mediante procedimientos familiares (CLSOn3), en Segundo de Bachillerato, maneja procedimientos y fórmulas, resolviendo y calculando (RLSOn3), reproduce el ejercicio de manera cerrada (RRPn2) y le resuelve (RRPn3), justificando las fórmulas utilizadas y los resultados (RAn3).

Finalmente, describe los resultados obtenidos (RCn3) y comunica de manera elemental los resultados del modelo (RMn3).

\section{FICHA 2.75.2. COMPETENCIAS IMPLÍCITAS EN LA RESOLUCIÓN DE LA C75}

\begin{tabular}{|l|c|c|c|c|c|c|c|c|}
\hline & Nivel 1 & Nivel 2 & Nivel 3 & Nivel 1 & Nivel 2 & Nivel 3 & Nivel 1 & Nivel 2 \\
\hline PR & $*$ & $*$ & $*$ & & & & & \\
\hline A & $*$ & $*$ & $*$ & & & & & \\
\hline C & $*$ & $*$ & $*$ & & & & & \\
\hline M & $*$ & & $*$ & & & & & \\
\hline RP & $*$ & $*$ & $*$ & & & & & \\
\hline R & & & & $*$ & $*$ & $*$ & & \\
\hline LSO & & & $*$ & & & $*$ & & \\
\hline
\end{tabular}

\section{ANÁLISIS DE LA CUESTIÓN C97}

La cuestión de la ficha 2.97.1 reproduce situaciones similares a las estudiadas en clase, pero no son de mera rutina, por tanto se trata de un nivel de conexión. 


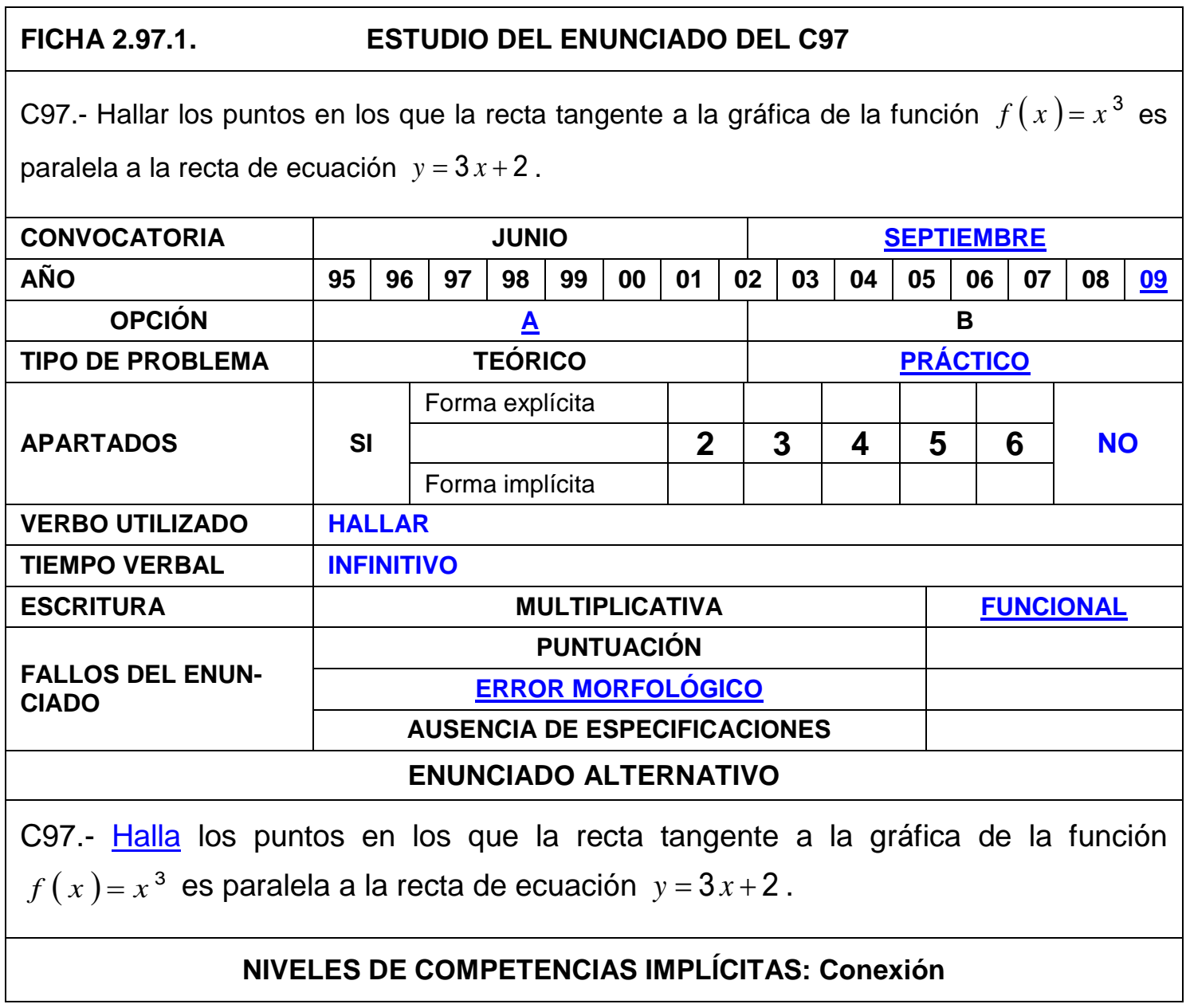

Para obtener los puntos pedidos, el alumno tiene que pensar en el tratamiento matemático necesario (CPRn1), desarrollar procedimientos intuitivos ya practicados, pero no rutinarios (CRPn1) y estructurar la situación que debe modelizar (CMn1).

El alumno comprende que tiene que emplear conceptos matemáticos intermedios (CPRn2) y aplica los conceptos matemáticos apropiados (CPRn3).

Calcula la función derivada:

$$
f^{\prime}(x)=3 x^{2}
$$

En los puntos buscados, la recta tangente es paralela a la recta $y=3 x+2$, luego tienen la misma pendiente $m=3$.

La función derivada, evaluada en el punto, es la pendiente de la recta tangente, por tanto hay que resolver la ecuación $3 x^{2}=3$

Al resolver la ecuación el alumno maneja procedimientos y fórmulas, resolviendo y calculando (RLSOn3), obteniendo las soluciones 


$$
x_{1}=-1 \text { y } \quad x_{2}=1
$$

Con este discurso el alumno sabe expresarse sobre cuestiones matemáticas (CCn1), explica los cálculos y sus propiedades (CCn2) e interpreta las relaciones implicadas (CCn3), a la par que interpreta y alterna diferentes modelos, comunicando los resultados (CMn3).

El alumno elige las estrategias apropiadas más independientes que conexionen áreas matemáticas (CRPn2); la resolución de la ecuación (álgebra) y el cálculo de la función derivada (análisis) y aplica las estrategias apropiadas (CRPn3).

Los puntos se obtienen sustituyendo los valores obtenidos de $x$, en la función.

El alumno razona matemáticamente de manera simple (CAn1), sigue el encadenamiento de argumentos matemáticos particulares (CAn2).

$$
\begin{array}{cl}
f(1)=1 & \Rightarrow P_{1}=(1,1) \\
f(-1)=-1 & \Rightarrow \quad P_{2}=(-1,-1)
\end{array}
$$

Con este razonamiento, evalúa el encadenamiento de argumentos matemáticos particulares (CAn3) e interpreta las relaciones implicadas (CCn3).

Se tiene una función definida analíticamente, que es preciso interpretar, seleccionar $y$ cambiar entre diferentes formas de representación (CRn1, CRn2), analítica y gráfi-

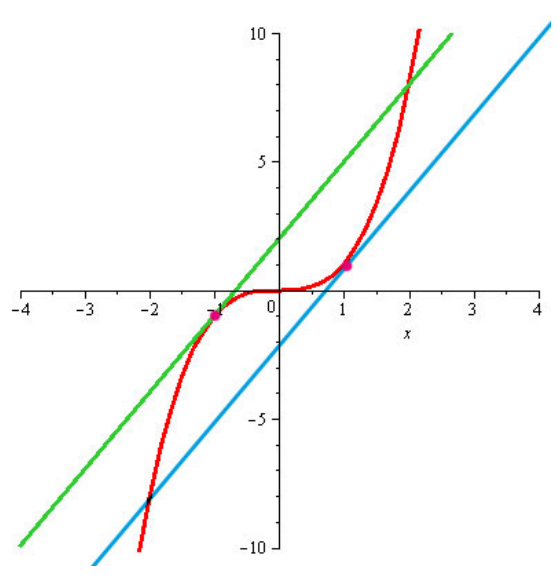

Figura 2.97 camente, diferenciando entre ambas formas de representación (CRn3). Figura 2.97 .

\begin{tabular}{|l|c|c|c|c|c|c|c|c|}
\hline \multicolumn{7}{|l|}{ FICHA 2.97.2. COMPETENCIAS IMPLíCITAS EN LA RESOLUCIÓN DE LA C97 } \\
\hline & Nivel 1 & Nivel 2 & Nivel 3 & Nivel 1 & Nivel 2 & Nivel 3 & Nivel 1 & Nivel 2 \\
\hline PR & & & & $*$ & $*$ & $*$ & & \\
\hline A & & & & $*$ & $*$ & $*$ & & \\
\hline C & & & & $*$ & $*$ & $*$ & & \\
\hline M & & & & $*$ & & & & \\
\hline RP & & & & $*$ & $*$ & $*$ & & \\
\hline R & & & & $*$ & $*$ & $*$ & & \\
\hline LSO & & & $*$ & & & $*$ & & \\
\hline & \multicolumn{2}{|l|}{ Reproducción } & & \multicolumn{7}{|c|}{ Conexión } & & Reflexión \\
\hline
\end{tabular}




\section{ANÁLISIS DE LA CUESTIÓN C99}

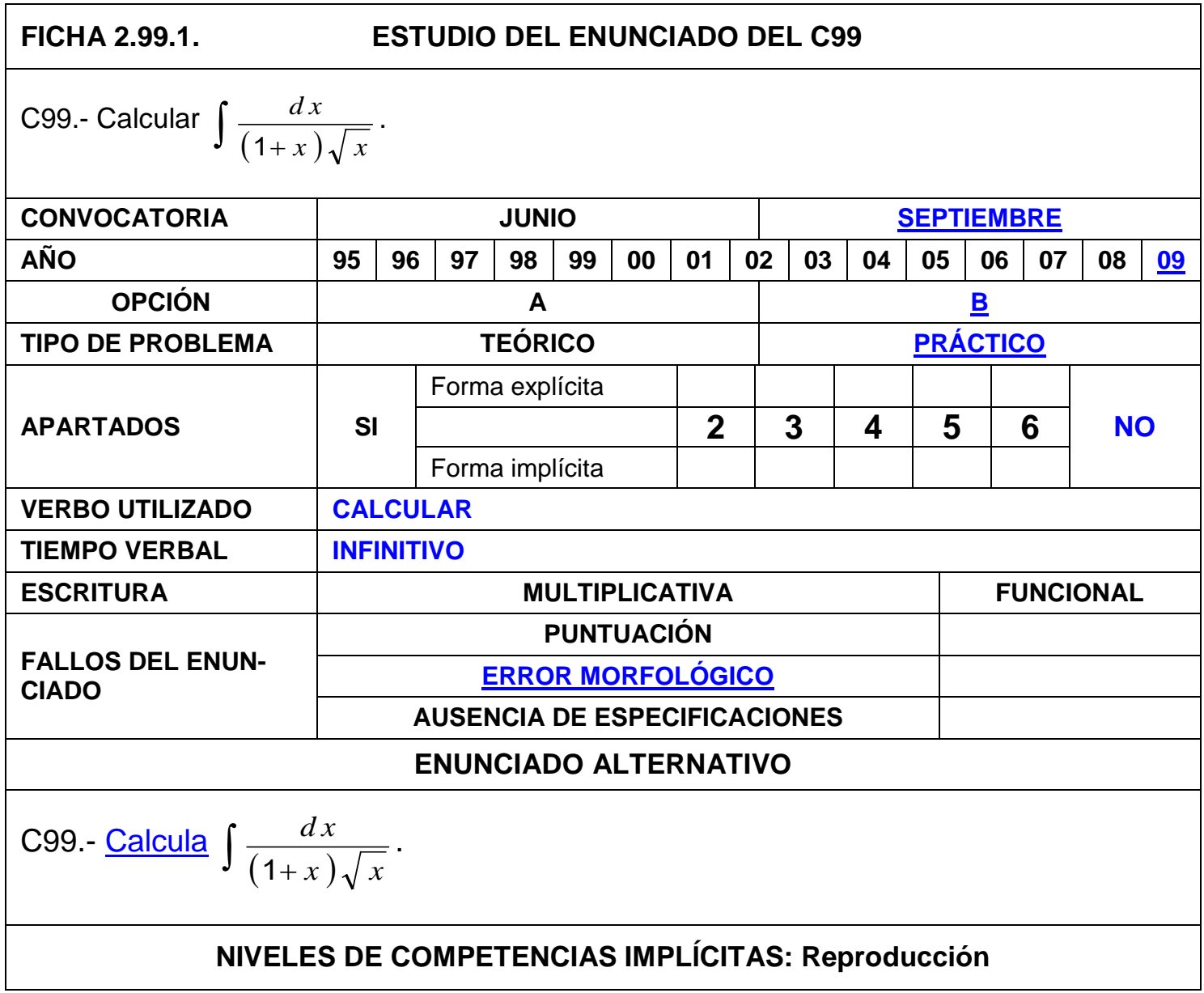

La cuestión de la ficha 2.99.1 es un ejercicio de reproducción del conocimiento estudiado, reconocimiento de equivalentes, ejecución de problemas rutinarios, aplicación de destrezas técnicas y de algoritmos habituales, manejo de expresiones y fórmulas establecidas y realización de cálculos.

Hay que calcular una integral indefinida $\int \frac{d x}{(1+x) \sqrt{x}}$

Con este razonamiento, el alumno identifica el problema (RAn1), reconoce representaciones de los datos del ejercicio (RPRn1), comprende la expresión escrita (RCn1), identifica que es un modelo similar a otros vistos con anterioridad (RMn1) y le reconoce como problema ya practicado (RRPn1).

A continuación, plantea los algoritmos correspondientes (RPRn2), expone el proceso de cálculo (RAn2), realizando explicaciones sencillas ( $\mathrm{RCn} 2)$, asocia con fórmulas establecidas y realiza los cálculos (RPRn3), con lo que reproduce problemas ya practicados de manera cerrada (RRPn2). 
Mediante el cambio de variable $\sqrt{x}=t$ se transforma en una integral racional, que es una integral inmediata, de tipo arco tangente

$$
\int \frac{d x}{(1+x) \sqrt{x}} \stackrel{(1)}{=} \int \frac{2 t d t}{t\left(1+t^{2}\right)}=\int \frac{2 d t}{1+t^{2}}=2 \operatorname{arctg}(t) \stackrel{(2)}{=} 2 \operatorname{arctg}(\sqrt{x})+C
$$

(1) Cambio de variable

(2) Deshaciendo el cambio de variable

$$
\int \frac{d x}{(1+x) \sqrt{x}}=2 \operatorname{arctg}(\sqrt{x})+C
$$

El alumno, al calcular la integral, realiza cálculos mediante procedimientos familiares (CLSOn3) resuelve problemas rutinarios estandarizados (RRPn3), justifica las fórmulas utilizadas y los resultados (RAn3), describe los resultados obtenidos (RCn3), comunicando de manera elemental los resultados del modelo (RMn3).

\begin{tabular}{|l|c|c|c|c|c|c|c|c|}
\hline \multicolumn{6}{|c|}{ FICHA 2.99.2. COMPETENCIAS IMPLÍCITAS EN LA RESOLUCIÓN DE LA C99 } \\
\hline & Nivel 1 & Nivel 2 & Nivel 3 & Nivel 1 & Nivel 2 & Nivel 3 & Nivel 1 & Nivel 2 \\
\hline PR & $*$ & $*$ & $*$ & & & & & \\
\hline A & $*$ & $*$ & $*$ & & & & & \\
\hline C & $*$ & $*$ & $*$ & & & & & \\
\hline M & $*$ & & $*$ & & & & & \\
\hline RP & $*$ & $*$ & $*$ & & & & & \\
\hline R & & & & & & & & \\
\hline LSO & & & & & & $*$ & & \\
\hline & Reproducción & & Conexión & & Reflexión \\
\hline
\end{tabular}

\section{IV.4. REFLEXIÓN DEL ANÁLISIS SOBRE LAS PAEU DE ANÁ- LISIS MATEMÁTICO}

Se concluye el capítulo con dos tablas que resumen las competencias implícitas presentes en la resolución de los 61 problemas y 99 cuestiones de A. M. propuestos durante los quince años de Pruebas LOGSE. 


\begin{tabular}{|c|c|c|c|c|c|c|c|c|}
\hline \multicolumn{9}{|c|}{$\begin{array}{l}\text { NIVELES DE COMPETENCIAS IMPLÍCITAS } \\
\text { PROBLEMAS DE ANÁLISIS MATEMÁTICO }\end{array}$} \\
\hline & Nivel 1 & Nivel 2 & Nivel 3 & Nivel 1 & Nivel 2 & Nivel 3 & Nivel 1 & Nivel 2 \\
\hline PR & 17 & 22 & 22 & 60 & 58 & 59 & 0 & 7 \\
\hline A & 41 & 39 & 40 & 58 & 48 & 46 & 12 & 3 \\
\hline $\mathrm{C}$ & 15 & 16 & 43 & 59 & 59 & 60 & 9 & 4 \\
\hline$M$ & 34 & 0 & 45 & 57 & 51 & 30 & 0 & 2 \\
\hline RP & 35 & 24 & 33 & 56 & 38 & 40 & 2 & 0 \\
\hline $\mathbf{R}$ & 2 & 7 & 0 & 55 & 43 & 36 & 0 & 0 \\
\hline LSO & 2 & 10 & 50 & 54 & 52 & 58 & 0 & 1 \\
\hline & \multicolumn{3}{|c|}{ Reproducción: 497} & \multicolumn{3}{|c|}{ Conexión: 1077} & \multicolumn{2}{|c|}{ Reflexión: 40} \\
\hline
\end{tabular}

Los problemas propuestos presentan varios apartados, por esa razón están ubicados en los niveles de reproducción y conexión, ya que alguno de los apartados pertenece a uno u otro nivel. En general, los subniveles 1,2 y 3 son semejantes en las distintas competencias, por esta circunstancia tan solo referimos los que presentan disparidad de resultados.

El subnivel 2 del nivel reproducción, en la competencia de Modelizar, no se presenta nunca, pues corresponde a la modelización de la realidad y en ningún ejercicio se plantea esta situación.

En el nivel de reproducción de la competencia Representar, el subnivel 2 sólo aparece en 7 ocasiones, las que se refieren a interpretar el enunciado de un teorema o propiedad, solicitado en algún apartado de los 7 problemas. No aparece ningún otro subnivel. Muchos ejercicios requieren una representación gráfica y en otros ésta ha complementado la resolución y se ha considerado en el nivel de conexión, dado que su frecuencia de aparición no lleva aparejada un simple automatismo.

Concerniente a Utilizar el lenguaje simbólico, formal y técnico, y las operaciones, en el nivel de reproducción, el alumno realiza operaciones elementales en contextos conocidos (operaciones aritméticas) (RLSOn1), interpreta el lenguaje formal y simbólico rutinario en segundo de bachillerato (RLSOn2) resolviendo ecuaciones, pero se han considerado en un subnivel superior (RLSOn3), en el que genéricamente están implícitos el subnivel 1 y 2; pues el alumno maneja procedimientos y fórmulas resolviendo y calculando. 
Por tanto, dentro de un nivel de conexión, se encuentran la mayoría de los problemas de A.M., pues el cálculo de límites, derivadas, integrales, aún siendo conceptos conocidos por un alumno de segundo de bachillerato, se encuadran en esos subniveles, en los que el alumno interpreta el lenguaje formal y simbólico básico en situaciones menos conocidas (CLSOn1), maneja afirmaciones sencillas y expresiones con símbolos y fórmulas no rutinarias (CLSOn2) y, finalmente, el alumno utiliza variables y realiza ecuaciones y cálculos mediante procedimientos familiares, en segundo de Bachillerato (CLSOn3).

En cuanto a la competencia de Resolución de problemas el subnivel 1 de la competencia de conexión es el que tiene mayor frecuencia de aparición, pues el alumno desarrolla procedimientos ya practicados durante la instrucción, pero no son rutinarios ya que cada uno de ellos (límite, derivada, integral) tiene una propiedad.

El nivel de reflexión se presenta en escasas ocasiones y vienen generados por la actitud con la que el alumno puede resolver el ejercicio, ya que es éste el que razona de forma sencilla distinguiendo formas más amplias de argumentación (RfAn1), ampliando la simple exposición del resultado con argumentos de nivel superior. Es obvio que el alumno sabe explicar esos argumentos, con lo que sabe explicar cuestiones matemáticas,cálculos y resultados (RfCn1).

\begin{tabular}{|l|c|c|c|c|c|c|c|c|}
\hline \multicolumn{7}{|c|}{$\begin{array}{c}\text { NIVELES DE COMPETENCIAS IMPLÍCITAS } \\
\text { CUESTIONES DE ANÁLISIS MATEMÁTICO }\end{array}$} \\
\hline & Nivel 1 & Nivel 2 & Nivel 3 & Nivel 1 & Nivel 2 & Nivel 3 & Nivel 1 & Nivel 2 \\
\hline PR & 67 & 63 & 68 & 37 & 35 & 37 & 0 & 0 \\
\hline A & 76 & 77 & 77 & 35 & 21 & 17 & 3 & 0 \\
\hline C & 67 & 68 & 77 & 38 & 36 & 36 & 3 & 1 \\
\hline M & 76 & 0 & 86 & 35 & 30 & 11 & 0 & 0 \\
\hline RP & 76 & 62 & 74 & 35 & 14 & 20 & 1 & 0 \\
\hline R & 0 & 2 & 0 & 28 & 27 & 17 & 0 & 0 \\
\hline LSO & 1 & 4 & 60 & 20 & 21 & 80 & 0 & 0 \\
\hline & Reproducción: 1081 & Conexión: 630 & Reflexión: 8 \\
\hline
\end{tabular}

En lo relativo a las cuestiones de $\mathrm{A}$. M. lo que cabe destacar es el número de veces que se presenta el nivel de reproducción, abundan los ejercicios en los que se pide el cálculo de un límite (21 cuestiones) y dado que el alumno no uti- 
liza más método que la regal de L'Hôpital, al haber sido eliminado del currículo los infinitésimos equivalentes, son meras representaciones de problemas comunes que se resuelven con la aplicación de destrezas técnicas y algoritmos habituales.

Los dos ejercicios que tienen niveles de reflexión están reflejados en las fichas 2.11.1 y 2.43.1. La ficha 2.11 presenta un enunciado tan engorroso de entender que esa es la principal razón para que su resolución alcance el nivel 3 de Reflexión. La cuestión 2.43 es sencilla, es el cálculo del límite de un cociente de funciones que alcanza el nivel de reflexión si el alumno observa los órdenes de infinitud de numerador y denominador.

La lectura de las tablas avala nuestras hipótesis H4: Los niveles de reproducción son los que más se repiten y H5: Apenas se presentan niveles de reflexión. 


\section{CAPÍTULO V}

\section{ANÁLISIS EN COMPETENCIAS DE LOS ENUNCIADOS DE ÁGEBRA}

\section{V.1 INTRODUCCIÓN}

En este capítulo se hace el estudio de una selección de los 28 problemas y de las 57 cuestiones de Álgebra que se han propuesto en las pruebas PAEU en el periodo comprendido entre 1995 y 2009. La selección se hace tomando como parámetro la variedad de los enunciados, ya que la repetición es la característica más destacada en los ejercicios propuestos en Álgebra. En la mayoría de los problemas se pide el estudio y resolución de un sistema de ecuaciones lineales, dependiente de un parámetro y en cuestiones los ejercicios en los que se pide la resolución de un sistema matricial.

La técnica del análisis es la misma que se ha descrito en el capítulo precedente en el que se han considerado competencias implícitas en cada uno de los enunciados y competencias en la resolución. Siguiendo el mismo patrón se resuelven todos los problemas y todas las cuestiones (recogidos en los anexos III y IV) y a la vez se van fijando las competencias correspondientes.

\section{V.2. ESTUDIO DE LOS PROBLEMAS DE ÁLGEBRA}

Los problemas de álgebra son muy repetitivos. El estudio del sistema lineal corresponde a un nivel de conexión por la presencia de parámetros lo que hace que aún siendo ejercicios que se repiten durante la instrucción en el aula no sean una rutina, pues el estudio es diferente. La resolución del sistema lineal, de a lo sumo tres ecuaciones y tres incógnitas, para unos coeficientes determinados, corresponde a un nivel de reproducción. 


\section{ANÁLISIS DEL PROBLEMA P1}

\section{FICHA 3.1.1. \\ ESTUDIO DEL ENUNCIADO DEL P1}

P1.- Discutir, según los valores de $a$ y $b$, y resolver cuando sea posible el sistema

$$
\left\{\begin{array}{c}
2 x-5 y+a z=-2 \\
3 x-y+2 z=1 \\
x+4 y+z=b
\end{array}\right.
$$

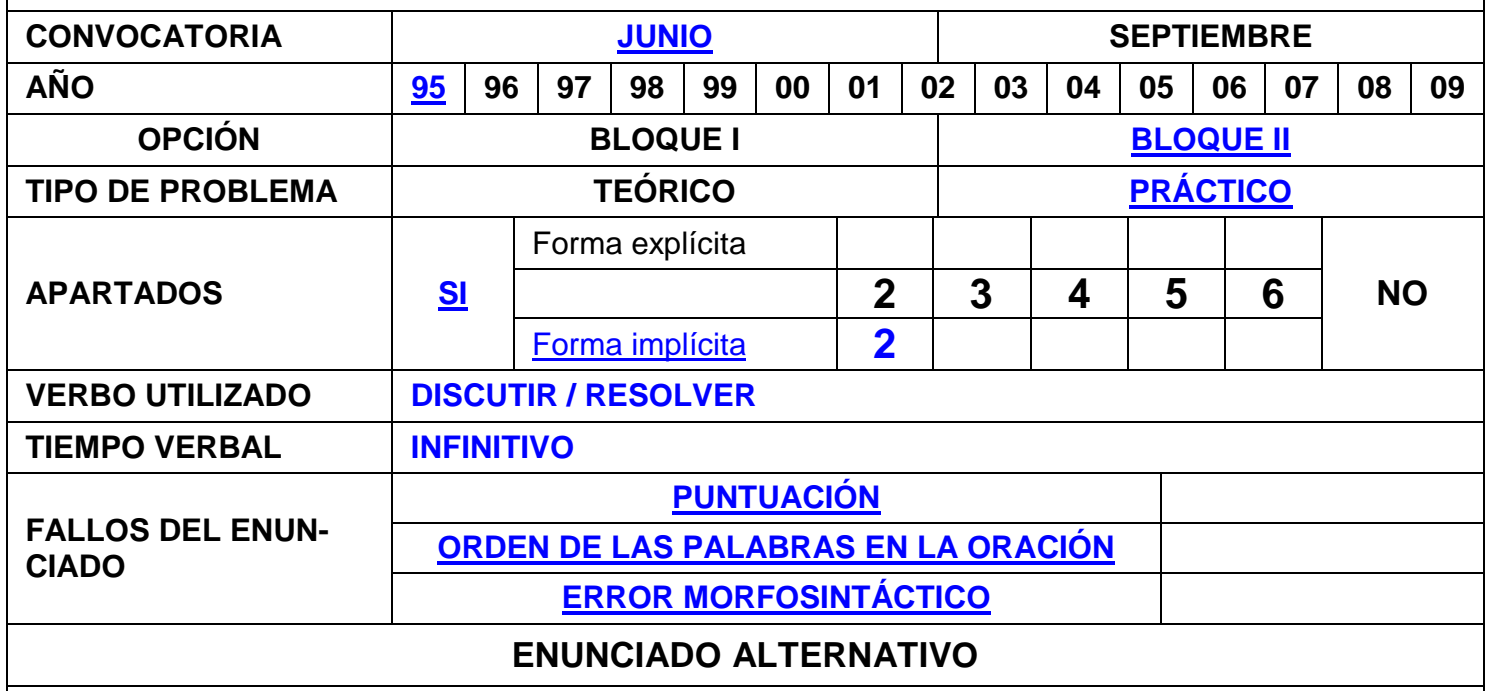

P1.- Discute el sistema, según los valores de $a$ y $b$ :

$$
\left\{\begin{array}{c}
2 x-5 y+a z=-2 \\
3 x-y+2 z=1 \\
x+4 y+z=b
\end{array}\right.
$$

b) Resuelve el sistema, cuando sea posible.

\section{NIVELES DE COMPETENCIAS IMPLÍCITAS: Reproducción y conexión}

El problema que se presenta en la ficha 3.1.1 se encuadra en los niveles de reproducción y conexión pues pide estudiar las características de una familia de sistemas, uno para cada valor de cada parámetro. En realidad son infinitos sistemas que dependen de dos parámetros, y este es un problema que reproduce situaciones similares pero que ya no son de mera rutina, y a continuación hay que resolver ese sistema lo que corresponde al nivel de reproducción del conocimiento estudiado, es la ejecución de un problema rutinario, mediante la aplicación de destrezas técnicas y de algoritmos habituales, manejando expresiones y fórmulas establecidas y realizando cálculos, -el desarrollo de varios determinantes, si utiliza la regla de Cramer-. 
El alumno tiene que pensar en el tratamiento matemático necesario (CPRn1), escribir las matrices de los coeficientes del sistema y la matriz ampliada con los términos independientes-.

Matriz de coeficientes: $M=\left(\begin{array}{rrr}2 & -5 & a \\ 3 & -1 & 2 \\ 1 & 4 & 1\end{array}\right)$

Matriz ampliada: $M *=\left(\begin{array}{rrrr}2 & -5 & a & -2 \\ 3 & -1 & 2 & 1 \\ 1 & 4 & 1 & b\end{array}\right)$

El alumno razona matemáticamente de manera simple (CAn1), -el estudio del sistema se reduce al estudio de los rangos de la matriz de coeficientes y de la matriz ampliada- y estructura la situación que debe modelizar (CMn1).

Para estudiar el rango de las matrices se resuelve el determinante:

$$
\left|\begin{array}{rrr}
2 & -5 & a \\
3 & -1 & 2 \\
1 & 4 & 1
\end{array}\right|=13 a-13
$$

El alumno desarrolla procedimientos intuitivos ya practicados, pero no rutinarios (CRPn1). Al calcular el determinante, comprende que tiene que emplear conceptos matemáticos intermedios (CPRn2) y aplica los conceptos matemáticos apropiados (CPRn3).

Resuelve la ecuación: $13 a-13=0$, con lo que maneja procedimientos y fórmulas, resolviendo y calculando (RLSOn3), obteniendo la solución:

$$
a=1
$$

Si $a \neq 1$ el rango de la matriz de coeficientes $M$ es $3 ; \operatorname{rango}(M)=3$

Dado que la matriz ampliada $M *$ sólo tiene tres filas, el rango de $M *$ sólo puede ser $3, \operatorname{rango}(M *)=3$

Con ese argumento, el alumno sigue y evalúa el encadenamiento de argumentos matemáticos particulares (CAn2, CAn3).

Si $a \neq 1, \forall b, \operatorname{rango}(M)=\operatorname{rango}(M *)=3=$ número de incógnitas 
Por el teorema de Rouché-Frobenius,

Si $a \neq 1, \forall b$, el sistema es compatible determinado.

Explica los cálculos y sus propiedades (CCn2) e interpreta las relaciones implicadas (CCn3).

Si $a=1, \operatorname{rango}(M)=2$ el, pues el menor $\left|\begin{array}{cc}2 & -5 \\ 3 & -1\end{array}\right| \neq 0$

Al hacer las operaciones correspondientes al cálculo de determinantes, el alumno realiza operaciones elementales en contextos conocidos (RLSOn1), interpreta el lenguaje formal y simbólico rutinario (RLSOn2) -en Segundo de Bachiller-, maneja procedimientos y fórmulas resolviendo y calculando (RLSOn3) y utiliza variables y realiza ecuaciones y cálculos mediante procedimientos familiares (CLSOn3).

Se considera que es un nivel de reproducción porque problemas de este tipo se resuelven de forma habitual en el aula.

Estudia el rango de la matriz ampliada, para lo que calcula el valor del determinante:

$$
\left|\begin{array}{rrr}
2 & -5 & -2 \\
3 & -1 & 1 \\
1 & 4 & b
\end{array}\right|=13 b-39
$$

Resolviendo la ecuación: $13 b-39=0$,

$$
\text { obtiene la solución } b=3
$$

El alumno usa un único tipo de representación estándar, ya utilizada (RRn1), la representación algebraica, maneja procedimientos y fórmulas, resolviendo y calculando (RLSOn3) y utiliza variables y realiza ecuaciones y cálculos mediante procedimientos familiares (CLSOn3).

$$
\text { Si } a=1 \text { y } b \neq 3, \operatorname{rango}(M)=2 \text { y } \operatorname{rango}\left(M^{*}\right)=3
$$

El alumno sabe expresarse sobre cuestiones matemáticas (CCn1), sigue el encadenamiento de argumentos matemáticos particulares (CAn2) y evalúa el encadenamiento de argumentos matemáticos particulares (CAn3), explicando los 
cálculos y sus propiedades (CCn2) e interpretando las relaciones implicadas (CCn3).

Según el teorema de Rouché,

Si $a=1$ y $b \neq 3, r g(M) \neq r g(M *)$, el sistema es incompatible.

Si $a=1$ y $b=3, \operatorname{rango}(M)=\operatorname{rango}(M *)=2<n^{\circ}$ de incógnitas,

Si $a=1$ y $b=3$, el sistema es compatible indeterminado.

El apartado b) del problema 3.1.1 corresponde al nivel de reproducción del conocimiento estudiado, es la ejecución de un problema rutinario,-resolver el sistema en el caso $a \neq 1, \forall b-$, mediante la aplicación de destrezas técnicas y de algoritmos habituales, manejando expresiones y fórmulas establecidas y realizando cálculos, -el desarrollo de varios determinantes-.

En realidad se trata de infinitos sistemas de ecuaciones, ya que hay uno por cada valor del parámetro. Sin embargo, hecha esta aclaración, seguimos utilizando el singular, sistema, ya que es el término que se utiliza en todos los enunciados, a sabiendas de que es un término erróneo y los alumnos pueden entenderlo mal, aunque tratan de resolverlo sin pensar en ello, porque es la rutina que se sigue en la clase.

Reconoce representaciones de los datos del ejercicio (RPRn1), -las ecuaciones del sistema-, plantea los algoritmos correspondientes (RPRn2) y asocia con fórmulas establecidas (RPRn3), -consiste en resolver un sistema lineal de tres ecuaciones con tres incógnitas-.

El alumno comprende la expresión escrita ( $\mathrm{RCn} 1)$, identifica el problema (RAn1), identifica que el modelo es similar a otros vistos con anterioridad (RMn1) y le reconoce como problema ya practicado (RRPn1).

Se tiene el sistema dado por las ecuaciones: $\left\{\begin{array}{c}2 x-5 y+a z=-2 \\ 3 x-y+2 z=1 \\ x+4 y+z=b\end{array}\right.$

El alumno expone el proceso de cálculo (RAn2), realiza explicaciones sencillas (RCn2), plantea los algoritmos correspondientes (RPRn2) y reproduce un problema ya practicado, de manera cerrada (RRPn2). 
Resuelve el sistema por el método de Cramer.

Una situación análoga y directamente relacionada con lo anterior es el término solución, ya que en estos casos hay una solución para cada sistema.

Obteniendo como solución:

$$
x=\frac{\left|\begin{array}{rrr}
-2 & -5 & a \\
1 & -1 & 2 \\
b & 4 & 1
\end{array}\right|}{\left|\begin{array}{rrr}
2 & -5 & a \\
3 & -4 & 2 \\
1 & 4 & 1
\end{array}\right|}=\frac{23-10 b+4 a+a b}{13 a-13}
$$

$$
y=\frac{\left|\begin{array}{rrr}
2 & -2 & a \\
3 & 1 & 2 \\
1 & b & 1
\end{array}\right|}{\left|\begin{array}{rrr}
2 & -5 & a \\
3 & -4 & 2 \\
1 & 4 & 1
\end{array}\right|}=\frac{4-4 b-a+3 a b}{13 a-13} ; \quad z=\frac{\left|\begin{array}{rrr}
2 & -5 & -2 \\
3 & -1 & 1 \\
1 & 4 & b
\end{array}\right|}{\left|\begin{array}{rrr}
2 & -5 & a \\
3 & -4 & 2 \\
1 & 4 & 1
\end{array}\right|}=\frac{b-3}{13 a-13}
$$

El alumno realiza cálculos mediante procedimientos familiares (CLSOn3), describe los resultados obtenidos (RCn3), justifica las fórmulas utilizadas y los resultados (RAn3), resuelve problemas rutinarios estandarizados (RRPn3) y comunica de manera elemental los resultados (RMn3).

Como ya se ha estudiado, si $a=1$ y $b=3$, el sistema es compatible indeterminado.

En esta situación se tiene el sistema: $\left\{\begin{array}{c}2 x-5 y+z=-2 \\ 3 x-y+2 z=1 \\ x+4 y+z=3\end{array}\right.$

En este sistema nos encontramos, entre otras, la siguiente combinación lineal, entre filas:

$$
F_{2}-F_{1}=F_{3}
$$

Con esta argumentación, el alumno sabe expresarse sobre cuestiones matemáticas (CCn1) e interpreta las relaciones implicadas (CCn3).

Llamando $z=\lambda$, considera el sistema: 


$$
\left\{\begin{array}{c}
2 x-5 y=-2-\lambda \\
3 x-y=1-2 \lambda
\end{array},\right.
$$

Utilizando la regla de Cramer para su resolución, se obtienen infinitas soluciones:

$$
x=\frac{\left|\begin{array}{cc}
-2-\lambda & -5 \\
1-2 \lambda & -1
\end{array}\right|}{\left|\begin{array}{ll}
2 & -5 \\
3 & -1
\end{array}\right|}=\frac{7}{13}-\frac{9}{13} \lambda ; \quad y=\frac{\left|\begin{array}{cc}
2 & -2-\lambda \\
3 & 1-2 \lambda
\end{array}\right|}{\left|\begin{array}{ll}
2 & -5 \\
3 & -1
\end{array}\right|}=\frac{8}{13}-\frac{\lambda}{13}
$$

El alumno realiza cálculos mediante procedimientos familiares (CLSOn3), describe los resultados obtenidos (RCn3), justifica las fórmulas utilizadas y los resultados (RAn3), resuelve problemas rutinarios estandarizados (RRPn3) у comunica de manera elemental los resultados (RMn3).

\section{FICHA 3.1.2. COMPETENCIAS IMPLÍCITAS EN LA RESOLUCIÓN DEL P1}

\begin{tabular}{|l|c|c|c|c|c|c|c|c|}
\hline & Nivel 1 & Nivel 2 & Nivel 3 & Nivel 1 & Nivel 2 & Nivel 3 & Nivel 1 & Nivel 2 \\
\hline PR & $*$ & $*$ & $*$ & $*$ & $*$ & $*$ & & \\
\hline A & $*$ & $*$ & $*$ & $*$ & $*$ & $*$ & & \\
\hline C & $*$ & $*$ & $*$ & $*$ & $*$ & $*$ & & \\
\hline M & $*$ & & $*$ & $*$ & & & & \\
\hline RP & $*$ & $*$ & $*$ & $*$ & & & & \\
\hline R & $*$ & & & & & & & \\
\hline LSO & $*$ & $*$ & $*$ & & & $*$ & & \\
\hline & \multicolumn{2}{|c|}{${ }^{*}$ *eproducción } & & \multicolumn{2}{c|}{ Conexión } & & \multicolumn{2}{l|}{ Reflexión } \\
\hline
\end{tabular}

\section{ANÁLISIS DEL PROBLEMA P4}

El apartado a) del problema que se presenta en la ficha 3.4.1 se encuadra en el nivel de reproducción del conocimiento estudiado, se trata de la ejecución de un problema rutinario, mediante la aplicación de destrezas técnicas y de algoritmos habituales, manejando expresiones y fórmulas establecidas y realizando cálculos.

El apartado b) del problema que se presenta en la tabla 3.4.1 se encuadra en el nivel de conexión, al tener que hacer una demostración es un problema que reproduce situaciones similares a las estudiadas en la instrucción, pero que no son de mera rutina. 
FICHA 3.4.1.

ESTUDIO DEL ENUNCIADO DEL P4

P4.- a) ¿Es siempre cierta la propiedad conmutativa del producto de matrices? En caso afirmativo probarlo y en caso negativo poner un ejemplo en el que no se verifique.

b) Si $A$ y $B$ son matrices diagonales de orden $2 \times 2$, demostrar que $A B=B A$.

c) Determinar las matrices $2 \times 2$ diagonales $A$ tales que $A A=\left(\begin{array}{ll}1 & 0 \\ 0 & 1\end{array}\right)$

\begin{tabular}{|c|c|c|c|c|c|c|c|c|c|c|c|}
\hline CONVOCATORIA & \multicolumn{5}{|c|}{ JUNIO } & \multicolumn{6}{|c|}{ SEPTIEMBRE } \\
\hline AÑO & \begin{tabular}{l|l}
95 & 96
\end{tabular} & 97 & \begin{tabular}{l|l}
98 & 99
\end{tabular} & 00 & 01 & \begin{tabular}{l|l}
02 & 03
\end{tabular} & 04 & 05 & \begin{tabular}{l|l}
06 & 07
\end{tabular} & 08 & 09 \\
\hline OPCIÓN & \multicolumn{5}{|c|}{$\underline{A 1}$} & \multicolumn{6}{|c|}{ B } \\
\hline TIPO DE PROBLEMA & \multicolumn{5}{|c|}{ TEÓRICO } & \multicolumn{6}{|c|}{ PRÁCTICO } \\
\hline \multirow{3}{*}{ APARTADOS } & \multirow{3}{*}{ SI } & Form & explícita & & & 3 & & & & \multirow{3}{*}{\multicolumn{2}{|c|}{ NO }} \\
\hline & & & & & 2 & 3 & 4 & 5 & 6 & & \\
\hline & \multirow{2}{*}{\multicolumn{11}{|c|}{ PROBAR I DEMOSTRAR I DETERMINAR }} \\
\hline VERBO UTILIZADO & & & & & & & & & & & \\
\hline TIEMPO VERBAL & \multicolumn{11}{|c|}{ INFINITIVO } \\
\hline \multirow{3}{*}{$\begin{array}{l}\text { FALLOS DEL ENUN- } \\
\text { CIADO }\end{array}$} & \multicolumn{11}{|c|}{ PUNTUACIÓN } \\
\hline & \multicolumn{11}{|c|}{ ESTRUCTURA ORACIONAL } \\
\hline & \multicolumn{11}{|c|}{ ERROR MOIRFOLÓGICO } \\
\hline \multicolumn{12}{|c|}{ ENUNCIADO ALTERNATIVO } \\
\hline
\end{tabular}

P4.- a) Escribe razonadamente si es cierta la propiedad conmutativa del producto de $\underline{\text { matrices. }}$

En caso afirmativo demuéstralo y en caso negativo escribe un ejemplo en el que no se verifique.

b) Si $A$ y $B$ son matrices diagonales de orden $2 \times 2$, demuestra que $A B=B A$.

c) Determina las matrices $2 \times 2$ diagonales $A$ tales que $A \cdot A=\left(\begin{array}{ll}1 & 0 \\ 0 & 1\end{array}\right)$

\section{NIVELES DE COMPETENCIAS IMPLÍCITAS: Reproducción y conexión}

El apartado a) del problema que aparece en la ficha 3.4.1 es una definición teórica, por tanto es una mera reproducción del conocimiento estudiado, usa un único tipo de representación estándar, ya utilizada $(R R n 1)$, la representación algebraica, interpreta representaciones estándar de objetos matemáticos (RRn2) e interpreta el lenguaje formal y simbólico rutinario (RLSOn2).

Un contraejemplo que demuestra que el producto de matrices no es conmutativo es: 
Considerando las matrices $A=\left(\begin{array}{rr}2 & -1 \\ 1 & 3\end{array}\right)$ y $B=\left(\begin{array}{rr}3 & 1 \\ -2 & 1\end{array}\right)$

Se tiene

$$
A \cdot B=\left(\begin{array}{rr}
8 & 1 \\
-3 & 4
\end{array}\right) \quad B \cdot A=\left(\begin{array}{rr}
7 & 0 \\
-3 & 5
\end{array}\right)
$$

El alumno comprende la expresión escrita ( $\mathrm{RCn} 1)$, reconoce las representaciones de los datos del ejercicio (RPRn1), identifica el problema (RAn1), reconoce el problema como ya practicado (RRPn1) e identifica que es un modelo similar a otros vistos con anterioridad (RMn1).

A continuación realiza explicaciones sencillas (RCn2), justifica las fórmulas utilizadas (RAn3), reproduce problemas ya practicados, de manera cerrada (RRPn2), resuelve problemas rutinarios estandarizados (RRPn3), en un nivel de Matemáticas II, comunica de manera elemental los resultados (RMn3) y describe los resultados obtenidos (RCn3).

El apartado b) de la ficha 3.4.1 pide que el alumno haga una demostración, pero tan solo se trata de efectuar un producto de matrices, lo que corresponde al nivel de reproducción, se trata del reconocimiento de equivalentes, ejecución de problemas rutinarios, aplicación de destrezas técnicas y algoritmos habituales, manejo de expresiones y fórmulas establecidas y realización de cálculos.

El alumno plantea los algoritmos correspondientes (RPRn2) y asocia con fórmulas establecidas (RPRn3) y expone el proceso de cálculo (RAn2).

Consideramos las matrices

$$
A=\left(\begin{array}{cc}
\lambda_{1} & 0 \\
0 & \lambda_{2}
\end{array}\right) \text { y } B=\left(\begin{array}{cc}
\mu_{1} & 0 \\
0 & \mu_{2}
\end{array}\right)
$$

Obtenemos los productos

$$
A \cdot B=\left(\begin{array}{cc}
\lambda_{1} \cdot \mu_{1} & 0 \\
0 & \lambda_{2} \cdot \mu_{2}
\end{array}\right) \quad B \cdot A=\left(\begin{array}{cc}
\mu_{1} \cdot \lambda_{1} & 0 \\
0 & \mu_{2} \cdot \lambda_{2}
\end{array}\right)
$$

El producto $A \cdot B=B \cdot A$, pues, el producto de números es conmutativo.

El alumno realiza operaciones elementales en contextos conocidos (RLSOn1), sabe expresarse sobre cuestiones matemáticas (CCn1), realiza explicaciones 
sencillas (RCn2), resuelve problemas rutinarios estandarizados (RRPn3), comunica de manera elemental los resultados (RMn3) y describe los resultados obtenidos (RCn3).

El apartado c) del problema que se presenta en la tabla 3.4.1 se encuadra en el nivel de conexión, es un problema que reproduce situaciones similares a las estudiadas en la instrucción, pero que no son de mera rutina, pues no se trata únicamente de realizar un producto de matrices, sino que debe resolver el problema utilizando parámetros.

El alumno tiene que pensar en el tratamiento matemático necesario (CPRn1), razona matemáticamente de manera simple (CAn1), y estructura la situación que debe modelizar (CMn1).

Siendo $A=\left(\begin{array}{ll}a & 0 \\ 0 & b\end{array}\right)$; se tiene que cumplir que:

$$
A \cdot A=\left(\begin{array}{cc}
a^{2} & 0 \\
0 & b^{2}
\end{array}\right)=\left(\begin{array}{ll}
1 & 0 \\
0 & 1
\end{array}\right)
$$

Al hacer este razonamiento, sigue y evalúa el encadenamiento de argumentos matemáticos particulares (CAn2, CAn3), explica los cálculos y sus propiedades (CCn2) e interpreta las relaciones implicadas (CCn3).

Asimismo, desarrolla procedimientos intuitivos ya practicados, pero no rutinarios (CRPn1), comprende que tiene que emplear conceptos matemáticos intermedios (CPRn2) y aplica los conceptos matemáticos apropiados (CPRn3).

Tenemos el sistema: $\left\{\begin{array}{l}a^{2}=1 \\ b^{2}=1\end{array}\right.$, con soluciones

$$
a_{1}=1, \quad a_{2}=-1, \quad b_{1}=1, \quad b_{2}=-1
$$

El alumno tiene que efectuar un producto de matrices $y$, al efectuar estas operaciones, el alumno maneja procedimientos y fórmulas, resolviendo y calculando (RLSOn3) y utiliza variables y realiza ecuaciones y cálculos mediante procedimientos familiares (CLSOn3).

$$
A_{1}=\left(\begin{array}{ll}
1 & 0 \\
0 & 1
\end{array}\right), A_{2}=\left(\begin{array}{rr}
-1 & 0 \\
0 & 1
\end{array}\right), A_{3}=\left(\begin{array}{rr}
1 & 0 \\
0 & -1
\end{array}\right), A_{4}=\left(\begin{array}{rr}
-1 & 0 \\
0 & -1
\end{array}\right)
$$


Al hacer este razonamiento, sigue y evalúa el encadenamiento de argumentos matemáticos particulares (CAn2, CAn3), explica los cálculos y sus propiedades (CCn2) e interpreta las relaciones implicadas (CCn3).

FICHA 3.4.2. COMPETENCIAS IMPLÍCITAS EN LA RESOLUCIÓN DEL P4

\begin{tabular}{|c|c|c|c|c|c|c|c|c|}
\hline & Nivel 1 & Nivel 2 & Nivel 3 & Nivel 1 & Nivel 2 & Nivel 3 & Nivel 1 & Nivel 2 \\
\hline PR & * & * & * & * & * & * & & \\
\hline A & * & & * & * & * & * & & \\
\hline C & & * & * & * & * & * & & \\
\hline M & * & & * & * & & & & \\
\hline $\mathbf{R P}$ & * & * & * & * & & & & \\
\hline $\mathbf{R}$ & * & * & & & & & & \\
\hline LSO & * & * & * & & . & * & & \\
\hline & \multicolumn{3}{|c|}{ Reproducción } & \multicolumn{3}{|c|}{ Conexión } & \multicolumn{2}{|c|}{ Reflexión } \\
\hline
\end{tabular}

\section{ANÁLISIS DEL PROBLEMA P5}

El apartado a) del problema que aparece en la ficha 3.5.1 es una definición teórica, por tanto es una mera reproducción del conocimiento estudiado, interpreta representaciones estándar de objetos matemáticos (RRn2) e interpreta el lenguaje formal y simbólico rutinario (RLSOn2).

El apartado b) del problema de la ficha 3.5.1 es, también, un ejercicio que se corresponde con un nivel de reproducción; corresponde al reconocimiento de equivalentes, ejecución de problemas rutinarios, aplicación de destrezas técnicas y algoritmos habituales, manejo de expresiones y fórmulas establecidas y realización de cálculos.

El alumno identifica el problema (RAn1), comprende la expresión escrita (RCn1), -el determinante-, reconoce las representaciones de los datos del ejercicio (RPRn1), -es una ecuación polinómica-, identifica que es un modelo similar a otros vistos con anterioridad (RMn1) y reconoce el problema como ya practicado (RRPn1), plantea los algoritmos correspondientes (RPRn2), asocia con fórmulas establecidas y realiza cálculos (RPRn3).

A continuación, usa un único tipo de representación estándar, ya utilizada (RRn1), la representación algebraica y expone el proceso de cálculo (RAn2). 
FICHA 3.5.1.

ESTUDIO DEL ENUNCIADO DEL P5

P5.- a) Enunciar dos propiedades de los determinantes.

b) Calcular el siguiente determinante $\left|\begin{array}{cccc}x & 1 & 1 & 1 \\ 1 & x & 1 & 1 \\ 1 & 1 & x & 1 \\ 1 & 1 & 1 & x\end{array}\right|$

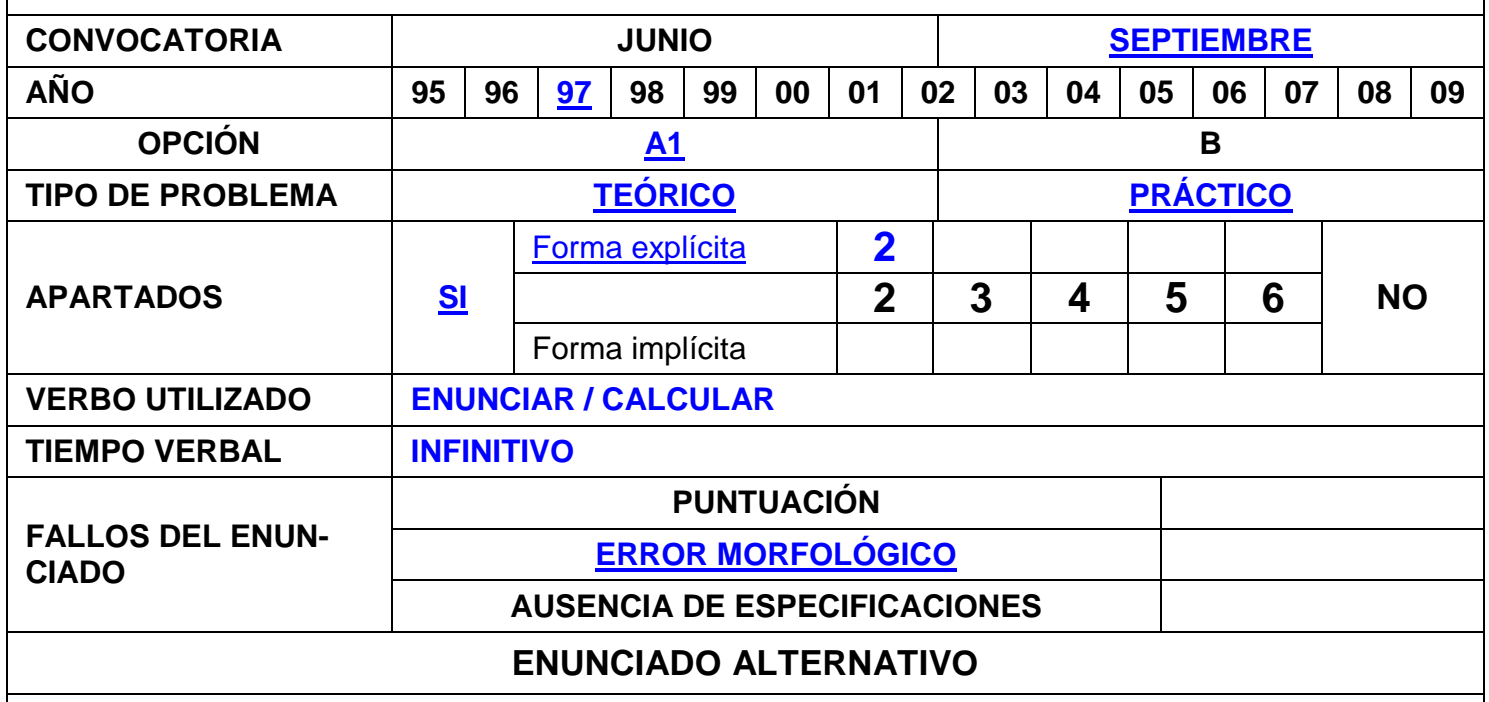

P5.- a) Enuncia dos propiedades de los determinantes.

b) Calcula el siguiente determinante $\left|\begin{array}{llll}x & 1 & 1 & 1 \\ 1 & x & 1 & 1 \\ 1 & 1 & x & 1 \\ 1 & 1 & 1 & x\end{array}\right|$

NIVELES DE COMPETENCIAS IMPLÍCITAS: Reproducción y conexión

$$
\begin{aligned}
& \left|\begin{array}{llll}
x & 1 & 1 & 1 \\
1 & x & 1 & 1 \\
1 & 1 & x & 1 \\
1 & 1 & 1 & x
\end{array}\right|{ }_{(1)}\left|\begin{array}{cccc}
x+3 & 1 & 1 & 1 \\
x+3 & x & 1 & 1 \\
x+3 & 1 & x & 1 \\
x+3 & 1 & 1 & x
\end{array}\right|(2)=(x+3) \cdot\left|\begin{array}{cccc}
1 & 1 & 1 & 1 \\
1 & x & 1 & 1 \\
1 & 1 & x & 1 \\
1 & 1 & 1 & x
\end{array}\right|= \\
& F_{1} \\
& =\begin{array}{l}
F_{2}-F_{1} \\
F_{3}-F_{1} \\
F_{4}-F_{1}
\end{array}=(x+3) \cdot\left|\begin{array}{cccc}
1 & 1 & 1 & 1 \\
0 & x-1 & 0 & 0 \\
0 & 0 & x-1 & 0 \\
0 & 0 & 0 & x-1
\end{array}\right|=(x+3) \cdot(x-1)^{3}
\end{aligned}
$$

(1) Como $\operatorname{det}\left(C_{1}, C_{2}, C_{3}, C_{4}\right)=\operatorname{det}\left(C_{1}+C_{2}+C_{3}+C_{4}, C_{2}, C_{3}, C_{4}\right)$ 
(2) Sacando factor común $(x+3)$ en $C_{1}$

El alumno tiene que desarrollar un determinante, es decir, desarrolla procedimientos intuitivos ya practicados, pero no rutinarios (CRPn1), utiliza variables y realiza ecuaciones y cálculos mediante procedimientos familiares (CLSOn3), que no corresponde al nivel básico de reproducción, estaríamos en un nivel de conexión.

El alumno sabe expresarse sobre cuestiones matemáticas (CCn1), realiza explicaciones sencillas (RCn2), justifica las fórmulas utilizadas (RAn3) y reproduce problemas ya practicados, de manera cerrada (RRPn2).

Asimismo realiza operaciones elementales en contextos conocidos (RLSOn1), interpreta el lenguaje formal y simbólico rutinario (RLSOn2), maneja procedimientos y fórmulas, resolviendo y calculando (RLSOn3) y, de este modo, resuelve problemas rutinarios estandarizados (RRPn3), describe los resultados obtenidos (RCn3) y comunica de manera elemental los resultados del modelo (RMn3).

FICHA 3.5.2. COMPETENCIAS IMPLÍCITAS EN LA RESOLUCIÓN DEL P5

\begin{tabular}{|c|c|c|c|c|c|c|c|c|}
\hline & Nivel 1 & Nivel 2 & Nivel 3 & Nivel 1 & Nivel 2 & Nivel 3 & Nivel 1 & Nivel 2 \\
\hline PR & * & * & * & & & & & \\
\hline A & * & * & * & & & & & \\
\hline C & & * & * & * & & & & \\
\hline M & * & & * & & & & & \\
\hline RP & * & * & * & * & & & & \\
\hline $\mathbf{R}$ & * & * & & & & & & \\
\hline LSO & * & * & * & & & * & & \\
\hline & \multicolumn{3}{|c|}{ Reproducción } & \multicolumn{3}{|c|}{ Conexión } & \multicolumn{2}{|c|}{ Reflexión } \\
\hline
\end{tabular}

\section{ANÁLISIS DEL PROBLEMA P8}

El apartado a) del problema que aparece en la ficha 3.8.1 es una definición teórica, por tanto es una mera reproducción del conocimiento estudiado, interpreta representaciones estándar de objetos matemáticos (RRn2) e interpreta el lenguaje formal y simbólico rutinario (RLSOn2). 
FICHA 3.8.1.

ESTUDIO DEL ENUNCIADO DEL P8

P8.- Definir el concepto de matriz inversible. Dar un criterio para asegurar que una matriz es inversible.

b) Dada la matriz $A=\left(\begin{array}{rrr}1 & -1 & -1 \\ 1 & -1 & 0 \\ 1 & 0 & m\end{array}\right)$ Determinar, para qué valores del parámetro $m$, existe $A^{-1}$

c) Para $m=-1$, resolver $\operatorname{det}\left|A^{-1}-x I\right|=0 .\left(I=\left(\begin{array}{lll}1 & 0 & 0 \\ 0 & 1 & 0 \\ 0 & 0 & 1\end{array}\right)\right.$ matriz unidad $)$

\begin{tabular}{|c|c|c|c|c|c|c|c|c|c|c|c|c|c|c|c|}
\hline CONVOCATORIA & \multicolumn{7}{|c|}{ JUNIO } & \multicolumn{8}{|c|}{ SEPTIEMBRE } \\
\hline AÑO & 95 & 96 & 97 & 98 & $\underline{99}$ & 00 & 01 & 02 & 03 & 04 & 05 & 06 & 07 & 08 & 09 \\
\hline OPCIÓN & \multicolumn{8}{|c|}{$\underline{A}$} & \multicolumn{7}{|c|}{ B } \\
\hline TIPO DE PROBLEMA & \multicolumn{7}{|c|}{ TEÓRICO } & \multicolumn{8}{|c|}{ PRÁCTICO } \\
\hline \multirow{3}{*}{ APARTADOS } & \multirow{3}{*}{\multicolumn{2}{|c|}{ SI }} & Form & $\exp$ & ícita & & & & 3 & & & & & \multirow{3}{*}{\multicolumn{2}{|c|}{ NO }} \\
\hline & & & & & & & 2 & & 3 & 4 & 5 & & 6 & & \\
\hline & & & \multicolumn{4}{|c|}{ Forma implícita } & & & & & & & & & \\
\hline VERBO UTILIZADO & \multicolumn{15}{|c|}{ DEFINIR / DAR I DETERMINAR / RESOLVER } \\
\hline TIEMPO VERBAL & \multicolumn{15}{|c|}{ INFINITIVO } \\
\hline \multirow{3}{*}{$\begin{array}{l}\text { FALLOS DEL ENUN- } \\
\text { CIADO }\end{array}$} & \multicolumn{10}{|c|}{ PUNTUACIÓN } & & & & & \\
\hline & \multicolumn{10}{|c|}{ ERROR MORFOLÓGICO } & & & & & \\
\hline & \multicolumn{10}{|c|}{ AUSENCIA DE ESPECIFICACIONES } & & & & & \\
\hline & & & vUN & A & $A$ & 5. & RNA & TIVO & & & & & & & \\
\hline
\end{tabular}

P8.- a) Define el concepto de matriz inversible. Da un criterio para asegurar que una matriz es inversible.

b) Dada la matriz $A=\left(\begin{array}{ccc}1 & -1 & -1 \\ 1 & -1 & 0 \\ 1 & 0 & m\end{array}\right)$, determina, para qué valores del parámetro $m$, existe $A^{-1}$.

c) Para $m=-1$, resuelve $\operatorname{det}\left|A^{-1}-x I\right|=0 .\left(I=\left(\begin{array}{lll}1 & 0 & 0 \\ 0 & 1 & 0 \\ 0 & 0 & 1\end{array}\right)\right.$ matriz unidad $)$

NIVELES DE COMPETENCIAS IMPLÍCITAS: Reproducción y conexión

El apartado b) del problema de la ficha 3.8.1 es un ejercicio que se corresponde con un nivel de conexión; no es una mera rutina, debido a la presencia de un parámetro que generaliza una situación. 
Por tanto el alumno tiene que pensar en el tratamiento matemático necesario (CPRn1), razonar matemáticamente de manera simple (CAn1), estructurar la situación que se debe modelizar (CMn1), desarrollar procedimientos ya practicados, pero no rutinarios (CRPn1), pues para ver si la matriz es regular y, por tanto, admite inversa hay que estudiar el rango de la misma, dependiendo de los posibles valores del parámetro $m$.

El alumno calcula el valor del determinante:

$$
\left|\begin{array}{rrr}
1 & -1 & -1 \\
1 & -1 & 0 \\
1 & 0 & m
\end{array}\right|=-1
$$

El alumno usa un único tipo de representación estándar, ya utilizada (RRn1), la representación algebraica, realiza operaciones elementales en contextos conocidos (RLSOn1), interpreta el lenguaje formal y simbólico rutinario (RLSOn2), maneja procedimientos y fórmulas resolviendo y calculando (RLSOn3) y utiliza variables y realiza ecuaciones y cálculos mediante procedimientos familiares (CLSOn3).

Como $\forall m$ el determinante es distinto de cero, por tanto,

$$
\text { Existe } A^{-1}, \forall m
$$

El alumno sabe expresarse sobre cuestiones matemáticas (CCn1), explica los cálculos y sus propiedades (CCn2), sigue el encadenamiento del argumento matemático particular (CAn2), haciendo una evaluación del mismo (CAn3) e interpretando las relaciones implicadas (CCn3), al tiempo que traduce, en la práctica, el modelo a seguir, que es algo diferente de los estudiados (CMn2) aplicando, de este modo, conceptos matemáticos apropiados (CPRn3) y comunica los resultados (CMn3).

El apartado c) del problema de la ficha 3.8.1 es un ejercicio que se corresponde con un nivel de reproducción se trata del reconocimiento de equivalentes, ejecución de problemas rutinarios, aplicación de destrezas técnicas y algoritmos habituales, manejo de expresiones y fórmulas establecidas y realización de cálculos.

El alumno reconoce las representaciones de los datos del ejercicio (RPRn1), identifica el problema (RAn1), reconoce el problema como ya practicado 
(RRPn1) e identifica que es un modelo similar a otros vistos con anterioridad (RMn1).

Como $|A| \neq 0, \forall m$ existe $A^{-1}$, y $A^{-1}=\frac{1}{|A|} \cdot \operatorname{Adj}\left(A^{t}\right)$, donde $\operatorname{Adj}\left(A^{t}\right)$ es la matriz transpuesta de la matriz de adjuntos de $A$.

A continuación, expone el proceso de cálculo (RAn2), plantea los algoritmos correspondientes (RPRn2), asocia con fórmulas establecidas y realiza cálculos (RPRn3).

El alumno realiza explicaciones sencillas (RCn2), justifica las fórmulas utilizadas (RAn3) y reproduce problemas ya practicados, de manera cerrada (RRPn2).

Calcula la matriz $A^{-1}$ en el caso $m=-1$.

$$
A^{-1}=\left(\begin{array}{lll}
-1 & 1 & 1 \\
-1 & 0 & 1 \\
-1 & 1 & 0
\end{array}\right)
$$

El alumno resuelve problemas rutinarios estandarizados (RRPn3), en un nivel de Matemáticas II, comunica de manera elemental los resultados (RMn3) y describe los resultados obtenidos (RCn3).

El alumno tiene que calcular la matriz inversa y efectuar un producto de matrices $\mathrm{y}$, al efectuar estas operaciones, realiza operaciones elementales en contextos conocidos (RLSOn1), interpreta el lenguaje formal y simbólico rutinario (RLSOn2) -en Segundo de Bachiller-, maneja procedimientos y fórmulas resolviendo y calculando (RLSOn3) y utiliza variables y realiza ecuaciones y cálculos mediante procedimientos familiares (CLSOn3).

El alumno identifica el problema (RAn1), -es una ecuación polinómica-, identifica que es un modelo similar a otros vistos con anterioridad (RMn1) y reconoce el problema como ya practicado (RRPn1), plantea los algoritmos correspondientes (RPRn2), asocia con fórmulas establecidas y realiza cálculos (RPRn3).

$$
A^{-1}-x I=\left(\begin{array}{rrr}
-1-x & 1 & 1 \\
-1 & -x & 1 \\
-1 & 1 & -x
\end{array}\right)
$$

A continuación, expone el proceso de cálculo (RAn2). 


$$
\left|A^{-1}-x I\right|=\left|\begin{array}{rrr}
-1-x & 1 & 1 \\
-1 & -x & 1 \\
-1 & 1 & -x
\end{array}\right|=-x^{3}-x^{2}-x-1
$$

La ecuación

$$
-x^{3}-x^{2}-x-1=0
$$

tiene como única solución real el valor $x=-1$.

El alumno sabe expresarse sobre cuestiones matemáticas (CCn1), realiza explicaciones sencillas (RCn2), justifica las fórmulas utilizadas (RAn3), maneja procedimientos y fórmulas, resolviendo y calculando (RLSOn3) y, de este modo, resuelve problemas rutinarios estandarizados (RRPn3) y comunica de manera elemental los resultados (RMn3).

En la resolución de la ecuación el alumno tiene que desarrollar un determinante, es decir, utiliza variables y realiza ecuaciones y cálculos mediante procedimientos familiares (CLSOn3), que no corresponde al nivel básico de reproduc-

\begin{tabular}{|c|c|c|c|c|c|c|c|c|}
\hline \multicolumn{2}{|c|}{ FICHA 3.8.2. } & \multicolumn{7}{|c|}{ COMPETENCIAS IMPLÍCITAS EN LA RESOLUCIÓN DEL P8 } \\
\hline & Nivel 1 & Nivel 2 & Nivel 3 & Nivel 1 & Nivel 2 & Nivel 3 & Nivel 1 & Nivel 2 \\
\hline PR & * & * & * & * & & * & & \\
\hline A & * & * & * & * & * & * & & \\
\hline C & & * & * & * & * & * & & \\
\hline M & * & & * & * & * & * & & \\
\hline RP & * & * & * & * & & & & \\
\hline $\mathbf{R}$ & * & * & & & & & & \\
\hline LSO & * & * & * & & & * & & \\
\hline & \multicolumn{3}{|c|}{ Reproducción } & \multicolumn{3}{|c|}{ Conexión } & \multicolumn{2}{|c|}{ Reflexión } \\
\hline
\end{tabular}
ción, estaríamos en un nivel de conexión.

\section{ANÁLISIS DEL PROBLEMA P9}

El apartado a) del problema que aparece en la ficha 3.9.1 es una definición teórica, se trata del reconocimiento de equivalentes, por tanto es una mera reproducción del conocimiento estudiado. El alumno comprende la expresión escrita (RCn1), interpreta representaciones estándar de objetos matemáticos (RRn2) e interpreta el lenguaje formal y simbólico rutinario (RLSOn2). 
FICHA 3.9.1.

ESTUDIO DEL ENUNCIADO DEL P9

P9.- a) De las siguientes operaciones con determinantes de orden $2 \times 2$ señalar las que son correctas y, en su caso, enunciar las propiedades que se utilizan:

$$
\left|\begin{array}{ll}
a & a \\
b & b
\end{array}\right|=0,\left|\begin{array}{ll}
2 & 2 \\
2 & 6
\end{array}\right|=4\left|\begin{array}{ll}
1 & 1 \\
1 & 3
\end{array}\right| \text { y }\left|\begin{array}{ll}
2 & 2 \\
2 & 6
\end{array}\right|=2\left|\begin{array}{ll}
1 & 1 \\
1 & 3
\end{array}\right|
$$

b) Dadas las matrices $A$ y $B$ de orden 4 × 4 con $|A|=3$ y $|B|=2$, calcular $\left|A^{-1}\right|$, $\left|B^{t} A\right|$ y $\left|\left(A B^{-1}\right)^{t}\right|$, justificando la respuesta. (Se recuerda que $A^{t}$ representa la transpuesta de $A$.)

\begin{tabular}{|c|c|c|c|c|c|c|c|c|c|c|c|c|}
\hline CONVOCATORIA & \multicolumn{6}{|c|}{ JUNIO } & \multicolumn{6}{|c|}{ SEPTIEMBRE } \\
\hline AÑO & \begin{tabular}{l|l}
95 & 96
\end{tabular} & \begin{tabular}{|l|}
97 \\
\end{tabular} & 98 & $\underline{99}$ & 00 & 01 & \begin{tabular}{l|l}
02 & 03
\end{tabular} & 04 & 05 & \begin{tabular}{l|l}
06 & 07
\end{tabular} & 08 & 09 \\
\hline OPCIÓN & \multicolumn{6}{|c|}{$\underline{A}$} & \multicolumn{6}{|c|}{ B } \\
\hline TIPO DE PROBLEMA & \multicolumn{6}{|c|}{ TEÓRICO } & \multicolumn{6}{|c|}{ PRÁCTICO } \\
\hline \multirow{3}{*}{ APARTADOS } & \multirow{3}{*}{ SI } & \multicolumn{4}{|c|}{ Forma explícita } & $\underline{2}$ & & & \multirow{2}{*}{5} & \multirow[b]{2}{*}{6} & \multirow{3}{*}{\multicolumn{2}{|c|}{ NO }} \\
\hline & & & & & & 2 & 3 & 4 & & & & \\
\hline & & \multicolumn{4}{|c|}{ Forma implícita } & & 3 & & & & & \\
\hline VERBO UTILIZADO & \multicolumn{12}{|c|}{ SEÑALAR / ENUNCIAR / CALCULAR } \\
\hline TIEMPO VERBAL & \multicolumn{12}{|c|}{ INFINITIVO } \\
\hline \multirow{3}{*}{$\begin{array}{l}\text { FALLOS DEL ENUN- } \\
\text { CIADO }\end{array}$} & \multicolumn{8}{|c|}{ PUNTUACIÓN } & & & & \\
\hline & \multicolumn{8}{|c|}{ ERROR MORFOLÓGICO } & & & & \\
\hline & \multicolumn{8}{|c|}{ AUSENCIA DE ESPECIFICACIONES } & & & & \\
\hline & & ENUN & CIAD & $\mathrm{OAl}$ & LTEF & RNAT & rIVO & & & & & \\
\hline
\end{tabular}

P9.- a) De las siguientes operaciones con determinantes de orden $2 \times 2$ señala las que son correctas $y$, en su caso, enuncia las propiedades que se utilizan:

$$
\left|\begin{array}{ll}
a & a \\
b & b
\end{array}\right|=0,\left|\begin{array}{ll}
2 & 2 \\
2 & 6
\end{array}\right|=4\left|\begin{array}{ll}
1 & 1 \\
1 & 3
\end{array}\right| \text { y }\left|\begin{array}{ll}
2 & 2 \\
2 & 6
\end{array}\right|=2\left|\begin{array}{ll}
1 & 1 \\
1 & 3
\end{array}\right|
$$

b) Dadas las matrices $A$ y $B$ de orden $4 \times 4$ con $|A|=3$ y $|B|=2$, calcula $\left|A^{-1}\right|$, $\left|B^{t} A\right|$ y $\left|\left(A B^{-1}\right)^{t}\right|$, justificando la respuesta. (Se recuerda que $A^{t}$ representa la transpuesta de $A$.)

\section{NIVELES DE COMPETENCIAS IMPLÍCITAS: Reproducción}

La igualdad $\left|\begin{array}{ll}a & a \\ b & b\end{array}\right|=0$ es cierta dado que la $F_{2}$ es un múltiplo (combinación lineal) de la $F_{1}$. 


$$
\text { La igualdad }\left|\begin{array}{ll}
2 & 2 \\
2 & 6
\end{array}\right|=4\left|\begin{array}{ll}
1 & 1 \\
1 & 3
\end{array}\right| \text { es cierta. }
$$

Se ha sacado factor común el número 2 de cada una de las filas o columnas.

La igualdad $\left|\begin{array}{ll}2 & 2 \\ 2 & 6\end{array}\right|=2\left|\begin{array}{ll}1 & 1 \\ 1 & 3\end{array}\right|$ es, evidentemente, falsa, en primer lugar porque contradice la afirmación anterior y en segundo lugar porque al extraer factor común del determinante el número 2 se habría extraído sólo de una fila o columna.

El alumno reconoce las representaciones de los datos del ejercicio (RPRn1), determinantes de orden dos-, identifica el problema (RAn1), reconoce el problema como ya practicado (RRPn1) e identifica que es un modelo similar a otros vistos con anterioridad (RMn1).

A continuación, expone el proceso de cálculo (RAn2), plantea los algoritmos correspondientes (RPRn2), asocia con fórmulas establecidas y realiza cálculos (RPRn3).

El alumno usa un único tipo de representación estándar, ya utilizada (RRn1), la representación algebraica, realiza explicaciones sencillas (RCn2), justifica las fórmulas utilizadas (RAn3), realiza operaciones elementales en contextos conocidos (RLSOn1), interpreta el lenguaje formal y simbólico rutinario (RLSOn2), maneja procedimientos y fórmulas, resolviendo y calculando (RLSOn3) y, de este modo, resuelve problemas rutinarios estandarizados (RRPn3), describe los resultados obtenidos (RCn3) y comunica de manera elemental los resultados (RMn3).

El apartado b) del problema que aparece en la ficha 3.9.1 es una aplicación directa de un concepto teórico, por tanto es una mera reproducción del conocimiento estudiado.

El alumno identifica el problema (RAn1), le reconoce como problema ya practicado (RRPn1), identifica que es un modelo similar a otros vistos con anterioridad (RMn1), plantea los algoritmos correspondientes (RPRn2), asocia con fórmulas establecidas y realiza cálculos (RPRn3).

A continuación, realiza explicaciones sencillas (RCn2) y expone el proceso de cálculo (RAn2). 
Como $A \cdot A^{-1}=I$ y, utilizando las propiedades de los determinantes,

$$
\left|A \cdot A^{-1}\right|=|A| \cdot\left|A^{-1}\right|=|I|=1
$$

se tiene que

$$
\begin{gathered}
\left|A^{-1}\right|=\frac{1}{|A|}=\frac{1}{3} \\
\left|B^{t} \cdot A\right|=\left|B^{t}\right| \cdot|A|=|B| \cdot|A|=2 \cdot 3=6 \\
\left|\left(A \cdot B^{-1}\right)^{t}\right|=\left|A \cdot B^{-1}\right|=|A| \cdot\left|B^{-1}\right|=3 \cdot \frac{1}{2}=\frac{3}{2}
\end{gathered}
$$

El alumno sabe expresarse sobre cuestiones matemáticas (CCn1), reproduce problemas ya practicados, de manera cerrada (RRPn2), realiza explicaciones sencillas ( $\mathrm{RCn} 2)$, justifica las fórmulas utilizadas (RAn3), realiza operaciones elementales en contextos conocidos (RLSOn1), interpreta el lenguaje formal y simbólico rutinario (RLSOn2), maneja procedimientos y fórmulas, resolviendo y

\begin{tabular}{|c|c|c|c|c|c|c|c|c|}
\hline \multicolumn{2}{|c|}{ FICHA 3.9.2. } & \multicolumn{7}{|c|}{ COMPETENCIAS IMPLÍCITAS EN LA RESOLUCIÓN DEL P9 } \\
\hline & Nivel 1 & Nivel 2 & Nivel 3 & Nivel 1 & Nivel 2 & Nivel 3 & Nivel 1 & Nivel 2 \\
\hline PR & * & * & * & & & & & \\
\hline A & * & * & * & & & & & \\
\hline C & * & * & * & * & & & & \\
\hline M & * & & * & & & & & \\
\hline RP & * & * & * & & & & & \\
\hline $\mathbf{R}$ & * & * & & & & & & \\
\hline LSO & * & * & * & & & & & \\
\hline & \multicolumn{3}{|c|}{ Reproducción } & \multicolumn{3}{|c|}{ Conexión } & \multicolumn{2}{|c|}{ Reflexión } \\
\hline
\end{tabular}
calculando (RLSOn3) y, de este modo, resuelve problemas rutinarios estandarizados (RRPn3), describe los resultados obtenidos ( $\mathrm{RCn} 3$ ) y comunica de manera elemental los resultados (RMn3).

\section{ANÁLISIS DEL PROBLEMA P10}

El apartado a) del problema de la ficha 3.10.1 es un ejercicio que se corresponde con un nivel de conexión; reproduce una situación similar a la referente en su etapa de aprendizaje, pero no es una mera rutina, dado que el alumno 
tiene que pensar en el tratamiento matemático necesario (CPRn1),-para demostrar que la matriz tiene inversa suponemos que ésta existe y la calcula-.

FICHA 3.10.1.

ESTUDIO DEL ENUNCIADO DEL P10

P10.- Una matriz cuadrada $A$ tiene la propiedad de que $A^{2}=2 A+I$, donde $I$ es la matriz unidad.

a) Demostrar que $A$ admite inversa, y obtenerla en función de $A$.

b) Dada la matriz $B=\left(\begin{array}{cc}1+m & 1 \\ 1 & 1-m\end{array}\right)$, hallar para qué valores de $m$ se verifica que $B^{2}=2 B+I$ y para esos valores escribir la matriz inversa de $B$.

\begin{tabular}{|c|c|c|c|c|c|c|c|c|c|c|c|c|c|}
\hline CONVOCATORIA & \multicolumn{7}{|c|}{ JUNIO } & \multicolumn{6}{|c|}{ SEPTIEMBRE } \\
\hline AÑO & 95 & 96 & 97 & 98 & 99 & $\underline{00}$ & 01 & \begin{tabular}{l|l}
02 & 03 \\
\end{tabular} & 04 & 05 & \begin{tabular}{|l|l|}
06 & 07 \\
\end{tabular} & 08 & 09 \\
\hline OPCIÓN & \multicolumn{7}{|c|}{$\underline{A}$} & \multicolumn{6}{|c|}{ B } \\
\hline TIPO DE PROBLEMA & \multicolumn{7}{|c|}{ TEÓRICO } & \multicolumn{6}{|c|}{ PRÁCTICO } \\
\hline \multirow{3}{*}{ APARTADOS } & \multirow{3}{*}{\multicolumn{2}{|c|}{ SI }} & \multicolumn{4}{|c|}{ Forma explícita } & 2 & & & \multirow{3}{*}{5} & \multirow[b]{2}{*}{6} & \multirow{3}{*}{\multicolumn{2}{|c|}{ NO }} \\
\hline & & & & & & & 2 & 3 & 4 & & & & \\
\hline & & & \multicolumn{4}{|c|}{ Forma implícita } & & & & & & & \\
\hline VERBO UTILIZADO & \multicolumn{13}{|c|}{ DEMOSTRAR / OBTENER / HALLAR / ESCRIBIR } \\
\hline TIEMPO VERBAL & \multicolumn{13}{|c|}{ INFINITIVO } \\
\hline \multirow{3}{*}{$\begin{array}{l}\text { FALLOS DEL ENUN- } \\
\text { CIADO }\end{array}$} & \multicolumn{13}{|c|}{ ORDEN DE LAS PALABRAS EN LA ORACIÓN } \\
\hline & \multicolumn{9}{|c|}{ ERROR MORFOSINTÁCTICO } & & & & \\
\hline & \multicolumn{9}{|c|}{ AUSENCIA DE ESPECIFICACIONES } & & & & \\
\hline
\end{tabular}

P10.- Dada una matriz cuadrada $A$ con la siguiente propiedad: $A^{2}=2 A+I$, donde $I$ es la matriz unidad.

a) Demuestra que $A$ admite inversa, y escríbela en función de $A$.

b) Dada la matriz $B=\left(\begin{array}{cc}1+m & 1 \\ 1 & 1-m\end{array}\right)$, halla para qué valores de $m$ se verifica que $B^{2}=2 B+I$ y escribe la matriz inversa de $B$, para esos valores.

NIVELES DE COMPETENCIAS IMPLÍCITAS: Reproducción y conexión

El alumno estructura la situación que se debe modelizar (CMn1), desarrolla procedimientos ya practicados, pero no rutinarios (CRPn1) y razona matemáticamente de manera simple (CAn1). 
Suponiendo que existe la matriz $A^{-1}$

$$
A^{-1} \cdot\left(A^{2}\right)=A^{-1} \cdot(2 A+I)
$$

Utilizando las propiedades asociativa y distributiva del producto de matrices

$$
\left(A^{-1} \cdot A\right) \cdot A=A^{-1} \cdot 2 A+A^{-1} \cdot I
$$

Operando y simplificando, utilizando las propiedades del elemento neutro y elemento simétrico

$$
I \cdot A=2 I+A^{-1}
$$

Despejando

$$
A-2 I=A^{-1}
$$

Sabe expresarse sobre cuestiones matemáticas (CCn1), explica los cálculos y sus propiedades (CCn2) y traduce, en la práctica, el modelo a seguir, que es algo diferente de los estudiados (CMn2).

El alumno utiliza el lenguaje formal y simbólico básico, en situaciones menos conocidas (CLSOn1), comprende que tiene que emplear conceptos matemáticos intermedios (CPRn2), aplica conceptos matemáticos apropiados (CPRn3), desarrolla procedimientos intuitivos ya practicados, pero no rutinarios (CRPn1), maneja afirmaciones sencillas y expresiones con símbolos y fórmulas no rutinarias (CLSOn2), interpreta las relaciones implicadas (CCn3) y comunica los resultados (CMn3).

El apartado b) del problema de la ficha 3.10.1 es un ejercicio que se corresponde con un nivel de reproducción; con el reconocimiento de equivalentes, es la ejecución de problemas rutinarios, con la aplicación de destrezas técnicas y algoritmos habituales, el manejo de expresiones y fórmulas establecidas y la realización de cálculos.

El alumno comprende la expresión escrita $(\mathrm{RCn} 1)$, reconoce representaciones de los datos del ejercicio (RPRn1), identifica el problema (RAn1), identifica que es un modelo similar a otros vistos con anterioridad (RMn1), reconoce el problema como ya practicado (RRPn1), plantea los algoritmos correspondientes (RPRn2), expone el proceso de cálculo (RAn2) y asocia con fórmulas establecidas y realiza cálculos (RPRn3). 


$$
\begin{gathered}
B^{2}=\left(\begin{array}{cc}
1+m & 1 \\
1 & 1-m
\end{array}\right) \cdot\left(\begin{array}{cc}
1+m & 1 \\
1 & 1-m
\end{array}\right)=\left(\begin{array}{cc}
m^{2}+2 m+2 & 2 \\
2 & m^{2}-2 m+2
\end{array}\right) \\
2 B+I=\left(\begin{array}{cc}
2+2 m & 2 \\
2 & 2-2 m
\end{array}\right)+\left(\begin{array}{ll}
1 & 0 \\
0 & 1
\end{array}\right)=\left(\begin{array}{cc}
2 m+3 & 2 \\
2 & 3-2 m
\end{array}\right) \\
B^{2}=2 B+I \Rightarrow\left(\begin{array}{cc}
m^{2}+2 m+2 & 2 \\
2 & m^{2}-2 m+2
\end{array}\right)=\left(\begin{array}{cc}
2 m+3 & 2 \\
2 & 3-2 m
\end{array}\right)
\end{gathered}
$$

Para que se verifique, se tienen que cumplir las siguientes condiciones

$$
\left\{\begin{array}{l}
m^{2}+2 m+2=2 m+3 \\
m^{2}-2 m+2=3-2 m
\end{array}\right.
$$

El alumno realiza explicaciones sencillas ( $\mathrm{RCn} 2)$, justifica las fórmulas utilizadas (RAn3), reproduce problemas ya practicados, de manera cerrada (RRPn2) y resuelve problemas rutinarios estandarizados (RRPn3).

El sistema lineal definido a partir de las condiciones tiene soluciones

$$
m_{1}=1 \text { y } m_{2}=-1
$$

Si $m=1$, la matriz buscada es $B_{1}=\left(\begin{array}{ll}2 & 1 \\ 1 & 0\end{array}\right)$.

Si $m=-1$, la matriz buscada es $B_{2}=\left(\begin{array}{ll}0 & 1 \\ 1 & 2\end{array}\right)$.

El alumno usa un único tipo de representación estándar, ya utilizada (RRn1), la representación algebraica, realiza operaciones elementales en contextos conocidos (RLSOn1), interpreta el lenguaje formal y simbólico rutinario (RLSOn2) y maneja procedimientos y fórmulas resolviendo y calculando (RLSOn3), al tiempo que utiliza variables y realiza ecuaciones y cálculos mediante procedimientos familiares (CLSOn3), describe los resultados obtenidos (RCn3) y comunica de manera elemental los resultados (RMn3).

Utilizando el apartado a) del problema $B^{-1}=B-2 I$

$$
B_{1}{ }^{-1}=\left(\begin{array}{rr}
0 & 1 \\
1 & -2
\end{array}\right) \text { y } B_{2}{ }^{-1}=\left(\begin{array}{rr}
-2 & 1 \\
1 & 0
\end{array}\right)
$$


El alumno realiza explicaciones sencillas ( $\mathrm{RCn} 2)$, justifica las fórmulas utilizadas (RAn3), resuelve problemas rutinarios estandarizados (RRPn3) y comunica de manera elemental los resultados (RMn3).

\begin{tabular}{|c|c|c|c|c|c|c|c|c|}
\hline \multicolumn{2}{|c|}{ FICHA 3.10.2. } & \multicolumn{7}{|c|}{ COMPETENCIAS IMPLÍCITAS EN LA RESOLUCIÓN DEL P10 } \\
\hline & Nivel 1 & Nivel 2 & Nivel 3 & Nivel 1 & Nivel 2 & Nivel 3 & Nivel 1 & Nivel 2 \\
\hline PR & * & * & * & * & * & * & & \\
\hline A & * & * & * & * & & & & \\
\hline C & * & * & * & * & * & * & & \\
\hline M & * & & * & * & * & * & & \\
\hline $\mathbf{R P}$ & * & * & * & * & & & & \\
\hline $\mathbf{R}$ & * & & & & & & & \\
\hline \multirow[t]{2}{*}{ LSO } & * & * & * & * & * & * & & \\
\hline & \multicolumn{3}{|c|}{ Reproducción } & \multicolumn{3}{|c|}{ Conexión } & \multicolumn{2}{|c|}{ Reflexión } \\
\hline
\end{tabular}

\section{ANÁLISIS DEL PROBLEMA P11}

El apartado a) del problema que aparece en la ficha 3.11.1 es una definición teórica, por tanto es una mera reproducción del conocimiento estudiado, interpreta representaciones estándar de objetos matemáticos (RRn2) e interpreta el lenguaje formal y simbólico rutinario (RLSOn2).

El apartado b) del problema que aparece en la ficha 3.11.1 corresponde a los niveles de conexión y reflexión, es un problema que reproduce situaciones similares a las ya practicadas, pero que no son de mera rutina.

Para resolver el ejercicio, el alumno piensa en el tratamiento matemático necesario (CPRn1), estructura la situación que debe modelizar (CMn1), traduce en la práctica el modelo a seguir, que es algo diferente de los estudiados (CMn2) y desarrolla procedimientos ya practicados, pero no rutinarios (CRPn1).

Realiza las operaciones con matrices:

$$
\begin{aligned}
A^{t} \cdot X & =A \cdot X^{t} \\
\left(\begin{array}{rr}
2 & a \\
-1 & a
\end{array}\right) \cdot\left(\begin{array}{ll}
x & y \\
z & x
\end{array}\right) & =\left(\begin{array}{rr}
2 & -1 \\
a & a
\end{array}\right) \cdot\left(\begin{array}{ll}
x & y \\
z & x
\end{array}\right)
\end{aligned}
$$


FICHA 3.11.1.

ESTUDIO DEL ENUNCIADO DEL P11

P11.- a) Concepto de sistema de ecuaciones compatible determinado y de sistema incompatible.

b) Consideramos la matriz $A=\left(\begin{array}{rr}2 & -1 \\ a & a\end{array}\right)$. Calcular, en función del parámetro $a$, las matrices $X$ de la forma $X=\left(\begin{array}{cc}x & y \\ z & x\end{array}\right)$ que verifican que $A^{t} \cdot X=A \cdot X^{t}$. (Se recuerda que $A^{t}$ es la matriz traspuesta de la matriz A.)

\begin{tabular}{|c|c|c|c|c|c|c|c|c|c|c|c|c|c|}
\hline \multirow{2}{*}{$\begin{array}{l}\text { CONVOCATORIA } \\
\text { AÑO }\end{array}$} & \multicolumn{6}{|c|}{ JUNIO } & \multicolumn{7}{|c|}{ SEPTIEMBRE } \\
\hline & $95 \quad 96$ & 97 & 98 & 99 & $\underline{00}$ & 01 & $02 \quad 03$ & 04 & 05 & 06 & 07 & 08 & 09 \\
\hline OPCIÓN & \multicolumn{6}{|c|}{ A } & \multicolumn{7}{|c|}{$\underline{B}$} \\
\hline TIPO DE PROBLEMA & \multicolumn{6}{|c|}{ TEÓRICO } & \multicolumn{7}{|c|}{ PRÁCTICO } \\
\hline \multirow{3}{*}{ APARTADOS } & \multirow{3}{*}{$\underline{\text { SI }}$} & \multirow{2}{*}{\multicolumn{4}{|c|}{ Forma explícita }} & 2 & & & & & \multirow[b]{2}{*}{6} & \multirow{3}{*}{\multicolumn{2}{|c|}{ NO }} \\
\hline & & & & & & 2 & 3 & 4 & 5 & & & & \\
\hline & & \multicolumn{4}{|c|}{ Forma implícita } & & & & & & & & \\
\hline VERBO UTILIZADO & \multicolumn{13}{|c|}{ CALCULAR } \\
\hline TIEMPO VERBAL & \multicolumn{13}{|c|}{ INFINITIVO } \\
\hline \multirow{3}{*}{$\begin{array}{l}\text { FALLOS DEL ENUN- } \\
\text { CIADO }\end{array}$} & \multicolumn{8}{|c|}{ PUNTUACIÓN } & & & & & \\
\hline & \multicolumn{8}{|c|}{ ESTRUCTURA DE LA ORACIÓN } & & & & & \\
\hline & \multicolumn{8}{|c|}{ ORDEN DE LAS PALABRAS EN LA ORACIÓN } & & & & & \\
\hline
\end{tabular}

P11.- a) Escribe el concepto de sistema de ecuaciones compatible determinado y de sistema incompatible.

b) Consideramos la matriz $A=\left(\begin{array}{cc}2 & -1 \\ a & a\end{array}\right)$. Calcula las matrices $X$ de la forma $X=\left(\begin{array}{ll}x & y \\ z & x\end{array}\right)$ que verifican que $A^{t} \cdot X=A \cdot X^{t}$, en función del parámetro $a$. (Se recuerda que $A^{t}$ es la matriz traspuesta de la matriz $A$.)

NIVELES DE COMPETENCIAS IMPLÍCITAS: Conexión y reflexión

$$
\left(\begin{array}{cc}
2 x+a z & 2 y+a x \\
-x+a z & -y+a x
\end{array}\right)=\left(\begin{array}{cc}
2 x-y & 2 z-x \\
a x+a y & a z+a x
\end{array}\right)
$$

El alumno realiza operaciones elementales en contextos conocidos (RLSOn1), interpreta el lenguaje formal y simbólico rutinario (RLSOn2) y maneja procedimientos y fórmulas resolviendo y calculando (RLSOn3), usa un único tipo de representación estándar, ya utilizada (RRn1), la representación algebraica, y realiza cálculos mediante procedimientos familiares (CLSOn3). 
Para que ambas matrices sean iguales, deben darse las siguientes condiciones:

$$
\left\{\begin{array}{c}
2 x+a z=2 x-y \\
2 y+a x=2 z-x \\
-x+a z=a x+a y \\
-y+a x=a z+a x
\end{array}\right.
$$

Tanto de la ecuación (1) como de la ecuación (4) se desprende que $y=-a z$.

Sustituyendo este valor en la ecuación (2):

$$
\begin{gathered}
-2 a z+a x=2 z-x \Rightarrow-a(2 z-x)=2 z-x \\
\text { Si } 2 z-x \neq 0 \Rightarrow a=-1
\end{gathered}
$$

$$
\text { Si } 2 z-x=0 \Rightarrow x=2 z
$$

El alumno razona matemáticamente de manera simple (CAn1), comprende que tiene que emplear conceptos matemáticos intermedios (CPRn2) y aplica los conceptos matemáticos apropiados (CPRn3).

Sin embargo, sustituyendo este valor, $y=-a z$, en la ecuación (3):

$$
-x+a z=a x+a \cdot(-a z)=a x-a^{2} x
$$

Sacando factor común - $a$, en el segundo miembro de la igualdad:

$$
-x+a z=-a \cdot(-x+a z)
$$

En esa igualdad, si $-x+a z \neq 0 \Rightarrow a=-1$.

$$
\text { Si }-x+a z=0 \Rightarrow x=a z
$$

Para que las igualdades $\left(^{\star}\right)$ y $\left(^{\star \star}\right)$ sean compatibles:

$$
2 z=a z \quad \Rightarrow a=2 \text { siempre que } z \neq 0
$$

El alumno sabe expresarse sobre cuestiones matemáticas (CCn1), explica los cálculos y sus propiedades (CCn2) e interpreta las relaciones implicadas (CCn3). Asimismo, sigue el encadenamiento del argumento matemático particular (CAn2) y evalúa el encadenamiento de argumentos matemáticos particulares (CAn3). 
Aparece aquí el nivel de reflexión por parte del estudiante para aplicar estrategias en la resolución de un problema que contiene elementos inusuales.

Si consideramos la opción $x=a z$, pues el enunciado pide que se de la solución en función del parámetro $a$, se obtiene la matriz:

$$
X=\left(\begin{array}{cc}
a z & -a z \\
z & a z
\end{array}\right)
$$

Comprobamos la validez de la solución:

$$
\begin{aligned}
& A^{t} \cdot X=\left(\begin{array}{rr}
2 & a \\
-1 & a
\end{array}\right) \cdot\left(\begin{array}{cc}
a z & -a z \\
z & a z
\end{array}\right)=\left(\begin{array}{cc}
3 a z & -2 a z+a^{2} z \\
0 & a z+a^{2} z
\end{array}\right) \\
& A \cdot X^{t}=\left(\begin{array}{rr}
2 & -1 \\
a & a
\end{array}\right) \cdot\left(\begin{array}{cc}
a z & z \\
-a z & a z
\end{array}\right)=\left(\begin{array}{cc}
3 a z & 2 z-a z \\
0 & a z+a^{2} z
\end{array}\right)
\end{aligned}
$$

Para que se cumpla la igualdad: $A^{t} \cdot X=A \cdot X^{t}$

$$
\left(\begin{array}{cc}
3 a z & -2 a z+a^{2} z \\
0 & a z+a^{2} z
\end{array}\right)=\left(\begin{array}{cc}
3 a z & 2 z-a z \\
0 & a z+a^{2} z
\end{array}\right) \Rightarrow a=-1
$$

Si $a=2$, tenemos las matrices:

$$
A=\left(\begin{array}{rr}
2 & -1 \\
2 & 2
\end{array}\right) \text { y } X=\left(\begin{array}{cr}
2 z & -2 z \\
z & 2 z
\end{array}\right)
$$

El alumno sabe expresarse sobre cuestiones matemáticas (CCn1), razona de manera sencilla, distinguiendo formas más amplias de argumentación (RfAn1), elabora encadenamientos de argumentos de diferentes tipos (RfAn2), sabe explicar cuestiones matemáticas, cálculos y resultados (RfCn1), expone problemas más allá de la reproducción de los ya practicados (RfRPn1) y explica asuntos que implican relaciones complejas (RfCn2).

Si $a=2$, tenemos las matrices:

$$
A=\left(\begin{array}{rr}
2 & -1 \\
2 & 2
\end{array}\right) \text { y } X=\left(\begin{array}{rr}
2 z & -2 z \\
z & 2 z
\end{array}\right)
$$

Para resolver el problema, el alumno podía estudiar el sistema en función de los valores del parámetro $a$. 


$$
\left\{\begin{array}{c}
y+a z=0 \\
(a+1) x+2 y-2 z=0 \\
(a+1) x+a y-a z=0
\end{array}\right.
$$

Con matriz de coeficientes $A=\left(\begin{array}{ccc}0 & 1 & a \\ a+1 & 2 & -2 \\ a+1 & a & -a\end{array}\right)$ y cuyo determinante vale

$$
|A|=\left(a^{2}-a-2\right) \cdot(a+1)
$$

Si $a \neq-1$ y $a \neq 2$, el determinante es distinto de cero, y la solución del sistema es la trivial, con lo que la matriz solución es la matriz nula. $(X=0)$

Si $a=-1$ o $a=2$ las soluciones coinciden con las calculadas anteriormente.

El alumno razona de manera sencilla, distinguiendo formas más amplias de argumentación (RfAn1), elabora encadenamientos de argumentos de diferentes tipos (RfAn2), sabe explicar cuestiones matemáticas, cálculos y resultados (RfCn1)

\begin{tabular}{|l|c|c|c|c|c|c|c|c|}
\hline \multicolumn{6}{|c|}{ FICHA 3.11.2. COMPETENCIAS IMPLÍCITAS EN LA RESOLUCIÓN DEL P11 } \\
\hline & Nivel 1 & Nivel 2 & Nivel 3 & Nivel 1 & Nivel 2 & Nivel 3 & Nivel 1 & Nivel 2 \\
\hline PR & & & & $*$ & $*$ & $*$ & & \\
\hline A & & & & $*$ & $*$ & $*$ & $*$ & $*$ \\
\hline C & & & & $*$ & $*$ & $*$ & $*$ & $*$ \\
\hline M & & & & $*$ & $*$ & & & \\
\hline RP & & & & $*$ & & & $*$ & \\
\hline R & $*$ & $*$ & & & & & & \\
\hline LSO & $*$ & $*$ & $*$ & & & $*$ & & \\
\hline & Reproducción & & \multicolumn{7}{c|}{ Conexión } & & Reflexión \\
\hline
\end{tabular}

\section{ANÁLISIS DEL PROBLEMA P14}

El apartado a) del ejercicio de la ficha 3.14.1 corresponde al nivel de reproducción. Se trata del reconocimiento de equivalentes, ejecución de problemas rutinarios, aplicación de destrezas técnicas y algoritmos habituales, manejo de expresiones y fórmulas establecidas y realización de cálculos. 
FICHA 3.14.1.

ESTUDIO DEL ENUNCIADO DEL P14

P14.- Sean $A, B$ y $X$ tres matrices cuadradas del mismo orden que verifican la relación $A \cdot X \cdot B=I$, siendo $I$ la matriz unidad.

a) Si el determinante de $A$ vale -1 y el de $B$ vale 1 , calcular razonadamente el determinante de $X$.

b) Calcular de forma razonada la matriz $X$ si $A=\left(\begin{array}{ll}2 & 3 \\ 3 & 4\end{array}\right)$ y $B=\left(\begin{array}{ll}1 & -2 \\ 2 & -3\end{array}\right)$.

\begin{tabular}{|c|c|c|c|c|c|c|c|c|c|c|c|c|c|c|c|}
\hline CONVOCATORIA & \multicolumn{8}{|c|}{ JUNIO } & \multicolumn{7}{|c|}{ SEPTIEMBRE } \\
\hline AÑO & 95 & 96 & 97 & 98 & 99 & 00 & 01 & $\underline{02}$ & 03 & 04 & 05 & 06 & 07 & 08 & 09 \\
\hline OPCIÓN & \multicolumn{8}{|c|}{$\underline{A}$} & \multicolumn{7}{|c|}{ B } \\
\hline TIPO DE PROBLEMA & \multicolumn{7}{|c|}{ TEÓRICO } & & \multicolumn{7}{|c|}{ PRÁCTICO } \\
\hline \multirow{3}{*}{ APARTADOS } & \multirow{3}{*}{\multicolumn{2}{|c|}{$\underline{\text { SI }}$}} & \multicolumn{4}{|c|}{ Forma explícita } & 2 & & & & & & \multirow[b]{2}{*}{6} & \multirow{3}{*}{\multicolumn{2}{|c|}{ NO }} \\
\hline & & & & & & & 2 & & 3 & 4 & 5 & & & & \\
\hline & & & \multicolumn{4}{|c|}{ Forma implícita } & & & & & & & & & \\
\hline VERBO UTILIZADO & \multicolumn{15}{|c|}{ CALCULAR } \\
\hline TIEMPO VERBAL & \multicolumn{15}{|c|}{ INFINITIVO } \\
\hline \multirow{3}{*}{$\begin{array}{l}\text { FALLOS DEL ENUN- } \\
\text { CIADO }\end{array}$} & \multicolumn{10}{|c|}{ ERROR MORFOLÓGICO } & & & & & \\
\hline & \multicolumn{10}{|c|}{ ORDEN DE LAS PALABRAS EN LA ORACIÓN } & & & & & \\
\hline & \multicolumn{10}{|c|}{ AUSENCIA DE ESPECIFICACIONES } & & & & & \\
\hline & & & ENU & $\mathrm{CIA}$ & O & 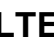 & $\mathbf{N}$ & IV & & & & & & & \\
\hline
\end{tabular}

P14.- Dadas tres matrices cuadradas: $A, B$ y $X$, del mismo orden, que verifican la relación $A \cdot X \cdot B=I$, siendo $I$ la matriz unidad.

a) Si el determinante de $A$ vale -1 y el de $B$ vale 1 , calcula razonadamente el valor del determinante de $X$.

b) Calcula de forma razonada la matriz $X$ si $A=\left(\begin{array}{ll}2 & 3 \\ 3 & 4\end{array}\right)$ y $B=\left(\begin{array}{ll}1 & -2 \\ 2 & -3\end{array}\right)$.

\section{NIVELES DE COMPETENCIAS IMPLÍCITAS: Reproducción}

El alumno comprende la expresión escrita (RCn1), identifica el problema (RAn1), reconoce el problema como ya practicado (RRPn1), identifica que es un modelo similar a otros vistos con anterioridad (RMn1).

A continuación, expone el proceso de cálculo (RAn2), plantea los algoritmos correspondientes (RPRn2), asocia con fórmulas establecidas y realiza los cálculos (RPRn3).

Como $A X B=I$ y $|A \cdot X \cdot B|=|A| \cdot|X| \cdot|B|=|I|=1$, utilizando las propiedades 
de los determinantes, se tiene que

$$
|X|=\frac{1}{|A| \cdot|B|}=-1
$$

El alumno realiza explicaciones sencillas ( $\mathrm{RCn} 2)$, justifica las fórmulas utilizadas (RAn3), reproduce problemas ya practicados, de manera cerrada (RRPn2), resuelve problemas rutinarios estandarizados (RRPn3), comunica de manera elemental los resultados (RMn3) y describe los resultados obtenidos (RCn3).

El apartado b) del problema de la ficha 3.14.1 pide que el alumno resuelva una ecuación matricial, lo que corresponde al nivel de reproducción, se trata del reconocimiento de equivalentes, ejecución de problemas rutinarios, aplicación de destrezas técnicas y algoritmos habituales, manejo de expresiones y fórmulas establecidas y realización de cálculos.

El alumno reconoce las representaciones de los datos del ejercicio (RPRn1), identifica el problema (RAn1), reconoce el problema como ya practicado (RRPn1) e identifica que es un modelo similar a otros vistos con anterioridad (RMn1).

A continuación, usa un único tipo de representación estándar, ya utilizada (RRn1), la representación algebraica, expone el proceso de cálculo (RAn2), plantea los algoritmos correspondientes (RPRn2), asocia con fórmulas establecidas y realiza cálculos (RPRn3).

Despejando la incógnita

$$
A X B=I \quad \Rightarrow \quad X=A^{-1} \cdot B^{-1}
$$

Como $|A|=-1 \neq 0$ y $|B|=1 \neq 0$, existen las matrices $A^{-1}$ y $B^{-1}$.

El alumno realiza explicaciones sencillas (RCn2), justifica las fórmulas utilizadas (RAn3) y reproduce problemas ya practicados, de manera cerrada (RRPn2).

Calcula las matrices $A^{-1}$ y $B^{-1}$

$$
A^{-1}=\left(\begin{array}{rr}
-4 & 3 \\
3 & -2
\end{array}\right) \text { y } B^{-1}=\left(\begin{array}{rr}
-3 & 2 \\
-2 & 1
\end{array}\right)
$$

$\mathrm{Y}$, en consecuencia, 


$$
X=A^{-1} \cdot B^{-1} \Rightarrow X=\left(\begin{array}{rr}
-4 & 3 \\
3 & -2
\end{array}\right) \cdot\left(\begin{array}{rr}
-3 & 2 \\
-2 & 1
\end{array}\right)=\left(\begin{array}{rr}
6 & -5 \\
-5 & 4
\end{array}\right)
$$

El alumno tiene que calcular la matriz inversa y efectuar un producto de matrices y, al efectuar estas operaciones, realiza operaciones elementales en contextos conocidos (RLSOn1), interpreta el lenguaje formal y simbólico rutinario (RLSOn2) -en Segundo de Bachillerato-, maneja procedimientos y fórmulas resolviendo y calculando (RLSOn3) y utiliza variables y realiza ecuaciones $y$ cálculos mediante procedimientos familiares (CLSOn3) y así resuelve problemas rutinarios estandarizados (RRPn3).

Finalmente, comunica de manera elemental los resultados (RMn3) y describe los resultados obtenidos ( $\mathrm{RCn} 3)$.

\begin{tabular}{|l|c|c|c|c|c|c|c|c|}
\hline \multicolumn{7}{|c|}{ FICHA 3.14.2. COMPETENCIAS IMPLÍCITAS EN LA RESOLUCIÓN DEL P14 } \\
\hline & Nivel 1 & Nivel 2 & Nivel 3 & Nivel 1 & Nivel 2 & Nivel 3 & Nivel 1 & Nivel 2 \\
\hline PR & $*$ & $*$ & $*$ & & & & & \\
\hline A & $*$ & $*$ & $*$ & & & & & \\
\hline C & $*$ & $*$ & $*$ & & & & & \\
\hline M & $*$ & & $*$ & & & & & \\
\hline RP & $*$ & $*$ & $*$ & & & & & \\
\hline R & $*$ & & & & & & & \\
\hline LSO & $*$ & $*$ & $*$ & & & $*$ & & \\
\hline & Reproducción & & Conexión & & Reflexión \\
\hline
\end{tabular}

\section{ANÁLISIS DEL PROBLEMA P15}

El apartado a) del problema de la ficha 3.15.1 es un ejercicio que se corresponde con un nivel de conexión; reproduce una situación similar a la referente en su etapa de aprendizaje, pero no es una mera rutina, dado que el alumno tiene que pensar en el tratamiento matemático necesario (CPRn1).

Hay que estudiar el rango de una matriz dependiendo de los posibles valores del parámetro $m, y$, para ello vamos a utilizar determinantes.

El alumno razona matemáticamente de manera simple (CAn1), estructurarla situación que se debe modelizar (CMn1) y desarrolla procedimientos intuitivos ya practicados, pero no rutinarios (CRPn1). 
FICHA 3.15.1.

ESTUDIO DEL ENUNCIADO DEL P15

P15.- Dadas las dos matrices $A=\left(\begin{array}{rrr}-1 & 0 & 1 \\ 2 & 1 & 0 \\ 3 & 2 & -1\end{array}\right)$ y $B=\left(\begin{array}{rrr}1 & 0 & -1 \\ 1 & 1 & 1 \\ -2 & 0 & 0\end{array}\right)$, se define la matriz $C=A+m B$.

a) Hallar para qué valores de $m$ la matriz $C$ tiene rango menor que 3.

b) Para $m=-1$, resolver el sistema lineal homogéneo cuya matriz de coeficientes es $C$.

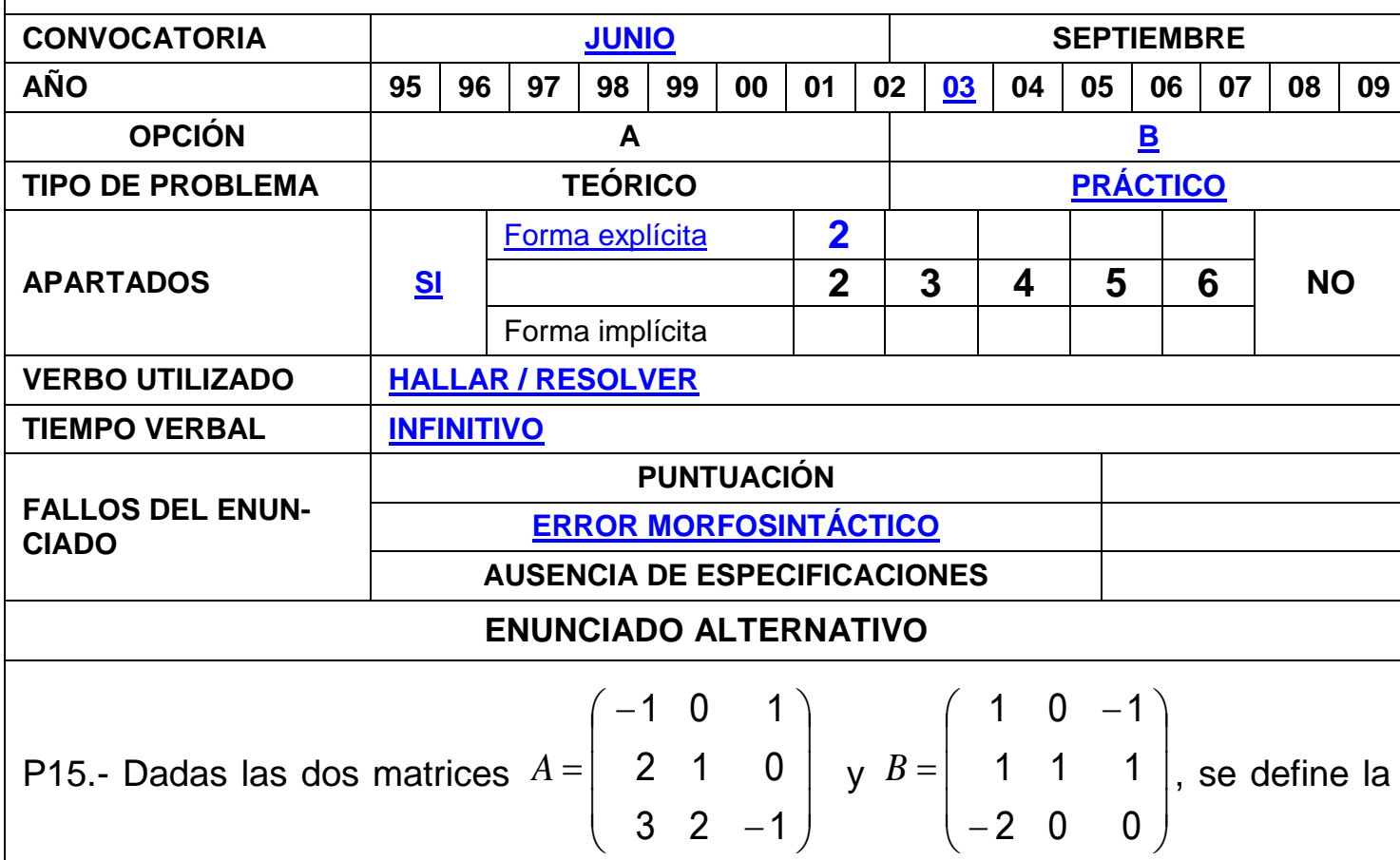

matriz $C=A+m B$.

a) Halla para qué valores de $m$ la matriz $C$ tiene rango menor que 3 .

b) Para $m=-1$, resuelve el sistema lineal homogéneo cuya matriz de coeficientes es $C$.

NIVELES DE COMPETENCIAS IMPLÍCITAS: Reproducción y conexión

$$
C=\left(\begin{array}{rrr}
-1 & 0 & 1 \\
2 & 1 & 0 \\
3 & 2 & -1
\end{array}\right)+m \cdot\left(\begin{array}{rrr}
1 & 0 & -1 \\
1 & 1 & 1 \\
-2 & 0 & 0
\end{array}\right)=\left(\begin{array}{ccc}
-1+m & 0 & 1-m \\
2+m & 1+m & m \\
3-2 m & 2 & -1
\end{array}\right)
$$

Calculamos el determinante: $\left|\begin{array}{ccc}-1+m & 0 & 1-m \\ 2+m & 1+m & m \\ 3-2 m & 2 & -1\end{array}\right|=-2\left(m^{3}+m^{2}-m-1\right)$ 
Resolviendo la ecuación $-2\left(m^{3}+m^{2}-m-1\right)=0$, se obtienen las soluciones:

$$
m=1 \quad \mathrm{y} \quad m=-1
$$

El alumno tiene que efectuar operaciones con matrices, calcular un determinante, resolver una ecuación y, al realizar esos cálculos, realiza operaciones elementales en contextos conocidos (RLSOn1), interpreta el lenguaje formal $y$ simbólico rutinario (RLSOn2) -en Segundo de Bachillerato-, maneja procedimientos y fórmulas resolviendo y calculando (RLSOn3) y utiliza variables y realiza ecuaciones y cálculos mediante procedimientos familiares (CLSOn3).

Por otra parte, el alumno sabe expresarse sobre cuestiones matemáticas (CCn1), comprende que tiene que emplear métodos matemáticos intermedios (CPRn2).

Si $m \neq 1$ y $m \neq-1$, el determinante es distinto de cero y el $\operatorname{rango}(C)=3$.

Si $m=1$, sustituyendo ese valor en el enunciado, tenemos la matriz:

$$
C=\left(\begin{array}{rrr}
0 & 0 & 0 \\
3 & 2 & 1 \\
1 & 2 & -1
\end{array}\right)
$$

Si $m=1$ entonces $\operatorname{rango}(C)=2$

Si $m=-1$, sustituyendo ese valor en el enunciado, tenemos la matriz:

$$
C=\left(\begin{array}{rrr}
-2 & 0 & 2 \\
1 & 0 & -1 \\
5 & 2 & -1
\end{array}\right)
$$

El rango $(C)=2$, dado que $F_{1}=-2 \cdot F_{1}$ y $\left|\begin{array}{ll}1 & 0 \\ 5 & 2\end{array}\right| \neq 0$

$$
\text { Si } m=-1 \text { entonces } \operatorname{rango}(C)=2
$$

El alumno sabe expresarse sobre cuestiones matemáticas (CCn1), explica los cálculos y sus propiedades (CCn2) e interpreta las relaciones implicadas (CCn3).

Igualmente, sigue el encadenamiento del argumento matemático particular (CAn2), evalúa el encadenamiento de argumentos matemáticos particulares (CAn3), traduce, en la práctica, el modelo a seguir, que es algo diferente de los 
estudiados (CMn2) aplicando, de este modo, conceptos matemáticos apropiados (CPRn3) y comunica los resultados (CMn3).

El apartado b) del problema de la ficha 3.15.1 es la resolución del sistema

$$
\left\{\begin{array}{c}
-2 x+2 z=0 \\
x-z=0 \\
5 x+2 y-z=0
\end{array}\right.
$$

lo que corresponde al nivel de reproducción del conocimiento estudiado, es la ejecución de un problema rutinario,-resolver el sistema cuando $m=-1$, mediante la aplicación de destrezas técnicas y de algoritmos habituales, manejando expresiones y fórmulas establecidas y realizando cálculos.

El alumno comprende la expresión escrita ( $\mathrm{RCn} 1)$, reconoce representaciones de los datos del ejercicio (RPRn1), -las ecuaciones del sistema-, le reconoce como problema ya practicado (RRPn1), usa un único tipo de representación estándar, ya utilizada (RRn1), la representación algebraica, plantea los algoritmos correspondientes (RPRn2) y asocia con fórmulas establecidas (RPRn3), consiste en resolver un sistema lineal homogéneo de tres ecuaciones con tres incógnitas-.

Identifica el problema (RAn1), identifica que el modelo es similar a otros vistos con anterioridad (RMn1) y le reconoce como problema ya practicado (RRPn1).

Dado que $\left|\begin{array}{ll}1 & 0 \\ 5 & 2\end{array}\right| \neq 0$, consideramos las ecuaciones $\left\{\begin{array}{c}x-z=0 \\ 5 x+2 y-z=0\end{array}\right.$

Expone el proceso de cálculo (RAn2), realiza explicaciones sencillas (RCn2) y reproduce un problema ya practicado, de manera cerrada (RRPn2), planteando los algoritmos correspondientes (RPRn2).

El sistema es compatible indeterminado, con solución:

$$
x=\lambda, y=-2 \lambda, z=\lambda
$$

El alumno resuelve problemas rutinarios estandarizados (RRPn3), describe los resultados obtenidos (RCn3), justifica las fórmulas utilizadas y los resultados (RAn3) y comunica de manera elemental los resultados (RMn3). 


\begin{tabular}{|l|c|c|c|c|c|c|c|c|}
\hline \multicolumn{7}{|c|}{ FICHA 3.15.2. COMPETENCIAS IMPLíCITAS EN LA RESOLUCIÓN DEL P15 } \\
\hline & Nivel 1 & Nivel 2 & Nivel 3 & Nivel 1 & Nivel 2 & Nivel 3 & Nivel 1 & Nivel 2 \\
\hline PR & $*$ & $*$ & $*$ & $*$ & $*$ & $*$ & & \\
\hline A & $*$ & $*$ & $*$ & $*$ & $*$ & $*$ & & \\
\hline C & $*$ & $*$ & $*$ & $*$ & $*$ & $*$ & & \\
\hline M & $*$ & & $*$ & $*$ & $*$ & $*$ & & \\
\hline RP & $*$ & $*$ & $*$ & $*$ & & & & \\
\hline R & $*$ & & & & & & & \\
\hline LSO & $*$ & $*$ & $*$ & & & $*$ & & \\
\hline & Reproducción & & Conexión & & Reflexión \\
\hline
\end{tabular}

\section{ANÁLISIS DEL PROBLEMA P18}

El apartado a) del problema que se presenta en la ficha 3.18.1 se encuadra en el nivel de conexión. Hay que estudiar las características de una familia de sistemas que dependen de un parámetro y este es un problema que reproduce situaciones similares a las estudiadas en la instrucción, pero que no son de mera rutina.

El alumno tiene que pensar en el tratamiento matemático necesario (CPRn1), escribir las matrices de los coeficientes del sistema y la matriz ampliada con los términos independientes-, tiene que comprender que debe emplear conceptos matemáticos intermedios (CPRn2) y aplicar los conceptos matemáticos apropiados (CPRn3).

Se tienen las matrices:Matriz de coeficientes $A=\left(\begin{array}{ccc}1 & 2 & 3 \\ 1 & a & 3 \\ 2 & 2+a & 6\end{array}\right) y$

matriz ampliada: $A^{*}=\left(\begin{array}{cccc}1 & 2 & 3 & 1 \\ 1 & a & 3 & 2 \\ 2 & 2+a & 6 & 3\end{array}\right)$

Hacemos el estudio del sistema a partir del examen de los rangos de la matriz de coeficientes y de la matriz ampliada.

Al hacer esta disertación, el alumno razona matemáticamente de manera simple (CAn1), sabe expresarse sobre cuestiones matemáticas (CCn1), estructura la situación que debe modelizar (CMn1) y explica los cálculos y sus propiedades (CCn2). 
FICHA 3.18.1.

ESTUDIO DEL ENUNCIADO DEL P18

P18.- Se considera el sistema de ecuaciones lineales $\left\{\begin{array}{c}x+2 y+3 z=1 \\ x+a y+3 z=2 \\ 2 x+(2+a) y+6 z=3\end{array}\right.$

a) ¿Existe algún valor del parámetro $a$ para el cual el sistema sea incompatible?

b) ¿Existe algún valor del parámetro a para el cual el sistema sea compatible determinado?

c) Resuélvase el sistema para $a=0$.

\begin{tabular}{|c|c|c|c|c|c|c|c|c|c|c|c|c|}
\hline CONVOCATORIA & \multicolumn{6}{|c|}{ JUNIO } & \multicolumn{6}{|c|}{ SEPTIEMBRE } \\
\hline AÑO & \begin{tabular}{l|l}
95 & 96
\end{tabular} & 97 & 98 & 99 & 00 & \begin{tabular}{l|l}
01 & 0 \\
\end{tabular} & \begin{tabular}{l|l}
02 & 03
\end{tabular} & $\underline{04}$ & 05 & \begin{tabular}{l|l|}
06 & 07 \\
\end{tabular} & 08 & 09 \\
\hline OPCIÓN & \multicolumn{6}{|c|}{ A } & \multicolumn{6}{|c|}{ B } \\
\hline TIPO DE PROBLEMA & \multicolumn{6}{|c|}{ TEÓRICO } & \multicolumn{6}{|c|}{ PRÁCTICO } \\
\hline \multirow{3}{*}{ APARTADOS } & \multirow{3}{*}{$\underline{\text { SI }}$} & \multicolumn{4}{|c|}{ Forma explícita } & & \multicolumn{2}{|l|}{3} & & \multirow[b]{2}{*}{6} & \multirow{3}{*}{\multicolumn{2}{|c|}{ NO }} \\
\hline & & & & & & 2 & 3 & 4 & 5 & & & \\
\hline & & \multicolumn{4}{|c|}{ Forma implícita } & & & & & & & \\
\hline VERBO UTILIZADO & \multicolumn{12}{|c|}{ EXISTIR / RESOLVER } \\
\hline TIEMPO VERBAL & \multicolumn{12}{|c|}{ PRESENTE DE INDICATIVO/ IDEM CON PRONOMBRE CLÍTICO } \\
\hline \multirow{3}{*}{$\begin{array}{l}\text { FALLOS DEL ENUN- } \\
\text { CIADO }\end{array}$} & \multicolumn{8}{|c|}{ PUNTUACIÓN } & & & & \\
\hline & \multicolumn{8}{|c|}{ ESTRUCTURA DE LA ORACIÓN } & & & & \\
\hline & \multicolumn{8}{|c|}{ EXPRESIÓN FARRAGOSA } & & & & \\
\hline \multicolumn{13}{|c|}{ ENUNCIADO ALTERNATIVO } \\
\hline \multirow{3}{*}{\multicolumn{7}{|c|}{ P18.- Se considera el sistema de ecuaciones lineales }} & \multicolumn{6}{|c|}{$x+2 y+3 z=1$} \\
\hline & & & & & & & \multicolumn{6}{|c|}{$x+a y+3 z=2$} \\
\hline & & & & & & & \multicolumn{6}{|c|}{$2 x+(2+a) y+6 z=3$} \\
\hline
\end{tabular}

a) Analiza si existe algún valor del parámetro a para el cual el sistema sea incompatible

b) Determina algún valor del parámetro a para el cual el sistema sea compatible determinado

c) Resuelve el sistema para $a=0$.

\section{NIVELES DE COMPETENCIAS IMPLÍCITAS: Reproducción y conexión}

En el determinante se puede observar que $F_{3}=F_{1}+F_{2}$, o que $C_{3}=3 \cdot C_{1}$

Resolviendo el determinante:

$$
\left|\begin{array}{ccc}
1 & 2 & 3 \\
1 & a & 3 \\
2 & 2+a & 6
\end{array}\right|=0
$$


independientemente del valor de $a$.

Al hacer esta observación, el alumno sabe expresarse sobre cuestiones matemáticas (CCn1), interpreta las relaciones implicadas (CCn3) sigue el encadenamiento de argumentos matemáticos particulares (CAn2) y evalúa el encadenamiento de argumentos matemáticos particulares (CAn3).

El alumno comprende que tiene que emplear conceptos matemáticos intermedios (CPRn2), aplica los conceptos matemáticos apropiados (CPRn3) y desarrolla procedimientos intuitivos ya practicados, pero no rutinarios (CRPn1).

Al calcular el determinante, realiza operaciones elementales en contextos conocidos (RLSOn1), interpreta el lenguaje formal y simbólico rutinario (RLSOn2), maneja procedimientos y fórmulas resolviendo y calculando (RLSOn3), usa un único tipo de representación estándar, ya utilizada (RRn1), la representación algebraica y utiliza variables y realiza ecuaciones y cálculos mediante procedimientos familiares (CLSOn3).

Considerando el menor:

$$
\left|\begin{array}{ll}
1 & 2 \\
1 & a
\end{array}\right|=a-2
$$

Resolviendo la ecuación:

$$
a-2=0,
$$

Obtiene la solución $a=2$.

Si $a \neq 2$ el rango de la matriz de coeficientes $A$ es $2 ; \operatorname{rango}(A)=2$.

Ampliando este menor con la columna de los términos independientes, tenemos el determinante:

$$
\left|\begin{array}{ccc}
1 & 2 & 1 \\
1 & a & 2 \\
2 & 2+a & 3
\end{array}\right|=0
$$

Cuyo valor es cero independientemente del valor del parámetro $a$, pues

$$
F_{3}=F_{1}+F_{2}
$$

Por tanto, 
Si $a \neq 2, \quad r g(A)=r g\left(A^{*}\right)=2<\mathrm{n}^{\circ}$ de incógnitas, por el teorema de RouchéFrobenius,

$$
\text { Si } a \neq 2 \text { el sistema es compatible indeterminado. }
$$

Tanto en la matriz de coeficientes, $A$, como en la matriz ampliada con los términos independientes, $A^{\star}$, se da la relación: $F_{3}=F_{1}+F_{2}$

Con este razonamiento, sigue y evalúa el encadenamiento de argumentos matemáticos particulares (CAn2, CAn3) e interpreta las relaciones implicadas (CCn3).

Si $a=2$, sustituyendo este valor, se obtienen las matrices:

$$
A=\left(\begin{array}{lll}
1 & 2 & 3 \\
1 & 2 & 3 \\
2 & 4 & 6
\end{array}\right) y \quad A^{*}=\left(\begin{array}{llll}
1 & 2 & 3 & 1 \\
1 & 2 & 3 & 2 \\
2 & 4 & 6 & 3
\end{array}\right)
$$

El $\operatorname{rango}(A)=1$, pues $F_{3}=2 F_{1}$ y $F_{2}=F_{1}$

$\operatorname{El~rango}\left(A^{*}\right)=2$, pues el menor $\left|\begin{array}{ll}1 & 1 \\ 1 & 2\end{array}\right| \neq 0$

Al calcular los determinantes, el alumno realiza operaciones elementales en contextos conocidos (RLSOn1), interpreta el lenguaje formal y simbólico rutinario (RLSOn2) -en Segundo de Bachiller-, maneja procedimientos y fórmulas resolviendo y calculando (RLSOn3) y utiliza variables y realiza ecuaciones y cálculos mediante procedimientos familiares (CLSOn3).

Si $a=2, r g(A) \neq r g\left(A^{*}\right)$, por el teorema de Rouché-Frobenius:

$$
\text { Si } a=2 \text {, el sistema es incompatible. }
$$

La respuesta al apartado a) del problema que se presenta en la ficha 3.18.1 es:

$$
\text { El sistema es incompatible para el valor } a=2 \text {. }
$$

Con lo que sigue el encadenamiento de argumentos matemáticos particulares (CAn2) y evalúa el encadenamiento de argumentos matemáticos particulares (CAn3), explicando los cálculos y sus propiedades (CCn2) e interpretando las relaciones implicadas (CCn3), a la par que sabe comunicar los resultados (CMn3). 
El apartado b) del problema de la ficha 3.18 .1 corresponde al nivel de reproducción del conocimiento estudiado, es la ejecución de un problema rutinario, mediante la aplicación de destrezas técnicas y de algoritmos habituales, manejando expresiones y fórmulas establecidas y realizando cálculos.

Con el estudio realizado en el apartado a) se deduce que

No existe ningún valor del parámetro a para el cual el sistema es compatible determinado.

En el apartado c) del problema de la ficha 3.18.1 nos piden resolver un sistema lineal, para el valor $a=0$, lo que corresponde al nivel de reproducción del conocimiento estudiado, es la ejecución de un problema rutinario, mediante la aplicación de destrezas técnicas y de algoritmos habituales, manejando expresiones y fórmulas establecidas y realizando cálculos.

Reconoce representaciones de los datos del ejercicio (RPRn1), comprende la expresión escrita (RCn1) -las ecuaciones del sistema-, plantea los algoritmos correspondientes (RPRn2) y asocia con fórmulas establecidas (RPRn3), consiste en resolver un sistema lineal de tres ecuaciones con tres incógnitas-.

Identifica el problema (RAn1), identifica que el modelo es similar a otros vistos con anterioridad (RMn1) y le reconoce como problema ya practicado (RRPn1).

Si $a=0$, se tiene el sistema dado por las ecuaciones:

$$
\left\{\begin{array}{l}
x+2 y+3 z=1 \\
x+3 z=2 \\
2 x+2 y+6 z=3
\end{array}\right.
$$

Como se ha estudiado, el sistema es compatible indeterminado, pues:

$$
F_{3}=F_{1}+F_{2}
$$

Si desechamos la tercera ecuación, tenemos el sistema dado por las ecuaciones:

$$
\left\{\begin{array}{c}
x+2 y+3 z=1 \\
x+3 z=2
\end{array}\right.
$$


Llamando $z=\lambda$, tenemos el sistema: $\left\{\begin{array}{c}x+2 y=1-3 \lambda \\ x=2-3 \lambda\end{array}\right.$

Como las ecuaciones son tan sencillas, hacemos la resolución por el método de Gauss, pues ya está calculada una incógnita.

Expone el proceso de cálculo (RAn2), realiza explicaciones sencillas (RCn2) y reproduce un problema ya practicado, de manera cerrada (RRPn2), planteando los algoritmos correspondientes (RPRn2).

$$
2 y=1-3 \lambda-(2-3 \lambda) \Rightarrow y=-\frac{1}{2}
$$

Justifica las fórmulas utilizadas y los resultados (RAn3), reproduce problemas ya practicados de manera cerrada (RRPn2), resuelve problemas rutinarios estandarizados (RRPn3) y comunica de manera elemental los resultados del modelo (RMn3).

\begin{tabular}{|c|c|c|c|c|c|c|c|c|}
\hline \multicolumn{2}{|c|}{ FICHA 3.18.2. } & \multicolumn{7}{|c|}{ COMPETENCIAS IMPLÍCITAS EN LA RESOLUCIÓN DEL P18 } \\
\hline & Nivel 1 & Nivel 2 & Nivel 3 & Nivel 1 & Nivel 2 & Nivel 3 & Nivel 1 & Nivel 2 \\
\hline PR & * & * & * & * & * & * & & \\
\hline A & * & * & * & * & * & * & & \\
\hline C & * & * & * & * & * & * & & \\
\hline M & * & & * & * & & & & \\
\hline $\mathbf{R P}$ & * & * & * & * & & & & \\
\hline $\mathbf{R}$ & * & & & & & & & \\
\hline \multirow[t]{2}{*}{ LSO } & * & * & * & & & * & & \\
\hline & \multicolumn{3}{|c|}{ Reproducción } & \multicolumn{3}{|c|}{ Conexión } & \multicolumn{2}{|c|}{ Reflexión } \\
\hline
\end{tabular}

\section{ANÁLISIS DEL PROBLEMA P22}

El problema que se presenta en la ficha 3.22.1 se encuadra en los niveles de reproducción y conexión.

El alumno tiene que pensar en el tratamiento matemático necesario (CPRn1), razona matemáticamente de manera simple (CAn1) y estructura la situación que debe modelizar (CMn1). 
FICHA 3.22.1.

ESTUDIO DEL ENUNCIADO DEL P22

P22.- Discútase, en función del parámetro real $k$, el siguiente sistema de ecuaciones lineales:

$$
\left\{\begin{array}{l}
k x+3 y=0 \\
3 x+2 y=k \\
3 x+k y=0
\end{array}\right.
$$

Resuélvase el sistema cuando sea posible.

\begin{tabular}{|c|c|c|c|c|c|c|c|c|c|c|c|}
\hline CONVOCATORIA & \multicolumn{5}{|c|}{ JUNIO } & \multicolumn{6}{|c|}{ SEPTIEMBRE } \\
\hline AÑO & \begin{tabular}{l|l}
95 & 96 \\
\end{tabular} & 97 & \begin{tabular}{l|l}
98 & 99
\end{tabular} & 00 & 01 & \begin{tabular}{l|l}
02 & 03 \\
\end{tabular} & 04 & 05 & \begin{tabular}{l|l}
$\underline{06}$ & 07
\end{tabular} & 08 & 09 \\
\hline OPCIÓN & \multicolumn{5}{|c|}{ A } & \multicolumn{6}{|c|}{$\underline{B}$} \\
\hline TIPO DE PROBLEMA & \multicolumn{5}{|c|}{ TEÓRICO } & \multicolumn{6}{|c|}{ PRÁCTICO } \\
\hline \multirow{3}{*}{ APARTADOS } & \multirow{3}{*}{ SI } & \multicolumn{3}{|c|}{ Forma explícita } & 2 & & & & \multirow[b]{2}{*}{6} & \multirow{3}{*}{\multicolumn{2}{|c|}{ NO }} \\
\hline & & & & & 2 & 3 & 4 & 5 & & & \\
\hline & & \multicolumn{3}{|c|}{ Forma implícita } & & & & 5 & & & \\
\hline VERBO UTILIZADO & \multicolumn{11}{|c|}{ DISCUTIR / RESOLVER } \\
\hline TIEMPO VERBAL & \multicolumn{11}{|c|}{ PRESENTE DE SUBJUNTIVO CON PRONOMBRE CLÍTICO } \\
\hline \multirow{3}{*}{$\begin{array}{l}\text { FALLOS DEL ENUN- } \\
\text { CIADO }\end{array}$} & \multicolumn{7}{|c|}{ PUNTUACIÓN } & & & & \\
\hline & \multicolumn{7}{|c|}{ ORDEN DE LAS PALABRAS EN LA ORACIÓN } & & & & \\
\hline & \multicolumn{7}{|c|}{ ERROR MORFOLÓGICO } & & & & \\
\hline
\end{tabular}

P22.- a) Discute el siguiente sistema de ecuaciones lineales, en función del parámetro real $k$ :

$$
\left\{\begin{array}{l}
k x+3 y=0 \\
3 x+2 y=k \\
3 x+k y=0
\end{array}\right.
$$

b) Cuando sea posible, resuelve el sistema

NIVELES DE COMPETENCIAS IMPLÍCITAS: Reproducción y conexión

Como el sistema tiene más ecuaciones que incógnitas, se empieza el estudio con el determinante de la matriz ampliada: $K^{*}=\left(\begin{array}{ccc}k & 3 & 0 \\ 3 & 2 & k \\ 3 & k & 0\end{array}\right)$

El alumno comprende que debe emplear conceptos matemáticos intermedios (CPRn2) y aplicar los conceptos matemáticos apropiados (CPRn3). 


$$
\left|K^{*}\right|=\left|\begin{array}{ccc}
k & 3 & 0 \\
3 & 2 & k \\
3 & k & 0
\end{array}\right|=k^{3}-9 k
$$

El alumno resuelve la ecuación:

$$
k^{3}-9 k=0
$$

Obteniendo las soluciones:

$$
k_{1}=0, k_{2}=-3 \text { y } k_{3}=3
$$

Al calcular el determinante, comprende que tiene que emplear conceptos matemáticos intermedios (CPRn2), utiliza variables y realiza ecuaciones y cálculos mediante procedimientos familiares (CLSOn3) y al resolver la ecuación, el alumno realiza operaciones elementales en contextos conocidos (RLSOn1), interpreta el lenguaje formal y simbólico rutinario (RLSOn2), maneja procedimientos y fórmulas resolviendo y calculando (RLSOn3).

Para todos los valores $k \neq 0, k \neq-3$ y $k \neq 3$ el rango de la matriz $K^{\star}$ es 3 , rango $\left(K^{*}\right)=3$ y dado que el sistema sólo tiene dos columnas, el $\operatorname{rango}(K)=2$.

Si $k \neq 0, k \neq-3$ y $k \neq 3 \Rightarrow \operatorname{rango}(K) \neq \operatorname{rango}\left(K^{*}\right)$

Si $k \neq 0, k \neq-3$ y $k \neq 3$ el sistema es incompatible.

El alumno aplica los conceptos matemáticos apropiados (CPRn3), explicando los cálculos y sus propiedades (CCn2), desarrolla procedimientos intuitivos ya practicados, pero no rutinarios (CRPn1) e interpreta las relaciones implicadas (CCn3).

A continuación el alumno tiene que resolver tres sistemas para los valores $k_{1}=0, k_{2}=-3$ y $k_{3}=3$, lo que corresponde al nivel de reproducción del conocimiento estudiado, es la ejecución de un problema rutinario, mediante la aplicación de destrezas técnicas y de algoritmos habituales, manejando expresiones y fórmulas establecidas y realizando cálculos.

Si $k=0$, el sistema es $\left\{\begin{array}{c}3 y=0 \\ 3 x+2 y=0 \\ 3 x=0\end{array}\right.$ 
El alumno reconoce representaciones de los datos del ejercicio (RPRn1), -las ecuaciones del sistema-, plantea los algoritmos correspondientes (RPRn2) y asocia con fórmulas establecidas (RPRn3).

Identifica el problema (RAn1), identifica que el modelo es similar a otros vistos con anterioridad (RMn1) y le reconoce como problema ya practicado (RRPn1).

Expone el proceso de cálculo (RAn2), plantea los algoritmos correspondientes (RPRn2), usa un único tipo de representación estándar, ya utilizada (RRn1), la representación algebraica, realiza explicaciones sencillas (RCn2) y reproduce un problema ya practicado, de manera cerrada (RRPn2).

Si $k=0$,el sistema es compatible determinado, con solución $x=0, y=0$

Si $k=3$, el sistema es $\left\{\begin{array}{l}3 x+3 y=0 \\ 3 x+2 y=3 \\ 3 x+3 y=0\end{array}\right.$

Si $k=3, \operatorname{rango}(K)=\operatorname{rango}\left(K^{*}\right)=2=n^{\circ}$ de incógnitas, pues es evidente que $F_{1}=F_{3}$.

Por el teorema de Rouché-Frobenius,

Si $k=3$ el sistema es compatible determinado, con solución $x=3, y=-3$

Si $k=-3$, el sistema es $\left\{\begin{array}{c}-3 x+3 y=0 \\ 3 x+2 y=-3 \\ 3 x-3 y=0\end{array}\right.$

Si $k=-3, \operatorname{rango}(K)=\operatorname{rango}\left(K^{*}\right)=2=n^{\circ}$ de incógnitas, pues es evidente que $F_{1}=-F_{3}$.

Por el teorema de Rouché-Frobenius,

Si $k=-3$ el sistema es compatible determinado con solución

$$
x=-\frac{3}{5}, y=-\frac{3}{5} .
$$

El alumno describe los resultados obtenidos (RCn3), justifica las fórmulas utilizadas y los resultados (RAn3), resuelve problemas rutinarios estandarizados (RRPn3) y comunica de manera elemental los resultados del modelo (RMn3). 


\begin{tabular}{|l|c|c|c|c|c|c|c|c|}
\hline \multicolumn{6}{|c|}{ FICHA 3.22.2. } & COMPETENCIAS IMPLÍCITAS EN LA RESOLUCIÓN DEL P22 \\
\hline & Nivel 1 & Nivel 2 & Nivel 3 & Nivel 1 & Nivel 2 & Nivel 3 & Nivel 1 & Nivel 2 \\
\hline PR & $*$ & $*$ & $*$ & $*$ & $*$ & $*$ & & \\
\hline A & $*$ & $*$ & $*$ & $*$ & $*$ & $*$ & & \\
\hline C & $*$ & $*$ & $*$ & $*$ & $*$ & $*$ & & \\
\hline M & $*$ & & $*$ & $*$ & & & & \\
\hline RP & $*$ & $*$ & $*$ & $*$ & & & & \\
\hline R & $*$ & & & & & & & \\
\hline LSO & $*$ & $*$ & $*$ & & & $*$ & & \\
\hline & Reproducción & & Conexión & & Reflexión \\
\hline
\end{tabular}

\section{ANÁLISIS DEL PROBLEMA P23}

El problema de la ficha 3.23.1 pide que el alumno resuelva un sistema de ecuaciones lineales y realice unas operaciones con matrices, lo que corresponde al nivel de reproducción, se trata del reconocimiento de equivalentes, ejecución de problemas rutinarios, aplicación de destrezas técnicas y algoritmos habituales, manejo de expresiones y fórmulas establecidas y realización de cálculos.

En el apartado a) el alumno reconoce las representaciones de los datos del ejercicio (RPRn1), comprende la expresión escrita (RCn1), identifica el problema (RAn1), reconoce el problema como ya practicado (RRPn1) e identifica que es un modelo similar a otros vistos con anterioridad (RMn1). A continuación, expone el proceso de cálculo (RAn2).

El alumno plantea los algoritmos correspondientes (RPRn2) y asocia con fórmulas establecidas y realiza cálculos (RPRn3).

$$
A B^{T}=\left(\begin{array}{l}
1 \\
2 \\
3
\end{array}\right) \cdot\left(\begin{array}{lll}
7 & 2 & -2
\end{array}\right)=\left(\begin{array}{ccc}
7 & 2 & -2 \\
14 & 4 & -4 \\
21 & 6 & -6
\end{array}\right)
$$

Esa matriz no admite inversa pues en ella $F_{2}=2 F_{1}$ y $F_{3}=3 F_{1}$ y por tanto es una matriz singular.

El alumno realiza explicaciones sencillas (RCn2), justifica las fórmulas utilizadas (RAn3) y reproduce problemas ya practicados, de manera cerrada (RRPn2). 
FICHA 3.23.1.

ESTUDIO DEL ENUNCIADO DEL P23

P23.- Sean las matrices $A=\left(\begin{array}{l}1 \\ 2 \\ 3\end{array}\right), B=\left(\begin{array}{r}7 \\ 2 \\ -2\end{array}\right), C=\left(\begin{array}{lll}0 & 0 & 0 \\ 0 & 1 & 0 \\ 0 & 0 & 1\end{array}\right), D=\left(\begin{array}{l}0 \\ 2 \\ 2\end{array}\right)$ y $E=\left(\begin{array}{l}2 \\ 5 \\ 3\end{array}\right)$.

a) Hallar la matriz $A B^{T}$ donde $B^{T}$ indica la matriz traspuesta de $B$. ¿Es inversible?

b) Hallar el rango de la matriz $A^{T} D$.

c) Calcular $M=\left(\begin{array}{l}x \\ y \\ z\end{array}\right)$ que verifique la ecuación $\left(A B^{T}+C\right) M=E$.

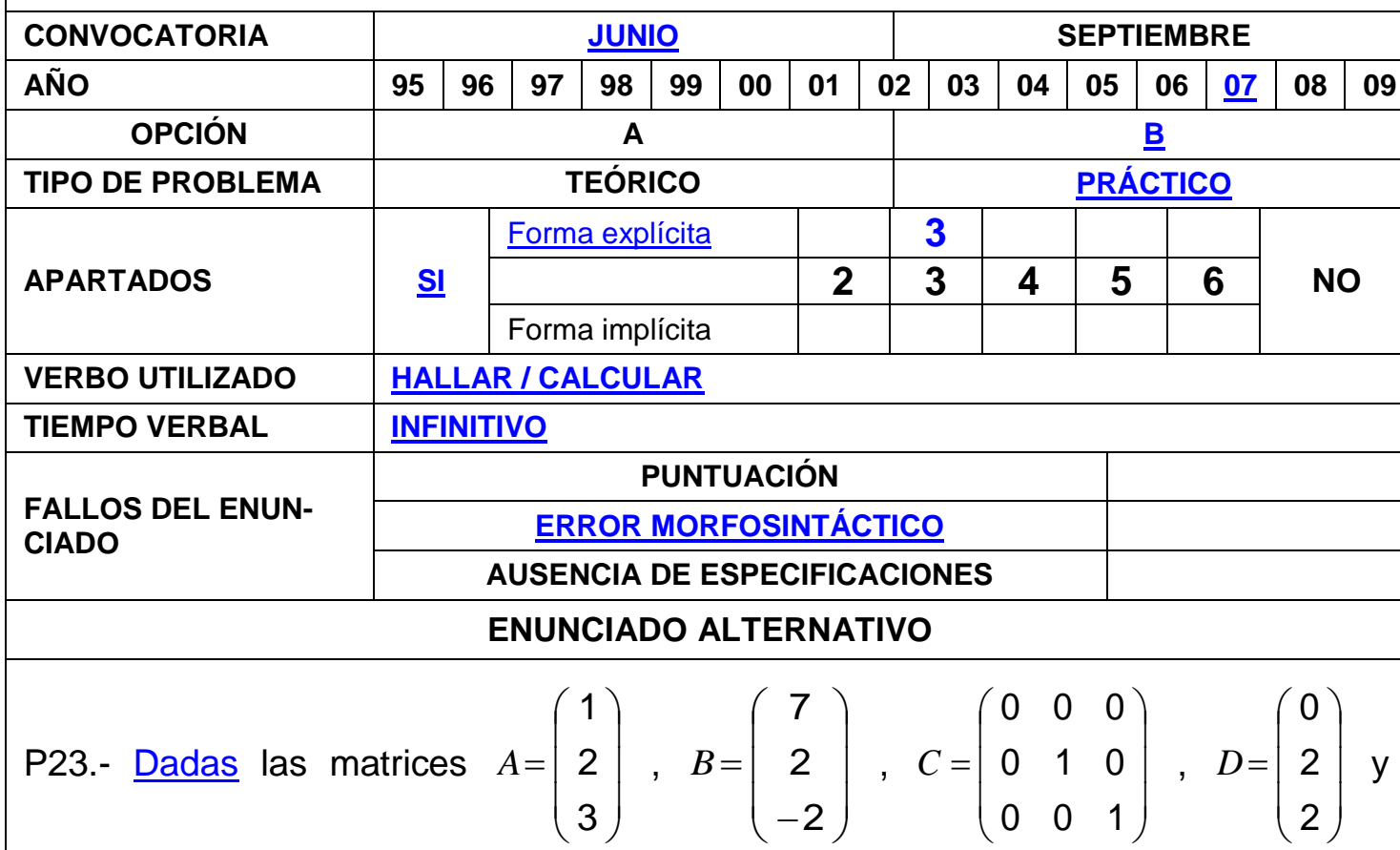

$E=\left(\begin{array}{l}2 \\ 5 \\ 3\end{array}\right)$

a) Halla la matriz $A B^{T}$ donde $B^{T}$ indica la matriz traspuesta de $B$.

b) Estudia si la matriz $A B^{T}$ es inversible.

c) Halla el rango de la matriz $A^{T} D$.

d) Calcula la matriz $M=\left(\begin{array}{l}x \\ y \\ z\end{array}\right)$ que verifica la ecuación $\left(A B^{T}+C\right) M=E$.

NIVELES DE COMPETENCIAS IMPLÍCITAS: Reproducción 
El apartado b) del problema de la ficha 3.23.1 también corresponde al nivel de reproducción.

$$
A^{T} D=\left(\begin{array}{lll}
1 & 2 & 3
\end{array}\right) \cdot\left(\begin{array}{l}
0 \\
2 \\
2
\end{array}\right)=10
$$

$\mathrm{Y}$, en consecuencia, rango $\left(A^{T} D\right)=1$

El alumno usa un único tipo de representación estándar, ya utilizada (RRn1), la representación algebraica.

Al hacer las operaciones correspondientes al producto de matrices, realiza operaciones elementales en contextos conocidos (RLSOn1), interpreta el lenguaje formal y simbólico rutinario (RLSOn2) -en Segundo de Bachiller-, maneja procedimientos y fórmulas resolviendo y calculando (RLSOn3) y utiliza variables y realiza ecuaciones y cálculos mediante procedimientos familiares (CLSOn3).

El apartado c) del problema de la ficha 3.23.1 corresponde al nivel de reproducción del conocimiento estudiado. Conocimiento de hechos, representaciones de problemas comunes, reconocimiento de equivalentes, ejecución de problemas rutinarios mediante la aplicación de destrezas técnicas y de algoritmos habituales y realización de cálculos.

Se pide la resolución de un sistema lineal de ecuaciones, el alumno reconoce las representaciones de los datos del ejercicio (RPRn1), comprende la expresión escrita (RCn1), identifica el problema (RAn1), reconoce el problema como ya practicado (RRPn1) e identifica que es un modelo similar a otros vistos con anterioridad (RMn1).

$$
A B^{T}+C=\left(\begin{array}{ccc}
7 & 2 & -2 \\
14 & 4 & -4 \\
21 & 6 & -6
\end{array}\right)+\left(\begin{array}{lll}
0 & 0 & 0 \\
0 & 1 & 0 \\
0 & 0 & 1
\end{array}\right)=\left(\begin{array}{ccc}
7 & 2 & -2 \\
14 & 5 & -4 \\
21 & 6 & -5
\end{array}\right)
$$

Se pide resolver el sistema:

$$
\left.\begin{array}{c}
7 x+2 y-2 z=2 \\
14 x+5 y-4 z=5 \\
21 x+6 y-5 z=3
\end{array}\right\}
$$


El alumno reconoce representaciones de los datos del ejercicio (RPRn1), -las ecuaciones del sistema-, expone el proceso de cálculo (RAn2), realiza explicaciones sencillas (RCn2), plantea los algoritmos correspondientes (RPRn2) y asocia con fórmulas establecidas (RPRn3).

Resuelve el sistema por el método de Gauss, haciendo combinaciones lineales entre filas

$$
\left(\begin{array}{cccc}
7 & 2 & -2 \vdots & 2 \\
14 & 4 & -4 \vdots & 5 \\
21 & 6 & -5 \vdots & 3
\end{array}\right) \rightarrow \begin{gathered}
F_{1} \\
F_{2}+F_{1} \cdot(-2) \\
F_{3}+F_{1} \cdot(-3)
\end{gathered} \rightarrow\left(\begin{array}{rrrr}
7 & 2 & -2 \vdots & 2 \\
0 & 1 & 0 \vdots & 1 \\
0 & 0 & 1 \vdots & -3
\end{array}\right)
$$

El alumno realiza operaciones elementales en contextos conocidos (RLSOn1), interpreta el lenguaje formal y simbólico rutinario (RLSOn2) -en Segundo de Bachiller-, reproduce un problema ya practicado, de manera cerrada (RRPn2), maneja procedimientos y fórmulas resolviendo y calculando (RLSOn3).

Al realizar las operaciones matriciales utiliza variables y realiza ecuaciones y cálculos mediante procedimientos familiares (CLSOn3).

Y la solución del sistema es:

$$
x=-\frac{6}{7}, y=1, z=-3
$$

El alumno resuelve problemas rutinarios estandarizados (RRPn3), en un nivel de Matemáticas II, comunica de manera elemental los resultados (RMn3) y describe los resultados obtenidos (RCn3).

\begin{tabular}{|l|c|c|c|c|c|c|c|c|}
\hline \multicolumn{7}{|c|}{ FICHA 3.23.2. COMPETENCIAS IMPLíCITAS EN LA RESOLUCIÓN DEL P23 } \\
\hline & Nivel 1 & Nivel 2 & Nivel 3 & Nivel 1 & Nivel 2 & Nivel 3 & Nivel 1 & Nivel 2 \\
\hline PR & $*$ & $*$ & $*$ & & & & & \\
\hline A & $*$ & $*$ & $*$ & & & & & \\
\hline C & $*$ & $*$ & $*$ & & & & & \\
\hline M & $*$ & & $*$ & & & & & \\
\hline RP & $*$ & $*$ & $*$ & & & & & \\
\hline R & $*$ & & & & & & & \\
\hline LSO & $*$ & $*$ & $*$ & & & $*$ & & \\
\hline & Reproducción & & Conexión & & Reflexión \\
\hline
\end{tabular}




\section{ANÁLISIS DEL PROBLEMA P28}

FICHA 3.28.1.

ESTUDIO DEL ENUNCIADO DEL P28

P28.- a) Discutir, según el valor del parámetro real $a$, el siguiente sistema de ecuaciones:

$$
\left\{\begin{array}{c}
2 x+y+z=4 \\
x-a y+z=a \\
3 x+2 z=5
\end{array}\right.
$$

b) Interpretar la discusión realizada en a) en términos de la posición relativa de los planos dados por cada una de las tres ecuaciones del sistema.

\begin{tabular}{|c|c|c|c|c|c|c|c|c|c|c|c|c|}
\hline CONVOCATORIA & \multicolumn{6}{|c|}{ JUNIO } & \multicolumn{6}{|c|}{ SEPTIEMBRE } \\
\hline AÑO & \begin{tabular}{l|l}
95 & 96 \\
\end{tabular} & 97 & 98 & 99 & 00 & 01 & \begin{tabular}{l|l|}
02 & 03 \\
\end{tabular} & 04 & 05 & \begin{tabular}{l|l}
06 & 07
\end{tabular} & 08 & 09 \\
\hline OPCIÓN & \multicolumn{6}{|c|}{ A } & \multicolumn{6}{|c|}{ B } \\
\hline TIPO DE PROBLEMA & \multicolumn{6}{|c|}{ TEÓRICO } & \multicolumn{6}{|c|}{ PRÁCTICO } \\
\hline \multirow{3}{*}{ APARTADOS } & \multirow{3}{*}{$\underline{\text { SI }}$} & \multicolumn{4}{|c|}{ Forma explícita } & 2 & & & \multirow{3}{*}{5} & \multirow[b]{2}{*}{6} & \multirow{3}{*}{\multicolumn{2}{|c|}{ NO }} \\
\hline & & & & & & 2 & 3 & 4 & & & & \\
\hline & & \multicolumn{4}{|c|}{ Forma implícita } & & & & & & & \\
\hline VERBO UTILIZADO & \multicolumn{12}{|c|}{ DISCUTIR / INTERPRETAR } \\
\hline TIEMPO VERBAL & \multicolumn{12}{|c|}{ INFINITIVO } \\
\hline \multirow{3}{*}{$\begin{array}{l}\text { FALLOS DEL ENUN- } \\
\text { CIADO }\end{array}$} & \multicolumn{8}{|c|}{ PUNTUACIÓN } & & & & \\
\hline & \multicolumn{8}{|c|}{ ERROR MORFOLÓGICO } & & & & \\
\hline & \multicolumn{8}{|c|}{ ORDEN DE LAS PALABRAS EN LA ORACIÓN } & & & & \\
\hline \multicolumn{13}{|c|}{ ENUNCIADO ALTERNATIVO } \\
\hline
\end{tabular}

P28.- a) Discute, el siguiente sistema de ecuaciones, según el valor del parámetro real $a$ :

$$
\left\{\begin{array}{c}
2 x+y+z=4 \\
x-a y+z=a \\
3 x+2 z=5
\end{array}\right.
$$

b) Interpreta la discusión realizada en a) en términos de la posición relativa de los planos dados por cada una de las tres ecuaciones del sistema.

NIVELES DE COMPETENCIAS IMPLÍCITAS: Reproducción y conexión

El problema que se presenta en la ficha 3.28.1 se encuadra en los niveles de reproducción y conexión pues pide estudiar las características de una familia de sistemas que depende de un parámetro, y este es un problema que reproduce situaciones similares pero que ya no son de mera rutina.

El apartado a) del problema que se presenta en la ficha 3.28.1 se encuadra en el nivel de conexión. 
Para discutir el sistema hay que hacer un estudio, en función de los valores del parámetro $a$, de los rangos de la matriz de coeficientes y de la matriz ampliada, con lo que el alumno piensa en el tratamiento matemático necesario (CPRn1) razona matemáticamente de manera simple (CAn1), y estructura la situación que debe modelizar (CMn1).

Tenemos las matrices:

coeficientes del sistema: $A=\left(\begin{array}{rrr}2 & 1 & 1 \\ 1 & -a & 1 \\ 3 & 0 & 2\end{array}\right) y$

matriz ampliada ccon los términos independientes $A^{*}=\left(\begin{array}{rrrr}2 & 1 & 1 & 4 \\ 1 & -a & 1 & a \\ 3 & 0 & 2 & 5\end{array}\right)$

El alumno desarrolla procedimientos intuitivos ya practicados, pero no rutinarios (CRPn1) y explica los cálculos y sus propiedades (CCn2).

Para estudiar el rango de las matrices se calcula el valor del determinante $\operatorname{det}(A)$.

Al efectuar esta disertación, el alumno razona matemáticamente de manera simple (CAn1), comprende que tiene que emplear conceptos matemáticos intermedios (CPRn2) y aplica los conceptos matemáticos apropiados (CPRn3) y utiliza variables y realiza ecuaciones y cálculos mediante procedimientos familiares (CLSOn3).

$$
\operatorname{det}(A)=\left|\begin{array}{rrr}
2 & 1 & 1 \\
1 & -a & 1 \\
3 & 0 & 2
\end{array}\right|=-a+1
$$

Resuelve la ecuación $-a+1=0$

\section{Obteniendo la solución $a=1$}

Al resolver la ecuación el alumno realiza operaciones elementales en contextos conocidos (RLSOn1), interpreta el lenguaje formal y simbólico rutinario (RLSOn2) -en Segundo de Bachiller-, maneja procedimientos y fórmulas resolviendo y calculando (RLSOn3) y utiliza variables y realiza ecuaciones y cálculos mediante procedimientos familiares (CLSOn3).

Si $a \neq 1$ el rango de la matriz de coeficientes $A$ es $3 ; \operatorname{rango}(A)=3$ 
Dado que la matriz ampliada $A^{*}$ sólo tiene tres filas, el rango de $A^{*}$ sólo puede ser $3, \operatorname{rango}\left(A^{*}\right)=3$

Con esta explicación, el alumno sigue y evalúa el encadenamiento de argumentos matemáticos particulares (CAn2, CAn3), explica los cálculos y sus propiedades (CCn2) e interpreta las relaciones implicadas (CCn3).

Si $a \neq 1 \operatorname{rango}(A)=\operatorname{rango}\left(A^{*}\right)=3=\mathrm{n}^{\circ}$ de incógnitas

Por el teorema de Rouché-Fröbenius,

Si $a \neq 1$, el sistema es compatible determinado.

Si $a=1$, se tiene el sistema $\left\{\begin{array}{c}2 x+y+z=4 \\ x-y+z=1 \\ 3 x+2 z=5\end{array}\right.$

Con matriz de los coeficientes del sistema

$$
A=\left(\begin{array}{rrr}
2 & 1 & 1 \\
1 & -1 & 1 \\
3 & 0 & 2
\end{array}\right)
$$

Y matriz ampliada

$$
A^{*}=\left(\begin{array}{rrrr}
2 & 1 & 1 & 4 \\
1 & -1 & 1 & 1 \\
3 & 0 & 2 & 5
\end{array}\right)
$$

En ambas matrices se da la combinación lineal $F_{3}=F_{1}+F_{2}$, y por consiguiente, si el alumno se diera cuenta de ello, sabe expresarse sobre cuestiones matemáticas (CCn1) y realizaría explicaciones sencillas (RCn2).

Se tiene $\operatorname{rango}(A)=2$, pues el menor $\left|\begin{array}{ll}2 & 1 \\ 1 & 1\end{array}\right| \neq 0$

Si $a=1, \operatorname{rango}(A)=\operatorname{rango}\left(A^{*}\right)=2<\mathrm{n}^{\circ}$ de incógnitas

Por el teorema de Rouché-Fröbenius,

Si $a=1$, el sistema es compatible indeterminado.

El alumno sigue el encadenamiento de argumentos matemáticos particulares (CAn2) y evalúa el encadenamiento de argumentos matemáticos particulares 
(CAn3), explicando los cálculos y sus propiedades (CCn2) e interpretando las relaciones implicadas (CCn3).

El apartado b) del problema de la ficha 3.28.1, la interpretación de la discusión en términos de la posición relativa de los planos corresponde al nivel de reproducción del conocimiento estudiado, es la ejecución de un problema rutinario mediante la aplicación de destrezas técnicas y de algoritmos habituales, manejando expresiones y fórmulas establecidas

Reconoce representaciones de los datos del ejercicio (RPRn1), comprende la expresión escrita (RCn1), -las ecuaciones de los planos-, plantea los algoritmos correspondientes (RPRn2) y asocia con fórmulas establecidas (RPRn3).

Identifica el problema (RAn1), identifica que el modelo es similar a otros vistos con anterioridad (RMn1) expone el proceso de cálculo (RAn2) y le reconoce como problema ya practicado (RRPn1).

Si $a \neq 1, \operatorname{rango}(A)=\operatorname{rango}\left(A^{*}\right)=3$, el sistema es compatible determinado, tiene solución única, y como consecuencia

Si $a \neq 1$, los tres planos se cortan en un punto.

Si $a=1, \operatorname{rango}(A)=\operatorname{rango}\left(A^{*}\right)=2$, el sistema es compatible indeterminado.

La resolución del sistema nos da infinitas soluciones que dependen de un parámetro, es decir, la ecuación de la recta de intersección de esos planos.

Si $a=1$ los planos se cortan en una recta.

El alumno usa un único tipo de representación estándar, ya utilizada (RRn1), la representación algebraica, interpreta representaciones estándar de objetos matemáticos (RRn2), las ecuaciones de los planos y realiza el paso establecido de una representación a otra (RRn3).

Asimismo, justifica las fórmulas utilizadas y los resultados (RAn3), plantea los algoritmos correspondientes (RPRn2), realiza explicaciones sencillas (RCn2), describe los resultados obtenidos ( $\mathrm{RCn} 3$ ), reproduce un problema ya practicado, de manera cerrada (RRPn2), resuelve problemas rutinarios estandarizados (RRPn3) y comunica de manera elemental los resultados (RMn3). 


\begin{tabular}{|c|c|c|c|c|c|c|c|c|}
\hline \multicolumn{2}{|c|}{ FICHA 3.28.2. } & \multicolumn{7}{|c|}{ COMPETENCIAS IMPLÍCITAS EN LA RESOLUCIÓN DEL P28 } \\
\hline & Nivel 1 & Nivel 2 & Nivel 3 & Nivel 1 & Nivel 2 & Nivel 3 & Nivel 1 & Nivel 2 \\
\hline PR & * & * & * & * & * & * & & \\
\hline A & * & * & * & * & * & * & & \\
\hline C & * & * & * & * & * & * & & \\
\hline$M$ & * & & * & * & & & & \\
\hline RP & * & * & * & * & & & & \\
\hline $\mathbf{R}$ & * & * & * & & & & & \\
\hline LSO & * & * & * & & & * & & \\
\hline & \multicolumn{3}{|c|}{ Reproducción } & \multicolumn{3}{|c|}{ Conexión } & \multicolumn{2}{|c|}{ Reflexión } \\
\hline
\end{tabular}

\section{V.3. ESTUDIO DE LAS CUESTIONES DE ÁLGEBRA}

Una muestra de 20 de las 57 cuestiones propuestas en las pruebas PAEU en las Universidades de Castilla y León en el periodo LOGSE sirve para confirmar que el nivel de Reproducciónes el que predomina en estas cuestiones.

Son cuestiones sencillas, pero variadas en su enunciado, al contrario que en los problemas en los que predomina el estudio y resolución de un sistema de ecuaciones lineales.

Siguiendo la pauta de los capítulos anteriores se presentan dos tablas para cada cuestión, una que contiene el enunciado y las competencias implícitas en el mismo, su ubicación temporal, un análisis gramatical y enunciaddo altenativo y, tras la conclusión, se presenta otra tabla de competencias que se detectan en su resolución.

\section{ANÁLISIS DE LA CUESTIÓN C2}

La cuestión de la ficha 4.2.1 corresponde al nivel de reproducción dado que pide la resolución de un sistema matricial equivalente a un sistema lineal básico. Se trata del reconocimiento de equivalentes, ejecución de problemas rutinarios, aplicación de destrezas técnicas y algoritmos habituales, manejo de expresiones y fórmulas establecidas y realización de cálculos.

El alumno reconoce las matrices, es decir, reconoce las representaciones de los datos del ejercicio (RPRn1), identifica el problema (RAn1), -es un sistema matricial-, comprende la expresión escrita (RCn1), identifica que es un modelo 
similar a otros vistos con anterioridad (RMn1) y reconoce el problema como ya practicado (RRPn1).

\section{FICHA 4.2.1. $\quad$ ESTUDIO DEL ENUNCIADO DEL C2}

C2.- Determinar las matrices $A$ y $B$ sabiendo que

$$
2 A+B=\left(\begin{array}{cc}
5 & 12 \\
4 & 2
\end{array}\right) \quad 3 A+2 B=\left(\begin{array}{ll}
11 & 25 \\
20 & 10
\end{array}\right)
$$

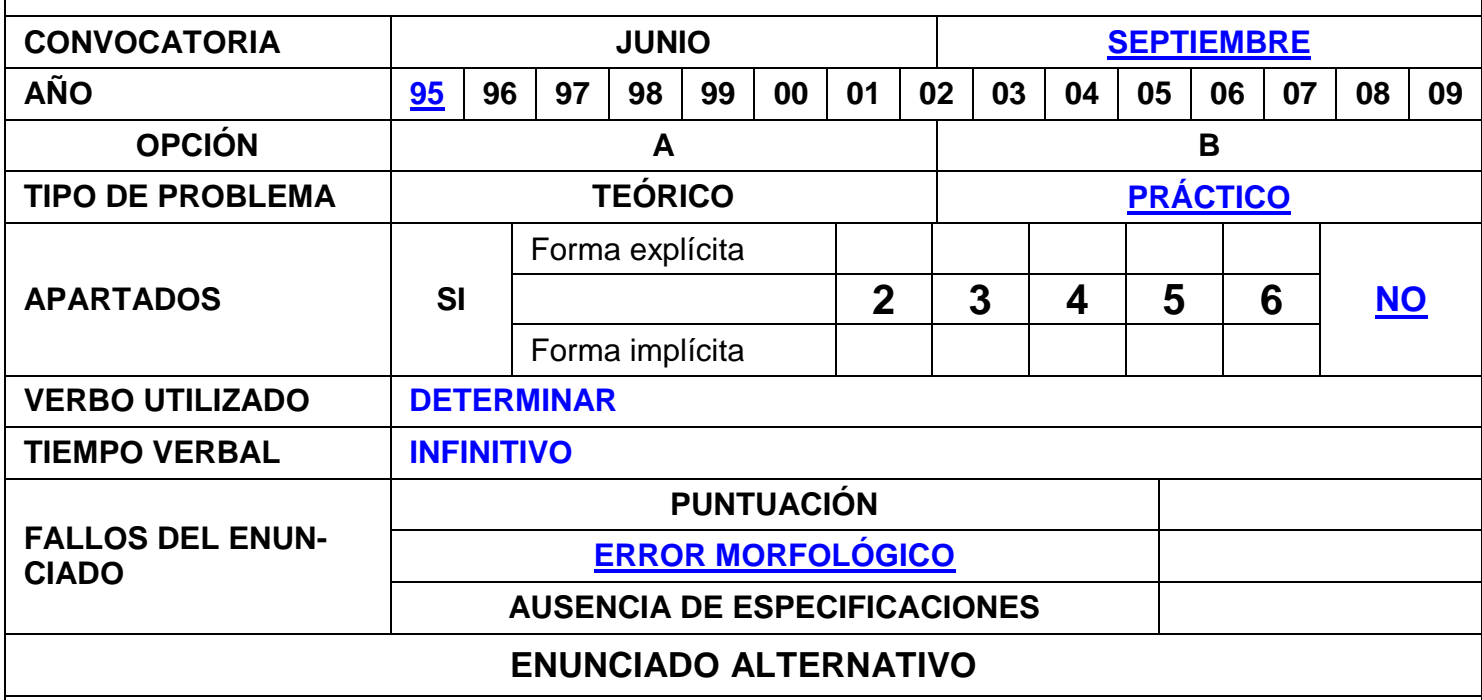

C2.- Determina las matrices $A$ y $B$ sabiendo que

$$
2 A+B=\left(\begin{array}{cc}
5 & 12 \\
4 & 2
\end{array}\right) \quad 3 A+2 B=\left(\begin{array}{ll}
11 & 25 \\
20 & 10
\end{array}\right)
$$

\section{NIVELES DE COMPETENCIAS IMPLÍCITAS: Reproducción}

A continuación, expone el proceso de cálculo (RAn2).

Llamando $C=\left(\begin{array}{cc}5 & 12 \\ 4 & 2\end{array}\right)$ y $D=\left(\begin{array}{ll}11 & 25 \\ 20 & 10\end{array}\right)$, se tiene el sistema:

$$
\left.\begin{array}{c}
2 A+B=C \\
3 A+2 B=D
\end{array}\right\}
$$

El alumno usa un único tipo de representación estándar, ya utilizada (RRn1), la representación algebraica.

El alumno reproduce problemas ya practicados, de manera cerrada (RRPn2), plantea los algoritmos correspondientes (RPRn2), asocia con fórmulas estable- 
cidas y realiza cálculos (RPRn3) y maneja procedimientos y fórmulas, resolviendo y calculando (RLSOn3).

Resolviendo el sistema, por el método de reducción, obtiene la solución:

$$
\begin{aligned}
& A=2 C-D \\
& B=C-2 A
\end{aligned}
$$

El alumno realiza explicaciones sencillas (RCn2), justifica las fórmulas utilizadas (Ran3), comunica de manera elemental los resultados del modelo (RMn3) y describe los resultados obtenidos (RCn3).

$$
A=\left(\begin{array}{cc}
-1 & -1 \\
-12 & -6
\end{array}\right) \text { y } B=\left(\begin{array}{cc}
7 & 14 \\
28 & 14
\end{array}\right)
$$

El alumno resuelve problemas rutinarios estandarizados (RRPn3) y, al efectuar las operaciones correspondientes a las matrices, usa un único tipo de representación estándar, ya utilizada (RRn1), la representación algebraica, realiza operaciones elementales en contextos conocidos (RLSOn1), interpreta el lenguaje formal y simbólico rutinario (RLSOn2) -en Segundo de Bachiller-, maneja procedimientos y fórmulas resolviendo y calculando (RLSOn3) y utiliza variables y realiza ecuaciones y cálculos mediante procedimientos familiares (CLSOn3).

\begin{tabular}{|l|c|c|c|c|c|c|c|c|}
\hline \multicolumn{7}{|c|}{ FICHA 4.2.2. COMPETENCIAS IMPLÍCITAS EN LA RESOLUCIÓN DE LA C2 } \\
\hline & Nivel 1 & Nivel 2 & Nivel 3 & Nivel 1 & Nivel 2 & Nivel 3 & Nivel 1 & Nivel 2 \\
\hline PR & $*$ & $*$ & $*$ & & & & & \\
\hline A & $*$ & $*$ & $*$ & & & & & \\
\hline C & $*$ & $*$ & $*$ & & & & & \\
\hline M & $*$ & & $*$ & & & & & \\
\hline RP & $*$ & $*$ & $*$ & & & & & \\
\hline R & $*$ & & & & & & & \\
\hline LSO & $*$ & $*$ & $*$ & & & $*$ & & \\
\hline & Reproducción & & \multicolumn{7}{|l|}{ Conexión } & & Reflexión \\
\hline
\end{tabular}

\section{ANÁLISIS DE LA CUESTIÓN C3}

La cuestión de la ficha 4.3.1 corresponde, al nivel de conexión. Es un problema que reproduce situaciones similares a las estudiadas, pero no son de mera rutina. 


\begin{tabular}{|c|c|c|c|c|c|c|c|c|c|c|c|c|c|c|}
\hline FICHA 4.3.1. & \multicolumn{14}{|c|}{ FICHA ESTUDIO DEL ENUNCIADO DEL C3 } \\
\hline \multicolumn{15}{|c|}{$\begin{array}{l}\text { C3.- Sea } A \text { una matriz cuadrada de números reales tal que } A^{4}=0 \text {. Prueba que la matriz in- } \\
\text { versa de la matriz } I-A \text { es la matriz } I+A+A^{2}+A^{3} \text {. (Como de costumbre, } 0 \text { representa la } \\
\text { matriz cero e } I \text { la matriz unidad) }\end{array}$} \\
\hline CONVOCATORIA & \multicolumn{7}{|c|}{ JUNIO } & \multicolumn{7}{|c|}{ SEPTIEMBRE } \\
\hline AÑO & 95 & $\underline{96}$ & 97 & 98 & 99 & 00 & 01 & $02 \quad 03$ & 04 & 05 & 06 & 07 & 08 & 09 \\
\hline OPCIÓN & \multicolumn{7}{|c|}{ A } & \multicolumn{7}{|c|}{ B } \\
\hline TIPO DE PROBLEMA & \multicolumn{7}{|c|}{ TEÓRICO } & \multicolumn{7}{|c|}{ PRÁCTICO } \\
\hline \multirow{3}{*}{ APARTADOS } & \multirow{3}{*}{\multicolumn{2}{|c|}{ SI }} & \multicolumn{4}{|c|}{ Forma explícita } & & & & & & \multirow[b]{2}{*}{6} & \multirow{3}{*}{\multicolumn{2}{|c|}{ NO }} \\
\hline & & & & & & & 2 & 3 & 4 & 5 & & & & \\
\hline & & & \multicolumn{4}{|c|}{ Forma implícita } & & & & & & & & \\
\hline VERBO UTILIZADO & \multicolumn{14}{|c|}{ PROBAR } \\
\hline TIEMPO VERBAL & \multicolumn{14}{|c|}{ IMPERATIVO } \\
\hline \multirow{3}{*}{$\begin{array}{l}\text { FALLOS DEL ENUN- } \\
\text { CIADO }\end{array}$} & \multicolumn{9}{|c|}{ PUNTUACIÓN } & & & & & \\
\hline & \multicolumn{9}{|c|}{ ESTRUCTURA DE LA ORACIÓN } & & & & & \\
\hline & \multicolumn{9}{|c|}{ ORDEN DE LAS PALABRAS EN LA ORACIÓN } & & & & & \\
\hline \multicolumn{15}{|c|}{ ENUNCIADO ALTERNATIVO } \\
\hline
\end{tabular}

C3.- Prueba que la matriz inversa de la matriz $I-A$ es la matriz $I+A+A^{2}+A^{3}$ siendo $A$ una matriz cuadrada de números reales que cumple $A^{4}=0$. (Como de costumbre, 0 representa la matriz cero e I la matriz unidad)

\section{NIVELES DE COMPETENCIAS IMPLÍCITAS: Conexión}

El alumno piensa en el tratamiento matemático necesario (CPRn1) y razona matemáticamente de manera simple (CAn1).

Para probar que la matriz inversa de $(I-A)$ es $\left(I+A+A^{2}+A^{3}\right)$ vamos a hacer el producto de ambas, pues la matriz inversa de una dada, $C$, es la única matriz que verifica $C \cdot C^{-1}=C^{-1} \cdot C=I$.

$$
\left(I+A+A^{2}+A^{3}\right) \cdot(I-A) \stackrel{(1)}{=} I^{2}-I A+A I-A^{2}+A^{2} I-A^{3}+A^{3} I-A^{4} \stackrel{(2)}{=}=I-A^{4}
$$

(1) utilizando la propiedad distributiva del producto de matrices

(2) operando y simplificando, utilizando la propiedad del elemento neutro

(3) y como, por enunciado, $A^{4}=0$

El alumno sabe expresarse sobre cuestiones matemáticas (CCn1) y explica los cálculos y sus propiedades (CCn2). 


$$
\left(I+A+A^{2}+A^{3}\right) \cdot(I-A)=I-A^{4} \stackrel{(3)}{=} I
$$

El alumno utiliza el lenguaje formal y simbólico básico, en situaciones menos conocidas (CLSOn1), aplica conceptos matemáticos apropiados (CPRn3), desarrolla procedimientos intuitivos ya practicados, pero no rutinarios (CRPn1), maneja afirmaciones sencillas y expresiones con símbolos y fórmulas no rutinarias (CLSOn2), interpreta las relaciones implicadas (CCn3) y comunica los resultados (CMn3).

Análogamente

$$
(I-A) \cdot\left(I+A+A^{2}+A^{3}\right)=I
$$

Se trata de un lenguaje abstracto teórico que entraña más dificultad que el práctico operativo, por eso se encuadra en el nivel de conexión.

\begin{tabular}{|l|c|c|c|c|c|c|c|c|}
\hline \multicolumn{7}{|c|}{ FICHA 4.3.2. COMPETENCIAS IMPLÍCITAS EN LA RESOLUCIÓN DE LA C3 } \\
\hline & Nivel 1 & Nivel 2 & Nivel 3 & Nivel 1 & Nivel 2 & Nivel 3 & Nivel 1 & Nivel 2 \\
\hline PR & & & & $*$ & & $*$ & & \\
\hline A & & & & $*$ & & & & \\
\hline C & & & & $*$ & $*$ & $*$ & & \\
\hline M & & & & & & $*$ & & \\
\hline RP & & & & $*$ & & & & \\
\hline R & & & & & & & & \\
\hline LSO & & & & $*$ & $*$ & & & \\
\hline & Reproducción & & Conexión & & Reflexión \\
\hline
\end{tabular}

\section{ANÁLISIS DE LA CUESTIÓN C5}

La cuestión de la ficha 4.5.1 corresponde al nivel de reproducción. Son representaciones de problemas comunes en un nivel de Matemáticas II, reconocimiento de equivalentes, ejecución de problemas rutinarios, aplicación de destrezas técnicas y algoritmos habituales, manejo de expresiones y fórmulas establecidas y realización de cálculos.

El alumno reconoce las matrices, es decir, reconoce las representaciones de los datos del ejercicio (RPRn1), comprende la expresión escrita (RCn1), identifica el problema (RAn1), -es una ecuación matricial-, reconoce el problema como ya practicado (RRPn1), identifica que es un modelo similar a otros vistos 
con anterioridad (RMn1), plantea los algoritmos correspondientes (RPRn2), asocia con fórmulas establecidas y realiza cálculos (RPRn3).

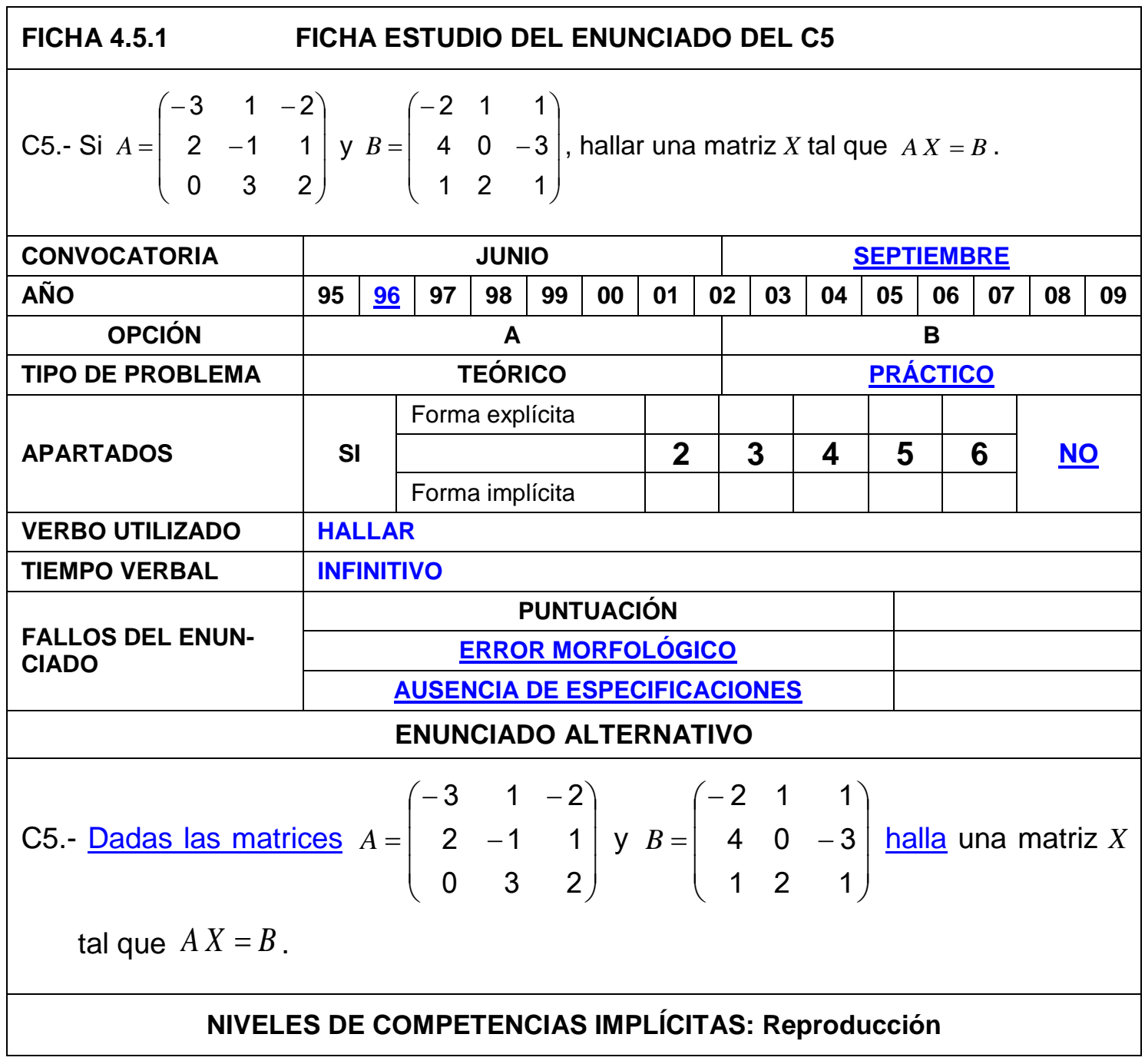

A continuación, expone el proceso de cálculo (RAn2).

Despejando la incógnita

$$
A X=B \quad \Rightarrow \quad X=A^{-1} \cdot B
$$

Calcula la matriz $A^{-1}$. Como $|A|=-1 \neq 0$, existe $A^{-1}$, y $A^{-1}=\frac{1}{|A|} \cdot \operatorname{Adj}\left(A^{t}\right)$, donde $\operatorname{Adj}\left(A^{t}\right)$ es la matriz transpuesta de la matriz de adjuntos de $A$.

El alumno usa un único tipo de representación estándar, ya utilizada (RRn1), la representación algebraica, realiza explicaciones sencillas (RCn2), justifica las 
fórmulas utilizadas (RAn3) y reproduce problemas ya practicados, de manera cerrada (RRPn2).

$$
A^{-1}=\left(\begin{array}{rrr}
5 & 8 & 1 \\
4 & 6 & 1 \\
-6 & -9 & -1
\end{array}\right)
$$

El alumno usa un único tipo de representación estándar, ya utilizada (RRn1), la representación algebraica, resuelve problemas rutinarios estandarizados (RRPn3), en un nivel de Matemáticas II, comunica de manera elemental los resultados (RMn3) y describe los resultados obtenidos (RCn3).

$$
X=A^{-1} \cdot B=\left(\begin{array}{rrr}
23 & 7 & -18 \\
17 & 6 & -13 \\
-25 & -8 & 20
\end{array}\right)
$$

Al hacer las operaciones correspondientes al cálculo de la matriz inversa y al producto de matrices, el alumno realiza operaciones elementales en contextos conocidos (RLSOn1), interpreta el lenguaje formal y simbólico rutinario (RLSOn2) -en Segundo de Bachiller-, maneja procedimientos y fórmulas resolviendo y calculando (RLSOn3) y utiliza variables y realiza ecuaciones y cálcu-

\begin{tabular}{|c|c|c|c|c|c|c|c|c|}
\hline \multicolumn{2}{|c|}{ FICHA 4.5.2. } & \multicolumn{7}{|c|}{ COMPETENCIAS IMPLÍCITAS EN LA RESOLUCIÓN DE LA C5 } \\
\hline & Nivel 1 & Nivel 2 & Nivel 3 & Nivel 1 & Nivel 2 & Nivel 3 & Nivel 1 & Nivel 2 \\
\hline PR & * & * & * & & & & & \\
\hline A & * & * & * & & & & & \\
\hline C & * & * & * & & & & & \\
\hline M & * & & * & & & & & \\
\hline RP & * & * & * & & & & & \\
\hline $\mathbf{R}$ & * & & & & & & & \\
\hline LSO & * & * & * & & & * & & \\
\hline & \multicolumn{3}{|c|}{ Reproducción } & \multicolumn{3}{|c|}{ Conexión } & \multicolumn{2}{|c|}{ Reflexión } \\
\hline
\end{tabular}
los mediante procedimientos familiares (CLSOn3).

\section{ANÁLISIS DE LA CUESTIÓN C8}

La cuestión de la ficha 4.8.1 corresponde, al nivel de reproducción del conocimiento estudiado, reconocimiento de equivalentes, ejecución de problemas 
rutinarios, aplicación de destrezas técnicas y algoritmos habituales, manejo de expresiones y fórmulas establecidas y realización de cálculos.

$$
\begin{aligned}
& \text { FICHA 4.8.1. } \\
& \text { ESTUDIO DEL ENUNCIADO DEL C8 } \\
& \text { C8.- Dadas las matrices } A=\left(\begin{array}{lll}
2 & 0 & 1 \\
1 & 2 & 0
\end{array}\right) \text { y } B=\cdot\left(\begin{array}{ll}
1 & 0 \\
0 & 1 \\
1 & 1
\end{array}\right) \text { y las ecuaciones matriciales } \\
& X-A=B, Y-A B=0 \text { y } Z-B A=0
\end{aligned}
$$

\begin{tabular}{|c|c|c|c|c|c|c|c|c|c|c|c|c|c|}
\hline CONVOCATORIA & \multicolumn{7}{|c|}{ JUNIO } & \multicolumn{6}{|c|}{ SEPTIEMBRE } \\
\hline AÑO & 95 & 96 & $\underline{97}$ & 98 & 99 & 00 & 01 & \begin{tabular}{l|l|}
02 & 03
\end{tabular} & 04 & 05 & $06 \quad 07$ & 08 & 09 \\
\hline OPCIÓN & \multicolumn{7}{|c|}{ A } & \multicolumn{6}{|c|}{ B } \\
\hline TIPO DE PROBLEMA & \multicolumn{7}{|c|}{ TEÓRICO } & \multicolumn{6}{|c|}{ PRÁCTICO } \\
\hline \multirow{3}{*}{ APARTADOS } & \multirow{3}{*}{\multicolumn{2}{|c|}{$\underline{\text { SI }}$}} & \multicolumn{4}{|c|}{ Forma explícita } & & & & & & \multirow{3}{*}{\multicolumn{2}{|c|}{ NO }} \\
\hline & & & \multirow{2}{*}{\multicolumn{4}{|c|}{ Forma implícita }} & 2 & 3 & 4 & 5 & 6 & & \\
\hline & & & & & & & & 3 & & 5 & & & \\
\hline VERBO UTILIZADO & \multicolumn{13}{|c|}{ SEÑALAR / CALCULAR / RAZONAR } \\
\hline TIEMPO VERBAL & \multicolumn{13}{|c|}{ INFINITIVO } \\
\hline \multirow{3}{*}{$\begin{array}{l}\text { FALLOS DEL ENUN- } \\
\text { CIADO }\end{array}$} & \multicolumn{9}{|c|}{ PUNTUACIÓN } & & & & \\
\hline & \multicolumn{9}{|c|}{ ERROR MORFOLCCÓGICO } & & & & \\
\hline & \multicolumn{9}{|c|}{ AUSENCIA DE ESPECIFICACIONES } & & & & \\
\hline \multicolumn{14}{|c|}{ ENUNCIADO ALTERNATIVO } \\
\hline
\end{tabular}

Se pide: señalar las correctamente planteadas y, en su caso calcular la matriz $X, Y$ ó $Z$. Razonar la respuesta.

C8.- Dadas las matrices $A=\left(\begin{array}{lll}2 & 0 & 1 \\ 1 & 2 & 0\end{array}\right)$ y $B=\cdot\left(\begin{array}{ll}1 & 0 \\ 0 & 1 \\ 1 & 1\end{array}\right)$ y las ecuaciones matriciales

$$
X-A=B, \quad Y-A B=0 \quad \text { y } \quad Z-B A=0 .
$$

a) Señala las planteadas correctamente y, en su caso, calcula la matriz $X, Y$ ó $Z$.

b) Razona la respuesta.

\section{NIVELES DE COMPETENCIAS IMPLÍCITAS: Reproducción}

El alumno comprende la expresión escrita (RCn1), identifica el problema (RAn1), -es una ecuación matricial-, reconoce las matrices, es decir, reconoce las representaciones de los datos del ejercicio (RPRn1), reconoce el problema 
como ya practicado (RRPn1), e identifica que es un modelo similar a otros vistos con anterioridad (RMn1).

La ecuación $X-A=B$ no tiene solución, dado que para operar $X-A=B$ las matrices $X, A$ y $B$ tienen que ser de la misma dimensión, pero la matriz $A$ es una matriz que tiene dos filas y tres columnas $(2 \times 3)$ mientras que la matriz $B$ tiene tres filas y dos columnas $(3 \times 2)$.

El alumno realiza explicaciones sencillas (RCn2), comunica de manera elemental los resultados (RMn3) y describe los resultados obtenidos (RCn3).

La ecuación $Y-A B=0$ tiene como solución $Y=A B$

$$
Y=\left(\begin{array}{lll}
2 & 0 & 1 \\
1 & 2 & 0
\end{array}\right) \cdot\left(\begin{array}{ll}
1 & 0 \\
0 & 1 \\
1 & 1
\end{array}\right)=\left(\begin{array}{ll}
3 & 1 \\
1 & 2
\end{array}\right)
$$

El alumno reconoce el problema como ya practicado (RRPn1), expone el proceso de cálculo (RAn2), plantea los algoritmos correspondientes (RPRn2), asocia con fórmulas establecidas y realiza cálculos (RPRn3), es decir, reproduce problemas ya practicados, de manera cerrada (RRPn2).

La ecuación $Z-B A=0$ tiene como solución $Z=B A$

$$
Z=\left(\begin{array}{ll}
1 & 0 \\
0 & 1 \\
1 & 1
\end{array}\right) \cdot\left(\begin{array}{lll}
2 & 0 & 1 \\
1 & 2 & 0
\end{array}\right)=\left(\begin{array}{lll}
2 & 0 & 1 \\
1 & 2 & 0 \\
3 & 2 & 1
\end{array}\right)
$$

El alumno usa un único tipo de representación estándar, ya utilizada (RRn1), la representación algebraica, realiza operaciones elementales en contextos conocidos (RLSOn1), interpreta el lenguaje formal y simbólico rutinario (RLSOn2) en Segundo de Bachiller-, maneja procedimientos y fórmulas resolviendo y calculando (RLSOn3) y utiliza variables y realiza ecuaciones y cálculos mediante procedimientos familiares (CLSOn3).

El alumno realiza explicaciones sencillas ( $\mathrm{RCn} 2)$, resuelve problemas rutinarios estandarizados (RRPn3), justifica las fórmulas utilizadas (RAn3) y describe los resultados obtenidos $(\mathrm{RCn} 3)$. 


\begin{tabular}{|c|c|c|c|c|c|c|c|c|}
\hline & Nivel 1 & Nivel 2 & Nivel 3 & Nivel 1 & Nivel 2 & Nivel 3 & Nivel 1 & Nivel 2 \\
\hline PR & * & * & * & & & & & \\
\hline A & * & * & * & & & & & \\
\hline C & * & * & * & & & & & \\
\hline M & * & & * & & & & & \\
\hline $\mathbf{R P}$ & * & * & * & & & & & \\
\hline $\mathbf{R}$ & * & & & & & & & \\
\hline LSO & * & * & * & & & * & & \\
\hline & \multicolumn{3}{|c|}{ Reproducción } & \multicolumn{3}{|c|}{ Conexión } & \multicolumn{2}{|c|}{ Reflexión } \\
\hline
\end{tabular}

\section{ANÁLISIS DE LA CUESTIÓN C12}

\section{FICHA 4.12.1.}

ESTUDIO DEL ENUNCIADO DEL C12

C12.- Si $A, B$ y $C$ son tres matrices tales que existe la matriz $A B+C^{t}$, analizar si existe la matriz $B C+A^{t}$. (Se recuerda que $M^{t}$ representa la traspuesta de la matriz $M$ )

\begin{tabular}{|c|c|c|c|c|c|c|c|c|c|c|c|c|c|c|}
\hline CONVOCATORIA & \multicolumn{7}{|c|}{ JUNIO } & \multicolumn{7}{|c|}{ SEPTIEMBRE } \\
\hline AÑO & 95 & 96 & 97 & $\underline{98}$ & 99 & 00 & 01 & $02 \quad 03$ & 04 & 05 & 06 & 07 & 08 & 09 \\
\hline OPCIÓN & \multicolumn{7}{|c|}{ A } & \multicolumn{7}{|c|}{ B } \\
\hline TIPO DE PROBLEMA & \multicolumn{7}{|c|}{ TEÓRICO } & \multicolumn{7}{|c|}{ PRÁCTICO } \\
\hline \multirow{3}{*}{ APARTADOS } & \multirow{3}{*}{\multicolumn{2}{|c|}{ SI }} & \multicolumn{4}{|c|}{ Forma explícita } & & & & & & \multirow[b]{2}{*}{6} & \multirow{3}{*}{\multicolumn{2}{|c|}{$\underline{\mathrm{NO}}$}} \\
\hline & & & & & & & 2 & 3 & 4 & 5 & & & & \\
\hline & & & \multicolumn{4}{|c|}{ Forma implícita } & & & & & & & & \\
\hline VERBO UTILIZADO & \multicolumn{14}{|c|}{ ANALIZAR } \\
\hline TIEMPO VERBAL & \multicolumn{14}{|c|}{ INFINITIVO } \\
\hline \multirow{3}{*}{$\begin{array}{l}\text { FALLOS DEL ENUN- } \\
\text { CIADO }\end{array}$} & \multicolumn{9}{|c|}{ PUNTUACIÓN } & & & & & \\
\hline & \multicolumn{9}{|c|}{ ERROR MORFOLÓGICO } & & & & & \\
\hline & \multicolumn{9}{|c|}{ AUSENCIA DE ESPECIFICACIONES } & & & & & \\
\hline \multicolumn{15}{|c|}{ ENUNCIADO ALTERNATIVO } \\
\hline
\end{tabular}

C12.- Si $A, B$ y $C$ son tres matrices tales que existe la matriz $A B+C^{t}$, analiza si existe la matriz $B C+A^{t}$. (Se recuerda que $M^{t}$ representa la traspuesta de la matriz $M$ )

\section{NIVELES DE COMPETENCIAS IMPLÍCITAS: Conexión}

La cuestión de la ficha 4.12.1 corresponde a un nivel de conexión; reproduce una situación similar a la referente en su etapa de aprendizaje, pero no es una 
mera rutina, dado que el alumno tiene que pensar en el tratamiento matemático necesario (CPRn1), es decir, en el estudio de las dimensiones de las matrices implicadas en la operación.

El alumno estructura la situación que debe modelizar (CMn1), razona matemáticamente de manera simple (CAn1) y desarrolla procedimientos intuitivos ya practicados, pero no rutinarios (CRPn1).

Sea $A_{(m \times n)}$ y para que exista el producto de matrices $A \cdot B$ la matriz $B$ tiene que tener orden $B_{(n \times p)}$ de lo que se deduce que el producto $A \cdot B_{(m \times p)}$.

Para poder efectuar la operación $A \cdot B+C^{t}$ la matriz $C$ tiene que ser una matriz de orden $(p \times m)$, es decir, $C_{(p \times m)}$ y $C_{(m \times p)}^{t}$, y el resultado es una matriz de orden $(m \times p)$.

La operación que nos pide el enunciado que realicemos es:

$$
B \cdot C+A^{t}=B_{(n \times p)} \cdot C_{(p \times m)}+A_{(n \times m)}^{t}
$$

El resultado es una matriz de orden $(n \times m)$.

Por otra parte, el alumno sabe expresarse sobre cuestiones matemáticas (CCn1) e interpreta el lenguaje formal y simbólico (CLSOn1). Estas categorías están inertes en el primer nivel de análisis, ya que, en primer lugar, el alumno debe comprender el enunciado.

Explica los cálculos y sus propiedades (CCn2) e interpreta las relaciones implicadas (CCn3); asimismo, sigue el encadenamiento del argumento matemático particular (CAn2), haciendo una evaluación del mismo (CAn3), aplicando, de este modo, conceptos matemáticos apropiados (CPRn3).

\begin{tabular}{|l|c|c|c|c|c|c|c|c|}
\hline \multicolumn{7}{|c|}{ FICHA 4.12.2. COMPETENCIAS IMPLÍCITAS EN LA RESOLUCIÓN DE LA C12 } \\
\hline & Nivel 1 & Nivel 2 & Nivel 3 & Nivel 1 & Nivel 2 & Nivel 3 & Nivel 1 & Nivel 2 \\
\hline PR & & & & $*$ & & $*$ & & \\
\hline A & & & & $*$ & $*$ & $*$ & & \\
\hline C & & & & $*$ & $*$ & $*$ & & \\
\hline M & & & & $*$ & & & & \\
\hline RP & & & & $*$ & & & & \\
\hline R & & & & & & & & \\
\hline LSO & & & & $*$ & & & & \\
\hline & Reproducción & & Conexión & & Reflexión \\
\hline
\end{tabular}


ANÁLISIS DE LA CUESTIÓN C14

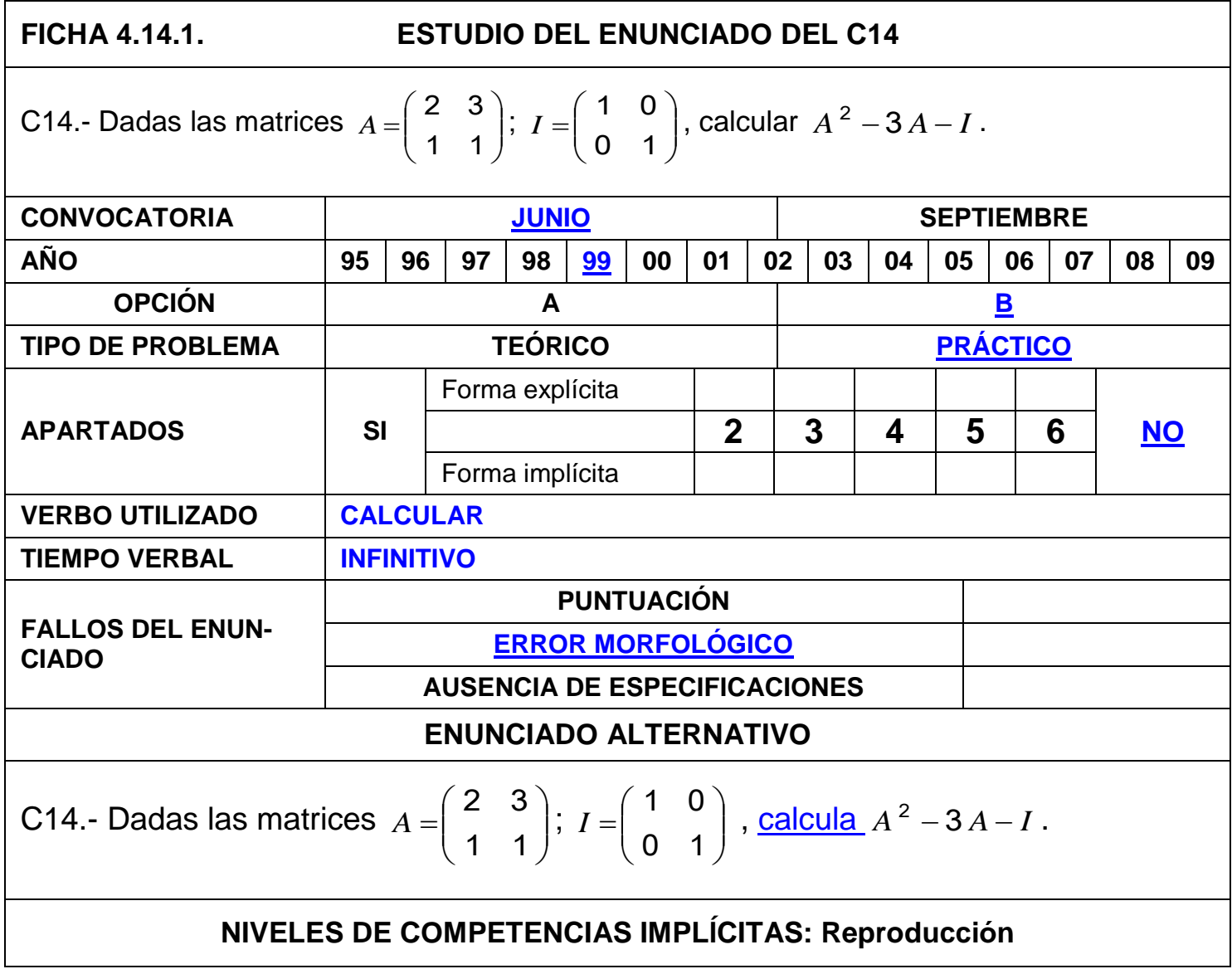

La cuestión de la ficha 4.14.1 es una cuestión de aplicación directa de la teoría impartida, pues se trata, sencillamente, de realizar unas operaciones con matrices lo que corresponde al nivel de reproducción del conocimiento estudiado, reconocimiento de equivalentes y ejecución de problemas rutinarios.

El alumno reconoce las representaciones de los datos del ejercicio (RPRn1), comprende la expresión escrita (RCn1), identifica el problema (RAn1) y reconoce el problema como ya practicado (RRPn1), plantea los algoritmos correspondientes (RPRn2), asocia con fórmulas establecidas y realiza cálculos (RPRn3).

$$
A^{2}-3 \cdot A-I=\left(\begin{array}{ll}
2 & 3 \\
1 & 1
\end{array}\right) \cdot\left(\begin{array}{ll}
2 & 3 \\
1 & 1
\end{array}\right)+\left(\begin{array}{rr}
-6 & -9 \\
-3 & -3
\end{array}\right)+\left(\begin{array}{rr}
-1 & 0 \\
0 & -1
\end{array}\right)=\left(\begin{array}{ll}
0 & 0 \\
0 & 0
\end{array}\right)
$$

El alumno usa un único tipo de representación estándar, ya utilizada (RRn1), la representación algebraica, realiza explicaciones sencillas (RCn2), describe los 
resultados obtenidos (RCn3), justifica las fórmulas utilizadas (RAn3) y reproduce problemas ya practicados, de manera cerrada (RRPn2).

El alumno tiene que efectuar sumas de matrices, dos tipos de producto, el producto de dos matrices y el producto de una matriz por un escalar y, al efectuar estas operaciones, realiza operaciones elementales en contextos conocidos (RLSOn1), interpreta el lenguaje formal y simbólico rutinario (RLSOn2), maneja procedimientos y fórmulas resolviendo y calculando (RLSOn3) y utiliza variables y realiza ecuaciones y cálculos mediante procedimientos familiares (CLSOn3).

De esta manera, el alumno resuelve problemas rutinarios estandarizados (RRPn3) y comunica de manera elemental los resultados (RMn3).

\begin{tabular}{|l|c|c|c|c|c|c|c|c|}
\hline \multicolumn{6}{|c|}{ FICHA 4.14.2. } \\
\hline & Nivel 1 & Nivel 2 & Nivel 3 & Nivel 1 & Nivel 2 & Nivel 3 & Nivel 1 & Nivel 2 \\
\hline PR & $*$ & $*$ & $*$ & & & & & \\
\hline A & $*$ & & $*$ & & & & & \\
\hline C & $*$ & $*$ & $*$ & & & & & \\
\hline M & & & $*$ & & & & & \\
\hline RP & $*$ & $*$ & $*$ & & & & & \\
\hline R & $*$ & & & & & & & \\
\hline LSO & $*$ & $*$ & $*$ & & & $*$ & & \\
\hline & Reproducción & & Conexión & & Reflexión \\
\hline
\end{tabular}

\section{ANÁLISIS DE LA CUESTIÓN C17}

La cuestión de la ficha 4.17.1 es un ejercicio que se corresponde con un nivel de conexión; reproduce una situación similar a la referente en su etapa de aprendizaje, pero no es una mera rutina, dado que el alumno tiene que pensar en el tratamiento matemático necesario (CPRn1), razonar matemáticamente de manera simple (CAn1), estructurar la situación que se debe modelizar (CMn1) y desarrollar procedimientos ya practicados, pero no rutinarios (CRPn1).

Para que la matriz ampliada tenga rango 4 es preciso que la matriz dada en el enunciado tenga rango 3.

Este argumento denota que el alumno sabe expresarse sobre cuestiones matemáticas (CCn1) e interpreta el lenguaje formal y simbólico básico, en situa- 
ciones menos conocidas (CLSOn1). Estas categorías están inertes en el primer nivel de análisis, ya que, en primer lugar, el alumno debe comprender el enunciado.

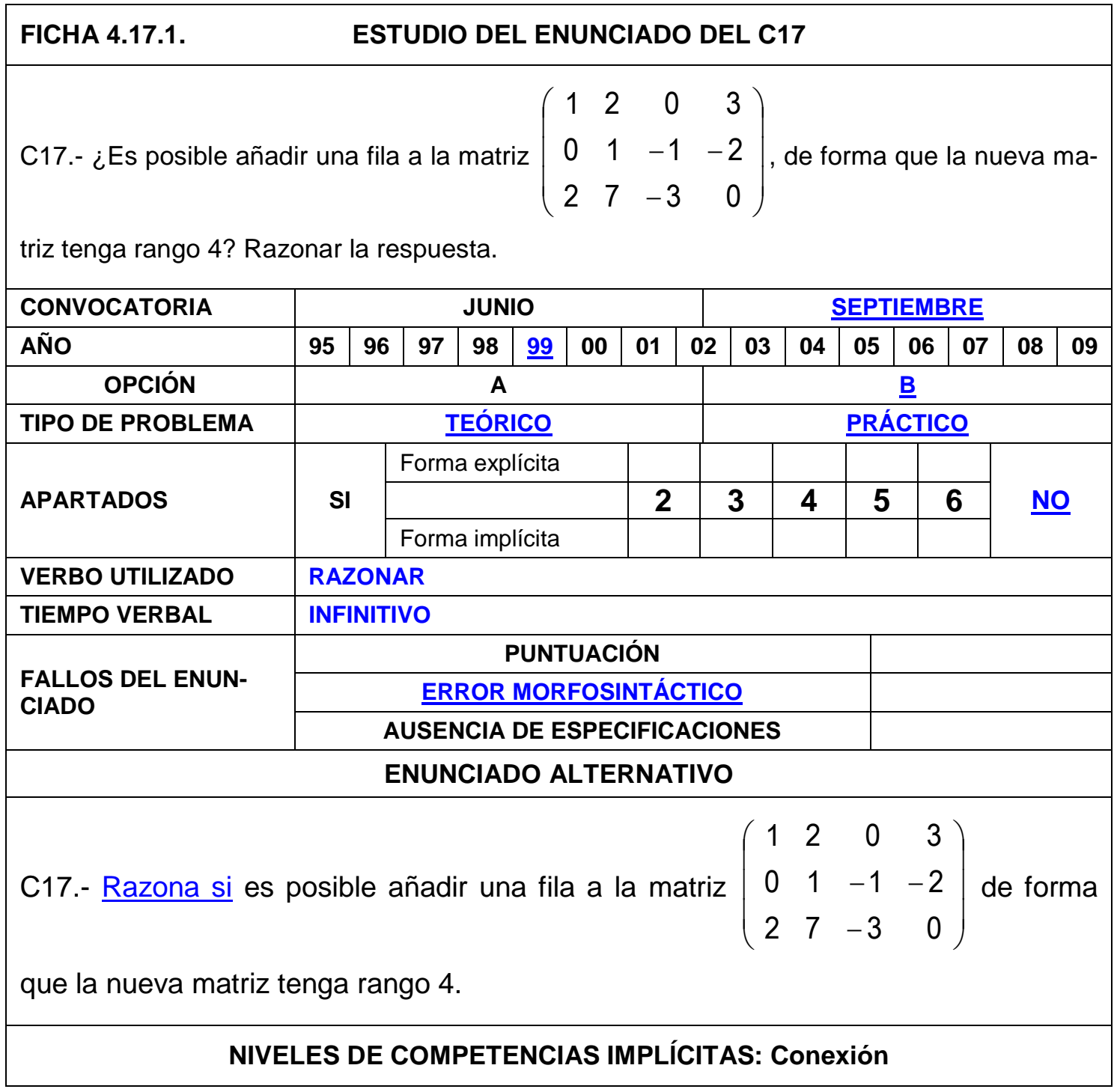

El alumno comprende que tiene que emplear métodos matemáticos intermedios (CPRn2), explica los cálculos y sus propiedades (CCn2) e interpreta las relaciones implicadas (CCn3), al tiempo que sigue el encadenamiento del argumento matemático particular (CAn2) haciendo una evaluación del mismo (CAn3).

Una combinación lineal entre las filas de la matriz dada es:

$$
2 F_{1}+3 F_{2}=F_{3}
$$


En consecuencia, como el rango de la matriz dada es 2 no puede ampliarse a rango 4 al añadir una fila, ya que a lo sumo sería de rango 3.

El alumno explica los cálculos y sus propiedades (CCn2) e interpreta las relaciones implicadas (CCn3).

Maneja afirmaciones sencillas en expresiones y fórmulas no rutinarias (CLSOn2), con lo que evalúa el encadenamiento de argumentos matemáticos particulares (CAn3) e interpreta las relaciones implicadas (CCn3); traduce, en la práctica, el modelo a seguir, que es algo diferente de los estudiados (CMn2) eligiendo las estrategias apropiadas que conexionen áreas matemáticas (CRPn2) y aplicándolas (CRPn3), aplicando, de este modo, conceptos matemáticos apropiados (CPRn3). y comunica los resultados (CMn3).

El alumno podía haber efectuado las operaciones correspondientes a los distintos determinantes y entonces estaría en un nivel de reproducción; pero, con los comentarios escritos anteriormente, se encuentra en un nivel de conexión.

Con esta reflexión, el alumno razona matemáticamente de manera simple (CAn1), sabe expresarse sobre cuestiones matemáticas (CCn1), estructura la situación que debe modelizar (CMn1) y desarrolla procedimientos intuitivos ya practicados, pero no rutinarios (CRPn1).

\begin{tabular}{|l|c|c|c|c|c|c|c|c|}
\hline \multicolumn{7}{|c|}{ FICHA 4.17.2. COMPETENCIAS IMPLÍCITAS EN LA RESOLUCIÓN DE LA C17 } \\
\hline & Nivel 1 & Nivel 2 & Nivel 3 & Nivel 1 & Nivel 2 & Nivel 3 & Nivel 1 & Nivel 2 \\
\hline PR & & & & $*$ & $*$ & $*$ & & \\
\hline A & & & & $*$ & $*$ & $*$ & & \\
\hline C & & & & $*$ & $*$ & $*$ & & \\
\hline M & & & & $*$ & $*$ & $*$ & & \\
\hline RP & & & & $*$ & $*$ & $*$ & & \\
\hline R & & & & & & & & \\
\hline LSO & & & & $*$ & $*$ & & & \\
\hline & Reproducción & & Conexión & & Reflexión \\
\hline
\end{tabular}

\section{ANÁLISIS DE LA CUESTIÓN C18}

La cuestión de la ficha 4.18.1 es un ejercicio que se corresponde con un nivel de conexión. Reproduce una situación similar a la referente en su etapa de aprendizaje, pero no es una mera rutina, pues hay que estudiar el rango de una matriz dependiendo de los valores de un parámetro $m$.. 


\begin{tabular}{|c|c|c|c|c|c|c|c|c|c|c|c|}
\hline \multicolumn{2}{|l|}{ FICHA 4.18.1. } & \multicolumn{10}{|c|}{ ESTUDIO DEL ENUNCIADO DEL C18 } \\
\hline \multicolumn{3}{|c|}{ C18.- Calcular el rango de la matriz } & $\begin{array}{rcr}2 & m-3 & \\
m & -1 & \\
-1 & m & -2\end{array}$ & $\left.\begin{array}{c}4 \\
2 \\
2 m\end{array}\right)$ & \multicolumn{7}{|c|}{ según los valores de $m$. } \\
\hline CONVOCATORIA & \multicolumn{4}{|c|}{$\underline{\text { JUNIO }}$} & \multicolumn{7}{|c|}{ SEPTIEMBRE } \\
\hline AÑO & 95 & \begin{tabular}{l|l}
96 & 97
\end{tabular} & \begin{tabular}{l|l|l}
98 & 99 & $\underline{00}$ \\
\end{tabular} & 01 & 02 & 03 & 04 & 05 & \begin{tabular}{l|l}
06 & 07
\end{tabular} & \begin{tabular}{|l|}
08 \\
\end{tabular} & 09 \\
\hline OPCIÓN & \multicolumn{4}{|c|}{ A } & \multicolumn{7}{|c|}{$\underline{B}$} \\
\hline TIPO DE PROBLEMA & \multicolumn{4}{|c|}{ TEÓRICO } & \multicolumn{7}{|c|}{ PRÁCTICO } \\
\hline \multirow{3}{*}{ APARTADOS } & \multirow{3}{*}{ SI } & \multicolumn{2}{|c|}{ Forma explícita } & & & & & \multirow{3}{*}{5} & \multirow{3}{*}{6} & \multirow{3}{*}{\multicolumn{2}{|c|}{$\underline{\text { NO }}$}} \\
\hline & & & & 2 & 3 & 3 & 4 & & & & \\
\hline & & \multicolumn{2}{|c|}{ Forma implícita } & & & & & & & & \\
\hline VERBO UTILIZADO & \multicolumn{11}{|c|}{ CALCULAR } \\
\hline TIEMPO VERBAL & \multicolumn{11}{|c|}{ INFINITIVO } \\
\hline \multirow{3}{*}{$\begin{array}{l}\text { FALLOS DEL ENUN- } \\
\text { CIADO }\end{array}$} & \multicolumn{7}{|c|}{ PUNTUACIÓN } & & & & \\
\hline & \multicolumn{7}{|c|}{ ERROR MORFOLÓGICO } & & & & \\
\hline & \multicolumn{7}{|c|}{ AUSENCIA DE ESPECIFICACIONES } & & & & \\
\hline \multicolumn{12}{|c|}{ ENUNCIADO ALTERNATIVO } \\
\hline \multicolumn{3}{|c|}{ C18.- Calcula el rango de la matriz } & $\left(\begin{array}{cc}2 & m-3 \\
m & -1 \\
-1 & m\end{array}\right.$ & -2 & $\left.\begin{array}{c}4 \\
2 \\
2 m\end{array}\right)$ & \multicolumn{6}{|c|}{ según los valores de $m$. } \\
\hline \multicolumn{12}{|c|}{ NIVELES DE COMPETENCIAS IMPLÍCITAS: Conexión } \\
\hline
\end{tabular}

El alumno piensa en el tratamiento matemático necesario (CPRn1), razona matemáticamente de manera simple (CAn1), estructura la situación que se debe modelizar (CMn1), desarrolla procedimientos intuitivos ya practicados, pero no rutinarios (CRPn1), pues hay que estudiar el rango de una matriz dependiendo de los posibles valores del parámetro $m$.

El alumno usa un único tipo de representación estándar, ya utilizada (RRn1), la representación algebraica.

Calculando el determinante: $\left|\begin{array}{ccc}2 & m-3 & 4 \\ m & -1 & 2 \\ -1 & m & -2 m\end{array}\right|=2\left(m^{3}-m^{2}-m+1\right)$

Resolviendo la ecuación $2\left(m^{3}-m^{2}-m+1\right)=0$, obtiene las soluciones:

$$
m=1 \quad \text { y } \quad m=-1
$$


Al hacer las operaciones correspondientes al cálculo del determinante y la resolución de la ecuación de tercer grado, el alumno realiza operaciones elementales en contextos conocidos (RLSOn1), interpreta el lenguaje formal y simbólico rutinario (RLSOn2), maneja procedimientos y fórmulas resolviendo y calculando (RLSOn3) y utiliza variables y realiza ecuaciones y cálculos mediante procedimientos familiares (CLSOn3).

Por otra parte, el alumno sabe expresarse sobre cuestiones matemáticas (CCn1) y comprende que tiene que emplear métodos matemáticos intermedios (CPRn2).

Si $m \neq 1$ y $m \neq-1$, el determinante de la matriz es distinto de cero.

Si $m \neq 1$ y $m \neq-1$, el rango de la matriz es 3 .

Si $m=1$, sustituyendo ese valor en el enunciado, tenemos la matriz:

$$
M=\left(\begin{array}{rrr}
2 & -2 & 4 \\
1 & -1 & 2 \\
-1 & 1 & -2
\end{array}\right)
$$

Si $m=1$, el rango de la matriz es 1

Si $m=1$ se tiene, entre otras combinaciones de filas y/o columnas, que $F_{1}=2 \cdot F_{2}=-2 \cdot F_{3}$.

Si $m=-1$, sustituyendo ese valor en el enunciado, tenemos la matriz:

$$
M=\left(\begin{array}{rrr}
2 & 4 & 4 \\
-1 & -1 & 2 \\
-1 & -1 & 2
\end{array}\right)
$$

Si $m=-1$ el rango de la matriz es 2

Dado que $F_{2}=F_{3}$ y a que se cumple que $\left|\begin{array}{rr}2 & 4 \\ -1 & -1\end{array}\right| \neq 0$

El alumno explica los cálculos y sus propiedades (CCn2).

Asimismo, interpreta las relaciones implicadas (CCn3) a la par que sigue el encadenamiento del argumento matemático particular (CAn2) haciendo una evaluación del mismo (CAn3). 
Igualmente maneja afirmaciones sencillas en expresiones y fórmulas no rutinarias (CLSOn2), con lo que evalúa el encadenamiento de argumentos matemáticos particulares (CAn3) e interpreta las relaciones implicadas (CCn3).

El alumno traduce, en la práctica, el modelo a seguir, que es algo diferente de los estudiados (CMn2) ya que, al depender de parámetros, cada ejercicio presenta una identidad particular; eligiendo las estrategias apropiadas que conexionen áreas matemáticas (CRPn2) y aplicándolas (CRPn3), aplicando, de este modo, conceptos matemáticos apropiados (CPRn3) y comunica los resultados (CMn3).

\section{FICHA 4.18.2. COMPETENCIAS IMPLÍCITAS EN LA RESOLUCIÓN DE LA C18}

\begin{tabular}{|c|c|c|c|c|c|c|c|c|}
\hline & Nivel 1 & Nivel 2 & Nivel 3 & Nivel 1 & Nivel 2 & Nivel 3 & Nivel 1 & Nivel 2 \\
\hline $\begin{array}{l}\text { PR } \\
\end{array}$ & & & & * & * & & & \\
\hline$A$ & & & & * & * & * & & \\
\hline C & & & & * & * & * & & \\
\hline $\mathbf{M}$ & & & & * & * & * & & \\
\hline RP & & & & * & * & * & & \\
\hline $\mathbf{R}$ & * & & & & & & & \\
\hline LSO & * & * & * & & * & * & & \\
\hline & \multicolumn{3}{|c|}{ Reproducción } & \multicolumn{3}{|c|}{ Conexión } & \multicolumn{2}{|c|}{ Reflexión } \\
\hline
\end{tabular}

\section{ANÁLISIS DE LA CUESTIÓN C22}

La cuestión de la ficha 4.22.1 corresponde al nivel de reproducción con el reconocimiento de equivalentes, es la ejecución de problemas rutinarios, con la aplicación de destrezas técnicas y algoritmos habituales, el manejo de expresiones y fórmulas establecidas y la realización de cálculos.

El alumno reconoce representaciones de los datos del ejercicio (RPRn1), identifica el problema (RAn1), comprende la expresión escrita (RCn1), identifica que es un modelo similar a otros vistos con anterioridad (RMn1), reconoce el problema como ya practicado (RRPn1), plantea los algoritmos correspondientes (RPRn2) y asocia con fórmulas establecidas y realiza cálculos (RPRn3).

$$
\left(\begin{array}{ll}
1 & a \\
b & 1
\end{array}\right) \cdot\left(\begin{array}{ll}
1 & 3 \\
2 & 0
\end{array}\right)=\left(\begin{array}{cc}
1+2 a & 3 \\
b+2 & 3 b
\end{array}\right)
$$


FICHA 4.22.1.

ESTUDIO DEL ENUNCIADO DEL C22

C22.- Encontrar todas las matrices $C=\left(\begin{array}{ll}1 & a \\ b & 1\end{array}\right)$ que verifiquen la igualdad

$C \cdot\left(\begin{array}{ll}1 & 3 \\ 2 & 0\end{array}\right)=\left(\begin{array}{ll}-5 & 3 \\ -8 & 6\end{array}\right) \cdot C$

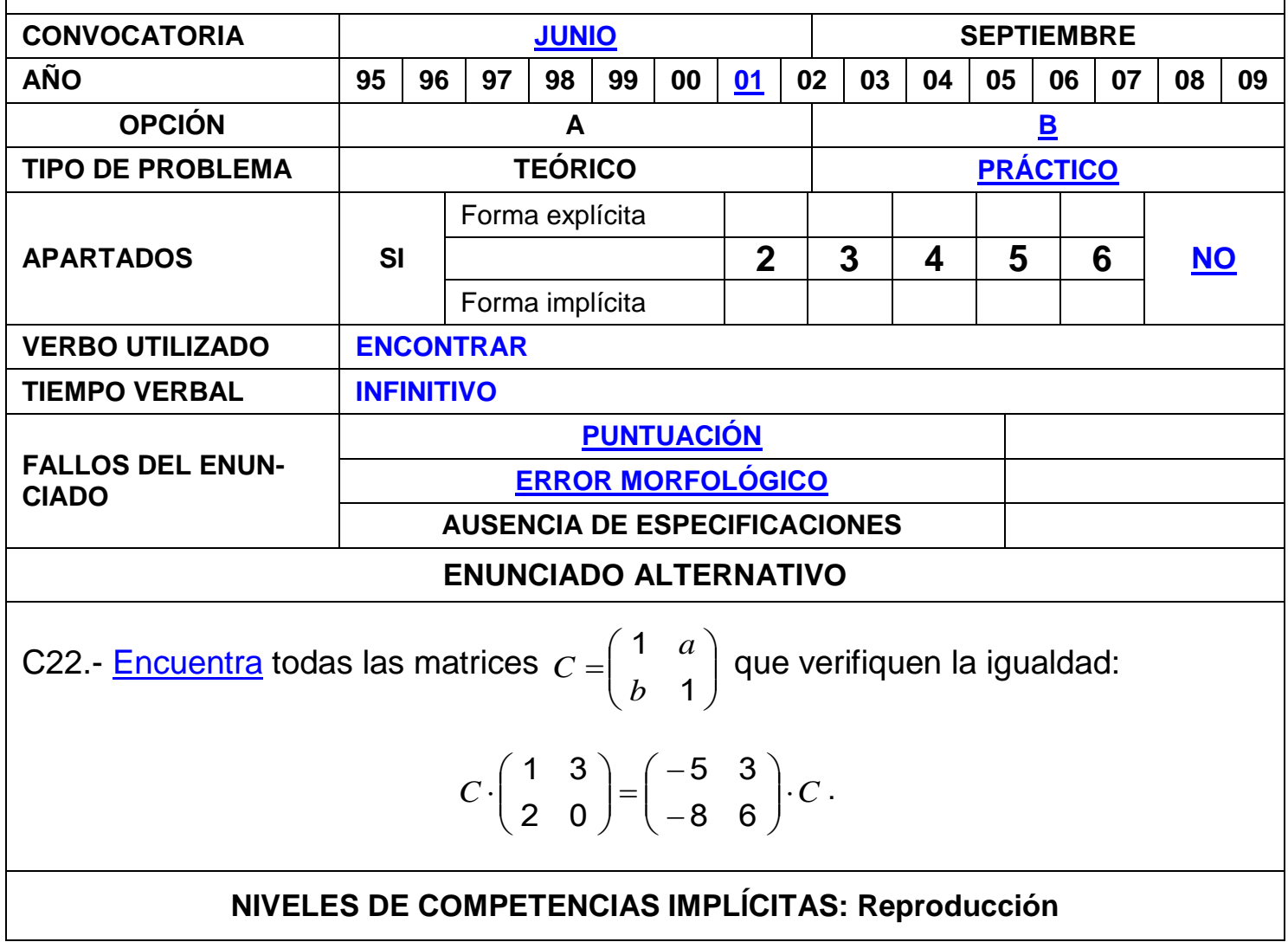

$$
\left(\begin{array}{ll}
-5 & 3 \\
-8 & 6
\end{array}\right) \cdot\left(\begin{array}{ll}
1 & a \\
b & 1
\end{array}\right)=\left(\begin{array}{ll}
-5+3 b & -5 a+3 \\
-8+6 b & -8 a+6
\end{array}\right)
$$

Para que se verifique la igualdad $\left(\begin{array}{ll}1 & a \\ b & 1\end{array}\right) \cdot\left(\begin{array}{ll}1 & 3 \\ 2 & 0\end{array}\right)=\left(\begin{array}{ll}-5 & 3 \\ -8 & 6\end{array}\right) \cdot\left(\begin{array}{ll}1 & a \\ b & 1\end{array}\right)$

Se tienen que cumplir las siguientes condiciones

$$
\left\{\begin{array}{c}
1+2 a=-5+3 b \\
3=-5 a+3 \\
b+2=-8+6 b \\
3 b=-8 a+6
\end{array}\right.
$$


El alumno realiza explicaciones sencillas (RCn2), justifica las fórmulas utilizadas (RAn3), reproduce problemas ya practicados, de manera cerrada (RRPn2) y resuelve problemas rutinarios estandarizados (RRPn3).

El sistema lineal definido a partir de las condiciones tiene solución

$$
a=0 \text { y } b=2 \text {. }
$$

Lo que implica que la matriz buscada es $C=\left(\begin{array}{ll}1 & 0 \\ 2 & 1\end{array}\right)$

El alumno usa un único tipo de representación estándar, ya utilizada (RRn1), la representación algebraica.

Para resolver el ejercicio tiene que hacer operaciones con matrices y resolver un sistema de ecuaciones, por tanto, el alumno realiza operaciones elementales en contextos conocidos (RLSOn1), interpreta el lenguaje formal y simbólico rutinario (RLSOn2), maneja procedimientos y fórmulas resolviendo y calculando (RLSOn3) y utiliza variables y realiza ecuaciones y cálculos mediante procedimientos familiares (CLSOn3).

Finalmente describe los resultados obtenidos (RCn3) y comunica de manera elemental los resultados del modelo (RMn3).

\begin{tabular}{|l|c|c|c|c|c|c|c|c|}
\hline \multicolumn{6}{|c|}{ FICHA 4.22.2. COMPETENCIAS IMPLÍCITAS EN LA RESOLUCIÓN DE LA C22 } \\
\hline & Nivel 1 & Nivel 2 & Nivel 3 & Nivel 1 & Nivel 2 & Nivel 3 & Nivel 1 & Nivel 2 \\
\hline PR & $*$ & $*$ & $*$ & & & & & \\
\hline A & $*$ & & $*$ & & & & & \\
\hline C & $*$ & $*$ & $*$ & & & & & \\
\hline M & $*$ & & $*$ & & & & & \\
\hline RP & $*$ & $*$ & $*$ & & & & & \\
\hline R & $*$ & & & & & & & \\
\hline LSO & $*$ & $*$ & $*$ & & & $*$ & & \\
\hline & Reproducción & & Conexión & & Reflexión \\
\hline
\end{tabular}

\section{ANÁLISIS DE LA CUESTIÓN C23}

La cuestión de la ficha 4.23.1 es un ejercicio que se corresponde con un nivel de conexión. 
FICHA 4.23.1.

ESTUDIO DEL ENUNCIADO DEL C23

C23.- Sea $A$ una matriz cuadrada tal que $A^{2}=A+I$, donde $I$ es la matriz identidad. ¿Se puede asegurar que $A$ admite inversa? Razonar la respuesta.

\begin{tabular}{|c|c|c|c|c|c|c|c|c|c|c|c|c|c|c|}
\hline CONVOCATORIA & \multicolumn{7}{|c|}{ JUNIO } & \multicolumn{7}{|c|}{ SEPTIEMBRE } \\
\hline AÑO & 95 & 96 & 97 & 98 & 99 & 00 & $\underline{01}$ & $02 \quad 03$ & 04 & 05 & 06 & 07 & 08 & 09 \\
\hline OPCIÓN & \multicolumn{7}{|c|}{ A } & \multicolumn{7}{|c|}{$\underline{\mathbf{B}}$} \\
\hline TIPO DE PROBLEMA & \multicolumn{7}{|c|}{ TEÓRICO } & \multicolumn{7}{|c|}{ PRÁCTICO } \\
\hline \multirow{3}{*}{ APARTADOS } & \multirow{3}{*}{\multicolumn{2}{|c|}{ SI }} & \multicolumn{4}{|c|}{ Forma explícita } & & & & & & \multirow[b]{2}{*}{6} & \multirow{3}{*}{\multicolumn{2}{|c|}{$\underline{\mathrm{NO}}$}} \\
\hline & & & & & & & 2 & 3 & 4 & 5 & & & & \\
\hline & & & \multicolumn{4}{|c|}{ Forma implícita } & & & & & & & & \\
\hline VERBO UTILIZADO & \multicolumn{14}{|c|}{ RAZONAR } \\
\hline TIEMPO VERBAL & \multicolumn{14}{|c|}{ INFINITIVO } \\
\hline \multirow{3}{*}{$\begin{array}{l}\text { FALLOS DEL ENUN- } \\
\text { CIADO }\end{array}$} & \multicolumn{9}{|c|}{ PUNTUACIÓN } & & & & & \\
\hline & \multicolumn{9}{|c|}{ ERROR MORFOSINTÁCTICO } & & & & & \\
\hline & \multicolumn{9}{|c|}{ AUSENCIA DE ESPECIFICACIONES } & & & & & \\
\hline \multicolumn{15}{|c|}{ ENUNCIADO ALTERNATIVO } \\
\hline
\end{tabular}

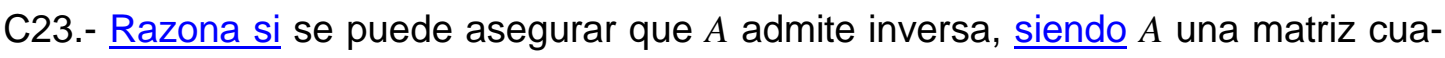
drada que cumple $A^{2}=A+I$, donde $I$ es la matriz identidad.

\section{NIVELES DE COMPETENCIAS IMPLÍCITAS: Conexión}

El alumno piensa en el tratamiento matemático necesario (CPRn1).

Para demostrar que la matriz tiene inversa suponemos que ésta existe y la calculamos.

Este discurso indica que el alumno sabe expresarse sobre cuestiones matemáticas (CCn1).

A continuación razona matemáticamente de manera simple (CAn1), estructura la situación que se debe modelizar (CMn1) y desarrolla procedimientos ya practicados, pero no rutinarios (CRPn1).

Suponiendo que existe la matriz $A^{-1}$

$$
A^{-1} \cdot\left(A^{2}\right)=A^{-1} \cdot(A+I)
$$

Utilizando las propiedades asociativa y distributiva del producto de matrices:

$$
\left(A^{-1} \cdot A\right) \cdot A=A^{-1} \cdot A+A^{-1} \cdot I
$$


Operando y simplificando, utilizando las propiedades del elemento neutro y elemento simétrico:

$$
I \cdot A=I+A^{-1}
$$

Despejando:

$$
A-I=A^{-1}
$$

Hemos comprobado que la matriz $A$ admite inversa dado que hemos obtenido su expresión en función de la matriz $A$ y de la identidad.

Sabe expresarse sobre cuestiones matemáticas (CCn1), explica los cálculos y sus propiedades (CCn2) y traduce, en la práctica, el modelo a seguir, que es algo diferente de los estudiados (CMn2).

El alumno utiliza el lenguaje formal y simbólico básico, en situaciones menos conocidas (CLSOn1), aplica conceptos matemáticos apropiados (CPRn3), desarrolla procedimientos intuitivos ya practicados, pero no rutinarios (CRPn1), maneja afirmaciones sencillas y expresiones con símbolos y fórmulas no rutinarias (CLSOn2), interpreta las relaciones implicadas (CCn3) y comunica los resultados (CMn3).

\begin{tabular}{|l|c|c|c|c|c|c|c|c|}
\hline \multicolumn{6}{|c|}{ FICHA 4.23.2. COMPETENCIAS IMPLÍCITAS EN LA RESOLUCIÓN DE LA C23 } \\
\hline & Nivel 1 & Nivel 2 & Nivel 3 & Nivel 1 & Nivel 2 & Nivel 3 & Nivel 1 & Nivel 2 \\
\hline PR & & & & $*$ & & $*$ & & \\
\hline A & & & & $*$ & & & & \\
\hline C & & & & $*$ & $*$ & $*$ & & \\
\hline M & & & & $*$ & $*$ & $*$ & & \\
\hline RP & & & & $*$ & & & & \\
\hline R & & & & & & & & \\
\hline LSO & & & & $*$ & $*$ & & & \\
\hline & Reproducción & & Conexión & & Reflexión \\
\hline
\end{tabular}

\section{ANÁLISIS DE LA CUESTIÓN C24}

La cuestión que se presenta en la ficha 4.24.1 corresponde, fundamentalmente, al nivel de reproducción del conocimiento estudiado, es la ejecución de un problema rutinario mediante la aplicación de destrezas técnicas y algoritmos 
habituales con el manejo de expresiones y fórmulas establecidas y la realización de cálculos.

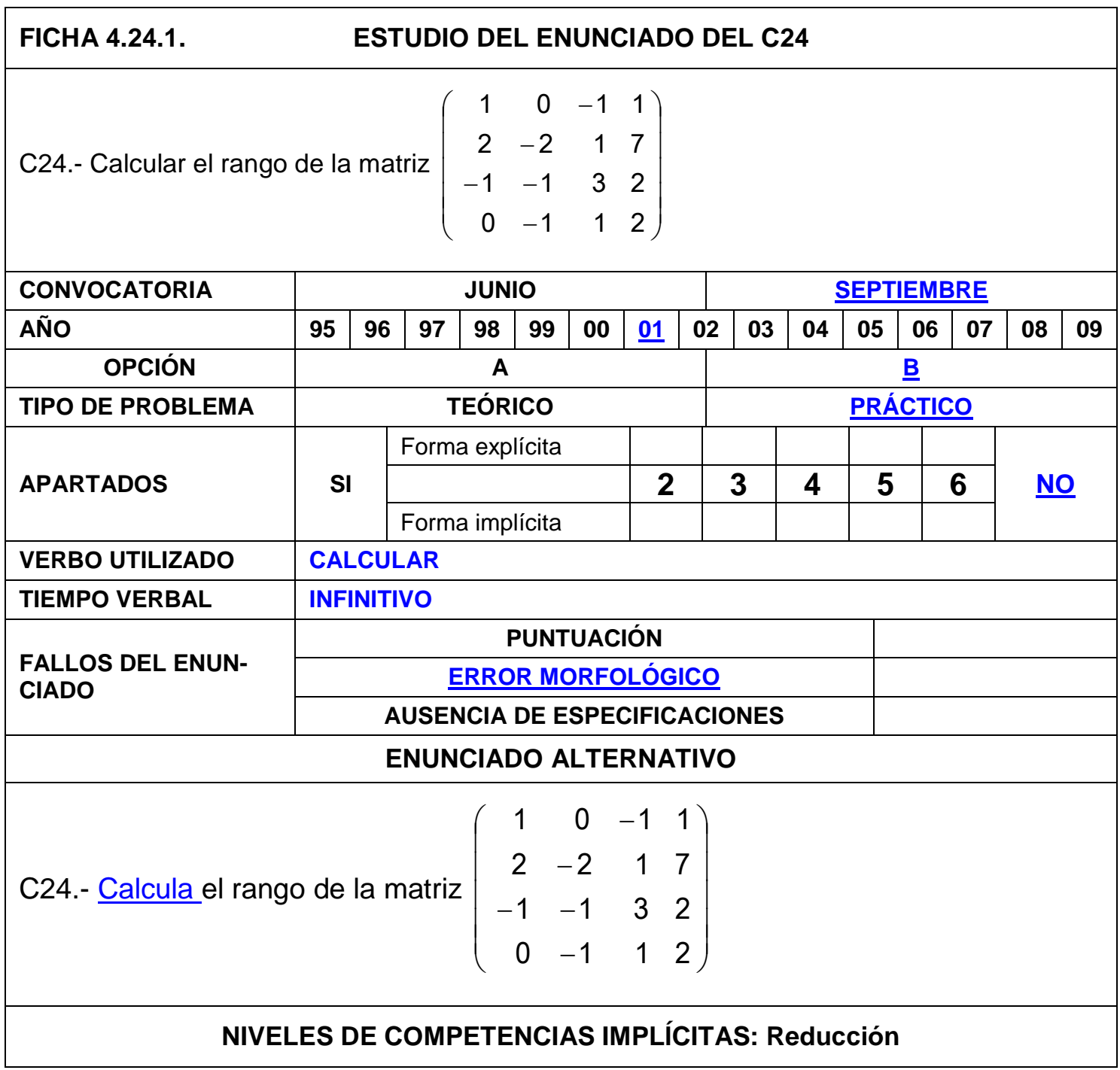

El alumno comprende la expresión escrita (RCn1), identifica el problema (RAn1), le reconoce como problema ya practicado (RRPn1), piensa en el tratamiento matemático necesario (CPRn1), plantea los algoritmos correspondientes (RPRn2) y realiza explicaciones sencillas (RCn2).

Ahora calcula el determinante formado por el menor de la matriz

$$
\operatorname{det}\left(C_{1}, C_{2}, C_{3}\right)=\left|\begin{array}{rrr}
1 & 0 & -1 \\
2 & -2 & 1 \\
-1 & -1 & 3
\end{array}\right|=-1 \neq 0
$$


Mediante operaciones elementales, se comprueba que en la matriz dada se tiene la siguiente combinación lineal de columnas

$$
C_{4}=2 C_{1}-C_{2}+C_{3}
$$

De lo que se deduce que el rango de la matriz no es cuatro, a lo sumo, es tres y como tenemos un determinante de orden tres distinto de cero, se deduce que el rango es tres.

El alumno asocia con fórmulas establecidas y realiza los cálculos (RPRn3), reproduce problemas ya practicados de manera cerrada (RRPn2), resuelve problemas rutinarios estandarizados (RRPn3), describe los resultados obtenidos (RCn3) y comunica de manera elemental los resultados del modelo (RMn3).

El alumno usa un único tipo de representación estándar, ya utilizada (RRn1), la representación algebraica, realiza operaciones elementales en contextos conocidos (RLSOn1), interpreta el lenguaje formal y simbólico rutinario (RLSOn2) y maneja procedimientos y fórmulas resolviendo y calculando (RLSOn3).

El cálculo del determinante corresponde al nivel de conexión, al realizar cálculos mediante procedimientos familiares (CLSOn3), para un alumno de Segundo de bachillerato.

\section{FICHA 4.24.2. COMPETENCIAS IMPLÍCITAS EN LA RESOLUCIÓN DE LA C24}

\begin{tabular}{|l|c|c|c|c|c|c|c|c|}
\hline & Nivel 1 & Nivel 2 & Nivel 3 & Nivel 1 & Nivel 2 & Nivel 3 & Nivel 1 & Nivel 2 \\
\hline PR & & $*$ & $*$ & $*$ & & & & \\
\hline A & $*$ & $*$ & & & & & & \\
\hline C & $*$ & $*$ & $*$ & & & & & \\
\hline M & & & $*$ & & & & & \\
\hline RP & $*$ & $*$ & $*$ & & & & & \\
\hline R & $*$ & & & & & & & \\
\hline LSO & $*$ & $*$ & $*$ & & & $*$ & & \\
\hline & \multicolumn{2}{|l|}{ Reproducción } & & \multicolumn{2}{l|}{ Conexión } & & \multicolumn{2}{l|}{ Reflexión } \\
\hline
\end{tabular}

\section{ANÁLISIS DE LA CUESTIÓN C25}

La cuestión de la ficha 4.25.1 corresponde al nivel de reproducción. El alumno tiene que resolver una ecuación matricial, lo que corresponde a representaciones de problemas comunes, reconocimiento de equivalentes, ejecución de pro- 
blemas rutinarios, aplicación de destrezas técnicas y algoritmos habituales, manejo de expresiones y fórmulas establecidas y realización de cálculos.

FICHA 4.25.1.

ESTUDIO DEL ENUNCIADO DEL C25

C25.- Calcular razonadamente la matriz A sabiendo que se verifica la igualdad

$$
A \cdot\left(\begin{array}{lll}
1 & 2 & 3 \\
0 & 2 & 3 \\
0 & 0 & 3
\end{array}\right)=\left(\begin{array}{lll}
2 & 0 & 0 \\
0 & 2 & 0 \\
0 & 0 & 2
\end{array}\right)
$$

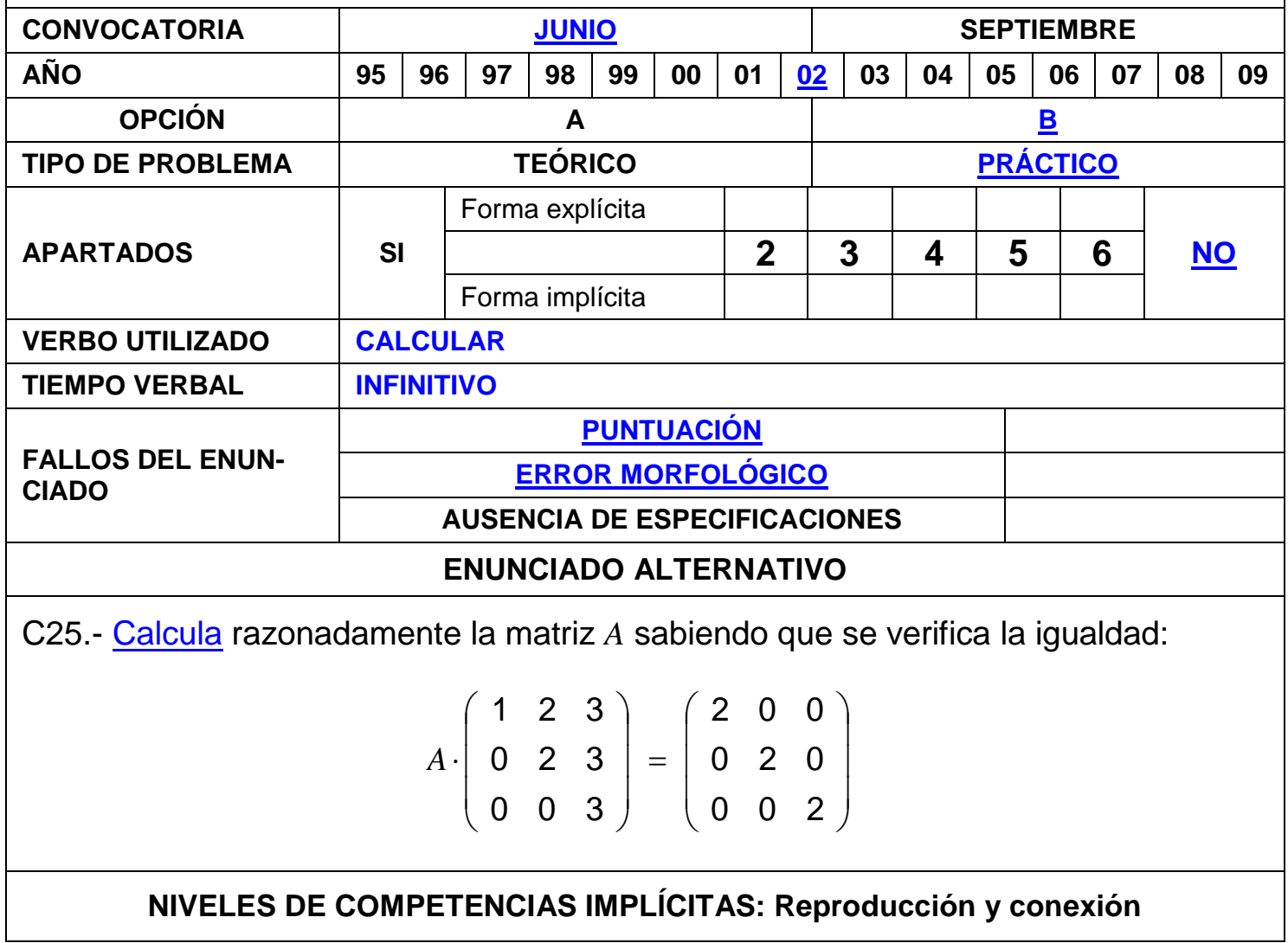

El alumno reconoce las matrices, es decir, reconoce las representaciones de los datos del ejercicio (RPRn1), comprende la expresión escrita (RCn1), identifica el problema (RAn1), -es una ecuación matricial-, reconoce el problema como ya practicado (RRPn1) e identifica que es un modelo similar a otros vistos con anterioridad (RMn1).

A continuación, expone el proceso de cálculo (RAn2), plantea los algoritmos correspondientes (RPRn2), asocia con fórmulas establecidas y realiza cálculos (RPRn3). 


$$
\text { Llamando } B=\left(\begin{array}{lll}
1 & 2 & 3 \\
0 & 2 & 3 \\
0 & 0 & 3
\end{array}\right) \text { y } C=\left(\begin{array}{lll}
2 & 0 & 0 \\
0 & 2 & 0 \\
0 & 0 & 2
\end{array}\right)
$$

Despeja la incógnita

$$
A \cdot B=C \quad \Rightarrow \quad A=C \cdot B^{-1}
$$

Calcula la matriz $B^{-1}$.

Dado que $|B|=6 \neq 0$, existe $B^{-1}$ y $B^{-1}=\frac{1}{|B|} \cdot \operatorname{Adj}\left(B^{t}\right)$, donde $\operatorname{Adj}\left(B^{t}\right)$ es la matriz de adjuntos de la transpuesta de la matriz $B$.

El alumno realiza explicaciones sencillas ( $\mathrm{RCn} 2)$, justifica las fórmulas utilizadas (RAn3) y reproduce problemas ya practicados, de manera cerrada (RRPn2).

También se puede calcular la matriz inversa $B^{-1}$ mediante transformaciones elementales, utilizando el método de Gauss, dada la forma tan sencilla que presenta la matriz $B$.

$$
\begin{aligned}
& \left(\begin{array}{lllllll}
1 & 2 & 3 & \vdots & 1 & 0 & 0 \\
0 & 2 & 3 & \vdots & 0 & 1 & 0 \\
0 & 0 & 3 & \vdots & 0 & 0 & 1
\end{array}\right) \stackrel{(1)}{\longrightarrow}\left(\begin{array}{lllllll}
1 & 2 & 3 & \vdots & 1 & 0 & 0 \\
0 & 2 & 3 & \vdots & 0 & 1 & 0 \\
0 & 0 & 1 & 1 & 0 & 0 & \frac{1}{3}
\end{array}\right)
\end{aligned}
$$

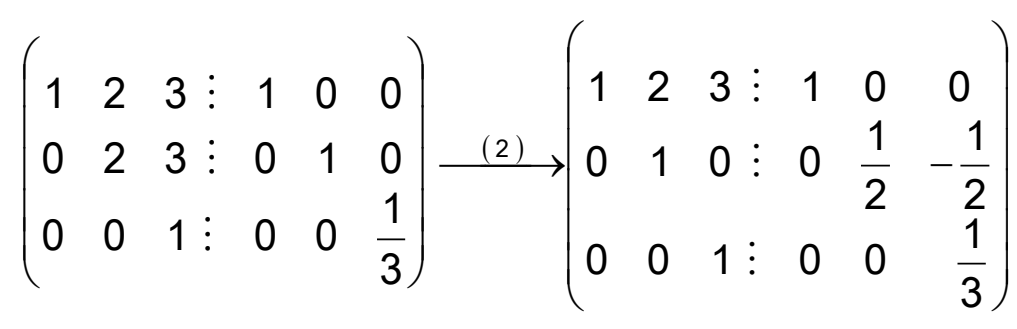

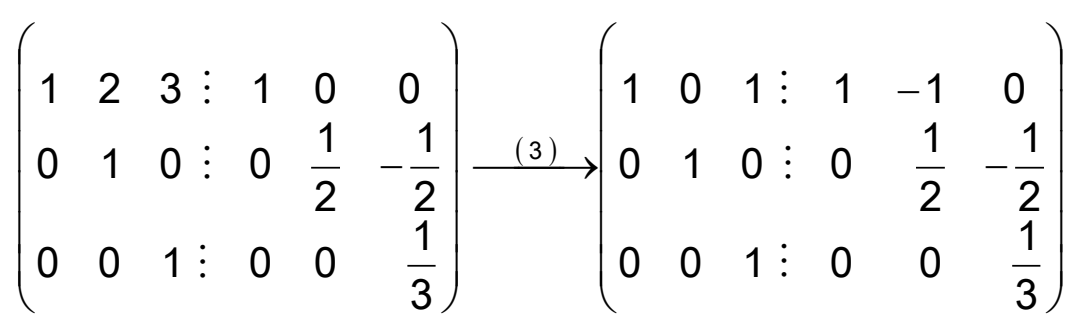

$$
\begin{aligned}
& \text { (1) }\left(\frac{1}{3}\right) \cdot F_{3}
\end{aligned}
$$


(2) $\left(-\frac{1}{3}\right) \cdot F_{2}+F_{3}$ y posteriormente $\left(-\frac{3}{2}\right) \cdot F^{\prime}{ }_{2}$

(3) $\left(-\frac{1}{3}\right) \cdot F_{1}+F_{3}$ y posteriormente $\left(\frac{3}{2}\right) \cdot F^{\prime}{ }_{1}+F^{\prime}{ }_{2}$ para finalizar con $(-2) \cdot F^{\prime \prime}$

El alumno usa un único tipo de representación estándar, ya utilizada (RRn1), la representación algebraica.

$$
B^{-1}=\left(\begin{array}{rrr}
1 & -1 & 0 \\
0 & \frac{1}{2} & -\frac{1}{2} \\
0 & 0 & \frac{1}{3}
\end{array}\right)
$$

Al hacer las operaciones correspondientes al cálculo de la matriz inversa y al producto de matrices, realiza operaciones elementales en contextos conocidos (RLSOn1), interpreta el lenguaje formal y simbólico rutinario (RLSOn2) y maneja procedimientos y fórmulas resolviendo y calculando (RLSOn3).y utiliza variables y realiza ecuaciones y cálculos mediante procedimientos familiares (CLSOn3).

$$
A=C \cdot B^{-1}=\left(\begin{array}{rrr}
2 & -2 & 0 \\
0 & 1 & -1 \\
0 & 0 & \frac{2}{3}
\end{array}\right)
$$

El alumno resuelve problemas rutinarios estandarizados (RRPn3), en un nivel de Matemáticas II, comunica de manera elemental los resultados (RMn3), justifica las fórmulas utilizadas y los resultados (RAn3) y describe los resultados obtenidos (RCn3).

El alumno puede razonar de la siguiente manera:

La matriz $C=2 \cdot I$, por tanto, la matriz $A=2 \cdot B^{-1}$

En esta situación tendríamos un nivel de conexión, dado que el alumno piensa en el tratamiento matemático necesario (CPRn1), aplica conceptos matemáticos apropiados (CPRn3), razona matemáticamente de manera simple (CAn1), sabe expresarse sobre cuestiones matemáticas (CCn1), explica los cálculos y sus propiedades (CCn2) e interpreta las relaciones implicadas (CCn3). 


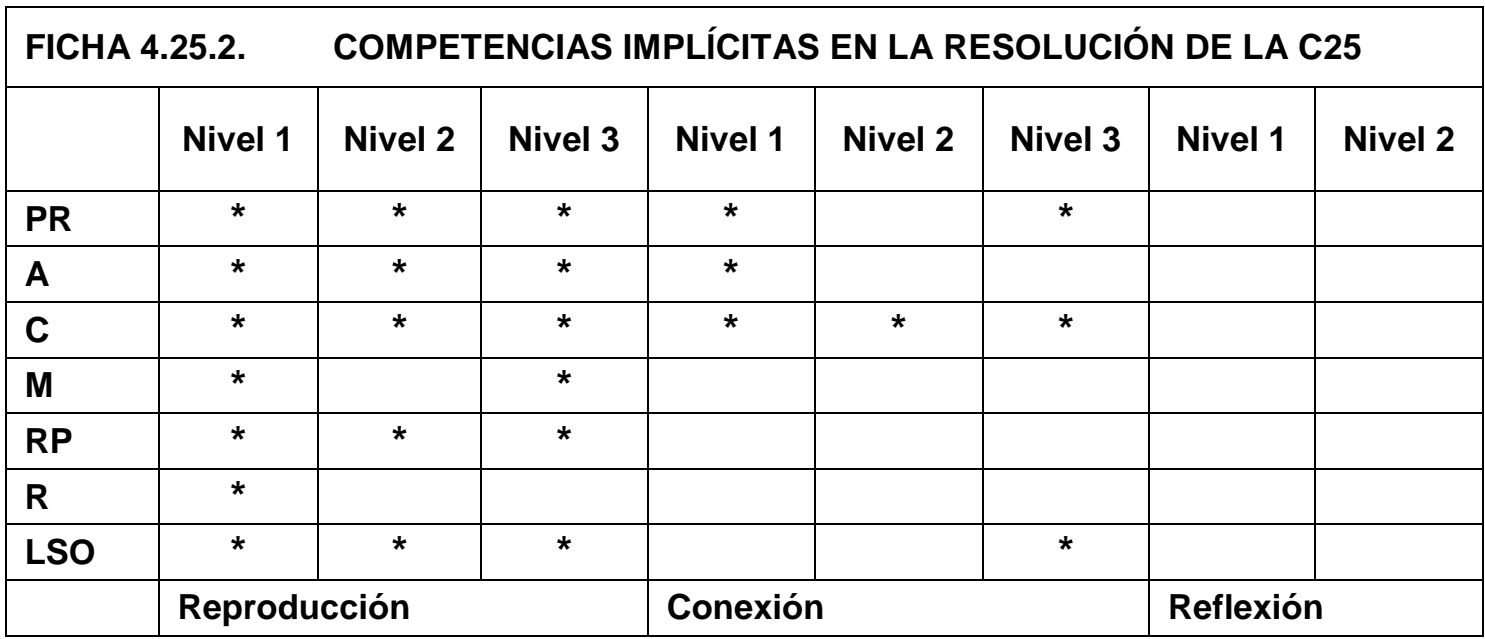

\section{ANÁLISIS DE LA CUESTIÓN C27}

\section{FICHA 4.27.1.}

\section{ESTUDIO DEL ENUNCIADO DEL C27}

C27.- Si los determinantes de las matrices cuadradas de orden tres $A$ y $2 A$ son iguales, calcular el determinante de $A$. ¿Existe la matriz inversa de $A$ ?

\begin{tabular}{|c|c|c|c|c|c|c|c|c|c|c|c|c|c|c|}
\hline CONVOCATORIA & \multicolumn{7}{|c|}{ JUNIO } & \multicolumn{7}{|c|}{ SEPTIEMBRE } \\
\hline AÑO & 95 & 96 & 97 & 98 & 99 & 00 & 01 & $\underline{02} 03$ & 04 & 05 & 06 & 07 & 08 & 09 \\
\hline OPCIÓN & \multicolumn{7}{|c|}{ A } & \multicolumn{7}{|c|}{$\underline{B}$} \\
\hline TIPO DE PROBLEMA & \multicolumn{7}{|c|}{ TEÓRICO } & \multicolumn{7}{|c|}{ PRÁCTICO } \\
\hline \multirow{3}{*}{ APARTADOS } & \multirow{3}{*}{\multicolumn{2}{|c|}{ SI }} & \multicolumn{4}{|c|}{ Forma explícita } & & & & & & \multirow[b]{2}{*}{6} & \multirow{3}{*}{\multicolumn{2}{|c|}{ NO }} \\
\hline & & & & & & & 2 & 3 & 4 & 5 & & & & \\
\hline & & & \multicolumn{4}{|c|}{ Forma implícita } & & & & & & & & \\
\hline VERBO UTILIZADO & \multicolumn{14}{|c|}{ RAZONAR } \\
\hline TIEMPO VERBAL & \multicolumn{14}{|c|}{ INFINITIVO } \\
\hline \multirow{3}{*}{$\begin{array}{l}\text { FALLOS DEL ENUN- } \\
\text { CIADO }\end{array}$} & \multicolumn{9}{|c|}{ PUNTUACIÓN } & & & & & \\
\hline & \multicolumn{9}{|c|}{ ERROR MORFOSINTÁCTICO } & & & & & \\
\hline & \multicolumn{9}{|c|}{ AUSENCIA DE ESPECIFICACIONES } & & & & & \\
\hline
\end{tabular}

C27.- Si los determinantes de las matrices cuadradas de orden tres $A$ y $2 A$ son iguales, calcula el determinante de $A$.

b) Razona si, con esa condición, existe la matriz inversa de $A$.

NIVELES DE COMPETENCIAS IMPLÍCITAS: Reproducción

La cuestión de la ficha 4.27.1 es de tipo teórico, corresponde pues al nivel de reproducción con el reconocimiento de equivalentes, es la ejecución de problemas rutinarios, con la aplicación de destrezas técnicas y algoritmos habitua- 
les, el manejo de expresiones y fórmulas establecidas y la realización de cálculos.

El alumno identifica el problema (RAn1), comprende la expresión escrita (RCn1), reconoce el problema como ya practicado (RRPn1), identifica que es un modelo similar a otros vistos con anterioridad (RMn1), plantea los algoritmos correspondientes (RPRn2), asocia con fórmulas establecidas y realiza cálculos (RPRn3).

A continuación, realiza operaciones elementales en contextos conocidos (RLSOn1), realiza explicaciones sencillas (RCn2) y expone el proceso de cálculo (RAn2).

Como la matriz A es de orden tres, utilizando las propiedades de los determinantes y sacando factor 2 de cada una de las filas (o columnas) de la matriz, se tiene:

$$
\operatorname{det}(2 \cdot A)=2^{3} \cdot \operatorname{det}(A)=8 \cdot \operatorname{det}(A)
$$

Además, como, por condición del enunciado, se verifica que

$$
\begin{gathered}
\operatorname{det}(2 \cdot A)=\operatorname{det}(A) \\
\operatorname{det}(2 \cdot A)=8 \cdot \operatorname{det}(A)=\operatorname{det}(A)
\end{gathered}
$$

Se trata de una ecuación polinómica con solución:

$$
\operatorname{det}(A)=0
$$

El alumno realiza explicaciones sencillas (RCn2), justifica las fórmulas utilizadas (RAn3) y reproduce problemas ya practicados, de manera cerrada (RRPn2). Asimismo, resuelve problemas rutinarios estandarizados (RRPn3), describe los resultados obtenidos (RCn3) y comunica de manera elemental los resultados (RMn3).

El apartado b) de la cuestión de la ficha 4.27.1 es una cuestión de aplicación directa de la teoría impartida lo que corresponde al nivel de reproducción del conocimiento estudiado.

$$
\text { Si } \operatorname{det}(A)=0 \text { la matriz no admite inversa. }
$$

El alumno resuelve problemas rutinarios estandarizados (RRPn3), describe los resultados obtenidos (RCn3) y comunica de manera elemental los resultados (RMn3). 


\section{FICHA 4.27.2. COMPETENCIAS IMPLÍCITAS EN LA RESOLUCIÓN DE LA C27}

\begin{tabular}{|l|c|c|c|c|c|c|c|c|}
\hline & Nivel 1 & Nivel 2 & Nivel 3 & Nivel 1 & Nivel 2 & Nivel 3 & Nivel 1 & Nivel 2 \\
\hline PR & & $*$ & $*$ & & & & & \\
\hline A & $*$ & $*$ & $*$ & & & & & \\
\hline C & $*$ & $*$ & $*$ & & & & & \\
\hline M & $*$ & & $*$ & & & & & \\
\hline RP & $*$ & $*$ & $*$ & & & & & \\
\hline R & & & & & & & & \\
\hline LSO & $*$ & & & & & & & \multicolumn{2}{l|}{ Reflexión } \\
\hline
\end{tabular}

\section{ANÁLISIS DE LA CUESTIÓN C29}

\section{FICHA 4.29.1. \\ ESTUDIO DEL ENUNCIADO DEL C29}

C29.- Si $A$ es una matriz cuadrada, ¿la matriz $A+A^{t}$ es igual a su traspuesta? Razonar la respuesta. ( $A^{t}$ es la matriz traspuesta de $A$ )

\begin{tabular}{|c|c|c|c|c|c|c|c|c|c|c|c|c|c|}
\hline CONVOCATORIA & \multicolumn{7}{|c|}{ JUNIO } & \multicolumn{6}{|c|}{ SEPTIEMBRE } \\
\hline AÑO & 95 & 96 & 97 & 98 & 99 & 00 & 01 & $02 \quad \underline{03}$ & 04 & 05 & \begin{tabular}{l|l}
06 & 07
\end{tabular} & 08 & 09 \\
\hline OPCIÓN & \multicolumn{7}{|c|}{ A } & \multicolumn{6}{|c|}{$\underline{B}$} \\
\hline TIPO DE PROBLEMA & \multicolumn{7}{|c|}{ TEÓRICO } & \multicolumn{6}{|c|}{ PRÁCTICO } \\
\hline \multirow{3}{*}{ APARTADOS } & \multirow{3}{*}{\multicolumn{2}{|c|}{ SI }} & \multicolumn{4}{|c|}{ Forma explícita } & & & & \multirow{3}{*}{5} & \multirow[b]{2}{*}{6} & \multirow{3}{*}{\multicolumn{2}{|c|}{ NO }} \\
\hline & & & & & & & 2 & 3 & 4 & & & & \\
\hline & & & \multicolumn{4}{|c|}{ Forma implícita } & & & & & & & \\
\hline VERBO UTILIZADO & \multicolumn{13}{|c|}{ ESBOZAR I DETERMINAR / PROBAR } \\
\hline TIEMPO VERBAL & \multicolumn{13}{|c|}{ INFINITIVO } \\
\hline \multirow{3}{*}{$\begin{array}{l}\text { FALLOS DEL ENUN- } \\
\text { CIADO }\end{array}$} & \multicolumn{9}{|c|}{ PUNTUACIÓN } & & & & \\
\hline & \multicolumn{9}{|c|}{ ERROR MORFOSINTÁCTICO } & & & & \\
\hline & \multicolumn{9}{|c|}{ ESTRUCTURA DE LA ORACIÓN } & & & & \\
\hline
\end{tabular}

C29.- A es una matriz cuadrada y $A^{t}$ es la matriz traspuesta de $A$. Se considera la matriz $B=A+A^{t}$. Escribe de forma razonada si la matriz $B$ coincide con su traspuesta.

\section{NIVELES DE COMPETENCIAS IMPLÍCITAS: Reproducción}

La cuestión de la ficha 4.29.1 es teórica, corresponde pues al nivel de reproducción. 
El alumno identifica el problema (RAn1), comprende la expresión escrita $(\mathrm{RCn} 1)$, reconoce el problema como ya practicado (RRPn1), identifica que es un modelo similar a otros vistos con anterioridad (RMn1), plantea los algoritmos correspondientes (RPRn2), asocia con fórmulas establecidas y realiza cálculos (RPRn3).

A continuación, realiza explicaciones sencillas (RCn2) y expone el proceso de cálculo (RAn2).

Calculando la matriz transpuesta

$$
\left(A+A^{t}\right)^{t}=A^{t}+\left(A^{t}\right)^{t} \stackrel{(1)}{=} A^{t}+\stackrel{(2)}{=} A+A^{t}
$$

(1) La matriz transpuesta de la matriz transpuesta coincide con la matriz inicial.

(2) La suma de matrices es conmutativa.

El alumno utiliza variables y realiza cálculos mediante procedimientos familiares (CLSOn3).

A continuación realiza explicaciones sencillas (RCn2), describe los resultados obtenidos (RCn3), justifica las fórmulas utilizadas y los resultados (RAn3) y reproduce problemas ya practicados de manera cerrada (RRPn2).

De esta manera resuelve problemas rutinarios estandarizados (RRPn3) y comunica de manera elemental los resultados (RMn3).

\begin{tabular}{|c|c|c|c|c|c|c|c|c|}
\hline \multicolumn{2}{|c|}{ FICHA 4.29.2. } & \multicolumn{7}{|c|}{ COMPETENCIAS IMPLÍCITAS EN LA RESOLUCIÓN DE LA C29 } \\
\hline & Nivel 1 & Nivel 2 & Nivel 3 & Nivel 1 & Nivel 2 & Nivel 3 & Nivel 1 & Nivel 2 \\
\hline PR & & * & * & & & & & \\
\hline$A$ & * & * & * & & & & & \\
\hline C & * & * & * & & & & & \\
\hline M & * & & * & & & & & \\
\hline RP & * & * & * & & & & & \\
\hline \multicolumn{9}{|l|}{$\mathbf{R}$} \\
\hline LSO & & & & & & * & & \\
\hline & \multicolumn{3}{|c|}{ Reproducción } & \multicolumn{3}{|c|}{ Conexión } & \multicolumn{2}{|c|}{ Reflexión } \\
\hline
\end{tabular}




\section{ANÁLISIS DE LA CUESTIÓN C32}

\section{FICHA 4.32.1. \\ ESTUDIO DEL ENUNCIADO DEL C32}

C32.- Se tiene una matriz $M$ cuadrada de orden 3 cuyas columnas son respectivamente $C_{1}, C_{2}$ y $C_{3}$ y cuyo determinante vale 2 . Se considera la matriz $A$ cuyas columnas son $-C_{2}, C_{3}+C_{2}, 3 C_{1}$. Calcúlese razonadamente el determinante de $A^{-1}$ en caso de que exista esa matriz.

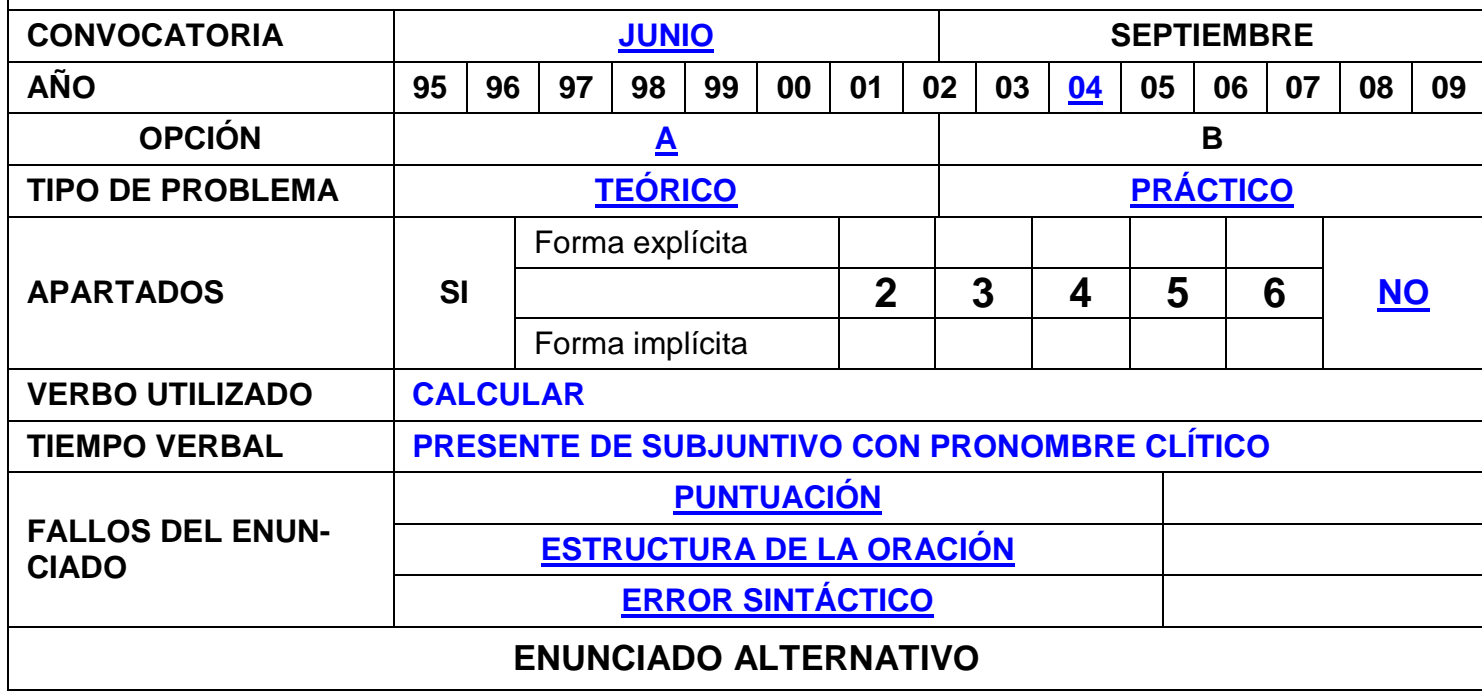

C32.- Dada una matriz cuadrada $M_{2}$ de orden $3_{2}$ cuyas columnas son respectivamente $C_{1}, C_{2}$ y $C_{3}$ y cuyo determinante vale 2 , se considera la matriz $A$ cuyas columnas son $-C_{2}, C_{3}+C_{2}, 3 C_{1}$. Calcula razonadamente el determinante de $A^{-1}$ en caso de que exista esa matriz.

\section{NIVELES DE COMPETENCIAS IMPLÍCITAS: Reproducción}

La cuestión de la ficha 4.32.1 es de tipo teórico, corresponde pues al nivel de reproducción con el reconocimiento de equivalentes, es la ejecución de un problema rutinario, con la aplicación de destrezas técnicas y algoritmos habituales, el manejo de expresiones y fórmulas establecidas y la realización de cálculos.

El alumno reconoce representaciones de los datos del ejercicio (RPRn1), -la matriz dada por sus columnas-, identifica el problema (RAn1), identifica que es un modelo similar a otros vistos con anterioridad (RMn1), reconoce el problema como ya practicado (RRPn1), plantea los algoritmos correspondientes (RPRn2) y asocia con fórmulas establecidas y realiza cálculos (RPRn3). 
Para la resolución del ejercicio el alumno realiza operaciones elementales en contextos conocidos (RLSOn1), interpreta el lenguaje formal y simbólico rutinario (RLSOn2) -en Segundo de Bachillerato-, maneja procedimientos y fórmulas resolviendo y calculando (RLSOn3) y utiliza variables y realiza ecuaciones $y$ cálculos mediante procedimientos familiares (CLSOn3).

Utilizando las propiedades de los determinantes,

$$
\begin{gathered}
\operatorname{det}(A)=\operatorname{det}\left(-C_{2}, C_{3}+C_{2}, 3 C_{1}\right) \stackrel{(1)}{=} \operatorname{det}\left(-C_{2}, C_{3}, 3 C_{1}\right)+\operatorname{det}\left(-C_{2}, C_{2}, 3 C_{1}\right)= \\
=\operatorname{det}\left(-C_{2}, C_{3}, 3 C_{1}\right)+0 \stackrel{(2)}{=}(-3) \cdot \operatorname{det}\left(C_{2}, C_{3}, C_{1}\right)=(-3) \cdot \operatorname{det}\left(C_{1}, C_{2}, C_{3}\right)= \\
=(-3) \cdot \operatorname{det}(M)=(-3) \cdot 2=(-6)
\end{gathered}
$$

(1) utilizando propiedades del determinante

(2) Sacando factor común en columna 1 y columna 3

Dado que $A \cdot A^{-1}=I$ se cumple

$$
\begin{gathered}
1=\operatorname{det}(I)=\operatorname{det}\left(A \cdot A^{-1}\right)=\operatorname{det}(A) \cdot \operatorname{det}\left(A^{-1}\right) \Rightarrow \operatorname{det}\left(A^{-1}\right)=\frac{1}{\operatorname{det}(A)} \\
\operatorname{det}\left(A^{-1}\right)=\frac{1}{\operatorname{det}(A)}=-\frac{1}{6}
\end{gathered}
$$

El alumno realiza explicaciones sencillas (RCn2), justifica las fórmulas utiliza-

\begin{tabular}{|c|c|c|c|c|c|c|c|c|}
\hline \multicolumn{2}{|c|}{ FICHA 4.32.2. } & \multicolumn{7}{|c|}{ COMPETENCIAS IMPLÍCITAS EN LA RESOLUCIÓN DE LA C32 } \\
\hline & Nivel 1 & Nivel 2 & Nivel 3 & Nivel 1 & Nivel 2 & Nivel 3 & Nivel 1 & Nivel 2 \\
\hline PR & * & * & * & & & & & \\
\hline A & * & & * & & & & & \\
\hline $\mathbf{C}$ & & * & * & & & & & \\
\hline M & * & & * & & & & & \\
\hline RP & * & * & * & & & & & \\
\hline \multicolumn{9}{|l|}{$\mathbf{R}$} \\
\hline LSO & * & * & * & & & * & & \\
\hline & \multicolumn{3}{|c|}{ Reproducción } & \multicolumn{3}{|c|}{ Conexión } & \multicolumn{2}{|c|}{ Reflexión } \\
\hline
\end{tabular}
das y los resultados (RAn3), reproduce problemas ya practicados de manera cerrada (RRPn2), resuelve problemas rutinarios estandarizados (RRPn3), describe los resultados obtenidos (RCn3) y comunica de manera elemental los resultados del modelo (RMn3). 


\section{ANÁLISIS DE LA CUESTIÓN C38}

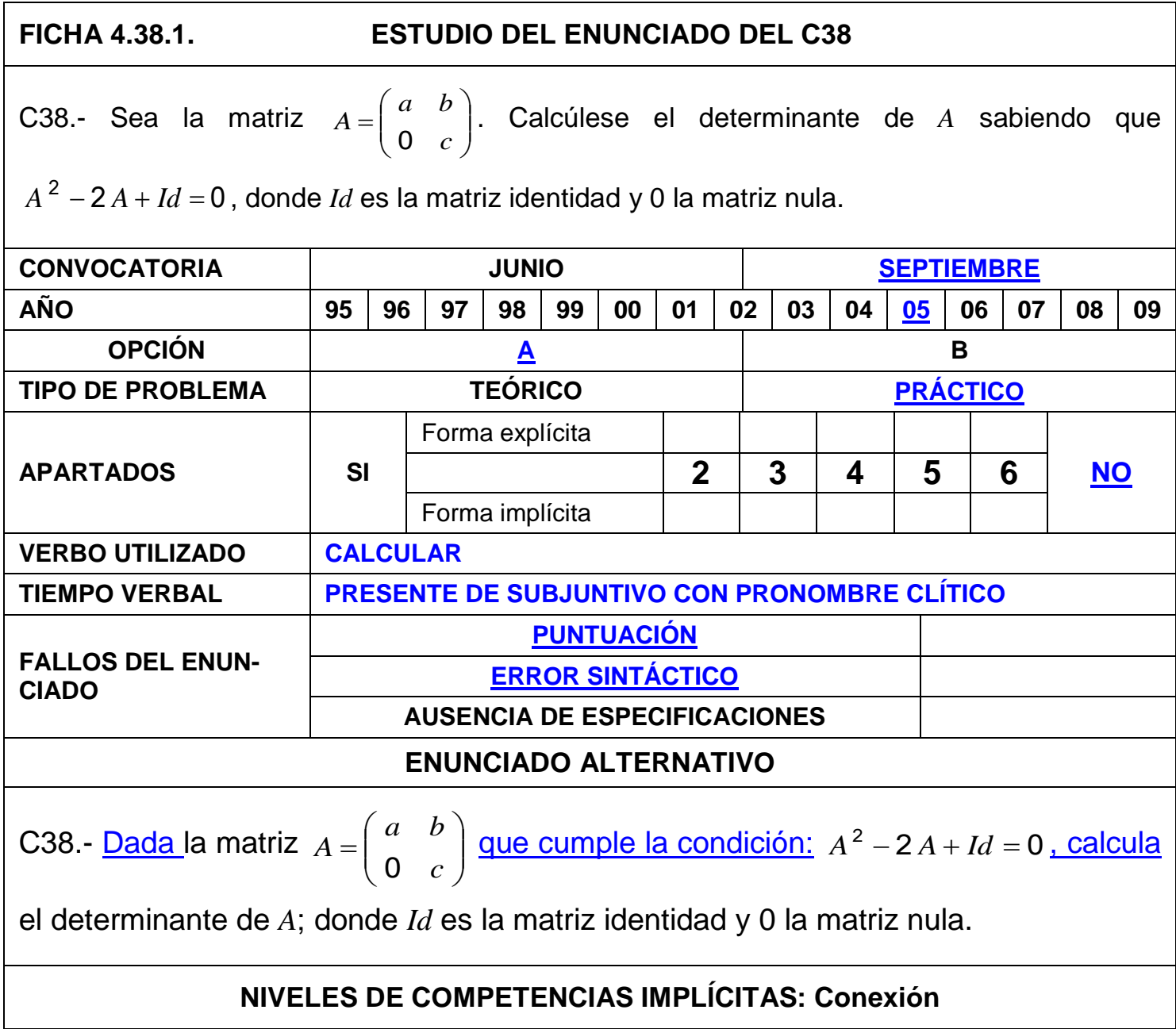

La cuestión de la ficha 4.38.1 es un ejercicio que se corresponde con un nivel de conexión; reproduce una situación similar a la referente en su etapa de aprendizaje, pero no es una mera rutina, dado que el alumno tiene que pensar en el tratamiento matemático necesario (CPRn1), razonar matemáticamente de manera simple (CAn1), estructurar la situación que se debe modelizar (CMn1), desarrollar procedimientos ya practicados, pero no rutinarios (CRPn1), pues hay que calcular el determinante de una matriz, pero dependiendo de los posibles valores de parámetros.

Realizando las operaciones matriciales

$$
A^{2}-2 A+I=\left(\begin{array}{cc}
a^{2} & a b+b c \\
0 & c^{2}
\end{array}\right)+\left(\begin{array}{cc}
-2 a & -2 b \\
0 & -2 c
\end{array}\right)+\left(\begin{array}{ll}
1 & 0 \\
0 & 1
\end{array}\right)=\left(\begin{array}{ll}
0 & 0 \\
0 & 0
\end{array}\right)
$$

El alumno realiza operaciones elementales en contextos conocidos (RLSOn1), 
interpreta el lenguaje formal y simbólico rutinario (RLSOn2) y maneja procedimientos y fórmulas resolviendo y calculando (RLSOn3).

De donde obtiene las ecuaciones

$$
\left\{\begin{array}{c}
a^{2}-2 a+1=0 \\
a b+b c-2 b=0 \\
c^{2}-2 c+1=0
\end{array}\right.
$$

\section{Con solución: $a=1$ y $c=1$}

Con esta reflexión, el alumno razona matemáticamente de manera simple (CAn1), sabe expresarse sobre cuestiones matemáticas (CCn1) y utiliza variables y realiza ecuaciones y cálculos mediante procedimientos familiares (CLSOn3).

El alumno comprende que tiene que emplear métodos matemáticos intermedios (CPRn2), traduce, en la práctica, el modelo a seguir, que es algo diferente de los estudiados (CMn2), explica los cálculos y sus propiedades (CCn2) e interpreta las relaciones implicadas (CCn3).

$\mathrm{Y}$, en consecuencia, el determinante de la matriz es: $\left|\begin{array}{ll}a & b \\ 0 & c\end{array}\right|=a \cdot c=1$

El alumno usa un único tipo de representación estándar, ya utilizada (RRn1), sigue el encadenamiento del argumento matemático particular (CAn2), aplicando, de este modo, conceptos matemáticos apropiados (CPRn3), haciendo una evaluación del mismo (CAn3) y comunica los resultados (CMn3).

FICHA 4.38.2. COMPETENCIAS IMPLÍCITAS EN LA RESOLUCIÓN DE LA C38

\begin{tabular}{|l|c|c|c|c|c|c|c|c|}
\hline & Nivel 1 & Nivel 2 & Nivel 3 & Nivel 1 & Nivel 2 & Nivel 3 & Nivel 1 & Nivel 2 \\
\hline PR & & & & $*$ & $*$ & $*$ & & \\
\hline A & & & & $*$ & $*$ & $*$ & & \\
\hline C & & & & $*$ & $*$ & $*$ & & \\
\hline M & & & & $*$ & $*$ & $*$ & & \\
\hline RP & & & & $*$ & & & & \\
\hline R & $*$ & & & & & & & \\
\hline LSO & $*$ & $*$ & $*$ & & & $*$ & & \\
\hline
\end{tabular}




\section{ANÁLISIS DE LA CUESTIÓN C41}

\section{FICHA 4.41.1.}

ESTUDIO DEL ENUNCIADO DEL C41

C41.- Hállense las matrices A cuadradas de orden 2, que verifican la igualdad:

$$
A\left(\begin{array}{ll}
1 & 0 \\
1 & 1
\end{array}\right)=\left(\begin{array}{ll}
1 & 0 \\
1 & 1
\end{array}\right) A
$$

\begin{tabular}{|c|c|c|c|c|c|c|c|c|c|c|c|c|c|c|c|}
\hline CONVOCATORIA & \multicolumn{7}{|c|}{ JUNIO } & \multicolumn{8}{|c|}{ SEPTIEMBRE } \\
\hline AÑO & 95 & 96 & 97 & 98 & 99 & 00 & 01 & 02 & 03 & 04 & 05 & 06 & 07 & 08 & 09 \\
\hline OPCIÓN & \multicolumn{8}{|c|}{$\underline{A}$} & \multicolumn{7}{|c|}{ B } \\
\hline TIPO DE PROBLEMA & \multicolumn{7}{|c|}{ TEÓRICO } & \multicolumn{8}{|c|}{ PRÁCTICO } \\
\hline \multirow{3}{*}{ APARTADOS } & \multirow{3}{*}{\multicolumn{2}{|c|}{ SI }} & \multicolumn{4}{|c|}{ Forma explícita } & & & & & & & \multirow[b]{2}{*}{6} & \multirow{3}{*}{\multicolumn{2}{|c|}{$\underline{\text { NO }}$}} \\
\hline & & & & & & & 2 & & 3 & 4 & 5 & & & & \\
\hline & & & \multicolumn{4}{|c|}{ Forma implícita } & & & & & & & & & \\
\hline VERBO UTILIZADO & \multicolumn{15}{|c|}{ HALLAR } \\
\hline TIEMPO VERBAL & \multicolumn{15}{|c|}{ PRESENTE DE SUBJUNTIVO CON PRONOMBRE CLÍTICO } \\
\hline \multirow{3}{*}{$\begin{array}{l}\text { FALLOS DEL ENUN- } \\
\text { CIADO }\end{array}$} & \multicolumn{10}{|c|}{ PUNTUACIÓN } & & & & & \\
\hline & \multicolumn{10}{|c|}{ ERROR MORFOLÓGICO } & & & & & \\
\hline & \multicolumn{10}{|c|}{ AUSENCIA DE ESPECIFICACIONES } & & & & & \\
\hline
\end{tabular}

C41.- Halla las matrices cuadradas de orden $2, A$, que verifican la igualdad:

$$
A\left(\begin{array}{ll}
1 & 0 \\
1 & 1
\end{array}\right)=\left(\begin{array}{ll}
1 & 0 \\
1 & 1
\end{array}\right) A
$$

\section{NIVELES DE COMPETENCIAS IMPLÍCITAS: Conexión}

La cuestión de la ficha 4.41 .1 es un ejercicio que se corresponde con un nivel de conexión; reproduce una situación similar a la referente en su etapa de aprendizaje, pero no es una mera rutina, dado que introduce la presencia de parámetros.

El alumno piensa en el tratamiento matemático necesario (CPRn1) y razona matemáticamente de manera simple (CAn1), estructura la situación que debe modelizar (CMn1) y desarrolla procedimientos ya practicados, pero no rutinarios (CRPn1), pues hay que resolver un sistema de ecuaciones, pero dependiendo de los posibles valores de parámetros.

Llamando a la matriz $A=\left(\begin{array}{ll}a & b \\ c & d\end{array}\right)$ y realizando los productos matriciales 


$$
\begin{aligned}
& A \cdot\left(\begin{array}{ll}
1 & 0 \\
1 & 1
\end{array}\right)=\left(\begin{array}{ll}
a & b \\
c & d
\end{array}\right) \cdot\left(\begin{array}{ll}
1 & 0 \\
1 & 1
\end{array}\right)=\left(\begin{array}{ll}
a+b & b \\
c+d & d
\end{array}\right) \\
&\left(\begin{array}{ll}
1 & 0 \\
1 & 1
\end{array}\right) \cdot A=\left(\begin{array}{ll}
1 & 0 \\
1 & 1
\end{array}\right) \cdot\left(\begin{array}{ll}
a & b \\
c & d
\end{array}\right)=\left(\begin{array}{cc}
a & b \\
a+c & b+d
\end{array}\right)
\end{aligned}
$$

Las operaciones con matrices y las ecuaciones que se deducen de la igualdad de matrices, revelan que el alumno utiliza variables y realiza cálculos mediante procedimientos familiares (CLSOn3).

Para que ambas matrices sean iguales, es preciso que: $\left\{\begin{array}{c}a+b=a \\ c+d=a+c \\ d=b+d\end{array}\right.$

Con esta reflexión, el alumno sabe expresarse sobre cuestiones matemáticas (CCn1) y sigue el encadenamiento del argumento matemático particular (CAn2) haciendo una evaluación del mismo (CAn3).

Lo que se cumple si se dan las condiciones: $b=0$ y $a=d$

El alumno usa un único tipo de representación estándar, ya utilizada (RRn1), realiza operaciones elementales en contextos conocidos (RLSOn1), interpreta el lenguaje formal y simbólico rutinario (RLSOn2) y maneja procedimientos y fórmulas resolviendo y calculando (RLSOn3)

El alumno comprende que tiene que emplear métodos matemáticos intermedios (CPRn2), traduce, en la práctica, el modelo a seguir, que es algo diferente de los estudiados (CMn2), explica los cálculos y sus propiedades (CCn2) e interpreta las relaciones implicadas (CCn3).

Asimismo, sigue el encadenamiento del argumento matemático particular (CAn2), aplicando, de este modo, conceptos matemáticos apropiados (CPRn3), aunque resuelve problemas rutinarios estandarizados (RRPn3), dado que este tipo de ejercicio suele repetirse en la fase de instrucción.

Por consiguiente, la matriz buscada es: $A=\left(\begin{array}{cc}a & 0 \\ c & a\end{array}\right)$

El alumno hace una evaluación del argumento matemático (CAn3) y comunica los resultados (CMn3). 


\begin{tabular}{|l|c|c|c|c|c|c|c|c|}
\hline \multicolumn{6}{|c|}{ FICHA 4.41.2. COMPETENCIAS IMPLÍCITAS EN LA RESOLUCIÓN DE LA C41 } \\
\hline & Nivel 1 & Nivel 2 & Nivel 3 & Nivel 1 & Nivel 2 & Nivel 3 & Nivel 1 & Nivel 2 \\
\hline PR & & & & $*$ & $*$ & $*$ & & \\
\hline A & & & & $*$ & $*$ & $*$ & & \\
\hline C & & & & $*$ & $*$ & $*$ & & \\
\hline M & & & & $*$ & $*$ & $*$ & & \\
\hline RP & & & $*$ & $*$ & & & & \\
\hline R & $*$ & & & & & & & \\
\hline LSO & $*$ & $*$ & $*$ & & & $*$ & & \\
\hline & Reproducción & & Conexión & & Reflexión \\
\hline
\end{tabular}

\section{ANÁLISIS DE LA CUESTIÓN C55}

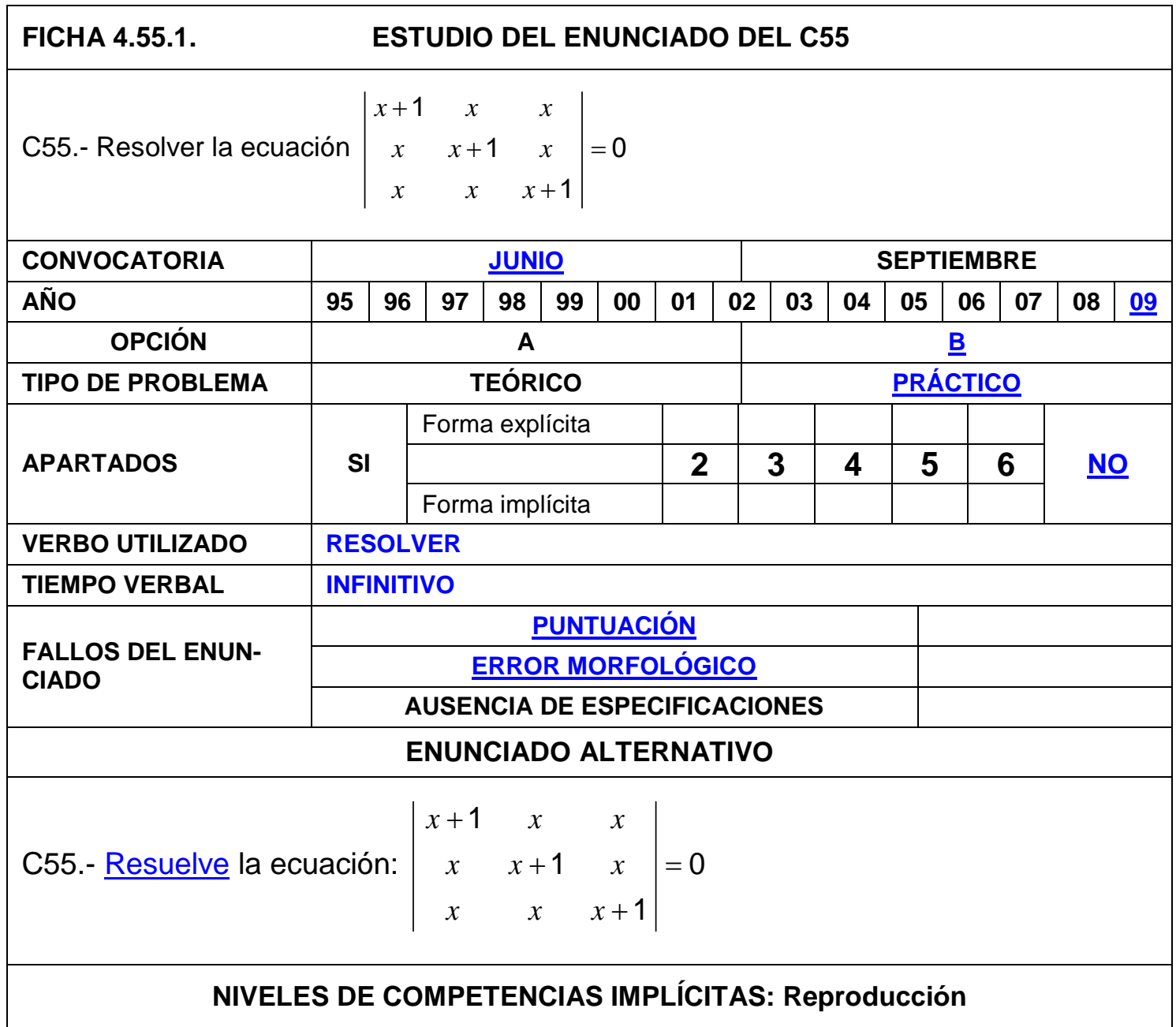

La cuestión de la ficha 4.55.1 es un ejercicio que se corresponde con un nivel de reproducción; corresponde al reconocimiento de equivalentes, ejecución 
de problemas rutinarios, aplicación de destrezas técnicas y algoritmos habituales, manejo de expresiones y fórmulas establecidas y realización de cálculos.

El alumno identifica el problema (RAn1), comprende la expresión escrita (RCn1),-el determinante-, reconoce las representaciones de los datos del ejercicio (RPRn1), -es una ecuación polinómica-, identifica que es un modelo similar a otros vistos con anterioridad (RMn1) y reconoce el problema como ya practicado (RRPn1), plantea los algoritmos correspondientes (RPRn2), asocia con fórmulas establecidas y realiza cálculos (RPRn3).

A continuación, expone el proceso de cálculo (RAn2).

$$
\begin{aligned}
& \left|\begin{array}{ccc}
x+1 & x & x \\
x & x+1 & x \\
x & x & x+1
\end{array}\right| \stackrel{(1)}{=}\left|\begin{array}{ccc}
3 x+1 & x & x \\
3 x+1 & x+1 & x \\
3 x+1 & x & x+1
\end{array}\right|=(3 x+1) \cdot\left|\begin{array}{ccc}
1 & x & x \\
1 & x+1 & x \\
1 & x & x+1
\end{array}\right|= \\
& \begin{array}{c}
F_{1} \\
F_{3}-F_{1} \\
F_{3}-F_{1}
\end{array}=(3 x+1) \cdot\left|\begin{array}{ccc}
1 & x & x \\
0 & 1 & 0 \\
0 & 0 & 1
\end{array}\right|=3 x+1
\end{aligned}
$$

(1) Como $\operatorname{det}\left(C_{1}, C_{2}, C_{3}\right)=\operatorname{det}\left(C_{1}+C_{2}+C_{3}, C_{2}, C_{3}\right)$

(2) Sacando factor común $(3 x+1)$ en $C_{1}$

La ecuación $3 x+1=0$ tiene como única solución real el valor $x=-\frac{1}{3}$.

En la resolución de la ecuación el alumno tiene que desarrollar un determinante, es decir, utiliza variables y realiza ecuaciones y cálculos mediante procedimientos familiares (CLSOn3), que no corresponde al nivel básico de reproducción, estaríamos en un nivel de conexión.

El alumno sabe expresarse sobre cuestiones matemáticas (CCn1), realiza explicaciones sencillas (RCn2), justifica las fórmulas utilizadas (RAn3) y reproduce problemas ya practicados, de manera cerrada (RRPn2).

El alumno realiza usa un único tipo de representación estándar, ya utilizada (RRn1), operaciones elementales en contextos conocidos (RLSOn1), interpreta el lenguaje formal y simbólico rutinario (RLSOn2), maneja procedimientos y fórmulas, resolviendo y calculando (RLSOn3) y, de este modo, resuelve problemas rutinarios estandarizados (RRPn3) y describe los resultados obtenidos (RCn3) y comunica los resultados (CMn3). 


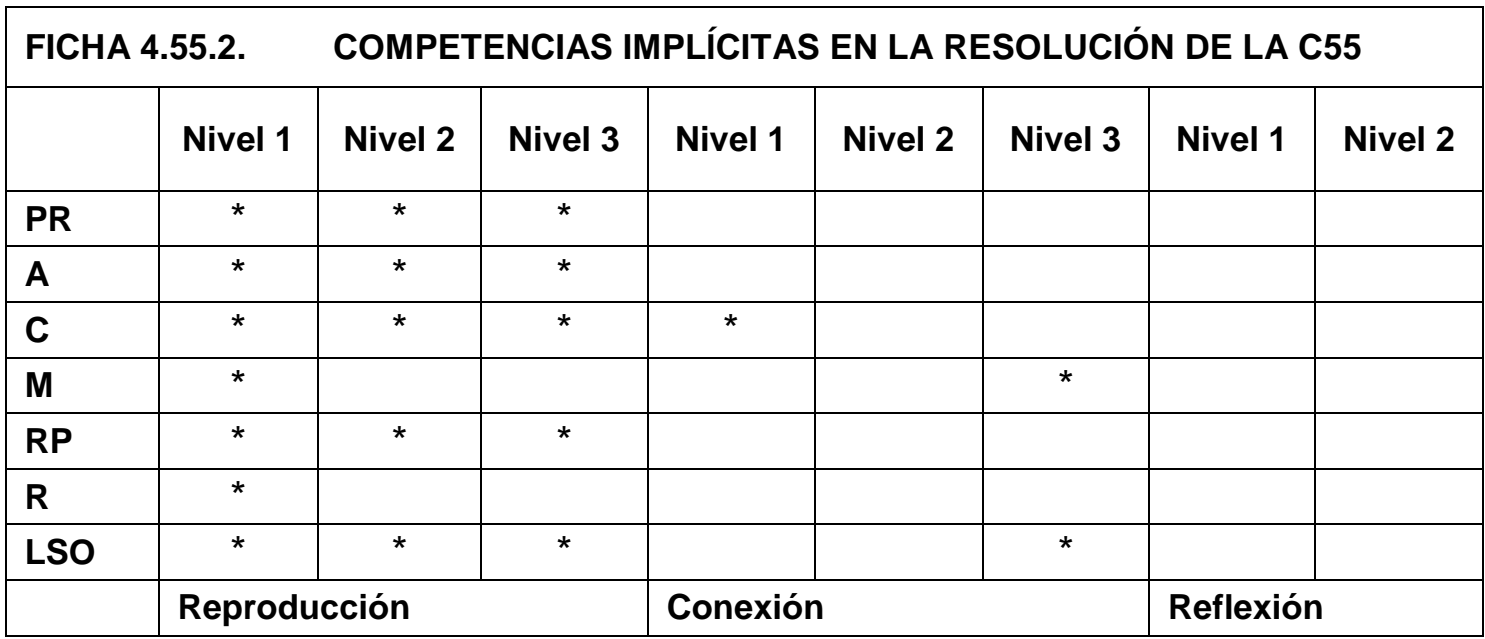

\section{ANÁLISIS DE LA CUESTIÓN C57}

\section{FICHA 4.57.1. ESTUDIO DEL ENUNCIADO DEL C57}

C57.- Estudiar, en función del parámetro real $\lambda$, el rango de la matriz

$$
A=\left(\begin{array}{ccc}
2-\lambda & 1 & 1 \\
1 & -\lambda & -1 \\
1 & -1 & 2-\lambda
\end{array}\right)
$$

\begin{tabular}{|c|c|c|c|c|c|c|c|c|c|c|c|c|c|}
\hline CONVOCATORIA & \multicolumn{7}{|c|}{ JUNIO } & \multicolumn{6}{|c|}{ SEPTIEMBRE } \\
\hline AÑO & 95 & 96 & 97 & 98 & 99 & 00 & 01 & \begin{tabular}{|l|l|}
02 & 03 \\
\end{tabular} & 04 & 05 & \begin{tabular}{|l|l|}
06 & 07 \\
\end{tabular} & 08 & $\underline{09}$ \\
\hline OPCIÓN & \multicolumn{7}{|c|}{ A } & \multicolumn{6}{|c|}{$\underline{B}$} \\
\hline TIPO DE PROBLEMA & \multicolumn{7}{|c|}{ TEÓRICO } & \multicolumn{6}{|c|}{ PRÁCTICO } \\
\hline \multirow{3}{*}{ APARTADOS } & \multirow{3}{*}{\multicolumn{2}{|c|}{ SI }} & \multicolumn{4}{|c|}{ Forma explícita } & & & & & \multirow[b]{2}{*}{6} & \multirow{3}{*}{\multicolumn{2}{|c|}{ NO }} \\
\hline & & & & & & & 2 & 3 & 4 & 5 & & & \\
\hline & & & \multicolumn{4}{|c|}{ Forma implícita } & & & & & & & \\
\hline VERBO UTILIZADO & \multicolumn{13}{|c|}{ ESTUDIAR } \\
\hline TIEMPO VERBAL & \multicolumn{13}{|c|}{ INFINITIVO } \\
\hline \multirow{3}{*}{$\begin{array}{l}\text { FALLOS DEL ENUN- } \\
\text { CIADO }\end{array}$} & \multicolumn{9}{|c|}{ PUNTUACIÓN } & & & & \\
\hline & \multicolumn{9}{|c|}{ ERROR MORFOLÓGICO } & & & & \\
\hline & \multicolumn{9}{|c|}{ ORDEN DE LAS PALABRAS EN LA ORACIÓN } & & & & \\
\hline
\end{tabular}

C57.- Estudia el rango de la matriz, en función del parámetro real $\lambda$ :

$$
A=\left(\begin{array}{ccc}
2-\lambda & 1 & 1 \\
1 & -\lambda & -1 \\
1 & -1 & 2-\lambda
\end{array}\right)
$$

NIVELES DE COMPETENCIAS IMPLÍCITAS: Conexión 
La cuestión de la ficha 4.57.1 es un ejercicio que se corresponde con un nivel de conexión; reproduce una situación similar a la referente en su etapa de aprendizaje, pero no es una mera rutina, dado que hay que pensar en el tratamiento matemático necesario (CPRn1), estructurar la situación que se debe modelizar (CMn1), desarrollar procedimientos ya practicados, pero no rutinarios (CRPn1), pues hay que estudiar el rango de una matriz dependiendo de los posibles valores del parámetro $\lambda$ y razonar matemáticamente de manera simple (CAn1).

Comprende que tiene que emplear métodos matemáticos intermedios (CPRn2),

Calcula el determinante:

$$
\left|\begin{array}{ccc}
2-\lambda & 1 & 1 \\
1 & -\lambda & -1 \\
1 & -1 & 2-\lambda
\end{array}\right|=-\lambda^{3}+4 \lambda^{2}-\lambda-6
$$

Resolviendo la ecuación $-\lambda^{3}+4 \lambda^{2}-\lambda-6=0$, obtiene las soluciones:

$$
\lambda=-1 \quad, \quad \lambda=2 \quad y \quad \lambda=3
$$

El alumno sabe expresarse sobre cuestiones matemáticas (CCn1), sigue el encadenamiento del argumento matemático particular (CAn2), haciendo una evaluación del mismo (CAn3) e interpretando las relaciones implicadas (CCn3).

En la resolución de la ecuación el alumno tiene que desarrollar un determinante, es decir, realiza operaciones elementales en contextos conocidos (RLSOn1), interpreta el lenguaje formal y simbólico rutinario (RLSOn2), maneja procedimientos y fórmulas, resolviendo y calculando (RLSOn3), utiliza variables y realiza ecuaciones y cálculos mediante procedimientos familiares (CLSOn3).

Si $\lambda \neq-1 ; \lambda \neq 2$ y $\lambda \neq 3$, el determinante es distinto de cero y el rango de la matriz es 3 .

Si $\lambda=-1$, sustituyendo ese valor en el enunciado, tenemos la matriz:

$$
A=\left(\begin{array}{rrr}
3 & 1 & 1 \\
1 & 1 & -1 \\
1 & -1 & 3
\end{array}\right)
$$

El rango es 2, dado que $C_{3}=C_{1}-2 C_{2}$ y $\left|\begin{array}{ll}3 & 1 \\ 1 & 1\end{array}\right| \neq 0$ 
Si $\lambda=2$, sustituyendo ese valor en el enunciado, tenemos la matriz:

$$
\begin{aligned}
& A=\left(\begin{array}{rrr}
0 & 1 & 1 \\
1 & -2 & -1 \\
1 & -1 & 0
\end{array}\right) \\
& \text { El rango es 2, dado que } F_{3}=F_{1}+F_{2} \text { y }\left|\begin{array}{rr}
1 & 1 \\
-1 & 0
\end{array}\right| \neq 0
\end{aligned}
$$

Si $\lambda=3$, sustituyendo ese valor en el enunciado, tenemos la matriz:

$$
A=\left(\begin{array}{rrr}
-1 & 1 & 1 \\
1 & -3 & -1 \\
1 & -1 & -1
\end{array}\right)
$$

El rango es 2, dado que $F_{1}=-F_{3}$ y $\left|\begin{array}{ll}-3 & -1 \\ -1 & -1\end{array}\right| \neq 0$

$$
\text { Si } \lambda=-1 \text { o } \lambda=2 \text { o } \lambda=3 \text {, el rango es } 2 \text {. }
$$

El alumno usa un único tipo de representación estándar, ya utilizada (RRn1), resuelve problemas rutinarios estandarizados (RRPn3), explica los cálculos y sus propiedades (CCn2), con lo que evalúa el encadenamiento de argumentos matemáticos particulares (CAn3); traduce, en la práctica, el modelo a seguir, que es algo diferente de los estudiados (CMn2) aplicando, de este modo, conceptos matemáticos apropiados (CPRn3) y comunica los resultados (CMn3).

\begin{tabular}{|l|c|c|c|c|c|c|c|c|}
\hline \multicolumn{6}{|l|}{ FICHA 4.57.2. COMPETENCIAS IMPLÍCITAS EN LA RESOLUCIÓN DE LA C57 } \\
\hline & Nivel 1 & Nivel 2 & Nivel 3 & Nivel 1 & Nivel 2 & Nivel 3 & Nivel 1 & Nivel 2 \\
\hline PR & & & & $*$ & $*$ & $*$ & & \\
\hline A & & & & $*$ & $*$ & $*$ & & \\
\hline C & & & & $*$ & $*$ & $*$ & & \\
\hline M & & & & $*$ & & $*$ & & \\
\hline RP & & & $*$ & $*$ & & & & \\
\hline R & $*$ & & & & & & & \\
\hline LSO & $*$ & $*$ & $*$ & & & $*$ & & \\
\hline & Reproducción & & Conexión & & Reflexión \\
\hline
\end{tabular}




\section{V.4. REFLEXIÓN DEL ANÁLISIS SOBRE LAS PAEU DE ÁLGE- BRA}

De los 28 problemas de Álgebra propuestos en los años de estudio, tan sólo 1 pertenece al nivel de reflexión, dado que en su resolución intervienen elementos inusuales. Es el ejercicio que se presenta en la ficha 3.11.1. En este problema aparecen niveles de reflexión asociados a las competencias argumentar, comunicar y resolver problemas, dado que el enunciado pide que el alumno calcule una matriz en función de un parámetro $a$ pero en ningún caso puede escribir la matriz en función de $a$, lo único que puede hacer es estudiar las posibles soluciones, en función de dicho parámetro.

\begin{tabular}{|l|c|c|c|c|c|c|c|c|}
\hline \multicolumn{1}{|c|}{ NIVELES DE COMPETENCIAS IMPLÍCITAS } \\
\hline & Nivel 1 & Nivel 2 & Nivel 3 & Nivel 1 & Nivel 2 & Nivel 3 & Nivel 1 & Nivel 2 \\
\hline PR & 27 & 27 & 27 & 24 & 23 & 24 & 0 & 0 \\
\hline A & 27 & 27 & 27 & 24 & 23 & 23 & 1 & 1 \\
\hline C & 27 & 27 & 27 & 26 & 24 & 24 & 1 & 1 \\
\hline M & 27 & 0 & 27 & 24 & 4 & 3 & 0 & 0 \\
\hline RP & 27 & 27 & 27 & 5 & 0 & 0 & 1 & 0 \\
\hline R & 28 & 6 & 1 & 0 & 0 & 0 & 0 & 0 \\
\hline LSO & 28 & 28 & 28 & 1 & 1 & 27 & 0 & 0 \\
\hline & Reproducción: & 497 & \multicolumn{7}{|c|}{ Conexión: 280 } & Reflexión: 5 \\
\hline
\end{tabular}

Los problemas propuestos presentan varios apartados, por esa razón están ubicados en los niveles de reproducción y conexión, ya que algùn apartado pertenece a uno u otro nivel. En general, los subniveles 1, 2 y 3 son semejantes en las distintas competencias, por esta circunstancia tan solo hacemos hincapié en los que presentan disparidad de resultados.

El subnivel 2 del nivel reproducción, en la competencia de Modelizar, no se presenta nunca, pues corresponde a la modelización de la realidad y en ningún ejercicio se plantea esta situación. En esta misma competencia, en el nivel de conexión, el alumno estructura la situación que debe modelizar (CMn1), pero el modelo no es diferente de los estudiados, salvo en raras ocasiones y, por tanto, no se traduce en la práctica ni confirma que sepa interpretar y alternar diferentes modelos (CMn2, CMn3) y aunque comunica los resultados; esto lo hace 
desde un nivel de reproducción (RMn3) en el que el alumno comunica de manera elemental los resultados del modelo. Los sistemas lineales de ecuaciones no corresponden a diferentes modelos.

Una situación análoga ocurre en el subnivel 2 del nivel reproducción, de la competencia Representar. Los problemas de Álgebra propuestos usan un único tipo de representación estándar (RRn1), la algebraica, dado que no hay ejercicios en los que se proponga un enunciado que apremie al alumno a interpretar formas de representación (CRn1), como pueden ser los "problemas con texto" y tan sólo en un problema, el de la ficha 3.28 en el que se pide que la discusión de un sistema de ecuaciones lineales se interprete en términos de la posición relativa de los planos dados por cada una de las ecuaciones, lo que impone al alumno que interprete representaciones estándar de objetos matemáticos $(R R n 2)$ y realice el paso de una representación a otra (RRn3). Hay cinco apartados en los que se pide que el alumno escriba unas propiedades o el enunciado de un teorema, éstos corresponden al nivel (RRn2), pues el alumno tiene que analizar una orden "verbal" e interpretarla en un objeto matemático como aparece en una propiedad o un teorema, y la sexta vez en la que aparece el subnivel 2 de representar es en la citada ficha 3.28.1.

En lo relativo a Utilizar el lenguaje simbólico, formal y técnico, y las operaciones, el alumno realiza operaciones elementales en contextos conocidos (operaciones aritméticas) (RLSOn1), interpreta el lenguaje formal y simbólico rutinario en segundo de bachillerato (RLSOn2) como son las matrices y los determinantes; maneja procedimientos y fórmulas, resolviendo y calculando determinantes, solucionando ecuaciones algebraicas y ecuaciones matriciales (RLSOn3), y, por tanto, dentro de un nivel de conexión, dado que muchas de estas operaciones se realizan con parámetros, el alumno utiliza variables y realiza ecuaciones y cálculos mediante procedimientos familiares (CLSOn3), en segundo de Bachillerato. Únicamente, en el problema de la ficha 3.10, se exige manejar expresiones con símbolos y fórmulas no rutinarias (CLSOn2) e interpretar el lenguaje formal y simbólico básico en situaciones menos conocidas (CLSOn1), pues la resolución se realiza mediante un proceso inverso; se supone que se ha obtenido la matriz inversa y utilizando sus propiedades se llega a conocerla.

En cuanto a la competencia de Resolver problemas los niveles de reproducción son los que se presentan, pues su carácter repetitivo hace que el alumno les reconozca como problemas ya practicados (RRPn1), les reproduzca de manera 
cerrada (RRPn2), como problemas ya ejercitados que son, aunque en la resolución se han propuesto como opciones utilizar varios métodos (Gauss, Cramer) y, en consecuencia, el alumno resuelva problemas rutinarios estandarizados (RRPn3).

El nivel de conexión corresponde a aquellos ejercicios que reproducen situaciones similares a las estudiadas, pero no son de mera rutina. En los problemas de Álgebra, en la mayoría de los casos, está asociado al estudio de situaciones dependientes de parámetros, pues esa característica hace que cada uno de ellos puede tener una idiosincrasia. En ellos, el alumno desarrolla procedimientos intuitivos ya practicados, pero no rutinarios (CRPn1) pero no se presentan los demás subniveles (CRPn2, CRPn3) pues no son ejercicios que relacionen áreas matemáticas y, por ende, el alumno no se ve en la necesidad de elegir ni de aplicar estrategias apropiadas más independientes que conexionen áreas matemáticas.

\begin{tabular}{|l|c|c|c|c|c|c|c|c|}
\hline \multicolumn{7}{|c|}{ NIVELES DE COMPETENCIAS IMPLÍCITAS } \\
CUESTIONES DE ÁLGEBRA \\
\hline PR & 30 & 34 & 35 & 22 & 13 & 21 & 0 & 0 \\
\hline A & 37 & 25 & 36 & 24 & 18 & 17 & 0 & 0 \\
\hline C & 27 & 38 & 38 & 28 & 21 & 21 & 0 & 0 \\
\hline M & 32 & 0 & 41 & 20 & 13 & 16 & 0 & 0 \\
\hline RP & 37 & 40 & 46 & 22 & 2 & 2 & 0 & 0 \\
\hline R & 39 & 0 & 0 & 0 & 0 & 0 & 0 & 0 \\
\hline LSO & 47 & 45 & 45 & 6 & 6 & 45 & 0 & 0 \\
\hline & Reproducción: & 672 & Conexión: 317 & Reflexión: 0 \\
\hline
\end{tabular}

En relación a las cuestiones la situación es muy similar y sólo merece la pena comentar que en la competencia de resolver, en conexiones, apenas se pasa a los niveles CRPn2 y CRPn3.

En suma, tanto en los problemas como en las cuestiones de Álgebra, se produce un sesgo muy grande hacia las reproducciones, no hay ni siquiera la mitad de conexiones y casi no aparecen reflexiones. 


\section{CAPÍTULO VI}

\section{ANÁLISIS, EN COMPETENCIAS, DE LOS ENUNCIADOS DE GEOMETRÍA.}

\section{VI.1. INTRODUCCIÓN}

En este capítulo se presenta una selección de 18 problemas y 15 cuestiones del los 30 problemas y 67 cuestiones de Geometría propuestos. El criterio elegido para la selección es el mismo que el utilizado en capítulos anteriores: Ejercicios variados o con nivel competencial de reflexión.

Es un hecho incuestionable que los ejercicios de geometría, en general, pueden ser resueltos de varias formas bastante diferentes, aunque, implícitamente, las competencias básicas sean las mismas en las diversas maneras de enfocarlos.

En el trabajo que se presenta en este capítulo se resuelven problemas similares de formas distintas, para no repetir un mismo problema con distintos métodos de estudio y se señalan las competencias implícitas en cada método. Así, por ejemplo, el cálculo de la ecuación de un plano puede hacerse utilizando determinantes, también utilizando dos rectas que se cortan, tres puntos, un punto y dos vectores, utilizando el vector normal, etc. Lógicamente, en el proceso del cálculo de la ecuación del plano influyen los datos del problema. Incluso con los mismos datos (un punto y dos vectores) se puede realizar el producto vectorial, desarrollando un determinante y realizar posteriormente un producto escalar; sin embargo, para utilizar la ecuación normal del plano, basta con obtener la ecuación general del mismo desarrollando el determinante formado por los tres vectores linealmente independientes que le determinan, evitando el trabajo "añadido" de realizar posteriormente el producto escalar. Corresponde este problema (el cálculo de la ecuación del plano) al nivel de reproducción del conocimiento estudiado, ejecución de problemas rutinarios mediante la aplicación 
de destrezas técnicas y de algoritmos habituales, con el manejo de expresiones y fórmulas establecidas y la realización de los cálculos.

A continuación se describen las competencias asociadas a estos procesos. Esta descripción constituye un modelo del análisis particular que se hará a continuación en cada uno de los problemas y cuestiones propuestos en las PAUs.

Tras identificar que el modelo es similar a otros vistos con anterioridad (RMn1) y reconocer el problema como ya practicado (RRPn1), plantea los algoritmos correspondientes (RPRn2), asocia con fórmulas establecidas y realiza los cálculos (RPRn3).

Identifica el problema (RAn1), expone el proceso de cálculo (RAn2), reproduce problemas ya practicados de manera cerrada (RRPn2) y resuelve problemas rutinarios estandarizados (RRPn3).

Mentalmente debe imaginar la situación que se presenta e incluso hacer un esquema de la misma, con lo que pasa a un nivel de conexión, interpreta formas de representación (CRn1) -gráfica, algebraica-, desarrolla procedimientos intuitivos ya practicados, pero no rutinarios (CRPn1), estructura la situación que debe modelizar (CMn1) y piensa en el tratamiento matemático necesario (CPRn1).

Comprende que tiene que emplear conceptos matemáticos intermedios (CPRn2) y les aplica (CPRn3), explicando los cálculos y sus propiedades (CCn2) e interpretando las relaciones implicadas (CCn3).

El alumno realiza operaciones elementales en contextos conocidos (RLSOn1), interpreta el lenguaje formal y simbólico rutinario (RLSOn2), maneja procedimientos y fórmulas, resolviendo y calculando (RLSOn3), maneja fórmulas no rutinarias (CLSOn2) y realiza cálculos mediante procedimientos familiares (CLSOn3), -cálculo de vectores, determinantes,...-

Pero también puede realizar el producto vectorial de esos dos vectores independientes que determinan el plano, junto con un punto del mismo, y utilizar la fórmula de la ecuación normal del plano..

En los dos métodos de resolución elige estrategias apropiadas que conexionen áreas matemáticas, -álgebra y geometría- (CRPn2) y aplica las estrategias apropiadas (CRPn3). 


\section{VI.2.ESTUDIO DE LOS PROBLEMAS DE GEOMETRÍA}

En este apartado se muestra una síntesis del análisis que se ha realizado sobre todos los problemas de Geometría que se han propuesto en la Universidad de Valladolid al amparo del currículo LOGSE. En la misma línea de los capítulos anteriores, se presentan dos tablas para cada problema; una contiene el enunciado, su ubicación temporal, un análisis gramatical y las competencias implícitas en la propuesta y al final otra tabla en la que se reflejan las competencias que se detectan en su resolución.

\section{ANÁLISIS DEL PROBLEMA P3}

\section{FICHA 5.3.1. ESTUDIO DEL ENUNCIADO DEL P3}

P3.- Dadas las rectas

$$
r_{1}:\left\{\begin{array}{c}
x+p y+z=1 \\
x+y=p
\end{array} \quad r_{2}: \frac{x-1}{1}=\frac{y+2}{-1}=\frac{z}{q}\right.
$$

hallar los valores de $p$ y $q$ para que sean coplanarias y perpendiculares. ¿Cuál es la ecuación del plano que las contiene?

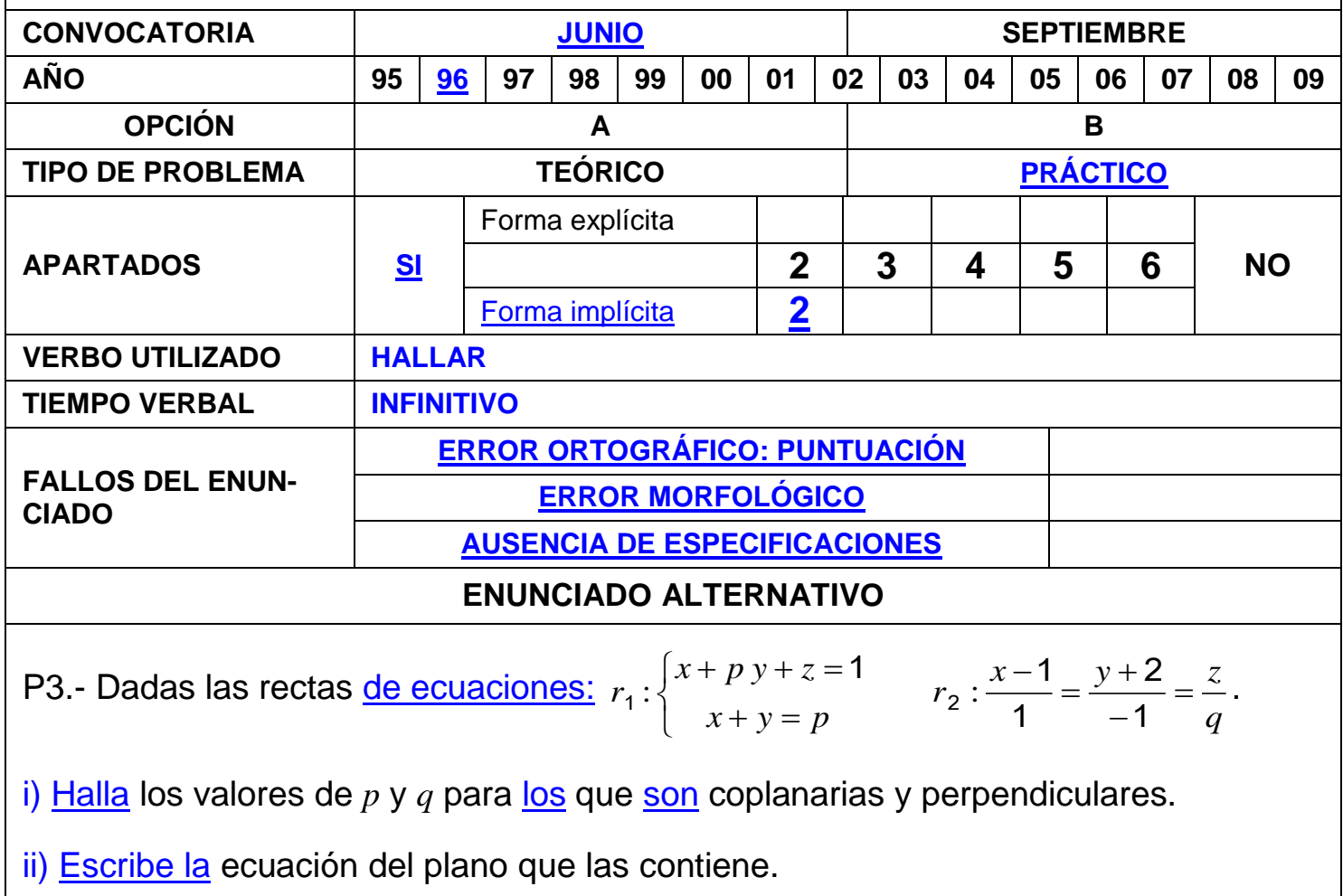

NIVELES DE COMPETENCIAS IMPLÍCITAS: Conexión y reflexión 
El problema que aparece en la ficha 5.3.1 se incluye en el nivel de conexión, dado que presenta parámetros, por tanto se trata de un ejercicio que reproduce situaciones similares a las estudiadas en la instrucción, pero que no son de mera rutina. El alumno piensa en el tratamiento matemático necesario (CPRn1).

Para que las rectas sean coplanarias, tienen que cortarse.

El alumno interpreta formas de representación (CRn1), -sistema de ecuaciones- y selecciona y cambia entre las diferentes formas de representación (CRn2), de forma geométrica a forma algebraica y, en base a ello, estructura la situación que debe modelizar (CMn1), razona matemáticamente de manera simple (CAn1), sabe expresarse sobre cuestiones matemáticas (CCn1) y desarrolla procedimientos intuitivos ya practicados, pero no rutinarios (CRPn1).

Dado que la recta $r_{1}$ está dada como intersección de dos planos:

$$
r_{1} \equiv\left\{\begin{array}{c}
x+p y+z=1 \\
x+y=p
\end{array}\right.
$$

Tiene que obtener el vector director de la misma, mediante el cálculo del producto vectorial de los vectores normales de ambos planos, o bien resolviendo un sistema lineal de dos ecuaciones con tres incógnitas.

En ambos casos elige estrategias apropiadas más independientes que conexionen áreas matemáticas (CRPn2), -álgebra y geometría-, y aplica las estrategias apropiadas más independientes (CRPn3).

El alumno comprende que tiene que emplear conceptos matemáticos intermedios (CPRn2) y aplica los conceptos matemáticos apropiados (CPRn3).

De la recta $r_{1}$ se obtiene el vector director, en este caso mediante el producto vectorial de los vectores normales de los planos.

$$
\overrightarrow{d_{r_{1}}}=\left|\begin{array}{ccc}
\vec{i} & \vec{j} & \vec{k} \\
1 & p & 1 \\
1 & 1 & 0
\end{array}\right|=-\vec{i}+\vec{j}+(1-p) \vec{k}
$$

De donde $\vec{d}_{r_{1}}=(-1,1,1-p)$ y un punto $P_{r_{1}}=(p, 0,1-p)$

El alumno reconoce representaciones de los datos del ejercicio (RPRn1), comprende la expresión escrita (RCn1) y asocia con fórmulas establecidas (RPRn3). 
La recta $r_{2}$ está dada en forma continua, $r_{2} \equiv \frac{x-1}{1}=\frac{y+2}{-1}=\frac{z}{q}$, y con su expresión se obtiene el vector director $\vec{d}_{r_{2}}=(1,-1, q)$ y un punto $P_{r_{1}}=(1,-2,0)$

Para que las rectas $r_{1}$ y $r_{2}$ sean perpendiculares el producto escalar de sus vectores directores tiene que valer cero, y para que sean coplanarias el vector $\overrightarrow{P_{r_{1}} P_{r_{2}}}$ tiene que ser combinación lineal de los vectores $\vec{d}_{r_{1}}=(-1,1,1-p)$ y $\vec{d}_{r_{2}}=(1,-1, q)$, es decir, $\operatorname{det}\left(\overrightarrow{d_{r_{1}}}, \overrightarrow{d_{r_{2}}}, \overrightarrow{P_{r_{1}} P_{r_{2}}}\right)=0$.

El alumno estructura la situación que debe modelizar (CMn1), traduce en la práctica el modelo a seguir, que es algo diferente de los estudiados (CMn2) y utiliza variables, y realiza ecuaciones y cálculos mediante procedimientos familiares (CLSOn3).

Además, sabe expresarse sobre cuestiones matemáticas (CCn1), explica los cálculos y sus propiedades (CCn2) e interpreta las relaciones implicadas (CCn3), a la par que aplica las estrategias apropiadas (CRPn3).

$$
(-1,1,1-p) \cdot(1,-1, q)=0
$$

El alumno realiza operaciones elementales en contextos conocidos (RLSOn1), interpreta el lenguaje formal y simbólico rutinario (RLSOn2), maneja procedimientos y fórmulas, resolviendo y calculando (RLSOn3) y utiliza variables y realiza ecuaciones y cálculos mediante procedimientos familiares (CLSOn3), producto escalar y producto mixto-.

$$
(-1) \cdot 1+1 \cdot(-1)+(1-p) \cdot q=0
$$

Obteniendo la ecuación: $q \cdot(1-p)=2$

$$
\begin{gathered}
\vec{d}_{r_{1}}=(-1,1,1-p), \vec{d}_{r_{2}}=(1,-1, q) \text { y } \overrightarrow{P_{r_{1}} P_{r_{2}}}=(1-p,-2, p-1) \\
\operatorname{det}\left(\overrightarrow{d_{r_{1}}}, \overrightarrow{d_{r_{2}}}, \overrightarrow{P_{r_{1}} P_{r_{2}}}\right)=\left|\begin{array}{ccc}
-1 & 1 & 1-p \\
1 & -1 & q \\
1-p & -2 & p-1
\end{array}\right|=0
\end{gathered}
$$

Desarrollando el determinante, agrupando y simplificando, obtiene la ecuación:

$$
(1-p)^{2}+(1-p) \cdot(q-2)-2 q=0
$$

Ésta, junto con la obtenida anteriormente, 


$$
q \cdot(1-p)=2
$$

forman un sistema, cuya resolución corresponde a un nivel de reflexión por parte del estudiante para planificar estrategias y aplicarlas en la resolución de un problema que contenga elementos inusuales.

Tiene que elaborar encadenamientos de argumentos de diferentes tipos (RfAn2), explicar asuntos que implican relaciones complejas (RfCn2) y resolver estableciendo conexiones entre las distintas áreas matemáticas (RfRPn2).

La solución de este sistema es:

$$
p=-1 \text { y } q=1
$$

El alumno sabe interpretar y alternar diferentes modelos y comunicar los resultados (CMn3).

Una vez obtenidos los valores de $p$ y $q$, el apartado b) de este problema, pertenece al nivel de reproducción del conocimiento estudiado, conocimiento de hechos, representaciones de problemas comunes, reconocimiento de equivalentes, ejecución de problemas rutinarios, aplicación de destrezas técnicas y de algoritmos habituales, mediante el manejo de expresiones y fórmulas establecidas y realización de cálculos.

El alumno reconoce el problema como practicado en la instrucción (RRPn1), reconoce representaciones de los datos del ejercicio (RPRn1), identifica el problema (RAn1), comprende la expresión escrita (RCn1), identifica que el modelo es similar a otros vistos con anterioridad (RMn1).

Seguidamente, plantea los algoritmos correspondientes (RPRn2), asocia con fórmulas establecidas y realiza los cálculos (RPRn3).

La ecuación del plano se obtiene mediante la fórmula:

$$
\operatorname{det}\left(\overrightarrow{d_{r_{1}}}, \overrightarrow{d_{r_{2}}}, \overrightarrow{X P_{r_{2}}}\right)=0
$$

Expone el proceso de cálculo (RAn2).

$$
\begin{aligned}
& \vec{d}_{r_{1}}=(-1,1,2), \vec{d}_{r_{2}}=(1,-1, q), P_{r_{2}}=(1,-2,0) \\
& \left|\begin{array}{rrc}
-1 & 1 & x-1 \\
1 & -1 & y+2 \\
2 & 1 & z
\end{array}\right|=0
\end{aligned}
$$


Justifica las fórmulas utilizadas y los resultados (RAn3) y realiza explicaciones sencillas ( $\mathrm{RCn} 2)$, reproduce problemas ya practicados de manera cerrada (RRPn2) y resuelve problemas rutinarios estandarizados (RRPn3).

Comunica de manera elemental los resultados del modelo (RMn3), y maneja procedimientos y fórmulas, resolviendo y calculando (RLSOn3).

Desarrollando el determinante, agrupando y simplificando obtiene la ecuación del plano:

$$
\pi \equiv x+y+1=0
$$

El alumno resuelve problemas rutinarios estandarizados (RRPn3), describe los resultados obtenidos (RCn3) y comunica de manera elemental los resultados del modelo (RMn3).

\begin{tabular}{|c|c|c|c|c|c|c|c|c|}
\hline \multicolumn{9}{|c|}{ COMPETENCIAS IMPLÍCITAS EN LA RESOLUCIÓN DEL P3 } \\
\hline & Nivel 1 & Nivel 2 & Nivel 3 & Nivel 1 & Nivel 2 & Nivel 3 & Nivel 1 & Nivel 2 \\
\hline PR & * & * & * & * & * & * & & \\
\hline A & * & * & * & * & & & & * \\
\hline $\mathbf{C}$ & * & * & * & * & * & * & & * \\
\hline M & * & & * & * & * & * & & \\
\hline $\mathbf{R P}$ & * & * & * & * & * & * & & * \\
\hline $\mathbf{R}$ & & & & * & * & & & \\
\hline \multirow[t]{2}{*}{ LSO } & * & * & * & & & * & & \\
\hline & \multicolumn{3}{|c|}{ Reproducción } & \multicolumn{3}{|c|}{ Conexión } & \multicolumn{2}{|c|}{ Reflexión } \\
\hline
\end{tabular}

\section{ANÁLISIS DEL PROBLEMA P6}

El apartado a) del problema que aparece en la ficha 5.6.1 se incluye en el nivel de conexión, dado que presenta parámetros, por tanto se trata de un ejercicio que reproduce situaciones similares a las estudiadas en la instrucción, pero que no son de mera rutina.

En primer lugar el alumno debe pensar en el tratamiento matemático necesario (CPRn1).

Dos planos distintos en $R^{3}$, son paralelos o se cortan. 


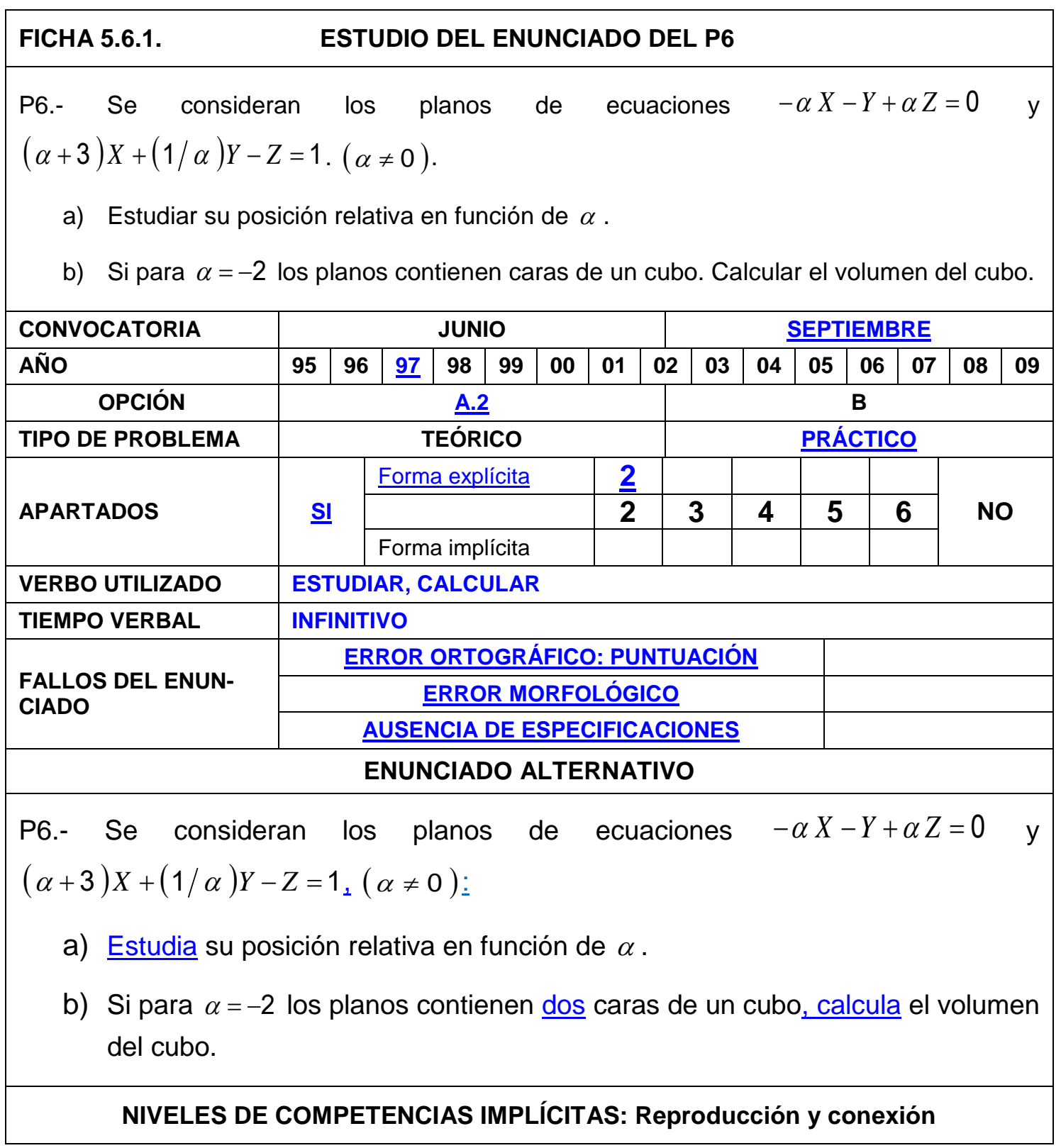

El punto $(0,0,0)$ pertenece al plano $\pi_{1} \equiv-\alpha X-Y+\alpha Z=0$, pero no pertenece al plano $\pi_{2} \equiv(\alpha+3) X+(1 / \alpha) Y-Z=1$, para cualquier valor del parámetro $\alpha$, por tanto los planos $\pi_{1}$ y $\pi_{2}$ son distintos.

El alumno razona matemáticamente de manera simple (CAn1), sabe expresarse sobre cuestiones matemáticas (CCn1) y desarrolla procedimientos intuitivos ya practicados, pero no rutinarios (CRPn1).

Estudia si existe proporcionalidad entre los vectores normales de ambos planos; para lo cual considera la siguiente serie de razones: 


$$
\frac{-\alpha}{\alpha+3}=\frac{-1}{1 / \alpha}=\frac{\alpha}{-1}
$$

El alumno estructura la situación que debe modelizar (CMn1), elige estrategias apropiadas más independientes que conexionen áreas matemáticas (CRPn2), aritmética y geometría-, y aplica las estrategias apropiadas más independientes (CRPn3).

$$
\text { De la proporción: } \frac{-\alpha}{\alpha+3}=\frac{-1}{\frac{1}{\alpha}}
$$

Manejando procedimientos y fórmulas, resolviendo y calculando (RLSOn3), obtiene la ecuación:

$$
\alpha=\alpha \cdot(\alpha+3) \text { con soluciones } \alpha=0, \quad \alpha=-2
$$

El enunciado especifica que $\alpha \neq 0$, de ahí obtiene la solución $\alpha=-2$

Ese valor verifica toda la cadena de razones:

$$
\frac{2}{(-2)+3}=\frac{-1}{\frac{1}{(-2)}}=\frac{(-2)}{-1}=2
$$

Explica los cálculos y sus propiedades (CCn2) e interpreta las relaciones implicadas $(\mathrm{CCn} 3)$.

Si $\alpha=-2$, los planos son paralelos.

Si $\alpha \neq-2$, los planos se cortan.

El alumno interpreta formas de representación (CRn1), selecciona y cambia entre las diferentes formas de representación, -geométrica, algebraica- (CRn2) y traduce y diferencia entre distintas formas de representación (CRn3) y sabe interpretar y alternar diferentes modelos y comunicar los resultados (CMn3)

El apartado b) del problema de la ficha 5.6.1 corresponde al nivel de reproducción, con el manejo de expresiones y fórmulas establecidas y realización de cálculos.

Para $\alpha=-2$ las ecuaciones de los planos son:

$$
\pi_{1} \equiv 2 X-Y-2 Z=0 \quad \text { y } \quad \pi_{2} \equiv X-(1 / 2) Y-Z=1
$$


El alumno reconoce la representación de los datos del ejercicio (RPRn1), -las ecuaciones de los planos-, plantea los algoritmos correspondientes (RPRn2) y asocia con fórmulas establecidas (RPRn3).

En consecuencia, identifica el problema (RAn1), comprende la expresión escrita (RCn1), identifica que el modelo es similar a otros vistos con anterioridad (RMn1) y le reconoce como problema ya practicado durante la instrucción (RRPn1).

La distancia entre dos planos paralelos se reduce a la distancia de un punto a un plano. Si la ecuación del plano es $a \cdot x+b \cdot y+c \cdot z+d=0$ y las coordenadas del punto son $\left(x_{0}, y_{0}, z_{0}\right)$, la distancia del punto al plano se obtiene mediante la fórmula:

$$
d=\frac{\left|a \cdot x_{0}+b \cdot y_{0}+c \cdot z_{0}+d\right|}{\left|\overrightarrow{n_{\pi}}\right|}
$$

El alumno expone el proceso de cálculo (RAn2) y comunica de manera elemental los resultados del modelo (RMn3).

$$
\pi_{2} \equiv X-(1 / 2) Y-Z=1 \Rightarrow 2 X-Y-2 Z-2=0
$$

El cálculo de la distancia de un punto, en este caso el $O(0,0,0)$, al plano, $\pi_{2} \equiv 2 X-Y-2 Z-2=0$ es:

$$
d=\frac{|2 \cdot 0-1 \cdot 0-2 \cdot 0-2|}{\sqrt{2^{2}+(-1)^{2}+(-2)^{2}}}=\frac{|-2|}{\sqrt{9}}=\frac{2}{3} u
$$

El alumno realiza operaciones elementales en contextos conocidos (RLSOn1), interpreta el lenguaje formal y simbólico rutinario (RLSOn2), -potencia, raíz, cociente-, y maneja procedimientos y fórmulas, resolviendo y calculando (RLSOn3), -valor absoluto- y utiliza variables y realiza ecuaciones y cálculos, mediante procedimientos familiares (CLSOn3), -módulo de un vector-, con lo que resuelve problemas rutinarios estandarizados (RRPn3).

El volumen del cubo es

$$
V=\left(\frac{2}{3}\right)^{3}=\frac{8}{27} u^{3}
$$


El alumno realiza explicaciones sencillas ( $\mathrm{RCn} 2)$, describe los resultados obtenidos (RCn3), justifica las fórmulas utilizadas y los resultados (RAn3), y comunica de manera elemental los resultados del modelo (RMn3).

FICHA 5.6.2. COMPETENCIAS IMPLÍCITAS EN LA RESOLUCIÓN DEL P6

\begin{tabular}{|c|c|c|c|c|c|c|c|c|}
\hline & Nivel 1 & Nivel 2 & Nivel 3 & Nivel 1 & Nivel 2 & Nivel 3 & Nivel 1 & Nivel 2 \\
\hline PR & * & * & * & * & & & & \\
\hline A & * & * & * & * & & & & \\
\hline C & * & * & * & * & * & * & & \\
\hline$M$ & * & & * & * & & * & & \\
\hline RP & * & & * & * & * & * & & \\
\hline $\mathbf{R}$ & & & & * & * & & & \\
\hline LSO & * & * & * & & & * & & \\
\hline & \multicolumn{3}{|c|}{ Reproducción } & \multicolumn{3}{|c|}{ Conexión } & \multicolumn{2}{|c|}{ Reflexión } \\
\hline
\end{tabular}

\section{ANÁLISIS DEL PROBLEMA P7}

El problema que se presenta en la ficha 5.7.1 corresponde a los niveles de reproducción del conocimiento estudiado y conexión. Es la ejecución de un problema rutinario mediante la aplicación de destrezas técnicas y de algoritmos habituales, con el manejo de fórmulas establecidas y la realización de cálculos.

El alumno comprende la expresión escrita (RCn1), identifica el problema (RAn1), reconoce la representación de los datos del ejercicio (RPRn1), -las ecuaciones de la recta y del plano-, plantea los algoritmos correspondientes (RPRn2) y asocia con fórmulas establecidas (RPRn3), identifica que el modelo es similar a otros vistos con anterioridad (RMn1) y expone el proceso de cálculo (RAn2).

A continuación realiza explicaciones sencillas (RCn2).

La recta está dada en ecuaciones paramétri-

cas: $r \equiv\left\{\begin{array}{c}x=1-t \\ y=4+3 t \\ z=-2 t\end{array}\right.$

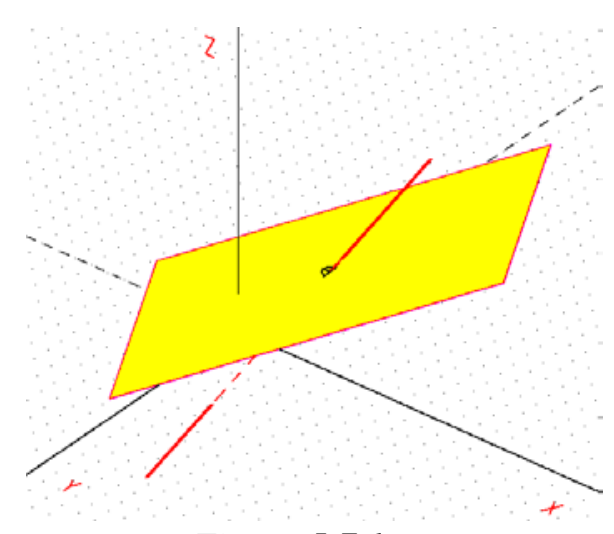

Figura 5.7.1.

Para calcular el punto de intersección, resuelve 
la ecuación obtenida al sustituir un punto genérico de la recta:

$$
(1-t, 4+3 t,-2 t)
$$

en la ecuación del plano

$$
\pi \equiv x+3 y-5 z+5=0
$$

FICHA 5.7.1.

ESTUDIO DEL ENUNCIADO DEL P7

P7.- Se consideran los puntos $A(1,2,3), B(-1,0,1)$ y el punto $C$, intersección de la recta

$$
r \equiv\left\{\begin{array}{c}
x=1-t \\
y=4+3 t \\
z=-2 t
\end{array}\right.
$$

\begin{tabular}{|c|c|c|c|c|c|c|c|c|c|c|c|c|}
\hline CONVOCATORIA & \multicolumn{6}{|c|}{ JUNIO } & \multicolumn{6}{|c|}{ SEPTIEMBRE } \\
\hline AÑO & \begin{tabular}{l|l}
95 & 96
\end{tabular} & 97 & $\underline{98}$ & 99 & 00 & 01 & \begin{tabular}{l|l}
02 & 03
\end{tabular} & 04 & 05 & \begin{tabular}{l|l}
06 & 07
\end{tabular} & 08 & 09 \\
\hline OPCIÓN & \multicolumn{6}{|c|}{ A } & \multicolumn{6}{|c|}{$\underline{B}$} \\
\hline TIPO DE PROBLEMA & \multicolumn{6}{|c|}{ TEÓRICO } & \multicolumn{6}{|c|}{ PRÁCTICO } \\
\hline \multirow{3}{*}{ APARTADOS } & \multirow{3}{*}{ SI } & \multicolumn{4}{|c|}{ Forma explícita } & & & & \multirow{3}{*}{\begin{tabular}{|l}
5 \\
\end{tabular}} & \multirow[b]{2}{*}{6} & \multirow{3}{*}{\multicolumn{2}{|c|}{ NO }} \\
\hline & & & & & & 2 & 3 & 4 & & & & \\
\hline & & \multicolumn{4}{|c|}{ Forma implícita } & & & & & & & \\
\hline VERBO UTILIZADO & \multicolumn{12}{|c|}{ DETERMINAR } \\
\hline TIEMPO VERBAL & \multicolumn{12}{|c|}{ INFINITIVO } \\
\hline \multirow{3}{*}{$\begin{array}{l}\text { FALLOS DEL ENUN- } \\
\text { CIADO }\end{array}$} & \multicolumn{8}{|c|}{ ERROR ORTOGRÁFICO: PUNTUACIÓN } & & & & \\
\hline & \multicolumn{8}{|c|}{ ESTRUCTURA DE LA ORACIÓN } & & & & \\
\hline & \multicolumn{8}{|c|}{ AUSENCIA DE ESPECIFICACIONES } & & & & \\
\hline \multicolumn{13}{|c|}{ ENUNCIADO ALTERNATIVO } \\
\hline
\end{tabular}

con el plano $x+3 y-5 z+5=0$. Determinar el área del triángulo $A B C$.

P7.- Calcula el área del triángulo $A B C$ determinado por los puntos $A(1,2,3), B(-1,0,1)$ y $C$, siendo $C$ el punto de intersección de la recta

$$
r \equiv\left\{\begin{array}{c}
x=1-t \\
y=4+3 t \\
z=-2 t
\end{array}\right.
$$

con el plano $x+3 y-5 z+5=0$.

NIVELES DE COMPETENCIAS IMPLÍCITAS: Reproducción y conexión

Obtiene la ecuación 


$$
(1-t)+3 \cdot(4+3 t)-5 \cdot(-2 t)+5=0
$$

Con solución $t=-1$

Realiza operaciones elementales en contetos conocidos (RLSOn1) y maneja procedimientos y fórmulas, resolviendo y calculando (RLSOn3), para obtener la solución de la ecuación.

En el nivel de conexión, desarrolla procedimientos intuitivos ya practicados, pero no rutinarios (CRPn1), razona matemáticamente de manera simple (CAn1), sabe expresarse sobre cuestiones matemáticas (CCn1) y explica los cálculos y sus propiedades (CCn2).

Interpreta formas de representación (CRn1), selecciona y cambia entre las diferentes formas de representación (CRn2). Figura 5.7.1.

Valor que, sustituido en la expresión del punto genérico de la recta, nos da:

$$
C(1-t, 4+3 t,-2 t)=(2,1,2)
$$

El alumno realiza explicaciones sencillas ( $\mathrm{RCn} 2)$, describe los resultados obtenidos (RCn3) y comunica de manera elemental los resultados del modelo (RMn3).

El problema se enuncia con un único apartado, el cálculo del área de un triángulo, pero previamente es necesario calcular el punto de intersección de una recta con un plano.

Una vez que se ha obtenido ese punto, $C(2,1,2)$, para efectuar el cálculo del área, el alumno identifica el problema (RAn1), reconoce la representación de los datos del ejercicio (RPRn1), plantea los algoritmos correspondientes (RPRn2) y asocia con fórmulas establecidas (RPRn3), -producto vectorial de dos vectores, módulo de un vector-.

A partir de ello, expone el proceso de cálculo (RAn2) y realiza explicaciones sencillas (RCn2).

La fórmula del área del triángulo, es

$$
\begin{gathered}
\text { Área }=\frac{1}{2} \cdot|\overrightarrow{B A} \times \overrightarrow{B C}| \\
\overrightarrow{B A}=(1-(-1), 2-0,3-1)=(2,2,2) \\
\overrightarrow{B C}=(2-(-1), 1-0,2-1)=(3,1,1)
\end{gathered}
$$

El alumno interpreta formas de representa-

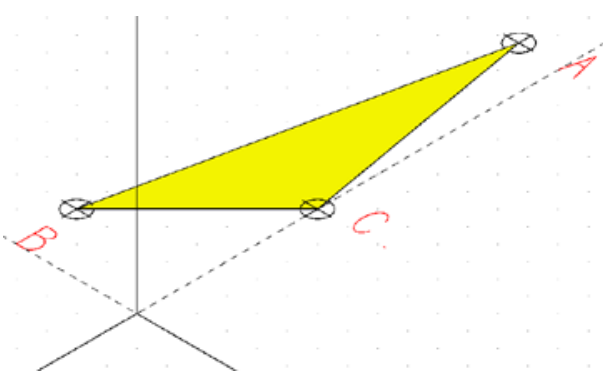

Figura 5.7.2. 
ción ( $\mathrm{CRn} 1)$, selecciona y cambia entre diferentes formas de representación (CRn2), -algebraica, geométrica y gráfica-. Figura 5.7.2.

Reconoce problemas ya practicados (RRPn1) y reproduce problemas ya practicados de manera cerrada (RRPn2).

El alumno aplica conceptos matemáticos apropiados (CPRn3), elige estrategias apropiadas más independientes que conexionen áreas matemáticas (CRPn2), álgebra y geometría-, y aplica las estrategias apropiadas más independientes (CRPn3).

Calcula el determinante:

$$
\begin{gathered}
\overrightarrow{B A} \times \overrightarrow{B C}=\left|\begin{array}{ccc}
\vec{i} & \vec{j} & \vec{k} \\
2 & 2 & 2 \\
3 & 1 & 1
\end{array}\right|=4 \vec{j}-4 \vec{k} \\
\text { Área }=\frac{1}{2} \cdot|\overrightarrow{B A} \times \overrightarrow{B C}|=\frac{\sqrt{0^{2}+4^{2}+(-4)^{2}}}{2}=2 \sqrt{2} u^{2}
\end{gathered}
$$

El alumno interpreta el lenguaje formal y simbólico rutinario (RLSOn2) y maneja procedimientos y fórmulas, resolviendo y calculando (RLSOn3), -las operaciones aritméticas- a la par que utiliza variables y realiza ecuaciones y cálculos mediante procedimientos familiares (CLSOn3), -producto vectorial, módulo de un vector- y así resuelve problemas rutinarios estandarizados (RRPn3).

Finalmente, realiza explicaciones sencillas ( $\mathrm{RCn} 2)$, describe los resultados obtenidos (RCn3), justifica las fórmulas utilizadas y los resultados (RAn3) y co-

\begin{tabular}{|c|c|c|c|c|c|c|c|c|}
\hline \multicolumn{2}{|c|}{ FICHA 5.7.2. } & \multicolumn{7}{|c|}{ COMPETENCIAS IMPLÍCITAS EN LA RESOLUCIÓN DEL P7 } \\
\hline & Nivel 1 & Nivel 2 & Nivel 3 & Nivel 1 & Nivel 2 & Nivel 3 & Nivel 1 & Nivel 2 \\
\hline PR & * & * & * & & & * & & \\
\hline A & * & * & * & * & * & * & & \\
\hline $\mathbf{C}$ & * & * & * & * & * & & & \\
\hline M & * & & * & & & & & \\
\hline $\mathbf{R P}$ & * & * & * & * & * & * & & \\
\hline $\mathbf{R}$ & & & & * & * & & & \\
\hline \multirow[t]{2}{*}{ LSO } & * & * & * & & & * & & \\
\hline & \multicolumn{3}{|c|}{ Reproducción } & \multicolumn{3}{|c|}{ Conexión } & \multicolumn{2}{|c|}{ Reflexión } \\
\hline
\end{tabular}
munica de manera elemental los resultados del modelo (RMn3). 


\section{ANÁLISIS DEL PROBLEMA P9}

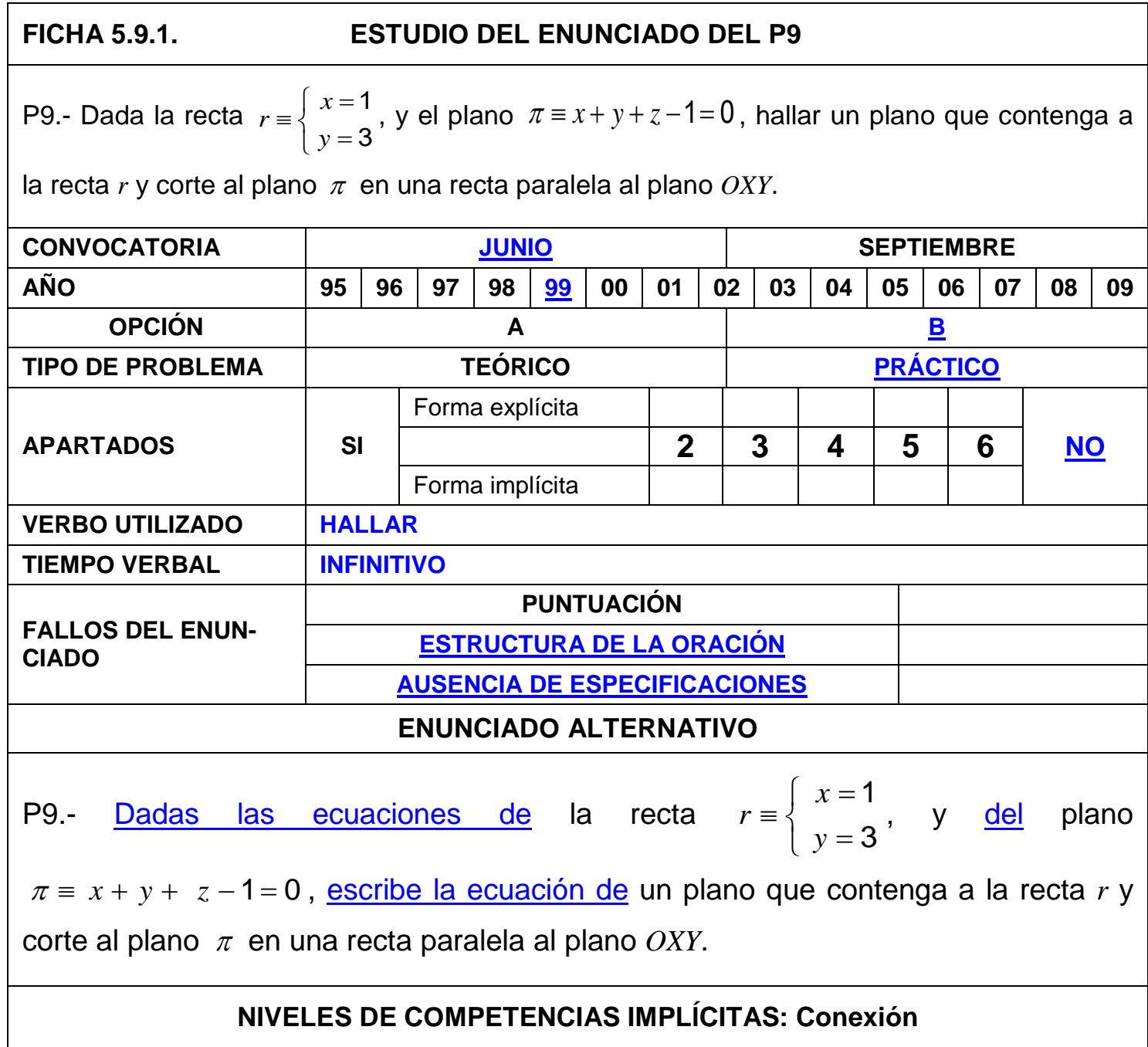

El problema que aparece en la ficha 5.9.1 corresponde al nivel de conexión. Se trata de un ejercicio que reproduce situaciones similares a las estudiadas en la instrucción, pero que no son de mera rutina.

La recta $r$ tiene como vector director $\overrightarrow{d_{r}}(0,0,1)$ y pasa por el punto $P_{r}=(1,3,0)$.

El alumno interpreta formas de representación (CRn1), selecciona y cambia entre diferentes formas de representación ( $\mathrm{CRn} 2)$, -algebraica, geométrica y gráfica-. Figura 5.9.

El alumno sabe expresarse sobre cuestiones matemáticas (CCn1) estructura la situación que debe modelizar (CMn1), razona matemáticamente de manera simple (CAn1) y piensa en el tratamiento matemático necesario (CPRn1). 
El plano $\sigma$ buscado corta al plano $\pi$ en una recta, $t$, paralela al plano $O X Y$, es decir; $\sigma$ contiene a la recta $t$.

Comienza calculando el vector director de la recta $t, \vec{d}_{t}$.

Como la recta $t$ es paralela al plano $O X Y$, el vector director de $t$ es perpendicular al vector normal del plano $\left(\vec{d}_{t} \perp \vec{n}_{O X Y}\right)$.

Como la recta $t$ pertenece al plano $\pi$, el vector director de $t$ es perpendicular al vector normal del plano $\left(\vec{d}_{t} \perp \vec{n}_{\pi}\right)$.

El alumno explica los cálculos y sus propiedades (CCn2) e interpreta las relaciones implicadas (CCn3), a la par que elige estrategias apropiadas que conexionan áreas matemáticas (CRPn2), -álgebra y geometría-, y aplica las estrategias apropiadas (CRPn3).

Vector normal del plano $O X Y, \vec{n}_{O X Y}=(0,0,1)$ y vector normal del plano $\pi$ $\vec{n}_{\pi}=(1,1,1)$.

Posteriormente, calcula el vector director de la recta $t$ mediante un producto vectorial,

$$
\begin{gathered}
\vec{d}_{t} \cong \vec{n}_{O X Y} \times \vec{n}_{\pi} \\
\overrightarrow{d_{t}}=\left|\begin{array}{ccc}
\vec{i} & \vec{j} & \vec{k} \\
0 & 0 & 1 \\
1 & 1 & 1
\end{array}\right|=-\vec{i}+\vec{j} \Rightarrow \vec{d}_{t}=(-1,1,0)
\end{gathered}
$$

El alumno desarrolla procedimientos intuitivos ya practicados, pero no rutinarios (CRPn1), comprende que tiene que emplear conceptos matemáticos intermedios (CPRn2) y aplica conceptos matemáticos apropiados (CPRn3).

El plano $\sigma$ contiene a la recta $r$ y al vector director de la recta $t, \overrightarrow{d_{t}}$. Desarrollando el determinante obtenemos la ecuación del plano.

$$
\sigma=\left|\begin{array}{ccc}
x-1 & y-3 & z \\
0 & 0 & 1 \\
-1 & 1 & 0
\end{array}\right|=0
$$

En el desarrollo del determinante el alumno realiza operaciones elementales en contextos conocidos (RLSOn1), interpreta el lenguaje formal y simbólico rutina- 
rio (RLSOn2), maneja procedimientos y fórmulas, resolviendo y calculando (RLSOn3).

Cuando efectúa el producto vectorial de vectores y el cálculo de determinantes, y utiliza variables, y realiza ecuaciones y cálculos mediante procedimientos familiares (CLSOn3), en un alumno de segundo de Bachillerato.

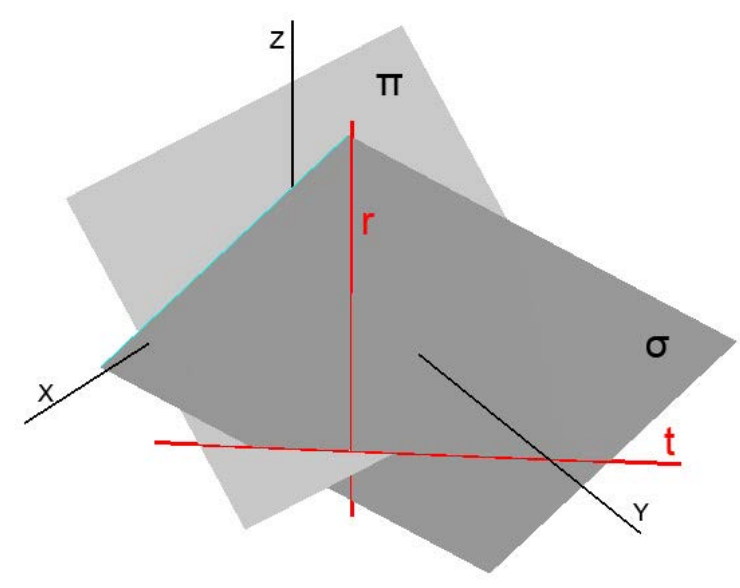

Figura 5.9

Desarrollando el determinante, operando y simplificando, obtiene la ecuación:

$$
\sigma \equiv x+y-4=0
$$

El alumno traduce en la práctica el modelo a seguir, que es algo diferente de los estudiados (CMn2) y sabe interpretar y alternar diferentes modelos y comunicar los resultados (CMn3) y justifica las fórmulas utilizadas y los resultados (RAn3).

\begin{tabular}{|l|c|c|c|c|c|c|c|c|}
\hline \multicolumn{6}{|l|}{ FICHA 5.9.2. COMPETENCIAS IMPLÍCITAS EN LA RESOLUCIÓN DEL P9 } \\
\hline & Nivel 1 & Nivel 2 & Nivel 3 & Nivel 1 & Nivel 2 & Nivel 3 & Nivel 1 & Nivel 2 \\
\hline PR & & & & $*$ & $*$ & $*$ & & \\
\hline A & & & $*$ & $*$ & & & & \\
\hline C & & & & $*$ & $*$ & $*$ & & \\
\hline M & & & & $*$ & $*$ & $*$ & & \\
\hline RP & & & & $*$ & $*$ & $*$ & & \\
\hline R & & & & $*$ & $*$ & & & \\
\hline LSO & $*$ & $*$ & $*$ & & & & & Reflexión \\
\hline
\end{tabular}

\section{ANÁLISIS DEL PROBLEMA P12}

El apartado a) del problema de la ficha 5.12.1 es un ejercicio que corresponde a un nivel de conexión.

El alumno piensa en el tratamiento matemático necesario (CPRn1). 
FICHA 5.12.1.

ESTUDIO DEL ENUNCIADO DEL P12

P12.- Consideramos los puntos $A(-5,2,4), B(-3,2,0)$ y la recta $s \equiv \frac{x-1}{-3}=\frac{y}{1}=\frac{z}{2}$

a) Calcular la recta que corta perpendicularmente a $s$ y pasa por $B$.

b) Consideramos el rectángulo que tiene por dos vértices opuestos a $A$ y $B$, y uno de los lados que pasa por $A$ está contenido en la recta s. Calcular su área.

\begin{tabular}{|c|c|c|c|c|c|c|c|c|c|c|c|c|}
\hline CONVOCATORIA & \multicolumn{6}{|c|}{ JUNIO } & \multicolumn{6}{|c|}{ SEPTIEMBRE } \\
\hline AÑo & \begin{tabular}{l|l}
95 & 96 \\
\end{tabular} & 97 & 98 & 99 & $\underline{00}$ & 01 & \begin{tabular}{l|l}
02 & 03 \\
\end{tabular} & 04 & 05 & \begin{tabular}{l|l}
06 & 07 \\
\end{tabular} & 08 & 09 \\
\hline OPCIÓN & \multicolumn{6}{|c|}{$\underline{\underline{A}}$} & \multicolumn{6}{|c|}{ B } \\
\hline TIPO DE PROBLEMA & \multicolumn{6}{|c|}{ TEÓRICO } & \multicolumn{6}{|c|}{ PRÁCTICO } \\
\hline \multirow{3}{*}{ APARTADOS } & \multirow{3}{*}{ SI } & \multicolumn{4}{|c|}{ Forma explícita } & $\underline{2}$ & & & \multirow{3}{*}{\begin{tabular}{|l|} 
\\
\end{tabular}} & \multirow[b]{2}{*}{6} & \multirow{3}{*}{\multicolumn{2}{|c|}{ NO }} \\
\hline & & & & & & 2 & 3 & 4 & & & & \\
\hline & & \multicolumn{4}{|c|}{ Forma implícita } & & & & & & & \\
\hline VERBO UTILIZADO & \multicolumn{12}{|c|}{ CALCULAR } \\
\hline TIEMPO VERBAL & \multicolumn{12}{|c|}{ INFINITIVO } \\
\hline \multirow{3}{*}{$\begin{array}{l}\text { FALLOS DEL ENUN- } \\
\text { CIADO }\end{array}$} & \multicolumn{8}{|c|}{ ERROR ORTOGRÁFICO: PUNTUACIÓN } & & & & \\
\hline & \multicolumn{8}{|c|}{ ESTRUCTURA DE LA ORACIÓN } & & & & \\
\hline & \multicolumn{8}{|c|}{ AUSENCIA DE ESPECIFICACIONES } & & & & \\
\hline \multicolumn{13}{|c|}{ ENUNCIADO ALTERNATIVO } \\
\hline
\end{tabular}

P12.- Consideramos los puntos de coordenadas $A(-5,2,4), B(-3,2,0)$ y la re-

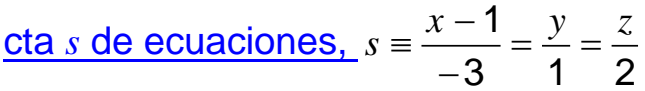

a) Determina las ecuaciones de la recta que corta perpendicularmente a la recta $s$ y pasa por el punto $B$.

b) Consideramos el rectángulo que tiene a $A$ y $B$ como dos vértices opuestos, y uno de sus lados, que pasa por $A_{\llcorner}$está contenido en la recta s. Calcula su área.

NIVELES DE COMPETENCIAS IMPLÍCITAS: Reproducción y conexión

Tiene que escribir la ecuación de un plano $\pi_{B}$ perpendicular a la recta $s$ que pase por el punto B; es decir, desarrollar procedimientos ya practicados, pero no rutinarios (CRPn1), razonar matemáticamente de manera simple (CAn1) y estructurar la situación que se debe modelizar (CMn1).

Todas las rectas perpendiculares a una dada se encuentran en un plano perpendicular a la recta, calculamos, pues, la ecuación de ese plano perpendicular que pasa por $B$. 


$$
\vec{d}_{s} \cong \vec{n}_{\pi_{B}} \Rightarrow \vec{n}_{\pi_{B}}=(-3,1,2)
$$

El alumno sabe expresarse sobre cuestiones matemáticas (CCn1), explica los cálculos y sus propiedades (CCn2) e interpreta las relaciones implicadas (CCn3). Asimismo, sigue el encadenamiento del argumento matemático particular (CAn2) haciendo una evaluación del mismo (CAn3).

Ecuación normal del plano

$$
\overrightarrow{B X} \cdot \vec{n}_{\pi_{B}}=(x+3, y-2, z) \cdot(-3,1,2)=0
$$

El alumno interpreta formas de representación (CRn1), selecciona y cambia entre las diferentes formas de representación, -geométrica, algebraica- (CRn2) y traduce y diferencia entre distintas formas de representación (CRn3).

Comprende que tiene que emplear métodos matemáticos intermedios (CPRn2), realiza operaciones elementales en contextos conocidos (RLSOn1), interpreta el lenguaje formal y simbólico rutinario (RLSOn2), maneja procedimientos y fórmulas, resolviendo y calculando (RLSOn3) y utiliza variables y realiza ecuaciones y cálculos mediante procedimientos familiares (CLSOn3), entre otros el producto escalar de dos vectores.

Efectuando las operaciones, obtiene la ecuación

$$
-3 x+y+2 z-11=0
$$

Calcula el punto de corte de la recta $s$ con el plano $\pi_{B}$. Como la recta $s$ está dada por su ecuación continua, considera un punto genérico de la recta $P_{s}=(1-3 \lambda, \lambda, 2 \lambda)$ y sustituye ese punto en la ecuación del plano, obteniendo la ecuación

$$
-3(1-3 \lambda)+\lambda+2 \lambda-11=0
$$

Que tiene como solución $\lambda=1$

$Y$ sustituyendo ese valor de $\lambda$ en $P_{s}=(1-3 \lambda, \lambda, 2 \lambda)$, nos da el punto $I=(-2,1,2)$.

La recta pedida pasa por el punto $B$ y tiene como vector director el vector

$$
\overrightarrow{B I}=(1,-1,2)
$$

El alumno explica los cálculos y sus propiedades (CCn2) interpretando las relaciones implicadas (CCn3). 
Ecuaciones de la recta en forma continua: $x+3=\frac{y-2}{-1}=\frac{z}{2}$

Con lo que evalúa el encadenamiento de argumentos matemáticos particulares (CAn3) eligiendo las estrategias apropiadas que conexionen áreas matemáticas (CRPn2) y aplicando, de este modo, conceptos matemáticos apropiados (CPRn3).

El apartado b) del problema que aparece en la ficha 5.12.1 corresponde al nivel de reproducción del conocimiento estudiado, es la ejecución de un problema rutinario mediante el manejo de expresiones y fórmulas establecidas y la realización de cálculos.

El alumno comprende la expresión escrita $(\mathrm{RCn} 1)$, reconoce representaciones de los datos del ejercicio (RPRn1), identifica el problema (RAn1), identifica que el modelo es similar a otros vistos con anterioridad (RMn1) y le reconoce como problema ya practicado (RRPn1).

El área del rectángulo se obtiene calculando el módulo del producto vectorial $\overrightarrow{A I} \times \overrightarrow{B I}$.

Expone el proceso de cálculo (RAn2), realiza explicaciones sencillas (RCn2) y reproduce un problema ya practicado, de manera cerrada (RRPn2), en consecuencia, plantea los algoritmos correspondientes (RPRn2) y asocia con fórmulas establecidas y realiza los cálculos (RPRn3).

$$
\begin{gathered}
A=(-5,2,4), I=(-2,1,2) \Rightarrow \overrightarrow{A I}=(-2+5,1-2,2-4)=(3,-1,-2) \\
B=(-3,2,0), I=(-2,1,2) \Rightarrow \overrightarrow{B I}=(-2+3,1-2,2-0)=(1,-1,2) . \\
\overrightarrow{A I} \times \overrightarrow{B I}=\left|\begin{array}{rrr}
\vec{i} & \vec{j} & \vec{k} \\
3 & -1 & -2 \\
1 & -1 & 2
\end{array}\right|=-4 \vec{i}-8 \vec{j}-2 \vec{k} \\
|\overrightarrow{A I} \times \overrightarrow{B I}|=\sqrt{(-4)^{2}+(-8)^{2}+(-2)^{2}}=\sqrt{84} u^{2}
\end{gathered}
$$

Con lo que maneja procedimientos y fórmulas, resolviendo y calculando (RLSOn3) y utiliza variables y realiza ecuaciones y cálculos mediante procedimientos familiares (CLSOn3).

El alumno resuelve problemas rutinarios estandarizados (RRPn3), describe los resultados obtenidos (RCn3), justifica las fórmulas utilizadas y los resultados 
(RAn3) y comunica de manera elemental los resultados del modelo (RMn3).

El alumno podía haber hecho otro razonamiento:

Como se trata de un rectángulo, se puede calcular el área utilizando la fórmula

$$
\text { Área }=|\overrightarrow{A I}| \cdot|\overrightarrow{B I}|
$$

Donde $|\overrightarrow{A I}|$ y $|\overrightarrow{B I}|$ son la base y la altura del rectángulo.

$$
\begin{gathered}
|\overrightarrow{A I}|=\sqrt{3^{2}+(-1)^{2}+(-2)^{2}}=\sqrt{14} \\
|\overrightarrow{B I}|=\sqrt{1^{2}+(-1)^{2}+(2)^{2}}=\sqrt{6} \\
\text { Área }=|\overrightarrow{A I}| \cdot|\overrightarrow{B I}|=\sqrt{14} \cdot \sqrt{6}=\sqrt{84} u^{2}
\end{gathered}
$$

Estaría entonces en el nivel de conexión, ya que el alumno sabe expresarse sobre cuestiones matemáticas (CCn1) y explica los cálculos y sus propiedades

\begin{tabular}{|c|c|c|c|c|c|c|c|c|}
\hline \multicolumn{2}{|c|}{ FICHA 5.12.2. } & \multicolumn{7}{|c|}{ COMPETENCIAS IMPLÍCITAS EN LA RESOLUCIÓN DEL P12 } \\
\hline & Nivel 1 & Nivel 2 & Nivel 3 & Nivel 1 & Nivel 2 & Nivel 3 & Nivel 1 & Nivel 2 \\
\hline PR & * & * & * & * & * & * & & \\
\hline A & * & * & * & * & * & * & & \\
\hline C & * & * & * & * & * & * & & \\
\hline M & * & & * & * & & & & \\
\hline RP & * & * & * & * & * & & & \\
\hline $\mathbf{R}$ & & & & * & * & * & & \\
\hline \multirow[t]{2}{*}{ LSO } & * & * & * & & & * & & \\
\hline & \multicolumn{3}{|c|}{ Reproducción } & \multicolumn{3}{|c|}{ Conexión } & \multicolumn{2}{|c|}{ Reflexión } \\
\hline
\end{tabular}
(CCn2), con lo que evalúa el encadenamiento del argumento matemático particular (CAn3), interpreta las relaciones implicadas (CCn3) y comunica los resultados (CMn3).

\section{ANÁLISIS DEL PROBLEMA P13}

El apartado a) del problema de la ficha 5.13.1 corresponde al nivel de reproducción del conocimiento estudiado. El ejercicio pide que se calculen dos puntos de corte entre una recta y dos planos, lo cual es la ejecución de un proble- 
ma rutinario mediante el manejo de expresiones y fórmulas establecidas y la realización de cálculos.

FICHA 5.13.1.

ESTUDIO DEL ENUNCIADO DEL P13

P13.- La recta

$$
r \equiv\left\{\begin{array}{c}
x=-2+3 t \\
y=4-2 t \\
z=-6+5 t
\end{array}\right.
$$

corta al plano $x-y-2 z=1$ en el punto $A$, y al plano $x+y-z=0$ en el punto $B$. Si $O$ es el origen de coordenadas:

a) Hallar el ángulo entre los vectores $\overrightarrow{O A}$ y $\overrightarrow{O B}$.

b) Hallar el área del triángulo $O A B$.

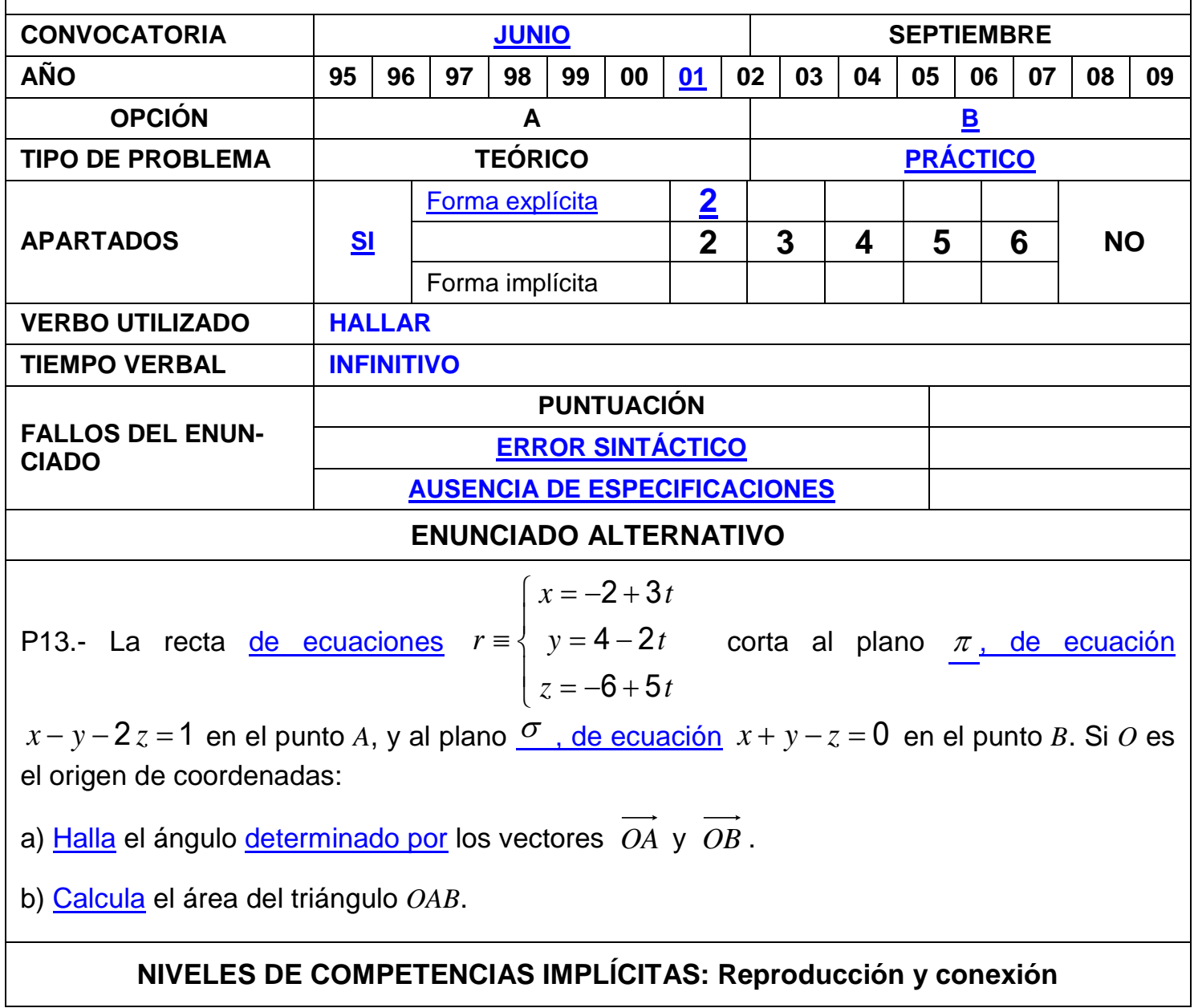

El alumno comprende la expresión escrita (RCn1). 
Identifica el problema (RAn1), reconoce representaciones de los datos del ejercicio (RPRn1), identifica que el modelo es similar a otros vistos con anterioridad (RMn1) y le reconoce como problema ya practicado (RRPn1).

La recta $r$ está dada mediante ecuaciones paramétricas, por lo que para calcular los puntos $A$ y $B$ de intersección con los planos

$$
\begin{gathered}
\pi \equiv x-y-2 z=1 \\
y \\
\sigma \equiv x+y-z=0
\end{gathered}
$$

Consideramos un punto genérico de la recta $r$,

$$
P_{r}=(-2+3 t, 4-2 t,-6+5 t)
$$

y sustituimos ese punto en las

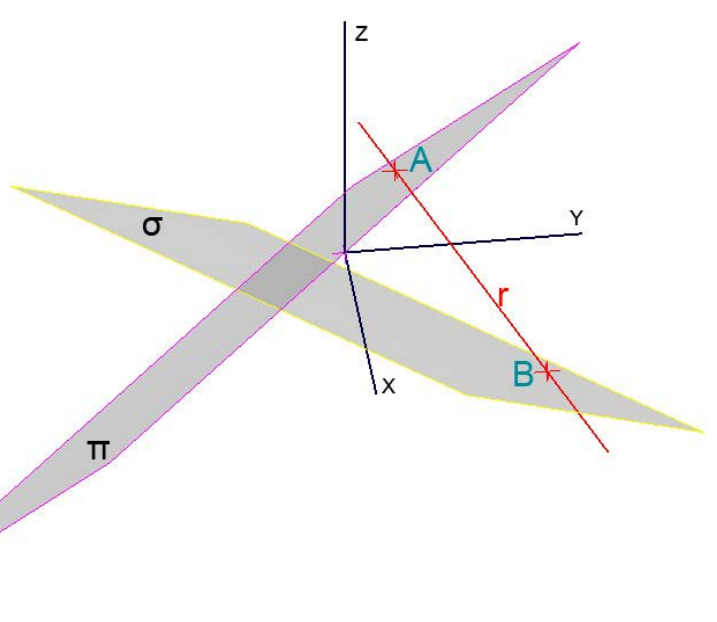

Figura 5.13.1 ecuaciones de los dos planos. Obteniendo las ecuaciones:

$$
\begin{gathered}
(-2+3 t)-(4-2 t)-2(-6+5 t)=1, \text { que tiene la solución } t=1 \\
y \\
(-2+3 t)+(4-2 t)-(-6+5 t)=0 \Rightarrow t=2
\end{gathered}
$$

Sustituyendo esos valores de $t$ en $P_{r}=(-2+3 t, 4-2 t,-6+5 t)$, nos da los puntos $A=(1,2,-1)$ y $B=(4,0,4)$.

El alumno expone el proceso de cálculo (RAn2), realiza explicaciones sencillas $(\mathrm{RCn} 2)$ y reproduce un problema ya practicado, de manera cerrada (RRPn2), en consecuencia, plantea los algoritmos correspondientes (RPRn2) y asocia con fórmulas establecidas y realiza los cálculos (RPRn3).

El ángulo de dos vectores se obtiene a partir del producto escalar de los mismos.

$$
\overrightarrow{O A} \cdot \overrightarrow{O B}=|\overrightarrow{O A}| \cdot|\overrightarrow{O B}| \cdot \cos (\alpha)
$$

El alumno realiza operaciones elementales en contextos conocidos (RLSOn1), interpreta el lenguaje formal y simbólico rutinario (RLSOn2), maneja procedimientos y fórmulas, resolviendo y calculando (RLSOn3) y utiliza variables y rea- 
liza ecuaciones y cálculos mediante procedimientos familiares (CLSOn3), entre otros el producto escalar de dos vectores: $\overrightarrow{O A}=(1,2,-1)$ y $\overrightarrow{O B}=(4,0,4)$

$$
\overrightarrow{O A} \cdot \overrightarrow{O B}=(1,2,-1) \cdot(4,0,4)=0 \Rightarrow \alpha=90^{\circ}
$$

El alumno resuelve problemas rutinarios estandarizados (RRPn3), realiza explicaciones sencillas (RCn2), describe los resultados obtenidos (RCn3), justifica las fórmulas utilizadas y los resultados (RAn3) y comunica de manera elemental los resultados del modelo (RMn3).

Además, interpreta formas de representación (CRn1), selecciona y cambia entre diferentes formas de representación (CRn2), -algebraica, geométrica y gráfica-. Figuras 5.13.1 y 5.13.2.

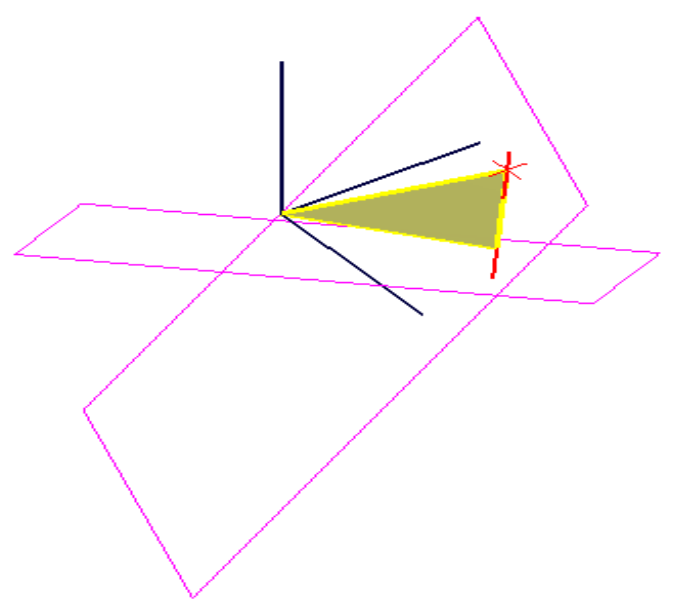

Figura 5.13.2

El apartado b) del problema que aparece en la ficha 5.13.1, el cálculo del área del triángulo corresponde al nivel de reproducción del conocimiento estudiado, es la ejecución de un problema rutinario mediante el manejo de expresiones y fórmulas establecidas y la realización de cálculos.

Comienza con el reconocimiento de la representación de los datos del ejercicio (RPRn1), comprendiendo la expresión escrita (RCn1), planteando los algoritmos correspondientes (RPRn2) y asociándole con fórmulas establecidas y realizando los cálculos (RPRn3).

El alumno identifica el problema (RAn1), identifica que el modelo es similar a otros vistos con anterioridad (RMn1) y le reconoce como problema ya practicado (RRPn1).

Como el triángulo es rectángulo, los vectores $\overrightarrow{O A}$ y $\overrightarrow{O B}$ son la base y la altura del mismo.

El alumno selecciona y cambia entre diferentes formas de representación (CRn2), -algebraica, geométrica y gráfica-Figura 5.13.3 
Este razonamiento implica que el alumno sabe expresarse sobre cuestiones matemáticas (CCn1) y, en consecuencia, expone el proceso de cálculo (RAn2), plantea los algoritmos correspondientes (RPRn2), realiza explicaciones sencillas $(\mathrm{RCn} 2)$ y reproduce problemas ya practicados de manera cerrada (RRPn2).

El área se obtiene mediante la fórmula:

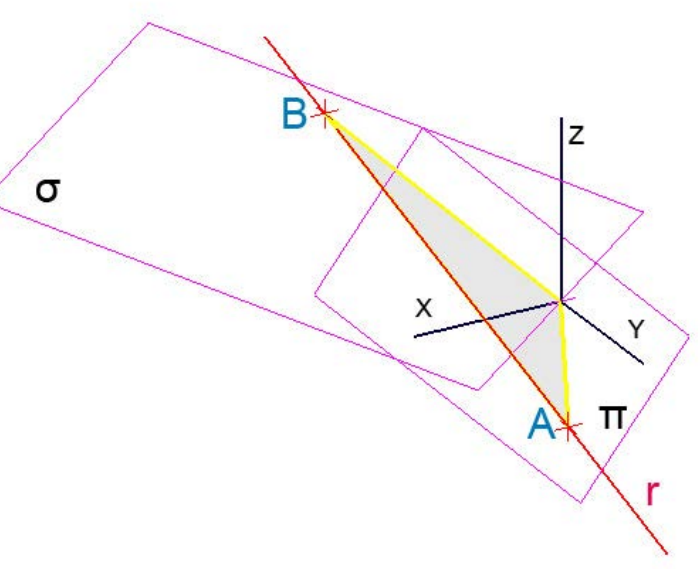

Figura 5.13.3

$$
\begin{gathered}
A=\frac{|\overrightarrow{O A}| \cdot|\overrightarrow{O B}|}{2} \\
A=\frac{|\overrightarrow{O A}| \cdot|\overrightarrow{O B}|}{2}=\frac{\sqrt{1^{2}+2^{2}+(-1)^{2}} \cdot \sqrt{4^{2}+0^{2}+4^{2}}}{2}=4 \sqrt{3} u^{2}
\end{gathered}
$$

El alumno utiliza variables y realiza ecuaciones y cálculos mediante procedimientos familiares (CLSOn3), -módulo de un vector- y maneja procedimientos y fórmulas, resolviendo y calculando (RLSOn3), -operaciones aritméticas-, resuelve problemas rutinarios estandarizados (RRPn3), describe los resultados obtenidos (RCn3), justifica las fórmulas utilizadas y los resultados (RAn3) y

\begin{tabular}{|c|c|c|c|c|c|c|c|c|}
\hline \multicolumn{2}{|c|}{ FICHA 5.13.2. } & \multicolumn{7}{|c|}{ COMPETENCIAS IMPLÍCITAS EN LA RESOLUCIÓN DEL P13 } \\
\hline & Nivel 1 & Nivel 2 & Nivel 3 & Nivel 1 & Nivel 2 & Nivel 3 & Nivel 1 & Nivel 2 \\
\hline PR & * & * & * & & & & & \\
\hline A & * & * & * & & & & & \\
\hline C & * & * & * & * & & & & \\
\hline M & * & & * & & & & & \\
\hline RP & * & * & * & & & & & \\
\hline $\mathbf{R}$ & & & & * & * & & & \\
\hline \multirow[t]{2}{*}{ LSO } & * & * & * & & & * & & \\
\hline & \multicolumn{3}{|c|}{ Reproducción } & \multicolumn{3}{|c|}{ Conexión } & \multicolumn{2}{|c|}{ Reflexión } \\
\hline
\end{tabular}
comunica de manera elemental los resultados del modelo (RMn3). 


\section{ANÁLISIS DEL PROBLEMA P19}

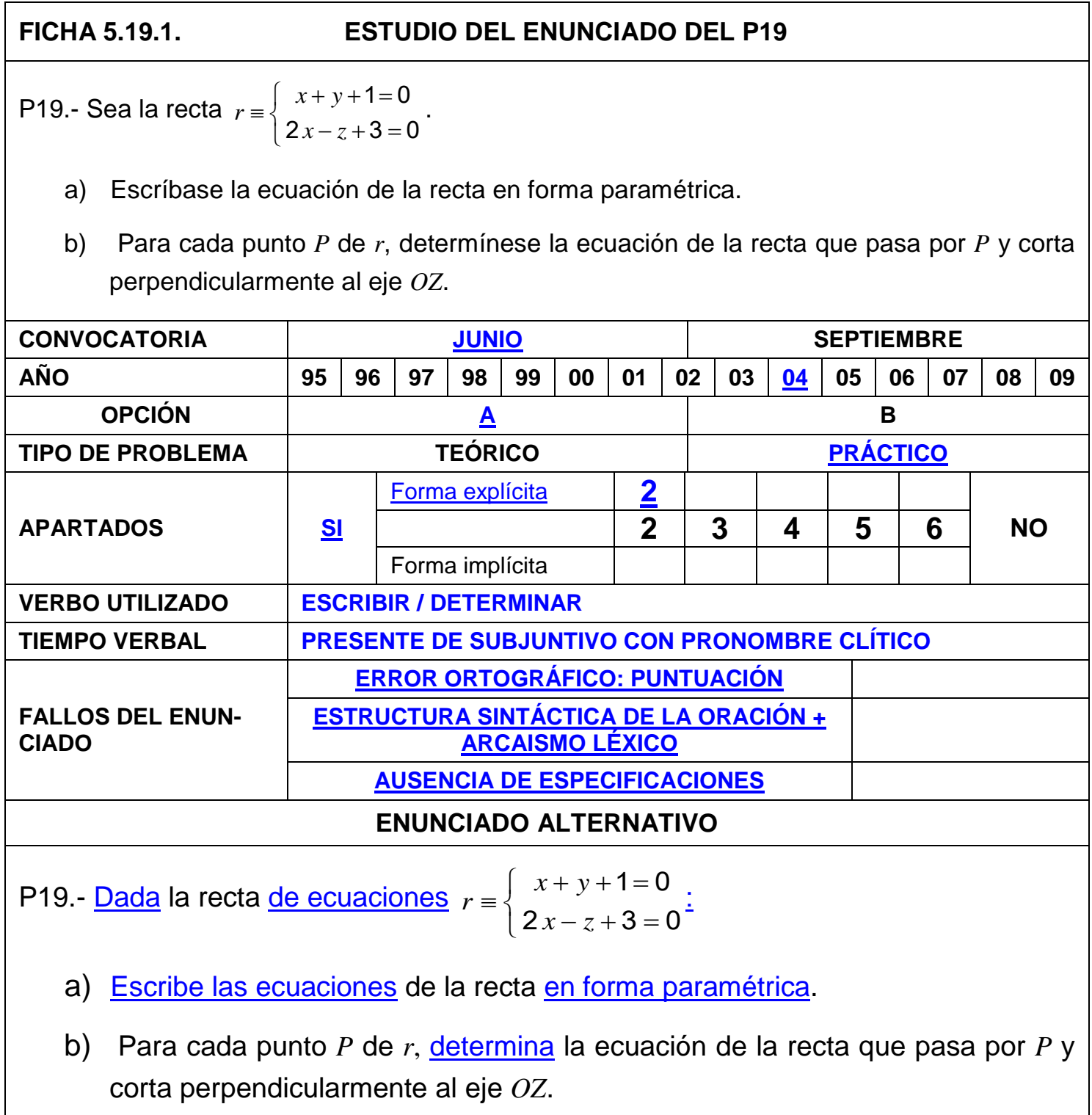

NIVELES DE COMPETENCIAS IMPLÍCITAS: Reproducción, conexión y reflexión

El apartado a) del problema de la ficha 5.19.1 se incluye en el nivel de reproducción del conocimiento estudiado.

El alumno reconoce representaciones de los datos del ejercicio (RPRn1), identifica el problema (RAn1), identifica que el modelo es similar a otros vistos con anterioridad (RMn1), comprende la expresión escrita (RCn1) y le reconoce como problema ya practicado (RRPn1).

El alumno reconoce representaciones de los datos del ejercicio (RPRn1) -los vectores normales de los planos-, expone el proceso de cálculo (RAn2), plan- 
tea los algoritmos correspondientes (RPRn2), asocia con fórmulas establecidas y realiza los cálculos (RPRn3).

Calculamos el vector director de la recta $r$ resolviendo el sistema

$$
\left\{\begin{array}{c}
x+y+1=0 \\
2 x-z+3=0
\end{array}\right.
$$

Obteniendo la solución

$$
x=\lambda \quad ; \quad y=1-\lambda \quad ; \quad z=3+2 \lambda
$$

Que es la ecuación de la recta escrita en forma paramétrica.

El alumno justifica las fórmulas utilizadas y los resultados (RAn3) y realiza explicaciones sencillas (RCn2), al tiempo que reproduce problemas ya practicados de manera cerrada (RRPn2), resuelve problemas rutinarios estandarizados (RRPn3), comunica de manera elemental los resultados del modelo (RMn3) y describe los resultados obtenidos (RCn3).

El apartado b) del problema que se presenta en la ficha 5.19.1 se encuadra en los niveles de conexión y reflexión. El alumno estructura la situación que debe modelizar (CMn1), piensa en el tratamiento matemático necesario (CPRn1).sabe expresarse sobre cuestiones matemáticas (CCn1), razona matemáticamente de manera simple (CAn1) y a continuación desarrolla procedimientos intuitivos ya practicados, pero no rutinarios (CRPn1).

Sea $P(\lambda, 1-\lambda, 3+2 \lambda)$ un punto de la recta $r$. Para cada valor de $\lambda$ consideramos el plano $\pi_{\lambda}$ perpendicular al eje $O Z$ que pasa por el punto $P$.

El vector normal del plano $\pi_{\lambda}$ es equipolente al vector director del eje $\mathrm{OZ}$.

$$
\vec{d}_{O Z}=(0,0,1) \cong \vec{n}_{\pi_{\lambda}}
$$

El alumno interpreta formas de representación (CRn1), -sistema de ecuaciones-, selecciona y cambia entre las diferentes formas de representación $(\mathrm{CRn} 2)$, traduce en la práctica el modelo a seguir, que es algo diferente de los estudiados (CMn2), explica los cálculos y sus propiedades (CCn2) e interpreta las relaciones implicadas (CCn3), comprende que tiene que emplear conceptos matemáticos intermedios (CPRn2) y aplica los conceptos matemáticos apropiados (CPRn3). 
Ecuación normal del plano

$$
(x-\lambda, y-(1-\lambda), z-(3+2 \lambda)) \cdot(0,0,1)=0
$$

El alumno interpreta el lenguaje formal y simbólico en situaciones menos conocidas (CLSOn1), maneja afirmaciones sencillas y expresiones con símbolos y fórmulas no rutinarias (CLSOn2) y utiliza variables, y realiza ecuaciones y cálculos mediante procedimientos familiares (CLSOn3), como son el vector director de la recta y el producto escalar de vectores, con la presencia de parámetros.

Efectuando el producto escalar, obtiene la solución

$$
\pi_{\lambda} \equiv z-(3+2 \lambda)=0
$$

Sabe expresarse sobre cuestiones matemáticas (CCn1), explica los cálculos y sus propiedades (CCn2) e interpreta las relaciones implicadas (CCn3), a la par que aplica las estrategias apropiadas (CPRn3).

Calcula el punto de intersección,

$$
I=(0,0,3+2 \lambda)
$$

de la recta $z=\mu$ con el plano $\pi_{\lambda} \equiv z-(3+2 \lambda)=0$.

La recta buscada tiene como vector director el vector:

$$
\begin{gathered}
\qquad \overrightarrow{I P}=(\lambda, 1-\lambda, 0) \\
\text { y pasa por el punto } P(\lambda, 1-\lambda, 3+2 \lambda)
\end{gathered}
$$

El alumno sabe expresarse sobre cuestiones matemáticas (CCn1), sigue el encadenamiento de argumentos matemáticos particulares (CAn2), evalúa el encadenamiento de argumentos matemáticos particulares (CAn3), interpreta las relaciones implicadas (CCn3), sabe alternar diferentes modelos y comunicar los resultados $(\mathrm{CMn} 3)$ y aplica las estrategias apropiadas más independientes (CRPn3).

La resolución del problema se encuentra también en el nivel de reflexión por parte del estudiante para planificar estrategias y aplicarlas en la resolución de un problema que contenga elementos inusuales, pues $P$ es un punto variable que depende del valor de $\lambda$ y la ecuación de la recta depende de dos parámetros. 
Ecuaciones de la recta en forma paramétrica:

$$
s \equiv\left\{\begin{array}{c}
x=\lambda \cdot \rho \\
y=(1-\lambda) \cdot \rho \\
z=3+2 \lambda
\end{array}\right.
$$

Las ecuaciones de la recta dependen de dos parámetros, por lo que el alumno aplica estrategias no rutinarias (RfPRn2), sabe explicar cuestiones matemáticas, cálculos y resultados (RfCn1), expone problemas más allá de la reproducción de los ya practicados (RfRPn1) y explica asuntos que implican relaciones complejas (RfCn2).

\begin{tabular}{|c|c|c|c|c|c|c|c|c|}
\hline \multicolumn{2}{|c|}{ FICHA 5.19.2. } & \multicolumn{7}{|c|}{ COMPETENCIAS IMPLÍCITAS EN LA RESOLUCIÓN DEL P19 } \\
\hline & Nivel 1 & Nivel 2 & Nivel 3 & Nivel 1 & Nivel 2 & Nivel 3 & Nivel 1 & Nivel 2 \\
\hline PR & * & * & * & * & * & * & & * \\
\hline A & * & * & * & * & * & * & & \\
\hline C & * & * & * & * & * & * & * & * \\
\hline M & * & & * & * & * & & & \\
\hline RP & * & * & * & * & * & * & * & \\
\hline $\mathbf{R}$ & & & & * & * & & & \\
\hline \multirow[t]{2}{*}{ LSO } & & & & * & * & * & & \\
\hline & \multicolumn{3}{|c|}{ Reproducción } & \multicolumn{3}{|c|}{ Conexión } & \multicolumn{2}{|c|}{ Reflexión } \\
\hline
\end{tabular}

\section{ANÁLISIS DEL PROBLEMA P24}

El apartado a) del problema que aparece en la ficha 5.24.1 es un ejercicio en el que hay que hacer un estudio dependiendo del valor de un parámetro, por lo que es un ejercicio correspondiente al nivel de conexión, pues se trata de un ejercicio que reproduce situaciones similares a las estudiadas en la instrucción, pero que no son de mera rutina.

El alumno piensa en el tratamiento matemático necesario (CPRn1), razona matemáticamente de manera simple (CAn1), sabe expresarse sobre cuestiones matemáticas (CCn1), estructura la situación que debe modelizar (CMn1), desarrolla procedimientos intuitivos ya practicados, pero no rutinarios (CRPn1) y sigue el encadenamiento de argumentos matemáticos particulares (CAn2). 
FICHA 5.24.1.

ESTUDIO DEL ENUNCIADO DEL P24

P24.- Hállese el valor de $a$ para el que la recta $r \equiv\left\{\begin{array}{c}x-y+2 z=1 \\ 2 x+y-5 z=2\end{array}\right.$ y el plano $\pi \equiv a x-y+z+1=0$ son paralelos.

b) Para $a=2$, calcúlese la ecuación del plano que contiene a $r$ y es perpendicular a $\pi, y$ hállese la distancia entre $r$ y $\pi$.

\begin{tabular}{|c|c|c|c|c|c|c|c|c|c|c|c|c|}
\hline CONVOCATORIA & \multicolumn{6}{|c|}{ JUNIO } & \multicolumn{6}{|c|}{ SEPTIEMBRE } \\
\hline AÑO & \begin{tabular}{l|l}
95 & 96
\end{tabular} & 97 & 98 & 99 & 00 & 01 & \begin{tabular}{l|l|}
02 & 03
\end{tabular} & 04 & 05 & \begin{tabular}{l|l}
$\underline{06}$ & 07
\end{tabular} & 08 & 09 \\
\hline OPCIÓN & \multicolumn{6}{|c|}{$\underline{\mathbf{A}}$} & \multicolumn{6}{|c|}{ B } \\
\hline TIPO DE PROBLEMA & \multicolumn{6}{|c|}{ TEÓRICO } & \multicolumn{6}{|c|}{ PRÁCTICO } \\
\hline \multirow{3}{*}{ APARTADOS } & \multirow{3}{*}{ SI } & \multicolumn{4}{|c|}{ Forma explícita } & $\underline{2}$ & & & & \multirow[b]{2}{*}{6} & \multirow{3}{*}{\multicolumn{2}{|c|}{ NO }} \\
\hline & & & & & & 2 & 3 & 4 & 5 & & & \\
\hline & & \multicolumn{4}{|c|}{ Forma implícita } & $\underline{2}$ & & & & & & \\
\hline VERBO UTILIZADO & \multicolumn{12}{|c|}{ HALLAR I CALCULAR } \\
\hline TIEMPO VERBAL & \multicolumn{12}{|c|}{ PRESENTE DE SUBJUNTIVO CON PRONOMBRE CLÍTICO } \\
\hline \multirow{3}{*}{$\begin{array}{l}\text { FALLOS DEL ENUN- } \\
\text { CIADO }\end{array}$} & \multicolumn{8}{|c|}{ PUNTUACIÓN } & & & & \\
\hline & \multicolumn{8}{|c|}{ ESTRUCTURA DE LA ORACIÓN } & & & & \\
\hline & \multicolumn{8}{|c|}{ AUSENCIA DE ESPECIFICACIONES } & & & & \\
\hline \multicolumn{13}{|c|}{ ENUNCIADO ALTERNATIVO } \\
\hline
\end{tabular}

P24.- $\underline{\text { Halla }}$ el valor de $a$ para el que la recta de ecuaciones $r \equiv\left\{\begin{array}{c}x-y+2 z=1 \\ 2 x+y-5 z=2\end{array}\right.$ y el plano de ecuación $\pi \equiv a x-y+z+1=0$ son paralelos.

b) Para $a=2$, calcula la ecuación del plano que contiene a $r$ y es perpendicular a $\pi$.

c) Halla la distancia de la recta $r$ al plano $\underline{\pi}$.

\section{NIVELES DE COMPETENCIAS IMPLÍCITAS: Reproducción y conexión}

Para que la recta y el plano sean paralelos el vector director de la recta tiene que ser perpendicular al vector normal del plano $\left(\overrightarrow{d_{r}} \perp \overrightarrow{n_{\pi}}\right)$.

Dado que la recta $r$ está dada como intersección de dos planos, el vector director de la misma se puede obtener resolviendo un sistema lineal de dos ecuaciones con tres incógnitas o mediante el cálculo del producto vectorial de los vectores normales de ambos planos.

$$
r \equiv\left\{\begin{array}{c}
x-y+2 z=1 \\
2 x+y-5 z=2
\end{array}\right.
$$


En ambos casos, el alumno interpreta formas de representación (CRn1), -el sistema de ecuaciones-, selecciona y cambia entre las diferentes formas de representación (CRn2), -algebraica y geométrica-, elige estrategias apropiadas más independientes que conexionen áreas matemáticas (CRPn2), y aplica las estrategias apropiadas más independientes que conexionen áreas matemáticas (CRPn2), -álgebra y geometría-.

$$
\overrightarrow{d_{r}}=\left|\begin{array}{rrr}
\vec{i} & \vec{j} & \vec{k} \\
1 & -1 & 2 \\
2 & 1 & -5
\end{array}\right|=3 \vec{i}+9 \vec{j}+3 \vec{k} \Rightarrow \overrightarrow{d_{r}}=(3,9,3) \cong(1,3,1)
$$

El alumno y les aplica (CPRn3), realiza operaciones elementales en contextos conocidos (RLSOn1), interpreta el lenguaje formal y simbólico rutinario (RLSOn2), maneja procedimientos y fórmulas, resolviendo y calculando (RLSOn3).

El alumno reconoce representaciones de los datos del ejercicio (RPRn1), comprende la expresión escrita (RCn1) y asocia con fórmulas establecidas (RPRn3), como son los vectores normales de los planos a partir de los datos del enunciado.

Asimismo, sabe expresarse sobre cuestiones matemáticas (CCn1), explica los cálculos y sus propiedades (CCn2) e interpreta las relaciones implicadas (CCn3), a la par que aplica las estrategias apropiadas (CRPn3).

$$
\vec{d}_{r} \cdot \vec{n}_{\pi}=(1,3,1) \cdot(a,-1,1)=0
$$

Efectuando las operaciones obtiene la ecuación

$$
a-2=0 \Rightarrow a=2
$$

El alumno utiliza variables, y realiza ecuaciones y cálculos mediante procedimientos familiares (CLSOn3), calculando determinantes y producto escalar de vectores, entre otros.

Para el valor $a=2$, la recta $r$ y el plano $\pi$ son paralelos.

Interpreta las relaciones implicadas (CCn3) y comunica de manera elemental los resultados del modelo (RMn3). 
El apartado b) del problema que aparece en la tabla 5.24 .1 se encuadra en el nivel de reproducción. Se trata de la reproducción del conocimiento estudiado, con el manejo de fórmulas establecidas y realización de cálculos.

Comienza con el reconocimiento de la representación de los datos del ejercicio (RPRn1), identifica el problema (RAn1) y comprende la expresión escrita (RCn1).

Como el plano pedido $\sigma$ contiene a la recta $r$, contiene todos los puntos de $r$, por ejemplo $P_{r}=(1,0,0)$.

Como el plano $\sigma$ contiene a la recta $r$, contiene a un vector equipolente al vector director de la recta $\vec{d}_{r}=(1,3,1)$ y como es perpendicular plano $\pi$ contiene a un vector equipolente al vector normal del plano $\vec{n}_{\pi}=(2,-1,1)$.

Identifica que el modelo es similar a otros modelos vistos con anterioridad, en la instrucción (RMn1), y le reconoce como problema ya practicado (RRPn1).

El alumno plantea los algoritmos correspondientes (RPRn2) y le asocia con fórmulas establecidas y realiza los cálculos (RPRn3), a la par que justifica las fórmulas utilizadas y los resultados (RAn3).

Entre las distintas fórmulas que se tienen para calcular la ecuación del plano pedido, utiliza:

$$
\operatorname{det}\left(\vec{P}_{r} X, \vec{d}_{r}, \vec{n}_{\pi}\right)=0
$$

Expone el proceso de cálculo (RAn2), realiza explicaciones sencillas (RCn2), reproduce problemas ya practicados de manera cerrada (RRPn2), eligiendo y aplicando las estrategias apropiadas que conexionen áreas matemáticas (CRPn2, CRPn3), -álgebra y geometría- y comunica de manera elemental los resultados del modelo (RMn3).

$$
\operatorname{det}\left(\overrightarrow{P_{r} X}, \vec{d}_{r}, \vec{n}_{\pi}\right)=\left|\begin{array}{crr}
x-1 & y & z \\
1 & 3 & 1 \\
2 & -1 & 1
\end{array}\right|=0
$$

En este proceso, maneja procedimientos y fórmulas, resolviendo y calculando (RLSOn3) y utiliza variables y realiza ecuaciones y cálculos mediante procedimientos familiares (CLSOn3). 
Desarrollando el determinante y realizando operaciones, obtiene la expresión que da la ecuación general del plano:

$$
\sigma \equiv 4 x+y-7 z-4=0
$$

Ahora hay que calcular la distancia entre la recta y el plano, lo que corresponde a una reproducción del conocimiento estudiado, con la aplicación de destrezas técnicas y de algoritmos habituales, el manejo de expresiones y fórmulas establecidas y realización de cálculos.

Identifica el problema (RAn1), comprende la expresión escrita (RCn1), identifica que el modelo es similar a otros vistos con anterioridad (RMn1) y le reconoce como problema ya practicado durante la instrucción (RRPn1).

Reconoce la representación de los datos del ejercicio (RPRn1), -las ecuaciones de la recta y del plano-, plantea los algoritmos correspondientes (RPRn2) y asocia con fórmulas establecidas (RPRn3).

La distancia entre una recta paralela a un plano y el mismo se reduce a la distancia de un punto de la recta, por ejemplo el punto $P_{r}=(1,0,0)$ al plano, y se obtiene mediante la fórmula:

$$
d=\frac{\left|a \cdot x_{0}+b \cdot y_{0}+c \cdot z_{0}+d\right|}{\left|\overrightarrow{n_{\pi}}\right|}
$$

Siendo $a \cdot x+b \cdot y+c \cdot z+d=0$ la ecuación del plano y $\left(x_{0}, y_{0}, z_{0}\right)$ las coordenadas del punto.

El alumno realiza explicaciones sencillas (RCn2) y expone el proceso de cálculo (RAn2).

El plano $\pi$ tiene de ecuación

$$
\pi \equiv 2 x-y+z+1=0
$$

La distancia es

$$
d=\frac{\left|a \cdot x_{0}+b \cdot y_{0}+c \cdot z_{0}+d\right|}{\left|\overrightarrow{n_{\pi}}\right|}=\frac{|2 \cdot 1-1 \cdot 0+1 \cdot 0+1|}{\sqrt{2^{2}+(-1)^{2}+1^{2}}}=\frac{3}{\sqrt{6}}=\frac{\sqrt{6}}{2} u
$$

El alumno justifica las fórmulas utilizadas y los resultados (RAn3), comunica de manera elemental los resultados del modelo (RMn3), realiza operaciones elementales en contextos conocidos (RLSOn1), interpreta el lenguaje formal $y$ 
simbólico rutinario (RLSOn2), -potencia, raíz, cociente-, y maneja procedimientos y fórmulas, resolviendo y calculando (RLSOn3), racionalizar, utiliza variables y realiza ecuaciones y cálculos, mediante procedimientos familiares (CLSOn3), con lo que resuelve problemas rutinarios estandarizados (RRPn3) y describe los resultados obtenidos (RCn3).

\begin{tabular}{|l|c|c|c|c|c|c|c|c|}
\hline \multicolumn{6}{|c|}{ FICHA 5.24.2. COMPETENCIAS IMPLÍCITAS EN LA RESOLUCIÓN DEL P24 } \\
\hline & Nivel 1 & Nivel 2 & Nivel 3 & Nivel 1 & Nivel 2 & Nivel 3 & Nivel 1 & Nivel 2 \\
\hline PR & $*$ & $*$ & $*$ & $*$ & $*$ & $*$ & & \\
\hline A & $*$ & $*$ & $*$ & $*$ & $*$ & & & \\
\hline C & $*$ & $*$ & $*$ & $*$ & $*$ & $*$ & & \\
\hline M & $*$ & & $*$ & $*$ & & & & \\
\hline RP & $*$ & $*$ & $*$ & $*$ & $*$ & $*$ & & \\
\hline R & & & & $*$ & $*$ & & & \\
\hline LSO & $*$ & $*$ & $*$ & & & $*$ & & \\
\hline & Reproducción & & Conexión & & Reflexión \\
\hline
\end{tabular}

\section{ANÁLISIS DEL PROBLEMA P28}

El apartado a) del problema que se presenta en la ficha 5.28.1 corresponde al nivel de reproducción del conocimiento estudiado. Es la ejecución de un problema rutinario, mediante la aplicación de destrezas técnicas y de algoritmos habituales, manejando expresiones y fórmulas establecidas y realizando cálculos, -el estudio del rango de dos matrices-.

El alumno comprende la expresión escrita (RCn1), reconoce representaciones de los datos del ejercicio (RPRn1), -las ecuaciones de las rectas-, plantea los algoritmos correspondientes (RPRn2) y asocia con fórmulas establecidas (RPRn3).

Las ecuaciones de las rectas $r \equiv\left\{\begin{array}{l}y=1 \\ z=0\end{array}\right.$ y $s \equiv\left\{\begin{array}{l}x=0 \\ z=2\end{array}\right.$ están dadas como intersección de dos planos y de su expresión se obtienen los siguientes datos:

Un vector director y un punto de la recta $r: \overrightarrow{d_{r}}=(1,0,0)$ y $P_{r}=(0,1,0)$.

Un vector director y un punto de la recta $s: \overrightarrow{d_{s}}=(0,1,0)$ y $P_{s}=(0,0,2)$. 
FICHA 5.28.1.

ESTUDIO DEL ENUNCIADO DEL P28

P28.- Se consideran las rectas $r$ y $s$ de ecuaciones respectivas

$$
r \equiv\left\{\begin{array}{l}
y=1 \\
z=0
\end{array} \quad, \quad s \equiv\left\{\begin{array}{l}
x=0 \\
z=2
\end{array}\right.\right.
$$

a) Estudiar la posición relativa de $r$ y s.

b) Determinar la recta que corta perpendicularmente a $r$ y $s$.

c) Hallar la distancia entre $r$ y $s$.

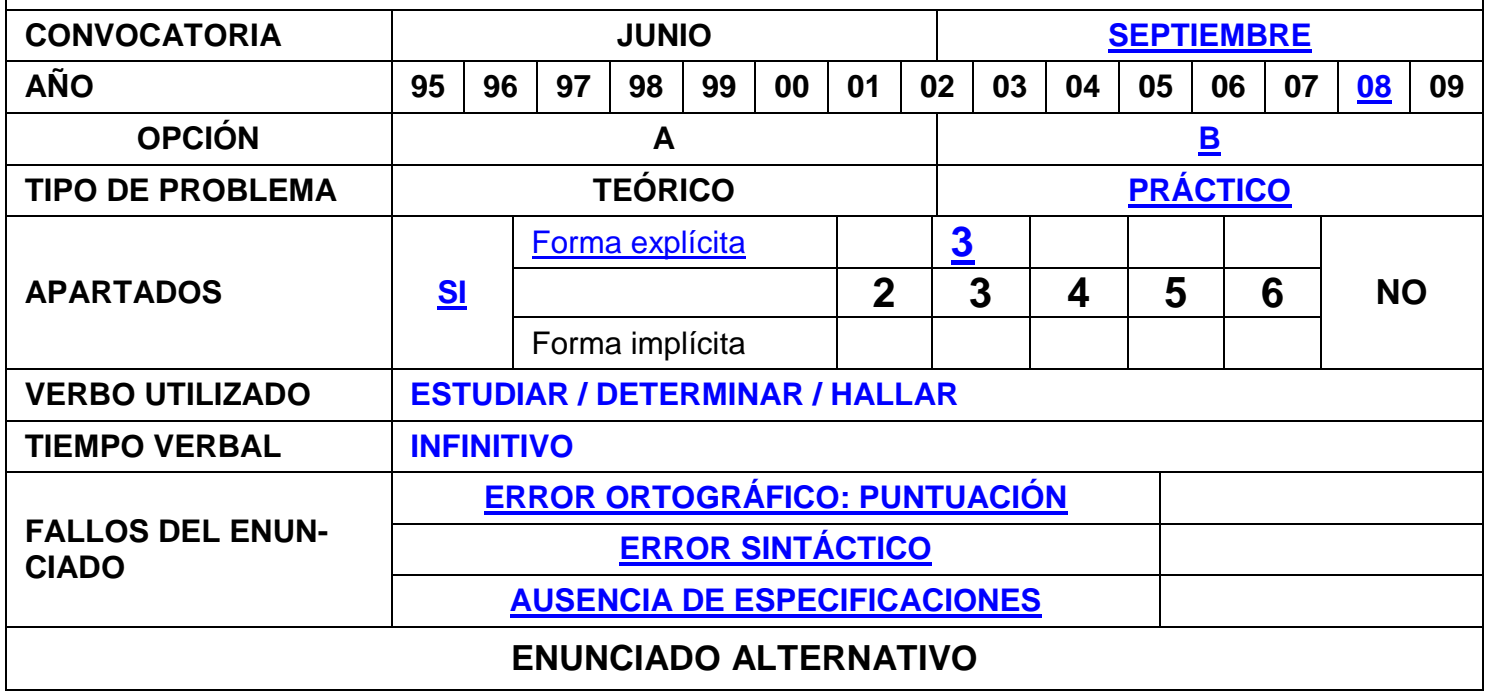

P28.- Se consideran las rectas $r$ y $s$ de ecuaciones respectivas

$$
r \equiv\left\{\begin{array}{l}
y=1 \\
z=0
\end{array}, \quad s \equiv\left\{\begin{array}{l}
x=0 \\
z=2
\end{array}\right.\right.
$$

a) Estudia la posición relativa de $r$ y $s$.

b) Escribe las ecuaciones de la recta que corta perpendicularmente a $r$ y $s$.

c) Halla la distancia de la recta $r$ a la recta $s$.

NIVELES DE COMPETENCIAS IMPLÍCITAS: Reproducción y conexión

El vector $\overrightarrow{P_{r} P_{s}}$, formado por un punto de la recta $r$ y otro de la recta $s$ es:

$$
\overrightarrow{P_{r} P_{s}}=(0,-1,2)
$$

El alumno identifica el problema (RAn1), identifica que el modelo es similar a otros vistos con anterioridad (RMn1) y le reconoce como problema ya practicado (RRPn1). 


$$
\begin{gathered}
\operatorname{rango}\left(\vec{d}_{r}, \vec{d}_{s}\right)=\operatorname{rango}\left(\begin{array}{lll}
1 & 0 & 0 \\
0 & 1 & 0
\end{array}\right)=2 \text {, pues }\left|\begin{array}{ll}
1 & 0 \\
0 & 1
\end{array}\right| \neq 0 \\
\operatorname{rango}\left(\vec{d}_{r}, \vec{d}_{s}, \overrightarrow{P_{r} P_{s}}\right)=\operatorname{rango}\left(\begin{array}{rrr}
1 & 0 & 0 \\
0 & 1 & 0 \\
0 & -1 & 2
\end{array}\right)=3
\end{gathered}
$$

A continuación, expone el proceso de cálculo (RAn2), realiza explicaciones sencillas $(\mathrm{RCn} 2)$ y reproduce un problema ya practicado, de manera cerrada (RRPn2).

$$
\operatorname{rango}\left(\vec{d}_{r}, \vec{d}_{s}\right) \neq \operatorname{rango}\left(\vec{d}_{r}, \vec{d}_{s},{\overrightarrow{P_{r} P_{s}}}\right)
$$

En consecuencia, las rectas se cruzan.

El alumno resuelve problemas rutinarios estandarizados (RRPn3), justifica las fórmulas utilizadas y los resultados (RAn3), describe los resultados obtenidos (RCn3) y comunica de manera elemental los resultados del modelo (RMn3).

El apartado b) del problema que aparece en la tabla 5.28.1 se incluye en el nivel de conexión. El alumno piensa en el tratamiento matemático necesario (CPRn1), estructura la situación que debe modelizar (CMn1) y desarrolla procedimientos intuitivos ya practicados, pero no rutinarios (CRPn1).

Considera un punto genérico de la recta $r, R=(\lambda, 1,0)$ y un punto genérico de la recta $s, S=(0, \mu, 2)$, para calcular el vector $\overrightarrow{R S}=(-\lambda, \mu-1,2)$.

El vector $\overrightarrow{R S}$ es perpendicular a la recta $r$ y a la recta $s$, luego es perpendicular a los vectores directores $\overrightarrow{d_{r}}=(1,0,0)$ y $\overrightarrow{d_{s}}=(0,1,0)$.

Razona matemáticamente de manera simple (CAn1) y sabe expresarse sobre cuestiones matemáticas (CCn1) y traduce en la práctica el modelo a seguir, que es algo diferente de los estudiados (CMn2).

El alumno elige estrategias apropiadas más independientes que conexionen áreas matemáticas (CRPn2), -álgebra y geometría-, y aplica las estrategias apropiadas más independientes (CRPn3).

Interpreta formas de representación (CRn1), -sistema de ecuaciones-, selecciona y cambia entre las diferentes formas de representación (CRn2), algebrai- 
ca y geométrica, comprende que tiene que emplear conceptos matemáticos intermedios (CPRn2) y aplica conceptos matemáticos apropiados (CPRn3).

$$
\begin{aligned}
& \overrightarrow{R S} \perp \vec{d}_{r} \Rightarrow(-\lambda, \mu-1,2) \cdot(1,0,0)=0 \\
& \overrightarrow{R S} \perp \vec{d}_{s} \Rightarrow(-\lambda, \mu-1,2) \cdot(0,1,0)=0
\end{aligned}
$$

Obteniendo soluciones

$$
\lambda=0 \text { y } \mu=1 \text { y el vector } \overrightarrow{R S}=(0,0,2) \cong(0,0,1)
$$

Reconoce representaciones de los datos del ejercicio (RPRn1), comprende la expresión escrita (RCn1) y asocia con fórmulas establecidas (RPRn3).

Ecuaciones de la recta en forma continua

$$
\frac{x}{0}=\frac{y-1}{0}=\frac{z}{2}
$$

El alumno realiza operaciones elementales en contextos conocidos (RLSOn1), interpreta el lenguaje formal y simbólico rutinario (RLSOn2), maneja procedimientos y fórmulas, resolviendo y calculando (RLSOn3) y utiliza variables, y realiza ecuaciones y cálculos mediante procedimientos familiares (CLSOn3) al tiempo que

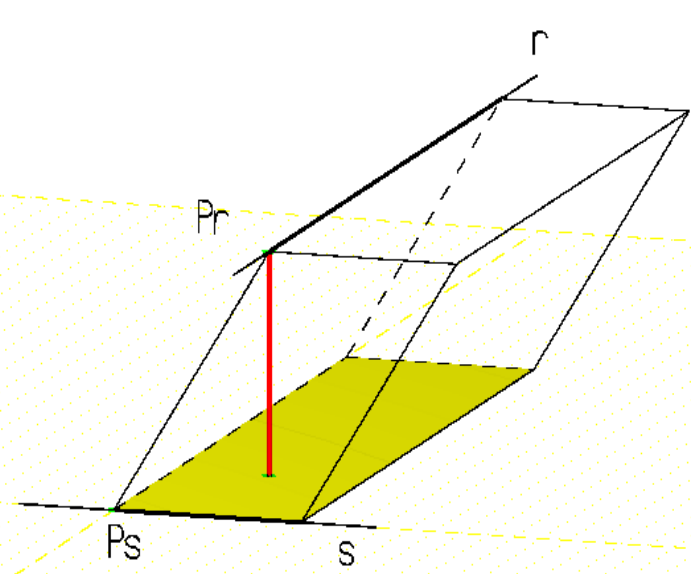

Figura 5.28 sabe expresarse sobre cuestiones matemáticas (CCn1), explica los cálculos y sus propiedades (CCn2) e interpreta las relaciones implicadas (CCn3).

El apartado c) del ejercicio que aparece en la ficha 5.28.1 se encuadra en el nivel de reproducción pues se trata de reproducción del conocimiento estudiado, con el manejo de fórmulas establecidas y realización de cálculos.

Comienza con el reconocimiento de la representación de los datos del ejercicio (RPRn1), planteando los algoritmos correspondientes (RPRn2) y asociándole con fórmulas establecidas y realizando cálculos (RPRn3). 
Como en el apartado b) del ejercicio se han calculado los puntos $R=(0,1,0)$ $R=(0,1,0)$ y $S=(0,1,2)$ de intersección de la recta perpendicular común a $r$ y $s$, el módulo del vector $\overrightarrow{R S}=(0,0,2)$ nos da la distancia entre ambas rectas.

$$
d(r, s)=|\overrightarrow{R S}|=2 u
$$

El alumno realiza operaciones elementales en contextos conocidos (RLSOn1), interpreta el lenguaje formal y simbólico rutinario (RLSOn2), maneja procedimientos y fórmulas, resolviendo y calculando (RLSOn3) y realiza ecuaciones y cálculos mediante procedimientos familiares (CLSOn3), justifica las fórmulas utilizadas y los resultados (RAn3), resuelve problemas rutinarios estandarizados (RRPn3), describe los resultados obtenidos (RCn3) y comunica de manera elemental los resultados del modelo (RMn3).

También puede usar la fórmula general para calcular la distancia entre dos rectas que se cruzan, en cuyo caso comienza con el reconocimiento de la representación de los datos del ejercicio (RPRn1), planteando los algoritmos correspondientes (RPRn2) y asociándole con fórmulas establecidas (RPRn3), productos de vectores: vectorial y mixto, con lo que el alumno realiza operaciones elementales en contextos conocidos (RLSOn1), interpreta el lenguaje formal y simbólico rutinario (RLSOn2), maneja procedimientos y fórmulas, resolviendo y calculando (RLSOn3) y utiliza variables y realiza ecuaciones y cálculos mediante procedimientos familiares (CLSOn3).

Identifica el problema (RAn1), comprende la expresión escrita (RCn1), identifica que el modelo es similar a otros modelos vistos con anterioridad, en la instrucción (RMn1), y le reconoce como problema ya practicado (RRPn1).

La distancia entre dos rectas se obtiene con la fórmula:

$$
d(r, s)=\frac{\left|\left[\overrightarrow{d_{r}}, \overrightarrow{d_{s}}, \overrightarrow{P_{r} P_{s}}\right]\right|}{\left|\overrightarrow{d_{r}} \times \overrightarrow{d_{s}}\right|}
$$

El módulo del producto mixto nos da el volumen del paralelepípedo determinado por los vectores $\overrightarrow{d_{r}}, \overrightarrow{d_{s}}$ y $\overrightarrow{P_{r} P_{s}}$ y el módulo del producto vectorial $\vec{d}_{r} \times \vec{d}_{s}$ nos da el área del paralelogramo determinado por los vectores $\overrightarrow{d_{r}}$ y $\overrightarrow{d_{s}}$.

Como Volumen = Área base $\times$ altura, despejando se obtiene: 


$$
\text { altura }=d(r, s)=\frac{\text { volumen }}{\text { Área base }}=\frac{\left|\left[\overrightarrow{d_{r}}, \overrightarrow{d_{s}} \overrightarrow{P_{r} P_{s}}\right]\right|}{\left|\overrightarrow{d_{r}} \times \overrightarrow{d_{s}}\right|}
$$

Justifica las fórmulas utilizadas y los resultados (RAn3).

Donde $\overrightarrow{d_{r}}$ es un vector director de la recta $r \equiv\left\{\begin{array}{l}y=1 \\ z=0\end{array}\right.$ y $\overrightarrow{d_{s}}$ es un vector director de la recta $s \equiv\left\{\begin{array}{l}x=0 \\ z=2\end{array}\right.$

En el apartado a) del problema se ha obtenido: Un vector director de la recta $r$, $\overrightarrow{d_{r}}=(1,0,0)$ y un punto de la recta $P_{r}=(0,1,0)$.

Un vector director de la recta $s, \overrightarrow{d_{s}}=(0,1,0)$ y un punto de la recta $P_{s}=(0,0,2)$.

El vector $\overrightarrow{P_{r} P_{s}}=(0,-1,2)$, formado por un punto de la recta $r$ y otro de la recta $s$.

El alumno realiza explicaciones sencillas ( $\mathrm{RCn} 2)$. A continuación expone el proceso de cálculo (RAn2), reproduce problemas ya practicados de manera cerrada (RRPn2) y comunica de manera elemental los resultados del modelo (RMn3).

$$
\begin{gathered}
{\left[\vec{d}_{r}, \vec{d}_{s}, \overrightarrow{P_{r} P_{s}}\right]=\left|\begin{array}{rrr}
1 & 0 & 0 \\
0 & 1 & 0 \\
0 & -1 & 2
\end{array}\right|=2} \\
\overrightarrow{d_{r}} \times \overrightarrow{d_{s}}=\left|\begin{array}{rrr}
\vec{i} & \vec{j} & \vec{k} \\
1 & 0 & 0 \\
0 & 1 & 0
\end{array}\right|=\vec{k} \Rightarrow \overrightarrow{d_{r}} \times \overrightarrow{d_{s}}=(0,0,1) \\
\text { Distancia }=d(r, s)=\frac{\left|\left[\overrightarrow{d_{r}}, \overrightarrow{d_{s}}, \overrightarrow{P_{r} P_{s}}\right]\right|}{\left|\overrightarrow{d_{r}} \times \overrightarrow{d_{s}}\right|}=\frac{2}{\sqrt{0^{2}+0^{2}+1^{2}}}=2 u
\end{gathered}
$$

Que, evidentemente, nos da el mismo resultado.

El alumno interpreta el lenguaje formal y simbólico rutinario (RLSOn2), potencia, raíz, cociente-, y maneja procedimientos y fórmulas, resolviendo y calculando (RLSOn3), utiliza variables y realiza cálculos mediante procedimien- 
tos familiares (CLSOn3), -módulo de un vector, determinantes-, justifica las fórmulas utilizadas y los resultados (RAn3), resuelve problemas rutinarios estandarizados (RRPn3), describe los resultados obtenidos (RCn3) y comunica de manera elemental los resultados del modelo (RMn3).

\begin{tabular}{|c|c|c|c|c|c|c|c|c|}
\hline \multicolumn{2}{|c|}{ FICHA 5.28.2. } & \multicolumn{7}{|c|}{ COMPETENCIAS IMPLÍCITAS EN LA RESOLUCIÓN DEL P28 } \\
\hline & Nivel 1 & Nivel 2 & Nivel 3 & Nivel 1 & Nivel 2 & Nivel 3 & Nivel 1 & Nivel 2 \\
\hline PR & * & * & * & * & * & * & & \\
\hline A & * & * & * & * & & & & \\
\hline C & * & * & * & * & * & * & & \\
\hline M & * & & * & & * & & & \\
\hline $\mathbf{R P}$ & * & * & * & & * & * & & \\
\hline $\mathbf{R}$ & & & & * & * & & & \\
\hline \multirow[t]{2}{*}{ LSO } & * & * & * & & & * & & \\
\hline & \multicolumn{3}{|c|}{ Reproducción } & \multicolumn{3}{|c|}{ Conexión } & \multicolumn{2}{|c|}{ Reflexión } \\
\hline
\end{tabular}

\section{VI.3.ESTUDIO DE LAS CUESTIONES DE GEOMETRÍA}

En este apartado se muestran 14 de las 61 cuestiones de Geometría que se han propuesto en las Pruebas de Acceso a las Universidades de Castilla y León en el periodo 1995-2009. El número es reducido dado que muchos ejercicios son repetitivos y se ha realizado la selección con criterios discriminatorios de variedad y nivel. En la estructura sigue la misma línea de los capítulos anteriores se presentan dos tablas para cada cuestión y el estudio y resolución del ejercicio.

\section{ANÁLISIS DE LA CUESTIÓN C1}

El ejercicio de la ficha 6.1 manda comprobar que unos puntos son vértices de un paralelogramo, para lo cual vamos a calcular los vectores determinados por esos puntos y a partir de dichos vectores comprobar lo que se pide y, a continuación, pide calcular un área, se trata pues de un ejercicio de reproducción.

El alumno comprende la expresión escrita (RCn1), identifica el problema (RAn1), identifica que el modelo es similar a otros vistos con anterioridad (RMn1) y le reconoce como problema ya practicado (RRPn1). 
FICHA 6.1.1.

ESTUDIO DEL ENUNCIADO DEL C1

C1.- Comprobar que los puntos $A=(3,2,2), B=(4,1,0), C=(0,1,1)$ y $D=(1,0,-1)$ son vértices de un paralelogramo y calcular su área.

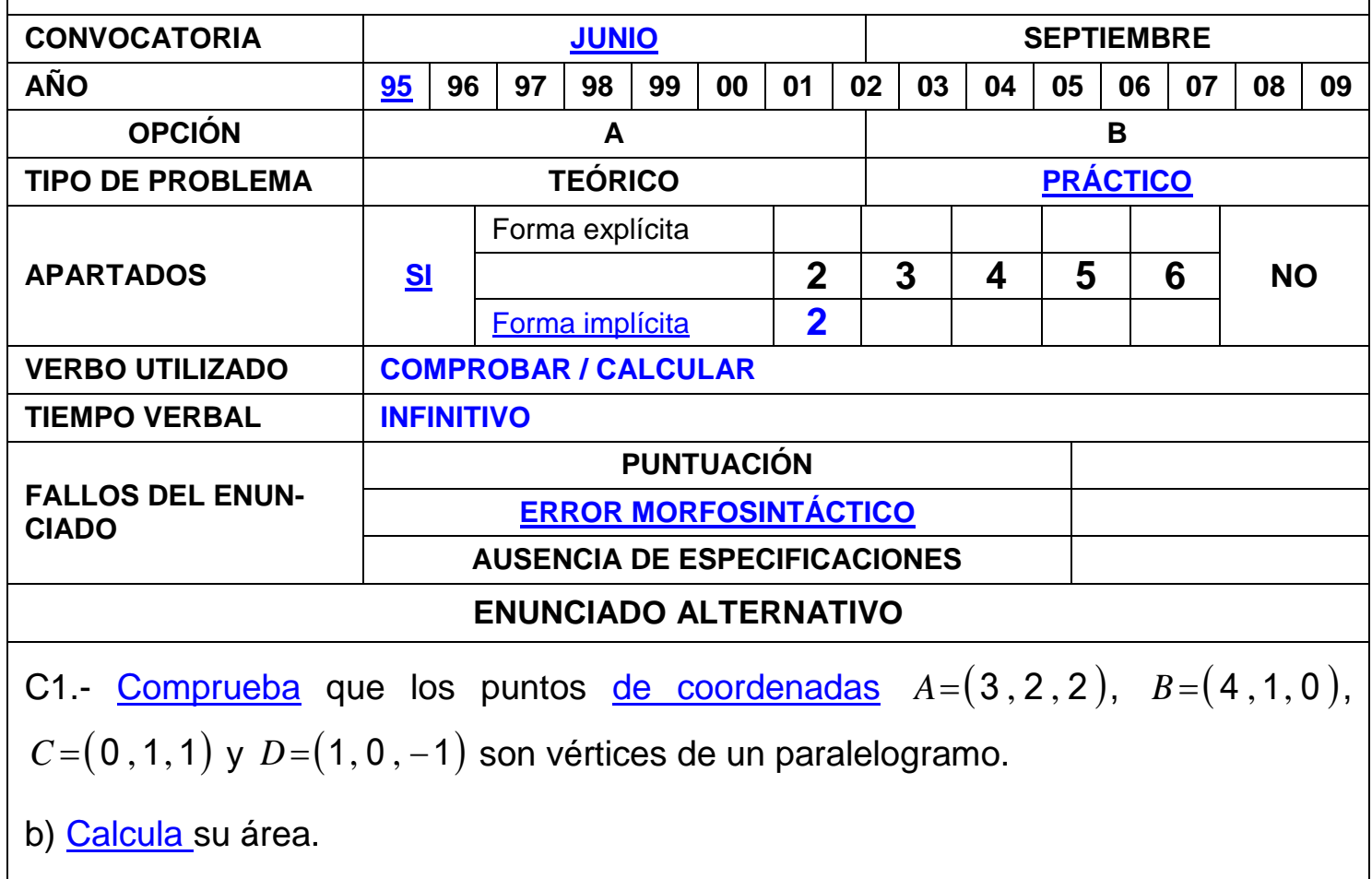

\section{NIVELES DE COMPETENCIAS IMPLÍCITAS: Reproducción}

El alumno interpreta representaciones estándar de objetos matemáticos $(\mathrm{RRn} 2)$, pasa de una representación a otra $(\mathrm{RRn3})$, la representación algebraica de los puntos mediante las coordenadas, reconoce representaciones de los datos del ejercicio (RPRn1), plantea los algoritmos correspondientes (RPRn2) y asocia con fórmulas establecidas (RPRn3).

Un vector director $\overrightarrow{A B}=(4-3,1-20-2)=(1,-1,-2)$

Otro vector $\overrightarrow{C D}=(1-0,0-1,-1-1)=(1,-1,-2)$

Luego los vectores $\overrightarrow{A B}$ y $\overrightarrow{C D}$ son paralelos, tienen la misma dirección y el mismo módulo

$$
|\overrightarrow{A B}|=|\overrightarrow{C D}|=\sqrt{1^{2}+(-1)^{2}+(-2)^{2}}=\sqrt{6} u
$$

Un vector director $\overrightarrow{A C}=(0-3,1-21-2)=(-3,-1,-1)$ 
Otro vector $\overrightarrow{D B}=(1-4,0-1,-1-0)=(-3,-1,-1)$

Luego los vectores $\overrightarrow{A C}$ y $\overrightarrow{D B}$ son paralelos, tienen la misma dirección y el mismo módulo

$$
|\overrightarrow{A C}|=|\overrightarrow{D B}|=\sqrt{(-3)^{2}+(-1)^{2}+(-1)^{2}}=\sqrt{11} u
$$

El alumno reproduce un problema ya practicado, de manera cerrada (RRPn2), expone el proceso de cálculo (RAn2), con lo que resuelve problemas rutinarios estandarizados (RRPn3).

En consecuencia, se trata de un paralelogramo.

A continuación realiza explicaciones sencillas ( $\mathrm{RCn} 2)$, describe los resultados obtenidos (RCn3), justifica las fórmulas utilizadas y los resultados (RAn3) y comunica de manera elemental los resultados del modelo (RMn3).

El apartado b) del ejercicio que aparece en la ficha 6.1.1 se incluye en el nivel de reproducción. Se trata de reproducción del conocimiento estudiado, con el manejo de fórmulas establecidas y realización de cálculos.

Comienza con el reconocimiento de la representación de los datos del ejercicio (RPRn1), planteando los algoritmos correspondientes (RPRn2), asociándole con fórmulas establecidas y realizando cálculos (RPRn3) -productos de vectores: vectorial y mixto-.

El alumno identifica el problema (RAn1), comprende la expresión escrita (RCn1), identifica que el modelo es similar a otros modelos vistos con anterioridad, en la instrucción (RMn1), y le reconoce como problema ya practicado (RRPn1).

Para calcular el área utilizamos la fórmula: Área $=|\overrightarrow{A C} \times \overrightarrow{C D}|$

A continuación, expone el proceso de cálculo (RAn2), realiza explicaciones sencillas $(\mathrm{RCn} 2)$, reproduce problemas ya practicados de manera cerrada (RRPn2), con lo que resuelve problemas rutinarios estandarizados (RRPn3).

$$
\overrightarrow{A C} \times \overrightarrow{C D}=\left|\begin{array}{rrr}
\vec{i} & \vec{j} & \vec{k} \\
-3 & -1 & -1 \\
1 & -1 & -2
\end{array}\right|=\vec{i}-7 \vec{j}+4 \vec{k}
$$




$$
\text { Área }=\sqrt{(1)^{2}+(-7)^{2}+4^{2}}=\sqrt{66} u^{2}
$$

El alumno realiza operaciones elementales en contextos conocidos (RLSOn1), interpreta el lenguaje formal y simbólico rutinario (RLSOn2), -potencia, raíz, cociente- maneja procedimientos y fórmulas resolviendo y calculando (RLSOn3) y utiliza variables y realiza ecuaciones y cálculos mediante procedimientos familiares (CLSOn3), como es el cálculo del determinante y el cálculo del módulo de un vector.

El alumno podía comprobar que los vectores $\overrightarrow{A C}=(-3,-1,-1)$ y $\overrightarrow{C D}=(1,-1,-2)$ son perpendiculares, lo que indica que el paralelogramo es un rectángulo y entonces el área del mismo se puede calcular mediante la fórmula

$$
\begin{gathered}
\text { Área }=|\overrightarrow{A C}| \times|\overrightarrow{C D}| \\
\text { Área }=\sqrt{11} \times \sqrt{6}=\sqrt{66} u^{2}
\end{gathered}
$$

Posteriormente, justifica las fórmulas utilizadas y los resultados (RAn3), comunica de manera elemental los resultados del modelo (RMn3).y describe los re-

\begin{tabular}{|c|c|c|c|c|c|c|c|c|}
\hline & Nivel 1 & Nivel 2 & Nivel 3 & Nivel 1 & Nivel 2 & Nivel 3 & Nivel 1 & Nivel 2 \\
\hline PR & * & * & * & & & & & \\
\hline A & * & * & * & & & & & \\
\hline C & * & * & * & & & & & \\
\hline$M$ & * & & * & & & & & \\
\hline $\mathbf{R P}$ & * & * & * & & & & & \\
\hline $\mathbf{R}$ & & * & * & & & & & \\
\hline LSO & * & * & * & & & * & & \\
\hline & \multicolumn{3}{|c|}{ Reproducción } & \multicolumn{3}{|c|}{ Conexión } & \multicolumn{2}{|c|}{ Reflexión } \\
\hline
\end{tabular}
sultados obtenidos (RCn3).

\section{FICHA 6.1.2. COMPETENCIAS IMPLÍCITAS EN LA RESOLUCIÓN DE LA C1}

\section{ANÁLISIS DE LA CUESTIÓN C5}

El ejercicio de la ficha 6.5.1 se trata de un ejercicio de reproducción, la ejecución de un problema rutinario, mediante la aplicación de destrezas técnicas y de algoritmos habituales, manejando expresiones y fórmulas establecidas y realizando cálculos. 


\begin{tabular}{|c|c|c|c|c|c|c|c|c|c|c|c|}
\hline FICHA 6.5.1. & \multicolumn{11}{|c|}{ ESTUDIO DEL ENUNCIADO DEL C5 } \\
\hline \multicolumn{12}{|c|}{ C5.- ¿Son coplanarios los puntos $A(1,0,0), B(0,1,0), C(2,1,0)$ y $D(-1,2,1)$ ? } \\
\hline CONVOCATORIA & \multicolumn{5}{|c|}{ JUNIO } & \multicolumn{6}{|c|}{ SEPTIEMBRE } \\
\hline AÑO & \begin{tabular}{|l|l|}
$\underline{95}$ & 96 \\
\end{tabular} & 97 & \begin{tabular}{l|l}
98 & 99 \\
\end{tabular} & 00 & 01 & \begin{tabular}{|l|l|}
02 & 03 \\
\end{tabular} & 04 & \begin{tabular}{l|l}
05 & 1 \\
\end{tabular} & \begin{tabular}{l|l|}
06 & 07 \\
\end{tabular} & 08 & 09 \\
\hline OPCIÓN & \multicolumn{5}{|c|}{ A } & \multicolumn{6}{|c|}{ B } \\
\hline TIPO DE PROBLEMA & \multicolumn{5}{|c|}{ TEÓRICO } & \multicolumn{6}{|c|}{ PRÁCTICO } \\
\hline \multirow{3}{*}{ APARTADOS } & \multirow{3}{*}{ SI } & Forma & explícita & & & & & & & \multirow{3}{*}{\multicolumn{2}{|c|}{$\underline{\text { NO }}$}} \\
\hline & & & & & 2 & 3 & 4 & 5 & 6 & & \\
\hline & & Forma & implícita & & & & & & & & \\
\hline VERBO UTILIZADO & \multicolumn{11}{|l|}{ SER } \\
\hline TIEMPO VERBAL & \multicolumn{11}{|c|}{ PRESENTE DE INDICATIVO } \\
\hline \multirow{3}{*}{$\begin{array}{l}\text { FALLOS DEL ENUN- } \\
\text { CIADO }\end{array}$} & \multicolumn{7}{|c|}{ PUNTUACIÓN } & & & & \\
\hline & \multicolumn{7}{|c|}{ ESTRUCTURA SINTÁCTICA DE LA ORACIÓN } & & & & \\
\hline & \multicolumn{7}{|c|}{ AUSENCIA DE ESPECIFICACIONES } & & & & \\
\hline \multicolumn{12}{|c|}{ ENUNCIADO ALTERNATIVO } \\
\hline \multicolumn{12}{|c|}{$\begin{array}{l}\text { C5.- Dados los puntos } A, B, C \text { y } D \text {, de coordenadas, } A(1,0,0), B(0,1,0) \text {, } \\
C(2,1,0) \text { y } D(-1,2,1) \text { razona si son coplanarios. }\end{array}$} \\
\hline
\end{tabular}

El alumno reconoce representaciones de los datos del ejercicio (RPRn1), identifica el problema (RAn1), comprende la expresión escrita (RCn1), identifica que el modelo es similar a otros vistos con anterioridad (RMn1) y le reconoce como problema ya practicado (RRPn1).

A continuación interpreta representaciones estándar de objetos matemáticos (RRn2), los puntos mediante sus coordenadas, pasa de una representación a otra (RRn3) e interpreta formas de representación (CRn1), algebraica, geométrica, gráfica; plantea los algoritmos correspondientes (RPRn2) y asocia con fórmulas establecidas (RPRn3).

El alumno expone el proceso de cálculo (RAn2).

Para estudiar si los puntos son coplanarios comprueba si los vectores $\overrightarrow{A D}$, $\overrightarrow{B D}$ y $\overrightarrow{C D}$ son linealmente independientes, para lo cual calcula el valor del determinante cuyas filas son las coordenadas de esos vectores.

Realiza explicaciones sencillas (RCn2) y reproduce un problema ya practicado, de manera cerrada (RRPn2). 


$$
\begin{aligned}
& \overrightarrow{A D}=(-2,2,1), \overrightarrow{B D}=(-1,1,1), \overrightarrow{C D}=(-3,1,1) \\
& \left|\begin{array}{rrr}
-2 & 2 & 1 \\
-1 & 1 & 1 \\
-3 & 1 & 1
\end{array}\right|=-2 \neq\left. 0 \quad\right|^{z}
\end{aligned}
$$

El alumno realiza operaciones elementales en contextos conocidos (RLSOn1), interpreta el lenguaje formal y simbólico rutinario (RLSOn2), maneja procedimientos y fórmulas resolviendo y calculando (RLSOn3) y utiliza variables y realiza ecuaciones $y$ cálculos mediante procedimientos familiares (CLSOn3), el cálculo de vectores y el producto escalar de los mismos.

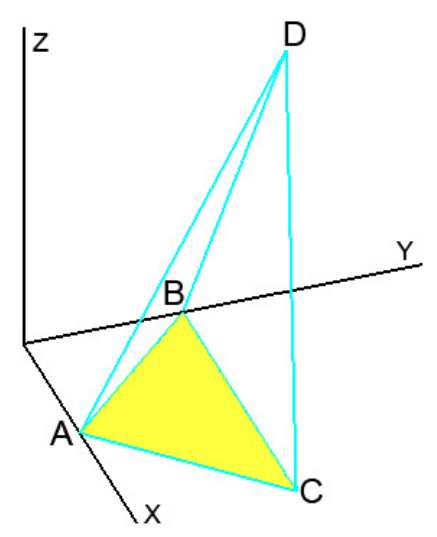

Figura 6.5

Como el valor del determinante es distinto de cero, los puntos no están alineados. Figura 6.5.

El alumno justifica las fórmulas utilizadas y los resultados (RAn3), con lo que resuelve problemas rutinarios estandarizados (RRPn3), comunica de manera elemental los resultados del modelo (RMn3) y describe los resultados obtenidos (RCn3).

\begin{tabular}{|l|l|l|l|l|l|l|l|l|}
\hline \multicolumn{6}{|c|}{ FICHA 6.5.2. COMPETENCIAS IMPLÍCITAS EN LA RESOLUCIÓN DE LA C5 } \\
\hline & Nivel 1 & Nivel 2 & Nivel 3 & Nivel 1 & Nivel 2 & Nivel 3 & Nivel 1 & Nivel 2 \\
\hline PR & $*$ & $*$ & $*$ & & & & & \\
\hline A & $*$ & $*$ & $*$ & & & & & \\
\hline C & $*$ & $*$ & $*$ & & & & & \\
\hline M & $*$ & & $*$ & & & & & \\
\hline RP & $*$ & $*$ & $*$ & & & & & \\
\hline R & & $*$ & $*$ & $*$ & & & & \\
\hline LSO & $*$ & $*$ & $*$ & & & $*$ & & \\
\hline & Reproducción & & Conexión & & Reflexión \\
\hline
\end{tabular}

\section{ANÁLISIS DE LA CUESTIÓN C10}

La cuestión de la ficha 6.10.1 es un ejercicio que se encuadra en el nivel de reproducción. 
FICHA 6.10.1.

ESTUDIO DEL ENUNCIADO DEL C10

C10.- ¿Se puede encontrar un punto sobre la recta

$$
\frac{x}{2}=\frac{y-1}{3}=\frac{z+2}{-1}
$$

que diste 4 unidades del plano $x-y-z+2=0$ ? Interpreta el resultado obtenido.

\begin{tabular}{|c|c|c|c|c|c|c|c|c|c|c|c|c|c|c|}
\hline CONVOCATORIA & \multicolumn{7}{|c|}{ JUNIO } & \multicolumn{7}{|c|}{ SEPTIEMBRE } \\
\hline AÑO & 95 & $\underline{96}$ & 97 & 98 & 99 & 00 & 01 & $02 \quad 03$ & 04 & 05 & 06 & 07 & 08 & 09 \\
\hline OPCIÓN & \multicolumn{7}{|c|}{ A } & \multicolumn{7}{|c|}{ B } \\
\hline TIPO DE PROBLEMA & \multicolumn{7}{|c|}{ TEÓRICO } & \multicolumn{7}{|c|}{ PRÁCTICO } \\
\hline \multirow{3}{*}{ APARTADOS } & \multirow{3}{*}{\multicolumn{2}{|c|}{ SI }} & \multicolumn{4}{|c|}{ Forma explícita } & & & & & & \multirow[b]{2}{*}{6} & \multirow{3}{*}{\multicolumn{2}{|c|}{$\underline{\text { NO }}$}} \\
\hline & & & & & & & 2 & 3 & 4 & 5 & & & & \\
\hline & & & \multicolumn{4}{|c|}{ Forma implícita } & & & & & & & & \\
\hline VERBO UTILIZADO & \multicolumn{14}{|c|}{ PODER ENCONTRAR } \\
\hline TIEMPO VERBAL & \multicolumn{14}{|c|}{ PERÍFRASIS DE INFINITIVO } \\
\hline \multirow{3}{*}{$\begin{array}{l}\text { FALLOS DEL ENUN- } \\
\text { CIADO }\end{array}$} & \multicolumn{9}{|c|}{ PUNTUACIÓN } & & & & & \\
\hline & \multicolumn{9}{|c|}{ ESTRUCTURA DE LA ORACIÓN } & & & & & \\
\hline & \multicolumn{9}{|c|}{ AUSENCIA DE ESPECIFICACIONES } & & & & & \\
\hline \multicolumn{15}{|c|}{ ENUNCIADO ALTERNATIVO } \\
\hline
\end{tabular}

C10.- Dada la recta $r$ de ecuaciones: $r \equiv \frac{x}{2}=\frac{y-1}{3}=\frac{z+2}{-1}$, encuentra un punto de la misma que diste 4 unidades del plano $\pi$ de ecuación: $\pi \equiv x-y-z+2=0$, si es posible. Interpreta el resultado obtenido.

NIVELES DE COMPETENCIAS IMPLÍCITAS: Reproducción

El alumno comprende la expresión escrita $(\mathrm{RCn} 1)$, reconoce representaciones de los datos del ejercicio (RPRn1), las ecuaciones de la recta y el plano, identifica el problema (RAn1), identifica que el modelo es similar a otros vistos con anterioridad (RMn1) y le reconoce como problema ya practicado (RRPn1).

A continuación interpreta representaciones estándar de objetos matemáticos (RRn2), la expresión algebraica de las ecuaciones de la recta y el plano, pasa de una representación a otra (RRn3), y en consecuencia, plantea los algoritmos correspondientes (RPRn2) y asocia con fórmulas establecidas (RPRn3).

Un punto genérico de la recta es $P=(2 \lambda, 1+3 \lambda,-2-\lambda)$

El alumno expone el proceso de cálculo (RAn2), realiza explicaciones sencillas (RCn2) y reproduce un problema ya practicado, de manera cerrada (RRPn2). 
La distancia del punto al plano se obtiene mediante la fórmula:

$$
\frac{|2 \lambda-(1+3 \lambda)-(-2-\lambda)+2|}{\sqrt{1^{2}+(-1)^{2}+(-1)^{2}}}=\frac{3}{\sqrt{3}}=\sqrt{3}
$$

El alumno realiza operaciones elementales en contextos conocidos (RLSOn1), interpreta el lenguaje formal y simbólico rutinario (RLSOn2), maneja procedimientos y fórmulas resolviendo y calculando (RLSOn3) y utiliza variables y realiza ecuaciones y cálculos mediante procedimientos familiares (CLSOn3), el módulo del vector.

No existe ningún punto de la recta $\frac{x}{2}=\frac{y-1}{3}=\frac{z+2}{-1}$ cuya distancia al plano $x-y-z+2=0$ sea 4 , dado que la recta es paralela al plano y su distancia es siempre $\sqrt{3}$.

El alumno justifica las fórmulas utilizadas y los resultados (RAn3), con lo que resuelve problemas rutinarios estandarizados (RRPn3), comunica de manera elemental los resultados del modelo (RMn3) y describe los resultados obtenidos (RCn3).

El vector director de la recta es perpendicular al vector normal del plano, pues el producto escalar de ambos vectores es 0 .

$$
(2,3,-1) \cdot(1,-1,-1)=0
$$

Este razonamiento indica que el alumno sabe expresarse sobre cuestiones matemáticas (CCn1), explica los cálculos y sus propiedades (CCn2) e interpreta las relaciones implicadas (CCn3).

\section{FICHA 6.10.2. COMPETENCIAS IMPLÍCITAS EN LA RESOLUCIÓN DE LA C10}

\begin{tabular}{|l|c|c|c|c|c|c|c|c|}
\hline & Nivel 1 & Nivel 2 & Nivel 3 & Nivel 1 & Nivel 2 & Nivel 3 & Nivel 1 & Nivel 2 \\
\hline PR & $*$ & $*$ & $*$ & & & & & \\
\hline A & $*$ & $*$ & $*$ & & & & & \\
\hline C & $*$ & $*$ & $*$ & $*$ & $*$ & $*$ & & \\
\hline M & $*$ & & $*$ & & & & & \\
\hline RP & $*$ & $*$ & $*$ & & & & & \\
\hline R & & $*$ & $*$ & & & & & \\
\hline LSO & $*$ & $*$ & $*$ & & & $*$ & & \multicolumn{2}{l|}{ Reflexión } \\
\hline
\end{tabular}




\section{ANÁLISIS DE LA CUESTIÓN C14}

\section{FICHA 6.14.1. \\ ESTUDIO DEL ENUNCIADO DEL C14}

C14.- En $R^{4}$ se consideran los vectores $(5,1,2,-1),(4,3,4,-3)$ y $(2,6,3,-2)$. Comprobar que son linealmente independientes y encontrar un cuarto vector que forme con ellos una base de $R^{4}$.

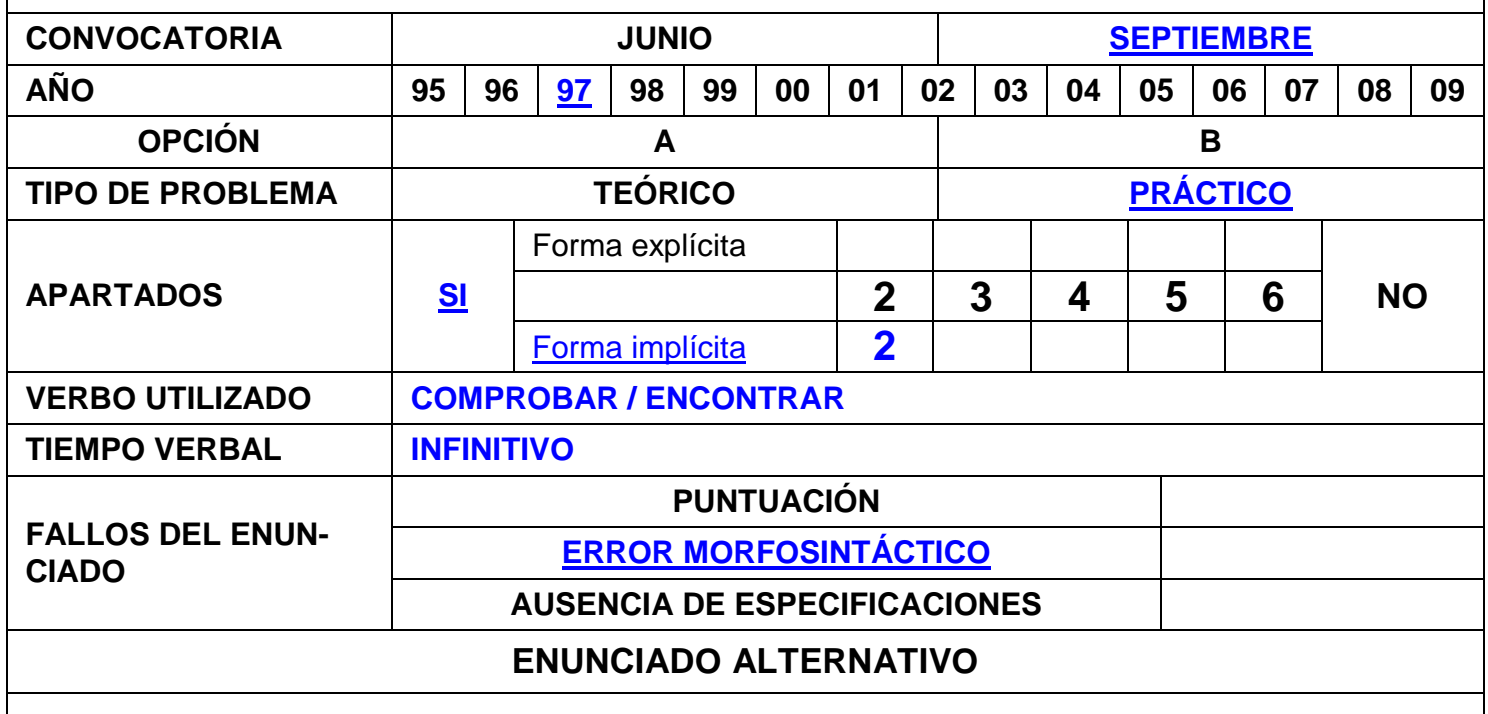

C14.- En $R^{4}$ se consideran los vectores de coordenadas $(5,1,2,-1)$, $(4,3,4,-3)$ y $(2,6,3,-2)$. Comprueba que son linealmente independientes.

b) Escribe las coordenadas de un cuarto vector que forme con ellos una base de $R^{4}$ NIVELES DE COMPETENCIAS IMPLÍCITAS: Reproducción

El ejercicio de la ficha 6.14.1 es un ejercicio que se encuadra en el nivel de reproducción, es la ejecución de un problema rutinario, mediante la aplicación de destrezas técnicas y de algoritmos habituales, manejando expresiones y fórmulas establecidas y realizando cálculos.

El alumno comprende la expresión escrita (RCn1), los vectores, reconoce representaciones de los datos del ejercicio (RPRn1).

El alumno identifica el problema (RAn1), identifica que el modelo es similar a otros vistos con anterioridad (RMn1) y le reconoce como problema ya practicado (RRPn1). Asimismo, interpreta representaciones estándar de objetos matemáticos (RRn2), los vectores representados por sus coordenadas, en lenguaje algebraico y pasa de una representación a otra (RRn3), 
A continuación plantea los algoritmos correspondientes (RPRn2) y asocia con fórmulas establecidas (RPRn3).

Para estudiar si los vectores son linealmente independientes, calcula el rango de la matriz cuyas filas son las coordenadas de esos vectores.

$$
\left(\begin{array}{llll}
5 & 1 & 2 & -1 \\
4 & 3 & 4 & -3 \\
2 & 6 & 3 & -2
\end{array}\right)
$$

El alumno expone el proceso de cálculo (RAn2), realiza explicaciones sencillas $(\mathrm{RCn} 2)$ y reproduce un problema ya practicado, de manera cerrada (RRPn2).

$$
\left|\begin{array}{ccc}
1 & 2 & -1 \\
3 & 4 & -3 \\
6 & 3 & -2
\end{array}\right|=-8 \neq 0
$$

El alumno realiza operaciones elementales en contextos conocidos (RLSOn1), interpreta el lenguaje formal y simbólico rutinario (RLSOn2), maneja procedimientos y fórmulas resolviendo y calculando (RLSOn3) y utiliza variables y realiza ecuaciones y cálculos mediante procedimientos familiares (CLSOn3), el cálculo del determinante.

Como el valor del determinante es distinto de cero, el rango de la matriz es 3, por tanto los vectores son linealmente independientes.

Hay infinitas soluciones para encontrar un cuarto vector que forme base con los tres dados, es decir, un vector linealmente independiente de los dados.

La forma más sencilla es elegir el vector $(1,0,0,0)$, pues desarrollando el determinante $\left|\begin{array}{rrrr}5 & 1 & 2 & -1 \\ 4 & 3 & 4 & -3 \\ 2 & 6 & 3 & -2 \\ 1 & 0 & 0 & 0\end{array}\right|$ por los adjuntos de la $F_{4}$, el resultado será:

$$
\left|\begin{array}{rrrr}
5 & 1 & 2 & -1 \\
4 & 3 & 4 & -3 \\
2 & 6 & 3 & -2 \\
1 & 0 & 0 & 0
\end{array}\right|=(-1) \cdot\left|\begin{array}{rrr}
1 & 2 & -1 \\
3 & 4 & -3 \\
6 & 3 & -2
\end{array}\right|=8 \neq 0
$$

El alumno justifica las fórmulas utilizadas y los resultados (RAn3), con lo que resuelve problemas rutinarios estandarizados (RRPn3), comunica de manera 
elemental los resultados del modelo (RMn3) y describe los resultados obtenidos (RCn3).

\begin{tabular}{|l|c|c|c|c|c|c|c|c|}
\hline \multicolumn{6}{|c|}{ FICHA 6.14.2. COMPETENCIAS IMPLíCITAS EN LA RESOLUCIÓN DE LA C14 } \\
\hline & Nivel 1 & Nivel 2 & Nivel 3 & Nivel 1 & Nivel 2 & Nivel 3 & Nivel 1 & Nivel 2 \\
\hline PR & $*$ & $*$ & $*$ & & & & & \\
\hline A & $*$ & $*$ & $*$ & & & & & \\
\hline C & $*$ & $*$ & $*$ & & & & & \\
\hline M & $*$ & & $*$ & & & & & \\
\hline RP & $*$ & $*$ & $*$ & & & & & \\
\hline R & & $*$ & $*$ & & & & & \\
\hline LSO & $*$ & $*$ & $*$ & & & $*$ & & \\
\hline & Reproducción & & Conexión & & Reflexión \\
\hline
\end{tabular}

\section{ANÁLISIS DE LA CUESTIÓN C20}

La cuestión que aparece en la ficha 6.20.1 es un ejercicio que se encuadra en el nivel de reproducción, es la ejecución de un problema rutinario, mediante la aplicación de destrezas técnicas y de algoritmos habituales, manejando expresiones y fórmulas establecidas y realizando cálculos.

Comienza con el reconocimiento de la representación de los datos del ejercicio (RPRn1), identifica el problema (RAn1) y comprende la expresión escrita (RCn1), interpreta representaciones estándar de objetos matemáticos (RRn2) y pasa de una representación a otra (RRn3).

Dado que las ecuaciones de la recta $r$ están dadas en forma continua,

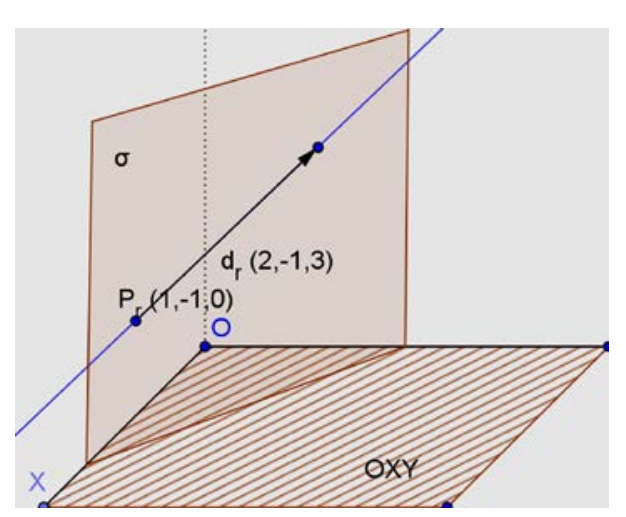

Figura 6.20

$$
r \equiv \frac{x-1}{2}=\frac{y+1}{-1}=\frac{z}{3}
$$

con su expresión se obtiene el vector director: $\vec{d}_{r}=(2,-1,3)$ y un punto, por ejemplo, $P_{r}=(1,-1,0)$.

El alumno identifica que el modelo es similar a otros modelos vistos con anterioridad, en la instrucción (RMn1). 


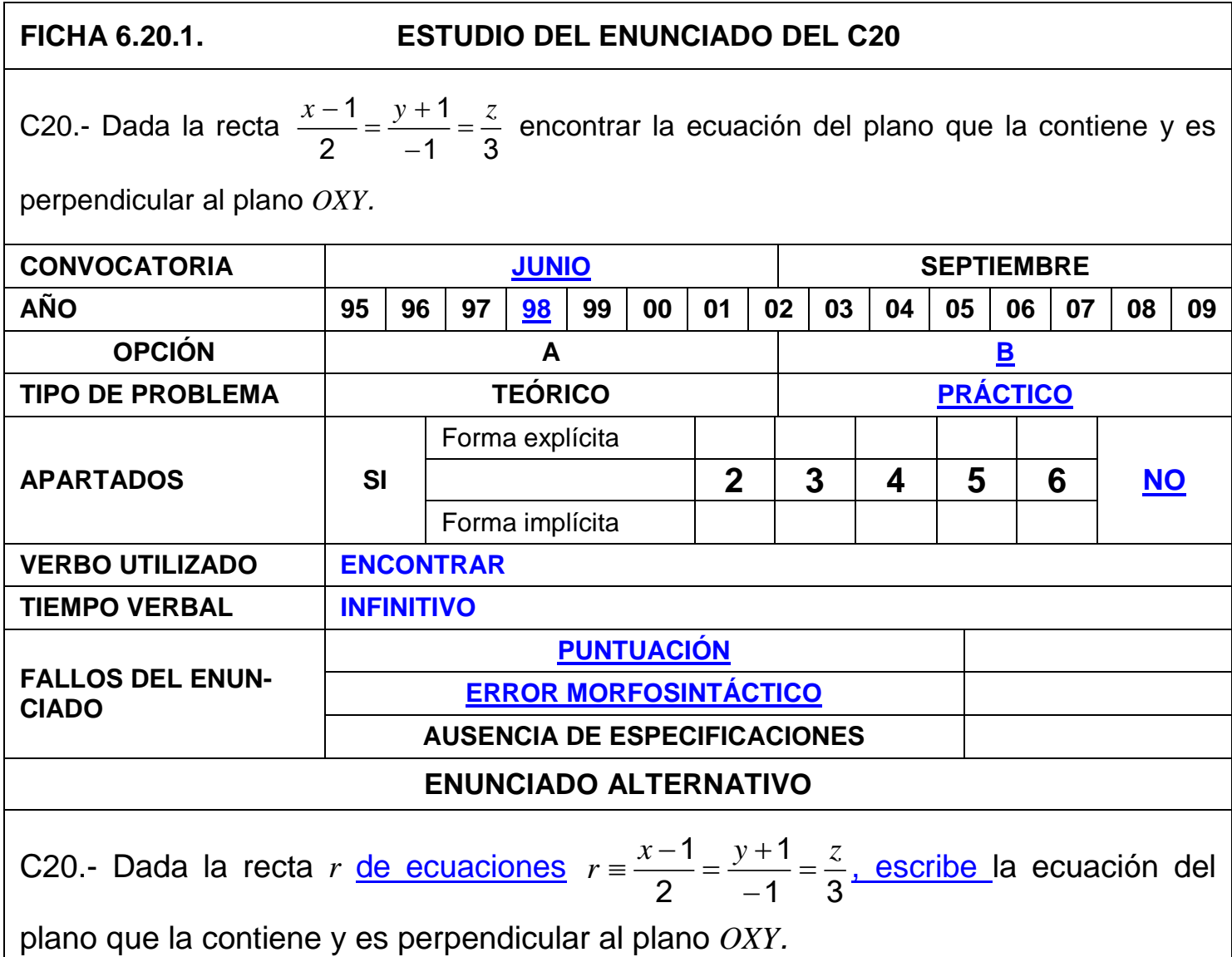

NIVELES DE COMPETENCIAS IMPLÍCITAS: Reproducción y conexión

Le reconoce como problema ya practicado (RRPn1), piensa en el tratamiento matemático necesario (CPRn1), comprende que tiene que emplear conceptos matemáticos intermedios (CPRn2), y aplica esos conceptos matemáticos apropiados (CPRn3).

El plano $\sigma$ contiene a la recta $r \equiv \frac{x-1}{2}=\frac{y+1}{-1}=\frac{z}{3}$,

luego contiene a todos los puntos de la recta, entre ellos al $P_{r}$ y al vector $\vec{d}_{r}=(2,-1,3)$.

Como el plano $\sigma$, cuya ecuación se pide, tiene que ser perpendicular al plano $O X Y$, cuya ecuación es: $z=0$, contiene a un vector equipolente al vector normal del plano $O X Y, \overrightarrow{n_{\pi}}(0,0,1)$.

Plantea los algoritmos correspondientes (RPRn2) y le asocia con fórmulas establecidas y realiza los cálculos (RPRn3), a la par que expone el proceso de cálculo (RAn2). 
Entre las distintas fórmulas que se tienen para calcular la ecuación del plano pedido, utiliza:

$$
\operatorname{det}\left(\vec{P}_{r} X, \vec{d}_{r}, \vec{n}_{\pi}\right)=0
$$

El alumno, realiza explicaciones sencillas $(\mathrm{RCn} 2)$, reproduce problemas ya practicados de manera cerrada (RRPn2), eligiendo y aplicando las estrategias apropiadas que conexionen áreas matemáticas (CRPn2, CRPn3), -álgebra y geometría-.y comunica de manera elemental los resultados del modelo (RMn3).

$$
\operatorname{det}\left(\overrightarrow{P_{r} X}, \vec{d}_{r}, \vec{n}_{\pi}\right)=\left|\begin{array}{ccc}
x-1 & y+1 & z-0 \\
2 & -1 & 3 \\
0 & 0 & 1
\end{array}\right|=0
$$

Desarrollando el determinante y realizando operaciones, obtiene la expresión que da la ecuación general del plano:

$$
\sigma \equiv x+2 y-2=0
$$

En este proceso, el alumno maneja procedimientos y fórmulas, resolviendo y calculando (RLSOn3), utiliza variables y realiza ecuaciones y cálculos mediante procedimientos familiares (CLSOn3), comunica de manera elemental los resultados del modelo (RMn3), justifica las fórmulas utilizadas y los resultados

\begin{tabular}{|c|c|c|c|c|c|c|c|c|}
\hline \multicolumn{2}{|c|}{ FICHA 6.20.2. } & \multicolumn{7}{|c|}{ COMPETENCIAS IMPLÍCITAS EN LA RESOLUCIÓN DE LA C20 } \\
\hline & Nivel 1 & Nivel 2 & Nivel 3 & Nivel 1 & Nivel 2 & Nivel 3 & Nivel 1 & Nivel 2 \\
\hline PR & * & * & * & * & * & * & & \\
\hline A & * & * & * & & & & & \\
\hline C & * & * & * & & & & & \\
\hline M & * & & * & & & & & \\
\hline RP & * & * & * & & * & * & & \\
\hline $\mathbf{R}$ & & * & * & & & & & \\
\hline LSO & & & * & & & * & & \\
\hline & \multicolumn{3}{|c|}{ Reproducción } & \multicolumn{3}{|c|}{ Conexión } & \multicolumn{2}{|c|}{ Reflexión } \\
\hline
\end{tabular}
(RAn3), describe los resultados obtenidos (RCn3) y resuelve problemas rutinarios estandarizados (RRPn3). 


\section{ANÁLISIS DE LA CUESTIÓN C26}

\begin{tabular}{|c|c|c|c|c|c|c|c|c|c|c|c|c|c|c|}
\hline \multicolumn{15}{|l|}{ FICHA 6.26.1. } \\
\hline \multicolumn{15}{|c|}{$\begin{array}{l}\text { C26.- Sean } A\left(x_{1}, y_{1}, z_{1}\right), B\left(x_{2}, y_{2}, z_{2}\right) \text { dos puntos del plano } a x+b y+c z+d=0 \text {. Demos- } \\
\text { trar que el vector } \vec{n}(a, b, c) \text { es perpendicular al vector } \overrightarrow{A B} \text {. }\end{array}$} \\
\hline CONVOCATORIA & \multicolumn{7}{|c|}{ JUNIO } & \multicolumn{7}{|c|}{ SEPTIEMBRE } \\
\hline AÑO & \begin{tabular}{l|l}
95 & 96
\end{tabular} & 97 & 98 & $\underline{99}$ & 00 & 01 & 02 & 03 & 04 & 05 & 06 & 07 & 08 & 09 \\
\hline OPCIÓN & \multicolumn{7}{|c|}{ A } & \multicolumn{7}{|c|}{ B } \\
\hline TIPO DE PROBLEMA & \multicolumn{6}{|c|}{ TEÓRICO } & \multicolumn{8}{|c|}{ PRÁCTICO } \\
\hline \multirow{3}{*}{ APARTADOS } & \multirow{3}{*}{ SI } & \multirow{2}{*}{\multicolumn{4}{|c|}{ Forma explícita }} & & & & & & & \multirow[b]{2}{*}{6} & \multirow{3}{*}{\multicolumn{2}{|c|}{ NO }} \\
\hline & & & & & & 2 & & 3 & 4 & 5 & & & & \\
\hline & & \multicolumn{4}{|c|}{ Forma implícita } & & & & & & & & & \\
\hline VERBO UTILIZADO & \multicolumn{14}{|c|}{ DEMOSTRAR } \\
\hline TIEMPO VERBAL & \multicolumn{14}{|c|}{ INFINITVO } \\
\hline \multirow{3}{*}{$\begin{array}{l}\text { FALLOS DEL ENUN- } \\
\text { CIADO }\end{array}$} & \multicolumn{9}{|c|}{ PUNTUACIÓN } & & & & & \\
\hline & \multicolumn{9}{|c|}{ ERROR MORFOSINTÁCTICO } & & & & & \\
\hline & \multicolumn{9}{|c|}{ AUSENCIA DE ESPECIFICACIONES } & & & & & \\
\hline \multicolumn{15}{|c|}{ ENUNCIADO ALTERNATIVO } \\
\hline \multicolumn{15}{|c|}{$\begin{array}{l}\text { C26.- Sean } A\left(x_{1}, y_{1}, z_{1}\right), B\left(x_{2}, y_{2}, z_{2}\right) \text {, dos puntos del plano } a x+b y+c z+d=0 \text {. } \\
\text { Demuestra que el vector } \vec{n}(a, b, c) \text { es perpendicular al vector } \overrightarrow{A B} \text {. }\end{array}$} \\
\hline
\end{tabular}

La cuestión de la ficha 6.26.1 es teórica, corresponde pues al nivel de reproducción, es la ejecución de un problema rutinario, mediante la aplicación de destrezas técnicas y de algoritmos habituales, manejando expresiones y fórmulas establecidas y realizando cálculos.

El alumno identifica el problema (RAn1), comprende la expresión escrita (RCn1), puntos, vectores, la ecuación del plano, reconoce el problema como ya practicado (RRPn1), identifica que es un modelo similar a otros vistos con anterioridad (RMn1), plantea los algoritmos correspondientes (RPRn2), asocia con fórmulas establecidas y realiza cálculos (RPRn3).

A continuación, realiza explicaciones sencillas (RCn2) y expone el proceso de cálculo (RAn2).

Para que el vector $\vec{n}(a, b, c)$ sea perpendicular al vector $\overrightarrow{A B}$ el producto esca$\operatorname{lar} \vec{n} \cdot \overrightarrow{A B}=0$ 
$\vec{n} \cdot \overrightarrow{A B}=(a, b, c) \cdot\left(x_{2}-x_{1}, y_{2}-y_{1}, z_{2}-z_{1}\right) \stackrel{(1)}{=} a \cdot\left(x_{2}-x_{1}\right)+b \cdot\left(y_{2}-y_{1}\right)+c \cdot\left(z_{2}-z_{1}\right)^{(2)}=$

$=a \cdot x_{2}-a \cdot x_{1}+b \cdot y_{2}-b \cdot y_{1}+c \cdot z_{2}-c \cdot z_{1}=\left(a \cdot x_{2}+b \cdot y_{2}+c \cdot z_{2}\right)-\left(a \cdot x_{1}+b \cdot y_{1}+c \cdot z_{1}\right) \stackrel{(3)}{=}$ $=d-d=0$

(1) Definición de producto escalar.

(2) Propiedad distributiva.

(3) Como los puntos $A\left(x_{1}, y_{1}, z_{1}\right)$ y $B\left(x_{2}, y_{2}, z_{2}\right)$ pertenecen al plano, cumplen su ecuación.

El alumno interpreta el lenguaje formal y simbólico rutinario (RLSOn2), maneja procedimientos y fórmulas resolviendo y calculando (RLSOn3).

A continuación describe los resultados obtenidos (RCn3), justifica las fórmulas utilizadas (RAn3) y reproduce problemas ya practicados, de manera cerrada (RRPn2). De esta manera resuelve problemas rutinarios estandarizados (RRPn3) y comunica de manera elemental los resultados (RMn3).

FICHA 6.26.2. COMPETENCIAS IMPLÍCITAS EN LA RESOLUCIÓN DE LA C26

\begin{tabular}{|l|c|c|c|c|c|c|c|c|}
\hline & Nivel 1 & Nivel 2 & Nivel 3 & Nivel 1 & Nivel 2 & Nivel 3 & Nivel 1 & Nivel 2 \\
\hline PR & $*$ & $*$ & $*$ & & & & & \\
\hline A & $*$ & $*$ & $*$ & & & & & \\
\hline C & $*$ & $*$ & $*$ & & & & & \\
\hline M & $*$ & & $*$ & & & & & \\
\hline RP & $*$ & $*$ & $*$ & & & & & \\
\hline R & & & & & & & & \\
\hline LSO & & $*$ & $*$ & & & & & \\
\hline & \multicolumn{2}{|l|}{ Reproducción } & & Conexión & & \multicolumn{2}{l|}{ Reflexión } \\
\hline
\end{tabular}

\section{ANÁLISIS DE LA CUESTIÓN C27}

La cuestión de la ficha 6.27.1 corresponde a los niveles de conexión y reflexión. En el nivel de conexión, pues este es un problema que reproduce situaciones similares pero que ya no son de mera rutina, dado que tiene que trabajar con parámetros.

El alumno tiene que pensar en el tratamiento matemático necesario (CPRn1), escribir la relación de dependencia entre los tres vectores-, razonar matemáti- 
camente de manera simple (CAn1) y estructurar la situación que debe modelizar (CMn1).

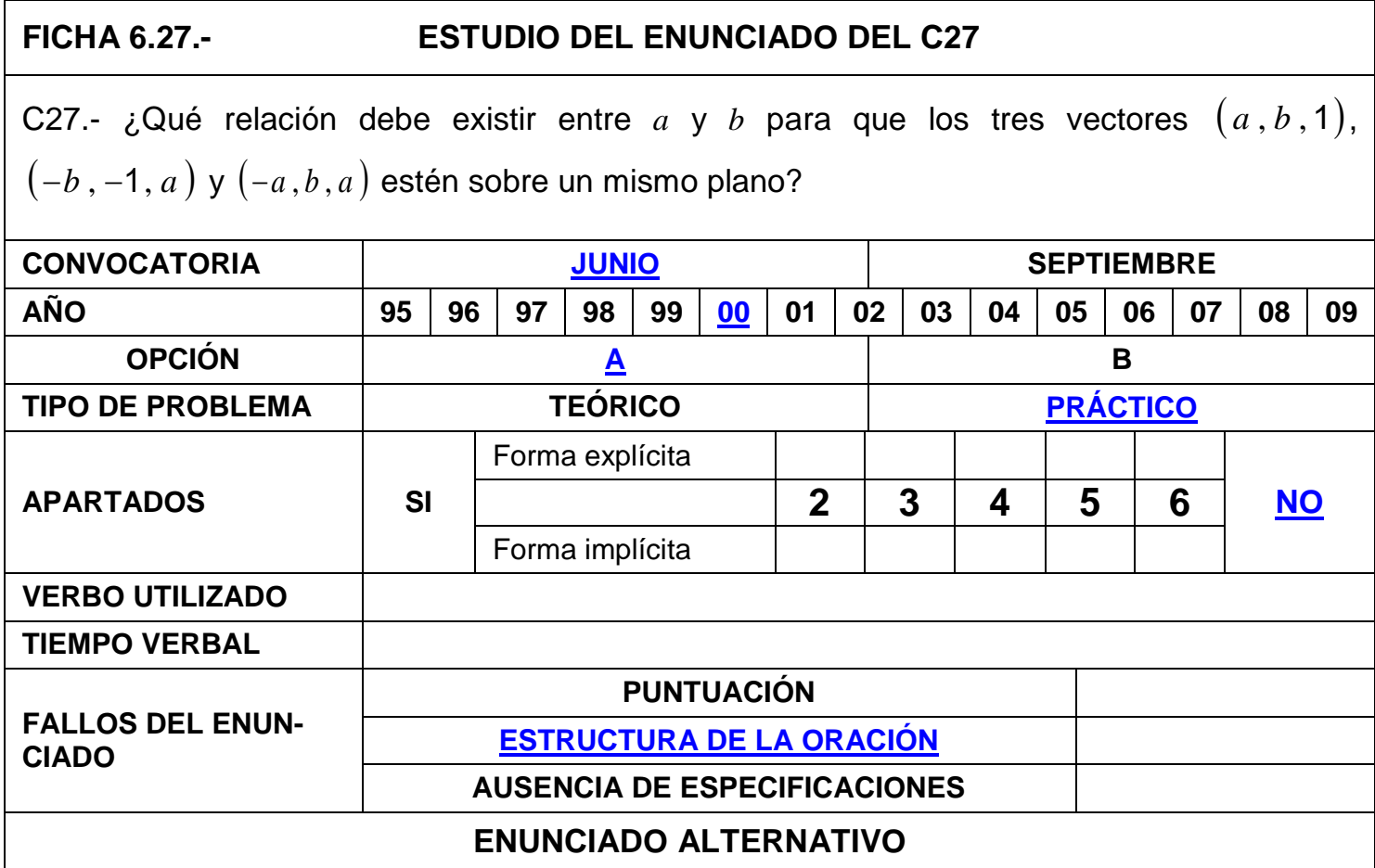

C27.- Escribe la relación que debe existir entre $a$ y $b$ para que los tres vectores de coordenadas $(a, b, 1),(-b,-1, a)$ y $(-a, b, a)$ estén sobre un mismo plano.

\section{NIVELES DE COMPETENCIAS IMPLÍCITAS: Conexión}

Para que los vectores estén en el mismo plano tienen que ser linealmente dependientes, o dicho con otras palabras, el volumen determinado por esos tres vectores tiene que valer cero.El alumno desarrolla procedimientos intuitivos ya practicados, pero no rutinarios (CRPn1), comprende que tiene que emplear conceptos matemáticos intermedios (CPRn2) y aplica los conceptos matemáticos apropiados (CPRn3).

El volumen del paralelepípedo determinado por esos tres vectores viene dado por el módulo del producto mixto, es decir, llamando:

$$
\vec{u} \equiv(a, b, 1), \vec{v} \equiv(-b,-1, a) \text { y } \vec{w} \equiv(-a, b, a)
$$

Tiene que verificar que $|[\vec{u}, \vec{v}, \vec{w}]|=0$ : 


$$
\left|\begin{array}{ccc}
a & -b & -a \\
b & -1 & b \\
1 & a & a
\end{array}\right|=0
$$

El alumno sabe expresarse sobre cuestiones matemáticas (CCn1), sigue el encadenamiento de argumentos matemáticos particulares (CAn2), evalúa el encadenamiento de argumentos matemáticos particulares (CAn3), explica los cálculos y sus propiedades (CCn2), traduce en la práctica el modelo a seguir, que es algo diferente de los estudiados (CMn2) y utiliza variables y realiza ecuaciones y cálculos mediante procedimientos familiares (CLSOn3), -producto mixto de vectores-.

Efectuando las operaciones y simplificando, se obtiene la ecuación:

$$
\begin{gathered}
a^{2}(-1-2 b)+a\left(b^{2}-1\right)-b^{2}=0 \\
b^{2}(a-1)-2 a^{2} b-a^{2}-a=0
\end{gathered}
$$

La relación entre $a$ y $b$ viene dada por una ecuación de segundo grado.

El alumno justifica las fórmulas utilizadas (RAn3), interpreta las relaciones implicadas (CCn3) y describe los resultados obtenidos (RCn3).

Si el alumno resuelve la ecuación

$$
b^{2}(a-1)-2 a^{2} b-a^{2}-a=0
$$

estaría en el nivel de reflexión, razonando de forma sencilla, distinguiendo formas más amplias de argumentación (RfAn1), porque resuelve una ecuación de segundo grado con dos variables, una de ellas la considera como incógnita y la otra como coeficiente paramétrico.

La relación entre $a$ y $b$ es:

$$
b=\frac{2 a^{2} \pm \sqrt{4 a^{4}+4 a^{3}-4 a}}{2(a-1)}=\frac{a^{2} \pm \sqrt{a^{4}+a^{3}-a}}{a-1}
$$

El alumno interpreta el lenguaje formal y simbólico rutinario (RLSOn2), maneja procedimientos y fórmulas, resolviendo y calculando (RLSOn3). 


\section{FICHA 6.27.2. COMPETENCIAS IMPLÍCITAS EN LA RESOLUCIÓN DE LA C27}

\begin{tabular}{|l|c|c|c|c|c|c|c|c|}
\hline & Nivel 1 & Nivel 2 & Nivel 3 & Nivel 1 & Nivel 2 & Nivel 3 & Nivel 1 & Nivel 2 \\
\hline PR & & & & $*$ & $*$ & $*$ & & \\
\hline A & & & $*$ & $*$ & $*$ & $*$ & $*$ & \\
\hline C & & & $*$ & $*$ & $*$ & $*$ & & \\
\hline M & & & & $*$ & $*$ & & & \\
\hline RP & & & & $*$ & & & & \\
\hline R & & & & & & & & \\
\hline LSO & & $*$ & $*$ & & & $*$ & & \\
\hline & \multicolumn{2}{|l|}{ Reproducción } & & \multicolumn{2}{c|}{ Conexión } & & \multicolumn{2}{|c|}{ Reflexión } \\
\hline
\end{tabular}

\section{ANÁLISIS DE LA CUESTIÓN C28}

\section{FICHA 6.28.1. \\ ESTUDIO DEL ENUNCIADO DEL C28}

C28.- Dados los planos $\pi_{1} \equiv 3 x+4 y+5 z=0, \pi_{2} \equiv 2 x+y+z=0$ y el punto $A(-1,2,1)$. Hallar el plano que pasa por el punto $A$ y por la recta intersección de los planos $\pi_{1}$ y $\pi_{2}$.

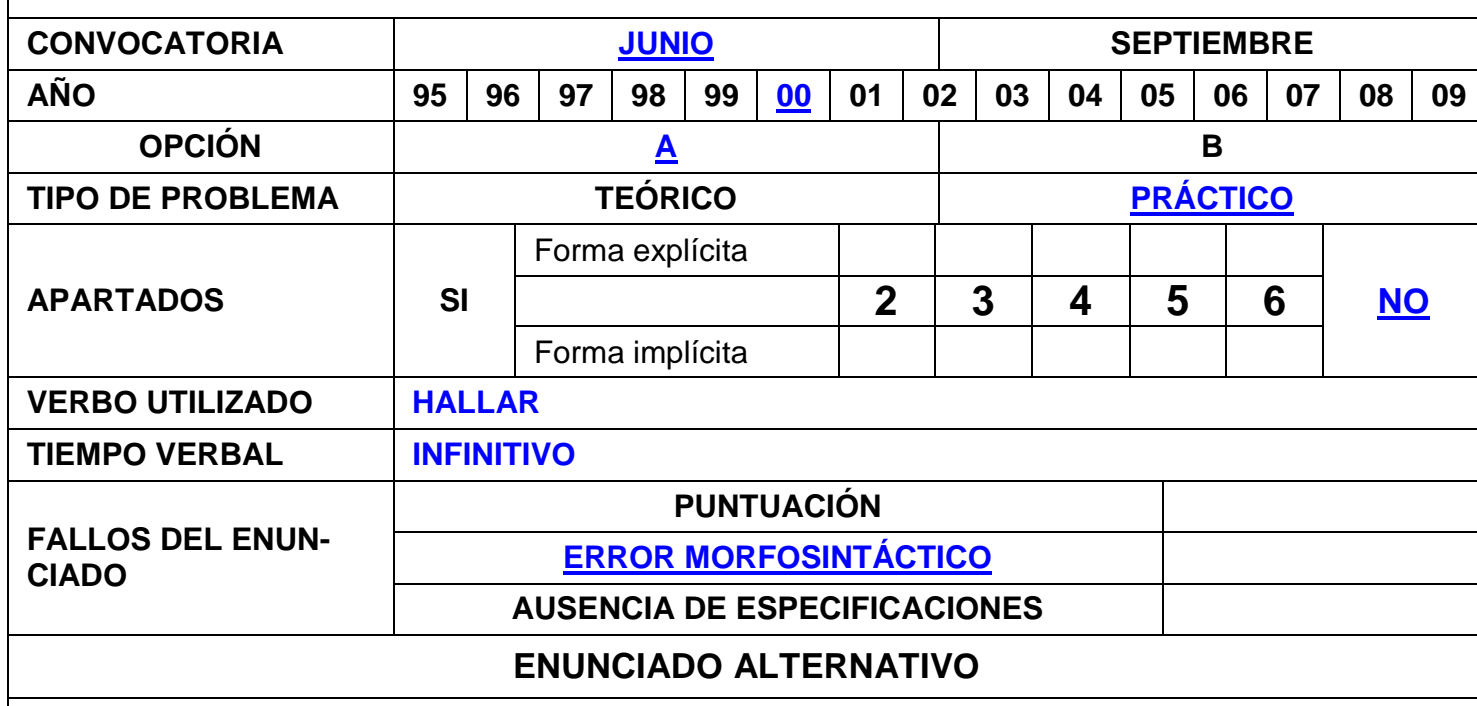

C28.- Dados los planos $\pi_{1} \equiv 3 x+4 y+5 z=0, \quad \pi_{2} \equiv 2 x+y+z=0 \quad$ y el punto $A(-1,2,1)$ escribe la ecuación del plano que pasa por el punto $A$ y por la recta de intersección de los planos $\pi_{1}$ y $\pi_{2}$.

NIVELES DE COMPETENCIAS IMPLÍCITAS: Reproducción y conexión

La cuestión que se presenta en la ficha 6.28.1 corresponde al nivel de reproducción del conocimiento estudiado. 
Es la ejecución de un problema rutinario, mediante la aplicación de destrezas técnicas y de algoritmos habituales, manejando expresiones y fórmulas establecidas y realizando cálculos.

El alumno reconoce representaciones de los datos del ejercicio (RPRn1), -las ecuaciones de los planos- y comprende la expresión escrita (RCn1), identifica el problema (RAn1), identifica que el modelo es similar a otros vistos con anterioridad (RMn1), le reconoce como problema ya practicado (RRPn1) y plantea los algoritmos correspondientes (RPRn2).

Dado que la recta $r$ está dada como intersección de dos planos:

$$
r \equiv\left\{\begin{array}{c}
3 x+4 y+5 z=0 \\
2 x+y+z=0
\end{array}\right.
$$

Para obtener un vector director de la misma, se pueden utilizar varios procedimientos, bien mediante el cálculo del producto vectorial de los vectores normales de ambos planos, o bien resolviendo un sistema lineal de dos ecuaciones con tres incógnitas, en ambos casos elige estrategias apropiadas más independientes que conexionen áreas matemáticas (CRPn2), -álgebra y geometría, y aplica las estrategias apropiadas más independientes (CRPn3).

Interpreta formas de representación (CRn1), -sistema de ecuaciones-, selecciona y cambia entre las diferentes formas de representación -algebraica, gráfica- (CRn2). Figura 6.28.

El alumno expone el proceso de cálculo (RAn2), realiza explicaciones sencillas $(\mathrm{RCn} 2)$ y reproduce un problema ya practicado, de manera cerrada (RRPn2).

En este caso desarrolla el determinante:

$$
\begin{gathered}
\vec{d}_{r}=\left|\begin{array}{ccc}
\vec{i} & \vec{j} & \vec{k} \\
3 & 4 & 5 \\
2 & 1 & 1
\end{array}\right|=-\vec{i}+7 \vec{j}-5 \vec{k} \\
\vec{d}_{r}(-1,7,-5) \approx(1,-7,5)
\end{gathered}
$$

Un punto de la recta $r, P_{r}=(0,0,0)$. Con ese punto y el punto $A=(-1,2,1)$, tiene el vector $\overrightarrow{P_{r} A}(-1,2,1)$.

El alumno estructura la situación que debe modelizar (CMn1), sabe expresarse sobre cuestiones matemáticas (CCn1), explica los cálculos y sus propiedades 
(CCn2) e interpreta las relaciones implicadas (CCn3), y asocia con fórmulas establecidas (RPRn3).

El plano que contiene a la recta $r$ y pasa por el punto $A$ contiene a los vectores $\overrightarrow{d_{r}}(1,-7,5)$ y $\overrightarrow{P_{r} A}(-1,2,1)$.

$$
\operatorname{det}\left(\overrightarrow{A X}, \overrightarrow{P_{r} A}, \overrightarrow{d_{r}}\right)=\left|\begin{array}{rrc}
X+1 & y-2 & z-1 \\
-1 & 2 & 1 \\
1 & -7 & 5
\end{array}\right|=0
$$

El alumno maneja procedimientos y fórmulas, resolviendo y calculando (RLSOn3), utiliza va-

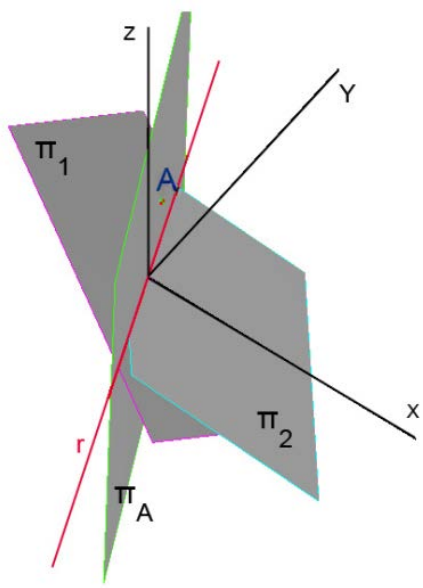

Figura 6.28 riables y realiza ecuaciones y cálculos mediante procedimientos familiares (CLSOn3), -determinante-, obteniendo la ecuación del plano

$$
\pi_{A} \equiv 17 x+6 y+5 z=0
$$

El alumno realiza operaciones elementales en contextos conocidos (RLSOn1), interpreta el lenguaje formal y simbólico rutinario (RLSOn2), realiza explicaciones sencillas (RCn2), describe los resultados obtenidos (RCn3), justifica las fórmulas utilizadas y los resultados (RAn3), resuelve problemas rutinarios estandarizados (RRPn3) y comunica de manera elemental los resultados del mo-

\begin{tabular}{|c|c|c|c|c|c|c|c|c|}
\hline \multicolumn{2}{|c|}{ FICHA 6.28.2. } & \multicolumn{7}{|c|}{ COMPETENCIAS IMPLÍCITAS EN LA RESOLUCIÓN DE LA C28 } \\
\hline & Nivel 1 & Nivel 2 & Nivel 3 & Nivel 1 & Nivel 2 & Nivel 3 & Nivel 1 & Nivel 2 \\
\hline PR & * & * & * & & & & & \\
\hline A & * & * & * & & & & & \\
\hline C & * & * & * & & & & & \\
\hline M & * & & * & * & & & & \\
\hline RP & * & * & * & & * & * & & \\
\hline $\mathbf{R}$ & & & & * & * & & & \\
\hline \multirow[t]{2}{*}{ LSO } & * & * & * & & & * & & \\
\hline & \multicolumn{3}{|c|}{ Reproducción } & \multicolumn{3}{|c|}{ Conexión } & \multicolumn{2}{|c|}{ Reflexión } \\
\hline
\end{tabular}
delo (RMn3). 


\section{ANÁLISIS DE LA CUESTIÓN C30}

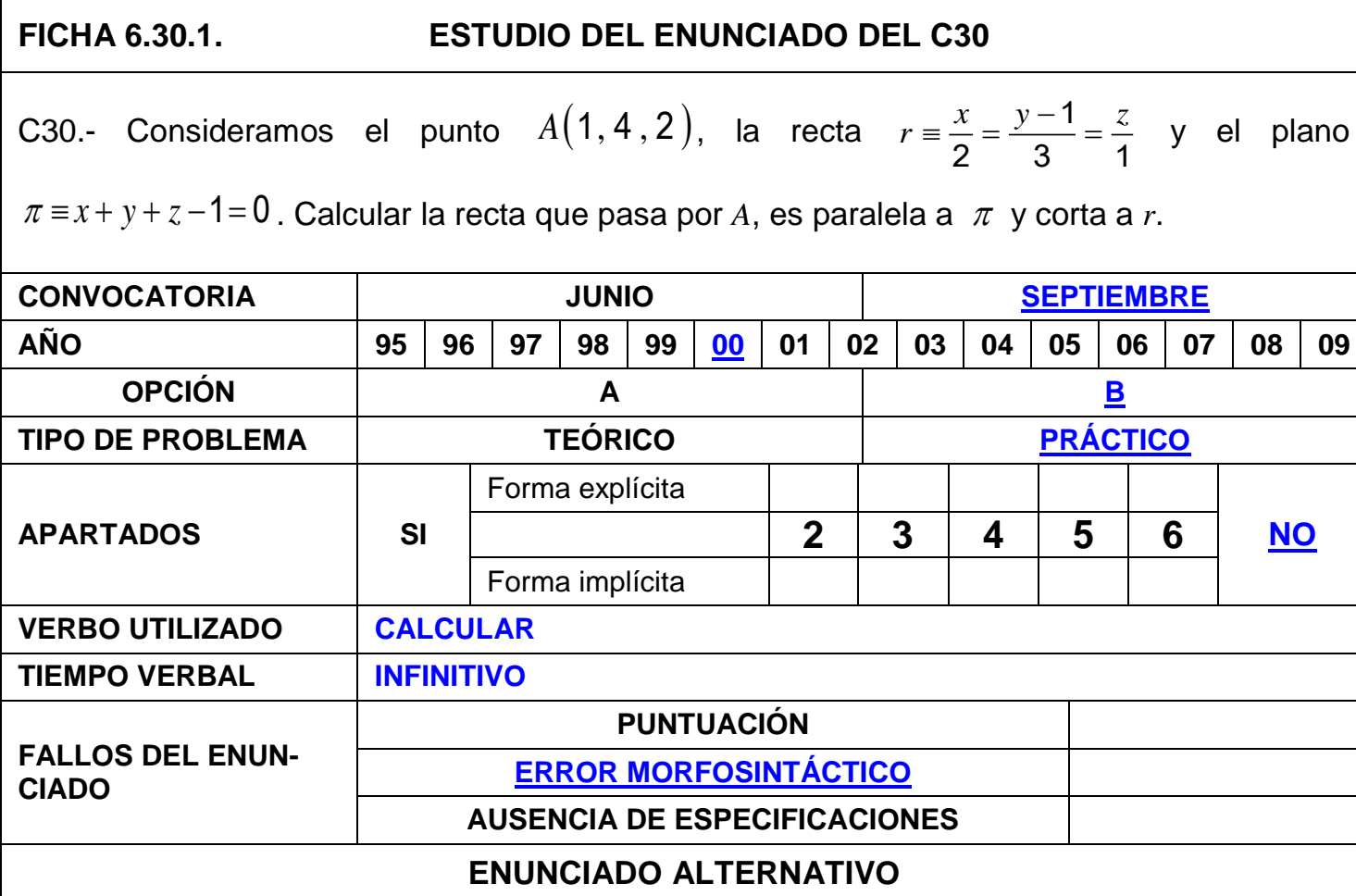

C30.- Consideramos el punto de coordenadas $A(1,4,2)$, la recta de ecuaciones $r \equiv \frac{x}{2}=\frac{y-1}{3}=\frac{z}{1}$ y el plano de ecuación $\pi \equiv x+y+z-1=0$; escribe la ecuación de la recta que pasa por $A$, es paralela a $\pi$ y corta a $r$.

NIVELES DE COMPETENCIAS IMPLÍCITAS: Conexión

La cuestión que se presenta en la ficha 6.30.1 corresponde al nivel de conexión, por tanto se trata de un ejercicio que reproduce situaciones similares a las estudiadas en la instrucción, pero que no son de mera rutina.

El alumno tiene que pensar en el tratamiento matemático necesario (CPRn1), razonar matemáticamente de manera simple (CAn1) y estructurar la situación que debe modelizar (CMn1).

Como la recta buscada, $s$, que pasa por el punto $A$, es paralela al plano $\pi$, se encuentra en un plano $\sigma$ paralelo a $\pi$ que contiene al punto.

Ecuación del plano paralelo a $\pi$ :

$$
\sigma \equiv x+y+z+k=0
$$


El plano contiene al punto $A(1,4,2)$, luego

$$
1+4+2+k=0 \Rightarrow k=-7
$$

Ecuación del plano: $\sigma \equiv x+y+z-7=0$

El alumno desarrolla procedimientos intuitivos ya practicados, pero no rutinarios (CRPn1), comprende que tiene que emplear conceptos matemáticos intermedios (CPRn2) y aplica los conceptos matemáticos apropiados (CPRn3).

Calcula el punto de intersección de la recta $r \equiv \frac{x}{2}=\frac{y-1}{3}=\frac{z}{1}$ con el plano $\sigma$.

Entre los distintos procedimientos para calcular ese punto, dado que la recta está dada por su ecuación continua, escribe la ecuación de la recta como intersección de dos planos y resuelve el sistema lineal de tres ecuaciones con tres incógnitas.

$$
\left\{\begin{array}{c}
x=2 z \\
y=3 z+1 \\
x+y+z-7=0
\end{array}\right.
$$

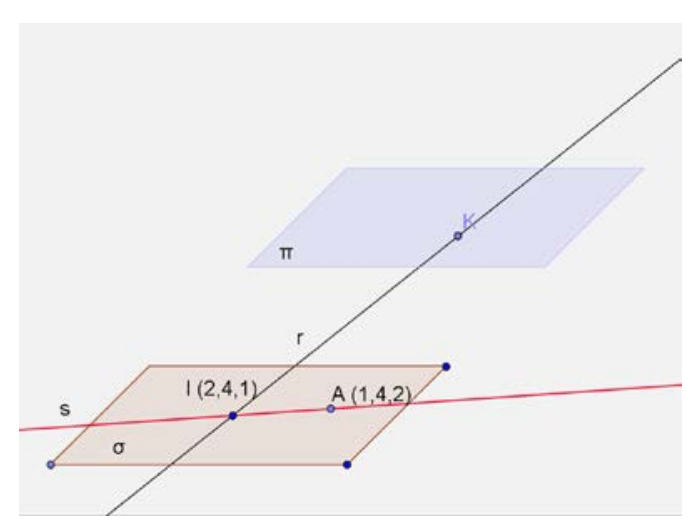

Con solución

$$
x=2, y=4, \quad z=1
$$

Para resolver el sistema, realiza operaciones elementales en contextos conocidos (RLSOn1), interpreta el lenguaje formal y simbólico rutinario (RLSOn2) y maneja procedimientos y fórmulas, resolviendo y calculando (RLSOn3).

Así, el alumno sabe expresarse sobre cuestiones matemáticas (CCn1), explica los cálculos y sus propiedades (CCn2) e interpreta las relaciones implicadas (CCn3), traduce en la práctica el modelo a seguir, que es algo diferente de los estudiados (CMn2) y utiliza variables y realiza ecuaciones y cálculos mediante procedimientos familiares (CLSOn3).

La recta buscada pasa por los puntos $A(1,4,2)$ e $I(2,4,1)$. 
El alumno sigue el encadenamiento de argumentos matemáticos particulares (CAn2) y evalúa el encadenamiento de argumentos matemáticos particulares (CAn3).

Vector director $\overrightarrow{A I}=(1,0,-1)$ y pasa por $A(1,4,2)$.

Ecuaciones de la recta, en forma paramétrica: $s \equiv\left\{\begin{array}{c}x=1+\lambda \\ y=4 \\ z=2-\lambda\end{array}\right.$

Con este razonamiento, el alumno desarrolla procedimientos intuitivos ya practicados, pero no rutinarios (CRPn1), elige las estrategias apropiadas más independientes que conexionen áreas matemáticas (CRPn2), -álgebra y geometríay aplica las estrategias apropiadas más independientes (CRPn3). Finalmente, sabe interpretar y alternar diferentes modelos y comunicar los resultados (CMn3).

El alumno interpreta formas de representación (CRn1), -sistema de ecuaciones- y selecciona y cambia entre las diferentes formas de representación (CRn2), de forma geométrica a forma algebraica y representación gráfica. Figura 6.30 .

\begin{tabular}{|l|c|c|c|c|c|c|c|c|}
\hline \multicolumn{7}{|c|}{ FICHA 6.30.2. COMPETENCIAS IMPLÍCITAS EN LA RESOLUCIÓN DE LA C30 } \\
\hline & Nivel 1 & Nivel 2 & Nivel 3 & Nivel 1 & Nivel 2 & Nivel 3 & Nivel 1 & Nivel 2 \\
\hline PR & & & & $*$ & $*$ & $*$ & & \\
\hline A & & & & $*$ & $*$ & $*$ & & \\
\hline C & & & & $*$ & $*$ & $*$ & & \\
\hline M & & & & $*$ & $*$ & $*$ & & \\
\hline RP & & & & $*$ & $*$ & $*$ & & \\
\hline R & & & & $*$ & $*$ & & & \\
\hline LSO & $*$ & $*$ & $*$ & & & $*$ & & \\
\hline & Reproducción & & Conexión & & Reflexión \\
\hline
\end{tabular}

\section{ANÁLISIS DE LA CUESTIÓN C31}

La cuestión que se presenta en la ficha 6.31.1 corresponde al nivel de conexión, pues se trata de un ejercicio que reproduce situaciones similares a las estudiadas en la instrucción, pero que no son de mera rutina. 


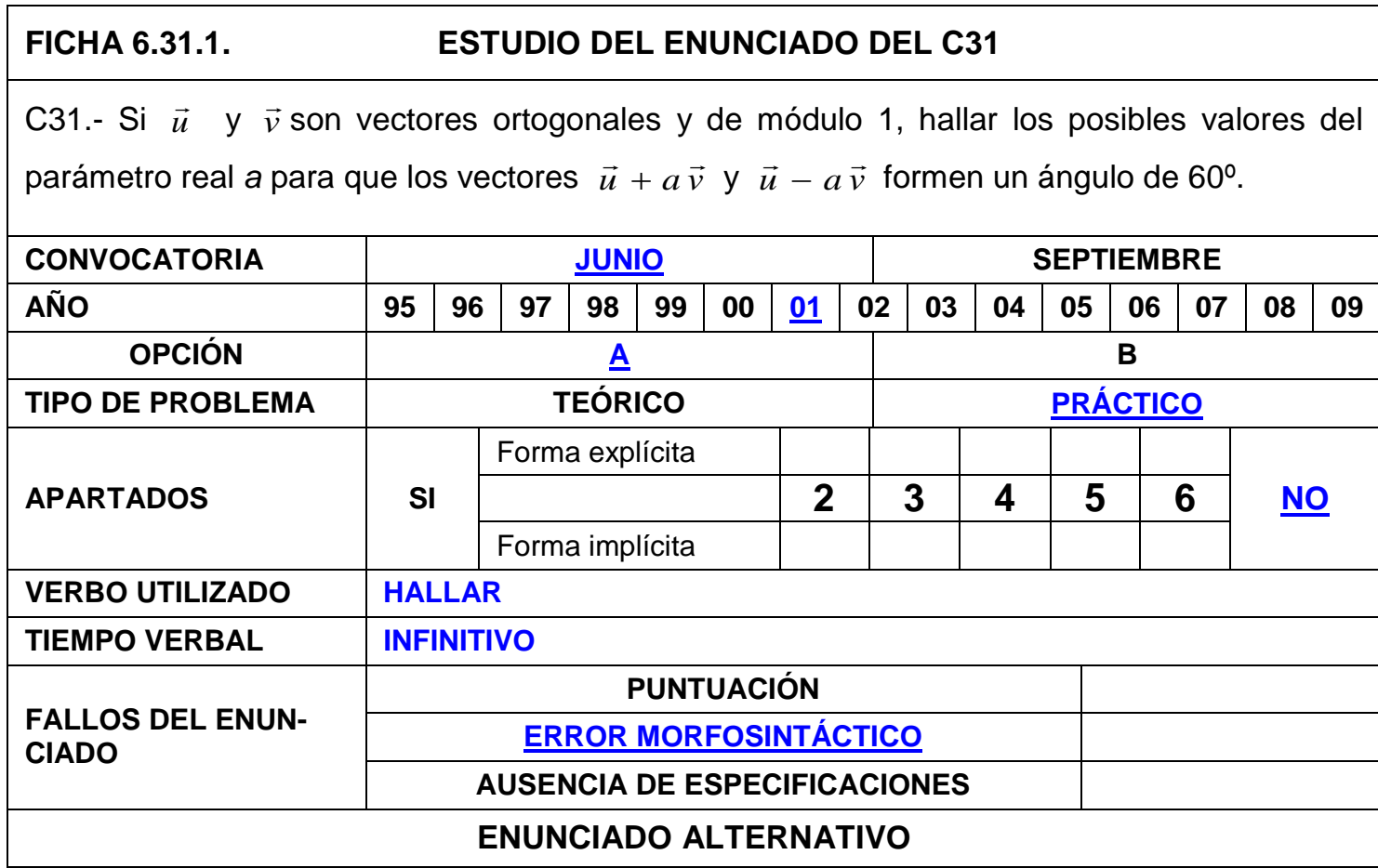

C31.- Si $\vec{u}$ y $\vec{v}$ son vectores ortogonales y de módulo 1, halla los posibles valores del parámetro real $a$ para que los vectores $\vec{u}+a \vec{v}$ y $\vec{u}-a \vec{v}$ formen un ángulo de $60^{\circ}$.

\section{NIVELES DE COMPETENCIAS IMPLÍCITAS: Conexión}

El alumno tiene que pensar en el tratamiento matemático necesario (CPRn1), razonar matemáticamente de manera simple (CAn1) y estructurar la situación que debe modelizar (CMn1).

Efectúa el producto escalar.

$$
(\vec{u}+a \vec{v}) \cdot(\vec{u}-a \vec{v})=\vec{u} \cdot \vec{u}-a^{2} \cdot \vec{v} \cdot \vec{v}=|\vec{u}|^{2}-a^{2} \cdot|\vec{v}|^{2} \stackrel{(1)}{=} 1-a^{2}
$$

(1) Los vectores $\vec{u}$ y $\vec{v}$ tienen módulo 1.

Asimismo, por definición de producto escalar, dado que los vectores $(\vec{u}+a \vec{v})$ y $(\vec{u}-a \vec{v})$ forman un ángulo de $60^{\circ}$

$$
(\vec{u}+a \vec{v}) \cdot(\vec{u}-a \vec{v})=|\vec{u}+a \vec{v}| \cdot|\vec{u}-a \vec{v}| \cdot \cos (60)
$$

Calcula los módulos de los vectores $(\vec{u}+a \vec{v})$ y $(\vec{u}-a \vec{v})$

$$
(\vec{u}+a \vec{v}) \cdot(\vec{u}+a \vec{v})=|\vec{u}+a \vec{v}|^{2}
$$




$$
(\vec{u}+a \vec{v}) \cdot(\vec{u}+a \vec{v})=\vec{u} \cdot \vec{u}+2 a \vec{u} \cdot \vec{v}+a^{2} \cdot \vec{v} \cdot \vec{v} \stackrel{(2)}{=}|\vec{u}|^{2}+a^{2}|\vec{v}|^{2} \stackrel{(3)}{=} 1+a^{2}
$$

(2) Los vectores $\vec{u}$ y $\vec{v}$ son ortogonales.

(3) Los vectores $\vec{u}$ y $\vec{v}$ tienen módulo 1 .

$$
\begin{gathered}
|\vec{u}+a \vec{v}|^{2}=1+a^{2} \Rightarrow|\vec{u}+a \vec{v}|=\sqrt{1+a^{2}} \\
\text { Análogamente }|\vec{u}-a \vec{v}|=\sqrt{1+a^{2}}
\end{gathered}
$$

Así, el alumno sabe expresarse sobre cuestiones matemáticas (CCn1), explica los cálculos y sus propiedades (CCn2) e interpreta las relaciones implicadas (CCn3), traduce en la práctica el modelo a seguir, que es algo diferente de los estudiados (CMn2) y, al realizar el producto escalar y el módulo de los vectores, utiliza variables y realiza ecuaciones y cálculos mediante procedimientos familiares (CLSOn3).

$$
\begin{gathered}
1-a^{2}=|\vec{u}+a \vec{v}| \cdot|\vec{u}-a \vec{v}| \cdot \cos (60)=\sqrt{1+a^{2}} \cdot \sqrt{1+a^{2}} \cdot \frac{1}{2} \\
1-a^{2}=\left(1+a^{2}\right) \cdot \frac{1}{2}
\end{gathered}
$$

El alumno desarrolla procedimientos intuitivos ya practicados, pero no rutinarios (CRPn1) y aplica los conceptos matemáticos apropiados (CPRn3).

Resolviendo la ecuación, obtiene las soluciones

$$
a_{1}=\frac{\sqrt{3}}{3} \text { y } a_{2}=-\frac{\sqrt{3}}{3}
$$

Para resolver el sistema, realiza operaciones elementales en contextos conocidos (RLSOn1), interpreta el lenguaje formal y simbólico rutinario (RLSOn2) y maneja procedimientos y fórmulas, resolviendo y calculando (RLSOn3).

El alumno sabe interpretar y alternar diferentes modelos y comunicar los resultados (CMn3), describe los resultados obtenidos (RCn3), justifica las fórmulas utilizadas y los resultados (RAn3) y comunica de manera elemental los resultados del modelo (RMn3). 


\section{FICHA 6.31.2. COMPETENCIAS IMPLÍCITAS EN LA RESOLUCIÓN DE LA C31}

\begin{tabular}{|l|c|c|c|c|c|c|c|c|}
\hline & Nivel 1 & Nivel 2 & Nivel 3 & Nivel 1 & Nivel 2 & Nivel 3 & Nivel 1 & Nivel 2 \\
\hline PR & & & & $*$ & & $*$ & & \\
\hline A & & & $*$ & $*$ & & & & \\
\hline C & & & $*$ & $*$ & $*$ & $*$ & & \\
\hline M & & & $*$ & $*$ & $*$ & $*$ & & \\
\hline RP & & & & $*$ & & & & \\
\hline R & & & & & & & & \\
\hline LSO & $*$ & $*$ & $*$ & & & $*$ & & \\
\hline & Reproducción & & \multicolumn{7}{c|}{ Conexión } & & Reflexión \\
\hline
\end{tabular}

\section{ANÁLISIS DE LA CUESTIÓN C37}

\section{FICHA 6.37.1. \\ ESTUDIO DEL ENUNCIADO DEL C37}

C37.- Calcular el ángulo que forma la recta $\frac{x-3}{2}=\frac{y+1}{5}=\frac{z-1}{-1}$ con el plano $2 x-5 y+7 z-11=0$.

\begin{tabular}{|c|c|c|c|c|c|c|c|c|c|c|c|c|c|}
\hline CONVOCATORIA & \multicolumn{7}{|c|}{ JUNIO } & \multicolumn{6}{|c|}{ SEPTIEMBRE } \\
\hline AÑO & 95 & 96 & 97 & 98 & 99 & 00 & 01 & 0203 & 04 & 05 & \begin{tabular}{l|l}
06 & 07
\end{tabular} & 08 & 09 \\
\hline OPCIÓN & \multicolumn{7}{|c|}{ A } & \multicolumn{6}{|c|}{$\underline{B}$} \\
\hline TIPO DE PROBLEMA & \multicolumn{7}{|c|}{ TEÓRICO } & \multicolumn{6}{|c|}{ PRÁCTICO } \\
\hline \multirow{3}{*}{ APARTADOS } & \multirow{3}{*}{\multicolumn{2}{|c|}{ SI }} & \multicolumn{4}{|c|}{ Forma explícita } & & & & \multirow[b]{2}{*}{5} & \multirow[b]{2}{*}{6} & \multirow{3}{*}{\multicolumn{2}{|c|}{ No }} \\
\hline & & & & & & & 2 & 3 & 4 & & & & \\
\hline & & & \multicolumn{4}{|c|}{ Forma implícita } & & & & & & & \\
\hline VERBO UTILIZADO & \multicolumn{13}{|c|}{ CALCULAR } \\
\hline TIEMPO VERBAL & \multicolumn{13}{|c|}{ INFINITIVO } \\
\hline \multirow{3}{*}{$\begin{array}{l}\text { FALLOS DEL ENUN- } \\
\text { CIADO }\end{array}$} & \multicolumn{9}{|c|}{ PUNTUACIÓN } & & & & \\
\hline & \multicolumn{9}{|c|}{ ERROR MORFOLÓGICO } & & & & \\
\hline & \multicolumn{9}{|c|}{ AUSENCIA DE ESPECIFICACIONES } & & & & \\
\hline \multicolumn{14}{|c|}{ ENUNCIADO ALTERNATIVO } \\
\hline
\end{tabular}

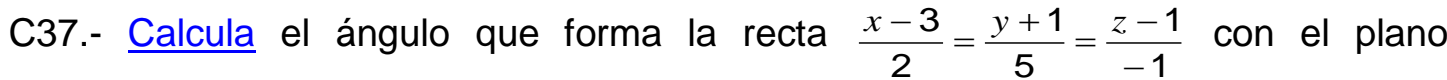
$2 x-5 y+7 z-11=0$.

\section{NIVELES DE COMPETENCIAS IMPLÍCITAS: Reproducción}

La cuestión que aparece en la ficha 6.37.1 se encuadra en el nivel de reproducción, se trata de la reproducción del conocimiento estudiado, es la ejecu- 
ción de un problema rutinario mediante la aplicación de destrezas técnicas con el manejo de fórmulas establecidas y realización de cálculos.

Comienza reconociendo la representación de los datos del ejercicio (RPRn1), comprende la expresión escrita (RCn1), identifica el problema (RAn1), identifica que el modelo es similar a otros modelos vistos con anterioridad (RMn1), le reconoce como problema ya practicado durante la instrucción (RRPn1) y continúa planteando los algoritmos correspondientes (RPRn2).

Si el ángulo formado entre la recta y el plano es $\alpha$, entonces

$$
\left|\overrightarrow{d_{r}} \cdot \overrightarrow{n_{\pi}}\right|=\left|\overrightarrow{d_{r}}\right| \cdot\left|\overrightarrow{n_{\pi}}\right| \cdot \cos (90-\alpha)
$$

Siendo $\overrightarrow{d_{r}}$ el vector director de la recta $r$ y $\overrightarrow{n_{\pi}}$ el vector normal del plano.

La recta $r$ está dada en forma continua y un vector director es $\overrightarrow{d_{r}}=(2,5,-1)$

$$
\text { Vector normal del plano } \overrightarrow{n_{\pi}}=(2,-5,7)
$$

El alumno interpreta formas de representación (CRn1) y selecciona y cambia entre las diferentes formas de representación (CRn2), algebraica, geométrica y gráfica. Figura 6.37

El alumno expone el proceso de cálculo (RAn2), realiza explicaciones sencillas (RCn2) y reproduce problemas ya practicados de manera cerrada (RRPn2).

$$
\begin{gathered}
|(2,5,-1) \cdot(2,-5,7)|=\sqrt{2^{2}+5^{2}+(-1)^{2}} \cdot \sqrt{2^{2}+(-5)^{2}+7^{2}} \cdot \cos (90-\alpha) \\
28=\sqrt{30} \cdot \sqrt{78} \cdot \cos (90-\alpha) \Rightarrow \quad \cos (90-\alpha)=\frac{28}{\sqrt{30} \cdot \sqrt{78}} \\
\quad 90-\alpha=\arccos \left(\frac{28}{\sqrt{2340}}\right)=54^{\circ} 37^{\prime} 54^{\prime \prime}
\end{gathered}
$$

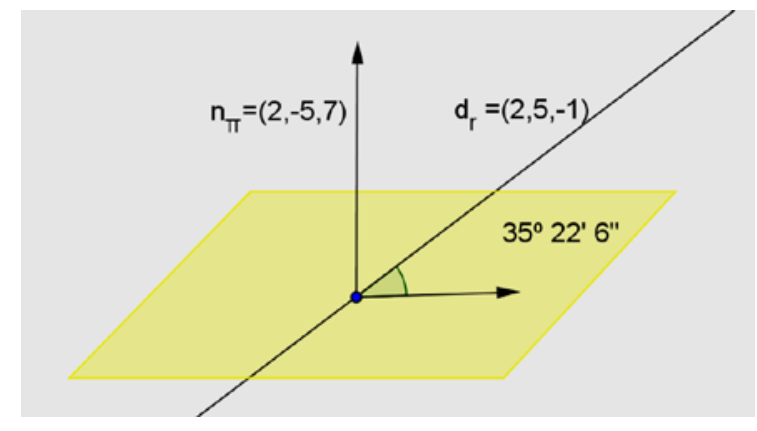

Figura 6.37
El ángulo entre la recta y el plano es

$$
\alpha=90^{\circ}-54^{\circ} 37^{\prime} 54^{\prime \prime}=35^{\circ} 22^{\prime} 6^{\prime \prime}
$$

El alumno asocia con fórmulas establecidas y realiza los cálculos (RPRn3), resuelve problemas rutinarios estandarizados (RRPn3) y justifi- 
ca las fórmulas utilizadas y los resultados (RAn3).

Realiza operaciones elementales en contextos conocidos (RLSOn1), interpreta el lenguaje formal y simbólico rutinario (RLSOn2), maneja procedimientos y fórmulas, resolviendo y calculando (RLSOn3) y utiliza variables y realiza ecuaciones y cálculos mediante procedimientos familiares (CLSOn3), el módulo de un vector, el producto escalar de vectores.

Concluye comunicando de manera elemental los resultados del modelo (RMn3) y describe los resultados obtenidos (RCn3).

\begin{tabular}{|c|c|c|c|c|c|c|c|c|}
\hline \multicolumn{2}{|c|}{ FICHA 6.37.2. } & \multicolumn{7}{|c|}{ COMPETENCIAS IMPLÍCITAS EN LA RESOLUCIÓN DE LA C37 } \\
\hline & Nivel 1 & Nivel 2 & Nivel 3 & Nivel 1 & Nivel 2 & Nivel 3 & Nivel 1 & Nivel 2 \\
\hline PR & * & * & * & & & & & \\
\hline A & * & * & * & & & & & \\
\hline C & * & * & * & & & & & \\
\hline $\mathbf{M}$ & * & & * & & & & & \\
\hline RP & * & * & * & & & & & \\
\hline $\mathbf{R}$ & & & & * & * & & & \\
\hline LSO & * & * & * & & & * & & \\
\hline & \multicolumn{3}{|c|}{ Reproducción } & \multicolumn{3}{|c|}{ Conexión } & \multicolumn{2}{|c|}{ Reflexión } \\
\hline
\end{tabular}

\section{ANÁLISIS DE LA CUESTIÓN C44}

La cuestión que se presenta en la ficha 6.44 .1 se encuadra en los niveles de reproducción y conexión. Comienza reconociendo la representación de los datos del ejercicio (RPRn1) y comprende la expresión escrita (RCn1).

Identifica el problema (RAn1), identifica que el modelo es similar a otros modelos vistos con anterioridad (RMn1), interpreta representaciones estándar de objetos matemáticos (RRn2), realiza el paso de una representación a otra (RRn3), de geométrica a algebraica y le reconoce como problema ya practicado (RRPn1).

Escribe las ecuaciones de la recta que pasa por los puntos $A$ y $B$ y calcula el punto de intersección del plano con la recta. 
FICHA 6.44.1.

ESTUDIO DEL ENUNCIADO DEL C44

C44.- Determínese si el plano $\pi \equiv 2 x+3 y-4=0$ corta o no al segmento de extremos $A(2,1,3)$ y $B(3,2,1)$.

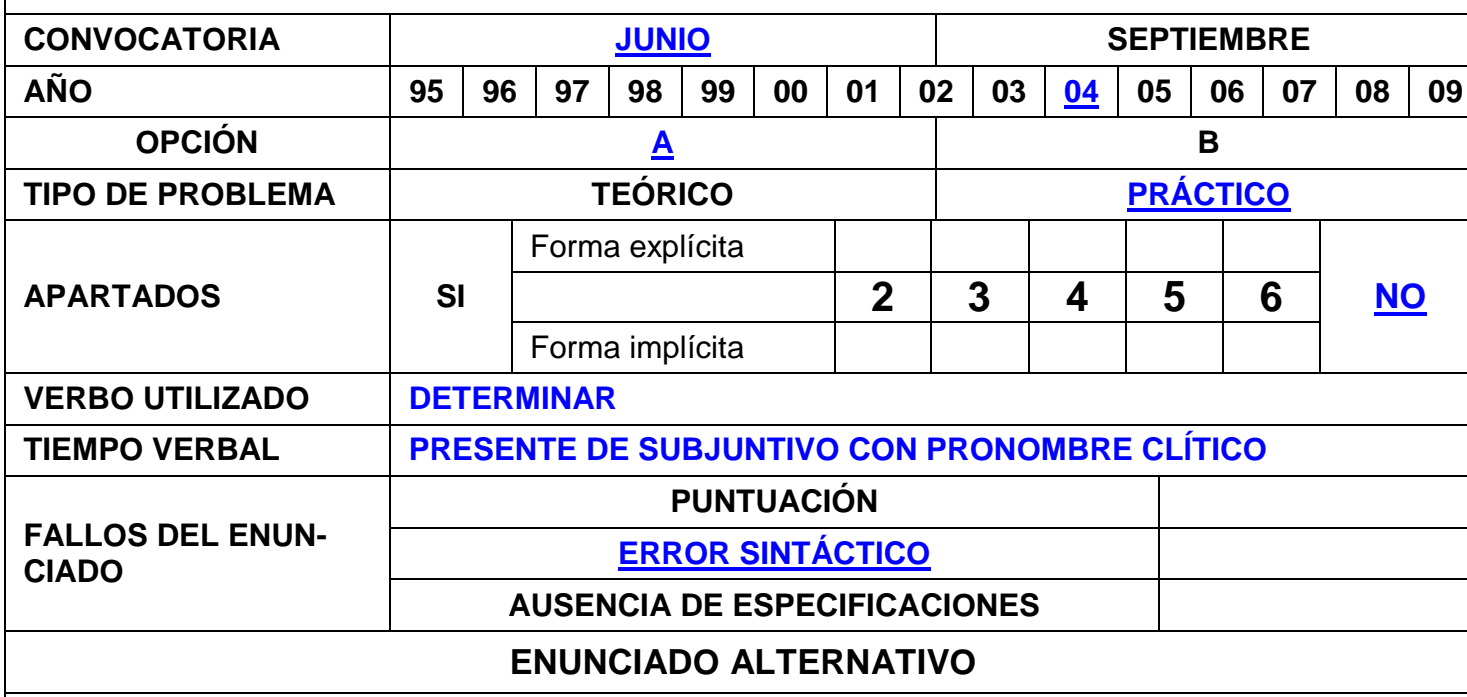

C44.- Determina si el plano de ecuación $\pi \equiv 2 x+3 y-4=0$ corta o no al segmento que tiene como extremos los puntos de coordenadas $A(2,1,3)$ y $B(3,2,1)$.

NIVELES DE COMPETENCIAS IMPLÍCITAS: Reproducción y conexión

El alumno expone el proceso de cálculo (RAn2), realiza explicaciones sencillas (RCn2), plantea los algoritmos correspondientes (RPRn2) y reproduce problemas ya practicados de manera cerrada (RRPn2).

Ecuaciones de la recta que tiene como vector director $\overrightarrow{A B}=(1,1,-2)$ y pasa por el punto $A=(2,1,3)$, en forma continua

$$
\frac{x-2}{1}=\frac{y-1}{1}=\frac{z-3}{-2}
$$

Para calcular el punto de intersección de la recta con el plano $\pi \equiv 2 x+3 y-4=0$ sustituye un punto genérico de la recta $(2+\lambda, 1+\lambda, 3-2 \lambda)$ en la ecuación del plano.

$$
2 \cdot(2+\lambda)+3 \cdot(1+\lambda)-4=0
$$

Realizando los cálculos obtiene la ecuación $5 \lambda+3=0$, cuya solución es

$$
\lambda=-\frac{3}{5}
$$


El alumno asocia con fórmulas establecidas y realiza los cálculos (RPRn3), justifica las fórmulas utilizadas y los resultados (RAn3), realiza operaciones elementales en contextos conocidos (RLSOn1), interpreta el lenguaje formal y simbólico rutinario (RLSOn2), maneja procedimientos y fórmulas, resolviendo y calculando (RLSOn3) y utiliza variables y realiza ecuaciones y cálculos mediante procedimientos familiares (CLSOn3).

Sustituido ese valor en la expresión del punto genérico de la recta obtiene el punto de intersección

$$
I=\left(\frac{7}{5}, \frac{2}{5}, \frac{21}{5}\right)
$$

Resuelve problemas rutinarios estandarizados (RRPn3).

Y comunica de manera elemental los resultados del modelo (RMn3) y describe los resultados obtenidos ( $\mathrm{RCn} 3)$.

Comprobar si el punto es interior al segmento corresponde al nivel de conexión pues reproduce situaciones similares a las estudiadas en la instrucción, pero que no son de mera rutina.

El alumno interpreta formas de representación (CRn1), piensa en el tratamiento matemático necesario (CPRn1), razona matemáticamente de manera simple (CAn1), -si el punto es interior al segmento, los vectores $\overrightarrow{A I}$ y $\overrightarrow{A B}$ tienen el misma sentido y $|\overrightarrow{A I}|<|\overrightarrow{A B}|$ y, en consecuencia, estructura la situación que debe modelizar (CMn1).

$$
\overrightarrow{A I}=\left(-\frac{3}{5},-\frac{3}{5}, \frac{6}{5}\right) \text { y } \overrightarrow{A B}=(1,1,-2)
$$

Los vectores tienen sentido opuesto, por tanto el punto $I$ no es interior al segmento $\overline{A B}$.

\section{El plano no corta al segmento $\overline{A B}$.}

Así, el alumno desarrolla procedimientos intuitivos ya practicados, pero no rutinarios (CRPn1) sabe expresarse sobre cuestiones matemáticas (CCn1), explica los cálculos y sus propiedades (CCn2) e interpreta las relaciones implicadas (CCn3), aplica los conceptos matemáticos apropiados (CPRn3) y al calcular los vectores, utiliza variables y realiza ecuaciones y cálculos mediante procedimientos familiares (CLSOn3). 
FICHA 6.44.2. COMPETENCIAS IMPLÍCITAS EN LA RESOLUCIÓN DE LA C44

\begin{tabular}{|l|c|c|c|c|c|c|c|c|}
\hline & Nivel 1 & Nivel 2 & Nivel 3 & Nivel 1 & Nivel 2 & Nivel 3 & Nivel 1 & Nivel 2 \\
\hline PR & $*$ & $*$ & $*$ & $*$ & $*$ & $*$ & & \\
\hline A & $*$ & $*$ & $*$ & $*$ & & & & \\
\hline C & $*$ & $*$ & $*$ & $*$ & $*$ & $*$ & & \\
\hline M & $*$ & & $*$ & $*$ & & & & \\
\hline RP & $*$ & $*$ & $*$ & $*$ & & & & \\
\hline R & & $*$ & $*$ & $*$ & & & & \\
\hline LSO & $*$ & $*$ & $*$ & & & $*$ & & \\
\hline & \multicolumn{2}{|c|}{ Reproducción } & & \multicolumn{2}{|l|}{ Conexión } & & Reflexión \\
\hline
\end{tabular}

\section{ANÁLISIS DE LA CUESTIÓN C50}

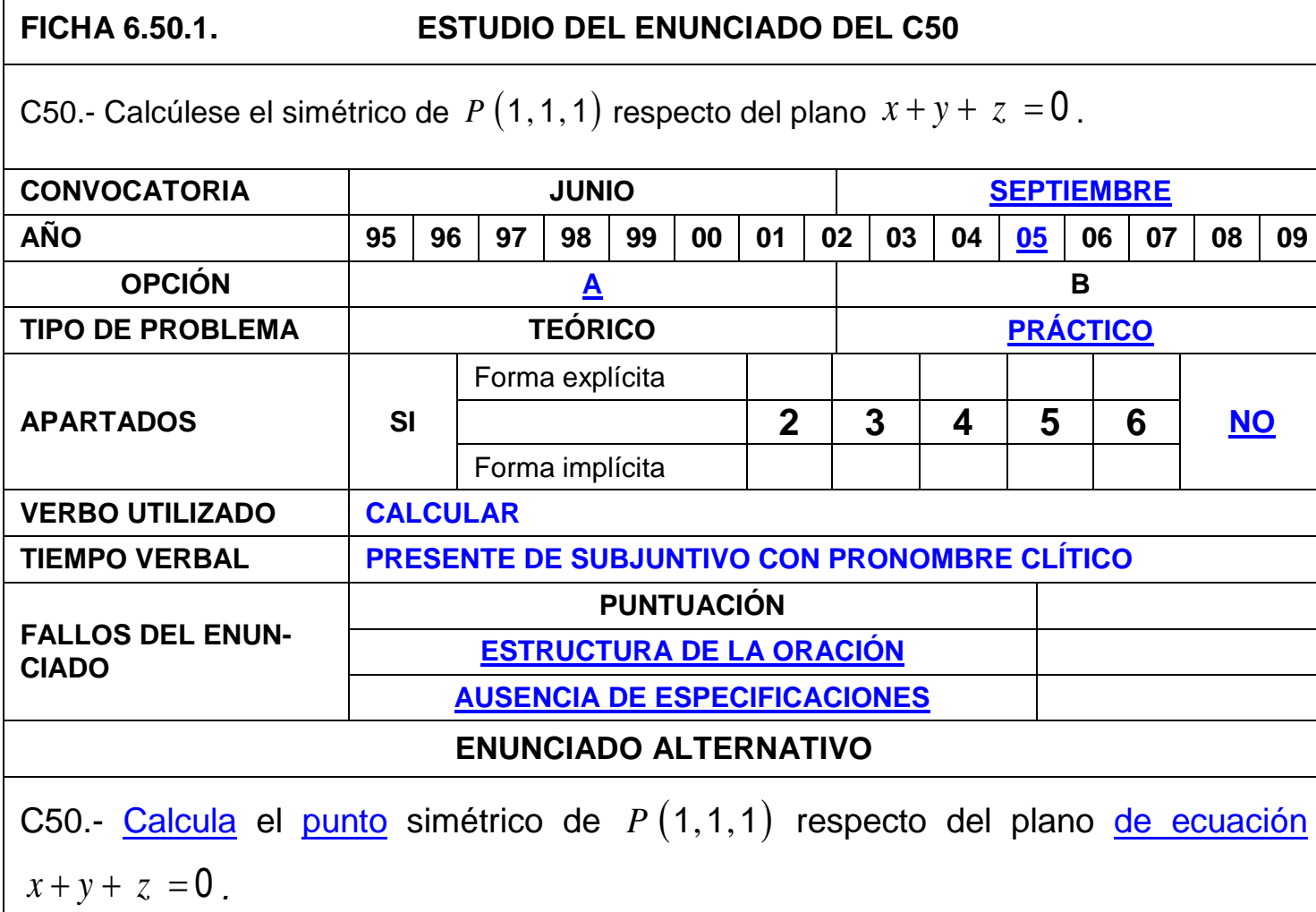

\section{NIVELES DE COMPETENCIAS IMPLÍCITAS: Reproducción}

El ejercicio que se presenta en el problema de la ficha 6.50.1 corresponde al nivel de reproducción del conocimiento estudiado, conocimiento de hechos, representaciones de problemas comunes, reconocimiento de equivalentes, ejecución de problemas rutinarios, aplicación de destrezas técnicas y de algorit- 
mos habituales, mediante el manejo de expresiones y fórmulas establecidas y realización de cálculos.

El alumno reconoce representaciones de los datos del ejercicio (RPRn1),-la ecuación general del plano-, identifica el problema (RAn1), comprende la expresión escrita (RCn1), identifica que el modelo es similar a otros vistos con anterioridad (RMn1) y le reconoce como problema ya practicado (RRPn1).

A continuación expone el proceso de cálculo (RAn2), plantea los algoritmos correspondientes (RPRn2) y asocia con fórmulas establecidas y realiza los cálculos (RPRn3).

Para calcular el punto simétrico de $P(1,1,1)$ respecto del plano $\pi \equiv x+y+z=0$ tiene que escribir las ecuaciones de la recta perpendicular al plano que pase por el punto $P$. El vector director de la recta es equipolente al vector normal del plano.

El alumno interpreta representaciones estándar de objetos matemáticos (RRn2) y realiza el paso de una representación a otra (RRn3), geométrica, algebraica, gráfica, realiza explicaciones sencillas $(\mathrm{RCn} 2)$ y reproduce problemas ya practicados de manera cerrada (RRPn2). Figura 6.50.

$$
\vec{d} \cong \vec{n}_{\pi} \equiv(1,1,1) \text { y pasa por el punto } P(1,1,1)
$$

Ecuaciones paramétricas de la recta:

$$
r \equiv\left\{\begin{array}{l}
x=1+\lambda \\
y=1+\lambda \\
z=1+\lambda
\end{array}\right.
$$

El punto de intersección de la recta y el plano, es el punto medio del segmento $\overline{P P^{\prime}}$.

Como la recta está expresada mediante las ecuaciones paramétricas, para calcular el punto de intersección, resuelve la ecuación obtenida al sustituir un punto genérico de la recta: $(1+\lambda, 1+\pi, 1+\lambda)$ en la ecuación del plano $\pi \equiv x+y+z=0$. 


$$
(1+\lambda)+(1+\lambda)+(1+\lambda)=0
$$

Maneja procedimientos y fórmulas, resolviendo y calculando (RLSOn3), para obtener el valor: $\lambda=-1$

Que, sustituido en la expresión del punto genérico de la recta, nos da el punto

$$
I=(0,0,0)
$$

Como $I$ es el punto medio entre $P$ y $P,\left(\frac{x+1}{2}, \frac{y+1}{2}, \frac{z+1}{2}\right)=(0,0,0)$

De donde se obtiene:

$$
P^{\prime}=(-1,-1,-1)
$$

El alumno interpreta el lenguaje formal y simbólico rutinario (RLSOn2), y maneja procedimientos y fórmulas, resolviendo y calculando (RLSOn3), resuelve problemas rutinarios estandarizados (RRPn3), justifica las fórmulas utilizadas y los resultados (RAn3), describe los resultados obtenidos (RCn3) y comunica de manera elemental los resultados del modelo (RMn3).

\begin{tabular}{|l|c|c|c|c|c|c|c|c|}
\hline \multicolumn{6}{|c|}{ FICHA 6.50.2. COMPETENCIAS IMPLÍCITAS EN LA RESOLUCIÓN DE LA C50 } \\
\hline & Nivel 1 & Nivel 2 & Nivel 3 & Nivel 1 & Nivel 2 & Nivel 3 & Nivel 1 & Nivel 2 \\
\hline PR & $*$ & $*$ & $*$ & & & & & \\
\hline A & $*$ & $*$ & $*$ & & & & & \\
\hline C & $*$ & $*$ & $*$ & & & & & \\
\hline M & $*$ & & $*$ & & & & & \\
\hline RP & $*$ & $*$ & $*$ & & & & & \\
\hline R & & $*$ & $*$ & & & & & \\
\hline LSO & & $*$ & $*$ & & & & & \\
\hline & Reproducción & & Conexión & & Reflexión \\
\hline
\end{tabular}

\section{ANÁLISIS DE LA CUESTIÓN C61}

La cuestión que se presenta en la ficha 6.61 corresponde al nivel de reproducción del conocimiento estudiado, conocimiento de hechos, representaciones de problemas comunes, reconocimiento de equivalentes, ejecución de problemas rutinarios, aplicación de destrezas técnicas y de algoritmos habituales, mediante el manejo de expresiones y fórmulas establecidas y realización de cálculos. 


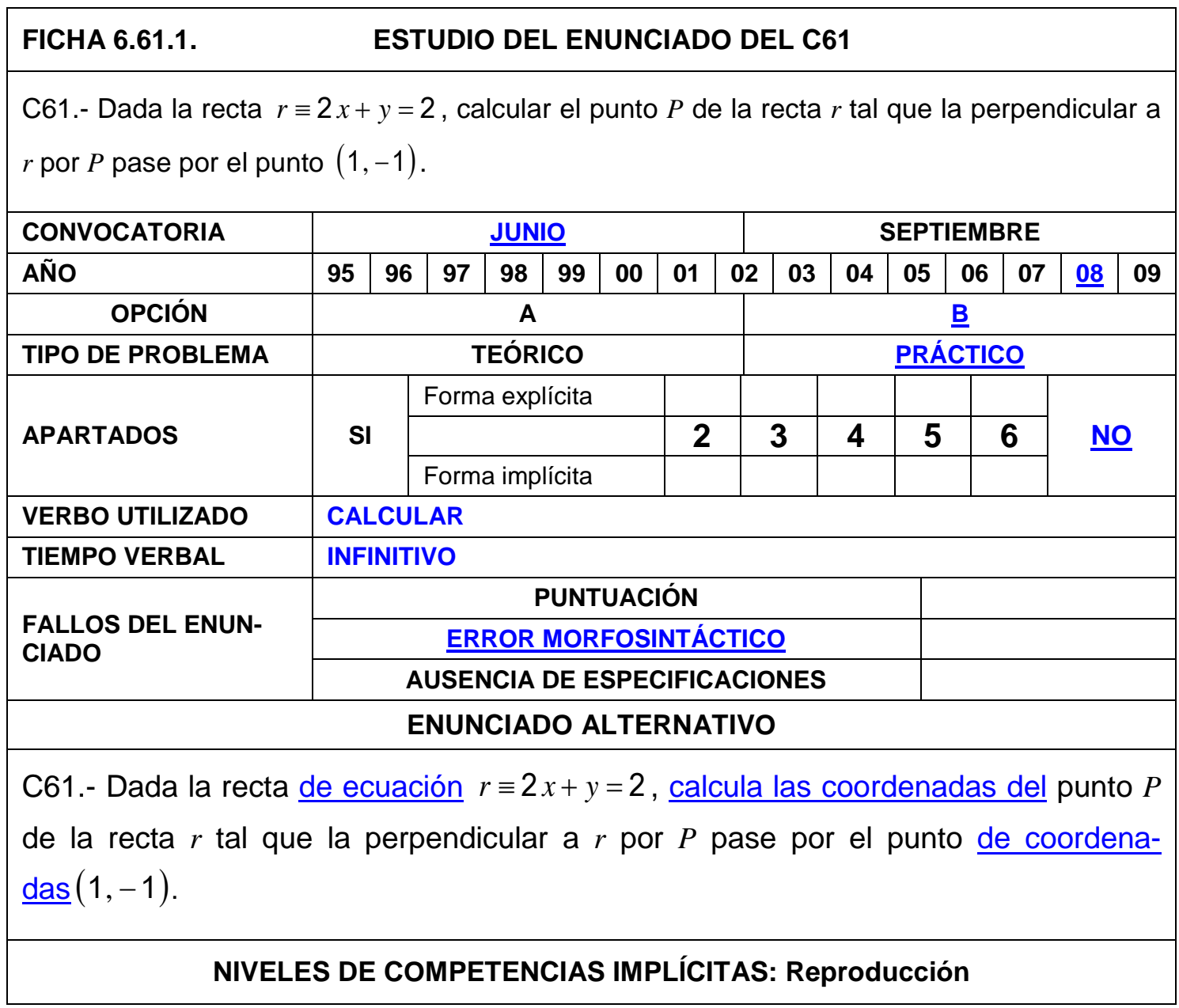

El alumno reconoce representaciones de los datos del ejercicio (RPRn1),-la ecuación general de la recta-, identifica el problema (RAn1), comprende la expresión escrita (RCn1), identifica que el modelo es similar a otros vistos con anterioridad (RMn1) y le reconoce como problema ya practicado durante la instrucción (RRPn1).

El alumno interpreta representaciones estándar de objetos matemáticos (RRn2), el punto dado por sus coordenadas, la recta dada como un sistema de ecuaciones (representación algebraica), representación gráfica (Figura 6.61) y pasa de una representación a otra (RRn3), plantea los algoritmos correspondientes (RPRn2), asocia con fórmulas establecidas y realiza los cálculos (RPRn3). A continuación

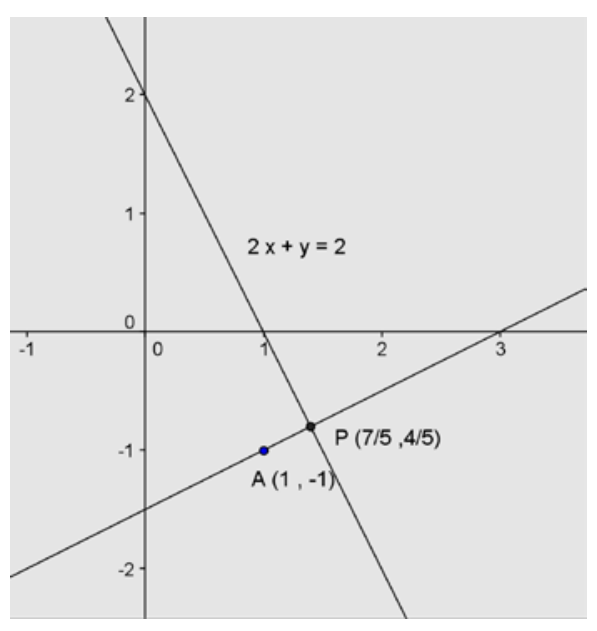

Figura 6.61 expone el proceso de cálculo (RAn2). 
La ecuación de la recta está dada en forma general, como ecuación en un plano determinado,

$$
r \equiv 2 x+y=2
$$

tiene como pendiente $m=-2$

La recta perpendicular a $r$ que pasa por el punto $P$ tiene como pendiente $m=\frac{1}{2}$ y pasa por el punto $A(1,-1)$

Con este razonamiento justifica las fórmulas utilizadas y los resultados (RAn3) y realiza explicaciones sencillas (RCn2), así reproduce problemas ya practicados de manera cerrada (RRPn2) y resuelve problemas rutinarios estandarizados (RRPn3).

Ecuación de la recta: $s \equiv x-2 y-3=0$

El punto pedido es el punto de intersección entre las rectas $r$ y $s$; y se obtiene resolviendo el sistema:

$$
\begin{aligned}
& \qquad\left\{\begin{array}{l}
2 x+y-2=0 \\
x-2 y-3=0
\end{array}\right. \\
& \text { El punto pedido es } P\left(\frac{7}{5},-\frac{4}{5}\right)
\end{aligned}
$$

El alumno comunica de manera elemental los resultados del modelo (RMn3), realiza operaciones elementales en contextos conocidos (RLSOn1), interpreta el lenguaje formal y simbólico rutinario (RLSOn2), y maneja procedimientos y

\begin{tabular}{|c|c|c|c|c|c|c|c|c|}
\hline \multicolumn{2}{|c|}{ FICHA 6.61.2. } & \multicolumn{7}{|c|}{ COMPETENCIAS IMPLÍCITAS EN LA RESOLUCIÓN DE LA C61 } \\
\hline & Nivel 1 & Nivel 2 & Nivel 3 & Nivel 1 & Nivel 2 & Nivel 3 & Nivel 1 & Nivel 2 \\
\hline PR & * & * & * & & & & & \\
\hline A & * & * & * & & & & & \\
\hline C & * & * & * & & & & & \\
\hline M & * & & * & & & & & \\
\hline $\mathbf{R P}$ & * & * & * & & & & & \\
\hline $\mathbf{R}$ & & * & * & & & & & \\
\hline \multirow[t]{2}{*}{ LSO } & * & * & * & & & & & \\
\hline & \multicolumn{3}{|c|}{ Reproducción } & \multicolumn{3}{|c|}{ Conexión } & \multicolumn{2}{|c|}{ Reflexión } \\
\hline
\end{tabular}
fórmulas, resolviendo y calculando (RLSOn3), y describe los resultados obtenidos (RCn3). 


\section{V.4. REFLEXIÓN DEL ANÁLISIS SOBRE LAS PAEU DE GEO- METRÍA}

De los 30 problemas de Geometría propuestos en los años de estudio, tan sólo 2 pertenecen al nivel de reflexión, dado que en su resolución intervienen elementos inusuales. Son los ejercicios que se presentan en las fichas 5.3.1 y 5.19.1. En el primer caso la resolución del sistema que resulta al estudiar la perpendicularidad de las dos rectas presenta niveles de reflexión asociados a las competencias argumentar, comunicar y resolver problemas.

\begin{tabular}{|c|c|c|c|c|c|c|c|c|}
\hline \multicolumn{9}{|c|}{$\begin{array}{c}\text { NIVELES DE COMPETENCIAS IMPLÍCITAS } \\
\text { PROBLEMAS DE GEOMETRÍA }\end{array}$} \\
\hline & Nivel 1 & Nivel 2 & Nivel 3 & Nivel 1 & Nivel 2 & Nivel 3 & Nivel 1 & Nivel 2 \\
\hline PR & 25 & 24 & 26 & 25 & 19 & 21 & 0 & 0 \\
\hline A & 26 & 27 & 28 & 24 & 10 & 10 & 0 & 1 \\
\hline C & 26 & 25 & 28 & 27 & 25 & 23 & 1 & 2 \\
\hline$M$ & 25 & 0 & 27 & 22 & 15 & 14 & 0 & 0 \\
\hline RP & 25 & 24 & 25 & 24 & 23 & 24 & 1 & 1 \\
\hline $\mathbf{R}$ & 0 & 2 & 1 & 27 & 27 & 3 & 0 & 0 \\
\hline LSO & 26 & 27 & 28 & 3 & 5 & 30 & 0 & 0 \\
\hline & \multicolumn{2}{|c|}{ Reproducción: } & 445 & \multicolumn{3}{|c|}{ Conexión: 401} & \multicolumn{2}{|c|}{ Reflexión: 6} \\
\hline
\end{tabular}

El problema de la ficha 5.19 se encuentra también en el nivel de reflexión por parte del estudiante para planificar estrategias y aplicarlas en la resolución de un problema que contiene elementos inusuales, pues tenemos un punto variable que depende del valor de un parámetro y nos piden las ecuaciones de una familia de rectas que dependen de dos parámetros, y tiene que aplicar estrategias no rutinarias (RfPRn2), explicar cuestiones matemáticas que implican relaciones complejas (RfCn1, RfCn2) para resolver problemas más allá de la reproducción de los ya practicados (RfRPn1).

Siguiendo la línea general de los ejercicios de las pruebas PAEU, los problemas propuestos presentan varios apartados, por esa razón están ubicados en los niveles de reproducción y conexión, ya que alguno de los apartados pertenece a un nivel o a otro. En general, los subniveles 1, 2 y 3 son semejantes en 
las distintas competencias y, al igual que en los estudios anteriores, tan solo referimos los que presentan disparidad de resultados.

El subnivel 2 del nivel reproducción, en la competencia de Modelizar, no se presenta nunca, pues corresponde a la modelización de la realidad y en ningún ejercicio de los propuestos en Gometría se plantea esta situación. Tampoco se presenta el subnivel 1 del nivel de reproducción en la competencia Representar, pues estos problemas no usan un único tipo de representación, es preciso interpretar distintas formas de representación la algebraica y la geométrica, cambiando entre las diferentes formas de representación y diferenciando entre ellas; y aunque en los ejercicios no se pide una representación gráfica, un esquema de la situación potencia la comprensión de las condiciones implicadas, lo que justifica que en la resolución de los ejercicios se realicen representaciones gráficas.

El subnivel 2 de la competencia Representar, en este nivel inferior de reproducción, está asociado a enunciados de cuestiones teóricas.

En la competencia de Argumentar, en el nivel de conexión, el alumno razona matemáticamente de manera simple (CAn1), pero el modelo no es diferente de los estudiados, salvo en raras ocasiones $y$, por tanto, no siempre sigue ni evalúa el encadenamiento de argumentos matemáticos particulares (CAn2, Can3), lo que justifica la diferencia entre dichos subniveles.

Desde el nivel de reproducción (RMn3) el alumno comunica de manera elemental los resultados del modelo, traduce en la práctica el modelo a seguir, que es algo diferente a los estudiados (CMn2) y sabe interpretar y alternar diferentes modelos y comunicar los resultados (CMn3) en la mitad de los ejercicios propuestos, pues tiene que modelizar algebraicamente situaciones geométricas.

En lo relativo a utilizar el lenguaje simbólico, formal y técnico, y las operaciones, el alumno realiza operaciones aritméticas, es decir, efectúa operaciones elementales en contextos conocidos ( (RLSOn1), interpreta el lenguaje formal y simbólico rutinario en segundo de bachillerato (RLSOn2) como son las ecuaciones de rectas y planos, las coordenadas de puntos y vectores; maneja procedimientos y fórmulas, resolviendo ecuaciones algebraicas, calculando el módulo de vectores, etc. (RLSOn3) y, en un nivel de conexión, resolviendo y calculando determinantes, en el cálculo de áreas, volúmenes, distancias, etc., el alumno utiliza variables y realiza ecuaciones y cálculos mediante procedi- 
mientos familiares, (CLSOn3) en segundo de Bachillerato. En 3 de los 30 problemas, los de las fichas $5.19,5.29$ y 5.30 se exige interpretar el lenguaje formal y simbólico básico en situaciones menos conocidas (CLSOn1), y en esos mismos ejercicios y en otros dos, el 5.18 y 5.20 es preciso manejar expresiones con símbolos y fórmulas no rutinarias (CLSOn2) .

El discurso anterior es válido para las cuestiones de Geometría. Solamente en el ejercicio de la ficha 6.40 aparece el nivel de reflexión en el subnivel 2 de la competencia Comunicar, cuando el alumno hace un razonamiento en el que explica asuntos que implican relaciones complejas, razonando sobre la posibilidad de utilizar vectores equipolentes cuando calculamos vectores directores y no poder utilizar vectores equipolentes cuando hay que calcular el área o el volumen de una figura geométrica, pues en este caso se alteran las medidas de los lados.

\begin{tabular}{|l|c|c|c|c|c|c|c|c|}
\hline \multicolumn{7}{|c|}{$\begin{array}{c}\text { NIVELS DE COMPETENCIAS IMPLÍ́CITAS } \\
\text { CUESTIONES DE GEOMETRÍA }\end{array}$} \\
\hline & Nivel 1 & Nivel 2 & Nivel 3 & Nivel 1 & Nivel 2 & Nivel 3 & Nivel 1 & Nivel 2 \\
\hline PR & 59 & 57 & 58 & 18 & 11 & 15 & 0 & 0 \\
\hline A & 58 & 56 & 61 & 16 & 4 & 4 & 1 & 0 \\
\hline C & 60 & 59 & 61 & 19 & 16 & 15 & 0 & 1 \\
\hline M & 58 & 0 & 63 & 14 & 6 & 5 & 0 & 0 \\
\hline RP & 58 & 54 & 60 & 16 & 13 & 13 & 0 & 0 \\
\hline R & 44 & 39 & 16 & 16 & 3 & 0 & 0 & 0 \\
\hline LSO & 46 & 61 & 63 & 0 & 0 & 55 & 0 & 0 \\
\hline & Reproducción: & 1091 & Conexión: 259 & Reflexión: 2 \\
\hline
\end{tabular}

En la cuestión de la ficha 6.27.1 se genera una ecuación de segundo grado en función de dos parámetros $a$ y $b$, para obtener la relación que existe entre eellos. Si el alumno resuelve la ecuación utilizando uno de los parámetros como incógnita, y el otro como coefientes, estará en un nivel de reflexión, razonando de forma sencilla, distinguiendo formas más amplias de argumentación (RfAn1).

La cuestión de la ficha 6.40.1 presenta el nivel de reflexión en la competencia de comunicar, si el alumno realiza un razonamientos concerniente a las características del vector que se origina al calcular la distancia. 
En 4 ocasiones únicamente se presentan los subniveles 2 y 3 de la competencia Argumentar, en el nivel de Conexión, en tres de ellas ambos subniveles a la vez, la cuestión de la ficha 6.23 el subnivel 2 (CAn2), pues el alumno sigue el encadenamiento de argumentos matemáticos particulares, al justificar que va a calcular la ecuación del plano perpendicular, a una recta dada, que pasa por un punto establecido; "pues todas las rectas de ese plano son perpendiculares a la recta fijada", mientras que en el de la ficha 6.55 el alumno tiene que calcular el valor de una incógnita que hace que tres puntos sean vértices de un triángulo rectángulo, y una vez obtenido ese valor evalúa el encadenamiento de argumentos matemáticos particulares (CAn3).

El lenguaje utilizado tanto en símbolos como en operaciones es rutinario para un alumno de este nivel, por tanto no se presentan los subniveles 1 y 2 del nivel conexión, en la competencia Utilizar el lenguaje formal, simbólico y técnico y las operaciones; aún cuando elalumno utiliza variables y realiza ecuaciones y cálculos mediante procedimientos familiares, (CLSOn3), pues el cálculo de determinantes, y de los productos con vectores, aún siendo reproducidos de manera repetitiva en la instrucción, no son de mera rutina.

Las cifras son claro referente de las hipótesis $\mathrm{H} 4$ y H5 formuladas. En cuestiones las reproducciones son el cuádruplo de las conexiones y en problemas más del doble. La presencia de los ejercicios que presentan nivel de reflexión es totalmente accidental. 


\section{CAPÍTULO VII}

\section{ANÁLISIS MORFOSINTÁCTICO DE LOS ENUNCIADOS}

\section{VII.1. INTRODUCCIÓN}

En el presente capítulo se analizan los enunciados de los problemas y de las cuestiones de Análisis, Álgebra y Geometría desde la perspectiva lexicográfica. Algunos enunciados son correctos desde este punto de vista, pero su comprensión mejora con una relación alternativa.

Por otra parte se tienen en cuenta las recomendaciones sobre la redacción de los enunciados de las pruebas que están destinadas a evaluar los conocimientos adquiridos por los alumnos.

Según Lansdheere $(1992,101)$, fue el racionalista Thorndike quien propuso una serie de características que deben estar implícitas en las pruebas de evaluación escritas y para él se deben observar las siguientes:

-Antes de comenzar a redactar el enunciado de una cuestión se debe considerar el proceso mental que se desea que el alumno utilice para dar respuesta a la misma.

-Las preguntas han de estar redactadas de forma que sean claras y concisas y que estén adaptadas en su complejidad al nivel de madurez del alumno; de hecho, en bastantes ocasiones, las respuestas equivocadas no se deben a la ignorancia de la materia, sino a la incomprensión del enunciado.

-El enunciado de un problema debe contener un imperativo en lugar de un interrogativo. Esta forma de enunciar un problema hace que falte la acción mandato principal: Calcula, halla, determina, etc. 


\section{VII.2. DESCRIPCIÓN DEL ANÁLISIS}

En este apartado, por razones de espacio, se realiza el análisis de los enunciados en unos cuantos problemas y cuestiones que constituyen ejemplos de las pruebas de acceso propuestas en las universidades de Castilla y León durante el periodo 1995-2009. En todos los casos se escribe el enunciado propuesto y el enunciado alternativo

La elección de los ejemplos que se reflejan en este capítulo no es totalmente aleatoria; no se van a repetir aquí todos los enunciados estudiados y por esta razón se han eligido algunos modelos que presenten pequeñas modificaciones.acompañados de otro en los que los cambios son más sustanciales.

Según la Real Academia Española (RAE) no es lo mismo limitar que delimitar, y la palabra apropiada en los enunciados del cálculo de áreas es la de delimitar: "Determinar o fijar con precisión los límites de una cosa" y no la palabra limitar: "Poner límites a un terreno, o bien, estar contiguos dos terrenos." Las dos tablas siguientes son un ejemplo de esta aseveración.

FICHA 1.11.1.

ESTUDIO DEL ENUNCIADO DEL P11

P11.- a) Enunciar la regla de Barrow.

b) Calcular el área limitada por la bisectriz del primer cuadrante y la curva de ecuación $y=3 x^{2}$.

ENUNCIADO ALTERNATIVO

P11.- a) Enuncia la regla de Barrow.

b) Calcula el área del recinto plano delimitado por la bisectriz del primer cuadrante y la curva de ecuación $y=3 x^{2}$.

FICHA 2.32.1.

ESTUDIO DEL ENUNCIADO DE LA C32

C32.- Hallar el área del recinto limitado por la recta $y=3-2 x$ y la parábola $y=2 x-x^{2}$.

ENUNCIADO ALTERNATIVO

C32.- Halla el área del recinto delimitado por la recta $y=3-2 x$ y la parábola $y=2 x-x^{2}$. 
FICHA 1.15.1.

ESTUDIO DEL ENUNCIADO DEL P15

P15.- Por el punto de abscisa $x=1$ de la parábola de ecuación $y=x-x^{2}$ se traza una recta $r$ perpendicular a la tangente a la curva en dicho punto. Hallar el área del recinto limitado por la recta $r$ y la parábola.

\section{ENUNCIADO ALTERNATIVO}

P15.- Considera la recta tangente en el punto $x=1$ a la parábola de ecuación $y=x-x^{2} \underline{\text { Por dicho punto, }}$ se traza una recta $r \underline{\text { que es }}$ perpendicular a esta tangente. Halla el área del recinto delimitado por la recta $r$ y la parábola.

Este error no supone un obstáculo para que el alumno resuelva el problema, ya que éste interpreta que le piden una integral definida y no cuestiona la significación del enunciado; sin embargo, la matemática debe contribuir al desarrollo de la competencia lingüística y, por tanto, se debe evitar escribiendo con precisión.

El uso del infinitivo como orden en el enunciado de un problema está admitido por la Real Academia, pero, como se ha indicado en la introducción, es más propio presentar el enunciado en forma imperativa. El infinitivo es una forma verbal no personal, y los enunciados se proponen a sujetos, los alumnos, luego lo indicado es estar enfocados a ellos.

FICHA 1.17.1.

ESTUDIO DEL ENUNCIADO DEL P17

P17.- Se consideran en la parábola $y=x^{2}$ los puntos $A$ y $B$ de abscisas $x=1$ y $x=3$.

a) Hallar la ecuación de la tangente a la parábola que es paralela a la recta que pasa por los puntos $A$ y $B$.

b) Hallar el área encerrada por la curva, la tangente obtenida y el eje $O Y$.

\section{ENUNCIADO ALTERNATIVO}

P17.- Se consideran en la parábola $y=x^{2}$ los puntos $A$ y $B$ de abscisas $x=1$ y $x=3$ :

a) Halla la ecuación de la recta tangente a la parábola que es paralela a la recta que pasa por los puntos $A$ y $B$.

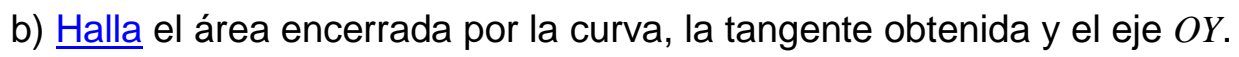


FICHA 6.6.1.

ESTUDIO DEL ENUNCIADO DEL C6

C6.- Estudiar la posición relativa de las rectas: $r: \frac{x-1}{2}=\frac{y-1}{3}=\frac{z-1}{2}$ y $s: x=1-y=1-2 z$.

\section{ENUNCIADO ALTERNATIVO}

C6.- Estudia la posición relativa de las rectas $\underline{r y s} \underline{\mathrm{y}} \underline{\mathrm{de}}$ ecuaciones: $r: \frac{x-1}{2}=\frac{y-1}{3}=\frac{z-1}{2}$ y $s: x=1-y=1-2 z$.

FICHA 3.3.1.

ESTUDIO DEL ENUNCIADO DEL P3

P3.- Estudiar, según los valores de $a$, la compatibilidad del sistema:

$$
\left\{\begin{array}{c}
-x+y-a z=-a \\
-x+y+z=1 \\
-3 x+(a+1) y+2 z=3
\end{array}\right.
$$

y resolverlo cuando sea compatible.

\section{ENUNCIADO ALTERNATIVO}

P3.- a) Estudia la compatibilidad del sistema, según los valores de $a$ :

$$
\left\{\begin{array}{l}
-x+y-a z=-a \\
-x+y+z=1 \\
-3 x+(a+1) y+2 z=3
\end{array}\right.
$$

b) Resuélvelo cuando sea compatible.

En los exámenes correspondientes al periodo 2004-2006, en el enunciado de los problemas y cuestiones aparece el verbo con un pronombre clítico. (Ejemplo: Calcúlese, estúdiese, etc.) que indica un mandato, que se realice esa acción.

La utilización de los clíticos denota un nivel alto en el conocimiento del lenguaje, es un lenguaje culto puesto que ese pronombre, en muchas ocasiones, hace de objeto indirecto, y con una palabra compuesta (verbo + pronombre = estudie + se) señala la cuestión que el alumno debe resolver. La presencia de clíticos es correcta, pero en Castilla no se suele utilizar esa formulación. Además es innegable que esta forma pronominal tiene cierto grado de impersonalidad (Hagáse tu voluntad así en la tierra como en el cielo). 
FICHA 6.45.1.

ESTUDIO DEL ENUNCIADO DEL C45

C45.- Hállese la ecuación del plano que contiene a la recta $r \equiv x=y=z$ y es perpendicular al plano $\pi \equiv x+y-z-1=0$.

\section{ENUNCIADO ALTERNATIVO}

C45.- Escribe la ecuación del plano que contiene a la recta de ecuaciones $r \equiv x=y=z$ y es perpendicular al plano de ecuación $\pi \equiv x+y-z-1=0$.

FICHA 1.43.1.

ESTUDIO DEL ENUNCIADO DEL P43

P43.- Sea $f(x)=e^{x}+\ln (x), x \in(0, \infty)$.

b) Estúdiense los intervalos de crecimiento y decrecimiento de $f$ y sus asíntotas.

b) Pruébese que $f$ tiene un punto de inflexión en el intervalo $\left[\frac{1}{2}, 1\right]$ y esbócese la gráfica de $f$.

\section{ENUNCIADO ALTERNATIVO}

P43.- Dada la función $f(x)=e^{x}+\ln (x), x \in(0, \infty)$.

e) Calcula los intervalos de crecimiento y decrecimiento de $\underline{f(x)}$.

f) Escribe las ecuaciones de sus asíntotas.

g) Prueba que $f(x)$ tiene un punto de inflexión en el intervalo $\left[\frac{1}{2}, 1\right]$.

h) Esboza la gráfica de $f(x)$.

Por otra parte, la forma verbal discutir, según la RAE, significa: "Dicho de dos o más personas: Examinar atenta y particularmente una materia", pero es evidente que existen otras formas verbales más adecuadas para este tipo de enunciados (analizar, discernir, ...)"analizar", "examinar", "discernir", "diferenciar", "especificar", "precisar", que se refieren directamente a la acción que el examinador desea que se realice, es decir, que el alumno diferencie los distintos tipos de sistemas lineales que se puede encontrar cuando el enunciado corresponde a una familia dependiente de un parámetro. 
FICHA 3.19.1.

ESTUDIO DEL ENUNCIADO DEL P19

P19.- a) Discútase el sistema $\left\{\begin{array}{c}x+a y-z=2 \\ 2 x+y+a z=0 \\ 3 x+(a+1) y-z=a-1\end{array}\right.$, en función del valor de $a$.

b) Para el valor $a=1$, hállese, si procede, la solución del sistema.

\section{ENUNCIADO ALTERNATIVO}

P19.- a) Analiza el sistema $\left\{\begin{array}{c}x+a y-z=2 \\ 2 x+y+a z=0 \\ 3 x+(a+1) y-z=a-1\end{array}\right.$, en función del valor de $a$.

b) Para el valor $a=1$ halla la solución del sistema, si procede.

En el apartado a) de los siguientes ejercicios no hay una oración gramatical, porque carece de verbo. Lo correcto es incluir un verbo en forma imperativa o con una enclisis gramatical para formular el mandato (se recaería en una forma clítica). La omisión de la acción verbal denota la ausencia de mandato y, en consecuencia, los alumnos podrían contestar de manera que sus respuestas no coincidieran en la dirección que se pretendía al formular la cuestión. En el ejemplo de la tabla 1.18.1 los alumnos podrían dar la definición de máximo y mínimo, pero también podrían haber hecho una descripción o una gráfica o poner un ejemplo o una tabla numérica. Así, el enunciado es ambiguo.

FICHA 1.18.1.

ESTUDIO DEL ENUNCIADO DEL P18

P18.- a) Concepto de máximo y mínimo local.

b) Se quiere dividir un alambre de 2 unidades de longitud en dos partes para construir un triángulo equilátero y una circunferencia, de forma que la suma del área del triángulo y del círculo correspondiente sea mínima. Determinar las longitudes de cada una de las partes.

\section{ENUNCIADO ALTERNATIVO}

P18.- a) Escribe el concepto de máximo y mínimo local.

b) Se quiere dividir un alambre de 2 unidades de longitud en dos partes para construir un triángulo equilátero y una circunferencia, de forma que la suma del área del triángulo y del círculo correspondiente sea mínima. Determina la longitud de cada una de las partes. 
FICHA 2.14.1.

ESTUDIO DEL ENUNCIADO DE LA C14

C14.- Concepto de función primitiva. Determinar una primitiva de la función $(\cos x) e^{\operatorname{sen} x}$.

\section{ENUNCIADO ALTERNATIVO}

C14.- a) Define el concepto de función primitiva.

b) Determina una función primitiva de la función $f(x)=(\cos (x)) e^{\operatorname{sen}(x)}$.

En la redacción de muchos enunciados se ha utilizado un método sintético y resulta más correcto hacerlo de una forma más analítica, pues cada parte tiene que llevar su verbo pertinente. Es decir, cuando hay varias preguntas es más correcto escribir un apartado para cada una de ellas. De hecho, a veces, el alumno no responde a algún apartado del problema, pues al ser propuesta la orden en forma implícita éste la olvida en el desarrollo del mismo. Como ejemplo en la tabla de la ficha 6.1.1 la orden "calcula el área" aparece escrita en una forma implícita y puede pasar fácilmente desapercibida en el contexto general del enunciado.

FICHA 1.42.1.

ESTUDIO DEL ENUNCIADO DEL P42

P42.- a) Calcúlense los intervalos de crecimiento y decrecimiento de la función $f(x)=e^{1-x^{2}}$, sus extremos relativos, puntos de inflexión y asíntotas.

b) Esbócese la gráfica de $f$ y calcúlese $\int_{1}^{3} x f(x) d x$.

P42.- a) Calcula los intervalos de crecimiento y decrecimiento de la función $f(x)=e^{1-x^{2}}$.

b) Calcula sus extremos relativos.

a) Calcula sus puntos de inflexión.

b) Escribe las ecuaciones de sus asíntotas.

c) Esboza la gráfica de $f(x)$.

d) Calcula $\int_{1}^{3} x f(x) d x$. 
FICHA 4.45.1.

ESTUDIO DEL ENUNCIADO DEL C45

C45.- Hallar para qué valores de $a$ es inversible la matriz $A=\left(\begin{array}{cc}a & 4+3 a \\ 1 & a\end{array}\right)$ y calcular la inversa para $a=0$.

\section{ENUNCIADO ALTERNATIVO}

C45.- $\underline{\text { a) }}$ Halla para qué valores de $a$ la matriz $A=\left(\begin{array}{cc}a & 4+3 a \\ 1 & a\end{array}\right)$ es inversible.

b) Calcula la inversa para $a=0$

FICHA 6.1.1.

ESTUDIO DEL ENUNCIADO DEL C1

C1.- Comprobar que los puntos $A=(3,2,2), B=(4,1,0), C=(0,1,1)$ y $D=(1,0,-1)$ son vértices de un paralelogramo y calcular su área.

\section{ENUNCIADO ALTERNATIVO}

C1.- Comprueba que los puntos de coordenadas $A=(3,2,2), B=(4,1,0)$, $C=(0,1,1)$ y $D=(1,0,-1)$ son vértices de un paralelogramo.

b) Calcula su área.

En muchos enunciados de Análisis Matemático encontramos que se pide el estudio y representación gráfica de una función, con apartados implícitos que bajo el mismo verbo piden acciones no correspondientes.

En la tabla de la ficha 1.24.1, por ejemplo: "Estudiar el dominio de definición, intervalos de crecimiento y decrecimiento, extremos relativos, puntos de inflexión y asíntotas, representando gráficamente la función dada" .y en ese genérico "estudiar" incluye acciones como: "Calcular el dominio de definición", "Escribir las coordenadas de los puntos" que son extremos relativos o puntos de inflexión", "Escribir la ecuación de la recta" que es una asíntota y explicitar el tipo de asíntota al que corresponde la ecuación. La redacción del problema expuesto a continuación, induce a que la orden pueda entenderse en el sentido contrario al que se requiere la acción; esto es, tras el estudio de una función ésta se representa, pero el enunciado parece indicar que primero se represente y a partir de esa imagen se realice el "estudio". 
P24.- Se considera la función $y=x^{2} \cdot e^{-x}$. Estudiar el dominio de definición, intervalos de crecimiento y decrecimiento, extremos relativos, puntos de inflexión y asíntotas, representando gráficamente la función dada.

\section{ENUNCIADO ALTERNATIVO}

P24.- Se considera la función $y=x^{2} \cdot e^{-x}$ :

a) Estudia el dominio de definición.

b) Determina los intervalos de crecimiento y decrecimiento,.

c) Calcula los extremos relativos.

d) Evalúa los puntos de inflexión

e) Escribe las ecuaciones de las asíntotas.

f) Representa gráficamente la función dada.

En los enunciados de Geometría la omisión de especificaciones es una constante repetida en muchos ejercicios. "Encontrar un plano, una recta, un punto o un vector" son propuestas continuas en los mismos, como si éstos fueran entes físicos, cuando el alumno a lo más que puede llegar es a escribir las ecuaciones de una recta o de un plano, las coordenadas de un punto o de un vector; etc.

FICHA 6.30.1. ESTUDIO DEL ENUNCIADO DEL C30

C30.- Consideramos el punto $A(1,4,2)$, la recta $r \equiv \frac{x}{2}=\frac{y-1}{3}=\frac{z}{1}$ y el plano $\pi \equiv x+y+z-1=0$. Calcular la recta que pasa por $A$, es paralela a $\pi$ y corta a $r$.

\section{ENUNCIADO ALTERNATIVO}

C30.- Dado el punto de coordenadas $A(1,4,2)$, la recta de ecuaciones $r \equiv \frac{x}{2}=\frac{y-1}{3}=\frac{z}{1}$ y el plano de ecuación $\pi \equiv x+y+z-1=0$. Escribe las ecuaciones de la recta que pasa por $A$, es paralela a $\pi$ y corta a $r$. 
FICHA 5.10.1.

ESTUDIO DEL ENUNCIADO DEL P10

P10.- Dadas las rectas $r \equiv \frac{x-1}{1}=\frac{y+1}{2}=\frac{z-2}{1} ; s \equiv\left\{\begin{array}{c}x-y+z=2 \\ 3 x-y-z=-4\end{array}\right.$

Determinar:

a) Posición relativa de ambas rectas.

b) Área de uno de los cuadrados, dos de cuyos lados están sobre $r$ y $s$.

\section{ENUNCIADO ALTERNATIVO}

P10.- Dadas las rectas $r y s$ de ecuaciones: $\quad r \equiv \frac{x-1}{1}=\frac{y+1}{2}=\frac{z-2}{1} \quad \mathrm{y}$ $s \equiv\left\{\begin{array}{c}x-y+z=2 \\ 3 x-y-z=-4\end{array}\right.$

a) Estudia la posición relativa de ambas rectas.

b) Calcula el área de uno de los cuadrados, dos de cuyos lados están sobre las rectas $r$ y s.

Este lapsus no es óbice para que el alumno realice cálculos, mediante procedimientos mecánicos, que le conducen a escribir ecuaciones y coordenadas sin cuestionarse la imposibilidad de encontrar una recta o un plano, ambos objetos abstractos e infinitos, en un mundo real.

FICHA 6.32.1.

ESTUDIO DEL ENUNCIADO DEL C32

C32.- Calcular la distancia entre la recta $r \equiv \frac{x-1}{2}=y-2=\frac{z-1}{-1}$ y el plano $\pi \equiv x-y+z+2=0$.

\section{ENUNCIADO ALTERNATIVO}

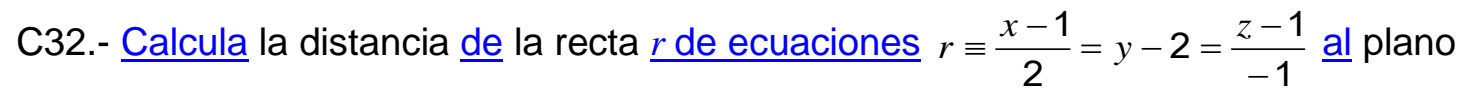
de ecuación $\pi \equiv x-y+z+2=0$.

La preposición entre, según la RAE, "Denota la situación o estado en medio de dos o más cosas" y no es la expresión adecuada para pedir el cálculo de distancias, pues lo que se requiere es la distancia total que hay de un punto a una recta, de una recta a un plano o de un plano a otro plano, no los valores intermedios. 
La respuesta a esa pregunta debiera darse en términos de desigualdades y el alumno no lo hace porque ha aprendido a responder lo que se supone que le quieren preguntar y en las sesiones de coordinación para la corrección de las pruebas nunca se ha hecho mención a esa particularidad.

\section{FICHA 5.5.1.}

\section{ESTUDIO DEL ENUNCIADO DEL P5}

P5.- Se consideran las rectas $r \equiv x=\frac{y}{2}=\frac{z}{3}$ y $s \equiv x-1=y-2=z-1$.

a) Determinar su posición relativa.

b) Calcular la distancia entre ambas rectas.

\section{ENUNCIADO ALTERNATIVO}

P5.- Se consideran las rectas de ecuaciones, $r \equiv x=\frac{y}{2}=\frac{z}{3}$ y $s \equiv x-1=y-2=z-1$ :

a) Determina su posición relativa.

b) Calcula la distancia de la recta $r$ a la recta $s$.

Las expresiones sea o sean no están registradas en el Diccionario y son arcaísmos léxicos; sin embargo aparecen repetidas veces en enunciados como: "Sea la función, sea la matriz, sean las rectas, etc." En su lugar existen otras expresiones como "dada una función", "se considera la matriz", etc.

\section{FICHA 1.39.1.}

\section{ESTUDIO DEL ENUNCIADO DEL P39}

P39.- Sea $f(x)=x^{3}+a x^{2}+b x+c$. Determínense $a, b$ y $c$ de modo que $f(x)$ tenga un extremo relativo en $x=0$, la recta tangente a la gráfica de $f(x)$ en $x=1$ sea paralela a la recta $y-4 x=0$, y el área comprendida por la gráfica de $f(x)$, el eje $O X$ y las rectas $x=0$, $x=1$, sea igual a 1 .

\section{ENUNCIADO ALTERNATIVO}

P39.- Dada la función $f(x)=x^{3}+a x^{2}+b x+c$. Determina los valores de $a, b$ y $c$ de modo que $f(x)$ tenga un extremo relativo en $x=0$, la recta tangente a la gráfica de $f(x)$ en $x=1$ sea paralela a la recta $y-4 x=0$, y el área comprendida entre la gráfica de $f(x)$, el eje $O X$ y las rectas $x=0, x=1$, sea igual a 1 . 
FICHA 1.38.1.

ESTUDIO DEL ENUNCIADO DEL P38

P38.- Sea la función $y=2 e^{-2|x|}$.

e) Estúdiese su monotonía, extremos relativos y asíntotas.

f) Calcúlese el área de la región plana comprendida entre la gráfica de la función y las rectas $x=1$ y $x=-1$.

\section{ENUNCIADO ALTERNATIVO}

P38.- Dada la función $y=2 e^{-2|x|}$.

a) Estudia su monotonía.

b) Calcula sus extremos relativos

c) Escribe las ecuaciones de sus asíntotas.

d) Calcula el área de la región plana comprendida entre la gráfica de la función $y$ las rectas $x=1$ y $x=-1$.

FICHA 4.20.1.

ESTUDIO DEL ENUNCIADO DEL C20

C20.- Sean $A$ y $B$ matrices cuadradas con $|A|=2$ y $|B|=3$. Razonar cuánto vale el determinante de la matriz $B^{-1} \cdot A \cdot B$.

\section{ENUNCIADO ALTERNATIVO}

C20.- Dadas dos matrices cuadradas $A$ y $B$ con $|A|=2$ y $|B|=3$, razona cuánto vale el determinante de la matriz $B^{-1} \cdot A \cdot B$.

FICHA 5.8.1.

ESTUDIO DEL ENUNCIADO DEL P8

P8.- Sean los puntos $A(7,4,5)$ y $B(-5,-4,-1)$ y sea $\pi$ el plano perpendicular al segmento $A B$ en su punto medio. Calcular el área del triángulo $P Q R$, siendo $P, Q$ y $R$ los puntos en que $\pi$ corta a los ejes coordenados.

\section{ENUNCIADO ALTERNATIVO}

P8.- $\underline{\text { Dados }}$ los puntos de coordenadas $A(7,4,5)$ y $B(-5,-4,-1)$ se considera el plano $\pi$ perpendicular al segmento $A B$ en su punto medio. Calcula el área del triángulo $P Q R$, siendo $P, Q$ y $R$ los puntos en los que el plano $\pi$ corta a los ejes coordenados. 
En los siguientes enunciados hemos escrito el artículo (determinado o indeterminado), que es la parte de la oración que concreta y limita el significado del nombre al que acompaña.

\section{FICHA 1.16.1.}

\section{ESTUDIO DEL ENUNCIADO DEL P16}

P16.- Se quiere vallar un terreno rectangular situado junto a una carretera. Si la valla que está junto a la carretera cuesta a 2.400 pesetas por metro, y la del resto a 1.200 pesetas por metro, hallar el área del mayor campo que puede cercarse con un presupuesto de 432.000 ptas.

\section{ENUNCIADO ALTERNATIVO}

P16.- Se quiere vallar un terreno rectangular situado junto a una carretera. La valla que está junto a la misma cuesta a 2.400 pesetas el metro, y la del resto a 1.200 pesetas el metro. Halla el área del mayor campo que puede cercarse, con un presupuesto de 432.000 ptas.

FICHA 1.8.1.

ESTUDIO DEL ENUNCIADO DEL P8

P8- De todos los recipientes en forma de cono de revolución cuya generatriz mide $20 \mathrm{~cm}$, halla la altura del que tiene volumen máximo.

\section{ENUNCIADO ALTERNATIVO}

P8- De todos los recipientes en forma de cono de revolución ${ }_{2}$ cuya generatriz mide $20 \mathrm{~cm}$, halla la altura del que tiene el volumen máximo.

\section{FICHA 5.3.1.}

\section{ESTUDIO DEL ENUNCIADO DEL P3}

P3.- Dadas las rectas

$$
r_{1}:\left\{\begin{array}{c}
x+p y+z=1 \\
x+y=p
\end{array} \quad r_{2}: \frac{x-1}{1}=\frac{y+2}{-1}=\frac{z}{q}\right.
$$

hallar los valores de $p$ y q para que sean coplanarias y perpendiculares. ¿Cuál es la ecuación del plano que las contiene?

ENUNCIADO ALTERNATIVO

P3.- Dadas las rectas de ecuaciones: $r_{1}:\left\{\begin{array}{c}x+p y+z=1 \\ x+y=p\end{array} \quad r_{2}: \frac{x-1}{1}=\frac{y+2}{-1}=\frac{z}{q}\right.$.

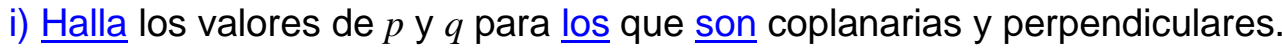

ii) Escribe la ecuación del plano que las contiene. 
Algunos enunciados han tenido que ser totalmente reestructurados pues su expresión, cuando menos, es ambigua.

FICHA 2.8.1.

ESTUDIO DEL ENUNCIADO DE LA C8

C8- La derivada de la función $f(x)=(x-1)(x+2) e^{-x^{2}}+3$ ¿Se anula por lo menos en un punto del intervalo $(-2,1)$ ? Razona tu respuesta, indicando en qué resultado teórico te has basado.

\section{ENUNCIADO ALTERNATIVO}

C8- Se considera la función $f(x)=(x-1)(x+2) e^{-x^{2}}+3$. Explica si la función derivada se anula por lo menos en un punto del intervalo $(-2,1)$, indicando en qué resultado teórico te has basado.

FICHA 2.4.1.

ESTUDIO DEL ENUNCIADO DE LA C4

C4.- ¿Puedes poner un ejemplo de función continua en un punto y no derivable en el mismo? ¿Y de una función derivable en un punto pero no continua en él?

\section{ENUNCIADO ALTERNATIVO}

C4.- a) Escribe un ejemplo de función continua en un punto que no sea derivable en dicho punto.

b) Explica si una función derivable en un punto puede ser no continua en él.

FICHA 1.25.ESTUDIO DEL ENUNCIADO DEL P25

P25.- Tenemos que vallar un terreno circular y un terreno cuadrado, que por uno de sus lados está limitado por una casa. Calcular el área del terreno circular y del terreno cuadrado que se pueden cercar, utilizando 150 metros de valla, con la condición de que la suma de dichas áreas sea mínima.

P25.- Se quiere vallar dos terrenos: uno circular y otro cuadrado. El cuadrado tiene uno de sus lados limitado por una casa. Calcula las áreas del terreno circular y del terreno cuadrado que se pueden cercar, utilizando 150 metros de valla, con la condición de que la suma de dichas áreas sea mínima. 
FICHA 1.13.1.

ESTUDIO DEL ENUNCIADO DEL P13

P13.- a) Concepto de máximo y mínimo relativo.

b) El coste de un marco para una ventana se estima en 1.250 ptas. por cada metro de altura y 880 ptas. por cada metro de anchura. La ventana tendrá una superficie de un metro cuadrado. ¿Qué dimensiones debe tener la ventana para que el marco resulte lo más económico posible?

\section{ENUNCIADO ALTERNATIVO}

P13.- a) Escribe el concepto de máximo y mínimo relativo.

b) La superficie de una ventana es de $1 \mathrm{~m}^{2}$. Calcula qué dimensiones debe tener para que el marco resulte lo más económico posible; sabiendo que el metro lineal de los listones verticales es de 1.250 ptas y el de los horizontales 880 ptas.

En ejercicios como el siguiente se presentan errores de puntuación.

FICHA 1.20.1.

ESTUDIO DEL ENUNCIADO DEL P20

P20.- Una partícula se mueve por la curva $y=\frac{2 x+1}{x-2} \quad x>2$. En el punto $P$ de abscisa $x=3$, abandona la curva y se desplaza a lo largo de la recta tangente a la curva en dicho punto.

a) Calcular la ecuación de la recta tangente en $P$.

b) Hallar el punto en el que la partícula encuentra a la asíntota horizontal de la curva.

c) Hallar el área encerrada por la curva, la recta tangente y las rectas cuyas ecuaciones son $x=3$ y $x=4$.

\section{ENUNCIADO ALTERNATIVO}

P20.- Una partícula se mueve por la curva $y=\frac{2 x+1}{x-2} \quad x>2$. En el punto $P_{2}$ de abscisa $x=3$ abandona la curva y se desplaza a lo largo de la recta tangente a la curva en dicho punto.

a) Calcula la ecuación de la recta tangente en el punto $P$.

b) Halla el punto en el que la partícula corta a la asíntota horizontal de la curva.

c) Halla el área encerrada por la curva, la recta tangente y las rectas cuyas ecuaciones son $x=3$ y $x=4$. 
FICHA 4.32.1.

ESTUDIO DEL ENUNCIADO DEL C32

C32.- Se tiene una matriz $M$ cuadrada de orden 3 cuyas columnas son respectivamente $C_{1}, C_{2}$ y $C_{3}$ y cuyo determinante vale 2 . Se considera la matriz $A$ cuyas columnas son $-C_{2}, C_{3}+C_{2}, 3 C_{1}$. Calcúlese razonadamente el determinante de $A^{-1}$ en caso de que exista esa matriz.

\section{ENUNCIADO ALTERNATIVO}

C32.- Dada una matriz cuadrada $M_{2}$ de orden $3_{1}$ cuyas columnas son $C_{1}, C_{2}$ y $C_{3}$, respectivamente, y cuyo determinante vale 2 . Se considera la matriz A cuyas columnas son $-C_{2}, C_{3}+C_{2}, 3 C_{1}$. Calcula razonadamente el determinante de $A^{-1}$ en caso de que exista esa matriz.

$Y$ aquellos ejercicios que se formulan como una pregunta tan impersonal y carente de sentido que el alumno podría responder con un lacónico Si o NO, y la puntuación del ejercicio debiera ser positiva.

FICHA 2.15.1.

ESTUDIO DEL ENUNCIADO DE LA C15

C15.- ¿Una función polinómica de grado 2 puede tener dos máximos? ¿Y algún punto de inflexión? Razonar las respuestas.

\section{ENUNCIADO ALTERNATIVO}

C15.- a) Analiza de forma razonada si una función polinómica de grado 2 puede tener dos máximos

b) Estudia si dicha función polinómica puede tener algún punto de inflexión.

FICHA 6.3.1.

ESTUDIO DEL ENUNCIADO DEL C3

C3.- El vector $\vec{v}$ es ortogonal a los vectores $\vec{a}$ y $\vec{b}$. ¿Será ortogonal al vector $\vec{a}+\vec{b}$ ? ¿Y al $\vec{a}-\vec{b}$ ?

\section{ENUNCIADO ALTERNATIVO}

C3.- El vector $\vec{v}$ es ortogonal a los vectores $\vec{a}$ y $\vec{b}$. Estudia si es ortogonal al vector $\vec{a}+\vec{b}$.

b) Estudia también si es ortogonal al vector $\vec{a}-\vec{b}$ 


\section{VII.3 REFLEXIONES}

Del análisis previo se deduce que los enunciados tienen bastantes incorrecciones, entre las que abundan el uso de infinitivos, ausencia de determinantes, utilización de vocablos cuyo significado no corresponde a la acción que se requiere (limitar en lugar de delimitar, entre para denotar la distancia de un objeto a otro objeto, ...), utilizar una oración interrogativa en lugar de una oración imperativa, enunciados con una redacción, cuando menos, ambigua, ...

De todo lo expuesto anteriormente se deduce que los enunciados admiten una redacción más precisa. La discusión más amplia aparece en el capítulo de conclusiones. 



\section{CAPÍTULO VIII}

\section{CONCLUSIONES}

\section{VIII.1. INTRODUCCIÓN}

En este capítulo se presentan las conclusiones de la investigación realizada, apoyadas en las distintas secciones de análisis y de resolución de ejercicios. El trabajo como profesora de alumnos que han realizado las pruebas PAU me lleva a conocer los ejercicios propuestos y a observar la cadencia repetitiva que las determina. Preparar pruebas de examen es un arduo trabajo, eso no se duda, pero es seguro que la comisión de expertos que realiza esta tarea están capacitados para ella, y por eso surge la pregunta, ¿será la excesiva conformidad con la obtención de resultados positivos la que lleva a la monotonía y la reiteración de enunciados?

Examinamos trabajos de investigación sobre enseñanza y aprendizaje de las matemáticas, sobre evaluación y sobre competencias matemáticas. Tras revisar la documentación que pudimos obtener, observamos que ninguna publicación trataba el estudio de los ejercicios de selectividad en la línea que nosotros le habíamos enfocado. Hay páginas en internet con ejercicios resueltos de selectividad, hay algunos estudios de problemas de primaria y las competencias matemáticas que se examinan en ellos, pero el estudio que nosotros presentamos es más profundo y abarca un abanico más amplio. No se trata simplemente de un solucionario de los ejercicios propuestos en las pruebas de selectividad a las universidades de Castilla y León, trabajo que está al alcance de la mano de cualquier profesor de matemáticas de Bachillerato, sino de un detallado análisis de las competencias presentes en las etapas de resolución y una pretendida mejora en la propuesta de unos enunciados, que en muchos casos son manifiestamente mejorables.

A continuación señalamos las aportaciones que podemos hacer con nuestra monografía, las conclusiones a las que hemos llegado con nuestra investiga- 
ción, hacemos una propuesta de evaluación, relatamos las limitaciones que hemos tenido en la realización del estudio y, finalmente, los problemas abiertos que dejamos para posteriores investigaciones.

\section{VIII.2. APORTACIONES DE LA INVESTIGACIÓN}

Una de las aportaciones de nuestra investigación es, sin duda, todo el material que hemos elaborado con la solución de todas las pruebas propuestas en los quince años de estudio, para que los alumnos puedan disponer de una batería de ejercicios resueltos de Matemáticas II; pero, sin duda, es mucho más interesante para el profesorado y también, por qué no, para los encargados de proponer las PAEU, ya que, junto con la solución de los mismos, aparecen las competencias ligadas a la misma. Este análisis competencial de todos los enunciados puede ser una ayuda en la instrucción y la propuesta de pruebas. Su baremo sirve para adecuar el nivel de dificultad que se desee pedir en una prueba que el docente proponga a sus estudiantes.

El estudio lexicográfico invita al docente a cuidar la estructura de los enunciados de ejercicios que conciba proponer. Es muy importante desterrar la ambigüedad de los enunciados, tener muy presente la acción verbal y, como indica Thorndike (citado por Lansdere 1992, 101; Gimenez, 1997) esta acción debiera escribirse de forma imperativa. Asimismo debieran evitarse los infinitivos ocomenzar las cuestiones con palabras como: ¿¿Qué?, ¿Cuándo?, etc.

Practicamente se han redactado todos los ejercicios con variaciones en su enunciado primitivo e, igualmente, se aportan enunciados alternativos en aquellos casos en los que la redacción es bastante confusa.

\section{VIII.3. CONCLUSIONES}

Como ya se ha indicado en el desarrollo de la tesis, para realizar la investigación se han utilizado las categorías de contenido matemático del Currículo de Bachillerato, la metodología de Fox, el marco competencial de PISA y teoría lexicográfica.

Seguidamente reproducimos cada hipótesis formulada y, a continuación, presentamos las conclusiones relativas a ella. 
H1. Hay muchos conceptos matemáticos que o no se preguntan o se preguntan escasas veces. Las frecuencias de aparición de algunos conceptos como preguntas de examen son nulas o muy bajas.

Conclusión 1.1. En Análisis Matemático el "Límite de una sucesión. . Cálculo de límites utilizando técnicas de cancelación o racionalización" no se ha propuesto nunca como problema y tan sólo una vez como cuestión.

Las propiedades de las funciones continuas, así como el estudio de las discontinuidades de una función, no se han propuesto como problema ni como cuestión.

Tampoco se han propuesto ni en problemas ni en cuestiones nada relativo al teorema del valor medio para integrales, ni a las sumas de Riemann.

El teorema de Rolle como aplicación se pide en una cuestión y el enunciado del mismo en otra, así como el teorema del valor medio en cálculo diferencial que tan solo aparece dos veces como problema y otras dos como cuestión.

El cálculo de una integral en la que es preciso utilizar el método de integración por partes se pide en dos cuestiones y en tres ocasiones como un apartado de un problema.

Conclusión 1.2. En Álgebra no se han propuesto nunca problemas ni cuestiones en las que el alumno tenga que interpretar el enunciado de un problema y establecer él las ecuaciones que vienen implícitas en el mismo.

La libertad de elección, por parte del alumno, del método de resolución de los problemas lleva como consecuencia el hecho de que nunca se pida el estudio y/o la resolución de un sistema de ecuaciones lineales, ni el estudio del rango de una matriz o el cálculo de la matriz inversa, utilizando el método de Gauss.

Asimismo se observa que tan sólo en una ocasión se ha propuesto el desarrollo de un determinante de orden superior a tres, y nunca se solicita que se resuelvan determinantes utilizando las propiedades.

Conclusión 1.3. En problemas de Geometría no se ha propuesto ningún enunciado en el que haya que calcular un producto vectorial, escalar o mixto de vectores, así como el estudio de la base de un sistema de referencia, ni ningún 
ejercicio del cálculo de la ecuación de una esfera o de intersecciones entre planos y/o esfera.

La resolución de problemas de perpendicularidad entre rectas y planos o entre planos se propone tan solo en tres ocasiones, entre problemas y/o cuestiones.

La obtención del punto simétrico de uno dado, con respecto a punto, recta y/o plano se demanda un escaso número de veces en comparación con otros contenidos. El mismo trato recibe la resolución de problemas métricos relacionados con el cálculo de volúmenes.

H2. Algunos conceptos matemáticos se preguntan excesivamente. Las frecuencias de aparición de algunos conceptos como preguntas de examen son muy altas.

Conclusión 2.1. En Análisis Matemático el "estudio de una función: cálculo de asíntotas, intervalos de crecimiento y decrecimiento (monotonía) y cálculo de extremos relativos se presenta en más de 20 ejercicios, hay 15 problemas de optimización, y 23 veces se pide el cálculo del área de un recinto limitado por dos funciones (región plana) en problemas y 10 en cuestiones.

El cálculo de límites en los que es preciso utilizar la regla de L'Hôpital, dado que los infinitésimos equivalentes se han eliminado del currículo, se ha propuesto 22 veces como cuestión.

Ejercicios relativos a continuidad en intervalos cerrados, -aplicación del teorema de Bolzano-, se han propuesto 16 veces, 10 como cuestión y otras seis como apartado de un problema.

Conclusión 2.2. En Álgebra, en 16 cuestiones se pide la resolución de una ecuación matricial y el estudio y la resolución de sistemas de ecuaciones lineales se ha solicitado en 19 de los 28 problemas propuestos.

La obtención o el estudio de la existencia de matriz inversa de una dada se ha pedido 8 veces y el cálculo del rango de una matriz se ha pedido otras 9 veces, en cada caso 7 de ellas como cuestión. Si tenemos en cuenta que para el estudio de la existencia de matriz inversa, uno de los posibles métodos a utilizar 
es el estudio del rango de la misma, llegaríamos a la conclusión de que en 14 ocasiones se pide estudiar el rango de una matriz en función de un parámetro.

Conclusión 2.3. En Geometría, la obtención e interpretación de las ecuaciones de planos a partir de sistemas de referencia ortonormales se ha propuesto 14 veces como problema y 6 como cuestión y la resolución de problemas métricos relacionados con el cálculo de distancias se ha propuesto 17 veces.

La resolución de problemas de incidencia entre rectas se ha propuesto 8 veces como problema y otras 5 veces más como cuestión

De las conclusiones relativas a estas dos hipótesis se concluye que las PAEU sesgan el currículo. Por una parte, se invita a los profesores de bachillerato a que dediquen mayor atención a los conceptos que son preguntadas muchas veces y, por otra, que no se preste la atención debida a aquellos otros que no son preguntados de forma habitual.

H3. Se pueden adaptar los niveles de evaluación proporcionados por PISA (reproducción, conexión y reflexión) en función de las acciones verbales implícitas en sus enunciados.

Los resultados se basan en el análisis de la información que proporciona el enunciado. Con el fin de precisar nuestra atención en lo más relevante para nuestra investigación, prescindimos de los demás componentes del contexto y analizamos lo esencial.

El análisis de todos los enunciados, por una parte, nos ha permitido descubrir que tanto los problemas como las cuestiones propuestas invitan a plantear situaciones de aprendizaje orientados a técnicas y operaciones, centradas en la ejecución de tareas que, en su mayoría, plantean aspectos matemáticos, casi nunca en contextos reales, mediante enfoques rutinarios que no favorecen a la formación de las competencias matemáticas avanzadas (nivel reflexión).

Se incide en ejecutar procedimientos y técnicas de cálculo, y pocas veces se da oportunidad para que los estudiantes deduzcan o comprueben. Las preguntas teóricas aparecen fugazmente, sólo se pidieron enunciados de algún teorema o propiedad en escasas ocasiones y antes de 2004 (después no se han vuelto a preguntar). Además, estás cuestiones teóricas constituían un apartado y a éste le seguían otros de tipo procedimental en los que debían aplicarlo. 
También se observa una escasa exigencia de un razonamiento lógico-formal, de argumentación o demostración. A pesar de que en los Decretos 70/2002, de 23 de mayo (BOCYL 29 de Mayo 2002) y 42/2008, de 5 de junio (BOCYL 11 de Junio 2008), por los que se establece el Currículo de Bachillerato de la Comunidad de Castilla y León (CBCyL) manifiestan como objetivos a alcanzar: utilizar estrategias representativas de la investigación científica y los procedimientos propios de las matemáticas, como son plantear y resolver problemas, formular y contrastar hipótesis, justificar procedimientos utilizando un vocabulario específico de notaciones y términos matemáticos que les permita comunicarse con eficacia y precisión expresándose correctamente de forma oral, escrita y/o gráfica, en situaciones susceptibles de ser tratadas matemáticamente, con argumentaciones razonadas y demostraciones rigurosas; estos no se tienen en cuenta en las propuestas de los ejercicios de las PAU.

Los enunciados de los exámenes potencian el aprendizaje de los conceptos matemáticos como unidades de información ausentes de conexiones entre distintas áreas o materias, el uso de procedimientos y operaciones como si fueran resueltos por un autómata, la resolución de ejercicios tipo mediante la aplicación de fórmulas, el uso de una sola estrategia de solución, utilizando enfoques estandarizados, es decir, ofrecen escasas opciones para demostrar un aprendizaje significativo de las matemáticas, contradiciendo los objetivos curriculares señalados en los decretos anteriormente citados. En los decretos se insta a aplicar las estrategias y los procedimientos propios de las matemáticas: plantear problemas, formular y contrastar hipótesis, planificar, manipular y experimentar; como herramienta para analizar y valorar la información proveniente de diferentes fuentes y para formarse una opinión que les permita expresarse críticamente y con rigor sobre problemas procedentes de las actividades cotidianas y de diferentes ámbitos del saber.

No se ofrece al alumno la oportunidad de resolver problemas con demanda cognitiva de alto nivel, de probar su destreza en situaciones que impliquen procesos de pensamiento avanzado (nivel de reflexión).

Esta situación favorece una docencia basada en una preparación para que los alumnos superen una prueba de este tipo y, por tanto, condiciona a que los estudiantes realicen principalmente ejercicios con un requerimiento cognitivo inferior (el nivel de reproducción), y para los que es incierto que adquieran procesos apropiados a la actividad matemática de un nivel superior, tales como reflexión, abstracción, generalización, análisis y síntesis. 
Por tanto, aparecen dificultades en el momento de abordar tareas matemáticas más complejas, diferentes de las que resuelven en el aula, aquellas que no les resultan conocidas y que precisan procedimientos diferentes de los usados.

H4. El nivel de reproducción es el que más se repite en las cuestiones de las PAEU.

El análisis que aquí se ha realizado desde la perspectiva de las competencias (tablas II.1, II.2 y II.3) manifiesta un comportamiento sesgado. A continuación se hace una discusión sobre los resultados de esta hipótesis por niveles de respuesta. Sin embargo, habida cuenta de que los niveles superiores deben contener a los inferiores, es obvio que la mayor parte de competencias que aparecen en conexiones también están en los niveles de reproducción, pero no se han reflejado en la tabla, que sólo contiene los niveles de reproducción sin que se dé el paso a conexiones. En concreto, los alumnos tienen que proceder con pensamientos primarios antes de llegar a los secundarios (por ejemplo, reconocer una situación antes de planificar procedimientos y esto antes que resolver,...). Estas inclusiones competenciales se justificaron debidamente en el apartado correspondiente al marco teórico del capítulo II. Las siguientes tablas son un resumen de los niveles de competencia que se han encontrado en la resolución de los problemas y de las cuestiones:

Tabla VIII.1. Categorías de análisis de competencias en problemas

\begin{tabular}{|c|c|c|c|}
\hline \multicolumn{4}{|c|}{ PROBLEMAS } \\
\hline Área & Reproducción & Conexión & Reflexión \\
\hline Análisis matemático & 497 & 1077 & 40 \\
\hline Álgebra & 497 & 280 & 5 \\
\hline Geometría & 445 & 401 & 6 \\
\hline Totales & 1439 & 1758 & 51 \\
\hline
\end{tabular}


Como puede apreciarse en esta tabla general, el número de problemas que presentan únicamente el nivel de reproducción es casi equivalente al número de ejercicios que presentan un nivel 2 de conexión.

En A.M. hay más ejercicios de conexión que de reproducción pues los ejercicios no son rutinarios, aún cuando se repitan en la docencia. El simil sería comparar una suma numérica y una suma algebraica. Aún cuando las sumas algebraicas sean sencillas (al menos para el docente) el proceso mental que tiene que realizar el alumno en álgebra está en un nivel de mayor dificultad, y eso se confirma el hecho de que no se introduzca el álgebra en el currículo hasta la Enseñanza Secundaria.

En Álgebra las competencias que tienen un nivel 1 de reproducción son casi el doble de las de conexión, a pesar de que hay un elevado número de ejercicios en los que hay que utilizar parámetros en el estudio, y estos ejercicios están en el nivel 2.

El número de competencias de reproducción y conexión en Geometría es semejante, y el número de problemas que tienen esos niveles también, como se puede constatar en las tablas desglosadas del capítulo VI. Casi todos presentan los dos niveles, fruto de ejercicios con varios apartados, de los cuales unos pertenecen al nivel 2 de conexión y otros son derivados de los anteriores y pertenecen al nivel 1 de reproducción. El número de conexiones se incrementa gracias a la competencia de Representar, porque, como ha quedado reflejado en reflexiones anteriores, la tabla de competencias en la categoría de Representar no establece grandes diferencias entre un nivel de reproducción y uno de conexión, pero el criterio de la P.I. es que las representaciones gráficas que amparan la resolución de los ejercicios son claramente de nivel 2.

El estudio de la tabla de cuestiones evidencia que el número de las que presentan únicamente el nivel de reproducción es casi más del doble del número de ejercicios que presentan un nivel 2 de conexión.

En cuestiones la reflexión por áreas es confeccionar una relación de "modelos". La cuestión se valora con 1 punto, la dificultad es inherente a la puntuación y en consecuencia el nivel competencial. Los problemas que presentan varios apartados en su enunciado, suelen tener algún apartado del nivel de conexión.

El examen de la tabla que aparece a continuación lleva implícito el del nivel "complementario", conexión. En A.M. de las 99 cuestiones sólo 37 son de nivel conexión. 
Tabla VIII.2. Categorías de análisis de competencias en cuestiones

\begin{tabular}{|c|c|c|c|}
\hline \multicolumn{4}{|c|}{ CUESTIONES } \\
\hline Área & Reproducción & Conexión & Reflexión \\
\hline Análisis matemático & 1081 & 630 & 8 \\
\hline Álgebra & 672 & 317 & 0 \\
\hline Geometría & 1091 & 259 & 2 \\
\hline Totales & 2844 & 1206 & 10 \\
\hline
\end{tabular}

Los ejercicios de cálculo de límites y de integrales inmediatas "hinchan" las competencias del nivel reproducción y si las del nivel conexión tienen tanta presencia es debido a que se consideró, a priori, como criterio para asignar competencias el cálculo del área entre dos funciones como ejercicio que no es meramente rutinario, aún cuando las funciones que delimitan ese recinto sean polinómicas, o el estudio de una función, aún cuando no se pida explícitamente la representación gráfica, que el alumno ha asociado a la resolución; que es el tipo de cuestiones que se proponen con mayor frecuencia en ese nivel 2.

Las cuestiones en las que se pide la resolución de una ecuación matricial, sencilla, o unas simples operaciones con matrices, pertenecen al nivel de reproducción. De las 57 cuestiones de Álgebra, 22 alcanzan el nivel de conexión porque presentan parámetros en su enunciado.

En Geometría sólo 14 de las 67 cuestiones presentan un nivel de conexión y 59 presentan un nivel de reproducción, lo que significa que 53 cuestiones exclusivamente alcanzan el nivel inferior.

El contenido conceptual que se solicita en 17 cuestiones está relacionado con el cálculo de distancias y la puntuación condiciona el tipo de resolución; la aplicación directa de la fórmula que da el resultado.

H5. Los niveles de reflexión apenas aparecen en los problemas propuestos en las PAEU 
En las tablas anteriores se aprecia con absoluta claridad que apenas hay apartados cuya solución requiera niveles competenciales de relflexión.

En Análisis matemático el nivel de reflexión en la competencia pensar y razonar se presenta en 7 problemas, que impulsan al alumno para que aplique estrategias no rutinarias, aunque no conexionan con problemas reales.

En 12 de los 61 problemas el alumno razona de forma sencilla, distinguiendo formas más amplias de argumentación_(RfAn1) y de ellos, en 9 explica asuntos que implican relaciones complejas.

La complejidad de esos contenidos, en Análisis Matemático se ha presentado en la resolución de los ejercicios, debida, en unas ocasiones a un enunciado mal propuesto (ficha 1.39.1) y en otras a que la solución presentaba números irracionales, que debido a que su presencia es muy escasa, implican complejidad.

Dos cuestiones se han incluido en el nivel de reflexión, el correspondiente a la ficha 2.11.1 presenta un enunciado que incita a que la respuesta que dé el alumno, sea errónea, y el que se presenta en la ficha 2.54.1 porque, aunque sencillamente se trata de una integral trigonométrica, puede tener distinta solución dependiendo de los cambios trigonométricos que se realicen y en la resolución, bajo el supuesto de un alumno con buen nivel, se plantean y resuelven ambas soluciones y se comprueba que efectivamente coinciden.

De los 28 problemas de Álgebra propuestos en los años de estudio, tan sólo 1 pertenece al nivel de reflexión, dado que en su resolución intervienen elementos inusuales. Es el ejercicio que se presenta en la ficha 3.11.1. En este problema aparecen niveles de reflexión asociados a las competencias argumentar, comunicar y resolver problemas.

De los 30 problemas de Geometría propuestos en los años de estudio, tan sólo 2 pertenecen al nivel de reflexión, dado que en su resolución intervienen elementos inusuales. Son los ejercicios que se presentan en las ficha 5.3.1 y 5.19.1. En el problema 5.3.1 aparecen niveles de reflexión asociados a las competencias argumentar, comunicar y resolver problemas, por las características del sistema que aparece en su resolución.

En el problema 5.19.1 el nivel de reflexión viene relacionado con la presencia de dos parámetros en la obtención de la ecuación de la recta.

Finalmente, no hay cuestiones de Álgebra ni de Geometría que presenten niveles de reflexión. En suma, se verifica la hipótesis 5 y se puede afirmar con ro- 
tundidad que en los problemas y en las cuestiones de las PAU apenas aparecen preguntas de reflexión.

H6. Se puede mejorar sustancialmente la redacción de los enunciados.

En el capítulo anterior se hace un amplio estudio de incorrecciones detectadas en los enunciados de los problemas y cuestiones propuestos en las pruebas PAEU.

El uso del infinitivo como orden en el enunciado de un problema está admitido por la Academia de la Lengua, pero es más propio presentar el enunciado en forma imperativa.

Mayor transcendencia tiene la presencia de enunciados en los que se ha utilizado un método sintético, pues es frecuente que el alumno, en el transcurso del examen olvide alguna de las preguntas formuladas. Además resulta más correcto presentar el enunciado de una forma más analítica, pues cada parte tiene que llevar su verbo pertinente.

Las preguntas enunciadas en términos de interrogación ¿Puedes ...?, además de ser contradictorias con las propuiestas formuladas por Thorndike, llevan muchas veces a respuestas que no van en la dirección deseada.

De entre las poquísimas cuestiones teóricas formuladas, nos encontramos en repetidas ocasiones con la ausencia de acción verbal, por ejemplo, "Concepto de máximo y mínimo relativo". La ausencia de verbo es un error gramatical grave, pues sin verbo no hay oración.

Emplear la palabra "limitar"en lugar de la apropiada "delimitar", para referirse al recinto plano comprendido entre dos curvas, es un error semántico fácilmente subsanable con un poco de cuidado en la elección de las palabras adecuadas len las propuestas de enunciados de pruebas.

Igual consideración se puede aplicar al verbo discutir: "Dicho de dos o más personas: Examinar atenta y particularmente una materia", que, básicamente, se refiere a una acción verbal entre dos personas, y en su lugar se pueden utilizar otros verbos como "analizar", "examinar", "discernir", "diferenciar", "especificar", "precisar", que se refieren directamente a la acción que el examinador desea que se realice, es decir, que el alumno diferencie los distintos tipos de 
sistemas lineales que se puede encontrar cuando el enunciado corresponde a una familia dependiente de un parámetro.

En los enunciados de Geometría la omisión de especificaciones es una constante repetida en numerosos ejercicios. Encontrar un plano, una recta, un punto o un vector son propuestas continuas en los enunciados, como si estos fueran entes físicos, cuando el alumno a lo más que puede llegar es a escribir las ecuaciones de una recta o de un plano y las coordenadas de un punto o de un vector.

Asimismo, en Geometría se pide el cálculo de distancias entre objetos ( puntos, rectas, planos) utilizando la preposición entre" y no es la expresión adecuada, pues lo que se requiere es la distancia total que hay de un objeto a otro y no los valores intermedios.

En los exámenes correspondientes al periodo 2004-2006, en el enunciado de los problemas y cuestiones aparece el verbo con un pronombre clítico. La presencia de clíticos es correcta pero en Castilla no se suele utilizar esa formulación.

Las expresiones sea o sean no están registradas en el Diccionario y son arcaísmos léxicos; sin embargo aparecen repetidas veces en enunciados como: "Sea la función, sea la matriz, sean las rectas, etc." En su lugar existen otras expresiones como "dada una función", "se considera la matriz", etc.

Como última puntualización, digamos que algunos enunciados están redactados de una manera que es difícil de interpretar, tanto en las condiciones que dan como en la respuesta que piden, y a los que se ofrece una propuesta de enunciado totalmente modificada.

De lo expuesto anteriormente y de la lectura de todos los enunciados se puede concluir la $\mathrm{H} 6$ de esta memoria.

\section{VIII.4. PROPUESTA CURRICULAR}

Tras cotejar las tablas presentadas en el capítulo III es obvio que el currículo de Bachillerato en el que se ha basado este estudio Decreto 70/2002 de 23 de mayo queda mermado en la propuesta de pruebas, dado que hay bastantes contenidos curriculares que no han sido propuestos en las PAEU o que lo han sido en escasas ocasiones. 
La propuesta curricular que se hace en esta reflexión final va encaminada a evitar esos "recortes" que se realizan en el currículo y se fundamenta en la propuesta legal del currículo en el DECRETO 42/2008, de 5 de junio y en los acuerdos para las Pruebas de Acceso a Estudios Universitarios, con validez desde Junio de 2009 y trata de favorecer la práctica educativa en los Centros de Secundaria. Esta práctica no se favorece con los sesgos detectados, que en la práctica producen una reducción considerable de contenidos curriculares. Con el fin de evitar estas deficiencias se hace la siguiente propuesta.

Se recomienda proponer ejercicios de cálculo de límites en los que sea preciso utilizar técnicas de cancelación o racionalización, ejercicios en los que no se pueda aplicar la regla de L'Hôpital para su resolución; ejercicios en los que haya que aplicar conceptos y procedimientos de límites en la resolución razonada de problemas procedentes de actividades cotidianas, que enlaza con el objetivo de "expresarse verbalmente y por escrito en situaciones susceptibles de ser tratadas matemáticamente, comprendiendo y manejando términos, notaciones y representaciones matemáticas" (Decreto 42/2008, 11357)

Además, entre los objetivos curriculares de la asignatura de Matemáticas aparecen los siguientes

2.Considerar las argumentaciones razonadas y la existencia dedemostraciones rigurosas, mostrando una actitud flexible, abierta y crítica ante otros juicios y razonamientos.

3. Utilizar las estrategias características de la investigación científica y las destrezas propias de las matemáticas (planteamiento de problemas, planificación y ensayo, experimentación, aplicación de la inducción y deducción, formulación y aceptación o rechazo de las conjeturas, comprobación de los resultados obtenidos) para realizar investigaciones.

6. Utilizar el discurso racional para plantear acertadamente los problemas, justificar procedimientos, encadenar coherentemente los argumentos, comunicarse con eficacia y precisión, detectar incorrecciones lógicas y cuestionar aseveraciones carentes de rigor científico.

Estas proposiciones justifican legalmente propuestas curriculares en las que se pida al alumno demostraciones de conceptos teóricos, aún cuando se restrinja a demostraciones deductivas, como pueden ser aquellas en los que sea preciso utilizar teoremas del valor medio en cálculo diferencial (Rolle, Lagrange, Cauchy), y que tan solo se han propuesto dos veces como problema, de 61 problemas y otras dos como cuestión, de las 99 cuestiones planteadas, formular problemas o cuestiones relativas al teorema del valor medio del cálculo integral, y aplicar la relación existente entre el concepto de integral definida y el 
de primitiva de una función, mediante el teorema fundamental del cálculo integral, tanto desde una perspectiva práctica como teórica, pues, basándonos en el decreto legal, el aspecto teórico de las Matemáticas cumple un importante papel formativo, potenciando en el alumno capacidades de análisis, de abstracción, de generalización de formulación de conjeturas y su comproación, de rigor y formalización, capacidades que contribuyen a mejorar su intelecto y a adquirir hábitos y actitudes que transcienden las propias Matemáticas y quizás sería preciso eliminar el apartado "4. Generales" del tipo de preguntas, cuestiones, ejercicios o problemas del Anexo IV. Acuerdo de mínimos.

"Del buen hacer, tanto en el aspecto teórico como en el práctico, va a depender que las Matemáticas cumplan su papel formativo" (Decreto 42/2008, 11357), pero es un hecho incuestionable que las evaluaciones externas condicionan el currículo real del aula y la ausencia de contenidos teóricos en las pruebas que estamos analizando invita, con el pretexto de falta de tiempo, cuando menos, a no "profundizar" en los contenidos teóricos y utilizarlos como herramienta, tal y como se pide en el punto "4.Generales" del acuerdo de mínimos.

Análogamente, se considera necesario proponer ejercicios en los que se pida al alumno el estudio de las discontinuidades de una función, esto es, si se trata de una discontinuidad evitable o inevitable, ejercicios en los que la no existencia de la función en un punto no implique la presencia de asíntota vertical, y ejercicos de la conservación del signo en un entorno del límite.

De las integrales racionales no se proponen ejercicios en los que aparezcan a la vez raíces reales y complejas y del tipo arco tangente tan sólo se propone una cuestión, en septiembre de 2005. El cálculo de una integral en la que es preciso utilizar el método de integración por partes se pide en dos cuestiones y en tres ocasiones como un apartado de un problema, sin embargo en el "Acuerdo de mínimos" aparece este tipo de integrales y se puntualiza que no se pedirá aplicar el proceso más de dos veces, lo cual legitima el hecho de que en las contadísimas propuestas no se ha precisado utilizar el proceso más que una vez, pasando a ser unas integrales mecánicas, basadas en algoritmos habituales y por tanto correspondientes a niveles de Reproducción.

Es aconsejable la propuesta de ejercicios del tipo anteriormente reseñado, al igual que ejercicios de integrales trigonométricas cuyo procedimiento de ejecución es un cambio de variable, en función de ángulo doble, o integrales de funciones irracionales, resolubles mediante cambios trigonométricos, incluidas en 
el apartado de"utilizar técnicas de cambio de variable" y que no se han propuesto en ninguna convocatoria de las PAEU.

En Álgebra, la libertad de elección, que se da al alumno, del método de resolución de los problemas lleva asociado el hecho de que nunca se pida el estudio y/o la resolución de un sistema de ecuaciones lineales, ni el estudio del rango de una matriz o el cálculo de la matriz inversa, utilizando el método de Gauss, y es indicado que el alumno conozca y utilice diversos métodos de resolución, lo cual sucedería si en las propuestas de examen se pidiese uno u otro método de actuación ya que; nuevamente bajo la excusa de falta de tiempo, los ejerciccios con matrices en Matemáticas II se realizan, únicamente, utilizando determinantes.

En la propuesta de mínimos aparece "Determinar el rango de matrices numéricas hasta de dimensión $4 \times 4$ ", ejercicio que se ha formulado como cuestión en septiembre de 2001, de las 57 cuestiones de álgebra propuestas, que concierne al nivel de Reproducción y que "roza" el de Conexión, si el alumno observa alguna combinación lineal de las existentes entre las columnas, y continúa " $y$ de matrices dependientes de un parámetro hasta $3 \times 4$ ", nunca propuesto como ejercicio. Éste supuesto invita a propuestas en las que el tamaño de la matriz precise un amplio estudio, al depender de parámetros. Y elevando la propuesta a un nivel superior, el constreñir el estudio a un único parámetro constriñe el currículo, pues el estudio puede realizarse con más de un parámetro, aún ciñéndonos al reducido tamaño de la matriz.

El "acuerdo de mínimos" coarta la propuesta del Decreto 42/2008, 11359, de currículo que en sus criterios de evaluación para la materia de Matemáticas II insta a "utilizar el lenguaje matricial y las operaciones con matrices y determinantes como instrumento para representar e interpretar datos y relaciones $y$, en general, para resolver situaciones diversas" y a "transcribir problemas reales a un lenguaje algebraico, utilizar conceptos, propiedades y técnicas matemáticas específicas en cada caso para resolverlos y dar una interpretación de las soluciones obtenidas ajustada al contexto", directamente relacionadas con la propuesta de ejercicios en los que el alumno tenga que plantear un sistema de ecuaciones para su posterior resolución. Entender el lenguaje escrito y trasladarle a lenguaje algebraico enlaza contenidos matemáticos con problemas de la vida real, siguiendo la propuesta de las evaluaciones PISA, ayuda a "comprender y aplicar los conceptos y procedimientos matemáticos a situaciones diversas que permitan avanzar en el estudio de las propias matemáticas, así como en la resolución razonada de problemas procedentes de actividades coti- 
dianas", señalado como primer objetivo de la materia de Matemáticas de bachillerato.

Desarrollar explícitamente determinantes utilizando propiedades elementales está directamente implícito en los objetivos del currículo de Matemáticas de Bachillerato, entre otros el de utilizar las estrategias características y las destrezas propias de las matemáticas, pero no se ha propuesto nunca en las pruebas PAEU de 1995 a 2009. En septiembre de 1999 se propone como problema el cálculo de un determinante de orden cuatro y, en cursos posteriores, en algunas cuestiones se solicita al alumno que calcule el valor de un determinante y para ello es preciso utilizar las propiedades elementales de los determinantes, pero son ejercicios de reproducción del conocimiento estudiado, no incluyen niveles de reflexión, lo que se refleja en la docencia y el desarrollo del currículo real.

En la tabla de categorías curriculares de Geometría se ha considerado como contenido curricular "Vectores en el espacio n-dimensional" para incluir la cuestión propuesta en septiembre de 1997 en la que se solicita que el alumno encuentre un vector en el espacio $\mathrm{R}^{4}$. En los currículos de 2003 y 2008 los espacios vectoriales se restringen $a R^{3}$, pero los enunciados se reducen a la aplicación de vectores en su faceta geométrica, nunca como instrumento de interpretación de fenómenos físicos, que favorecería la relación entre ambas materias y la observación de la necesidad de utilizar herramientas matemáticas en problemas de la vida real. Tampoco se concibe que el cálculo de volumen se restrinja a un tetraedro y no se extienda a un prisma o una pirámide cuadrangular.

La propuesta curricular que proyectamos incluye ejercicios de estos modelos, calcular el volumen de un prisma, no utilizar únicamente la fórmula que obtiene la distancia de punto a plano, de recta a plano o que determina la posición relativa, en el espacio, de dos rectas.

En el Decreto de 2008 desaparece del currículo el estudio de la Esfera, pero cuando estuvo presente en el mismo y en el acuerdo de mínimos, período correspondiente a este estudio, tampoco se propuso ningún ejercico de examen relativo al cálculo de la ecuación de una esfera o al estudio de intersecciones entre planos y/o esfera, ni ejercicios de elipsoide.

No se hace referencia al contenido "Utilización de programas informáticos como apoyo para introducir superficies comunes" pues no puede ser evaluado con el tipo de examen estudiado. 
La propuesta curricular la referenciamos a documentos actuales, porque contenidos que aparecen en el Decreto 70/2002 de 23 de mayo han sido eliminados en el Decreto 42/2008, pero ello no es óbice para los principios de PISA de la consideración de las matemáticas como "modo de hacer" y con la noción de alfabetización que responde a un modelo funcional sobre el aprendizaje de las matemáticas. La situación actual favorece aprendizajes mecánicos a base de repeticiones, eludiendo ejercicios en los que esté inherente el nivel de reflexión. Proponemos recuperar todos los contenidos que se han ido eliminando paulatinamente del currículo.

No cuestionamos la dificultad que entraña la propuesta de pruebas y la adecuación a contextos reales, hecho cdestacado por Ortega, Pecharroman y Sosa (2011), pero la ausencia continuada de este tipo de propuestas incide directamente en la práctica docente, lo que provoca un sesgo curricular significativo. Ya se ha señalado que según Rico y Lupiañez hay cuatro modos de entender el conocimiento matemático escolar y esta clasificación, de algún modo, se puede considerar como otra variante de los niveles de evaluación de PISA, de los cuales se ven refutados el enfoque funcional, donde el conocimiento permite modelizar situaciones reales y está orientado a la resolución de cuestiones y problemas en diferentes contextos, y el enfoque integrado, donde el conocimiento es un objeto de actividad intelectual autónoma, creación e interacción en diversidad de situaciones y contextos.

Recomendaciones como fomentar las técnicas de investigación, aplicar los fundamentos teóricos y dar traslado de lo aprendido a la vida real, presentes en la ley, enlazan con la disertación realizada y ofertan un currículo en el que se proponene niveles de reflexión. La situación actual incide negativamente en el desarrollo curricular de la docencia produciendo sesgos deterministas hacia unas matemáticas prácticas centralizadas en el dominio y uso de destrezas y conceptos básicos que producen aprendizajes mecánicos y muy pobres en razonamientos.

El estudio de competencias patentiza la ausencia de niveles de reflexión. Esta ausencia de distintos niveles de dificultad en la propuesta de examen hace de la misma un instrumento carente de utilidad, en base a discriminar la profundidad de los conocimientos y destrezas adquiridas.

En el aspecto lexicográfico nuestra propuesta va orientada a instar a profesores y examinadores un esmerado cuidado en la redacción de los enunciados, pues el hecho de que las preguntas sean de matemáticas no debe ser obstáculo para que no estén expresadas en un correcto lenguaje. 
El razonamiento que acabamos de realizar se puede ultimar en que el profesorado, para mejorar su actividad docente, puede centrarse en los siguientes aspectos que ayudarían a incrementar el rendimiento en los niveles más altos:

- Proponer pruebas discriminatorias en la que estén presentes niveles de reflexión.

- Insistir en la obligación de una argumentación escrita.

- Proponer preguntas teóricas extensas que puedan incluir demostraciones.

- Proponer problemas y no sólo ejercicios.

- Cuidar la redacción de los enunciados que se proponen.

\section{VIII.5. DIFICULTADES DE LA INVESTIGACIÓN}

Al asociar las competencias a los ejercicios, la primera intención es encuadrarles en el grupo de reproducción, pues casi todos forman parte de esa batería de ejercicios que se practican reiteradamente en el aula, durante la instrucción, debido a su carácter repetitivo. Esto se manifiesta con intensidad en los "problemas" propuestos en Álgebra, en los que la tendencia refleja claramente un propósito: que los alumnos estudien una familia de sistemas de ecuaciones lineales según los valores de un parámetro y que los resuelvan cuando sea posible.

Los ejercicios propuestos han sido analizados siguiendo las siguientes pautas: los conocimientos matemáticos que exigen (conceptos y estructuras conceptuales, destrezas, estrategias generales, ...) y el tipo de actividad (ejercicios de reconocimiento; ejercicios algorítmicos; problemas de aplicación; problemas de enunciado abierto, ...).

Se han incluido competencias de representación en ejercicios de Geometría, pues aunque el enunciado no lo pide expresamente se plantea como parte de la solución del problema geométrico la representación mental de las condiciones del enunciado (recta, plano, posición relativa, etc.) reflejada posteriormente mediante un esquema gráfico como explicación del procedimiento y de las relaciones utilizadas usando el lenguaje verbal; lo cual también constituye la siguiente etapa y se convertirá en imprescindible para la comunicación.

En la tabla de competencias el nivel de conexión corresponde a aquellos ejercicios que reproducen situaciones similares a las estudiadas, pero no son de 
mera rutina, y ese es el rasgo que presentan esos ejercicios, pues al depender de parámetros cada uno de ellos puede tener una idiosincrasia.

Un razonamiento análogo se hace en el estudio de las funciones y en los problemas de optimización, tantas veces propuestos en Análisis Matemático. Nuestra experiencia como profesores nos permite entrever que los alumnos tienen serias dificultades en la interpretación de las propiedades globales de las funciones y su posterior esbozo de representación gráfica de una función, en el diagrama cartesiano, a partir de sus propiedades, deducidas del estudio de su expresión algebraica, límites y derivadas.

Al presentar algunos ejercicios varios apartados, habitualmente, se da la circunstancia de que pertenecen a distintos niveles competenciales, reproducción y conexión, por eso aparecen ambos en la tabla, de lo contrario se contempla el nivel superior, ya que niveles superiores absorben a los inferiores, por ejemplo el alumno reconoce representaciones de los datos del ejercicio corresponde al primer nivel de Pensar y razonar en reproducción, mientras que en conexión piensa en el tratamiento matemático necesario, acción que conlleva el haber reconocido qué tipo de ejercicio es y por tanto qué acciones incluye. Este razonamiento se puede extrapolar a otras competencias y niveles.

- Esa es una de las dificultades de la investigación, ¿qué nivel competencial asociar a cada acción verbal? ¿Estaría siendo muy benévola al asociar niveles superiores a ejercicios tantas veces repetidos en el aula?

La primera pretensión fue la de reflejar el número de veces que aparece cada competencia en un problema o cuestión, ello llevaba a una sobreinformación que provocaba un listado tan grande que conducía a un caos. ¿Cómo reflejar en cada acción que el alumno tiene que entender lo que se le pregunta, asociarlo con conocimientos adquiridos durante la instrucción y pasar a la fase de ejecución? Se ha optado por notar su presencia y escribir una vez cada competencia y nivel presentes en cada ejercicio, aún cuando en varios apartados puedan aparecer repetidas veces.

- ¿ La elección final de la presencia cuantitativa de competencias refleja con precisión el exhaustivo estudio realizado?

Como muchos problemas presentan varios apartados, ¿la tabla debería reflejar las competencias de cada uno de los apartados o únicamente el nivel superior alcanzado, dado que niveles superiores absorben a otros inferiores? La P.I. ha optado por una situación intermedia, como se ha mencionado en la disertación precedente. 
La lectura repetida de los enunciados de los ejercicios ha puesto de manifiesto que la redacción de los mismos puede ser notablemente mejorada. En un intento por presentar alternativas a los mismos se ofrece bajo el título "fallos del enunciado" unas exiguas etiquetas genéricas que indican propuestas de mejora. Así, un error morfológico es el que se presenta cuando se utiliza un tiempo verbal en lugar de otro. Aunque hemos comprobado que la RAE admite el uso del infinitivo con valor imperativo, siguiendo las directrices de Thorndike, consideramos más apropiado utilizar el verbo en imperativo.

La expresión "fallos" no indica exactamente errores gramaticales, son expresiones no adecuadas al contexto de un examen de selectividad dónde deben cuidarse las expresiones académicas.

\section{VIII.5. PUNTOS FUERTES Y DÉBILES}

Como puntos fuertes de este trabajo de investigación ,modestamente, consideramos que el presente trabajo puede ser considerado como una ayuda en la docencia, para alumnos y profesores.

$\checkmark$ Se ofrece una colección de ejercicios resuelta.

$\checkmark$ Los profesores pueden ver en cada ejercicio el nivel de dificultad asociado al nivel competencial, además de una guía para la redacción de enunciados.

$\checkmark$ La detección de los sesgos curriculares en los que pueden incidir si fundamentan su docencia en los niveles de exigencia de las pruebas PAEU.

$\checkmark$ El análisis resolutivo asociando las competencias en la resolución.

$\checkmark$ La detección de incorrecciones gramaticales en los enunciados.

Se ha consultado a varios profesores de Lengua Española y sus opiniones han sido tan diversas que al concluir este trabajo considero que el punto más débil de esta investigación es la falta de confirmación respecto al análisis lexicográfico de los enunciados.

Revisada la información que se presenta en este trabajo nos surge la inseguridad de si diversos aspectos de la investigación, ya sea por causas externas o por impericia, podían haberse desarrollado de una manera más eficaz. 


\section{VIII.6. PROBLEMAS ABIERTOS}

Es fundamental la necesidad de dar continuidad a todo trabajo de investigación, dado que este proceso afianza el aporte de resultados a los problemas existentes. Una línea abierta puede ser la relativa a la propuesta de enunciados en los que se presente el nivel de reflexión y la programación de actividades didácticas que presenten dicho nivel competencial.

La elaboración de enunciados de problemas que conexionen los conocimientos matemáticos de este nivel con situaciones de la vida real es otro problema abierto. Hay ejemplos de ejercicios en contexto real en las pruebas liberadas de PISA, pero su nivel matemático es de secundaria pues evalúa el conocimiento y las destrezas de los alumnos de 15 años.

Uno de los objetivos futuros es aplicar estos procedimientos de análisis competenciales en el análisis y elaboración de las pruebas que se hacen durante el curso en los Centros de Educación Secundaria, y crear una base de problemas para la secuenciación de tareas y la gestión del aula.

Se pueden analizar los procedimientos de resolución utilizados por los alumnos en las pruebas PAEU. En bastantes ocasiones he tenido la oportunidad de colaborar como correctora de dichas pruebas y al hacerlo he observado errores asociados a la docencia, por ejemplo calcular la matriz inversa de una dada, de orden $3 \times 3$, utilizando tres sistemas de tres ecuaciones lineales, que además el alumno resolvía, o intentaba resolver, por el método de sustitución.

En una convocatoria reciente se propone un ejercicio elemental utilizando el teorema fundamental del cálculo, pero este concepto no se había vuelto a proponer desde el curso 2002. Se pueden imaginar el resultado...Para mí fue la confirmación de todos los asertos incluidos en estas reflexiones. Esta reflexión avala la importancia de realizar una investigación profunda sobre la influencia que tienen las PAEU en el desarrollo del currículo.

Las actividades propuestas para realizar por el alumno deben presentar todas las variantes que posibilite el tema, así como los distintos niveles de dificultad,.Aspiramos a que nuestra herramienta de evaluación competencial permita mejorar las actividades que desarrollamos en el aula. 



\section{BIBLIOGRAFÍA}

Arce, R., Busto, A. I. y Hernández, B. (1999). Selectividad LOGSE. Pruebas de 1998. Matemáticas II. Madrid: Grupo Anaya.

Arce, R., Busto, A. I. y Hernández, B. (2000). Selectividad Logse. Pruebas de 1999. Matemáticas II. Madrid: Grupo Anaya.

Arce, R., Busto, A. I. y Hernández, B. (2001). Selectividad Logse. Matemáticas II. Pruebas de 2000. Madrid: Grupo Anaya.

Arce, R., Busto, A. I. y Hernández, B. (2002). Selectividad Logse. Matemáticas II. Pruebas de 2001. Madrid: Grupo Anaya.

Arce, R., Busto, A. I. y Hernández, B. (2003). Selectividad Logse. Matemáticas II. Pruebas de 2002. Madrid: Grupo Anaya.

Arce, R. y Busto, A. I. (2004). Selectividad Logse. Matemáticas II. Pruebas de 2003. Madrid: Grupo Anaya.

Artigue, M. \& Houdemont, C. (2007). Problem solving in France: didactic and curricular perspectives. ZDM The International Journal on Mathematics Education, 39, 5-6, pp.365-382.

Busto, A. I. (2005). Selectividad. Pruebas de 2004. Matemáticas II. Madrid: Grupo Anaya.

Busto, A. I. (2006). Selectividad. Pruebas de 2005. Matemáticas II. Madrid: Grupo Anaya.

Busto, A. I. (2007). Selectividad. Pruebas de 2006. Matemáticas II. Madrid: Grupo Anaya.

Busto, A. I. y Martínez, E. (2008). Selectividad. Pruebas de 2007. Matemáticas II. Madrid: Grupo Anaya. 
Busto, A. I. y Martínez, E. (2009). Selectividad. Pruebas de 2008. Matemáticas II. Madrid: Grupo Anaya.

Busto, A. I. (2010). Selectividad. Matemáticas II. Madrid: Grupo Anaya.

Cáceres, J. (2005). Análisis de un sistema de evaluación alternativa en la matemáticas de la enseñanza secundaria. Proyecto de Investigación para el Doctorado en Educación Matemática. Universidad de Salamanca.

Carrillo, J. (1995). Modos de resolver problemas y concepciones sobre la matemática y su enseñanza de profesores de matemáticas de alumnos de más de 14 años. Algunas aportaciones a la metodología de la investigación y estudio de posibles relaciones. Tesis doctoral. Universidad de Sevilla.

CEE (Comisión de las Comunidades Europeas) (2005). Propuesta de recomendación del Parlamento Europeo y del Consejo sobre las competencias clave para el aprendizaje permanente. 2005/0221 (COD). Bruselas.

Cockroft, W.H. (1985). Las Matemáticas sí cuentan. Informe Cockroft. Madrid. MEC.

Coello, J.L. (2007). La evaluación diagnóstica, formativa y sumativa. Tomado de la red en marzo de 2007 de

http://meltingpot.fortunecity.com/alberni/698/revista_docenti/ii_iv/b9.html

Coll, C. (2007). Psicología y currículum. México: Paidós Mexicana.

Comellas, J. y Serra, J. (2000). "El currículum en el bachillerato", en El currículum de matemáticas en los inicios del siglo XXI. Barcelona: Graó.

Consejería de Educación y Cultura (2002). Decreto 70/2002 de 23 de mayo por el que se establece el currículo del Bachillerato de la Comunidad de Castilla y León. B.O.C. y L. de 29 de mayo.

Consejería de Educación y Cultura (2008). Decreto 42/2008 de 5 de junio por el que se establece el currículo del Bachillerato de la Comunidad de Castilla y León. B.O.C y L. no 111 de 11 de junio.

Dreyfus, T., Hershkowitz, R y Schwarz, B. B.(2001). Abstraction in context II: The case of peer interaction. Cognitive Science Quarterly, 1, 307-368.

Eisenhart, M. (1998). The Ethnographic Research Tradition and Mathematics Education Research. Review of Educational Research, 68(4). 
Fernández, F. (1997). Evaluación de competencias en álgebra elemental a través de problemas verbales. Granada: Universidad de Granada.

Fernández Dominguez, J. y Muñoz Santonja, J. (2008). Un paseo matemático por las competencias básicas. Revista SIGMA n³3, 19-27. Departamento de Educación, Universidad del País Vasco.

Freudenthal, H. (1982). Fiabilité, validité et pertinence - critères de la recherche sur l'enseignement de la mathématique. Educational Studies in Mathematics, 13, 395-408.

Fox, D. (1981). El proceso de investigación en educación. Navarra: EUNSA.

Giménez, J. (1997). Evaluación en matemáticas. Integración de perspectivas. Madrid. Síntesis.

Godino, J. (2001). Confrontación de herramientas teóricas para el Análisis Cognitivo en Didáctica de las Matemáticas. Tomado de la red en junio 2012 de www.ugr.es/locel/jgodino/semiótica.htm.

Godino, J. D. (2002). Competencia y comprensión matemática: ¿qué son y cómo se consiguen? UNO. Revisa de Didáctica de las matemáticas, 29, 9-19.

Gómez, P. y Lupiánez, J. L. (2007). Trayectorias hipotéticas de aprendizaje en la formación inicial de profesores de matemáticas de secundaria. PNA, 1(2), 79-98.

Gómez Torrego, L. (1997). Gramática didáctica del español. Madrid: SM.

Goñi Zabala, J. Ma (2008). $3^{2}-2$ ideas clave. El desarrollo de la competencia matemática. Ed. Graó.

Grupo Cero (1984). De 12 a 16. Un proyecto de curriculum de matemáticas. Valencia: Nau Libres.

Gvirtz, S. y Plamidessi, M. (1998). El ABC de la tarea docente: currículum y enseñanza. Buenos Aires: Aique grupo editor.

de Guzmán, M. y Colera, J. (1996). Selectividad. Matemáticas I. Pruebas de 1995. Madrid: Grupo Anaya.

de Guzmán, M. y Colera, J. (1997). Selectividad. Matemáticas I. Pruebas de 1996. Madrid: Grupo Anaya. 
de Guzmán, M. y Colera, J. (1998). Selectividad. Matemáticas I. Pruebas de 1997. Madrid: Grupo Anaya.

de Guzmán, M. y Colera, J. (1999). Selectividad. Matemáticas I. Pruebas de 1998. Madrid: Grupo Anaya.

de Guzmán, M. y Colera, J. (2000). Selectividad. Matemáticas I. Pruebas de 1999. Madrid: Grupo Anaya.

de Guzmán, M. y Colera, J. (2001). Selectividad. Matemáticas I. Pruebas de 2000. Madrid: Grupo Anaya.

Hershkowitz, R., Schwarz, B. B., \& Dreyfus, T. (2001). Abstraction in Context: Epistemic Actions. Journal for Research in Mathematics Education, 32, 195222.

Howson, G., Keitel, C. \& Kilpatrick, J. (1988). Curriculum development in mathematics. Cambridge: Cambridge University Press.

Howson, G. (1991). National Curricula in Mathematics. London: The mathematical Association.

Howson, G. (1993). "The relationship between assessment, currículo and society" En Niss M (ed) Investigations into Assessment in Mathemathics Education. An ICMI Study. Dordrecht: Kluwer Academic Publishers.

INCE (2000). La medida de los conocimientos y destrezas de los alumnos. Un nuevo marcco de evaluación. Madrid: Ministerio de Educación, Cultura y Deporte.

INECSE (2004). Aprender para el mundo de mañana. Resumen de resultados PISA'2003. Madrid: Ministerio de Educación y Ciencia.

INECSE (2005). PISA 2003. Pruebas de Matemáticas y de Solución de Problemas. Madrid: Ministeriode Educación y Ciencia.

Jefatura del Estado (1990). Ley Orgánica 1/1990 de Ordenación General del Sistema Educativo. BOE número 238 de 4 de octubre. Madrid: BOE.

Kilpatrick, J.; Rico, L.; Sierra, M. (1994). Educación Matemática e Investigación. Madrid: Síntesis.

Kvale, S. (1989). Issues of Validity in Qualitative Research. Lund, Sweden :Studentlitteratur Kvale Steinar (Ed). 
Landsheere, G. de (1992). Evaluation continue et examens. Précis de Docimologie. Bruxelles: Labor. Education 2000.

Llinares, S. (2003). Matemáticas escolares y competencia matemática. En M.C. Chamorro (Coord), Didáctica de las Matemáticas (pp.4-29). Madrid: Pearson Prentice Hall.

Lupiáñez, J. L. y Rico, L. (2006). Análisis Didáctico y Formación Inicial de Profesores: Organización de Competencias y Capacidades de los escolares en el Caso de los Números Decimales. Indivisa, Monografía IV, pp. 47- 58.

Lupiáñez, J. L. y Rico, L. (2006). Análisis didáctico y formación inicial de profesores: competencias y capacidades del aprendizaje de los escolares. En P. Bolea; M. J. González y M. Moreno (Eds.), Investigación en Educación Matemática. X Simposio de la Sociedad Española de Investigación en Educación Matemática (SEIEM) (pp. 225-236). Huesca: Instituto de Estudios Altoaragoneses y Universidad de Zaragoza.

Lupiáñez, J. L. y Rico, L. (2008). Análisis didáctico y formación inicial de profesores:competencias y capacidades en el aprendizaje de los escolares. PNA, 3(1), 35-48. Rico, L.(2007) Tomado de la red en diciembre de 2010 de http ://www.pna.es/Numeros/pdf/Rico2007La.pdf

Lupiáñez, J. L. (2009). Expectativas de aprendizaje y planificación curricular en un programa de formación inicial de profesores de matemáticas de secundaria. Tesis Doctoral. Granada: Universidad de Granada.

Martínez Montero, J. (2008). Competencias básicas en Matemáticas. Madrid: Wolters Kluwer

MEC (2007). Instituto de evaluación. PISA 2006.Programa para la Evaluación Internacional de Alumnos de la OCDE. Informe español. Tomado de la red en enero de 2013 de:

www.institutodeevaluacion.mec.es/contenidos/internacional/pisainforme2006.

Ministerio de Educación y Ciencia (1975). Decreto 160/1975 de 23 de enero por el que se aprueba el Plan de Estudios del Bachillerato. BOE $\mathrm{n}^{\circ} 38$ de 13 de febrero. Madrid: BOE.

Ministerio de Educación y Ciencia (MEC). (1989). Diseño curricular base. Educación Secundaria Obligatoria. Madrid: El autor. 
Ministerio de Educación y Ciencia (1991a). Real Decreto 1700/1991 de 29 de noviembre, por el que se establece la estructura del Bachillerato. BOE $n^{0} 288$ de 2 de diciembre. Madrid: BOE.

Ministerio de Educación y Ciencia (1991b). Bachillerato. Estructura y contenidos. Madrid.

Ministerio de Educación y Ciencia (1992a). Real Decreto 1178/1992 de 2 de octubre por el que se establecen las enseñanzas mínimas del Bachillerato. BOE n० 253 de 21 de octubre. Madrid: BOE.

Ministerio de Educación y Ciencia (1992b). Real Decreto 1179/1992 de 2 de octubre por el que se establece el currículo de Bachillerato. BOE $n^{\circ} 253$ de de 21 de octubre. Madrid: BOE.

Ministerio de Educación y Ciencia (1999). Real Decreto 1640/1999 de 22 de octubre por el que se regula la prueba de acceso a estudios universitarios. BOE n 257 de 27 de octubre. Madrid: BOE.

Ministerio de Educación y Ciencia (2001). Real Decreto 3474/2000 de 29 de diciembre, por el que se modifican el Real Decreto 1700/1991, de 29 de noviembre por el que se establece la estructura del bachillerato y el Real Decreto $1178 / 1992$ de 2 de octubre, por el que se establecen las enseñanzas mínimas del Bachillerato. BOE no 14 de 16 de enero. Madrid: BOE.

Ministerio de Educación, Cultura y Deporte (2002): Real Decreto 1025/2002 de 4 de octubre, por el que se modifica el Real Decreto 1640/1999 de 22 de octubre, modificado y completado por el Real Decreto 990/2000 de 2 de junio, por el que se regula la prueba de acceso a estudios universitarios. BOE $\mathrm{n}^{\circ} 253$ de 22 de octubre. Madrid: BOE.

Ministerio de Educación, Cultura y Deporte (2003). Real Decreto 832/2003 de 27 de junio, por el que se establece la ordenación general y las enseñanzas comunes del Bachillerato. BOE no 159 de 4 de julio. Madrid: BOE.

Ministerio de Educación y Ciencia (2006). Ley Orgánica 2/2006, de 3 de mayo, de Educación (LOE). BOE no 106 de 4 de mayo, 17158-17207.Madrid: BOE.

Ministerio de Educación, Cultura y Deporte (2007). Real Decreto 1631/2006 de 29 de diciembre, por el que se establecen las enseñanzas mínimas correspondientes a la Educación Secundaria Obligatoria. BOE $n^{0} 5$ de 5 de enero, 677-773. Madrid: BOE. 
Moreno, M., Mesa, G. y Azcárate, C. (2007). En M.Camacho; P. Bolea; P. Flores; B. Gómez; J. Murillo y $\mathrm{M}^{\mathrm{a}} \mathrm{T}$. González (Eds.), Investigación en Educación Matemática. XI Simposio de la Sociedad Española de Investigación en Educación Matemática (SEIEM) (pp. 73-86). Tenerife.

Mosterin, J. (1987). Racionalidad y acción humana (2ª Ed.). Madrid: Alianza Editorial

NCTM (2003). Estándares Curriculares y para la evaluación matemática. Sevilla: SAEM Thales

Nesher, P. (2000). Posibles relaciones entre lenguaje natural y lenguaje matemático. Matemáticas y educación: Retos y cambios desde una perspectiva internacional (pp.109-121). Barcelona: Graó

Niss, M. (1999). Mathematical competencies and the learning of mathematics: The Danish KOM Project.

Niss, M. (2003). The Danish KOM project and possible consequences for teacher education. En R. Strässer, G. Brandell y B. Grevholm (Eds.), Educating for the future. Proceedings of an international symposium on mathematics teacher education (pp. 179-192). Göteborg: Royal Swedish Academy of Sciences.

OCDE (2002). The definition and Selection of Key Competences. Executive Summary. Tomado en enero de 2010 de www.OECD.org/edu/statistics/deseco.

OCDE (2005). Informe PISA 2003. Aprender para el mundo del mañana. Madrid: Santillana.

Ortega, T. Pecharromán, C. y Sosa, P. (2011). La importancia de los enunciados de problemas matemáticos. Revista Educatio Siglo XXI. Facultad de Educación. Universidad de Murcia. Vol. 29, Núm. 2, pp. 99-116.

Pérez Gómez, A. I. (2007). La naturaleza de las competencias básicas y sus aplicaciones pedagógicas. Cuadernos de Educación, $n^{\circ} 1$. Santander, Consejería de Educación del Gobierno de Cantabria.

Puig, L. y Calderón, J. (1996). Investigación y didáctica de las matemáticas. Madrid: CIDE.

Puig, L. (1996). Elementos de Resolución de Problemas. Granada: Comares. 
Puig, L. (1998). "Réplica a Elementos de resolución de problemas, cinco años después de $\mathrm{M}^{\mathrm{a}}$ Luz Callejo y José Carrillo". En J. R. Pascual (Ed.), Actas del Segundo Simposio de la Sociedad Española de Investigación en Educación matemática, pp. 107-112. Pamplona: Universidad Pública Navarra.

Reiss, K. \& Törner , G. (2007). "Problem solving in the mathematics classroom: the German perspective". ZDM The International Journal on Mathematics Education,39, 5-6, pp.431-441.

Rico L. (1993). "Mathematics Assessment in the Spanish Educational System". En Niss M. (ed.) Cases of Assessment in Mathematics Education. An ICMI Study. Dordrecht: Kluwer Academic Publishers.

Rico L. (1996). Evaluación en el Sistema Educativo Español: el caso de las Matemáticas. Granada: Universidad de Granada.

Rico L. (1997a). Bases Teóricas del Currículo de Matemáticas en Educación Secundaria. Madrid: Síntesis.

Rico L. (1997b). "Consideraciones sobre el Currículo de Matemáticas para Educación Secundaria" En La Educación Matemática en la Enseñanza Secundaria. ICE: Institut de Ciències de l'Educació.

Rico, L. y Sierra, M. (1997). Antecedentes del currículo de matemáticas, en Rico, L. (coord.) Bases teóricas del currículo de matemáticas en educación secundaria. Madrid: Síntesis.

Rico, L. (1998). Concepto de Currículum desde la Educación Matemática. Revista de Estudios del Currículum, 1(4), 7-42.

Rico, L. (2004a). Reflexiones sobre la formación inicial del profesor de matemáticas de secundaria. Profesorado. Revista de Currículum y Formación del Profesorado, 8(1), 1-15.

Rico, L. (2004b). Evaluación de competencias matemáticas. Proyecto PISA/OCDE 2003, en E. Castro; E. de la Torre (ed.): Actas del VIII Simposio de la Sociedad Española de Investigación en Educación Matemática (SEIEM). La Coruña: Universidad A Coruña.

Rico, L. (2005a). La alfabetización Matemática y el Proyecto PISA de la OCDE en España. Ceapa, 82, 7-13. 
Rico, L. (2005b). Competencias matemáticas e instrumentos de evaluación en el estudio PISA 2003. PISA 2003. Pruebas de matemáticas y de solución de problemas. Madrid: Ministerio de Educación y Ciencia

Rico, L. (2006). Marco teórico de evaluación en PISA sobre matemáticas y resolución de problemas. Revista de Educación, extraordinario 2006, 275294. Tomado de la red en enero de 2009 de www.revistaeducacion.mec.es/re2006/re2006_16.pdff

Rico, L. (2007). La competencia matemática en PISA. PNA, 1(2), 47-66.

Rico, L. y Lupiáñez, J.L. (2008). Competencias matemáticas desde una perspectiva curricular. Alianza Editorial: Madrid.

Rodríguez, F. (2009). Competencias básicas: competencia matemática Tomado de la red en octubre de 2010 de http://blogs.xeix.org/felix/files/2009/06/rodriguez-2009-competencias-basicascompetencia-matematica.pdf

Roig, A. I.; Linares, S., (2004). Dimensiones de la Competencia Matemática al finalizar la E.S.O. Caracterización y Análisis. Departamento Innovación y Formación Didáctica, Universidad de Alicante.

Romberg, T. (1992). Mathematics assessment and evaluation: Imperatives for mathematics educators. New York: SUNY Press.

Romberg, T. (1992). Problematic features of the school mathematics curriculum. En Philip W. Jackson (ed.), Handbook of research on curriculum: $A$ project of the American Educational Research Association. Macmillan. New York.

Ron, G., Dreyfus, T., \& Hershkowitz, R. (2006). Partial knowledge constructs. In J. Novotná, H. Moraová, M. Krátká, \& N. Stehliková (eds.), Proceedings of he $30^{\text {th }}$ Conference of the International Group for Psychology of Mathematics Education, Vol. 4. Prague, Czech Republic: Charles University Faculty of Education, pp. 449-456.

Rubio, R. Propuestas para mejorar la evaluación de las competencias matemáticas al finalizar la ESO en base a la evaluación PISA'2006. Una guía para las evaluaciones externas al sistema educativo. SIGMA, 34 (Septiembre 2009, pp. 11-19) 
Rupérez Padrón, J.A. y García Déniz, M. -Club Matemático- Competencias, matemáticas y resolución de problemas. Ideas y Recursos para el Aula. Tomado de la red en octubre de 2012 de http://www.sinewton.org/numeros/numeros/69/ideas_01.php

Santos-Trigo, M. (2007). Mathematical problem solving: an evolving research an practice domain. ZDM The International Journal on Mathematics Education, 39, 5-6, pp 523-536.

Sanmartí, N (2007). Evaluar para aprender. Col. 10 ideas clave. Barcelona. Graó.

Schoenfeld, A. (1985). Mathematical Problem Solving. New York: Academic Press.

Schoenfeld, A. H. (1992). Learning to think mathematically: Problem solving, metacognition, and sense making in mathematics. En D. A. Grows (Ed.), Handbookof Research on Mathematics Teaching and Learning (pp. 334-370). NY:Macmillan.

Schoenfeld, A. H. (1994). Reflections on doing and teaching mathematics. In A. H.Schoenfeld (Ed.), Mathematical thinking and problem solving (pp.53-70). Hillsdale, NJ: Lawrence Erlbaum Associates.

Schwarz, B. B. \& Dreyfus, T. (1995). New actions upon old objects: A new ontological perspective on functions. Educational Studies in Mathematics 29, 259-291.

Serradó, A., Cardeñoso, J.Ma y Azcárate, P. (2004). Las fuentes de información como recurso de la planificación, en E. Castro; E. de la Torre (ed.): Actas del VIII Simposio de la Sociedad Española de Investigación en Educación Matemática (SEIEM). La Coruña: Universidad A Coruña.

Silver, E.A. y Kilpatrick, J. (1988). Testing mathematical problema solving. En R.I.Charles \& E.A. Silver (Eds). The teaching and assessing of mathematical problem solving (178-186). Reston, VA: National Council of Teachers of Matemhatics.

Silver, E.A. y Kenney, P.A. (1995). Sources of assessment information for instructional guidance in mathematics. En T. Romberg (Ed.), Reform in school mathematics and authentic assessment (38-86). Albany: State University of New York Press. 
Shepard, L.A. (2001). The role of classroom assessment in teaching and learning. In V. Richardson (Ed.), The Handbook of Research on Teaching, Fourth Edition. Washington, DC: American Educational Research Association. Tomado de la red en febrero de 2011 de www.cse.ucla.edu/products/Reports/TECH517.pdf

Socas, M. (2001). Investigación didáctica de la matemática vía modelos de competencia. Un estudio en relación con el lenguaje algebraico. Universidad de la Laguna. Departamento de Análisis Matemático.

Tortosa, A. et al. (1992). La evaluación en el aula de matemáticas. Granada: Seminario CIEM. Sociedad Andaluza de Educación Matemática.

Van den Heuvel- Panhuizen, M y Becker, J. (2003). Towards a Didactic Model for Assessment Design in Mathematics Education. Tomado en meyo de 2011 de www.fisme.science.uu.nl/staff/marjah/documents/Marja_Assessment.pdf

Villanueva Aguilar G. Las matemáticas por competencias. Tomado en enero de 2011 de http://dcb.fiunam.mx/Eventos/Foro3/Memorias/Ponencia_67.pdf

Webb, N.L. (1992). Assessment of Students' Knowledge of Mathematics: Steps toward a Theory. En Grouws, D.A. (Ed.) Handbook of Research on Mathematics Teaching and Learning. New York: Macmillan, pp. 661-683. Traducción resumida del capítulo por Rico, L. (1996). Tomado de la red en mayo de 2011 de http://funes.uniandes.edu.co/494/

Zamora, R.F. (2012). Breve análisis de las pruebas de acceso a la universidad de Valladolid: Morfosintáctico, curricular y competencial. Burgos.

Zamora R.F. (2013). Ejemplos de Análisis en competencias de las PAEUs de la Universidad de Valladolid. Palma de Mallorca. 